\title{
SECONDARY WASTE MANAGEMENT STRATEGY FOR EARLY LOW ACTIVITY WASTE TREATMENT
}

\author{
T. W. Crawford, et. al. \\ CH2MHILL Hanford Group, Inc. \\ Richland, WA 99352 \\ U.S. Department of Energy Contract DE-AC27-99RL14047

$\begin{array}{lll}\text { EDT/ECN: } & \text { DRF } & \text { UC: N/A } \\ \text { Cost Center: } & \text { 76A00 } & \text { Charge Code: } \\ \text { B\&R Code: } & \text { N/A } & \text { Total Pages: } 260\end{array}$

Key Words: secondary waste streams, Early Low Activity Waste (LAW) operations, recommend a strategy for secondary waste management, groundwater impact, Interim Pretreatment System, IPS

\begin{abstract}
This study evaluates parameters relevant to River Protection Project secondary waste streams generated during Early Low Activity Waste operations and recommends a strategy for secondary waste management that considers groundwater impact, cost, and programmatic risk. The recommended strategy for managing River Protection Project secondary waste is focused on improvements in the Effluent Treatment Facility. Baseline plans to build a Solidification Treatment Unit adjacent to Effluent Treatment Facility should be enhanced to improve solid waste performance and mitigate corrosion of tanks and piping supporting the Effluent Treatment Facility evaporator. This approach provides a life-cycle benefit to solid waste performance and reduction of groundwater contaminants.
\end{abstract}

\footnotetext{
TRADEMARK DISCLAIMER. Reference herein to any specific commercial product, process, or service by trade name trademark, manufacturer, or otherwise, does not necessarily constitute or imply its endorsement, recommendation, or favoring by the United States Government or any agency thereof or its contractors or subcontractors.
}

Printed in the United States of America. To obtain copies of this document, contact: Document Control Services, P.O. Box 950, Mailstop H6-08, Richland WA 99352, Phone (509) 372-2420; Fax (509) 376-4989.

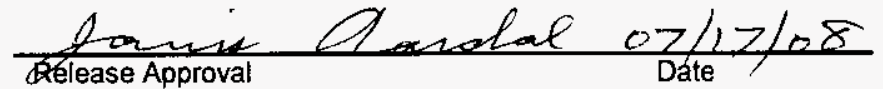

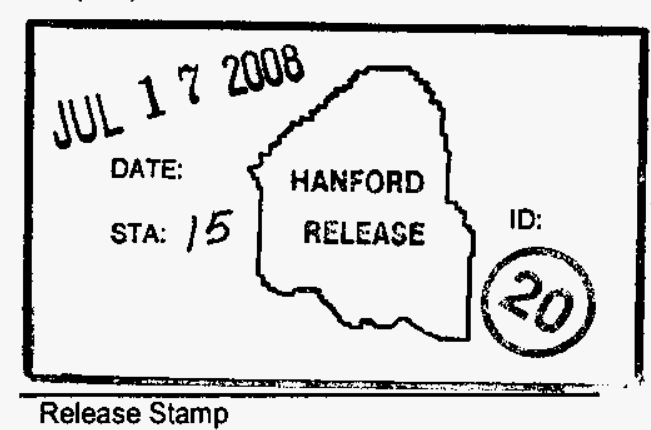

\section{Approved For Public Release}




\section{SECONDARY WASTE MANAGEMENT STRATEGY FOR EARLY LOW ACTIVITY WASTE TREATMENT}

CH2M HILL Hanford Group, Inc.

T. W. Crawford

J. M. Conner

M. E. Johnson

F. M. Mann

B. J. Unterreiner

R. D. Williamson

Fluor Hanford Inc.

K. J. Lueck

E. A. MeNamar

Date Published

July 2008

\section{CH2MHILL \\ Hanford Group, Inc.}

Post Office Box 1500

Richland, Washington

Prepared for the U.S. Department of Energy

Office of River Protection

Contract No. DE-AC27-99RL14047, Modification M120

Approved for public release; distribution is unlimited 


\section{EXECUTIVE SUMMARY}

This study evaluates parameters relevant to River Protection Project (RPP) secondary waste streams generated during Early Low Activity Waste (LAW) operations and recommend a strategy for secondary waste management that considers groundwater impact, cost and programmatic risk. Results of the study will be used by the U. S. Department of Energy Office of River Protection (DOE ORP) and the Interim Pretreatment System (IPS) Project to determine if additional systems are needed to mitigate potential groundwater impacts either within the IPS or in another part of the RPP Program.

The RPP baseline flowsheet recycles the WTP LAW secondary liquid effluent to the Pretreatment facility, which incorporates more ${ }^{99} \mathrm{Tc}$ into LAW glass. In the baseline, all WTP secondary liquid effluents are pumped to the Effluent Treatment Facility (ETF) for treatment. Under the early LAW scenario, early LAW operation does not have the ability to recycle this secondary liquid effluent to the WTP. Therefore, more ${ }^{99} \mathrm{Tc}$ is directed to a solidified waste form through the ETF. Estimates during 2007 indicated an increased quantity of ${ }^{99} \mathrm{Tc}$ in the secondary waste stream planned for treatment at the ETF when this stream cannot be recycled back to the WTP Pretreatment facility. This document compares groundwater impacts to baseline values and evaluates a variety of mitigating approaches.

A life-cycle evaluation of tank waste treatment tracks contaminants of concern (COC) technetium-99 $\left({ }^{99} \mathrm{Tc}\right)$, iodine-129 $\left({ }^{129} \mathrm{I}\right)$, mercury $(\mathrm{Hg})$, chromium $(\mathrm{Cr})$, nitrate $\left(\mathrm{NO}_{3}\right)$ and uranium (U). Technetium-99 is a key COC since the mobile long-lived radionuclide is volatile in high temperature LAW melters resulting in relatively high concentrations in melter offgas condensates. Ratios developed from previous environmental calculations are applied to the primary and secondary waste streams to compare groundwater concentrations to baseline conditions. No new environmental modeling was performed since ratios derived from 2005 calculations were used in the evaluation. Absolute groundwater concentrations are not discussed in developing this secondary waste management strategy.

A parametric analysis was used to evaluate a range of values to understand the sensitivities of LAW feed, changes to WTP LAW secondary waste stream, groundwater recharge rates, solid waste form performance, and vadose zone distribution coefficients. Several mitigating approaches were considered in the evaluation including feed tank selection, removing ${ }^{99} \mathrm{Tc}$, concentration and recycle of the WTP LAW secondary waste stream and solid waste form performance. The bases for the recommended approaches consider the ability to mitigate potential groundwater issues compared to the baseline. Also, costs and programmatic risks of the mitigating approaches were compared to further differentiate approaches.

The IPS proposes to pretreat selected LAW feed streams to the extent necessary to allow processing in the WTP LAW facility or a LAW supplemental treatment plant (STP) without initial processing through the WTP PT facility. The IPS Justification of Mission Need defines a treatment mission scope that includes early operations of the WTP LAW Facility or operation of a supplemental LAW immobilization technology.

The recommended strategy for managing RPP secondary waste is focused on improvements in the Effluent Treatment Facility. U. S. Department of Energy Richland Operations Office 
baseline plans to build a Solidification Treatment Unit adjacent to ETF should be enhanced to improve solid waste performance and mitigate corrosion of tanks and piping supporting the ETF evaporator. This approach provides a life-cycle benefit to solid waste performance and reduction of groundwater contaminants.

This recommended approach will be further evaluated as part of the Secondary Waste Roadmap Meeting scheduled for July $21-25,2008$ sponsored by DOE EM-21. Nationally recognized subject matter experts will address the same RPP secondary waste issues addressed in this document and develop a technology road map needed to resolve the issues. The road map will further address technical, programmatic and regulatory uncertainties associated with the recommendation.

A backup strategy, if solid waste performance improvements are unsuccessful, would be a recycle capability for transfer of concentrated liquid effluents from ETF to the DST system via pipeline or truck. This approach, while meeting near-term goals during early LAW operations, provides very little or no life-cycle benefit to the RPP mission after the WTP Pretreatment facility becomes operational.

Both the recommended and backup secondary waste management strategies provide high value technical solutions with low schedule risk that are outside of the scope of the IPS project. The recommended and backup strategies are the lowest life-cycle cost approaches with adequate mitigation of potential groundwater contamination compared to baseline values:

- Improve solid waste performance: Evaporator upgrades at ETF and solid waste performance testing program $(\$ 35 \mathrm{M}$ to $\$ 40 \mathrm{M})$

- $\quad$ Recycle to DSTs: ETF evaporator upgrades and new transfer capability at ETF $(\$ 35 \mathrm{M}$ to $\$ 45 \mathrm{M})$.

The recommended strategy includes an allowance of $\sim \$ 5 \mathrm{M}$ for additional solid waste formulation and performance testing which is estimated to meet the higher solid waste performance level. This includes $\$ 4 \mathrm{M}$ for lab testing and support and $\$ 1 \mathrm{M}$ for an independent external review of the program. The $\$ 5 \mathrm{M}$ is included in the $\$ 35 \mathrm{M}$ to $\$ 40 \mathrm{M}$ range shown above. 


\section{TABLE OF CONTENTS}

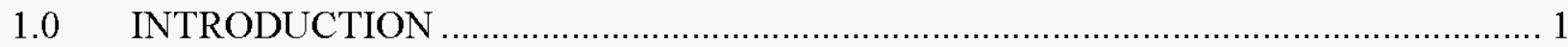

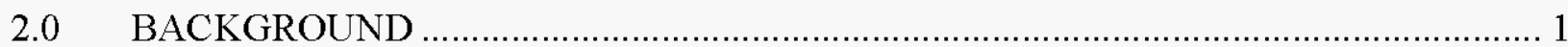

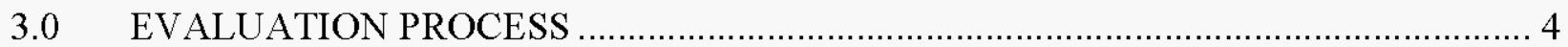

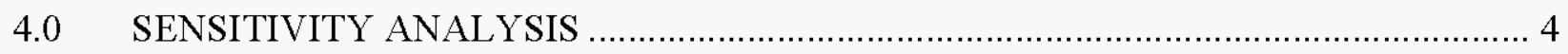

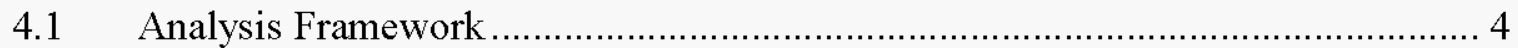

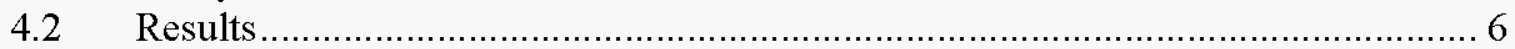

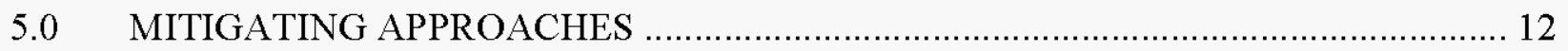

5.1 Select Feed Tanks with Lower Technetium Concentration ............................... 13

5.2 Remove Technetium .......................................................................... 14

5.3 Concentrate and Recycle Secondary Waste Stream to DSTs ........................... 16

5.3.1 Effluent Treatment Facility Concentration ........................................ 16

5.3.2 Recycle ETF Evaporator Brine to Tank Farms via Tanker Truck............ 18

5.3.3 Recycle ETF Evaporator Brine to Tank Farms via New Pipeline............ 18

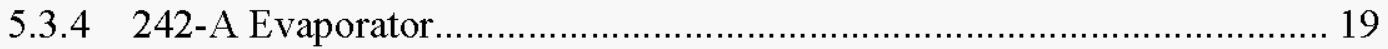

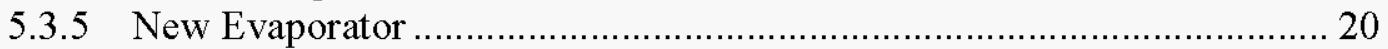

$5.4 \quad$ Improve Solid Waste Form Performance ................................................ 22

5.4.1 ETF Planned Solidification Treatment Unit ..................................... 22

5.4 .2 Improved Solid Waste Forms ................................................... 23

5.4.3 Other Solids Waste Forms .................................................................. 24

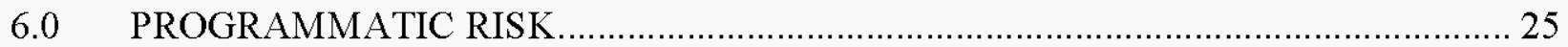

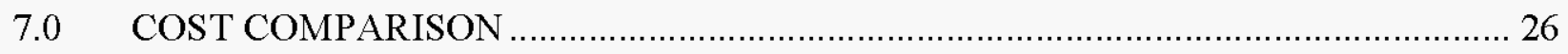

7.1 Cost of Selecting Alternative Feed Tank groups ........................................ 26

7.2 Cost to Remove Technetium OR Concentrate and Recycle Secondary Waste .... 26

7.3 Cost to improve secondary solid waste performance ......................................... 28

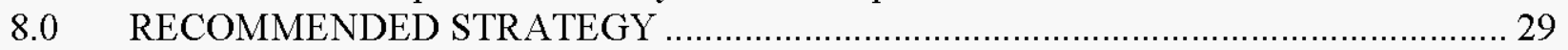

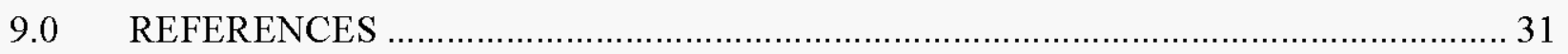

\section{TABLE OF APPENDICES}

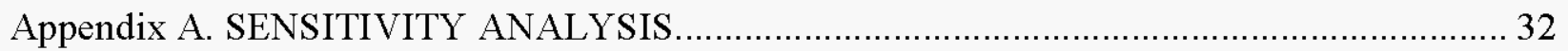

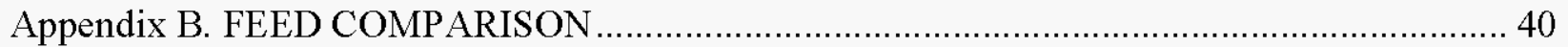

Appendix C. TECHNETIUM REMOVAL ................................................................ 44 Appendix D. HNF-37718, LOW ACTIVITY WASTE FACILITY SECONDARY WASTE TO EFFLUENT TREATMENT FACILITY TREATABILITY EVALUATION. .......................... 51 Appendix E. INTERIM PRETREATMENT SYSTEM SECONDARY WASTE STUDY -

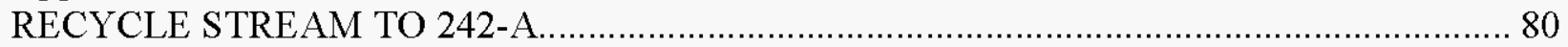
Appendix F. INTERIM PRETREATMENT SYSTEM SECONDARY WASTE EVAPORATOR

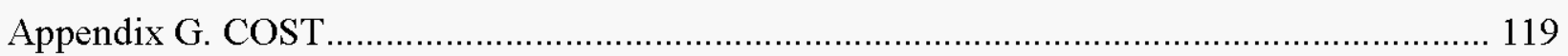




\section{TABLE OF FIGURES}

Figure 1. Early LAW Secondary Effluent Stream Compared to Baseline. .............................. 3

Figure 2. Effect of Various Methods on the Reduction of Groundwater ${ }^{99} \mathrm{Tc}$ Concentration ....... 7

Figure 3. Effect of Varying the Change to WTP LAW Secondary Waste Stream ..................... 8

Figure 4. Effect of Varying the Quantity of ${ }^{99} \mathrm{Tc}$ in the Feed ............................................. 9

Figure 5. Effect of Varying Waste Form Performance.................................................... 10

Figure 6. Tc Ion Exchange Process in New Vault............................................................ 15

Figure 7. Recycle to DSTs after Concentration in ETF ................................................... 17

Figure 8. Recycle to DSTs after Concentration in 242-A Evaporator or a New Evaporator ...... 19

Figure 9. Blend Secondary Effluent with IPS Product and Concentrate in New Evaporator to

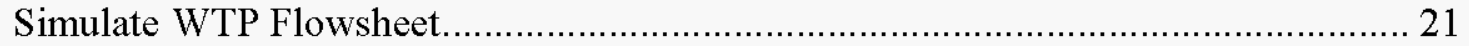

Figure 10. LAW Secondary Waste Stream Processing Life-Cycle Cost.............................. 28

Figure 11. Summary Basis for Recommended Approach. .............................................. 30

\section{TABLE OF TABLES}

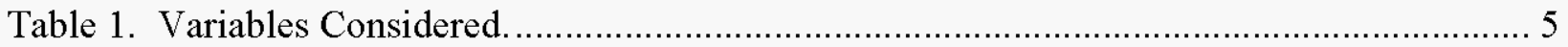

Table 2. Distribution of COCs in Final RPP Waste Forms. .................................................. 11

Table 3. Mitigating Approach Categories...................................................................... 12

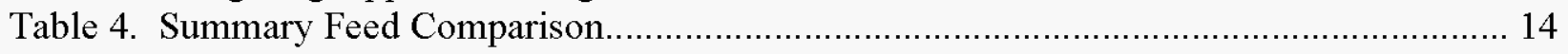

Table 5. Summary Cost of Potential Feed Selection. .............................................................. 26 


\section{LIST OF TERMS}

\section{Abbreviations and Acronyms}

\begin{tabular}{|c|c|}
\hline BBI & Best-Basis Inventory \\
\hline CH2M HILL & CH2M HILL Hanford Group, Inc. \\
\hline $\mathrm{COC}$ & contaminants of concern \\
\hline DCRT & double-contained receiver tank \\
\hline DF & decontamination factor \\
\hline DOE & U.S. Department of Energy \\
\hline DST & double-shell tank \\
\hline Ecology & Washington State Department of Ecology \\
\hline EM-21 & DOE, Office of Environmental Management, Office of Waste Processing \\
\hline ETF & Effluent Treatment Facility \\
\hline FRP & fiberglass reinforced panel \\
\hline FY & Fiscal Year \\
\hline HEPA & high-efficiency particular air (filter) \\
\hline HLW & high-level waste \\
\hline HVAC & heating, ventilation, and air conditioning \\
\hline LDR & land disposal restrictions \\
\hline IPS & Interim Pretreatment System \\
\hline IDF & Integrated Disposal Facility \\
\hline ILAW & immobilized low activity waste \\
\hline $\mathrm{Kd}$ & distribution coefficient \\
\hline LAW & low-activity waste \\
\hline LERF & Liquid Effluent Retention Facility \\
\hline MTT & main treatment train \\
\hline NEPA & National Environmental Policy Act \\
\hline ORP & U.S. Department of Energy, Office of River Protection \\
\hline PA & Performance Assessment \\
\hline PCT & product consistency test \\
\hline PT & Pretreatment \\
\hline RCRA & Resource Conservation and Recovery Act \\
\hline RL & U.S. Department of Energy, Richland Operations Office \\
\hline $\mathrm{RO}$ & reverse osmosis \\
\hline RPP & River Protection Project \\
\hline SBS & Submerged Bed Scrubber \\
\hline STP & supplemental treatment plant \\
\hline SST & single-shell tank \\
\hline SWE & Secondary Waste Evaporator \\
\hline Tc IX & technetium ion exchange \\
\hline $\mathrm{TFC}$ & Tank Farms Contractor \\
\hline TRD & technical requirements document \\
\hline WTP & Waste Treatment and Immobilization Plant \\
\hline
\end{tabular}




\section{Units}

$\begin{array}{ll}\mathrm{Ci} & \begin{array}{l}\text { Curie } \\ \text { gallon }\end{array} \\ \text { Kgal } & \begin{array}{l}\text { thousand gallons } \\ \text { L }\end{array} \\ \mathrm{mm} / \mathrm{yr} & \text { liter } \\ \mathrm{M} & \text { millimeters per year } \\ \mathrm{MCi} & \text { Molarity } \\ \mathrm{MT} & \text { million curies } \\ \mathrm{MTG} & \text { metric ton } \\ \mathrm{MTG} / \mathrm{d} & \text { metric ton glass } \\ \mathrm{MT} \mathrm{Na} / \mathrm{yr} & \text { metric ton glass per day } \\ \text { wt } \% & \text { metric ton Sodium per year }\end{array}$




\subsection{INTRODUCTION}

The purpose of this study is to evaluate parameters relevant to River Protection Project (RPP) secondary waste streams generated during Early Low Activity Waste (LAW) operations and recommend a strategy for secondary waste management that considers groundwater impact, cost and programmatic risk. Results of the study will be used by the U. S. Department of Energy Office of River Protection (DOE ORP) and the Interim Pretreatment System (IPS) Project to determine if additional systems are needed to mitigate potential groundwater impacts either within the IPS or in another part of the RPP Program.

A life-cycle evaluation of tank waste treatment tracks contaminants of concern (COC) technetium-99 $\left({ }^{99} \mathrm{Tc}\right)$, iodine-129 $\left({ }^{129} \mathrm{I}\right)$, mercury $(\mathrm{Hg})$, chromium $(\mathrm{Cr})$, nitrate $\left(\mathrm{NO}_{3}\right)$, uranium$238\left({ }^{238} \mathrm{U}\right)$ and uranium $(\mathrm{U})$. Technetium-99 is a key COC since the mobile, long-lived radionuclide is volatile in high temperature LAW melters resulting in relatively high concentrations in melter offgas condensates. The tank waste inventory is derived from ORP11242, River Protection Project System Plan, which partitions the Best Basis Inventory into liquid and solid streams.

Ratios developed from previous environmental calculations are applied to the primary and secondary waste streams to compare groundwater concentrations to baseline conditions. No new environmental modeling was performed since ratios derived from 2005 calculations were used RPP-RPT-37947, Extraction of Groundwater Impacts from the Integrated Disposal Facility. Absolute groundwater concentrations are not discussed in developing this secondary waste management strategy.

A parametric analysis was used to evaluate a range of values to understand the sensitivities of LAW feed, changes to Waste Treatment and Immobilization Plant (WTP) LAW secondary waste stream, groundwater recharge rates, solid waste form performance, and vadose zone distribution coefficients. Several mitigating approaches were considered in the evaluation including feed tank selection, removing ${ }^{99} \mathrm{Tc}$, concentration and recycle of the WTP LAW secondary waste stream and solid waste form performance. The bases for recommended approaches consider the ability to mitigate potential groundwater issues compared to the baseline. Also, costs and key programmatic risks of the mitigating approaches were compared to further differentiate approaches. The study evaluation, compositions, approaches, and tools will be available to support an EM-21 sponsored Secondary Waste Roadmap Meeting planned for July, 2008.

\subsection{BACKGROUND}

The DOE Hanford Site RPP mission includes tank waste retrieval, waste treatment, waste disposal, and tank farms closure activities. This mission will largely be accomplished by the construction and operation of three treatment facilities at the WTP. The treatment facilities include, 1) the WTP Pretreatment (PT) facility intended to separate the tank waste into HighLevel Waste (HLW) and LAW, 2) the HLW vitrification facility intended to immobilize the HLW for disposal at a geologic repository in Yucca Mountain, Nevada, and 3) the LAW vitrification facility intended to immobilize the LAW for shallow land burial at Hanford. A supplemental LAW treatment plant is being considered to augment the WTP LAW treatment 
capacity because the LAW facility has insufficient capacity to treat all of the LAW in the same time period as the HLW.

The IPS proposes to pretreat selected LAW feed streams to the extent necessary to allow processing in the WTP LAW facility or a LAW supplemental treatment plant (STP) without initial processing through the WTP PT facility. The IPS Justification of Mission Need defines a treatment mission scope that includes early operations of the WTP LAW Facility or operation of a supplemental LAW immobilization technology.

The RPP baseline flowsheet recycles the WTP LAW secondary liquid effluent to the Pretreatment facility, which incorporates more ${ }^{99} \mathrm{Tc}$ into LAW glass. In the baseline all WTP secondary liquid effluents are pumped to the Effluent Treatment Facility (ETF) for treatment. Under the early LAW scenario, early LAW operation does not have the ability to recycle this secondary liquid effluent to the WTP (Figure 1). Therefore, more ${ }^{99} \mathrm{Tc}$ is directed to a solidified waste form through the ETF. Estimates during 2007 indicated an increased quantity of ${ }^{99} \mathrm{Tc}$ in the secondary waste stream planned for treatment at the ETF when this stream cannot be recycled back to the WTP Pretreatment facility. This document evaluates a variety of mitigating approaches and compares groundwater impacts to baseline values.

Several waste streams will be generated during IPS operations including some streams that are returned to the DST farm system and some secondary waste requiring disposition. These waste streams are common to all of the mitigating approaches considered in this study and therefore are not included in the sensitivity analysis or comparison of mitigating approaches. Since the IPS technologies are the same as used in the WTP, the IPS secondary waste streams requiring disposition are the same type as those in the WTP.

Normal streams that will return to the DST system include entrained solids removed by filtration, neutralized cesium eluate removed by ion exchange, ventilation system condensate, condensate from the ion exchange resin drying operation and flush solutions. Off-normal streams that may be returned to the DST system include IPS product not meeting WTP specifications returned from IPS or WTP and potentially other off-normal streams from sumps, etc. Additional details on the IPS waste streams will be documented in the IPS Process Flowsheet document.

Secondary waste generated at IPS including spent ion exchange resin and other solid waste such as HEPA filters and failed equipment will be disposed of at the IDF after appropriate treatment. The ion exchange resin will be treated in the same manner as planned for disposition of the same WTP ion exchange resin. The current plan by the WTP for treatment of spent ion exchange resin is drying of the resin in a disposal cask so there is no free standing water. The cask will then be macro encapsulated onsite prior to disposition at the IDF. Failed equipment, HEPA filters and other miscellaneous solid waste will be packaged to meet IDF disposal criteria prior to shipment to IDF. The IPS System Specification document will identify an interface with the ETF to handle miscellaneous low volume low level secondary liquid wastes. This system will use a collection tank and a pump out capability to fill a tank truck for transportation.

Therefore, no new waste types are expected from the IPS and treatment of the IPS waste is expected to the same as the similar WTP waste types. 
RPP-RPT-37924, Rev. 0

Figure 1. Early LAW Secondary Effluent Stream Compared to Baseline.

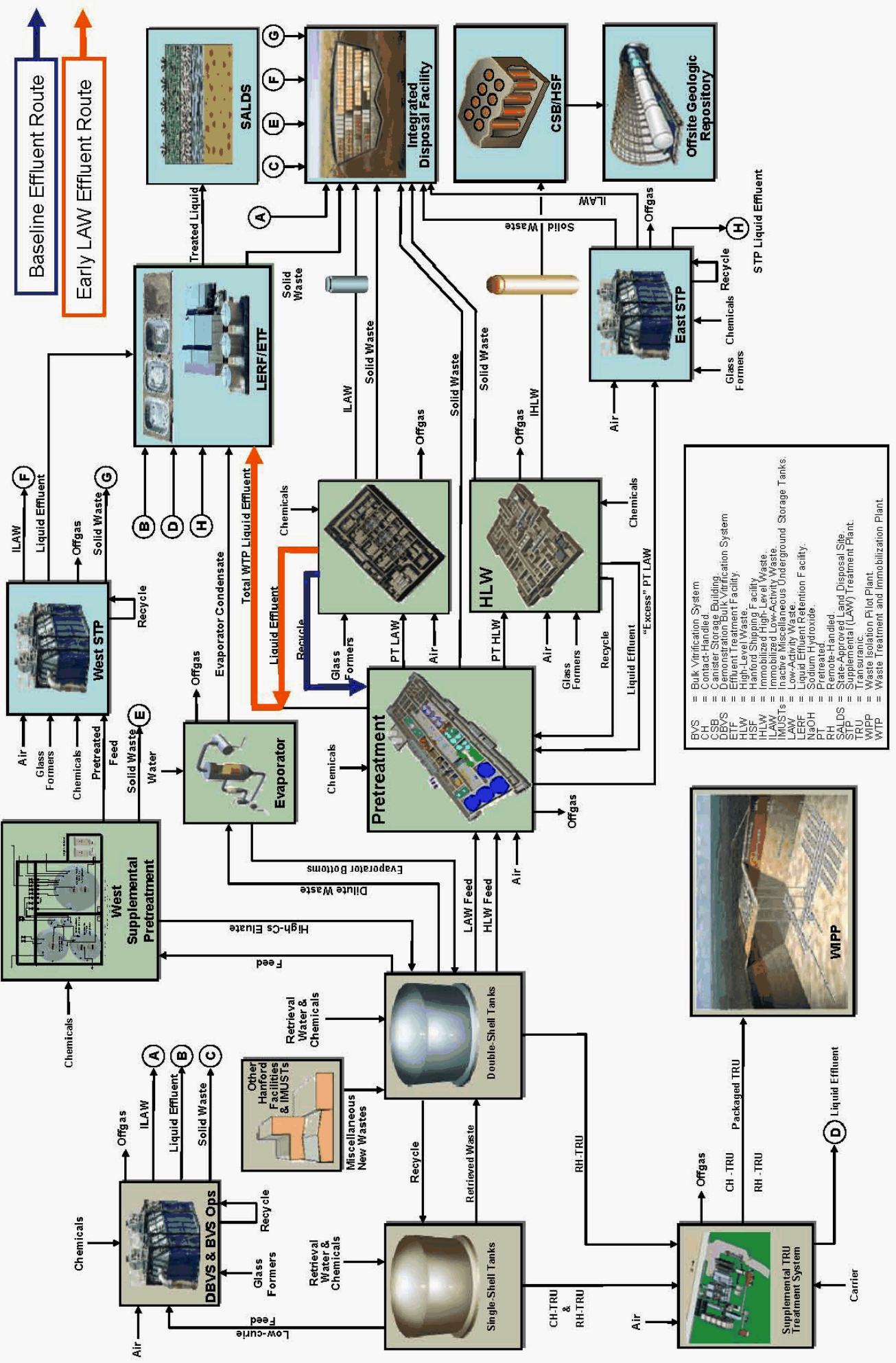




\subsection{EVALUATION PROCESS}

A parametric analysis was used to evaluate a range of values to understand the sensitivities of the following parameters:

- $\quad{ }^{99} \mathrm{Tc}$ quantity in the feed to Interim Pretreatment System

- $\quad$ Changes to WTP LAW secondary waste stream

- $\quad$ Recharge rates

- $\quad$ ETF solid waste form performance

- Vadose zone distribution coefficients.

Technetium, iodine, mercury, chromium, nitrate, uranium-238 and total uranium are used to distinguish approaches since they are contaminants of concern in long-term groundwater performance assessments. Since technetium has the largest impact on groundwater, it is used as the primary $\mathrm{COC}$ for developing mitigating approaches. Several mitigating approaches were considered in the evaluation including feed tank selection, removing ${ }^{99} \mathrm{Tc}$, concentration and recycle of the WTP LAW secondary waste stream and solid waste form performance. Roughorder-of-magnitude cost estimates and qualitative program risks were assessed for the mitigating approaches.

The bases for recommended approaches consider the ability to mitigate potential groundwater issues compared to the baseline. Also, costs and programmatic risks of the mitigating approaches are compared to further differentiate approaches.

\subsection{SENSITIVITY ANALYSIS}

\subsection{ANALYSIS FRAMEWORK}

One major risk in the path of early LAW treatment is a potentially higher groundwater concentration for several water soluble contaminants. The increased concentration of these contaminants is due to the early LAW operations lacking the recycle stream that routes these contaminants back to the LAW melters present in the finished WTP. The purpose of this analysis is to estimate the efficacy of several mitigating approaches in regards to lessening the environmental impact of the early LAW operations. Five variables were considered in the evaluation of peak groundwater concentrations over a 10,000 year period. Table 1 describes these variables and the values used to assess their impact on groundwater contamination.

Using the variables in Table 1, there are 216 possible combinations. However, in this study, evaluation of 18 cases provided adequate data for the sensitivity analysis. Each case was normalized to the base case of no early LAW to observe the relative effect on groundwater that utilizing early LAW would create. Absolute groundwater concentrations are not discussed in order to focus the study on developing a sound secondary waste management strategy without solving technical groundwater modeling controversies such as optimal recharge rates. 
Performance assessment efforts will formally assess impacts to groundwater after the Tank Closure and Waste Management Environmental Impact Statement for the Hanford Site, Richland, Washington, Record of Decision (ROD) is issued.

The effect of changing each variable was measured by comparing it to a reference case (Table 1, row 4). The reference case is defined as using the reference ${ }^{99} \mathrm{Tc}$ feed, not employing any ${ }^{99} \mathrm{Tc}$ removal or recycle operations, using a mid-performance solid waste, and assuming base case recharge rates and Kd coefficients. Our baseline, which assumes no Early LAW operations, uses the same base case values for key vadose and groundwater parameters as the reference case, which are described below. The effect of each of these five variables on groundwater compared to the baseline is discussed in Section 4.2.

Table 1. Variables Considered.

\begin{tabular}{|c|c|c|c|c|}
\hline $\begin{array}{c}{ }^{99} \mathrm{Tc} \text { Feed } \\
\text { Approaches - } \\
(1,175 \mathrm{MT} \text { Na/yr for } \\
\text { both WTP ILAW } \\
\text { and 1-line STP) }\end{array}$ & $\begin{array}{c}\text { Change to WTP LAW } \\
\text { Secondary Waste } \\
\text { Stream }\end{array}$ & $\begin{array}{l}\text { ETF Solid Waste } \\
\text { Form } \\
\text { Performance - } \\
\text { Diffusion } \\
\text { Coefficient, De } \\
\text { (cm2/s) }\end{array}$ & $\begin{array}{l}\text { Vadose Zone } \\
\text { Recharge Rate } \\
\text { (mm/yr) }\end{array}$ & $\begin{array}{c}\text { Vadose } \\
\text { Distribution } \\
\text { Coefficients , Kd } \\
(\mathrm{ml} / \mathrm{g})\end{array}$ \\
\hline & & & 1) High -4.2 & \\
\hline & & 1) Low - 3.0 E-8 & 2) Natural -0.9 & $\begin{array}{l}\text { 1) Low - } \\
\text { All zero }\end{array}$ \\
\hline $\begin{array}{c}\text { Reference }{ }^{99} \mathrm{Tc}- \\
\text { DST supernatant, } \\
\text { DST salt cake, \& } \\
\text { high SST salt if } \\
\text { needed }\end{array}$ & $\begin{array}{l}\text { 1) None - No }{ }^{99} \mathrm{Tc} \\
\text { removal nor any recycle } \\
\text { of WTP LAW secondary } \\
\text { liquid waste streams }\end{array}$ & 2) Mid - 5.0 E-9 & 3) Base - 0.5 & $\begin{array}{l}\text { 2) Base - } \\
129=0.1 \\
U=0.2 \\
\text { Others = } 0\end{array}$ \\
\hline $\begin{array}{c}\text { Mid }{ }^{99} \mathrm{Tc}-\mathrm{SST} \text { salt } \\
\text { cake West (Sound } \\
\text { tanks in U, S or SX } \\
\text { farms) \& DST feed } \\
\text { tanks }\end{array}$ & $\begin{array}{c}\text { 2) Remove }{ }^{99} \mathrm{Tc}- \\
\text { Reduction of }{ }^{99} \mathrm{Tc} \text { in } \\
\text { Vitrification Secondary } \\
\text { Waste Destined to ETF } \\
\text { by at least a factor of } 100\end{array}$ & 3) High $-5.0 \mathrm{E}-11$ & 4) Low -0.1 & \\
\hline $\begin{array}{c}\text { Low }^{99} \mathrm{Tc}-\mathrm{SST} \\
\text { salt cake East or } \\
\text { West \& DST feed } \\
\operatorname{tank(s)}\end{array}$ & $\begin{array}{l}\text { 3) Recycle - Recycle of } \\
\text { WTP ILAW secondary } \\
\text { waste streams } \\
\text { (Equivalent to No Early } \\
\text { LAW) }\end{array}$ & & & \\
\hline \multicolumn{5}{|c|}{ Estimated Range of Parameter } \\
\hline 5 & $>100$ & 600 & 42 & 0 for ${ }^{99} \mathrm{Tc}$ \\
\hline
\end{tabular}

The values used in Table 1 were calculated following the requirements in DOE 2005, Technical Requirements Document for Integrated Disposal Facilities Vadose Zone and Groundwater Revised Analyses in 2005. According to the technical requirements document (TRD), the base case values for key parameters were: 
- $\quad$ Recharge $=0.5 \mathrm{~mm} / \mathrm{yr}$

- Diffusion coefficient (De) $=5 \times 10^{-9} \mathrm{~cm}^{2} / \mathrm{s}$

- $\quad \mathrm{Kd}$ for $\mathrm{Tc}=0$

- $\quad \mathrm{Kd}$ for $\mathrm{I}=0.1 \mathrm{~mL} / \mathrm{g}$.

The TRD was silent on the $\mathrm{Kd}$ for $\mathrm{Hg}$, but a value of zero was used in the calculations, which is a conservative assumption.

The TRD also specified that the best estimate case would use a recharge value of $0.1 \mathrm{~mm} / \mathrm{yr}$.

In addition, to determine how parameter value selection affected results, the following sensitivity cases to the base case (among others) were performed:

- $\quad$ Recharge $=0.9 \mathrm{~mm} / \mathrm{yr}$ (the natural value over the past 10,000 years)

- $\quad$ Recharge $=4.2 \mathrm{~mm} / \mathrm{yr}$ (the value used in the 2001 ILAW PA analysis (DOE/ORP-2000-24, Hanford Immobilized Low-Activity Tank Waste Performance Assessment: 2001 Version)

- $\quad \mathrm{Kd}$ for ${ }^{129} \mathrm{I}=0$ (very conservative value)

- $\quad$ De $=3 \times 10^{-8} \mathrm{~cm}^{2} / \mathrm{s}$ (very conservative value)

Results of these sensitivity analysis calculations are in the following section.

\subsection{RESULTS}

The effect of independently changing three variables which are not controlled by nature is summarized in Figure 2. Recycling or removing ${ }^{99} \mathrm{Tc}$ from the secondary waste stream essentially sets the groundwater ${ }^{99} \mathrm{Tc}$ concentration back to the baseline with a normalized concentration ratio of one. Using a high performance solid waste lowers the ${ }^{99} \mathrm{Tc}$ concentration ratio to nearly the baseline value. Feeding a low ${ }^{99} \mathrm{Tc}$ feed lowers the ${ }^{99} \mathrm{Tc}$ concentration ratio to about twice the baseline value but increases the $\mathrm{Cr}$ concentration ratio from two to three times the baseline value. 
Figure 2. Effect of Various Methods on the Reduction of Groundwater COC Concentration.

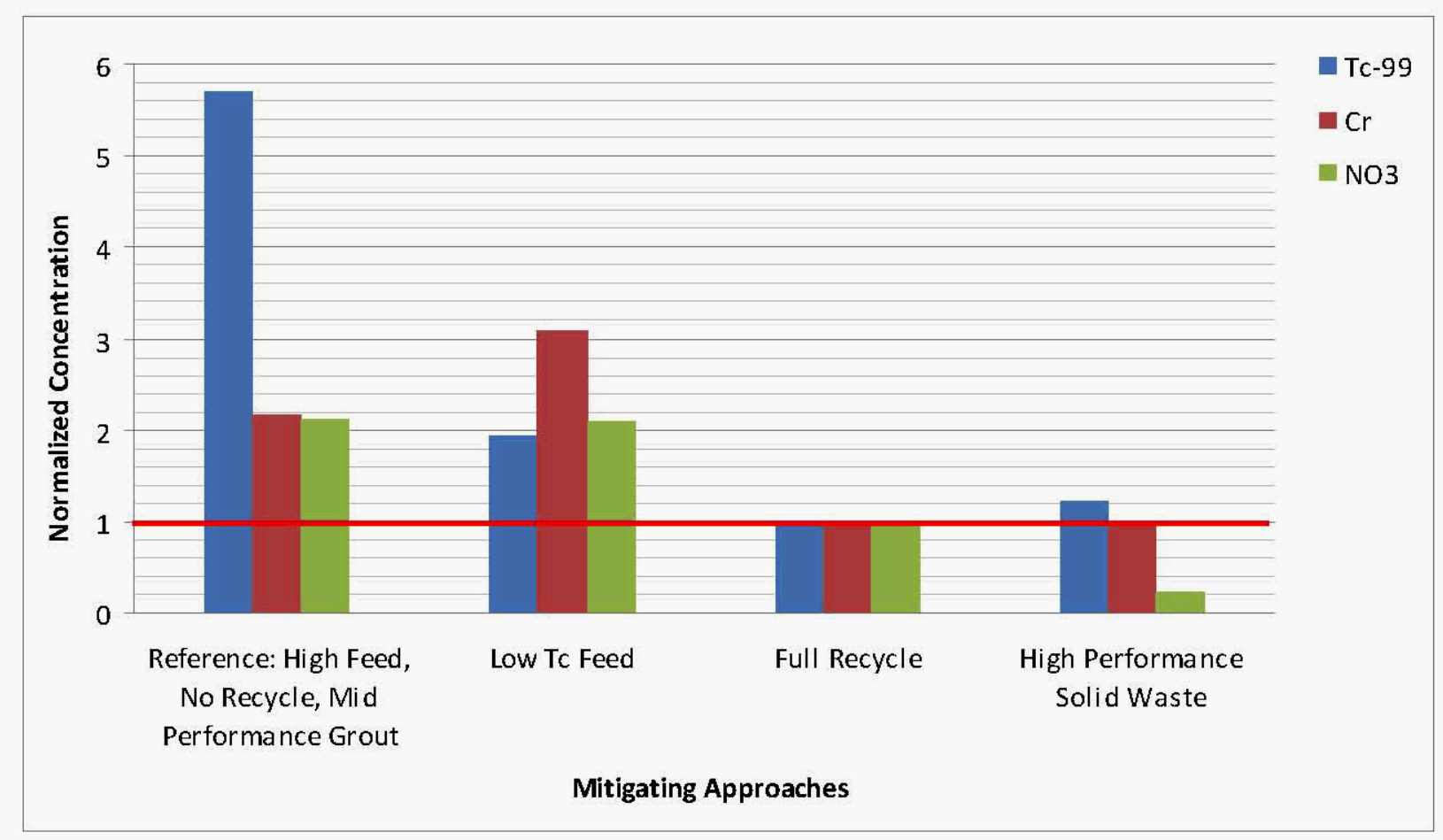

In Figure 3, the normalized maximum groundwater concentration in a ten thousand year window is shown for seven contaminants paired with three methods of handling the early LAW secondary waste stream. In the first method, None, represents all secondary waste going to the ETF. This represents a five to six fold increase in ${ }^{99} \mathrm{Tc}$ groundwater concentration above the baseline. The second method, ${ }^{99} \mathrm{Tc}$ Removal, represents the removal of $99 \%$ of ${ }^{99} \mathrm{Tc}$ within the secondary waste. This $99 \%$ represents a conservative ${ }^{99} \mathrm{Tc}$ removal estimate and could be accomplished through ion exchange or other processes. As shown in Figure 3, there is a negligible difference in groundwater ${ }^{99} \mathrm{Tc}$ concentration between ${ }^{99} \mathrm{Tc}$ removal and recycle. In the final method, Recycle, all secondary waste is recycled back to double-shell tanks (DST) for storage after concentration. This is equivalent to the base case by which all other cases are normalized. 
Figure 3. Effect of Varying the Change to WTP LAW Secondary Waste Stream.

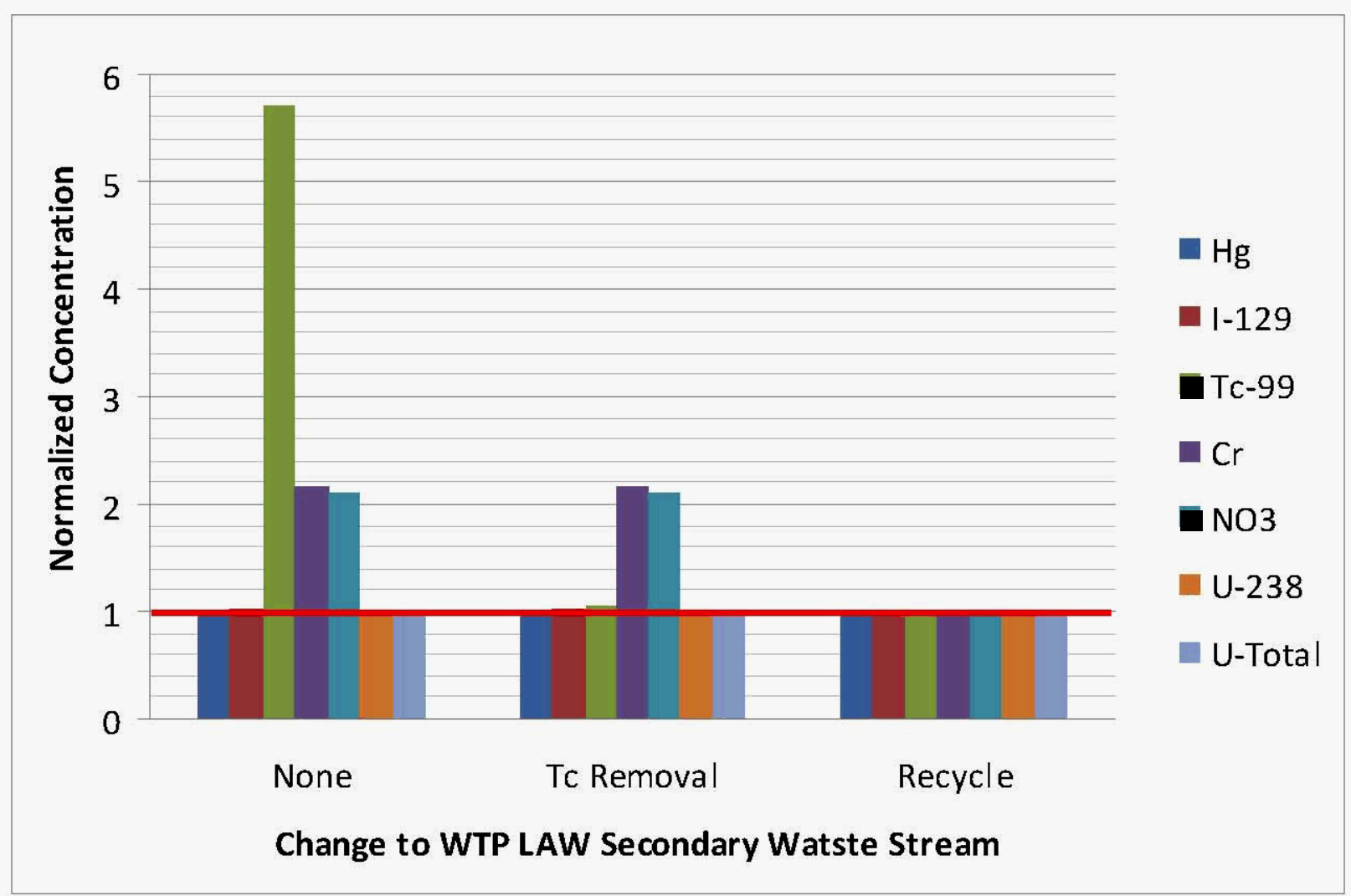

The normalized maximum groundwater concentration in a ten thousand year window is shown for seven contaminants paired with three types of waste feed as shown in Figure 4. As shown, the effect of different feeds is small on the groundwater concentration for $\mathrm{Hg},{ }^{129} \mathrm{I}$ and uranium. However, the concentration of ${ }^{99} \mathrm{Tc}$ increases approximately three fold between the low ${ }^{99} \mathrm{Tc}$ feed and the high ${ }^{99} \mathrm{Tc}$ feed. In this diagram, the high ${ }^{99} \mathrm{Tc}$ feed is representative of the waste within the DSTs, and represents approximately a three fold increase in ${ }^{99} \mathrm{Tc}$ groundwater concentration over the low ${ }^{99} \mathrm{Tc}$ feed. While changing to a low or mid $-{ }^{99} \mathrm{Tc}$ feed, lowers the ground water concentration of ${ }^{99} \mathrm{Tc}$, it actually increases the concentration of $\mathrm{Cr}$ and $\mathrm{NO}_{3}$. This is due to the categorization of feeds being based on their ${ }^{99} \mathrm{Tc}$ content, while being independent of nitrate and chromium. 
Figure 4. Effect of Varying the Quantity of ${ }^{99} \mathrm{Tc}$ in the Feed.

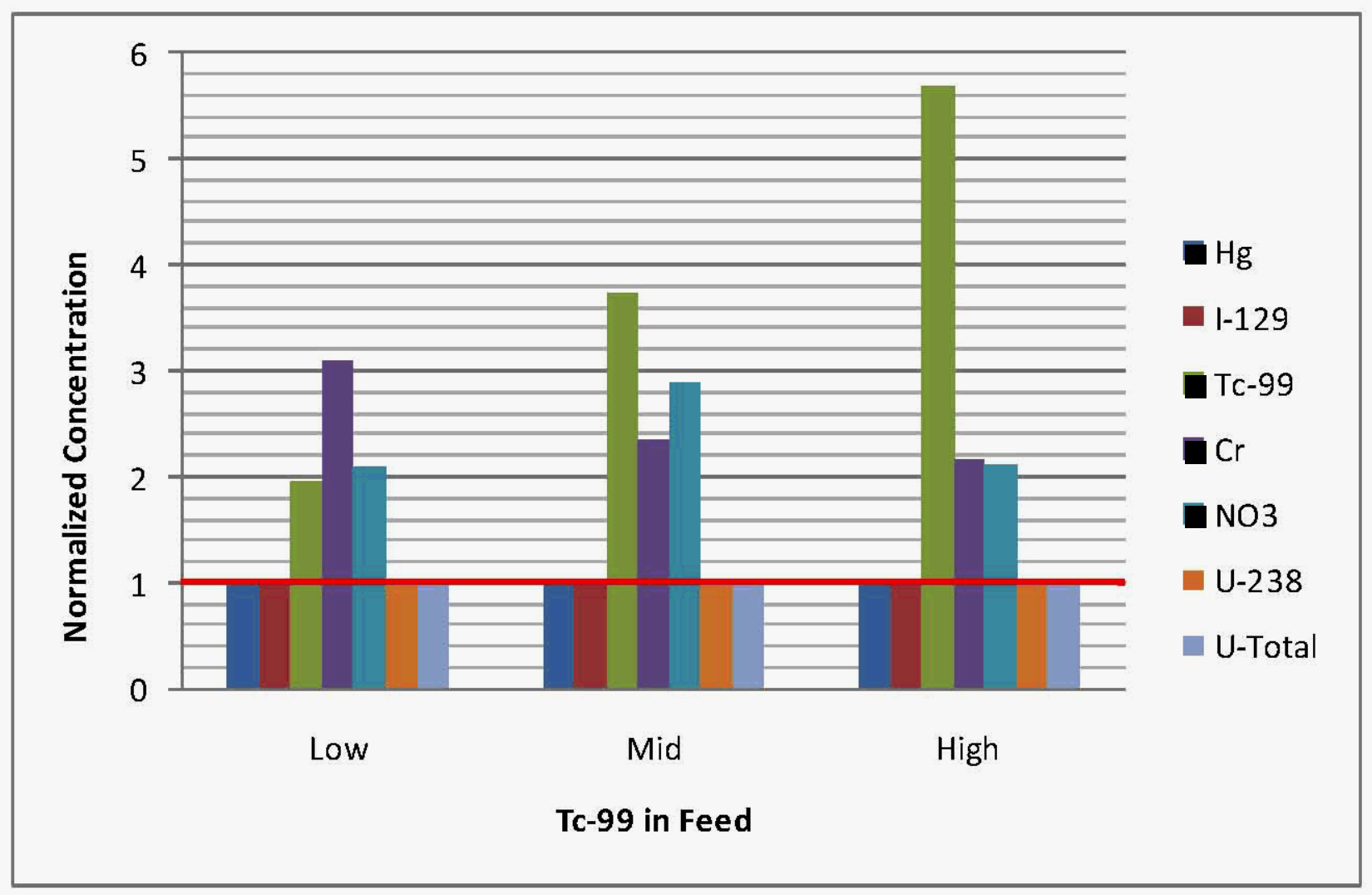

In Figure 5, the normalized maximum groundwater concentration in a ten thousand year window is shown for seven contaminants paired with three levels of solid waste performance. As shown, the concentration of ${ }^{99} \mathrm{Tc}$ increases to about 20 times that of the baseline when low performance solid waste form is used. However, when high performance solid waste form is used, the concentration is very close to the baseline and all other contaminants are at or below the baseline. The concentrations of other COCs diverge less from the baseline and as such are of a less concern. Results of additional sensitivity analyses are presented in Appendix A. 
Figure 5. Effect of Varying Waste Form Performance.

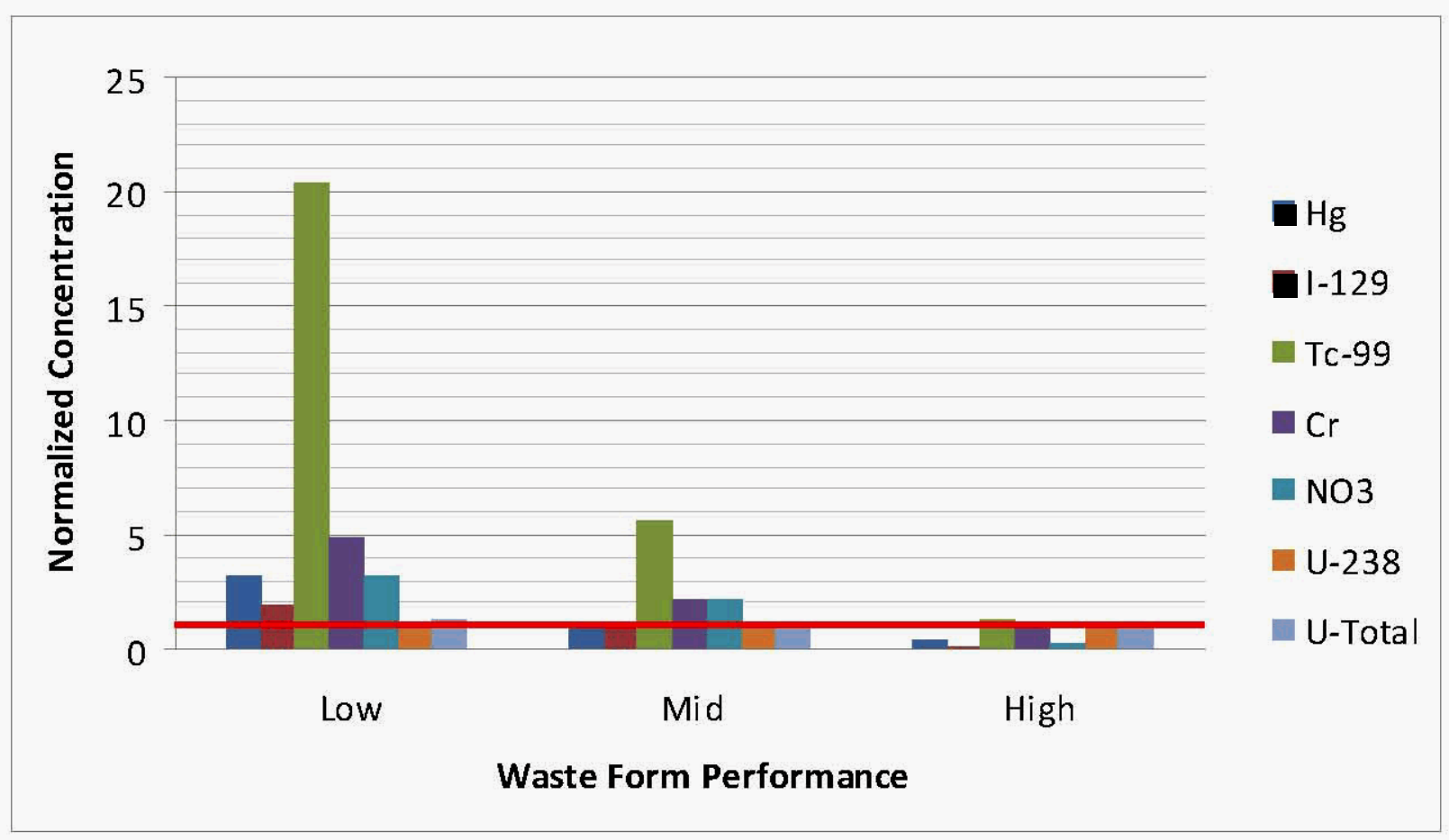

The groundwater impact is a function of COC inventories in all waste forms. Table 2 provides a perspective of the distribution of COCs in the anticipated waste forms for the baseline and the distribution of ${ }^{99} \mathrm{Tc}$ for the reference case and several mitigating approaches. The starting tank waste inventories for the COCs are shown in the top row. The distribution of COCs shown is over the life-cycle of the tank waste treatment mission. However, since the differences between the baseline and the other cases shown are driven by the five-year Early LAW treatment period, the comparison is applicable to the five-year period as well as the life-cycle period. This table does not show the contribution to groundwater contamination. A more detailed distribution of contaminants for the baseline and reference case is provided in Appendix A. , Tables A-2 and A-3. 
Table 2. Distribution of COCs in Final RPP Waste Forms.

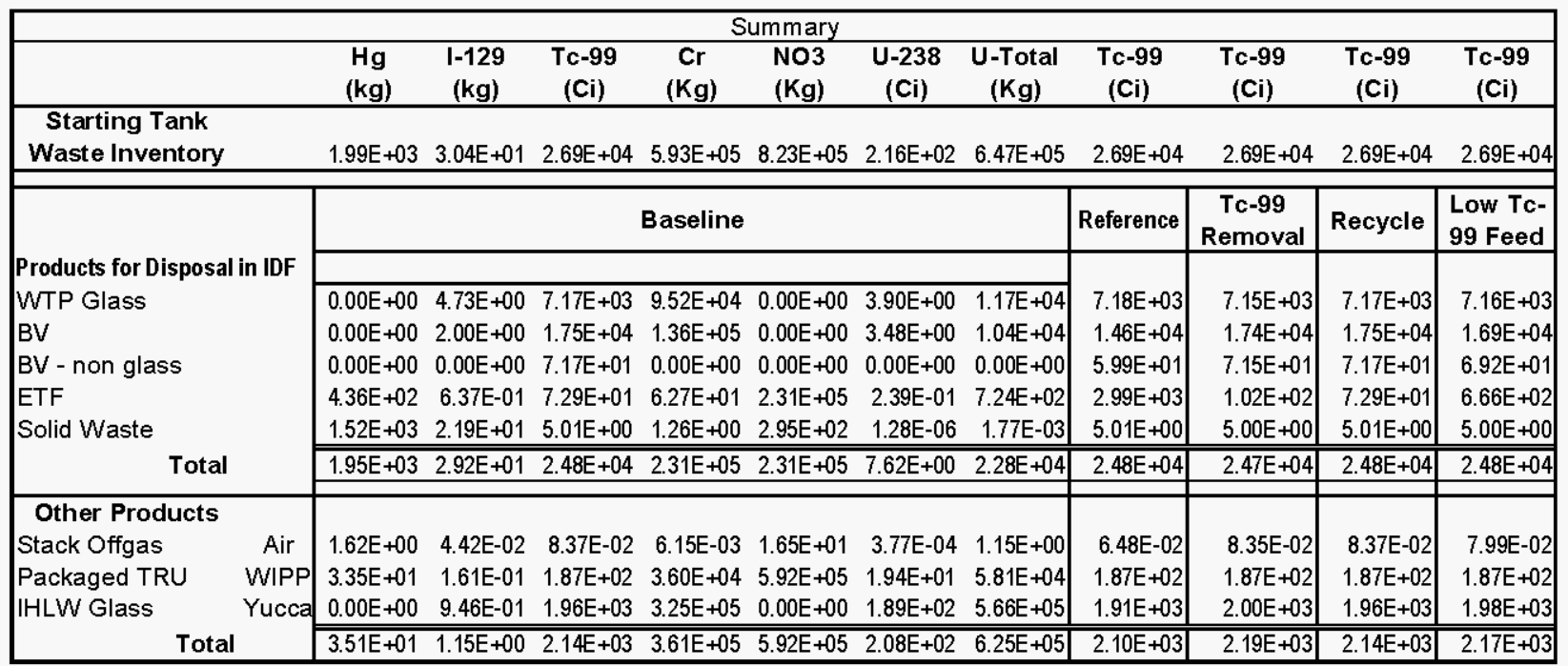




\subsection{MITIGATING APPROACHES}

As shown in section 4.0, the lack of a ${ }^{99} \mathrm{Tc}$ removal operation and LAW vitrification secondary waste recycle stream result in a higher concentration of ground water COCs. In lowering these concentrations to an acceptable level, several approaches were considered.

All of the mitigating approaches that were considered fit into one of four categories:

Table 3. Mitigating Approach Categories.

\begin{tabular}{|l|c|c|}
\hline \multicolumn{1}{|c|}{ Category } & Section & Mitigating Approaches \\
\hline $\begin{array}{l}\text { Select feed tanks with lower }{ }^{99} \mathrm{Tc} \\
\text { concentrations }\end{array}$ & 5.1 & 6 \\
\hline Remove Technetium & 5.2 & $5 \mathrm{a}, 5 \mathrm{~b}$ \\
\hline Concentrate and recycle secondary waste & 5.3 & $2 \mathrm{a}, 2 \mathrm{~b}, 3,4 \mathrm{a}, 4 \mathrm{~b}$ \\
\hline Improve secondary solid waste performance & 5.4 & $1 \mathrm{a}, 1 \mathrm{~b}$ \\
\hline
\end{tabular}

While several example approaches are examined in each category to define a reasonable range of technical solutions, not every possible approach is studied to limit the size and complexity of the evaluation. An example of an approach that was not considered was shipment of the secondary waste liquid effluent to an offsite treatment facility. The large volume of this waste stream, 4.7 million gallons per year, makes the transportation activity of this approach unattractive. Concentration of the effluent to a reasonable volume for transport is evaluated in this document. The difference in cost of treatment between offsite, onsite or storage in DSTs after concentration is expected to be small as described in Section 7.2

For approaches that recycle secondary waste, the waste first requires concentration to reduce the volume. The concentrate will be transferred to the double-shell tank system for interim storage and eventual processing in the WTP Pretreatment Facility. The condensate from the evaporator systems will be transferred to the ETF for treatment and disposal.

Ten approaches were considered as described above in Table 3:

- Approach 1a concentrates the waste at ETF to less than $10,000 \mathrm{ppm} \mathrm{Cl}$, cements the brine in the planned ETF Solidification Treatment Unit, and sends the cemented waste to IDF.

- Approach $1 \mathrm{~b}$ concentrates the waste at ETF to greater than $10,000 \mathrm{ppm} \mathrm{Cl}$, cements the brine in the planned ETF Solidification Treatment Unit, and sends the cemented waste to IDF. 
- $\quad$ Approach 2 a concentrates the waste at ETF to less than $10,000 \mathrm{ppm} \mathrm{Cl}$ and trucks the brine to a DST at the Tank Farm.

- $\quad$ Approach $2 \mathrm{~b}$ concentrates the waste at ETF to less than $10,000 \mathrm{ppm} \mathrm{Cl}$ and pumps the brine to a DST at the Tank Farm in a new pipeline.

- Approach 3 concentrates the waste at the 242-A Evaporator with the concentrate going to a DST.

- Approach 4a provides a new evaporator in a hardened facility in the $200 \mathrm{E}$ area to concentrate the secondary waste with the concentrate going to a DST.

- $\quad$ Approach $4 \mathrm{~b}$ provides a new evaporator in an industrial type facility in the $200 \mathrm{E}$ area to concentrate the secondary waste with the concentrate going to a DST.

- Approach 5a provides for technetium removal (ion exchange) in a DCRT-type facility in the $200 \mathrm{E}$ area.

- $\quad$ Approach 5b provides for technetium removal (ion exchange) in an industrial type facility in the $200 \mathrm{E}$ area.

- $\quad$ Approach 6 provides for early LAW feed selection from SSTs with a lower ${ }^{99} \mathrm{Tc}$ content.

\subsection{SELECT FEED TANKS WITH LOWER TECHNETIUM CONCENTRATION}

An adequate amount of feed was identified to meet mission requirements of $1,175 \mathrm{MT} \mathrm{Na} / \mathrm{yr}$ for both WTP ILAW and a single-line Supplemental Treatment system (RPP-RPT-37644, Interim Pretreatment System Mission Scoping Report). Three sets of tanks were selected to represent a range of ${ }^{99} \mathrm{Tc}$ in the feed. A high ${ }^{99} \mathrm{Tc}$ feed represents the reference case since DST waste was selected in an earlier engineering study on Early LAW Startup (RPP-29981, Evaluation of Starting the Waste Treatment and Immobilization Plant (WTP) Low Activity Waste (LAW) Facility First). The DST feed is mostly supernatant with DST salt cake and SST salt cake, if needed. Representing a Mid ${ }^{99}$ Tc feed is SST salt cake from $200-$ West Area U and S Farm tanks that are easily accessible and in sound condition and DST tanks to retrieve the SST waste into. Selection of Low- ${ }^{99} \mathrm{Tc}$ feed was opened up to all tanks including tanks assumed to have leaked, which led to 16 tanks in B- and BY-Farms. A summary of the feed groups are shown in Error! Reference source not found., which indicates a factor of 5 difference in ${ }^{99} \mathrm{Tc}$ content between the Reference group and the Low group of tanks. Further details of the feed groups can be found in SVF-1484, Interim Pretreatment System DST Feed Calculation, and SVF-1487, Interim Pretreatment System SST Feed Calculation. Identification of tanks and selected composition data are provided in Appendix B. Estimated costs to retrieve each of the tanks are provided in Appendix G. 
Table 4. Summary Feed Comparison.

\begin{tabular}{|l|l|c|c|c|c|}
\hline \multicolumn{2}{|c|}{ IPS Feed } & $\begin{array}{c}\text { Na } \\
\text { (MT) }\end{array}$ & $\begin{array}{c}{ }^{99} \mathbf{T c} \\
(\mathbf{C i})\end{array}$ & ${ }^{129} \mathbf{I}(\mathbf{C i})$ & Hg (kg) \\
\hline Reference & $\begin{array}{l}\text { DST supernatant \& salt cake as } \\
\text { needed - 8 tanks in AP \& AN } \\
\text { farms }\end{array}$ & 6,400 & 6,100 & 7.2 & 0.57 \\
\hline Mid & $\begin{array}{l}\text { SST saltcake, sound tanks, near } \\
\text { term access - 13 tanks in U and } \\
\text { S farms }\end{array}$ & 5,900 & 3,200 & 3.1 & 20 \\
\hline Low & $\begin{array}{l}\text { SST saltcake with lowest 99Tc } \\
\text { concentration - 16 tanks in B- } \\
\text { Complex }\end{array}$ & 5,900 & 1,200 & 1.8 & 32 \\
\hline
\end{tabular}

Note: Estimated DST compositions at start of FY2014

\subsection{REMOVE TECHNETIUM}

An evaluation of technetium removal technologies in support of an Early LAW study was completed in 2006 (RPP-RPT-30160, Supporting Information for the Evaluation of Waste Treatment and Immobilization Plant (WTP) Low Activity Waste (LAW) Startup First Scenario). This study selected ion exchange as the preferred technology. A summary of the technetium ion exchange approach is discussed below and details are provided in Appendix C.

The processes considered in the early study included:

- Fractional Crystallization

- Precipitation

- $\quad$ Tetraphenyl phosphonium (TPP) bromide precipitation

- $\quad$ Sulfide precipitation

- Ion Exchange

- Solvent Extraction.

A technetium ion exchange (Tc IX) process could be deployed in conjunction with the IPS cesium removal process or as separate facility built to treat the WTP LAW secondary liquid effluent.

SuperLig® 639 IX resin was selected for the high $\mathrm{pH}$ LAW feed stream where few resins provide adequate performance. Other less expensive resins are available for the near neutral $\mathrm{pH}$ secondary liquid effluent. Replacement of the Tc IX resin is not anticipated during the assumed five-year operating period of this process.

If the process were to be deployed as part of cesium removal process it would use a new process vault for the Tc IX equipment is shown in 
Figure 6 . The vault will be constructed with $3 \mathrm{ft}$ thick reinforced concrete walls and cover blocks. The vault would be lined with stainless steel to provide secondary containment for waste solutions. Cover blocks are removable shielding that provides maintenance access to the process piping and equipment. The vault is separated into three areas:

- valve area

- Te IX process area

- off-gas treatment area.

Figure 6. Tc Ion Exchange Process in New Vault.

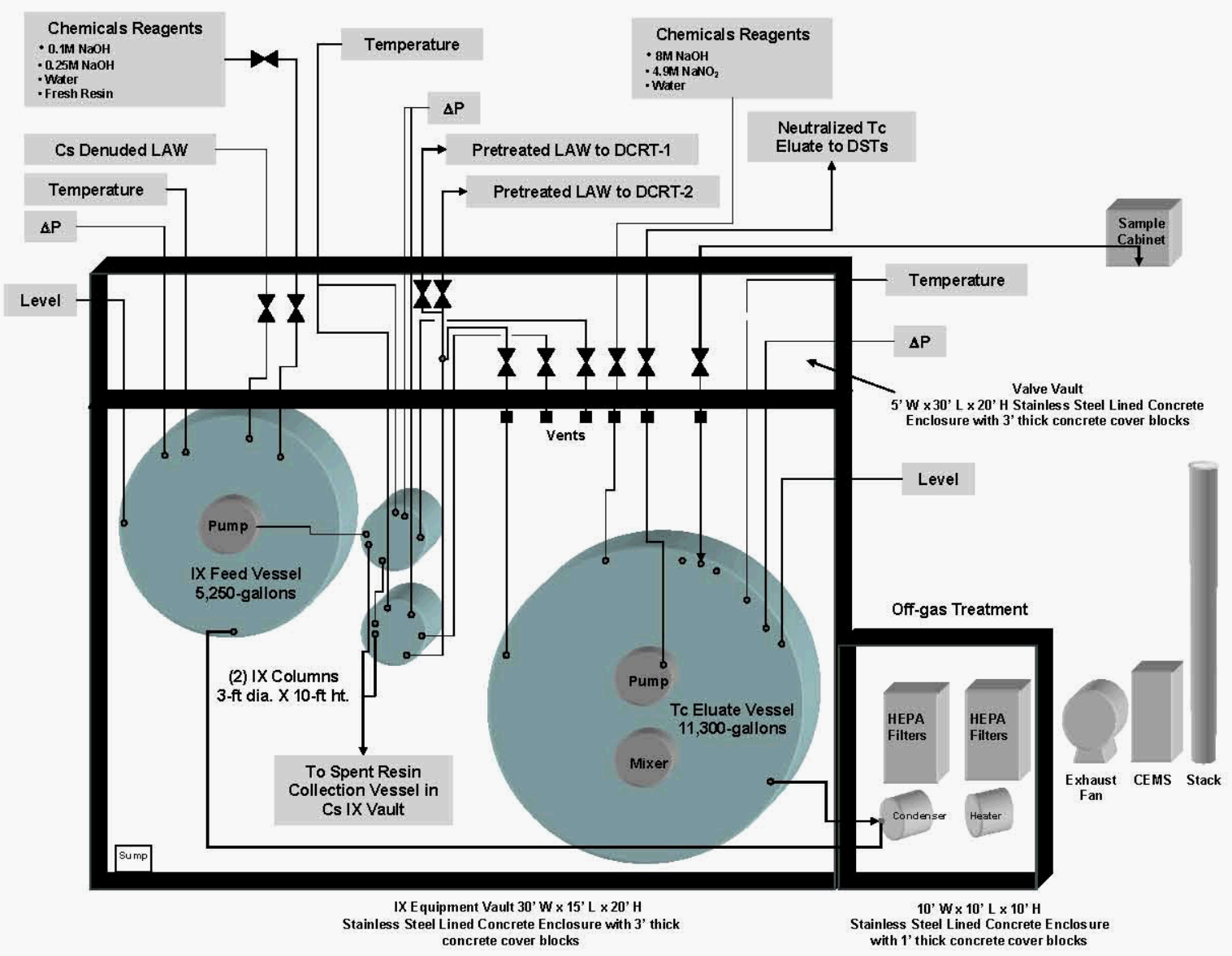

If the process were to be deployed as a separate facility built to treat the WTP LAW secondary liquid effluent, it would use an industrial structure similar to that used by ETF. Cost estimates of these two facility approaches are provided in Section 7.0. There is a high risk that this mitigating approach, which requires a large project, would not be completed in time to support early LAW operations due to the early nature of this concept and the required long funding cycle. 
RPP-RPT-37924, Rev. 0

\subsection{CONCENTRATE AND RECYCLE SECONDARY WASTE STREAM TO DSTS}

The reference case, as described in RPP-29981, does not remove ${ }^{99} \mathrm{Tc}$ during interim pretreatment or from the secondary waste and does not recycle LAW vitrification liquid secondary waste. Two distinct methods to reduce the amount of ${ }^{99} \mathrm{Tc}$ in the secondary waste during interim pretreatment operations by at least a factor of 100 include, 1) separation during pretreatment or from the secondary waste and 2) recycle of all or part of the secondary waste. Examples of ${ }^{99} \mathrm{Tc}$ separation technologies include ion exchange, fractional crystallization and solvent extraction. Examples of potential recycle approaches include, 1) recycle all to DST after concentration in the ETF, 2) recycle all to DST for concentration by 242-A Evaporator, 3) recycle all to new evaporator, and 4) recycle only SBS stream \& blend with IPS productconcentrate blend in new evaporator.

\subsubsection{Effluent Treatment Facility Concentration}

Fluor Hanford (FH) has performed a high-level treatability evaluation on the LAW effluent that is provided in Appendix D. Three approaches were evaluated including two concentration methods and one grouting method. The grouting approach is discussed in Section 5.4. Dilute secondary effluent from the WTP LAW facility can be concentrated in ETF with the concentrate transferred to DSTs via a tanker truck or a pipeline as shown in Figure 7.

Because of the small volume (4.7M gallons annual average) of LAW effluent that would be sent to Liquid Effluent Retention Facility (LERF) for treatment over a five-year period, FH could accept the LAW effluent at the LERF/ETF except for the LAW effluent generated from the treatment of Tank 107-AP waste, which exceeds the LERF safety basis. The ETF does not have the storage capacity required to maintain the radionuclide inventory below a Category 3 for the AP-107 effluent to bypass the LERF and be feed directly to the ETF.

The acceptance of the LAW effluent at LERF/ETF is contingent on the necessary permit modification and notifications being completed. Facility modifications are required to treat the LAW effluent through the LERF/ETF based on the final approach chosen. A complete list of necessary ETF equipment modifications for the two approaches is given in Appendix D. For the purposes of this treatability evaluation, it was assumed that the individual organics and applied waste codes (plus D007 for chromium) will be similar to those in the 242-A process condensate that ETF has successfully treated.

The two primary concerns with treating the LAW effluent through the ETF are scaling of unit operations and compatibility with the materials of construction. To mitigate these concerns, it is recommended that the ETF normal flowsheet be modified such that the LAW effluent is feed directly to the evaporator. Since the ETF main treatment train (MTT) is composed almost entirely of 304 stainless steel and to avoid irreversible scaling of the reverse osmosis (RO) unit, feeding the LAW effluent directly to the evaporator will reduce the cost of necessary modifications.

At a minimum, the two evaporator feed tanks (SWRTs) and all associated piping that comes in contact with the LAW effluent would need to be replaced with more corrosion resistant 
materials. Additionally, the existing cooling water system would be extended to cool the evaporator distillate.

Secondary waste effluent from WTP LAW during Early LAW operations contains chloride/fluoride concentrations of 500 to $1,200 \mathrm{ppm}$. Evaporation of the WTP effluent to two concentrations of chloride/fluoride, $10,000 \mathrm{ppm}$ and 40,000 ppm, were considered based on ETF equipment constraints. Replacing only the two SWRTs and associated piping results in a 10,000 ppm maximum concentration of chloride/fluoride in the evaporator brine. For waste minimization, replacing the two evaporator brine receiving tanks (CTs) and associated piping with corrosion resistant materials would allow the brine to be concentrated to $40,000 \mathrm{ppm}$ chloride/fluoride. The Inconel $\mathrm{TM}^{1}$ evaporator limits the brine to a concentration of $40,000 \mathrm{ppm}$ chloride/fluoride concentration.

Figure 7. Recycle to DSTs after Concentration in ETF.

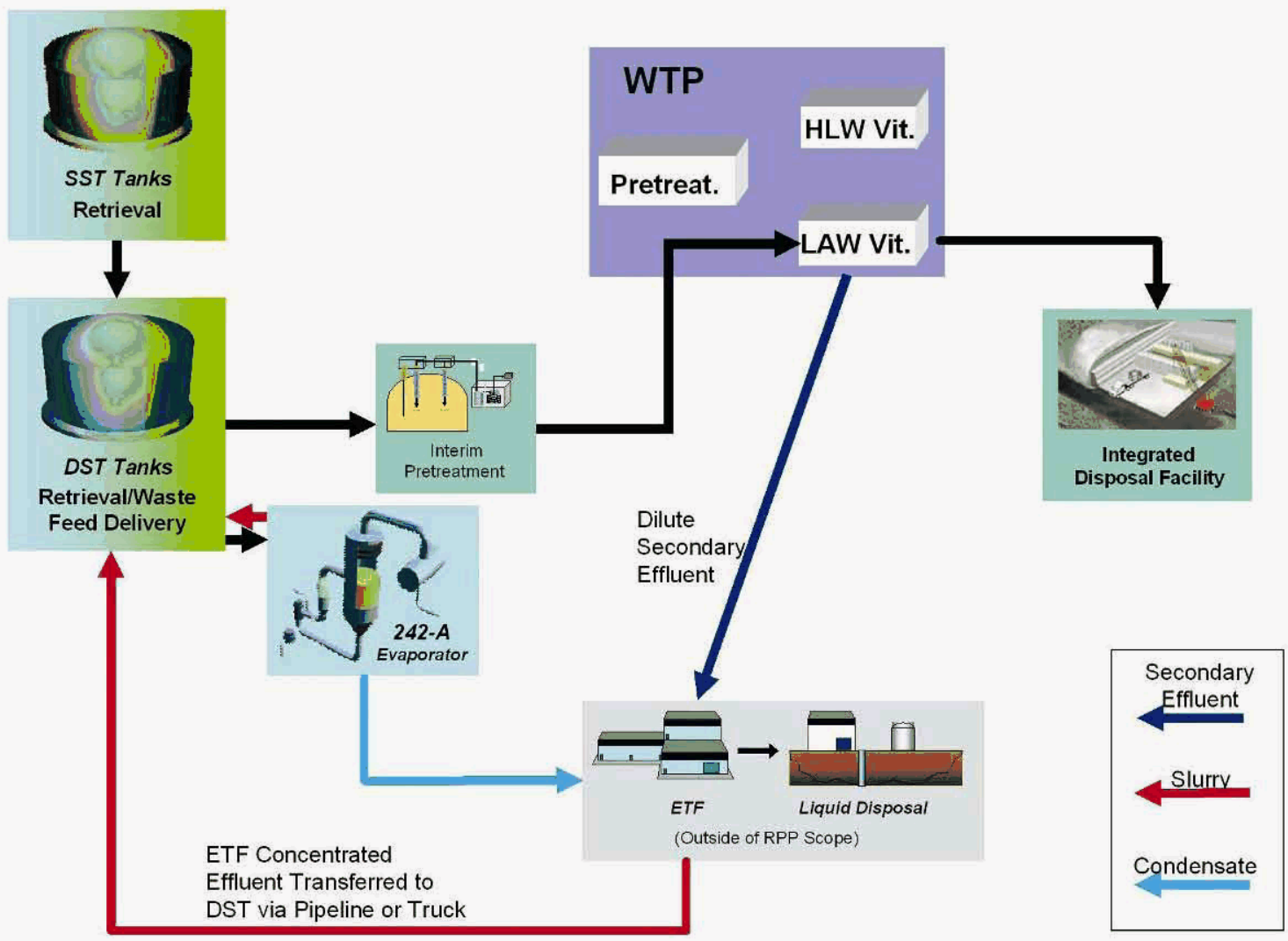

\footnotetext{
${ }^{1}$ Inconel is a registered trademark of Special Metals Corporation, Huntington, WV.
} 


\subsubsection{Recycle ETF Evaporator Brine to Tank Farms via Tanker Truck}

One approach for treatment of the ETF evaporator brine is to transport it to Tank Farms via tanker truck where it will be off-loaded into a DST. This approach would require construction of a separate tanker loading facility to the east of the ETF. The new facility would be a building approximately 75 by 100 feet with a confinement heating, ventilation, and air conditioning (HVAC) system. The building would be capable of holding a tanker and tractor, plus tanks and equipment for a solids removal and handling system. The solids removal system would be located in a separate room in order to provide containment of the radioactive solids. The equipment in the building would consist of:

- A tank to receive evaporator brine from the ETF concentrate tanks. The tank would be constructed of fiberglass reinforced panel (FRP) or Inconel.

- An agitator for the brine receiving tank.

- An Inconel pump and piping system to move the brine from the receipt tank to the solids removal system.

- A solids removal and handling system, most likely a filter press.

- A conveyed drum system to receive the solids from the filter press.

- A tank to receive the liquid effluent from the solids removal system. The tank would be constructed of FRP or Inconel.

- A pump and piping system to transfer from the effluent tank to a tanker. The wetted parts of the pump and piping would be constructed of Inconel.

- New tankers from corrosion resistant material such as Inconel, hastelloy, etc.

- Developing unloading technology at tank farms, which today does not exist.

At a minimum, tanker shipments of evaporator brine to Tank Farms would range from 1,500 gallons every two days to 3,000 gallons every two weeks depending on whether the chloride/fluoride concentration in the brine is less than or greater than $10,000 \mathrm{ppm}$.

\subsubsection{Recycle ETF Evaporator Brine to Tank Farms via New Pipeline}

This approach requires a new pipeline from the ETF to Tank Farms that meets all the current requirements that the existing Tank Farms pipelines meet (double encasement, leak detection, etc.). It is assumed that this pipeline will run from the ETF to the $\mathrm{SN}-701$ pipeline near the 242-A evaporator. This would require approximately 6,000 feet of new pipe. 
Evaporator brine is a continuous transfer to Tank Farms, or at a minimum of 1,500 gallons every two days to 3,000 gallons every two weeks, depending on whether the chloride/fluoride concentration in the brine is less than or greater than $10,000 \mathrm{ppm}$.

\subsubsection{2-A Evaporator}

Dilute secondary effluent from the WTP LAW facility can be concentrated in the 242-A evaporator or a new evaporator with the concentrated transferred to DSTs as shown in Figure 8. A new evaporator is discussed in Section 5.3.5.

Figure 8. Recycle to DSTs after Concentration in 242-A Evaporator or a New Evaporator.

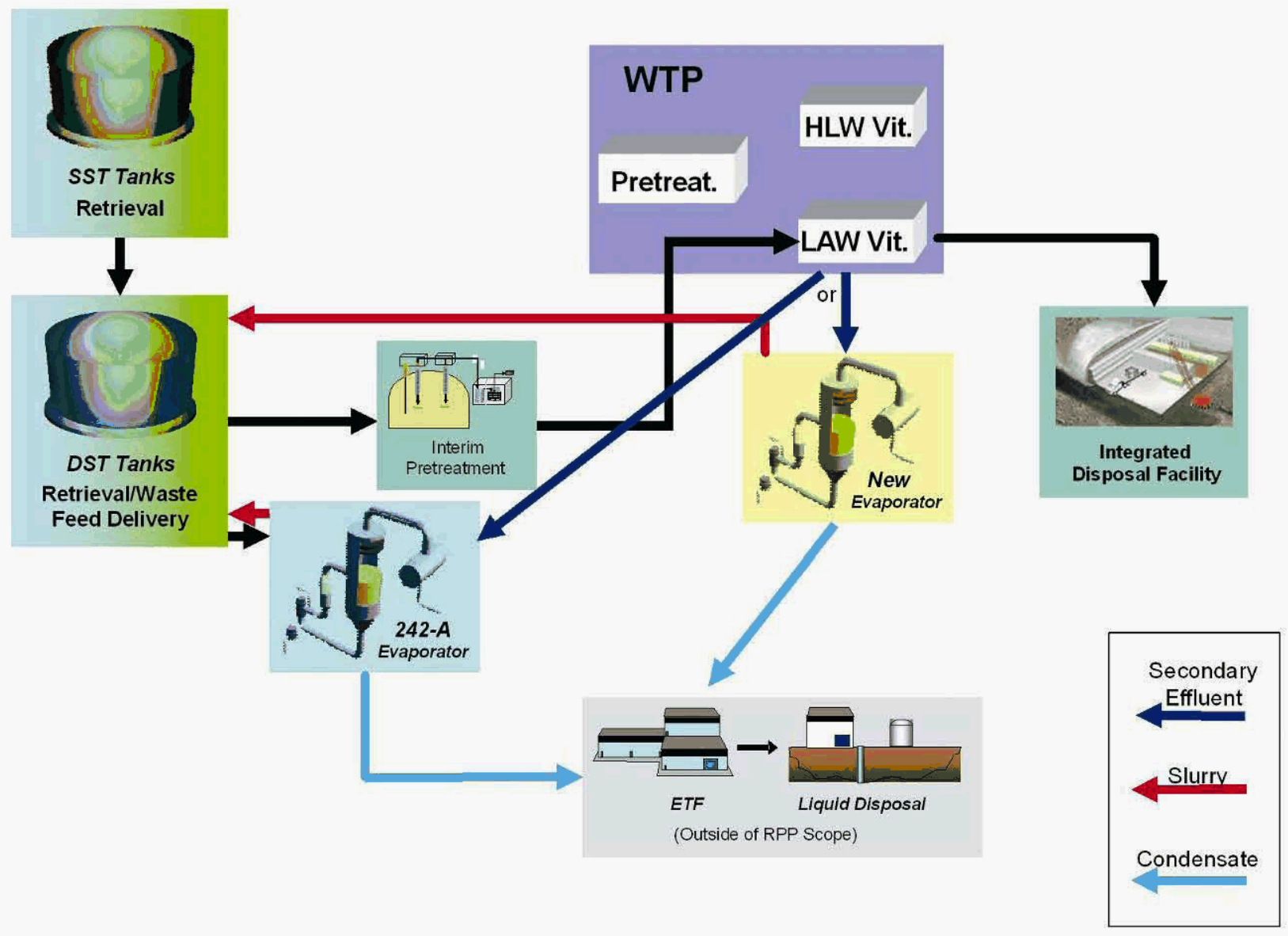

While it is technically feasible to concentrate the dilute secondary effluent in the 242-A evaporator, it is not recommended due to high corrosion risks to a facility which has a singlepoint failure for the RPP mission. These risks are described below and additional details of this mitigating approach are provided in Appendix A. .

Processing of the LAW secondary waste stream at 242-A increases risks to the plant. The stream has a higher concentration of chloride (relative to other waste constituents) than historical tank waste streams. Chloride is a major cause of corrosion in 304L stainless steel (which is the material of construction for 242-A). In addition, the recycle stream contains a small fraction of refractory elements resulting from LAW vitrification operations, of which aluminum and silicon 
are a special concern. Aluminosilicates are likely to form scale in the $242-\mathrm{A}$ system and possibly in distribution piping. Scale can affect processing and maintenance by reducing heat transfer rates and increasing dose rates. As aluminosilicate minerals are difficult to dissolve, acid dissolution may be necessary.

The 242-A Evaporator is essential to the Tank Farms mission. Previously identified mission risks include that 242-A is an aging facility, and that 242-A is a single-point failure facility (TFC-PLN-039, Risk Management Plan). Actions taken to mitigate risks include periodic upgrades (such as the ongoing ventilation and Monitoring and Control System upgrades) and maintaining a qualified and trained staff. Additional upgrades (such as, water supply, steam and electrical systems) will be necessary at some point during the extended mission. The worst-case impact for a 242-A single-point failure is a 5-year impact to the retrieval and WTP processing schedule ( $\$ 4.6$ billion cost impact), plus $\$ 100$ million for a replacement facility.

\subsubsection{New Evaporator}

\subsubsection{Concentrate Secondary Waste in Industrial Facility}

The approach discussed in this section is evaporation of the WTP LAW Vitrification Facility secondary waste solutions using a new evaporator system, referred to as the Secondary Waste Evaporator (SWE) system. A summary of the new evaporator approach is discussed below and details are provided in Appendix F.

The concentrate from the SWE system will be transferred to the double-shell tank system for interim storage and eventual processing in the WTP Pretreatment Facility. The condensate from the SWE system will be transferred to the ETF for treatment and disposal.

The SWE is similar to the Treated LAW Evaporation Process (TLP system) in the WTP Pretreatment Facility. The major differences are the feeds to be processed by each system. The TLP system is designed to increase the concentration of the pretreated LAW prior to transfer to the LAW vitrification facility and concentrate the SBS condensate recycled from the LAW vitrification facility. The TLP system is designed to process 10 to $38 \mathrm{gpm}$ of dilute feeds ${ }^{2}$. The SWE system could also perform these functions or may only process the SBS and caustic scrubber solutions.

It is assumed that the capacity and materials of construction for the SWE system will be the same as for the TLP system. The SWE system equipment description and capacity is taken from the design media prepared for the TLP system, with the capacity of support vessels recalculated to support the IPS system.

The 242-A Evaporator facility ${ }^{3}$ and the TLP Evaporator ${ }^{4}$ drawings were reviewed to gain insight into potential arrangement of process equipment for the SWE system. Based on review of these

\footnotetext{
2 24590-PTF-3PS-MEVV-TP001, River Protection Project - Waste Treatment Plant Engineering Specification for Forced Circulation Vacuum Evaporator System.

${ }^{3} \mathrm{H}-2-69269$, Architectural $1^{\text {st }}$ Floor Plan - 242-A, H-2-69270, Architectural $2^{\text {nd }}$ Floor Plan - 242-A, H-2-69271, Architectural Floor Plan - 242-A, H-2-69272, Architectural Elevations \& Sections - 242-A
} 
drawings, a preliminary arrangement of the SWE system was selected, as shown in Appendix F. The dimensions of the 242-A Evaporator building were generally used, with the exception of the process equipment area width and length being increased to incorporate the Secondary Waste Solutions Receipt Vessels within the SWE system building. The 242-A Evaporator building does not contain similar vessels and uses a double-shell tank as the feed vessel. The area for the control room, motor control centers, change rooms was also enlarged from approximately 42 (W) $\times 36(\mathrm{~L}) \times 11 \mathrm{ft}(\mathrm{H})$ for the 242-A Evaporator building to $75(\mathrm{~W}) \times 118(\mathrm{~L}) \times 12 \mathrm{ft}(\mathrm{H})$ for the SWE system. This change was made to remedy the congestion experienced in these areas within the 242-A Evaporator building. Similarly, the area of the Aqueous Make-up/HVAC systems was enlarged from approximately $25(\mathrm{~W}) \times 50(\mathrm{~L}) \times 47 \mathrm{ft}(\mathrm{H})$ for the 242-A Evaporator building to $25(\mathrm{~W}) \times 93(\mathrm{~L}) \times 47 \mathrm{ft}(\mathrm{H})$ for the SWE system to remedy congestion in this area as well. Use of horizontal evaporator instead of a vertical evaporator would not be expected to significantly change the facility size and therefore was not further considered.

\subsubsection{Concentrate Blended Secondary Waste with IPS Feed To Simulate WTP Pretreatment}

The SWE system could also be used to concentrate the pretreated LAW solution prior to transfer to the LAW Vitrification Facility. However, this approach was not evaluated in detail since the composition of the pretreated LAW and the secondary waste solutions would be altered and material balances were not prepared for this alternative by WTP personnel. If this approach was pursued, it is expected to closely mimic the baseline WTP flowsheet as shown in Figure 9.

There is a high risk that these mitigating approaches, which require a large project, would not be completed in time to support early LAW operations due to the early nature of this concept and the length of time required to secure capital funding. 
Figure 9. Blend Secondary Effluent with IPS Product and Concentrate in New Evaporator to Simulate WTP Flowsheet.

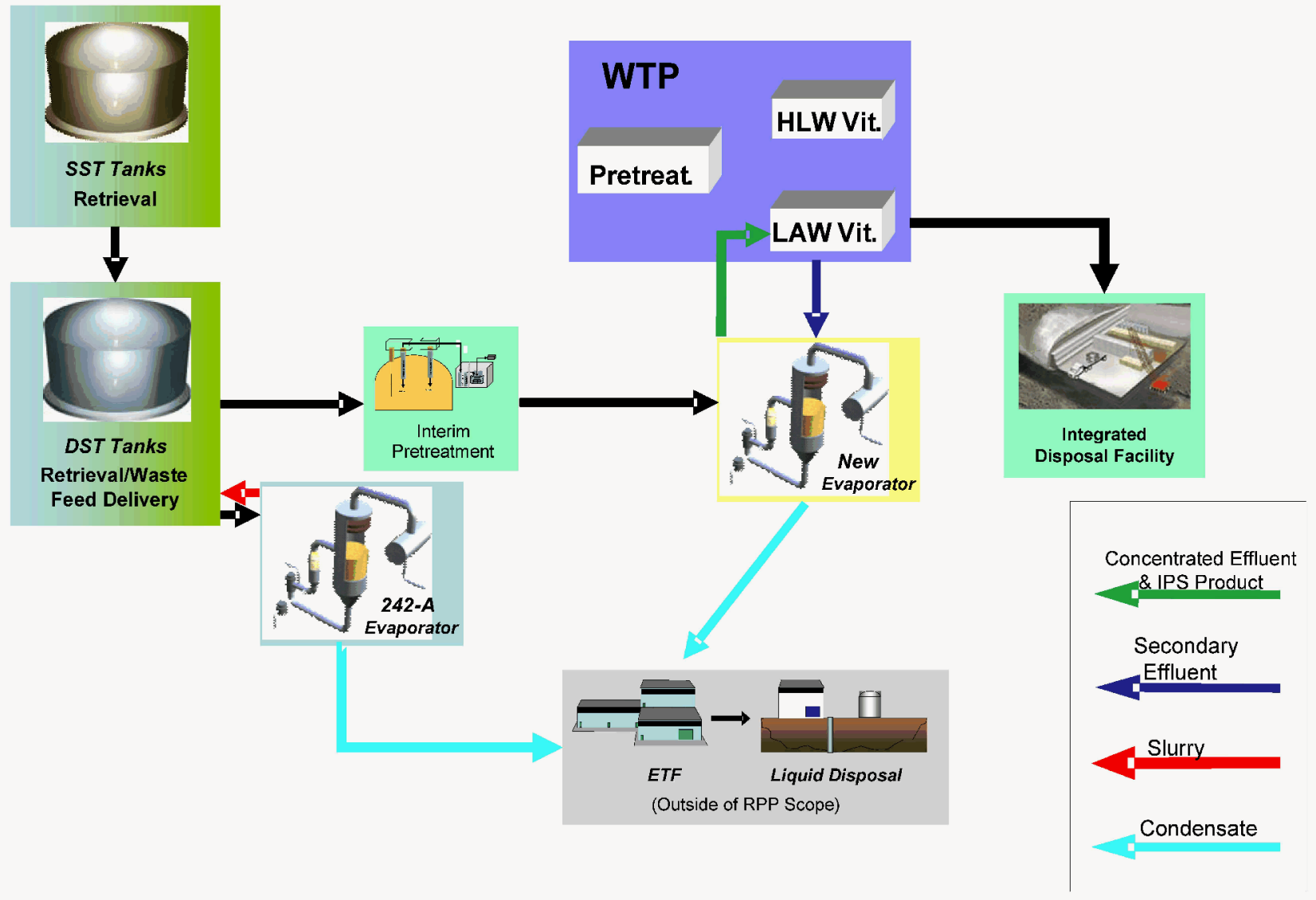

\subsection{IMPROVE SOLID WASTE FORM PERFORMANCE}

Solid waste performance improvements could be implemented at ETF to immobilize liquid secondary wastes from LAW vitrification as a mitigating approach to negative groundwater impacts. A performance improvement in the solid waste form diffusion coefficient from 5.0 E-9 to $5.0 \mathrm{E}-11 \mathrm{~cm} 2 / \mathrm{sec}$ is needed to mitigate the negative impact.

Ongoing work at ETF to establish a new solidification treatment unit and improvements in new solid waste forms are discussed below.

\subsubsection{ETF Planned Solidification Treatment Unit}

This approach currently plans a treatment unit that would solidify the evaporator brine into blocks and a storage building to cure blocks before they can be sent to IDF for disposal. The solidification treatment unit project is currently budgeted as a fiscal year 2010 line item project. 
The Critical Decision 0 (Mission Need Statement) for the Solidification Treatment Unit (STU) has been sent to DOE-RL but has not yet been approved.

The purpose of the STU is to replace or supplement the current operation at the 200 Area ETF for drying the secondary waste into powder in order to increase the capability of the ETF. Expanding ETF capabilities is needed in order to meet Tri-Party Agreement milestones associated with the Hanford cleanup, reduce worker chemical and radiological exposure, meet land disposal criteria, and decrease the cost of maintaining and operating the current thin-film dryer system.

Expanding the ETF capabilities allows the ETF to treat future waste streams with higher levels of heavy metals and mobile radionuclides, and waste streams with high dissolved solids content. Increasing the capacity of the secondary treatment train will allow full utilization of the existing capacity of the ETF main treatment train. Based on waste stream flowsheet projections, the increased capacity is needed by 2014 to support the Hanford Site cleanup mission.

Some preliminary testing of brine solidification has been completed on current waste streams processed through the ETF. Further testing would be necessary to establish the raw material mix (Portland cement, lime, fly ash, etc.) for the LAW brine. During the testing it will be necessary to measure chromium leachability to determine if the land disposal restrictions (LDR) treatment standard for chromium is met and the testing of getters that may be required to stabilize radionuclides if above the IDF acceptance criteria (such as, ${ }^{99} \mathrm{Tc},{ }^{129} \mathrm{I}$ ). There is uncertainty whether grout solidification is an acceptable waste form for stabilization of ${ }^{99} \mathrm{Tc}$ and ${ }^{129} \mathrm{I}$ for final disposal at IDF.

\subsubsection{Improved Solid Waste Forms}

Examples of recently tested low temperature waste forms with enhanced performance include DuraLith and Ceramicrete (PNNL-16052, Low Temperature Waste Immobilization Testing). These two waste forms perform better than a traditional LAW grout such as Cast Stone relative to leach resistance of ${ }^{99} \mathrm{Tc}$ and ${ }^{129} \mathrm{I}$. Development needs common to both waste forms include:

- $\quad$ Address the formulation issues identified through the ANSI/ANS-16.1-2003, Measurement of the Leachability of Solidified Low-Level Radioactive Wastes by a Short-Term Test Procedure, testing and perhaps also in the product consistency test (PCT) testing.

- Using waste simulants spiked with higher concentrations of I and Re, determine whether the waste forms can achieve sufficient reduction in the release of I and Tc.

- $\quad$ Based on observations from ANSI/ANS 16.1 testing and contractor thermal cycling tests on Ceramicrete, expand compressive strength testing to include impacts of thermal cycling and immersion in water. 
- Optimize the quantities of binder materials to improve waste loading. If acceptable, this may include the removal of water to concentrate the wastes to be immobilized

- $\quad$ Examine other binder materials that may be less costly.

- Demonstrate the long-term effectiveness of sequestering agents added to reduce the mobility of iodine and technetium in the wastes.

- Demonstrate the preparation of the waste forms on a production scale.

- Determine long-term waste-form-performance characteristics to support disposalsystem performance assessments.

An allowance of $\sim \$ 5 \mathrm{M}$ for additional waste form formulation and performance testing is estimated to meet the higher performance level. This includes $\$ 4 \mathrm{M}$ for lab testing and support and $\$ 1 \mathrm{M}$ for an independent external review of the program.

The efficacies of improved waste forms will be further addressed in July, 2008, at the Secondary Waste Roadmap Meeting at Richland, WA. At the request of the DOE Office of River Protection, DOE EM-21 agreed to sponsor a meeting to develop a roadmap to outline the steps necessary to design the secondary waste form to resolve uncertainties associated with disposal of secondary waste from treatment of tank waste at Hanford. In the Secondary Waste Roadmap Meeting, a "needs assessment" will be performed to identify issues, assess current capabilities versus those issues, and identify gaps and associated program goals, in the areas of interest. This assessment is complete when a consensus is developed and documented on the technical needs and gaps and the direction for the program.

\subsubsection{Other Solids Waste Forms}

Other solid waste forms in which WTP liquid secondary waste could be immobilized, such as Steam Reforming product, Bulk Vitrification glass and other thermal processes, were not analyzed in this evaluation for several reasons.

- Inadequate published data was available for Steam Reforming on secondary waste treatment to complete a technical evaluation. While increased waste loading in the Steam Reforming product may be feasible due to nitrate destruction and mineralization during the process, analysis of this benefit could not be quantified.

Bulk Vitrification and other high temperature processes are typically much more expensive than low temperature processes for immobilizing secondary waste. Approaches for recycling secondary waste in this report maximize the amount of COCs that can be placed in a glass waste form during the Early LAW operating period. Evaluation of glass as a waste form for secondary waste throughout the life-cycle of the RPP mission is outside of the scope of this study. 


\subsection{PROGRAMMATIC RISK}

Key programmatic risks are identified where a large impact is expected. Risks were identified where the outcome of a risk event was expected to have a large impact on a mitigating approach such that it clearly distinguishes approaches. A comprehensive risk assessment was not performed as part of this document. The IPS Project Risk Management List further addresses risk management.

There is a high risk that mitigating approaches requiring large capital projects including ${ }^{99} \mathrm{Tc}$ removal and a new evaporator would not be completed in time to support early LAW operations. This is due to the long procurement cycle of large DOE projects and the preliminary nature of these facility concepts. Schedule risk is carried as part of the IPS Risk List. Detailed schedule information about secondary waste mitigation will part of the overall Early LAW schedule.

All mitigating approaches that concentrate liquid effluents and recycle the stream to the DST system place some additional burden on the DST system capacity thereby increasing overall risk. If waste volume reductions of at least $90 \%$ to $95 \%$ are not achieved during evaporation then a volume in excess of $0.5 \mathrm{Mgal}$ could be returned to DSTs.

For low ${ }^{99} \mathrm{Tc}$ concentration feed tanks, the retrieval rates of salt cake in assumed leaker SSTs may not keep up with LAW treatment rates. Salt cake retrieval from two sound SSTs, S-102 and $\mathrm{S}-112$, have taken several years each. There is no experience yet retrieving waste from SSTs which are assumed to have leaked. Planning assumptions based on limited experience with a vacuum based retrieval system indicate longer periods will be required to retrieve waste from assumed leaker tanks than from sound tanks.

There is more uncertainty in the ${ }^{99} \mathrm{Tc}$ content of SST waste than in DST waste. Best-Basis Inventory (BBI) compositions for most DST are based on sample results providing a higher level of confidence in the values. The BBI compositions for most SSTs are based on engineering judgment, flowsheet data and common waste types yielding a lower level of confidence in the values. Factors influencing the technetium oxidation state in tank waste are not well understood. This can lead to erroneous assumptions on technetium partitioning and increased uncertainty in inventories. 


\subsection{COST COMPARISON}

Cost estimate data associated with each of the ten approaches are provided below. The cost estimates in this section are life-cycle based and include concept development, permitting, design, capital improvements, startup, 5 years of operations, decommissioning, contingency and escalation. The cost estimates only include the costs that are not included in the current baseline plans. For example, the $\$ 14.1$ million ETF Solidification Treatment Unit project is in the current baseline and is not included in the estimated cost for the ETF approaches. However, the ETF Solidification Unit operating cost is not in the current baseline and therefore is included in the estimated cost of applicable ETF approaches.

Cost estimates were prepared for mitigating approaches to assist in a quantitative approach comparison. The cost estimates are summarized in this section and provided in detail in Appendix G.

\subsection{COST OF SELECTING ALTERNATIVE FEED TANK GROUPS}

Cost estimates for Approach 6, potential feed selections, are accelerated costs from the Tank Farm baseline. A summary of these cost estimates are shown in Table 4 and details are provided in Appendix G.

Table 5. Summary Cost of Potential Feed Selection.

\begin{tabular}{|l|r|}
\hline & \multicolumn{1}{|c|}{$\begin{array}{c}\text { Total } \\
\mathbf{( \$ M )}\end{array}$} \\
\hline $\begin{array}{l}\text { High } \\
\text { (Reference) }\end{array}$ & $\$ 23$ \\
\hline Mid $^{99} \mathrm{Tc}$ Feed & $\$ 268$ \\
\hline Low ${ }^{99} \mathrm{Tc}$ Feed & $\$ 418$ \\
\hline
\end{tabular}

\subsection{COST TO REMOVE TECHNETIUM OR CONCENTRATE AND RECYCLE SECONDARY WASTE}

This section provides summary cost estimate data for the other nine mitigating approaches associated with early operations of the WTP LAW Facility. The detailed cost estimate for each approach is in Appendix G.

The assumed schedule is to complete development, design, construction and startup by 2013 and start 5 years of hot operation in 2014 operating for a period of five years followed by facility deactivation and decommissioning. 
The other nine approaches and estimated life-cycle cost are:

Approach 1a: Concentrate the waste at ETF to $\leq 10,000 \mathrm{ppm} \mathrm{Cl}$ and cement the brine in the planned ETF Solidification Treatment Unit. The cemented waste will be sent to IDF at a prorated disposal cost of $\$ 21,500$. The estimated cost for Approach 1a is $\$ 30.5$ million. The \$14.1 million planned for the ETF Solidification Treatment Unit is not included in the $\$ 30.5$ million. However, the additional cost to operate the cementation process is not in the baseline so it is included in this estimate.

Approach 1b: Concentrate the waste at ETF to $\geq 10,000 \mathrm{ppm} \mathrm{Cl}$ and cement the brine in the planned ETF Solidification Treatment Unit. The cemented waste will be sent to IDF at a prorated disposal cost of $\$ 6,100$. The estimated cost for Approach $1 \mathrm{~b}$ is $\$ 34.7$ million. The $\$ 14.1$ million planned for the ETF Solidification Treatment Unit is not included in the $\$ 34.7$ million. However, the additional cost to operate the cementation process is not in the baseline so it is included in this estimate.

Approach 2a: Concentrate the waste at ETF to $\leq 10,000 \mathrm{ppm} \mathrm{Cl}$ and truck the brine to a DST at the Tank Farm. The estimated cost for Approach 2a is \$33.6 million.

Approach 2b: Concentrate the waste at ETF to $\leq 10,000 \mathrm{ppm} \mathrm{Cl}$ and pump the brine to a DST at the Tank Farm in a new pipeline. The estimated cost for Approach $2 b$ is $\$ 43.4$ million.

Approach 3: Concentrate the waste at the 242-A Evaporator with the concentrate going to a DST. The estimated cost for Approach 3 is $\$ 50.0$ million.

Approach 4a: Develop a new evaporator facility in the 200-East area to concentrate the waste secondary waste with the concentrate going to a DST. Approach 4a includes constructing a hardened facility to enclose the new evaporator. The estimated cost for Approach $4 \mathrm{a}$ is $\$ 132.3$ million.

Approach 4b: Develop a new evaporator facility in the 200-East area to concentrate the waste secondary waste with the concentrate going to a DST. Approach 4b includes constructing an industrial facility to enclose the new evaporator. The estimated cost for Approach $4 \mathrm{~b}$ is $\$ 124.1$ million. A discussion of the differences in new evaporator building cost for approaches $4 \mathrm{a}$ and $4 \mathrm{~b}$ is provided in Appendix $\mathrm{G}$, Section H7.1.

Approach 5a: Develop a technetium removal facility in the 200-East area. Approach 5a includes constructing a DCRT-type facility to enclose the ion exchange equipment. The estimated cost for Approach 5a is \$106.6 million.

Approach 5b: Develop a technetium removal facility in the 200-East area. Approach 5b includes constructing a standard industrial enclose for the ion exchange equipment. The estimated cost for Approach $5 \mathrm{~b}$ is $\$ 94.2$ million.

A summary comparison of the estimated cost for approaches $1 \mathrm{a}$ through $5 \mathrm{~b}$ is shown in Figure 10 . 
Figure 10. LAW Secondary Waste Stream Processing Life-Cycle Cost.

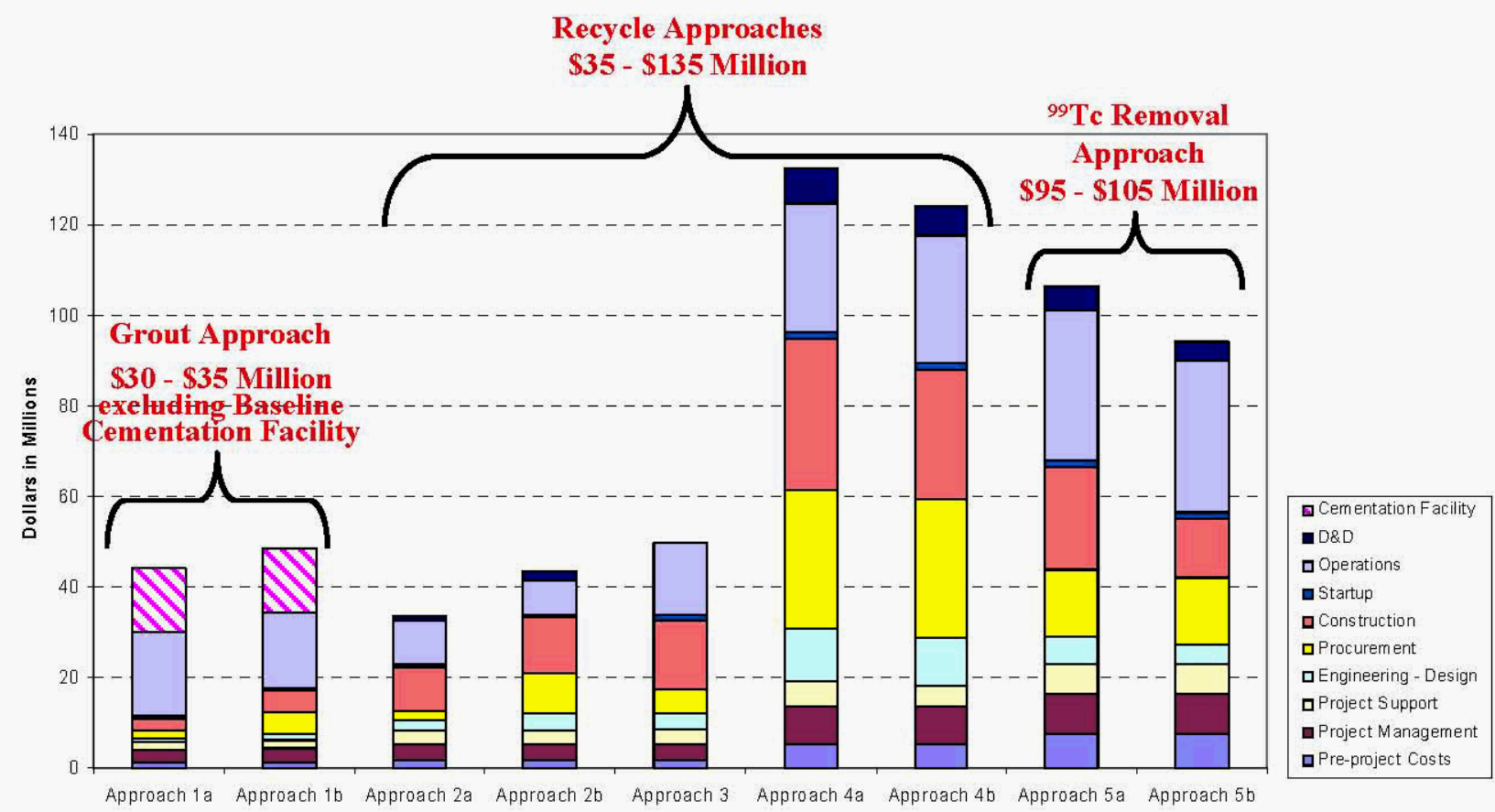

Cost estimates details and the basis used to develop the cost estimates for the 10 approaches are provided in Appendix G.

\subsection{COST TO IMPROVE SECONDARY SOLID WASTE PERFORMANCE}

An allowance of $\sim \$ 5 \mathrm{M}$ for additional solid waste formulation and performance testing is estimated to meet the higher solid waste performance level. This includes $\$ 4 \mathrm{M}$ for lab testing and support and $\$ 1 \mathrm{M}$ for an independent external review of the program. This is based on expansion of recent solid waste testing by Fluor Hanford for $\$ 250 \mathrm{~K}$ to meet the expected increased demands as a result of the Secondary Waste Roadmap Meeting. The total cost to improve secondary solid waste performance is $\$ 35 \mathrm{M}$ to $\$ 40 \mathrm{M}$ which is the sum of Approach 1a or $1 \mathrm{~b}$ as described for facility modifications at ETF and the $\$ 5 \mathrm{M}$ for additional solid waste formulation and performance testing. 
RPP-RPT-37924, Rev. 0

\subsection{RECOMMENDED STRATEGY}

The recommended strategy for managing RPP secondary waste is focused on improvements in the Effluent Treatment Facility. Baseline plans to build a Solidification Treatment Unit adjacent to ETF should be enhanced to improve solid waste performance and mitigate corrosion of tanks and piping supporting the ETF evaporator. This approach provides a life-cycle benefit to solid waste performance and reduction of groundwater contaminants for the entire RPP mission.

This recommended approach will be further evaluated as part of the Secondary Waste Roadmap Meeting scheduled for July $21-25,2008$, sponsored by DOE EM-21. Nationally recognized subject matter experts will address the same RPP secondary waste issues addressed in this document and develop a technology road map needed to resolve the issues. The road map will further address technical, programmatic and regulatory uncertainties associated with the recommendation.

A backup strategy, if solid waste performance improvements are unsuccessful, would be a recycle capability for transfer of concentrated liquid effluents from ETF to the DST system via pipeline or truck. This approach, while meeting near goals during early LAW operations, provides very little or no life-cycle benefit to the RPP mission after the WTP Pretreatment facility becomes operational.

Both the recommended and backup secondary waste management strategies provide high value technical solutions with low schedule risk that are outside of the scope of the IPS project.

The recommended and backup strategies are the lowest life-cycle cost approaches with adequate mitigation of potential groundwater contamination compared to baseline values:

- Improve solid waste performance: Evaporator upgrades at ETF and solid waste performance testing program ( $\$ 35 \mathrm{M}$ to $\$ 40 \mathrm{M})$

- $\quad$ Recycle to DSTs: Evaporator upgrades and new transfer capability at ETF $(\$ 35 \mathrm{M}$ to $\$ 45 \mathrm{M})$.

The recommended strategy includes an allowance of $\sim \$ 5 \mathrm{M}$ for additional solid waste formulation and performance testing is estimated to meet the higher performance level. This includes $\$ 4 \mathrm{M}$ for lab testing and support and $\$ 1 \mathrm{M}$ for an independent external review of the program. The $\$ 5 \mathrm{M}$ is included in the $\$ 35 \mathrm{M}$ to $\$ 40 \mathrm{M}$ range shown above.

The reference case (no mitigation) would increase the ${ }^{99} \mathrm{Tc}$ groundwater concentration ratio about 5.7 times relative to the baseline as shown in Figure 11. Changing to a lower ${ }^{99} \mathrm{Tc}$ feed does improve performance, but is still higher than the RPP baseline. This approach is not recommended due to the high accelerated cost of $\$ 400 \mathrm{M}$ to $\$ 450 \mathrm{M}$ and high risk associated with the fast retrieval rate needed to retrieve 16 SSTs in the B-Complex tank farms within a 5 year period.

Mitigating approaches such as ${ }^{99} \mathrm{Tc}$ removal or recycle to Tank Farms, or a better performing solid waste show near equivalent performance to the RPP baseline. Other approaches providing adequate groundwater mitigation but not recommended at this time, include:. 
- $\quad{ }^{99} \mathrm{Tc}$ removal with ion exchange, or another process, is estimated to cost between $\$ 95 \mathrm{M}$ to $\$ 105 \mathrm{M}$ which is much more expensive than the recommended strategy. It is unlikely the schedule for this approach could support the start of early LAW operations. Removal of ${ }^{99} \mathrm{Tc}$ at the IPS provides no continuing lifecycle benefit to the RPP Program.

- Recycle to Tanks Farms after concentration in the 242-A is not recommended due to an unacceptable risk from the loss of the evaporator due to incompatible materials of construction and the potential for excessive corrosion of the singlepoint failure facility. The worst-case impact for a 242-A single-point failure is a 5 -year impact to the retrieval and WTP processing schedule ( $\$ 4.6$ billion cost impact), plus $\$ 100$ million for a replacement facility.

- Recycle to Tanks Farms after concentration in a new evaporator is estimated to cost between $\$ 125 \mathrm{M}$ to $\$ 135 \mathrm{M}$ which is much more expensive than the recommended strategy. It is unlikely the schedule for this approach could support the start of early LAW operations.

Figure 12. Summary Basis for Recommended Approach.

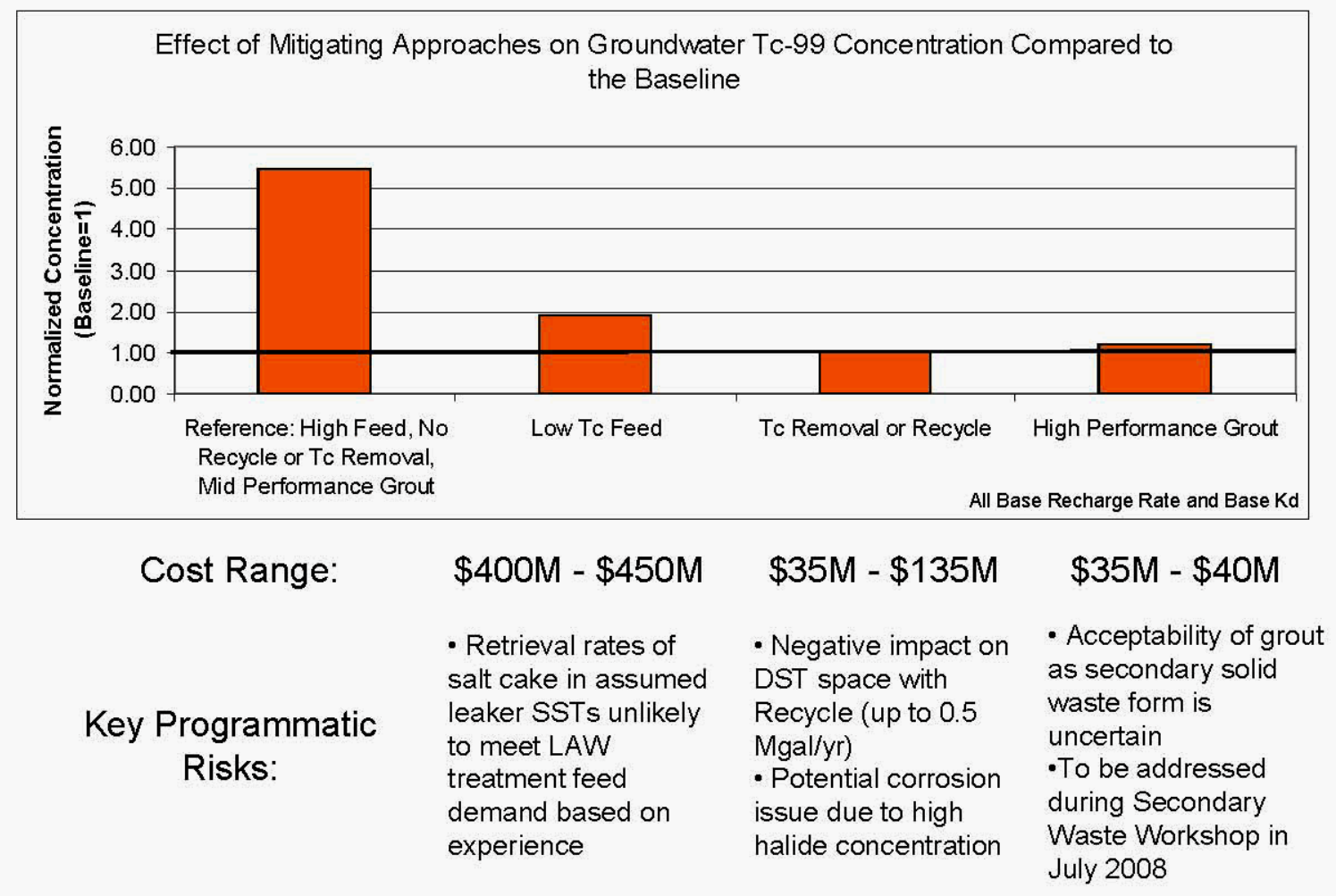


RPP-RPT-37924, Rev. 0

\subsection{REFERENCES}

24590-PTF-3PS-MEVV-TP001, 2005, River Protection Project-Waste Treatment Plant Engineering Specification for Forced Circulation Vacuum Evaporator System, Rev. 2, Bechtel National Inc., Richland WA.

ANSI/ANS-16.1-2003, 2003, Measurement of the Leachability of Solidified Low-Level Radioactive Wastes by a Short-Term Test Procedure, American Nuclear Society, La Grange Park, Illinois.

DOE G 430.1-1, March 1997, Cost Estimating Guide, U.S. Department of Energy Office of Management, Budget and Evaluation.

DOE/ORP-2000-24, F.M. Mann, K.C. Burgard, W.R. Root, P.J. Puigh, S.H. Finfrock, R. Khaleel, D.H. Bacon, E.J. Freeman, B.P. McGrail, S.K. Wurnster, and P.E. LaMont, Hanford Immobilized Low-Activity Tank Waste Performance Assessment: 2001 Version, DOE/ORP-2000-24, U.S. Department of Energy, Office of River Protection, Richland, Washington.

DOE 2005, November 2004, Technical Requirements Document for Integrated Disposal Facilities Vadose Zone and Groundwater Revised Analyses, Rev. 0, U.S. Department of Energy, Richland, Washington.

H-2-69269, 1976, Architectural $1^{\text {st }}$ Floor Plan - 242-A, Revision 1, U. S. Atomic Energy Commission Richland Operations Office, Richland WA.

H-2-69270, 1977, Architectural $2^{\text {nd }}$ Floor Plan - 242-A, Revision 2, U. S. Atomic Energy Commission Richland Operations Office, Richland WA.

H-2-69271, 1976, Architectural Floor Plan - 242-A, Revision 1, U. S. Atomic Energy Commission Richland Operations Office, Richland WA.

H-2-69272, 1976, Architectural Elevations \& Sections - 242-A, Revision 2, U. S. Atomic Energy Commission Richland Operations Office, Richland WA.

ORP-11242, May 2008, River Protection Project System Plan, Rev. 3, P.J. Certa, CH2M HILL Hanford Group Inc., Richland, WA.

PNNL-16052, September 2006, Low Temperature Waste Immobilization Testing, Rev. 1, R.L. Russell et al, Pacific Northwest National Laboratory, Richland, WA.

RPP-RPT-30160, 2006, Supporting Information for the Evaluation of Waste Treatment and Immobilization Plant (WTP) Low Activity Waste (LAW) Startup First Scenario, M. E. Johnson, CH2MHILL Hanford Group Inc., Richland WA.

RPP-29981, March, 2007, Evaluation of Starting the Waste Treatment and Immobilization Plant (WTP) Low Activity Waste (LAW) Facility First, Rev. 1, M.G.Thien, CH2M HILL Hanford Group Inc., Richland, Washington.

RPP-RPT-37644, 2008, Interim Pretreatment System Mission Scoping Report, Rev. 0, M.G. Thien, CH2M HILL Hanford Group Inc., Richland, Washington.

RPP-RPT-37947, June 2008, Extraction of Groundwater Impacts from the Integrated Disposal Facility., Rev. 0, Scott Finfrock, Fluor Federal Services, Richland, WA.

SVF-1484, 2008, IPS DST Feed Calculations, CH2M HILL Hanford Group Inc., Richland WA. SVF-1487, 2008, IPS SST Feed Calculations, Rev. 1, CH2M HILL Hanford Group Inc., Richland WA.

TFC-PLN-039, July 2006, Risk Management Plan, CH2M HILL Hanford Group Inc., Richland WA. 


\section{APPENDIX A. SENSITIVITY ANALYSIS}

The following table shows the results of the 18 case studies preformed.

Table A-1. Approaches Considered.

\begin{tabular}{|c|c|c|c|c|c|c|c|c|c|c|c|c|}
\hline Case & Tc-99 in Feed & $\begin{array}{l}\text { WITLAW } \\
\text { Secondary } \\
\text { Waste } \\
\text { Stream }\end{array}$ & $\begin{array}{c}\text { Vadose } \\
\text { Zone } \\
\text { Recharge } \\
\text { Rate }\end{array}$ & $\begin{array}{c}\text { ETF Grout } \\
\text { Performance }\end{array}$ & $\begin{array}{c}\text { Vadose } \\
\text { Dist. } \\
\text { Coef. }\end{array}$ & $\begin{array}{c}\mathrm{Hg} \\
\text { (Normalized) }\end{array}$ & $\begin{array}{c}1-129 \\
\text { (Normalized) }\end{array}$ & $\begin{array}{c}\text { Tc-99 } \\
\text { (Normalized) }\end{array}$ & $\begin{array}{c}\mathrm{Cr} \\
\text { (Nomalized) }\end{array}$ & $\begin{array}{c}\mathrm{NO} 3 \\
\text { (Normalized) }\end{array}$ & $\begin{array}{c}\mathrm{U}-238 \\
\text { (Nomalized) }\end{array}$ & $\begin{array}{c}\text { U-Total } \\
\text { (Normalized) }\end{array}$ \\
\hline 1 & No Early Law & None & Base & Base & Base & $1.00 \mathrm{E}+00$ & $1.00 \mathrm{E}+00$ & $1.00 \mathrm{E}+00$ & $1.00 \mathrm{E}+00$ & $1.00 \mathrm{E}+00$ & $1.00 \mathrm{E}+00$ & $1.00 \mathrm{E}+00$ \\
\hline 2 & Low & None & Base & Base & Base & $1.00 \mathrm{E}+00$ & $1.01 \mathrm{E}+00$ & $1.95 \mathrm{E}+00$ & $3.10 \mathrm{E}+00$ & $2.09 \mathrm{E}+00$ & $9.90 \mathrm{E}-01$ & $9.92 \mathrm{E}-01$ \\
\hline 3 & Mid & None & Base & Base & Base & $1.00 \mathrm{E}+00$ & $1.01 \mathrm{E}+00$ & $3.72 \mathrm{E}+00$ & $2.34 \mathrm{E}+00$ & $2.89 \mathrm{E}+00$ & $9.96 \mathrm{E}-01$ & $9.97 \mathrm{E}-01$ \\
\hline 4 & High & None & Base & Base & Base & $1.00 E+00$ & $1.02 \mathrm{E}+00$ & $5.70 \mathrm{E}+00$ & $2.16 \mathrm{E}+00$ & $2.12 \mathrm{E}+00$ & $9.98 \mathrm{E}-01$ & $9.98 \mathrm{E}-01$ \\
\hline 5 & High & TcRemoval & Base & Base & Base & $1.00 \mathrm{E}+00$ & $1.02 \mathrm{E}+00$ & $1.05 \mathrm{E}+00$ & $2.16 \mathrm{E}+00$ & $2.12 \mathrm{E}+00$ & $9.98 \mathrm{E}-01$ & $9.98 \mathrm{E}-01$ \\
\hline 6 & High & Recycle & Base & Base & Base & $1.00 \mathrm{E}+00$ & $1.00 \mathrm{E}+00$ & $1.00 \mathrm{E}+00$ & $1.00 \mathrm{E}+00$ & $1.00 \mathrm{E}+00$ & $1.00 \mathrm{E}+00$ & $1.00 \mathrm{E}+00$ \\
\hline 7 & High & None & Low & Base & Base & $2.14 \mathrm{E}-05$ & $1.98 \mathrm{E}-09$ & $1.04 \mathrm{E}-04$ & $9.16 \mathrm{E}-06$ & $3.15 \mathrm{E}-05$ & $5.14 \mathrm{E}-11$ & $4.77 \mathrm{E}-11$ \\
\hline 8 & High & None & Natural & Base & Base & $3.06 \mathrm{E}+00$ & $5.92 \mathrm{E}+03$ & $1.79 \mathrm{E}+01$ & $1.18 \mathrm{E}+01$ & $6.75 \mathrm{E}+00$ & $5.60 \mathrm{E}+05$ & $4.71 \mathrm{E}+05$ \\
\hline 9 & High & None & High & Base & Base & $6.27 \mathrm{E}+00$ & $3.82 \mathrm{E}+06$ & $4.21 \mathrm{E}+01$ & $1.71 \mathrm{E}+01$ & $1.39 \mathrm{E}+01$ & $3.59 \mathrm{E}+11$ & $3.64 \mathrm{E}+11$ \\
\hline 10 & High & None & Base & Low & Base & $3.19 \mathrm{E}+00$ & $1.91 \mathrm{E}+00$ & $2.04 \mathrm{E}+01$ & $4.87 \mathrm{E}+00$ & $3.16 \mathrm{E}+00$ & $1.01 \mathrm{E}+00$ & $1.25 \mathrm{E}+00$ \\
\hline 11 & High & None & Base & High & Base & $3.33 \mathrm{E}-01$ & $1.02 \mathrm{E}-01$ & $1.23 \mathrm{E}+00$ & $9.62 \mathrm{E}-01$ & $2.12 \mathrm{E}-01$ & $9.98 \mathrm{E}-01$ & $9.98 \mathrm{E}-01$ \\
\hline 12 & High & None & Base & Base & Low & $1.00 \mathrm{E}+00$ & $9.80 \mathrm{E}+05$ & $5.70 \mathrm{E}+00$ & $2.17 \mathrm{E}+00$ & $2.12 \mathrm{E}+00$ & $8.67 \mathrm{E}+10$ & $1.11 \mathrm{E}+11$ \\
\hline 13 & High & None & Low & Low & Base & $6.85 \mathrm{E}-05$ & $3.71 \mathrm{E}-09$ & $3.81 \mathrm{E}-04$ & $2.72 \mathrm{E}-05$ & $4.69 \mathrm{E}-05$ & $5.23 \mathrm{E}-11$ & $5.97 \mathrm{E}-11$ \\
\hline 14 & High & None & Low & High & Base & $7.14 \mathrm{E}-06$ & $1.98 \mathrm{E}-10$ & $1.94 \mathrm{E}-05$ & $1.17 \mathrm{E}-06$ & $3.15 \mathrm{E}-06$ & $5.14 \mathrm{E}-11$ & $4.77 \mathrm{E}-11$ \\
\hline 15 & High & None & Natural & Low & Base & $9.79 \mathrm{E}+00$ & $1.11 \mathrm{E}+04$ & $6.39 \mathrm{E}+01$ & $2.03 \mathrm{E}+01$ & $1.01 \mathrm{E}+01$ & $5.69 \mathrm{E}+05$ & $5.84 \mathrm{E}+05$ \\
\hline 16 & High & None & Natural & High & Base & $1.02 \mathrm{E}+00$ & $5.93 \mathrm{E}+02$ & $3.94 \mathrm{E}+00$ & $8.03 \mathrm{E}+00$ & $6.75 \mathrm{E}-01$ & $5.60 \mathrm{E}+05$ & $4.71 \mathrm{E}+05$ \\
\hline 17 & High & None & High & Low & Base & $2.00 \mathrm{E}+01$ & $7.14 \mathrm{E}+06$ & $1.38 \mathrm{E}+02$ & $3.35 \mathrm{E}+01$ & $2.08 \mathrm{E}+01$ & $3.63 E+11$ & $4.39 \mathrm{E}+11$ \\
\hline 18 & High & None & High & High & Base & $2.09 \mathrm{E}+00$ & $3.82 \mathrm{E}+05$ & $1.29 \mathrm{E}+01$ & $9.78 \mathrm{E}+00$ & $1.39 \mathrm{E}+00$ & $3.59 \mathrm{E}+11$ & $3.64 E+11$ \\
\hline
\end{tabular}

The following figures help illustrate in greater detail the sensitivity of contaminant groundwater concentration to several variables.

Figure A-1. Effect of Varying the Vadose Distribution Coefficient.

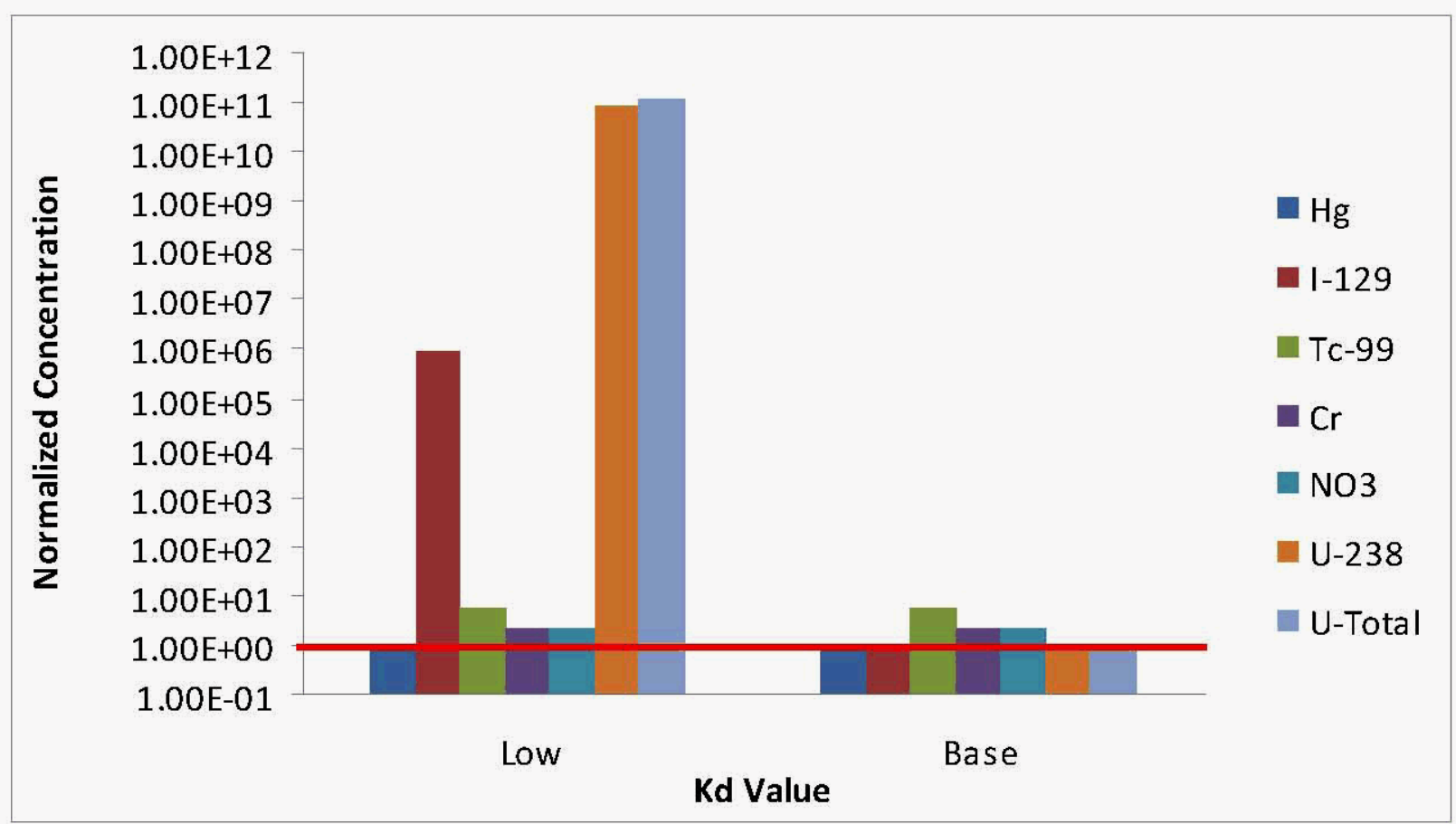


In Figure A-1 above, the normalized maximum groundwater concentration in a ten thousand year window is shown for seven contaminants paired with different predicted values of $\mathrm{Kd}$. As shown, only ${ }^{129} \mathrm{I}$ is assumed to be absorbed into the soil, and as such is the only contaminant whose concentration is affected by the change to a low $\mathrm{Kd}$ value. However, the assumption of setting the Kd of ${ }^{129} \mathrm{I}$ to zero as opposed to 0.1 has a profound affect on the concentration of ${ }^{129} \mathrm{I}$ in the groundwater, increasing it by 6 orders of magnitude. When a low Kd (set at 0 ) is chosen for Uranium, a resultant increase of over 11 orders of magnitude takes place. This shows that this system is extremely dependant on the selection of $\mathrm{Kd}$.

Figure A-2. Effect of Varying the Vadose Zone Recharge Rate.

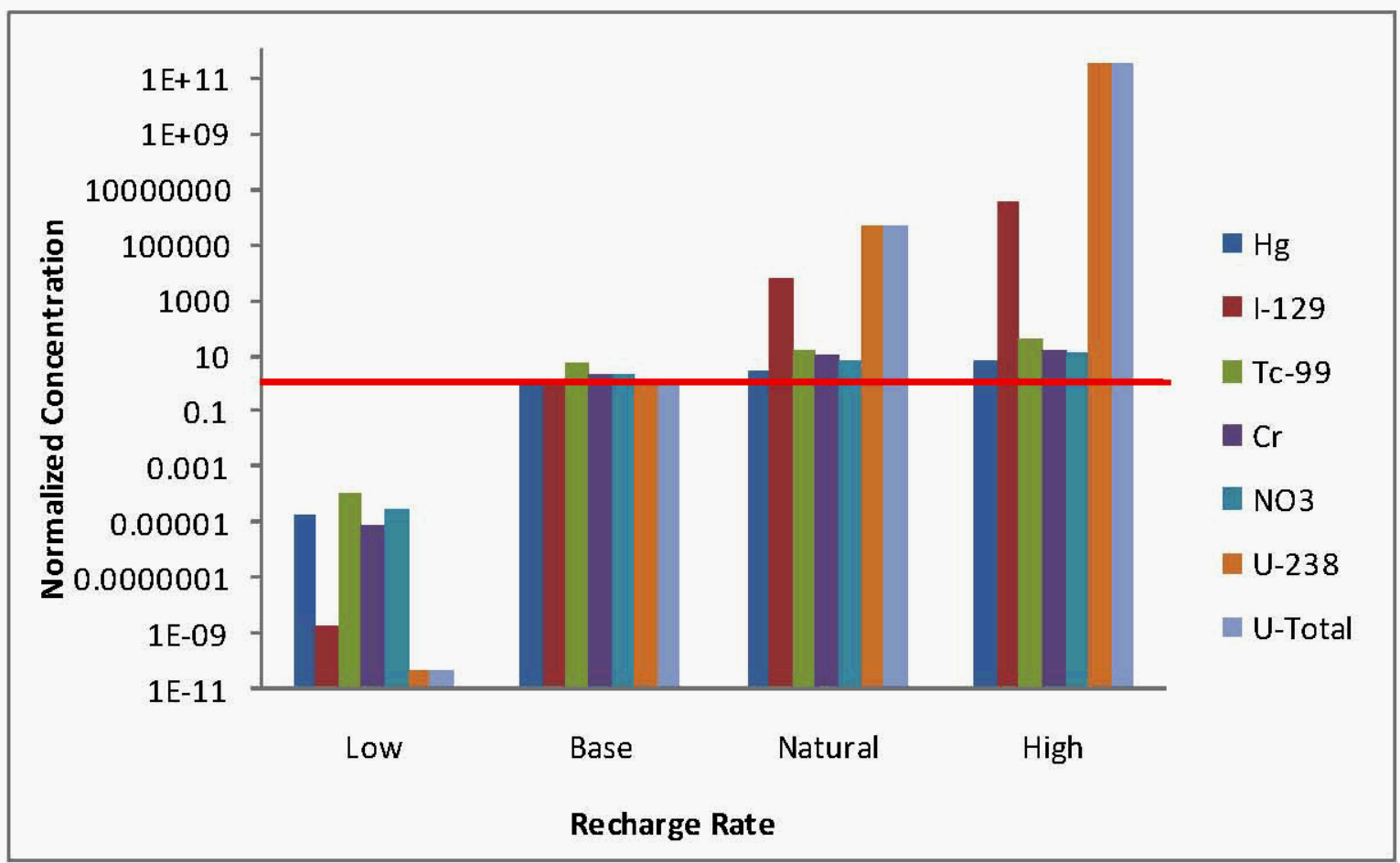

In Figure A-2, the normalized maximum groundwater concentration in a ten thousand year window is shown for seven contaminants paired with three rates of recharge. Take note that this chart is on a logarithmic scale, due to the large effect this variable has on all concentration. As shown here, for high recharge rates, the concentration of ${ }^{129} \mathrm{I}$ and Uranium becomes extremely high. 
Figure A-3. Effect of Varying the Vadose Zone Recharge Rate and Solid waste Type on Groundwater ${ }^{99} \mathrm{Tc}$.

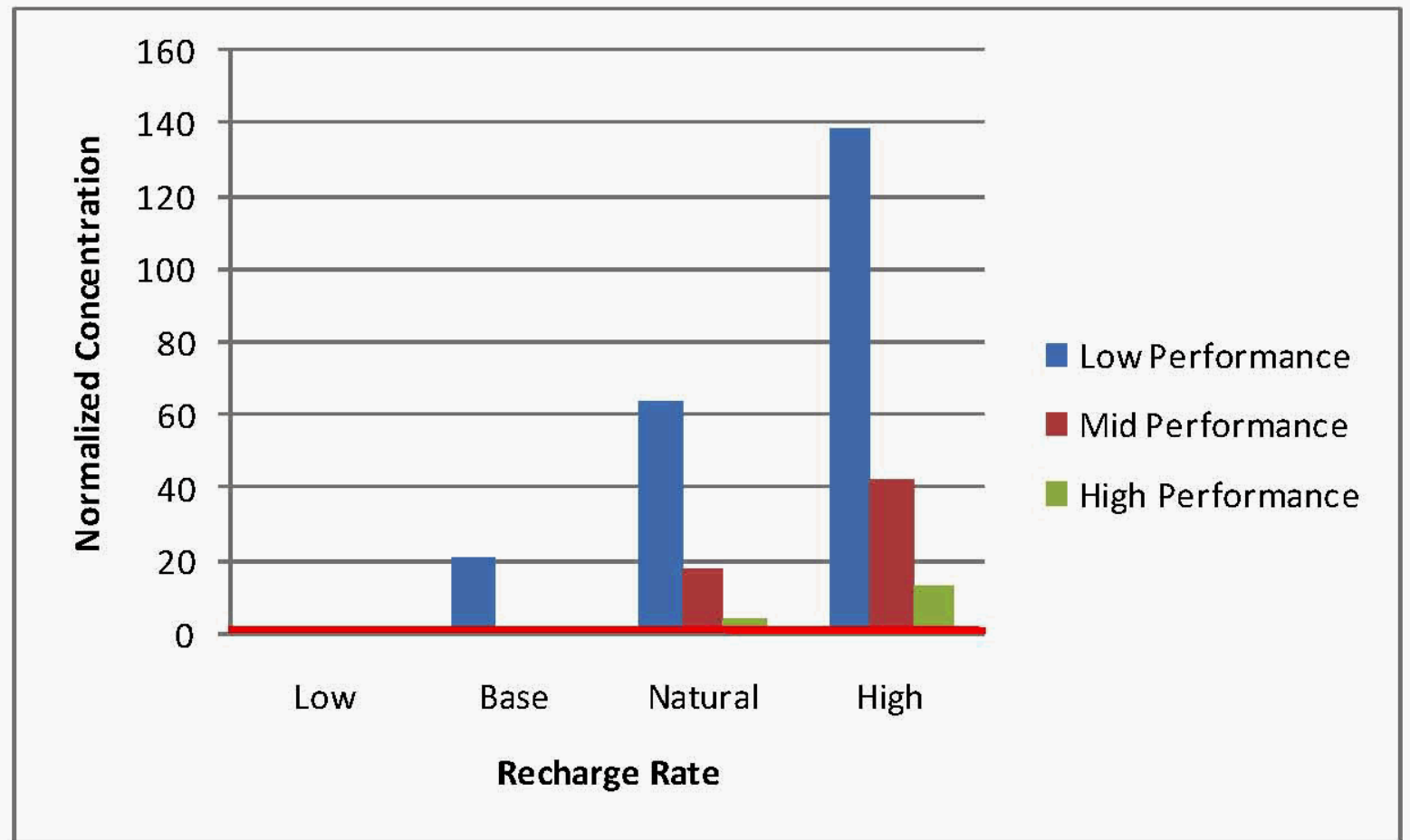

In Figure A-3 above, the normalized maximum groundwater concentration in a ten thousand year window for ${ }^{99} \mathrm{Tc}$ is shown when varying the type of solid waste used and the predicted recharge rate. The recharge rate and the ${ }^{99} \mathrm{Tc}$ groundwater concentration are positively correlated, while the solid waste performance has a negative correlation with groundwater concentration. Worth noting here is that in all cases using a high performance solid waste lowers the ${ }^{99} \mathrm{Tc}$ ground water concentration by about 1.5 orders of magnitude vs using a low performance grout. 
Figure A-4. Contribution to Groundwater ${ }^{99}$ Te for a Base Recharge Rate.

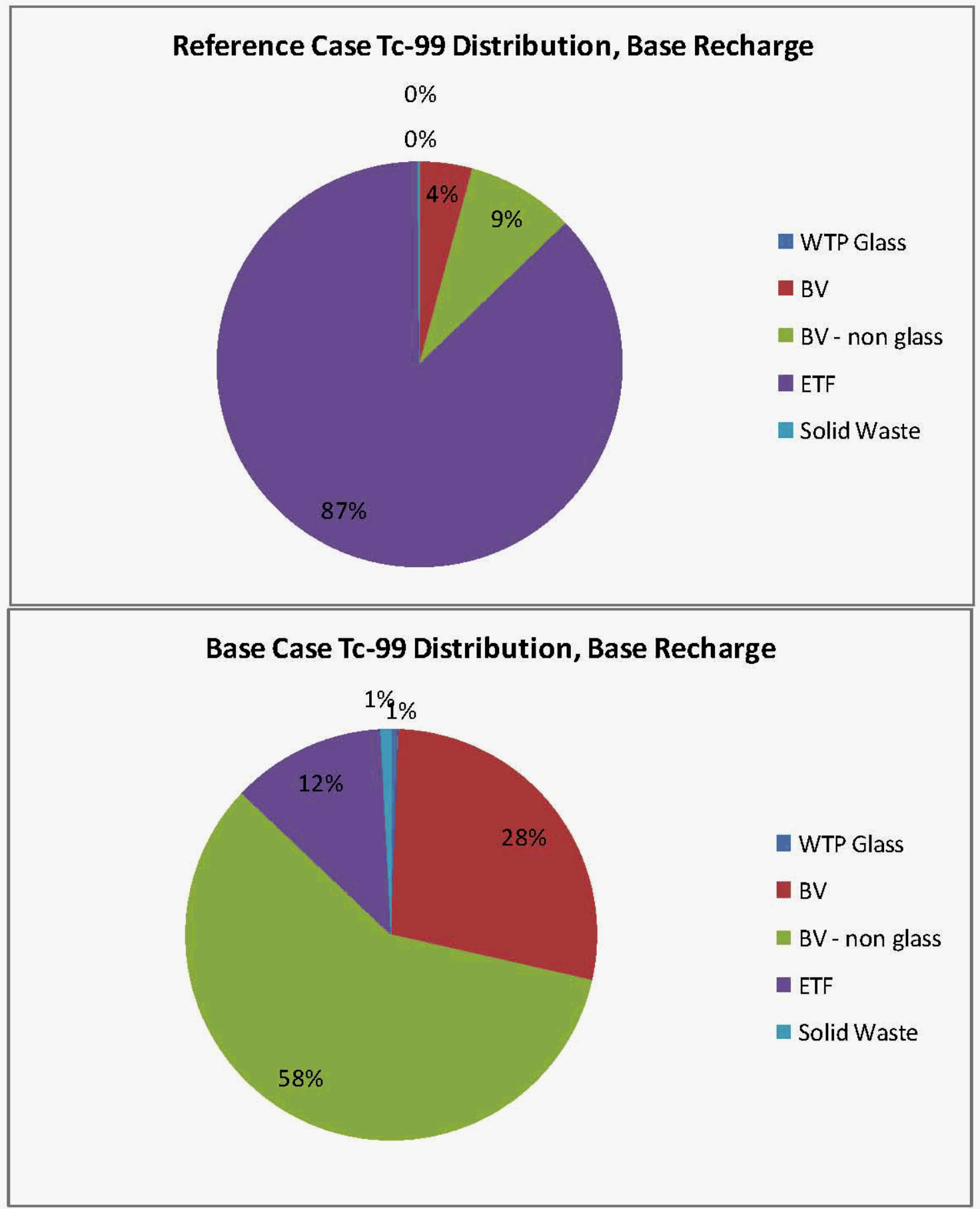

The relative contribution of ${ }^{99} \mathrm{Tc}$ to groundwater for each of the various sequestration mediums under a base recharge rate is shown in Figure A-4. As shown above, when no early LAW is used, the bulk of ${ }^{99} \mathrm{Tc}$ comes from Bulk Vitrification, while when Early LAW is used; the majority of ${ }^{99} \mathrm{Tc}$ comes from ETF. This is because the contaminants attributed to Bulk Vitrification stay relatively constant in both cases, while the contaminants in ETF and solid waste increase substantially when Early LAW is used due to a lack of a recycle stream. It is 
worth noting that the concentration of ${ }^{99} \mathrm{Tc}$ in the groundwater is approximately 5.7 times higher when Early LAW is used.
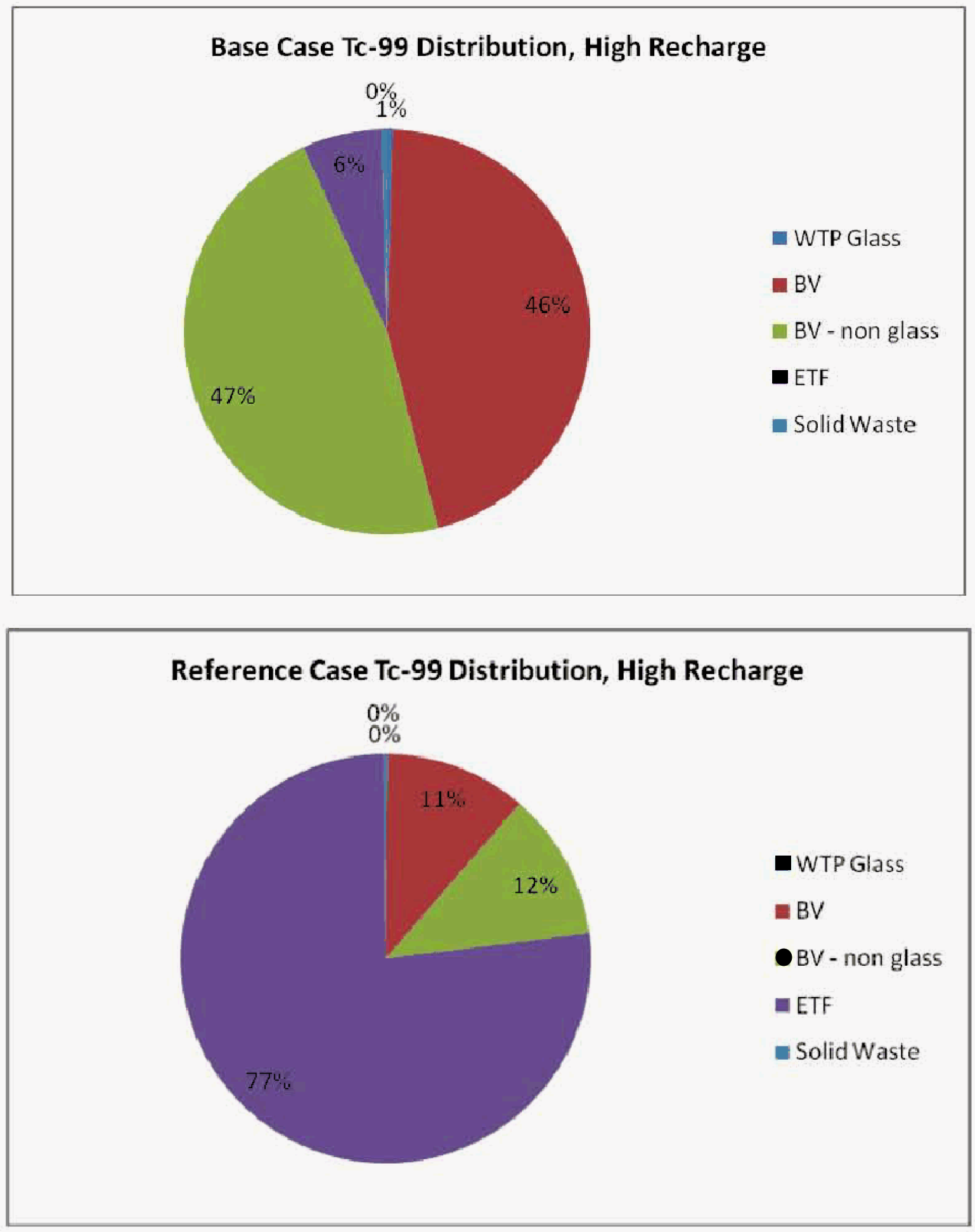

Figure A-5 represents the relative contribution of ${ }^{99} \mathrm{Tc}$ to groundwater for each of the various sequestration mediums under a high recharge rate. As with Figure A-, when no early LAW is 
used, the bulk of ${ }^{99} \mathrm{Tc}$ comes from Bulk Vitrification, while when early LAW is used; the majority of groundwater ${ }^{99} \mathrm{Tc}$ comes from the ETF. Also worth noting is that the concentration of ${ }^{99} \mathrm{Tc}$ in the groundwater is approximately 3.4 times higher when early LAW is used.

The above pie charts show that relative contribution of five waste sources to ${ }^{99} \mathrm{Tc}$ groundwater contamination. Tables A-2 and A-3 show the amount of contaminants that each disposal product actually contains. The first table represents the base case of no early LAW, while the second table represents the reference case of early LAW with high ${ }^{99} \mathrm{Tc}$ feed, no recycle or ${ }^{99} \mathrm{Tc}$ removal, base case recharge rates, mid performance solid waste, and base case Kd values. 
Table A-2. Contaminant Distribution, Base Case.

\begin{tabular}{|c|c|c|c|c|c|c|c|c|c|c|}
\hline \multicolumn{11}{|c|}{ Products for Disposal - Base Case } \\
\hline Facility & Type & Product & Via/To & $\begin{array}{c}\mathrm{Hg} \\
(\mathrm{Kg})\end{array}$ & $\begin{array}{c}\mathrm{I}-129 \\
\text { (Ci) }\end{array}$ & $\begin{array}{c}\text { Tc-99 } \\
\text { (Ci) }\end{array}$ & $\begin{array}{c}\mathrm{Cr} \\
(\mathrm{Kg})\end{array}$ & $\begin{array}{l}\text { NO3 } \\
(\mathrm{Kg})\end{array}$ & $\begin{array}{c}\text { U-238 } \\
\text { (Ci) }\end{array}$ & $\begin{array}{c}\text { U-Total } \\
\text { (Kg) }\end{array}$ \\
\hline WTP Glass & & & & $0.00 \mathrm{E}+00$ & $4.73 \mathrm{E}+00$ & $7.17 \mathrm{E}+03$ & $9.52 \mathrm{E}+04$ & $0.00 \mathrm{E}+00$ & $3.90 \mathrm{E}+00$ & 1.17E+04 \\
\hline Early WTP LAW Vit & Primary & ILAW Glass & IDF & $0.00 \mathrm{E}+00$ & $0.00 \mathrm{E}+00$ & $0.00 \mathrm{E}+00$ & $0.00 \mathrm{E}+00$ & $0.00 \mathrm{E}+00$ & $0.00 \mathrm{E}+00$ & $0.00 \mathrm{E}+00$ \\
\hline WTP LAW V it & Primary & ILAW Glass & IDF & $0.00 \mathrm{E}+00$ & $4.73 \mathrm{E}+00$ & $7.17 \mathrm{E}+03$ & $9.52 \mathrm{E}+04$ & $0.00 \mathrm{E}+00$ & $3.90 \mathrm{E}+00$ & 1.17E+04 \\
\hline & & & & & & & & & & \\
\hline BV & & & & $0.00 \mathrm{E}+00$ & $2.00 \mathrm{E}+00$ & $1.75 \mathrm{E}+04$ & $1.36 \mathrm{E}+05$ & $0.00 \mathrm{E}+00$ & $3.48 \mathrm{E}+00$ & $1.04 \mathrm{E}+04$ \\
\hline STP-E & Primary & ILAW Glass & IDF & $0.00 \mathrm{E}+00$ & $1.43 \mathrm{E}+00$ & $1.16 \mathrm{E}+04$ & $6.00 \mathrm{E}+04$ & $0.00 \mathrm{E}+00$ & $2.40 \mathrm{E}+00$ & $7.18 \mathrm{E}+03$ \\
\hline DBVS & Primary & ILAW Glass & IDF & $0.00 \mathrm{E}+00$ & $2.75 \mathrm{E}-02$ & $2.78 \mathrm{E}+02$ & $6.48 \mathrm{E}+02$ & $0.00 \mathrm{E}+00$ & $2.77 \mathrm{E}-03$ & $8.30 \mathrm{E}+00$ \\
\hline STP-W & Primary & ILAW Glass & IDF & $0.00 \mathrm{E}+00$ & $5.43 \mathrm{E}-01$ & $5.62 \mathrm{E}+03$ & $7.52 \mathrm{E}+04$ & $0.00 \mathrm{E}+00$ & $1.08 \mathrm{E}+00$ & $3.24 \mathrm{E}+03$ \\
\hline & & & & & & & & & & \\
\hline BV - non glass & & & & $0.00 \mathrm{E}+00$ & $0.00 \mathrm{E}+00$ & $7.17 \mathrm{E}+01$ & $0.00 \mathrm{E}+00$ & $0.00 \mathrm{E}+00$ & $0.00 \mathrm{E}+00$ & $0.00 \mathrm{E}+00$ \\
\hline STP-E & Secondary & ICV Box non-glass & IDF & $0.00 \mathrm{E}+00$ & $0.00 \mathrm{E}+00$ & $4.75 \mathrm{E}+01$ & $0.00 \mathrm{E}+00$ & $0.00 \mathrm{E}+00$ & $0.00 \mathrm{E}+00$ & $0.00 \mathrm{E}+00$ \\
\hline DBVS & Secondary & ICV Box non-glass & IDF & $0.00 \mathrm{E}+00$ & $0.00 \mathrm{E}+00$ & $1.14 \mathrm{E}+00$ & $0.00 \mathrm{E}+00$ & $0.00 \mathrm{E}+00$ & $0.00 \mathrm{E}+00$ & $0.00 \mathrm{E}+00$ \\
\hline STP-W & Secondary & ICV Box non-glass & IDF & $0.00 \mathrm{E}+00$ & $0.00 \mathrm{E}+00$ & $2.31 \mathrm{E}+01$ & $0.00 \mathrm{E}+00$ & $0.00 \mathrm{E}+00$ & $0.00 \mathrm{E}+00$ & $0.00 \mathrm{E}+00$ \\
\hline & & & & & & & & & & \\
\hline ETF & & & & $4.36 \mathrm{E}+02$ & $6.37 \mathrm{E}-01$ & $7.29 \mathrm{E}+01$ & $6.27 \mathrm{E}+01$ & $2.31 \mathrm{E}+05$ & $2.39 \mathrm{E}-01$ & $7.24 \mathrm{E}+02$ \\
\hline 242-A & Secondary & Condensate & ETF & $5.64 \mathrm{E}-01$ & $5.11 \mathrm{E}-04$ & $1.61 \mathrm{E}-03$ & $3.90 \mathrm{E}+00$ & $5.36 \mathrm{E}+04$ & $3.02 \mathrm{E}-03$ & $1.72 \mathrm{E}+01$ \\
\hline TRU & Secondary & Condensate & ETF & $3.36 \mathrm{E}-02$ & $5.76 \mathrm{E}-02$ & $1.88 \mathrm{E}-01$ & $1.96 \mathrm{E}+00$ & $8.49 \mathrm{E}+02$ & $3.13 \mathrm{E}-02$ & $9.39 \mathrm{E}+01$ \\
\hline WTP PT & Secondary & Condensate (FEP) & ETF & $2.22 \mathrm{E}+00$ & $5.97 \mathrm{E}-02$ & $2.38 \mathrm{E}+01$ & $1.37 \mathrm{E}+01$ & $5.86 \mathrm{E}+04$ & $1.95 \mathrm{E}-01$ & $5.84 \mathrm{E}+02$ \\
\hline WTP PT & Secondary & Condensate (TLP) & ETF & $7.21 \mathrm{E}-01$ & $8.83 \mathrm{E}-02$ & $3.02 \mathrm{E}+01$ & $4.45 \mathrm{E}+00$ & $5.83 \mathrm{E}+04$ & $6.23 \mathrm{E}-03$ & $1.87 \mathrm{E}+01$ \\
\hline Early WTP LAW Vit & Secondary & SBS+WESP Liquid & ETF & $0.00 \mathrm{E}+00$ & $0.00 \mathrm{E}+00$ & $0.00 \mathrm{E}+00$ & $0.00 \mathrm{E}+00$ & $0.00 \mathrm{E}+00$ & $0.00 \mathrm{E}+00$ & $0.00 \mathrm{E}+00$ \\
\hline Early WTP LAW Vit & Secondary & Caustic Scrubber Liquid & ETF & $0.00 \mathrm{E}+00$ & $0.00 \mathrm{E}+00$ & $0.00 \mathrm{E}+00$ & $0.00 \mathrm{E}+00$ & $0.00 \mathrm{E}+00$ & $0.00 \mathrm{E}+00$ & $0.00 \mathrm{E}+00$ \\
\hline WTP LAW V it & Secondary & SBS+WESP Liquid & ETF & $0.00 \mathrm{E}+00$ & $0.00 \mathrm{E}+00$ & $0.00 \mathrm{E}+00$ & $0.00 \mathrm{E}+00$ & $0.00 \mathrm{E}+00$ & $0.00 \mathrm{E}+00$ & $0.00 \mathrm{E}+00$ \\
\hline WTP LAW Vit & Secondary & Caustic Scrubber Liquid & ETF & $0.00 \mathrm{E}+00$ & $2.31 \mathrm{E}-02$ & $0.00 \mathrm{E}+00$ & $0.00 \mathrm{E}+00$ & $0.00 \mathrm{E}+00$ & $0.00 \mathrm{E}+00$ & $0.00 \mathrm{E}+00$ \\
\hline WTP HLW Vit & Secondary & SBS+WESP+HEME Liquid & ETF & $0.00 \mathrm{E}+00$ & $0.00 \mathrm{E}+00$ & $0.00 \mathrm{E}+00$ & $0.00 \mathrm{E}+00$ & $0.00 \mathrm{E}+00$ & $0.00 \mathrm{E}+00$ & $0.00 \mathrm{E}+00$ \\
\hline SR-E & Secondary & Liquid Effluent & ETF & $0.00 \mathrm{E}+00$ & $0.00 \mathrm{E}+00$ & $0.00 \mathrm{E}+00$ & $0.00 \mathrm{E}+00$ & $0.00 \mathrm{E}+00$ & $0.00 \mathrm{E}+00$ & $0.00 \mathrm{E}+00$ \\
\hline SR-W & Secondary & Liquid Effluent & ETF & $0.00 \mathrm{E}+00$ & $0.00 \mathrm{E}+00$ & $0.00 \mathrm{E}+00$ & $0.00 \mathrm{E}+00$ & $0.00 \mathrm{E}+00$ & $0.00 \mathrm{E}+00$ & $0.00 \mathrm{E}+00$ \\
\hline STP-E & Secondary & Front End Evap Condenstate & ETF & $0.00 \mathrm{E}+00$ & $0.00 \mathrm{E}+00$ & $0.00 \mathrm{E}+00$ & $0.00 \mathrm{E}+00$ & $0.00 \mathrm{E}+00$ & $0.00 \mathrm{E}+00$ & $0.00 \mathrm{E}+00$ \\
\hline STP-E & Secondary & Dryer Condenstate & ETF & $2.80 \mathrm{E}-01$ & $2.92 \mathrm{E}-01$ & $1.22 \mathrm{E}+01$ & $1.70 \mathrm{E}+01$ & $2.26 \mathrm{E}+04$ & $2.40 \mathrm{E}-03$ & $7.20 \mathrm{E}+00$ \\
\hline STP-E & Secondary & Bleed & ETF & $2.63 \mathrm{E}+02$ & $1.10 \mathrm{E}-05$ & $1.75 \mathrm{E}-01$ & $1.25 \mathrm{E}-01$ & $0.00 \mathrm{E}+00$ & $3.47 \mathrm{E}-06$ & $6.77 \mathrm{E}-03$ \\
\hline DBVS & Secondary & Front End Evap Condenstate & ETF & $0.00 \mathrm{E}+00$ & $0.00 \mathrm{E}+00$ & $0.00 \mathrm{E}+00$ & $0.00 \mathrm{E}+00$ & $0.00 \mathrm{E}+00$ & $0.00 \mathrm{E}+00$ & $0.00 \mathrm{E}+00$ \\
\hline DBVS & Secondary & Dryer Condenstate & ETF & $3.89 \mathrm{E}-03$ & $5.60 \mathrm{E}-03$ & $2.93 \mathrm{E}-01$ & $1.83 \mathrm{E}-01$ & $3.40 \mathrm{E}+03$ & $2.78 \mathrm{E}-06$ & $8.33 \mathrm{E}-03$ \\
\hline DBVS & Secondary & Bleed & ETF & $3.66 \mathrm{E}+00$ & $2.11 \mathrm{E}-07$ & $4.21 \mathrm{E}-03$ & $1.35 \mathrm{E}-03$ & $0.00 \mathrm{E}+00$ & $4.01 \mathrm{E}-09$ & $7.83 \mathrm{E}-06$ \\
\hline STP-W & Secondary & Front End Evap Condenstate & ETF & $0.00 \mathrm{E}+00$ & $0.00 \mathrm{E}+00$ & $0.00 \mathrm{E}+00$ & $0.00 \mathrm{E}+00$ & $0.00 \mathrm{E}+00$ & $0.00 \mathrm{E}+00$ & $0.00 \mathrm{E}+00$ \\
\hline STP-W & Secondary & Dryer Condenstate & ETF & $1.75 \mathrm{E}-01$ & 1.11E-01 & $5.93 \mathrm{E}+00$ & $2.13 \mathrm{E}+01$ & $3.33 \mathrm{E}+04$ & $1.08 \mathrm{E}-03$ & $3.25 \mathrm{E}+00$ \\
\hline STP-W & Secondary & Bleed & ETF & $1.65 \mathrm{E}+02$ & $4.18 \mathrm{E}-06$ & $8.51 \mathrm{E}-02$ & $1.56 \mathrm{E}-01$ & $0.00 \mathrm{E}+00$ & $1.56 \mathrm{E}-06$ & $3.05 \mathrm{E}-03$ \\
\hline So & & & & +03 & & 0 & & & & \\
\hline Early WTP LAW Vit & Secondary & Carbon Adsorber & IDF & $0.00 \mathrm{E}+00$ & $0.00 \mathrm{E}+00$ & $0.00 \mathrm{E}+00$ & $0.00 \mathrm{E}+00$ & $0.00 \mathrm{E}+00$ & $0.00 \mathrm{E}+00$ & $0.00 \mathrm{E}+00$ \\
\hline WTP LAW Vit & Secondary & Carbon Adsorber & IDF & $3.22 \mathrm{E}+02$ & $2.31 \mathrm{E}+00$ & $2.69 \mathrm{E}-06$ & $5.41 \mathrm{E}-07$ & 1.59E-04 & $3.10 \mathrm{E}-13$ & $9.28 \mathrm{E}-10$ \\
\hline WTP HLW Vit & Secondary & Carbon Adsorber & IDF & $1.17 \mathrm{E}+03$ & $0.00 \mathrm{E}+00$ & 1.09E-09 & $1.34 \mathrm{E}-05$ & $1.31 \mathrm{E}-06$ & $1.99 \mathrm{E}-11$ & 5.97E-08 \\
\hline STP-E & Secondary & HEGA & IDF & $0.00 \mathrm{E}+00$ & $2.97 \mathrm{E}+00$ & $0.00 \mathrm{E}+00$ & $0.00 \mathrm{E}+00$ & $0.00 \mathrm{E}+00$ & $0.00 \mathrm{E}+00$ & $0.00 \mathrm{E}+00$ \\
\hline DBVS & Secondary & HEGA & IDF & $0.00 \mathrm{E}+00$ & $5.71 \mathrm{E}-02$ & $0.00 \mathrm{E}+00$ & $0.00 \mathrm{E}+00$ & $0.00 \mathrm{E}+00$ & $0.00 \mathrm{E}+00$ & $0.00 \mathrm{E}+00$ \\
\hline STP-W & Secondary & HEGA & IDF & $0.00 \mathrm{E}+00$ & $1.13 \mathrm{E}+00$ & $0.00 \mathrm{E}+00$ & $0.00 \mathrm{E}+00$ & $0.00 \mathrm{E}+00$ & $0.00 \mathrm{E}+00$ & $0.00 \mathrm{E}+00$ \\
\hline TRU & Secondary & HEPA & IDF & $0.00 \mathrm{E}+00$ & $0.00 \mathrm{E}+00$ & $0.00 \mathrm{E}+00$ & $0.00 \mathrm{E}+00$ & $0.00 \mathrm{E}+00$ & $0.00 \mathrm{E}+00$ & $0.00 \mathrm{E}+00$ \\
\hline STP-E & Secondary & HEPA & IDF & $1.25 \mathrm{E}-01$ & $3.55 \mathrm{E}-06$ & $2.82 \mathrm{E}-03$ & $2.46 \mathrm{E}-05$ & $0.00 \mathrm{E}+00$ & $5.58 \mathrm{E}-08$ & $1.09 \mathrm{E}-04$ \\
\hline $\mathbf{z}$ & Secondary & HEPA & IDF & $1.74 \mathrm{E}-03$ & $6.81 \mathrm{E}-08$ & $6.77 \mathrm{E}-05$ & $2.66 \mathrm{E}-07$ & $0.00 \mathrm{E}+00$ & $6.46 \mathrm{E}-11$ & $1.26 \mathrm{E}-07$ \\
\hline STP-W & Secondary & HEPA & IDF & $7.85 \mathrm{E}-02$ & $1.35 \mathrm{E}-06$ & 1.37E-03 & 3.09E-05 & $0.00 \mathrm{E}+00$ & $2.52 \mathrm{E}-08$ & $4.91 \mathrm{E}-05$ \\
\hline Early WTP LAW Vit & Secondary & HEPA1 & IDF & $0.00 \mathrm{E}+00$ & $0.00 \mathrm{E}+00$ & $0.00 \mathrm{E}+00$ & $0.00 \mathrm{E}+00$ & $0.00 \mathrm{E}+00$ & $0.00 \mathrm{E}+00$ & $0.00 \mathrm{E}+00$ \\
\hline WTP LAW Vit & Secondary & HEPA1 & IDF & $0.00 \mathrm{E}+00$ & $0.00 \mathrm{E}+00$ & $4.99 \mathrm{E}+00$ & $1.00 \mathrm{E}+00$ & $2.95 \mathrm{E}+02$ & $5.73 \mathrm{E}-07$ & $0.00 \mathrm{E}+00$ \\
\hline WTP HLW Vit & Secondary & HEPA1 & IDF & $0.00 \mathrm{E}+00$ & $0.00 \mathrm{E}+00$ & $2.02 \mathrm{E}-03$ & $2.39 \mathrm{E}-01$ & $2.32 \mathrm{E}-02$ & $3.54 \mathrm{E}-07$ & $1.06 \mathrm{E}-03$ \\
\hline Early WTP LAW Vit & Secondary & HEPA2 & IDF & $0.00 \mathrm{E}+00$ & $0.00 \mathrm{E}+00$ & $0.00 \mathrm{E}+00$ & $0.00 \mathrm{E}+00$ & $0.00 \mathrm{E}+00$ & $0.00 \mathrm{E}+00$ & $0.00 \mathrm{E}+00$ \\
\hline WTP LAW V it & Secondary & HEPA2 & IDF & $0.00 \mathrm{E}+00$ & $0.00 \mathrm{E}+00$ & $1.49 \mathrm{E}-03$ & $3.00 \mathrm{E}-04$ & $8.84 \mathrm{E}-02$ & $1.72 \mathrm{E}-10$ & $5.15 \mathrm{E}-07$ \\
\hline WTP HLW Vit & Secondary & HEPA2 & IDF & $0.00 \mathrm{E}+00$ & $0.00 \mathrm{E}+00$ & $6.05 \mathrm{E}-07$ & $7.44 \mathrm{E}-03$ & $7.25 \mathrm{E}-04$ & 1.10E-08 & $3.31 \mathrm{E}-05$ \\
\hline STP-E & Secondary & Quencher Filter to IDF & IDF & $1.36 \mathrm{E}+01$ & $9.82 \mathrm{E}+00$ & $9.23 \mathrm{E}-03$ & $6.56 \mathrm{E}-03$ & $0.00 \mathrm{E}+00$ & $1.82 \mathrm{E}-07$ & $3.56 \mathrm{E}-04$ \\
\hline DBVS & Secondary & Quencher Filter to IDF & IDF & $1.90 \mathrm{E}-01$ & $1.89 \mathrm{E}-01$ & $2.21 \mathrm{E}-04$ & $7.08 \mathrm{E}-05$ & $0.00 \mathrm{E}+00$ & $2.11 \mathrm{E}-10$ & $4.12 \mathrm{E}-07$ \\
\hline STP-W & Secondary & Quencher Filter to IDF & IDF & $8.55 \mathrm{E}+00$ & $3.73 \mathrm{E}+00$ & $4.48 \mathrm{E}-03$ & $8.22 \mathrm{E}-03$ & $0.00 \mathrm{E}+00$ & $8.23 \mathrm{E}-08$ & $1.61 \mathrm{E}-04$ \\
\hline WTP HLW Vit & Secondary & Silver Mordinite & IDF & $0.00 \mathrm{E}+00$ & $1.66 \mathrm{E}+00$ & $1.09 \mathrm{E}-10$ & $1.34 \mathrm{E}-06$ & 1.31E-07 & $1.99 \mathrm{E}-12$ & 5.97E-09 \\
\hline
\end{tabular}


Table A-3. Contaminant Distribution, Reference Case.

\begin{tabular}{|c|c|c|c|c|c|c|c|c|c|c|}
\hline \multicolumn{11}{|c|}{ Products for Disposal - Reference Case } \\
\hline Facility & Type & Product & Via & $\begin{array}{c}\mathrm{Hg} \\
(\mathrm{Kg})\end{array}$ & $\begin{array}{c}\mathrm{I}-129 \\
\text { (Ci) }\end{array}$ & $\begin{array}{l}\text { Tc-99 } \\
\text { (Ci) }\end{array}$ & $\begin{array}{c}\mathrm{Cr} \\
(\mathrm{Kg})\end{array}$ & $\begin{array}{l}\text { NO3 } \\
(\mathrm{Kg})\end{array}$ & $\begin{array}{c}\mathrm{U}-238 \\
\text { (Ci) }\end{array}$ & $\begin{array}{c}\text { U-Total } \\
\text { (Kg) }\end{array}$ \\
\hline WTP Glass & & & & $0.00 \mathrm{E}+00$ & $4.64 \mathrm{E}+00$ & $7.18 \mathrm{E}+03$ & $1.02 \mathrm{E}+05$ & $0.00 \mathrm{E}+00$ & $3.97 E+00$ & $1.19 \mathrm{E}+04$ \\
\hline Early WTP LAW Vit & Primary & ILAW Glass & IDF & $0.00 \mathrm{E}+00$ & $1.20 \mathrm{E}+00$ & $1.79 \mathrm{E}+03$ & $1.75 \mathrm{E}+04$ & $0.00 \mathrm{E}+00$ & 1.96E-01 & $5.87 \mathrm{E}+02$ \\
\hline WTP LAW Vit & Primary & ILAW Glass & IDF & $0.00 \mathrm{E}+00$ & $3.44 \mathrm{E}+00$ & $5.39 \mathrm{E}+03$ & $8.42 \mathrm{E}+04$ & $0.00 \mathrm{E}+00$ & $3.77 \mathrm{E}+00$ & $1.13 \mathrm{E}+04$ \\
\hline BV & & & & $0.00 \mathrm{E}+00$ & $1.61 \mathrm{E}+00$ & $1.46 \mathrm{E}+04$ & $1.29 \mathrm{E}+05$ & $0.00 \mathrm{E}+00$ & $3.40 \mathrm{E}+00$ & $1.02 E+04$ \\
\hline STP-E & Primary & ILAW Glass & IDF & $0.00 \mathrm{E}+00$ & $1.04 \mathrm{E}+00$ & $8.70 \mathrm{E}+03$ & $5.30 \mathrm{E}+04$ & $0.00 \mathrm{E}+00$ & $2.32 \mathrm{E}+00$ & $6.94 \mathrm{E}+03$ \\
\hline DBVS & Primary & ILAW Glass & IDF & $0.00 \mathrm{E}+00$ & $2.75 \mathrm{E}-02$ & $2.78 \mathrm{E}+02$ & $6.48 \mathrm{E}+02$ & $0.00 \mathrm{E}+00$ & $2.77 \mathrm{E}-03$ & $8.30 \mathrm{E}+00$ \\
\hline STP-W & Primary & ILAW Glass & IDF & $0.00 \mathrm{E}+00$ & 5.43E-01 & $5.62 \mathrm{E}+03$ & $7.52 \mathrm{E}+04$ & $0.00 \mathrm{E}+00$ & $1.08 \mathrm{E}+00$ & $3.24 \mathrm{E}+03$ \\
\hline BV - non glass & & & & $0.00 \mathrm{E}+00$ & $0.00 \mathrm{E}+00$ & $5.99 \mathrm{E}+01$ & $0.00 \mathrm{E}+00$ & $0.00 \mathrm{E}+00$ & $0.00 \mathrm{E}+00$ & $0.00 \mathrm{E}+00$ \\
\hline STP-E & Secondary & ICV Box non-glass & IDF & $0.00 \mathrm{E}+00$ & $0.00 \mathrm{E}+00$ & $3.57 \mathrm{E}+01$ & $0.00 \mathrm{E}+00$ & $0.00 \mathrm{E}+00$ & $0.00 \mathrm{E}+00$ & $0.00 \mathrm{E}+00$ \\
\hline DBVS & Secondary & ICV Box non-glass & IDF & $0.00 \mathrm{E}+00$ & $0.00 \mathrm{E}+00$ & $1.14 \mathrm{E}+00$ & $0.00 \mathrm{E}+00$ & $0.00 \mathrm{E}+00$ & $0.00 \mathrm{E}+00$ & $0.00 \mathrm{E}+00$ \\
\hline STP-W & Secondary & ICV Box non-glass & IDF & $0.00 \mathrm{E}+00$ & $0.00 \mathrm{E}+00$ & $2.31 \mathrm{E}+01$ & $0.00 \mathrm{E}+00$ & $0.00 \mathrm{E}+00$ & $0.00 \mathrm{E}+00$ & $0.00 \mathrm{E}+00$ \\
\hline & & & & & & & & & & \\
\hline ETF & & & & $4.35 \mathrm{E}+02$ & $4.73 \mathrm{E}+00$ & $2.99 \mathrm{E}+03$ & $4.87 \mathrm{E}+02$ & $4.89 \mathrm{E}+05$ & $2.38 \mathrm{E}-01$ & $7.23 \mathrm{E}+02$ \\
\hline $242-A$ & Secondary & Condensate & ETF & $5.64 \mathrm{E}-01$ & $5.11 \mathrm{E}-04$ & $1.61 \mathrm{E}-03$ & $3.90 \mathrm{E}+00$ & $5.36 \mathrm{E}+04$ & $3.02 \mathrm{E}-03$ & $1.72 \mathrm{E}+01$ \\
\hline TRU & Secondary & Condensate & ETF & $3.36 \mathrm{E}-02$ & $5.76 \mathrm{E}-02$ & 1.88E-01 & $1.96 \mathrm{E}+00$ & $8.49 \mathrm{E}+02$ & $3.13 \mathrm{E}-02$ & $9.39 \mathrm{E}+01$ \\
\hline WTP PT & Secondary & Condensate (FEP) & ETF & $2.22 \mathrm{E}+00$ & $4.57 \mathrm{E}-02$ & $1.90 \mathrm{E}+01$ & $1.32 \mathrm{E}+01$ & $5.02 \mathrm{E}+04$ & $1.95 \mathrm{E}-01$ & $5.83 \mathrm{E}+02$ \\
\hline WTP PT & Secondary & Condensate (TLP) & ETF & $7.19 \mathrm{E}-01$ & $6.42 \mathrm{E}-02$ & $2.27 \mathrm{E}+01$ & $3.93 \mathrm{E}+00$ & $4.97 \mathrm{E}+04$ & $6.03 \mathrm{E}-03$ & $1.81 \mathrm{E}+01$ \\
\hline Early WTP LAW Vit & Secondary & SBS+WESP Liquid & ETF & $1.25 \mathrm{E}-01$ & $4.21 \mathrm{E}+00$ & $2.94 \mathrm{E}+03$ & $4.28 \mathrm{E}+02$ & $2.79 \mathrm{E}+05$ & $1.22 \mathrm{E}-04$ & $3.67 \mathrm{E}-01$ \\
\hline Early WTP LAW Vit & Secondary & Caustic Scrubber Liquid & ETF & $0.00 \mathrm{E}+00$ & $5.88 \mathrm{E}-03$ & $0.00 \mathrm{E}+00$ & $0.00 \mathrm{E}+00$ & $0.00 \mathrm{E}+00$ & $0.00 \mathrm{E}+00$ & $0.00 \mathrm{E}+00$ \\
\hline WTP LAW Vit & Secondary & SBS+WESP Liquid & ETF & $0.00 \mathrm{E}+00$ & $0.00 \mathrm{E}+00$ & $0.00 \mathrm{E}+00$ & $0.00 \mathrm{E}+00$ & $0.00 \mathrm{E}+00$ & $0.00 \mathrm{E}+00$ & $0.00 \mathrm{E}+00$ \\
\hline WTP LAW Vit & Secondary & Caustic Scrubber Liquid & ETF & $0.00 \mathrm{E}+00$ & $1.68 \mathrm{E}-02$ & $0.00 E+00$ & $0.00 \mathrm{E}+00$ & $0.00 \mathrm{E}+00$ & $0.00 \mathrm{E}+00$ & $0.00 \mathrm{E}+00$ \\
\hline WTP HLW Vit & Secondary & SBS+WESP+HEME Liquid & ETF & $0.00 \mathrm{E}+00$ & $0.00 \mathrm{E}+00$ & $0.00 \mathrm{E}+00$ & $0.00 \mathrm{E}+00$ & $0.00 \mathrm{E}+00$ & $0.00 \mathrm{E}+00$ & $0.00 \mathrm{E}+00$ \\
\hline SR-E & Secondary & Liquid Effluent & ETF & $0.00 \mathrm{E}+00$ & $0.00 \mathrm{E}+00$ & $0.00 \mathrm{E}+00$ & $0.00 \mathrm{E}+00$ & $0.00 \mathrm{E}+00$ & $0.00 \mathrm{E}+00$ & $0.00 \mathrm{E}+00$ \\
\hline SR-W & Secondary & Liquid Effluent & ETF & $0.00 \mathrm{E}+00$ & $0.00 \mathrm{E}+00$ & $0.00 \mathrm{E}+00$ & $0.00 \mathrm{E}+00$ & $0.00 \mathrm{E}+00$ & $0.00 E+00$ & $0.00 \mathrm{E}+00$ \\
\hline STP-E & Secondary & Front End Evap Condenstate & ETF & $0.00 \mathrm{E}+00$ & $0.00 \mathrm{E}+00$ & $0.00 \mathrm{E}+00$ & $0.00 \mathrm{E}+00$ & $0.00 \mathrm{E}+00$ & $0.00 \mathrm{E}+00$ & $0.00 \mathrm{E}+00$ \\
\hline STP-E & Secondary & Dryer Condenstate & ETF & $2.79 \mathrm{E}-01$ & $2.12 \mathrm{E}-01$ & $9.18 \mathrm{E}+00$ & $1.50 \mathrm{E}+01$ & $1.93 \mathrm{E}+04$ & $2.32 \mathrm{E}-03$ & $6.96 \mathrm{E}+00$ \\
\hline STP-E & Secondary & Bleed & ETF & $2.63 \mathrm{E}+02$ & 8.00E-06 & $1.32 \mathrm{E}-01$ & $1.10 \mathrm{E}-01$ & $0.00 \mathrm{E}+00$ & $3.35 \mathrm{E}-06$ & $6.54 \mathrm{E}-03$ \\
\hline DBVS & Secondary & Front End Evap Condenstate & ETF & $0.00 \mathrm{E}+00$ & $0.00 \mathrm{E}+00$ & $0.00 \mathrm{E}+00$ & $0.00 \mathrm{E}+00$ & $0.00 \mathrm{E}+00$ & $0.00 \mathrm{E}+00$ & $0.00 \mathrm{E}+00$ \\
\hline DBVS & Secondary & Dryer Condenstate & ETF & $3.89 \mathrm{E}-03$ & $5.60 \mathrm{E}-03$ & $2.93 \mathrm{E}-01$ & $1.83 \mathrm{E}-01$ & $3.40 \mathrm{E}+03$ & $2.78 \mathrm{E}-06$ & 8.33E-03 \\
\hline DBVS & Secondary & Bleed & ETF & $3.66 \mathrm{E}+00$ & $2.11 \mathrm{E}-07$ & $4.21 \mathrm{E}-03$ & $1.35 \mathrm{E}-03$ & $0.00 \mathrm{E}+00$ & $4.01 \mathrm{E}-09$ & $7.83 \mathrm{E}-06$ \\
\hline STP-W & Secondary & Front End Evap Condenstate & ETF & $0.00 \mathrm{E}+00$ & $0.00 \mathrm{E}+00$ & $0.00 \mathrm{E}+00$ & $0.00 \mathrm{E}+00$ & $0.00 \mathrm{E}+00$ & $0.00 \mathrm{E}+00$ & $0.00 \mathrm{E}+00$ \\
\hline STP-W & Secondary & Dryer Condenstate & ETF & $1.75 \mathrm{E}-01$ & $1.11 \mathrm{E}-01$ & $5.93 E+00$ & $2.13 E+01$ & $3.33 \mathrm{E}+04$ & $1.08 \mathrm{E}-03$ & $3.25 \mathrm{E}+00$ \\
\hline STP-W & Secondary & Bleed & ETF & $1.65 \mathrm{E}+02$ & $4.18 \mathrm{E}-06$ & $8.51 \mathrm{E}-02$ & $1.56 \mathrm{E}-01$ & $0.00 \mathrm{E}+00$ & $1.56 \mathrm{E}-06$ & $3.05 \mathrm{E}-03$ \\
\hline & & & & & & & & & & \\
\hline Solid Waste & & & & $1.52 \mathrm{E}+03$ & $1.83 \mathrm{E}+01$ & $5.01 \mathrm{E}+00$ & $1.33 \mathrm{E}+00$ & $3.20 \mathrm{E}+02$ & $1.29 \mathrm{E}-06$ & $1.84 \mathrm{E}-03$ \\
\hline Early WTP LAW Vit & Secondary & Carbon Adsorber & IDF & $3.11 \mathrm{E}-01$ & $5.88 \mathrm{E}-01$ & $6.73 \mathrm{E}-07$ & $9.96 \mathrm{E}-08$ & $3.70 \mathrm{E}-05$ & $1.56 \mathrm{E}-14$ & $4.66 \mathrm{E}-11$ \\
\hline WTP LAW Vit & Secondary & Carbon Adsorber & IDF & $3.21 \mathrm{E}+02$ & $1.68 \mathrm{E}+00$ & 2.03E-06 & $4.78 \mathrm{E}-07$ & 1.36E-04 & $3.00 \mathrm{E}-13$ & $8.98 \mathrm{E}-10$ \\
\hline WTP HLW Vit & Secondary & Carbon Adsorber & IDF & $1.17 \mathrm{E}+03$ & $0.00 \mathrm{E}+00$ & $1.06 \mathrm{E}-09$ & 1.34E-05 & 1.29E-06 & $1.99 \mathrm{E}-11$ & 5.97E-08 \\
\hline STP-E & Secondary & HEGA & IDF & $0.00 \mathrm{E}+00$ & $2.16 \mathrm{E}+00$ & $0.00 \mathrm{E}+00$ & $0.00 \mathrm{E}+00$ & $0.00 \mathrm{E}+00$ & $0.00 \mathrm{E}+00$ & $0.00 \mathrm{E}+00$ \\
\hline DBVS & Secondary & HEGA & IDF & $0.00 \mathrm{E}+00$ & $5.71 \mathrm{E}-02$ & $0.00 \mathrm{E}+00$ & $0.00 \mathrm{E}+00$ & $0.00 \mathrm{E}+00$ & $0.00 \mathrm{E}+00$ & $0.00 \mathrm{E}+00$ \\
\hline STP-W & Secondary & HEGA & IDF & $0.00 \mathrm{E}+00$ & $1.13 \mathrm{E}+00$ & $0.00 \mathrm{E}+00$ & $0.00 \mathrm{E}+00$ & $0.00 \mathrm{E}+00$ & $0.00 \mathrm{E}+00$ & $0.00 \mathrm{E}+00$ \\
\hline TRU & Secondary & HEPA & IDF & $0.00 \mathrm{E}+00$ & $0.00 \mathrm{E}+00$ & $0.00 \mathrm{E}+00$ & $0.00 \mathrm{E}+00$ & $0.00 \mathrm{E}+00$ & $0.00 \mathrm{E}+00$ & $0.00 \mathrm{E}+00$ \\
\hline STP-E & Secondary & HEPA & IDF & $1.25 \mathrm{E}-01$ & $2.58 \mathrm{E}-06$ & $2.12 \mathrm{E}-03$ & $2.18 \mathrm{E}-05$ & $0.00 \mathrm{E}+00$ & $5.40 \mathrm{E}-08$ & 1.05E-04 \\
\hline$z$ & Secondary & HEPA & IDF & 1.74E-03 & $6.81 \mathrm{E}-08$ & $6.77 \mathrm{E}-05$ & $2.66 \mathrm{E}-07$ & $0.00 \mathrm{E}+00$ & $6.46 \mathrm{E}-11$ & $1.26 \mathrm{E}-07$ \\
\hline STP-W & Secondary & HEPA & IDF & $7.85 \mathrm{E}-02$ & $1.35 \mathrm{E}-06$ & $1.37 \mathrm{E}-03$ & $3.09 \mathrm{E}-05$ & $0.00 \mathrm{E}+00$ & $2.52 \mathrm{E}-08$ & 4.91E-05 \\
\hline Early WTP LAW Vit & Secondary & HEPA1 & IDF & $0.00 \mathrm{E}+00$ & $0.00 \mathrm{E}+00$ & $1.25 \mathrm{E}+00$ & 1.84E-01 & $6.85 \mathrm{E}+01$ & $2.88 \mathrm{E}-08$ & 8.63E-05 \\
\hline WTP LAW Vit & Secondary & HEPA1 & IDF & $0.00 \mathrm{E}+00$ & $0.00 \mathrm{E}+00$ & $3.75 \mathrm{E}+00$ & $8.85 \mathrm{E}-01$ & $2.51 \mathrm{E}+02$ & $5.55 \mathrm{E}-07$ & $0.00 \mathrm{E}+00$ \\
\hline WTP HLW Vit & Secondary & HEPA1 & IDF & $0.00 \mathrm{E}+00$ & $0.00 \mathrm{E}+00$ & 1.97E-03 & 2.39E-01 & 2.29E-02 & 3.54E-07 & 1.06E-03 \\
\hline Early WTP LAW Vit & Secondary & HEPA2 & IDF & $0.00 \mathrm{E}+00$ & $0.00 \mathrm{E}+00$ & $3.73 \mathrm{E}-04$ & $5.52 \mathrm{E}-05$ & $2.05 \mathrm{E}-02$ & $8.62 \mathrm{E}-12$ & 2.59E-08 \\
\hline WTP LAW VIt & Secondary & HEPA2 & IDF & $0.00 \mathrm{E}+00$ & $0.00 \mathrm{E}+00$ & $1.12 \mathrm{E}-03$ & $2.65 \mathrm{E}-04$ & $7.53 \mathrm{E}-02$ & $1.66 \mathrm{E}-10$ & $4.98 \mathrm{E}-07$ \\
\hline WTP HLW Vit & Secondary & HEPA2 & IDF & $0.00 \mathrm{E}+00$ & $0.00 \mathrm{E}+00$ & $5.90 \mathrm{E}-07$ & 7.44E-03 & 7.15E-04 & $1.10 \mathrm{E}-08$ & 3.31E-05 \\
\hline STP-E & Secondary & Quencher Filter to IDF & IDF & $1.36 \mathrm{E}+01$ & $7.14 \mathrm{E}+00$ & $6.94 \mathrm{E}-03$ & $5.80 \mathrm{E}-03$ & $0.00 \mathrm{E}+00$ & $1.76 \mathrm{E}-07$ & 3.44E-04 \\
\hline DBVS & Secondary & Quencher Filter to IDF & IDF & $1.90 \mathrm{E}-01$ & 1.89E-01 & $2.21 \mathrm{E}-04$ & $7.08 \mathrm{E}-05$ & $0.00 \mathrm{E}+00$ & $2.11 \mathrm{E}-10$ & $4.12 \mathrm{E}-07$ \\
\hline STP-W & Secondary & Quencher Filter to IDF & IDF & $8.55 \mathrm{E}+00$ & $3.73 \mathrm{E}+00$ & $4.48 \mathrm{E}-03$ & $8.22 \mathrm{E}-03$ & $0.00 \mathrm{E}+00$ & $8.23 \mathrm{E}-08$ & $1.61 \mathrm{E}-04$ \\
\hline WTP HLW Vit & Secondary & Silver Mordinite & IDF & $0.00 \mathrm{E}+00$ & $1.62 \mathrm{E}+00$ & $1.06 \mathrm{E}-10$ & $1.34 \mathrm{E}-06$ & 1.29E-07 & 1.99E-12 & 5.97E-09 \\
\hline
\end{tabular}




\section{APPENDIX B. FEED COMPARISON}

Three sets of tanks were selected to represent a range of ${ }^{99} \mathrm{Tc}$ in the feed. A high ${ }^{99} \mathrm{Tc}$ feed represents the reference case since DST waste was selected in an earlier engineering study on Early LAW (RPP-29981, Rev. 1). The DST feed, shown is Table B-1, is mostly supernatant with DST salt cake and SST salt cake, if needed. Representing a Mid ${ }^{99} \mathrm{Tc}$ feed is SST salt cake from 200-West Area from tanks easily accessible and in sound condition (in $\mathrm{U}$ and $\mathrm{S}$ farms) and DST tanks to retrieve the SST waste into (Table B-2). Selection of Low ${ }^{99} \mathrm{Tc}$ feed was opened up to all tanks including tanks assumed to have leaked which led to 16 tanks in B- and BY-Farms as shown in Table B-3. Further details of the feed groups are found in SVF-1484, Interim Pretreatment System DST Feed Calculation, and SVF-1487, Interim Pretreatment System SST Feed Calculation. 
Table B-1. DST Supernatant and Salt Cake - 8 Tanks in AP \& AN Farms.

\begin{tabular}{|c|c|c|c|c|c|c|c|c|}
\hline Feed Order & & - & 3 & 4 & 5 & 0 & & 8 \\
\hline $\mathrm{Kg}$ or $\mathrm{Ci}$ & $1-\mathrm{AP}-104$ & 241-AP-102 & $41-\mathrm{AP}-101$ & $241-A P-103$ & $241-\mathrm{AP}-105$ & 241-AP-108 & $241-\mathrm{AP}-107$ & $241-\mathrm{AN}-104$ \\
\hline Volume (kL) & $3.79 \mathrm{E}+03$ & $4.00 \mathrm{E}+03$ & $4.13 \mathrm{E}+03$ & $4.25 \mathrm{E}+03$ & $3.94 \mathrm{E}+03$ & $4.34 \mathrm{E}+03$ & $4.32 \mathrm{E}+03$ & 5,528 \\
\hline$\overline{106 R u}$ & $2.16 \mathrm{E}-05$ & $1.40 \mathrm{E}-05$ & $1.88 \mathrm{E}+01$ & $2.31 \mathrm{E}-05$ & $1.25 \mathrm{E}+00$ & $1.02 \mathrm{E}-04$ & $6.16 \mathrm{E}+01$ & $9.56 \mathrm{E}-\mathrm{C}$ \\
\hline $113 \mathrm{mCd}$ & $1.17 \mathrm{E}+02$ & $9.21 \mathrm{E}+01$ & $1.51 \mathrm{E}+02$ & $1.28 \mathrm{E}+02$ & $1.09 \mathrm{E}+02$ & $1.99 \mathrm{E}+02$ & $1.80 \mathrm{E}+02$ & $0.00 \mathrm{E}+00$ \\
\hline $125 \mathrm{Sb}$ & $2.97 \mathrm{E}+01$ & $2.76 \mathrm{E}+01$ & $4.13 \mathrm{E}+02$ & $3.77 \mathrm{E}+01$ & $5.55 \mathrm{E}+01$ & $7.14 \mathrm{E}+01$ & $1.28 \mathrm{E}+03$ & $2.03 \mathrm{E}+0$ \\
\hline $126 \mathrm{Sn}$ & $5.40 \mathrm{E}+00$ & $3.67 \mathrm{E}+00$ & $6.36 \mathrm{E}+00$ & $5.48 \mathrm{E}+00$ & $4.47 \mathrm{E}+00$ & $8.24 \mathrm{E}+00$ & $5.66 \mathrm{E}+00$ & $1.52 \mathrm{E}+00$ \\
\hline 1291 & $6.76 \mathrm{E}-01$ & $1.23 \mathrm{E}+00$ & $7.07 \mathrm{E}-01$ & $1.38 \mathrm{E}+00$ & $1.05 \mathrm{E}+00$ & $1.04 \mathrm{E}+00$ & $6.40 \mathrm{E}-01$ & $4.72 \mathrm{E}-01$ \\
\hline $134 \mathrm{Cs}$ & $8.15 \mathrm{E}+00$ & $7.11 \mathrm{E}-01$ & $2.02 \mathrm{E}+02$ & $4.79 \mathrm{E}+00$ & $1.38 \mathrm{E}+01$ & $1.55 \mathrm{E}+01$ & $6.26 \mathrm{E}+02$ & $5.61 \mathrm{E}+00$ \\
\hline $137 \mathrm{Cs}$ & $7.26 \mathrm{E}+05$ & $9.63 \mathrm{E}+05$ & $1.28 \mathrm{E}+06$ & $1.02 \mathrm{E}+06$ & $1.07 \mathrm{E}+06$ & $8.99 \mathrm{E}+05$ & $2.72 \mathrm{E}+06$ & $1.04 \mathrm{E}+06$ \\
\hline $137 \mathrm{mBa}$ & $6.85 \mathrm{E}+05$ & $9.09 \mathrm{E}+05$ & $1.20 \mathrm{E}+06$ & $9.62 \mathrm{E}+05$ & $1.02 \mathrm{E}+06$ & $8.49 \mathrm{E}+05$ & $2.56 \mathrm{E}+06$ & $9.83 \mathrm{E}+05$ \\
\hline $14 \mathrm{C}$ & $5.34 \mathrm{E}+00$ & $1.09 \mathrm{E}+01$ & $1.78 \mathrm{E}+01$ & $2.77 \mathrm{E}+01$ & $1.00 \mathrm{E}+01$ & $1.10 \mathrm{E}+01$ & $1.47 \mathrm{E}+01$ & $1.13 \mathrm{E}+01$ \\
\hline $151 \mathrm{Sm}$ & $2.58 \mathrm{E}+04$ & $1.81 \mathrm{E}+04$ & $3.01 \mathrm{E}+04$ & $2.69 \mathrm{E}+04$ & $2.19 \mathrm{E}+04$ & $4.07 \mathrm{E}+04$ & $2.88 \mathrm{E}+04$ & $5.53 \mathrm{E}-03$ \\
\hline 152Eu & $5.72 \mathrm{E}+00$ & $4.40 \mathrm{E}+00$ & $8.98 \mathrm{E}+00$ & $6.39 \mathrm{E}+00$ & $5.17 \mathrm{E}+00$ & $9.53 \mathrm{E}+00$ & $1.40 \mathrm{E}+01$ & $3.76 \mathrm{E}-\mathrm{C}$ \\
\hline 154Eu & $3.03 E+01$ & $1.25 \mathrm{E}+02$ & $9.32 E+01$ & $6.03 \mathrm{E}+01$ & $1.86 \mathrm{E}+02$ & $6.57 \mathrm{E}+01$ & $1.53 \mathrm{E}+02$ & $1.77 \mathrm{E}-05$ \\
\hline 155Eu & $7.56 \mathrm{E}+01$ & $7.04 \mathrm{E}+01$ & $1.59 E+02$ & $7.93 \mathrm{E}+01$ & $1.65 \mathrm{E}+02$ & $7.09 \mathrm{E}+01$ & $2.64 \mathrm{E}+02$ & $6.82 \mathrm{E}-$ \\
\hline $226 \mathrm{Ra}$ & $3.36 \mathrm{E}-04$ & $2.28 \mathrm{E}-04$ & $3.60 \mathrm{E}-04$ & $3.68 \mathrm{E}-04$ & $2.87 \mathrm{E}-04$ & $5.34 \mathrm{E}-04$ & $3.53 \mathrm{E}-04$ & $4.91 \mathrm{E}-0$ \\
\hline $227 \mathrm{Ac}$ & $5.38 \mathrm{E}-03$ & $3.65 \mathrm{E}-03$ & $6.63 \mathrm{E}-03$ & $4.18 \mathrm{E}-03$ & $3.50 \mathrm{E}-03$ & $6.27 \mathrm{E}-03$ & $3.77 \mathrm{E}-03$ & $3.52 \mathrm{E}-09$ \\
\hline $228 \mathrm{Ra}$ & $7.08 \mathrm{E}-02$ & $3.02 \mathrm{E}-01$ & $7.94 \mathrm{E}-02$ & $1.49 \mathrm{E}-01$ & $2.01 \mathrm{E}-01$ & $3.62 \mathrm{E}-01$ & $9.07 \mathrm{E}-02$ & $1.39 \mathrm{E}-\mathrm{C}$ \\
\hline 229Th & $4.60 \mathrm{E}-03$ & $9.92 \mathrm{E}-03$ & $4.08 \mathrm{E}-03$ & $8.78 \mathrm{E}-03$ & $9.13 \mathrm{E}-03$ & $2.20 \mathrm{E}-02$ & $5.08 \mathrm{E}-03$ & $6.47 \mathrm{E}-06$ \\
\hline $231 \mathrm{~Pa}$ & $2.61 \mathrm{E}-02$ & $6.33 \mathrm{E}-03$ & $3.82 \mathrm{E}-02$ & $9.63 \mathrm{E}-03$ & $7.96 \mathrm{E}-03$ & $1.44 \mathrm{E}-02$ & $1.03 \mathrm{E}-02$ & 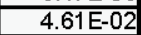 \\
\hline 232Th & $2.95 \mathrm{E}-03$ & $4.41 \mathrm{E}-02$ & $7.59 \mathrm{E}-03$ & $3.03 \mathrm{E}-02$ & $9.24 \mathrm{E}-03$ & $1.50 \mathrm{E}-02$ & $8.03 \mathrm{E}-03$ & $2.34 \mathrm{E}-05$ \\
\hline $232 \mathrm{U}$ & $1.21 \mathrm{E}-02$ & $2.55 \mathrm{E}-02$ & $6.09 \mathrm{E}-03$ & $1.47 \mathrm{E}-02$ & $5.04 \mathrm{E}-03$ & $1.62 \mathrm{E}-02$ & $4.44 \mathrm{E}-03$ & $4.53 \mathrm{E}-04$ \\
\hline $233 \mathrm{U}$ & $8.45 \mathrm{E}-02$ & $1.08 \mathrm{E}-01$ & $7.83 \mathrm{E}-02$ & $6.24 \mathrm{E}-02$ & $2.22 \mathrm{E}-02$ & $6.74 \mathrm{E}-02$ & $6.45 \mathrm{E}-02$ & $2.77 \mathrm{E}-\mathrm{C}$ \\
\hline $234 \mathrm{U}$ & $4.57 \mathrm{E}-02$ & $2.00 \mathrm{E}-02$ & $5.35 \mathrm{E}-02$ & $4.49 \mathrm{E}-02$ & $7.43 \mathrm{E}-03$ & $4.69 \mathrm{E}-02$ & $5.21 \mathrm{E}-02$ & $1.97 \mathrm{E}-02$ \\
\hline $235 \mathrm{U}$ & $1.76 \mathrm{E}-03$ & $7.93 \mathrm{E}-04$ & $1.99 \mathrm{E}-03$ & $1.92 \mathrm{E}-03$ & $3.01 \mathrm{E}-04$ & $1.83 \mathrm{E}-03$ & $2.12 \mathrm{E}-03$ & $7.77 \mathrm{E}-04$ \\
\hline $236 \mathrm{U}$ & $2.08 \mathrm{E}-03$ & $6.44 \mathrm{E}-04$ & $3.06 \mathrm{E}-03$ & $1.26 \mathrm{E}-03$ & $2.66 \mathrm{E}-04$ & $2.93 \mathrm{E}-03$ & $2.49 \mathrm{E}-03$ & $1.33 \mathrm{E}-$ \\
\hline $237 \mathrm{~Np}$ & $1.94 \mathrm{E}-01$ & $1.90 \mathrm{E}+00$ & $9.39 \mathrm{E}-01$ & $2.15 \mathrm{E}-01$ & $2.04 \mathrm{E}+00$ & $2.22 \mathrm{E}-01$ & $8.56 \mathrm{E}-01$ & $3.90 \mathrm{E}-02$ \\
\hline $238 \mathrm{Pu}$ & $4.77 \mathrm{E}-01$ & $3.23 \mathrm{E}-02$ & $5.79 \mathrm{E}-01$ & $8.25 \mathrm{E}-01$ & $5.87 \mathrm{E}-02$ & $1.08 \mathrm{E}-01$ & $1.71 \mathrm{E}+00$ & $2.14 \mathrm{E}$ \\
\hline $238 \mathrm{U}$ & $3.87 \mathrm{E}-02$ & $1.78 \mathrm{E}-02$ & $4.02 \mathrm{E}-02$ & $4.59 \mathrm{E}-02$ & $6.60 \mathrm{E}-03$ & $3.64 \mathrm{E}-02$ & $4.44 \mathrm{E}-02$ & $1.54 \mathrm{E}-02$ \\
\hline $239 \mathrm{Pu}$ & $2.50 \mathrm{E}+00$ & $1.24 \mathrm{E}+00$ & $7.99 \mathrm{E}+00$ & $6.00 \mathrm{E}+00$ & $1.15 \mathrm{E}+00$ & $1.74 \mathrm{E}+00$ & $1.86 \mathrm{E}+01$ & $2.95 \mathrm{E}-01$ \\
\hline $240 \mathrm{Pu}$ & $4.24 \mathrm{E}-01$ & $2.10 \mathrm{E}-01$ & $1.87 \mathrm{E}+00$ & $1.01 \mathrm{E}+00$ & $2.29 \mathrm{E}-01$ & $3.31 \mathrm{E}-01$ & $4.95 \mathrm{E}+00$ & $7.69 \mathrm{E}-\mathrm{C}$ \\
\hline $241 \mathrm{Am}$ & $7.69 \mathrm{E}+00$ & $6.97 \mathrm{E}+00$ & $2.64 \mathrm{E}+00$ & $2.94 \mathrm{E}+01$ & $8.63 \mathrm{E}+00$ & $8.22 \mathrm{E}+00$ & $3.25 \mathrm{E}+00$ & $4.87 \mathrm{E}+00$ \\
\hline $241 \mathrm{Pu}$ & $2.88 \mathrm{E}+00$ & $1.49 \mathrm{E}+00$ & $3.87 \mathrm{E}+01$ & $7.31 \mathrm{E}+00$ & $3.43 \mathrm{E}+00$ & $4.18 \mathrm{E}+00$ & $1.21 \mathrm{E}+02$ & $1.35 \mathrm{E}+$ \\
\hline $242 \mathrm{Cm}$ & $2.81 \mathrm{E}-02$ & $2.24 \mathrm{E}-02$ & $4.43 \mathrm{E}-03$ & $9.59 \mathrm{E}-02$ & $3.39 \mathrm{E}-02$ & $2.48 \mathrm{E}-02$ & $4.00 \mathrm{E}-03$ & $9.66 \mathrm{E}-$ \\
\hline $242 \mathrm{Pu}$ & $2.46 \mathrm{E}-05$ & $1.28 \mathrm{E}-05$ & $1.90 \mathrm{E}-04$ & $6.49 \mathrm{E}-05$ & $2.08 \mathrm{E}-05$ & $3.14 \mathrm{E}-05$ & $5.82 \mathrm{E}-04$ & $8.14 \mathrm{E}-06$ \\
\hline $243 \mathrm{Am}$ & $3.18 \mathrm{E}-04$ & $2.55 \mathrm{E}-04$ & $1.87 \mathrm{E}-04$ & $1.09 \mathrm{E}-03$ & $3.28 \mathrm{E}-04$ & $3.18 \mathrm{E}-04$ & $5.51 \mathrm{E}-04$ & $3.26 \mathrm{E}-$ \\
\hline $243 \mathrm{Cm}$ & $9.14 \mathrm{E}-02$ & $2.87 \mathrm{E}-03$ & $5.84 \mathrm{E}-03$ & $6.76 \mathrm{E}-02$ & $5.69 \mathrm{E}-03$ & $5.46 \mathrm{E}-03$ & $2.30 \mathrm{E}-03$ & $5.33 \mathrm{E}-04$ \\
\hline $244 \mathrm{Cm}$ & $2.14 \mathrm{E}+00$ & $4.17 \mathrm{E}-02$ & $1.31 \mathrm{E}-01$ & $1.48 \mathrm{E}+00$ & $9.77 \mathrm{E}-02$ & $9.19 \mathrm{E}-02$ & $5.02 \mathrm{E}-02$ & $1.26 \mathrm{E}-0$ \\
\hline $3 \mathrm{H}$ & $5.42 \mathrm{E}+00$ & $4.31 \mathrm{E}+01$ & $1.77 \mathrm{E}+02$ & $1.33 \mathrm{E}+02$ & $2.95 \mathrm{E}+01$ & $5.46 \mathrm{E}+01$ & $1.79 \mathrm{E}+02$ & $1.92 \mathrm{E}+01$ \\
\hline $59 \mathrm{Ni}$ & $4.28 \mathrm{E}+00$ & $1.25 \mathrm{E}+00$ & $5.65 \mathrm{E}+00$ & $2.15 \mathrm{E}+00$ & $1.27 \mathrm{E}+00$ & $4.94 \mathrm{E}+00$ & $3.34 \mathrm{E}+00$ & $1.68 \mathrm{E}-01$ \\
\hline $60 \mathrm{Co}$ & $2.51 \mathrm{E}+01$ & $1.50 \mathrm{E}+01$ & $2.42 \mathrm{E}+01$ & $4.09 \mathrm{E}+01$ & $2.89 \mathrm{E}+01$ & $1.75 \mathrm{E}+01$ & $3.94 \mathrm{E}+01$ & $3.36 \mathrm{E}-\mathrm{C}$ \\
\hline $63 \mathrm{Ni}$ & $3.93 \mathrm{E}+02$ & $1.16 \mathrm{E}+02$ & $5.18 \mathrm{E}+02$ & $1.99 \mathrm{E}+02$ & $1.18 \mathrm{E}+02$ & $4.08 \mathrm{E}+02$ & $3.08 \mathrm{E}+02$ & $1.55 \mathrm{E}+01$ \\
\hline $79 \mathrm{Se}$ & $2.68 \mathrm{E}+00$ & $6.89 \mathrm{E}+00$ & $3.17 \mathrm{E}+00$ & $5.47 \mathrm{E}+00$ & $8.71 \mathrm{E}+00$ & $5.50 \mathrm{E}+00$ & $3.80 \mathrm{E}+00$ & $3.13 \mathrm{E}+00$ \\
\hline $90 \mathrm{Sr}$ & $5.27 \mathrm{E}+03$ & $1.55 \mathrm{E}+03$ & $3.76 \mathrm{E}+03$ & $9.18 \mathrm{E}+03$ & $7.18 \mathrm{E}+03$ & $4.43 E+03$ & $7.54 \mathrm{E}+03$ & $3.97 \mathrm{E}+03$ \\
\hline $90 \mathrm{Y}$ & $5.27 \mathrm{E}+03$ & $1.55 \mathrm{E}+03$ & $3.76 \mathrm{E}+03$ & $9.18 \mathrm{E}+03$ & $E+03$ & $4.43 \mathrm{E}+03$ & $7.54 \mathrm{E}+03$ & $3.97 \mathrm{E}+0$ \\
\hline $93 \mathrm{mNb}$ & $3.68 \mathrm{E}+01$ & $2.93 \mathrm{E}+01$ & $6.06 \mathrm{E}+01$ & $2.92 \mathrm{E}+01$ & $2.32 \mathrm{E}+01$ & $4.81 \mathrm{E}+01$ & $6.94 \mathrm{E}+01$ & $1.23 \mathrm{E}+\mathrm{C}$ \\
\hline $93 Z \mathrm{Zr}$ & $4.40 \mathrm{E}+01$ & $3.40 \mathrm{E}+01$ & $7.88 \mathrm{E}+01$ & $3.55 \mathrm{E}+01$ & $2.59 \mathrm{E}+01$ & $5.74 \mathrm{E}+01$ & $1.05 \mathrm{E}+02$ & $8.50 \mathrm{E}+\mathrm{C}$ \\
\hline 99Tc & $29 \mathrm{E}+02$ & $6.52 \mathrm{E}+02$ & $6.82 \mathrm{E}+02$ & $9.40 \mathrm{E}+02$ & $=+02$ & $6.71 \mathrm{E}+02$ & $8.77 \mathrm{E}+02$ & $7.78 \mathrm{E}+\mathrm{C}$ \\
\hline $\mathrm{Al}$ & $6.44 \mathrm{E}+04$ & $9.69 E+04$ & $4.97 \mathrm{E}+04$ & $8.77 \mathrm{E}+04$ & $7.28 \mathrm{E}+04$ & $1.00 \mathrm{E}+05$ & $4.82 \mathrm{E}+04$ & $1.41 \mathrm{E}+05$ \\
\hline $\mathrm{Bi}$ & & & & & & $E+01$ & $E+01$ & 1.3 \\
\hline $\mathrm{Ca}$ & +02 & 2 & +02 & $2.98 \mathrm{E}+02$ & $\mathrm{E}+02$ & $9.98 \mathrm{E}+01$ & $9.49 \mathrm{E}+01$ & $1.25 \mathrm{E}+\mathrm{C}$ \\
\hline $\mathrm{Cl}$ & $88 \mathrm{E}+04$ & +04 & $1.21 \mathrm{E}+04$ & $2.31 \mathrm{E}+04$ & $E+04$ & $2.15 \mathrm{E}+04$ & $1.20 \mathrm{E}+04$ & $2.91 \mathrm{E}+04$ \\
\hline $\mathrm{Cr}$ & & & & $2.87 \mathrm{E}+03$ & & $E+03$ & $4.60 \mathrm{E}+03$ & $1.58 \mathrm{E}+03$ \\
\hline $\mathrm{F}$ & $55 \mathrm{E}+03$ & +02 & 3.63 & $2.98 \mathrm{E}+03$ & $6.04 \mathrm{E}+02$ & $1.57 \mathrm{E}+03$ & $3.20 \mathrm{E}+03$ & $2.06 \mathrm{E}+03$ \\
\hline $\mathrm{Fe}$ & +01 & +01 & $3.64 \mathrm{E}+01$ & $6.80 \mathrm{E}+01$ & $5.90 \mathrm{E}+01$ & $E+01$ & $1.93 \mathrm{E}+01$ & $6.03 \mathrm{E}+00$ \\
\hline $\mathrm{Hg}$ & & & & & & & & 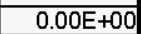 \\
\hline $\mathrm{K}$ & $2.43 \mathrm{E}+04$ & $1.83 E+04$ & $3.45 \mathrm{E}+04$ & $2.22 \mathrm{E}+04$ & $1.56 \mathrm{E}+04$ & $4.44 \mathrm{E}+04$ & $1.65 \mathrm{E}+04$ & $1.15 \mathrm{E}+04$ \\
\hline La & $27 \mathrm{E}+00$ & $1.06 \mathrm{E}+01$ & $E+01$ & $1.62 \mathrm{E}+01$ & 8.0 & $9.28 \mathrm{E}+00$ & $4.74 \mathrm{E}+00$ & $2.42 \mathrm{E}-10$ \\
\hline $\mathrm{Mn}$ & & & & & 5.8 & $7.54 \mathrm{E}+00$ & $E+00$ & $2.46 \mathrm{E}+\mathrm{C}$ \\
\hline $\mathrm{Na}$ & +05 & $7.40 \mathrm{E}+05$ & $8.27 \mathrm{E}+05$ & $8.27 \mathrm{E}+05$ & $8.07 \mathrm{E}+05$ & $8.99 \mathrm{E}+05$ & $7.80 \mathrm{E}+05$ & $7.63 \mathrm{E}+05$ \\
\hline $\mathrm{Ni}$ & & & $7.12 \mathrm{E}+01$ & $64 \mathrm{E}+02$ & & $1.26 \mathrm{E}+02$ & $5.87 \mathrm{E}+01$ & $2.70 \mathrm{E}+\mathrm{C}$ \\
\hline NO2 & $2.50 \mathrm{E}+05$ & $3.83 \mathrm{E}+05$ & $1.96 \mathrm{E}+05$ & $3.72 \mathrm{E}+05$ & $4.20 \mathrm{E}+05$ & $3.46 \mathrm{E}+05$ & $2.43 \mathrm{E}+05$ & $4.30 \mathrm{E}+05$ \\
\hline NO3 & +05 & +05 & $1.09 \mathrm{E}+06$ & +05 & +05 & $7.58 \mathrm{E}+05$ & $8.32 \mathrm{E}+05$ & $7.31 \mathrm{E}+05$ \\
\hline Oxalate & & $1.39 \mathrm{E}+03$ & $9.79 \mathrm{E}+03$ & $1.50 \mathrm{E}+04$ & $2.00 \mathrm{E}+03$ & $2.89 \mathrm{E}+03$ & $1.16 \mathrm{E}+04$ & $5.21 \mathrm{E}+\mathrm{C}$ \\
\hline $\mathrm{Pb}$ & $9.76 \mathrm{E}+01$ & $2.72 \mathrm{E}+02$ & $1.27 \mathrm{E}+02$ & $1.49 \mathrm{E}+02$ & $1.06 \mathrm{E}+02$ & $1.29 \mathrm{E}+02$ & $9.69 \mathrm{E}+01$ & $3.78 \mathrm{E}+0$ \\
\hline $\mathrm{PO4}$ & $2.55 \mathrm{E}+04$ & $1.17 \mathrm{E}+04$ & $2.56 \mathrm{E}+04$ & $2.30 \mathrm{E}+04$ & $1.64 \mathrm{E}+04$ & $8.21 \mathrm{E}+03$ & $2.15 \mathrm{E}+04$ & $1.49 \mathrm{E}+0$ \\
\hline $\mathrm{Si}$ & $2.71 \mathrm{E}+02$ & $2.03 E+02$ & $4.82 \mathrm{E}+02$ & $3.52 \mathrm{E}+02$ & $2.07 \mathrm{E}+02$ & $4.16 \mathrm{E}+02$ & $1.81 \mathrm{E}+02$ & $5.02 \mathrm{E}+\mathrm{C}$ \\
\hline $\mathrm{SO} 4$ & $2.37 \mathrm{E}+04$ & $1.11 \mathrm{E}+04$ & $4.46 E+04$ & $2.32 \mathrm{E}+04$ & $2.36 \mathrm{E}+04$ & $1.99 \mathrm{E}+04$ & $6.55 \mathrm{E}+04$ & $3.57 \mathrm{E}+04$ \\
\hline $\mathrm{Sr}$ & $4.03 \mathrm{E}+00$ & $4.66 \mathrm{E}+00$ & $5.93 \mathrm{E}+00$ & $7.16 \mathrm{E}+00$ & $2.43 \mathrm{E}+00$ & $2.59 \mathrm{E}+00$ & $1.10 \mathrm{E}+00$ & $2.09 \mathrm{E}+\mathrm{C}$ \\
\hline $\mathrm{TIC}$ as $\mathrm{CO} 3$ & $1.22 \mathrm{E}+05$ & $6.93 \mathrm{E}+04$ & $1.52 \mathrm{E}+05$ & $1.57 \mathrm{E}+05$ & $1.01 \mathrm{E}+05$ & $1.42 \mathrm{E}+05$ & $1.66 \mathrm{E}+05$ & $1.82 \mathrm{E}+05$ \\
\hline TOC & $1.64 \mathrm{E}+04$ & $9.52 \mathrm{E}+03$ & $1.07 \mathrm{E}+04$ & $3.01 \mathrm{E}+04$ & $2.04 \mathrm{E}+04$ & $1.52 \mathrm{E}+04$ & $1.11 \mathrm{E}+04$ & $7.43 \mathrm{E}+03$ \\
\hline UTOTAL & $1.16 \mathrm{E}+02$ & $5.33 \mathrm{E}+01$ & $1.21 \mathrm{E}+02$ & $1.37 \mathrm{E}+02$ & $1.98 \mathrm{E}+01$ & $1.08 \mathrm{E}+02$ & $1.33 \mathrm{E}+02$ & $4.62 \mathrm{E}+0$ \\
\hline $\mathrm{Zr}$ & $7.32 \mathrm{E}+00$ & $8.38 \mathrm{E}+00$ & $1.18 \mathrm{E}+01$ & $1.24 \mathrm{E}+01$ & $5.62 \mathrm{E}+00$ & $1.41 \mathrm{E}+01$ & $1.10 \mathrm{E}+01$ & $5.72 \mathrm{E}+00$ \\
\hline Free $\mathrm{OH}$ & $1.07 \mathrm{E}+05$ & $1.37 \mathrm{E}+05$ & $1.10 \mathrm{E}+05$ & $9.79 \mathrm{E}+04$ & $1.25 \mathrm{E}+05$ & $1.59 \mathrm{E}+05$ & $9.36 \mathrm{E}+04$ & $2.41 \mathrm{E}+\mathrm{C}$ \\
\hline
\end{tabular}


Table B-2. SST Salt Cake, Sound Tanks, Near Term Access - 13 Tanks in U And S Farms.

\begin{tabular}{|c|c|c|c|c|c|c|c|c|c|c|}
\hline \multirow{2}{*}{$\begin{array}{c}\text { Specify } \\
\text { Tanks } \\
\text { below }\end{array}$} & \multicolumn{10}{|c|}{ Retrieved Waste } \\
\hline & $\begin{array}{l}\mathrm{Hg} \\
\mathrm{kg}\end{array}$ & $\begin{array}{l}\mathrm{Na} \\
\mathrm{kg}\end{array}$ & $\begin{array}{c}\mathrm{NO3} \\
\mathrm{kg}\end{array}$ & $\begin{array}{c}\text { UTOTAL } \\
\mathrm{kg}\end{array}$ & $\begin{array}{c}99 \mathrm{Tc} \\
\mathrm{Ci}\end{array}$ & $\begin{array}{c}1291 \\
\mathrm{Ci}\end{array}$ & $\begin{array}{c}137 \mathrm{Cs} \\
\mathrm{Ci}\end{array}$ & $\begin{array}{c}99 \mathrm{Tc} / \mathrm{Na} \\
\mathrm{Ci} / \mathrm{kg}\end{array}$ & $\begin{array}{c}\text { Tank } \\
\text { Integrity }\end{array}$ & $\begin{array}{c}\text { Sludge } \\
\text { (kgal) }\end{array}$ \\
\hline SY-102 & $2.57 E+00$ & $1.55 E+05$ & $1.47 E+05$ & $1.13 E+02$ & $1.75 \mathrm{E}+02$ & $1.15 \mathrm{E}-01$ & $0.00 \mathrm{E}+00$ & $1.13 \mathrm{E}-03$ & & \\
\hline$S Y-101$ & $3.11 \mathrm{E}-01$ & $3.03 E+05$ & $3.03 E+05$ & $4.83 E+00$ & $2.83 \mathrm{E}+02$ & 2.06E-01 & $2.41 \mathrm{E}+05$ & $9.34 \mathrm{E}-04$ & & \\
\hline S-105 & $58 \mathrm{E}+00$ & $6.30 E+05$ & $1.38 E+06$ & 1.47E-08 & $3.34 \mathrm{E}+02$ & 3.34E-01 & $6.23 E+04$ & 5.31E-04 & OUND & 2 \\
\hline$S-106$ & $7.89 \mathrm{E}-01$ & $5.98 \mathrm{E}+05$ & $9.82 E+05$ & $4.21 E+01$ & $2.71 E+02$ & $2.71 \mathrm{E}-01$ & $2.38 \mathrm{E}+05$ & $4.53 \mathrm{E}-04$ & SOUND & 0 \\
\hline S-108 & $1.25 \mathrm{E}+00$ & $7.41 \mathrm{E}+05$ & $1.06 \mathrm{E}+06$ & $1.25 \mathrm{E}+02$ & $3.24 \mathrm{E}+02$ & $3.24 \mathrm{E}-01$ & $2.93 E+05$ & 4.37E-04 & SOUND & 5 \\
\hline$S-109$ & $1.86 \mathrm{E}+00$ & $7.60 \mathrm{E}+05$ & $1.72 E+06$ & $1.28 \mathrm{E}+01$ & $3.97 \mathrm{E}+02$ & $3.97 \mathrm{E}-01$ & $3.98 \mathrm{E}+04$ & $5.23 \mathrm{E}-04$ & SOUND & 13 \\
\hline$S-103$ & $2.36 \mathrm{E}+00$ & $2.75 E+05$ & $3.64 E+05$ & $9.88 \mathrm{E}-07$ & $1.61 \mathrm{E}+02$ & 1.63E-01 & $1.78 E+05$ & $5.84 \mathrm{E}-04$ & SOUND & 9 \\
\hline$S-111$ & $3.20 \mathrm{E}+00$ & $3.49 E+05$ & $5.01 E+05$ & $1.32 \mathrm{E}+02$ & $1.82 \mathrm{E}+02$ & $1.86 \mathrm{E}-01$ & $9.70 E+04$ & $5.22 \mathrm{E}-04$ & SOUND & 76 \\
\hline $\mathrm{U}-102$ & $2.54 \mathrm{E}+00$ & $3.36 \mathrm{E}+05$ & $5.28 \mathrm{E}+05$ & 4.13E+01 & $1.54 \mathrm{E}+02$ & $1.68 \mathrm{E}-01$ & $1.89 \mathrm{E}+05$ & 4.59E-04 & SOUND & 43 \\
\hline $\mathrm{U}-103$ & 8.67E-01 & $4.70 E+05$ & $5.03 E+05$ & $5.63 E+02$ & $2.19 E+02$ & 2.21E-01 & $2.41 \mathrm{E}+05$ & $4.65 E-04$ & SOUND & 11 \\
\hline U-107 & 1.87E-01 & $3.48 E+05$ & $6.36 \mathrm{E}+05$ & $1.35 E+01$ & $2.21 \mathrm{E}+02$ & 2.26E-01 & $9.48 E+04$ & 6.35E-04 & SOUND & 15 \\
\hline U-108 & 4.69E-01 & $4.91 E+05$ & $7.25 \mathrm{E}+05$ & $7.79 \mathrm{E}+01$ & $2.66 \mathrm{E}+02$ & 2.70E-01 & $2.20 \mathrm{E}+05$ & $5.42 \mathrm{E}-04$ & SOUND & 29 \\
\hline $\mathrm{U}-109$ & 4.07E-01 & $4.31 \mathrm{E}+05$ & $5.97 \mathrm{E}+05$ & $7.45 \mathrm{E}+00$ & $2.35 \mathrm{E}+02$ & $2.38 \mathrm{E}-01$ & $1.64 \mathrm{E}+05$ & $5.44 \mathrm{E}-04$ & SOUND & 35 \\
\hline Totals & $2.04 \mathrm{E}+01$ & $5.89 \mathrm{E}+06$ & $9.44 \mathrm{E}+06$ & $1.13 \mathrm{E}+03$ & $3.22 \mathrm{E}+03$ & $3.12 \mathrm{E}+00$ & $2.06 \mathrm{E}+06$ & $\begin{array}{l}5.47 \mathrm{E}-04 \\
\text { Average }\end{array}$ & & $\overline{238}$ \\
\hline
\end{tabular}


Table B-3. SST Salt Cake with Lowest ${ }^{99}$ Tc Concentration - 16 Tanks in B-Complex.

\begin{tabular}{|c|c|c|c|c|c|c|c|c|c|c|}
\hline Specify & \multicolumn{10}{|c|}{ Retrieved SST Waste } \\
\hline $\begin{array}{l}\text { Tanks } \\
\text { below }\end{array}$ & $\begin{array}{l}\mathrm{Hg} \\
\mathrm{kg}\end{array}$ & $\begin{array}{l}\mathrm{Na} \\
\mathrm{kg}\end{array}$ & $\begin{array}{c}\mathrm{NO3} \\
\mathrm{kg}\end{array}$ & $\begin{array}{c}\text { UTOTAL } \\
\mathrm{kg}\end{array}$ & $\begin{array}{c}99 \mathrm{Tc} \\
\mathrm{Ci}\end{array}$ & $\begin{array}{c}1291 \\
\mathrm{Ci}\end{array}$ & $\begin{array}{c}137 \mathrm{Cs} \\
\mathrm{Ci}\end{array}$ & $\begin{array}{c}99 \mathrm{Tc} / \mathrm{Na} \\
\mathrm{Ci} / \mathrm{kg}\end{array}$ & $\begin{array}{c}\text { Tank } \\
\text { Integrity }\end{array}$ & $\begin{array}{c}\text { Sludge } \\
\text { (kgal) }\end{array}$ \\
\hline B-105 & $.41 E+00$ & $3.36 \mathrm{E}+05$ & $1.84 \mathrm{E}+05$ & $0.00 E+00$ & $2.64 \mathrm{E}+00$ & $1.68 \mathrm{E}-03$ & $2.65 \mathrm{E}+01$ & $7.85 \mathrm{E}-06$ & ASMD LKR & 28 \\
\hline$\overline{B-109}$ & $6.96 \mathrm{E}-01$ & $1.47 \mathrm{E}+05$ & $9.38 \mathrm{E}+04$ & $1.21 \mathrm{E}+02$ & 4.57E-01 & 4.40E-02 & $3.82 \mathrm{E}+02$ & $3.11 \mathrm{E}-06$ & SOUND & 50 \\
\hline B-108 & $5.71 \mathrm{E}-01$ & $1.10 E+05$ & 4. $12 \mathrm{E}+04$ & $1.84 \mathrm{E}+01$ & 4.04E-01 & $2.75 \mathrm{E}-02$ & $2.23 E+03$ & $3.67 \mathrm{E}-06$ & OUND & 27 \\
\hline $\mathrm{B}-103$ & 3.97E-01 & $5.34 \mathrm{E}+04$ & $3.71 E+04$ & $3.51 \mathrm{E}+01$ & 3.31E-01 & $4.56 \mathrm{E}-04$ & $2.66 \mathrm{E}+02$ & $6.20 \mathrm{E}-06$ & ASMD LKR & \\
\hline B-102 & 2.06E-01 & $2.87 \mathrm{E}+04$ & $2.22 \mathrm{E}+04$ & $5.24 \mathrm{E}+00$ & 2.15E-01 & $2.98 \mathrm{E}-04$ & $1.73 E+02$ & 7.49E-06 & SOUND & 0 \\
\hline B-101 & $5.99 \mathrm{E}+00$ & $1.22 \mathrm{E}+05$ & $9.10 E+04$ & $4.96 \mathrm{E}+02$ & $1.50 \mathrm{E}+00$ & $1.07 \mathrm{E}-03$ & $1.90 E+03$ & $1.23 \mathrm{E}-05$ & ASMD LKR & 28 \\
\hline BY-105 & $3.43 \mathrm{E}+00$ & $6.24 \mathrm{E}+05$ & $1.36 \mathrm{E}+06$ & $4.82 \mathrm{E}+02$ & $4.07 \mathrm{E}+01$ & 2.26E-01 & $7.01 E+04$ & $6.53 \mathrm{E}-05$ & ASMD LKR & 48 \\
\hline BY-112 & 4.45E-01 & $5.36 \mathrm{E}+05$ & $1.40 \mathrm{E}+05$ & $1.03 E+02$ & 1.10E+02 & 1.22E-01 & $7.61 \mathrm{E}+04$ & 2.05E-04 & SOUND & \\
\hline BY-107 & $2.14 \mathrm{E}+00$ & $3.66 \mathrm{E}+05$ & $3.24 \mathrm{E}+05$ & $9.57 \mathrm{E}+01$ & $9.24 \mathrm{E}+01$ & $1.74 \mathrm{E}-01$ & $1.30 E+05$ & $2.53 \mathrm{E}-04$ & ASMD LKR & 15 \\
\hline BY-111 & 3.14E-01 & $5.75 \mathrm{E}+05$ & $3.67 \mathrm{E}+05$ & $2.27 \mathrm{E}+01$ & $1.40 \mathrm{E}+02$ & 2.17E-01 & $9.91 \mathrm{E}+04$ & $2.43 \mathrm{E}-04$ & SOUND & 0 \\
\hline BY-102 & 2.14E-01 & $3.89 E+05$ & $1.77 \mathrm{E}+05$ & $1.56 \mathrm{E}+01$ & $1.04 \mathrm{E}+02$ & 1.15E-01 & $6.98 E+04$ & 2.67E-04 & SOUND & $c$ \\
\hline BY-101 & $2.87 \mathrm{E}+00$ & $5.61 E+05$ & $8.73 \mathrm{E}+05$ & $4.21 \mathrm{E}+02$ & $1.48 \mathrm{E}+02$ & 1.63E-01 & $1.07 E+05$ & 2.63E-04 & SOUND & 37 \\
\hline BY-103 & $1.96 \mathrm{E}-01$ & $5.44 \mathrm{E}+05$ & $5.57 \mathrm{E}+05$ & $7.64 \mathrm{E}+01$ & $1.57 \mathrm{E}+02$ & 1.78E-01 & $7.96 \mathrm{E}+04$ & 2.88E-04 & ASMD LKR & s \\
\hline BY-110 & $3.65 \mathrm{E}+00$ & $4.35 \mathrm{E}+05$ & $2.34 \mathrm{E}+05$ & $9.32 \mathrm{E}+02$ & $1.15 \mathrm{E}+02$ & 1.47E-01 & 1.70E+05 & $2.65 \mathrm{E}-04$ & SOUND & 43 \\
\hline BY-104 & $0.00 \mathrm{E}+00$ & $5.36 \mathrm{E}+05$ & $5.69 \mathrm{E}+05$ & $0.00 \mathrm{E}+00$ & $1.51 \mathrm{E}+02$ & $1.68 \mathrm{E}-01$ & $1.05 \mathrm{E}+05$ & $2.82 \mathrm{E}-04$ & SOUND & 46 \\
\hline BY-106 & $8.71 \mathrm{E}+00$ & $5.17 \mathrm{E}+05$ & $8.08 \mathrm{E}+05$ & $1.40 \mathrm{E}+02$ & $1.41 \mathrm{E}+02$ & 1.70E-01 & $2.61 \mathrm{E}+05$ & 2.73E-04 & ASMD LKR & 32 \\
\hline Totals & 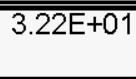 & 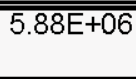 & 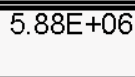 & $2.96 \mathrm{E}+03$ & $=1.20 \mathrm{E}+03$ & $1.75 \mathrm{E}+00$ & $1.17 \mathrm{E}+06$ & $\begin{array}{l}2.05 \mathrm{E}-0 \\
\text { Average }\end{array}$ & & $\overline{\overline{66}}$ \\
\hline
\end{tabular}


RPP-RPT-37924, Rev. 0

\section{APPENDIX C. TECHNETIUM REMOVAL}

\section{TECHNETIUM ION EXCHANGE IN NEW UNDERGROUND VAULTS}

\section{BACKGROUND}

Technetium-99 is one of the major contaminants of concern in Early LAW WTP secondary waste. Removal of technetium (Tc) from the Early LAW feed is one of several mitigating approaches considered in this study. An evaluation of technetium removal technologies in support of an Early LAW study and selection of ion exchange as the preferred technology was completed in $2006 .^{5}$

A technetium ion exchange (Tc IX) process could be deployed in conjunction with the IPS cesium removal process or as a separate facility built to treat the WTP LAW secondary liquid effluent. Since the costs of both approaches are expected to be similar, only the concept for deployment in conjunction with IPS is considered in this study.

Although not required to meet performance assessment requirements for the disposal of the ILAW glass, a separate system could be deployed to separate ${ }^{99} \mathrm{Tc}$ to support WTP LAW secondary waste disposal. Technetium is present as both the pertechnetate anion and a stable compound thought to be $\mathrm{Tc}(\mathrm{CO})_{3}$ (gluconate $)^{-2}$ complexes in the LAW solutions ${ }^{6}$. No process has been demonstrated that has successfully separated the $\mathrm{Tc}(\mathrm{CO})_{3}$ (gluconate) ${ }^{-2}$ complexes from LAW solutions. The pertechnetate anion could be separated from the pretreated LAW solution following cesium removal. The Department of Energy and other institutions has investigated technetium removal processes over the past 40-years. These technetium removal processes include:

- Fractional Crystallization

- Precipitation:

- $\quad$ Tetraphenyl phosphonium (TPP) bromide precipitation

- Sulfide precipitation

- Ion Exchange

- Solvent Extraction.

While other technologies, such as electrochemical separation that separate technetium from radioactive waste solutions may exist, the four technologies listed above represent a spectrum of available technologies that could possibly be deployed by the required schedule to pretreated

\footnotetext{
${ }^{5}$ RPP-RPT-30160, 2006, Supporting Information for the Evaluation of Waste Treatment and Immobilization Plant (WTP) Low Activity Waste (LAW) Startup First Scenario, M. E. Johnson, CH2MHILL Hanford Group Inc., Richland WA.

${ }^{6}$ LBNL-54240, 2003, Research Program to Investigate the Fundamental Chemistry of Technetium, page 20, D. K. Shun et al, Lawrence Berkeley National Laboratory, Berkeley CA.
} 
LAW solutions. The primary criteria used to evaluate these technetium removal technologies for pretreating LAW solutions for immobilization in the WTP LAW Vitrification facility are:

- $\quad$ Proven Technology

- $\quad$ Sufficient information must exist to design a full-scale cesium removal process to pretreat LAW solutions for immobilization in the WTP LAW Vitrification facility

- $\quad$ Candidate technology must have been demonstrated at the lab-scale or larger with LAW solutions or similar radioactive wastes

- Candidate technology must have been demonstrated at the pilot-scale or larger using non-radioactive LAW or similar simulants

- $\quad$ Proven performance

- $\quad$ Maximum use of DOE Technology investments

- $\quad$ Minimum impact to treated waste stream (e.g. composition)

- $\quad$ Minimum secondary wastes

- $\quad$ Ease of implementation

- $\quad$ Probability for success on schedule required.

These technologies are capable of removing technetium from typical SST salt cake waste and DST waste solutions; however the percentage of technetium removed can vary significantly between these technologies.

While IX and the selected resin are preferred to remove technetium from the Early LAW feed stream, a different IX resin or another technology may be preferred to remove technetium from the WTP secondary waste stream.

\section{PROCESS DESCRIPTION}

The deployment concept for the Tc IX process in a new underground vault is shown in Figure C1. Similar to the Cs IX process, the Tc IX process vessels and ion exchange columns are sized to supply pretreated LAW solution to support operation of two LAW Vitrification melters. This production rate of pretreated LAW is sufficient to support operation of two LAW Vitrification melters producing $30 \mathrm{MTG} /$ day with an average waste sodium oxide loading of $\sim 18 \mathrm{wt} \%$ and an operating efficiency of $70 \%$. 
Figure C-1. Tc Ion Exchange Process in New Vault.

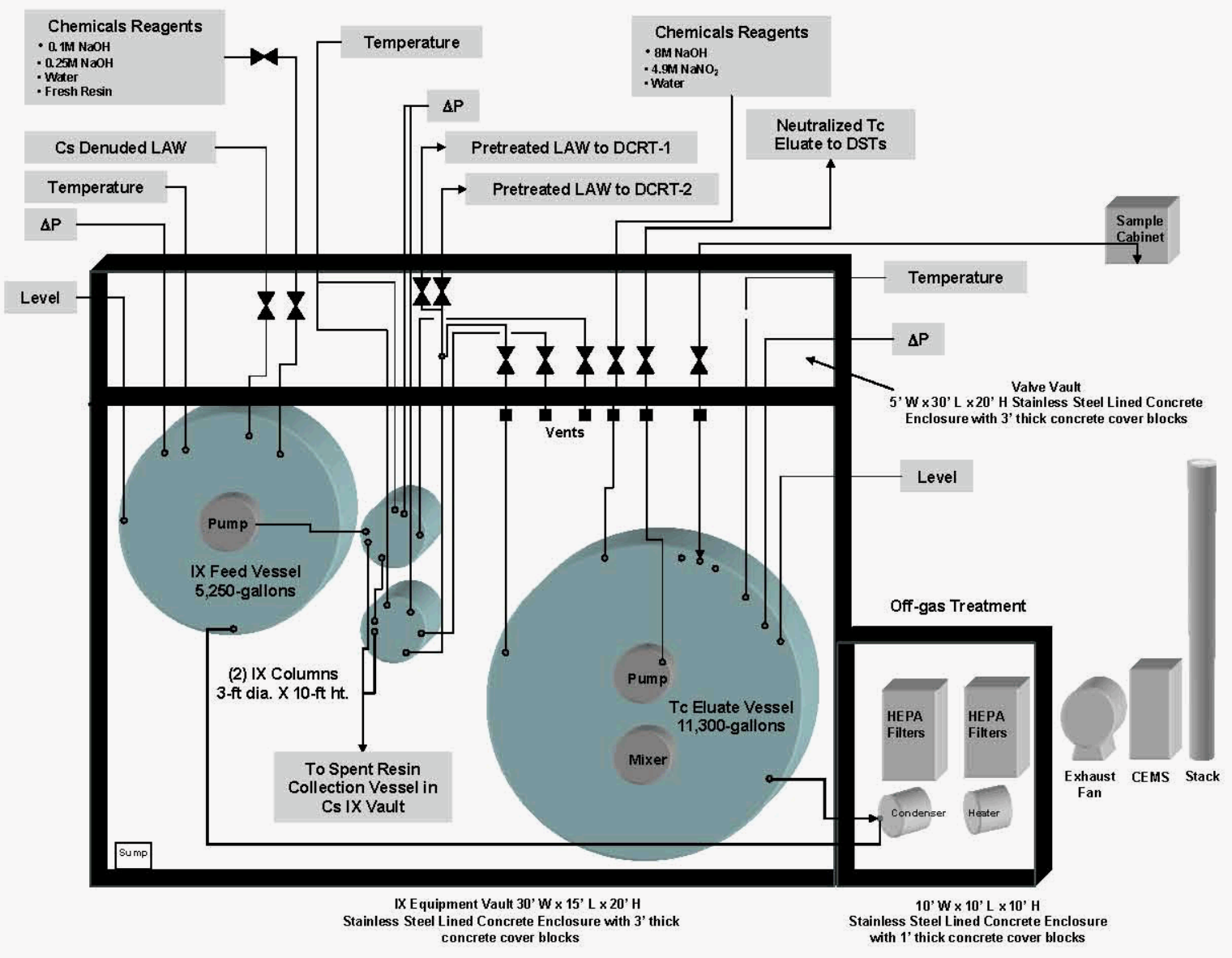

Cesium-denuded LAW solution exiting the Cs IX columns would be collected in the Tc IX feed vessel. The Tc IX feed vessel also receives and transfers to the IX columns all of the chemicals used to elute and regenerate the resin. The IX columns contain a total of 750 liters $(\sim 200$ gallons) of resin. The resin selected for pertechnetate removal from LAW solution is SuperLig ${ }^{\circledR} 639$, manufactured by IBC Advanced Technologies, American Fork, Utah. This resin was previously tested by the WTP project and demonstrated to be effective for pertechnetate removal from LAW solutions.

The IX columns are loaded in series (lead column and polishing column) to remove pertechnetate from the cesium-denuded LAW solutions. An estimated 99 to $99.5 \%$ of the pertechnetate is removed from the LAW solution, however, none of the non-pertechnetate is removed. Since the fraction of pertechnetate and non-pertechnetate (typically 1 to $5 \%$ of the total technetium) in each of the candidate LAW feeds is not known, the total Tc DF is not known at this time. The pretreated LAW solution is transferred from the lag IX column to two DCRTs (DCRT-1 and DCRT-2). The pretreated LAW solution is sampled and analyzed prior to transfer to the LAW Vitrification facility.

After loading, the two IX columns are flushed with $0.1 \mathrm{M}$ sodium hydroxide solution to remove residual feed solution, eluted with warm $\left(65^{\circ} \mathrm{C}\right)$ water and conditioned for re-use with $0.25 \mathrm{M}$ sodium hydroxide solution. A DCRT receives the technetium eluate from the IX columns, which 
is mixed with the column regeneration solutions and additional sodium hydroxide and sodium nitrite solutions, then transferred to an existing DST for interim storage.

Spent IX resin is fluidized from the columns and collected in the spent resin collection vessel installed as part of the cesium ion exchange process. Replacement of the Tc IX resin is not anticipated during the assumed five-year operating period of this process.

\section{EQUIPMENT}

The new process vault containing the Tc IX equipment is shown in Figure C-1. The vault will be constructed with $3 \mathrm{ft}$ thick reinforced concrete walls and cover blocks. The vault is lined with stainless steel to provide secondary containment for waste solutions. Cover blocks are removable shielding that provides maintenance access to the process piping and equipment. The vault is separated into three areas:

$$
\begin{array}{ll}
\text { - } & 5(\mathrm{~W}) \times 20(\mathrm{H}) \times 30 \mathrm{ft}(\mathrm{L}) \text { valve area } \\
\text { - } & 30(\mathrm{~W}) \times 20(\mathrm{H}) \times 15 \mathrm{ft}(\mathrm{L}) \mathrm{Te} \text { IX process area } \\
\text { - } & 10(\mathrm{~W}) \times 10(\mathrm{H}) \times 10 \mathrm{ft}(\mathrm{L}) \text { off-gas treatment area. }
\end{array}
$$

Table C- 1 lists the major process equipment associated with the Tc IX process. Table C- 2 lists the capacity and size of the chemical storage tanks associated with the Tc IX process. The Tc IX process would use the sodium hydroxide and sodium nitrite chemical storage tanks provided by the Cs IX process.

Table C- 1. Technetium Ion Exchange Process Vaults and Process Equipment.

\section{Component}

Valve Vault

- Adjacent to IX column vault

PUREX-type Jumpers
Dimensions

(d $x$ h or w $x 1 \times$ h)

$5 \times 30 \times 20 \mathrm{ft}$

(Internal Dimensions)

- Concrete below grade structure with $3 \mathrm{ft}$ thick walls

- $3 \mathrm{ft}$ thick concrete cover blocks at grade

- Stainless steel lined floor and walls up to bottom of cover blocks

- (1) sump, each with (1) remote read-out leak detector

- Remote connector heads

- (12) MOV chemical / waste service

- (12) Electrical power to MOVs

- (13) Instrumentation 


\section{Component}

IX Equipment Vault

Two (2) Ion Exchange Column

Hard Piping connections

IX Feed Vessel

Hard Piping Connections

\section{Pump}

Technetium Eluate Vessel
Dimensions

(d $x$ h or w x l x h)

$30 \times 15 \times 20 \mathrm{ft}$ (Internal Dimensions)

$3 \times 10 \mathrm{ft}$

(capacity 760-liters of resin per column)

$$
9.6 \times 9.6 \mathrm{ft}
$$

(capacity 5,250-gallons)

- (1) Electrical power to pump

- (1) Temperature element

- (1) Pressure

- (1) Liquid level

- (1) Vessel off-gas

- (3) Piping 75-gpm

$12.4 \times 12.4 \mathrm{ft}$ (capacity 11,300 -gallons)
- Concrete below grade structure with $3 \mathrm{ft}$ thick walls

- $3 \mathrm{ft}$ thick concrete cover blocks at grade

- Stainless steel lined floor and walls up to bottom of cover blocks

- (1) sump, each with (1) remote read-out leak detector

- Remote connector heads

- (2) resin retention screens internal to column

- Resin fluidization / extraction cone

- Remote connector heads

- (2) Remote ICP-AES unit

- (10) Chemical / waste service

- (2) Temperature element

- (2) Differential pressure
- Internal cooling coil

- Remote connector heads 
RPP-RPT-37924, Rev. 0

\section{Component}

Hard piping connections

Pump

Mixer/agitator

Sampler

Vessel Off-gas Treatment System Structures for IX Equipment and DCRT-3

Contains condenser, heater and HEPA filter units

Below grade

Above grade

\section{Dimensions}

\section{(d $x$ h or w $x$ l $x$ h)}

- (2) Electrical power to pump and mixer

- (1) Temperature element

- (1) Pressure

- (1) Liquid level

- (1) Vessel off-gas

- (1) Sample lines

- (2) Cooling water

- (4) Piping

- 75-gpm

- 7.5 amp motor

- Impeller type blades

- Remote sampler unit in cabinet

- Concrete below grade structure with $1 \mathrm{ft}$ thick walls

- $1 \mathrm{ft}$ thick concrete cover blocks at grade

- Stainless steel lined floor and walls up to bottom of cover blocks

- Remote connector heads

- Condenser

- Heater

- (2) filter units, each containing (2) $2 \times 2 \mathrm{ft}$ HEPA filters

- 500-cfm exhaust fan with damper controller

- Continuous emission monitoring system

- $50 \mathrm{ft}$ height stack

- $100 \mathrm{ft} \times 2 \mathrm{ft}$ diameter exhaust duct

(1) All vessels, jumpers, exhaust duct, stack, condenser, heater, filter housings, pump and agitator shafts are manufactured from 304-L or 316-L stainless steel

MOV - motor operated valve 
Table C- 2. Chemical Storage Tanks.

\begin{tabular}{|c|c|c|c|}
\hline Chemical $^{(1)}$ & $\begin{array}{l}\text { Dimensions } \\
\quad(\mathbf{d} \times \mathbf{h})\end{array}$ & $\begin{array}{c}\text { Material of } \\
\text { Construction }\end{array}$ & Components \\
\hline Hot Water & $\begin{array}{c}9.6 \times 9.6 \mathrm{ft} \\
\text { (capacity 5,250-gallons) }\end{array}$ & $\begin{array}{c}\text { Painted Carbon } \\
\text { Steel with } \\
\text { insulation }\end{array}$ & $\begin{array}{l}\text { - Variable flow rate pump } 0 \text { to } \\
10 \text { gpm } \\
\text { - Level measurement } \\
\text { - Painted concrete spill } \\
\text { containment basin } 14 \times 14 \times 4.5 \mathrm{ft} \\
\text { - In-line heater unit - discharge } \\
\text { water temperature } 65^{\circ} \mathrm{C}\end{array}$ \\
\hline Resin & $\begin{array}{c}5 \times 5 \mathrm{ft} \\
\text { (capacity } 735 \text {-gallons) }\end{array}$ & $\begin{array}{c}\text { Painted Carbon } \\
\text { Steel }\end{array}$ & $\begin{array}{l}\text { - Variable flow rate pump } 0 \text { to } \\
10 \mathrm{gpm} \\
\text { - Level measurement } \\
\text { - Painted concrete spill } \\
\text { containment basin } 7 \times 7 \times 2.52 \mathrm{ft}\end{array}$ \\
\hline
\end{tabular}


RPP-RPT-37924, Rev. 0

\section{APPENDIX D. HNF-37718, LOW ACTIVITY WASTE FACILITY SECONDARY WASTE TO EFFLUENT TREATMENT FACILITY TREATABILITY EVALUATION.}

\subsection{INTRODUCTION}

$\mathrm{CH} 2 \mathrm{M}$ Hill has requested that Fluor Hanford, Inc. (FH) perform a high level study on secondary waste streams from the Low Activity Waste (LAW) facility to determine the most suitable secondary waste management process. A forecast of the radioactive, dangerous liquid effluents expected to be produced by the LAW facility was provided in the Letter, Analyze and Predict Early LAW Secondary Waste Streams - Task Order no. 14 (Letter \# AEM 075). The forecast represents the liquid effluents generated from the processing of Tank Farm waste through the LAW facility which consists of submerged bed scrubber solution (SBS), wet electrostatic precipitator solution (WESP), and caustic scrubber solution. The LAW forecast is provided in the Appendix A. The LAW liquid effluents would be stored, treated, and disposed of in the Liquid Effluent Retention Facility (LERF) and the Effluent Treatment Facility (ETF). Both facilities are located in the 200 East Area and are operated by FH for the U.S. Department of Energy (DOE).

Three options were asked to be evaluated. In all three of the options, the LAW effluent is processed through ETF similarly; the only difference between the different options is the disposition of the evaporator brine as described below. Each of the options will be evaluated at an evaporator brine chloride/fluoride concentration of 10,000 parts per million (ppm) and 40,000 ppm.

Option 1: Process at ETF for Final Disposal. In this option the full LAW effluent would be sent to the ETF for processing for final disposal of secondary waste at the Integrated Disposal Facility (IDF).

Option 2: Recycle ETF Evaporator Brine to Tank Farms via Tanker. In this option, the full LAW effluent would be processed through the ETF evaporator and the brine recycled back to Tank Farms via tankers.

Option 3: Recycle ETF Evaporator Brine to Tank Farms via New Pipeline. In this option, the full LAW effluent would be processed through the ETF evaporator and the brine recycled back to Tank Farms via a new pipeline or hose-in-hose.

The treatability evaluation was conducted by comparing the LAW effluent forecast to the LERF/ETF treatability envelope (HNF-3172), which provides information on the items that determine if a liquid effluent is acceptable for receipt and treatment at the LERF/ETF. The format of the evaluation corresponds directly to the outline of the treatability envelope document. Background information on the LERF/ETF design basis is provided in the treatability envelope document. 


\subsection{WASTE ACCEPTANCE PROCESS}

The process for acceptance of a waste into the LERF/ETF involves a series of steps. The acceptance process is designed to take full advantage of the flexibility and robust nature of the LERF/ETF systems. The LERF/ETF aqueous waste acceptance process involves the following three steps: (1) assemble waste information and screen for completeness; (2) compare waste to regulatory envelope; (3) compare waste to design envelope.

\subsection{ADDITIONAL INFORMATION REQUIRED}

Below is a preliminary list of additional information that is required to provide a complete treatability evaluation.

- Regulatory designation of waste - this is required to complete the regulatory evaluation for permit compliance. For the purpose of this treatability evaluation, it is assumed that the 242-A process condensate waste codes, F001-F005, apply to the LAW effluent.

- Identification of specific Organics - this information is required to complete the regulatory evaluation for air and water discharges, and the design review for operation of the organic destruction unit. For the purposes of this treatability evaluation, it is assumed that the individual organics will be similar to those in the 242-A process condensate that ETF has successfully treated.

- Integrated Disposal Facility (IDF) acceptance criteria - this information is needed to determine the acceptability of the ETF generated secondary waste at IDF and if any additional treatment is required.

\subsection{REGULATORY ENVELOPE}

The operation of the LERF and ETF is regulated under permits and approvals issued by the Washington State Department of Ecology (Ecology), Washington State Department of Health (WDOH), and the U.S. Environmental Protection Agency (EPA). The operation of the LERF/ETF is also authorized by the Department of Energy (DOE) and is therefore subject to the requirements contained in DOE Orders. This section evaluates the LAW forecast against the LERF/ETF environmental regulations/permits and safety documentation as discussed in the LERF/ETF treatability envelope document.

\subsection{NEPA/SEPA}

The regulations require that all modifications associated with a given project be addressed in a single environmental document (e.g., Environmental Assessment, Environmental Impact Statement). It is assumed that the environmental document to be prepared by the LAW Project will address all changes to the LERF/ETF associated with LAW aqueous effluent discharges/recycles and will be in place prior to discharging any effluents to LERF or ETF. 
RPP-RPT-37924, Rev. 0

\subsection{DANGEROUS WASTE PERMIT AND DELISTING}

The LERF and ETF are permitted under the dangerous waste regulations in Washington Administrative Code (WAC) 173-303. The LERF and ETF are included in the Hanford Facility Resource Conservation and Recovery Act (RCRA) permit for treatment and storage of dangerous wastes with specific waste codes. The ETF treated effluent is also covered under a delisting (70 FR 44496, August 3,2005) that allows the ETF treated effluent to be discharged to a State Approved Land Disposal Site (SALDS). The permit and delisting allows for the acceptance of a variety of new feeds using a waste acceptance process. A designation of the LAW effluent has not been provided, however, the LERF/ETF has received Tank Farm waste via the 242-A Evaporator with waste codes F001 - F005, and it is assumed that these same waste codes would apply to the LAW effluent. Based on the forecast, the D007 waste code for chromium would also apply. Waste with these waste codes can be accepted at the LERF/ETF and the LAW effluent is within the delisting treatability envelope. However, this screening cannot be complete until individual organic analytes have been identified.

For each of the approaches, update of the ETF/LERF portion of the Hanford Facility RCRA permit would be necessary to include modifications to the tanks and operation of the ETF. It is assumed that any new pipeline from the ETF to Tank Farms would be covered under a CH2M Hill RCRA permit and they would be responsible for the necessary permit modifications.

\subsection{STATE WASTE DISCHARGE PERMIT}

Treated effluent from the ETF is discharged to a SALDS under the State Waste Discharge Permit ST4500. This permit allows the LERF/ETF to accept generator effluents containing approved constituents of concern at approved concentrations. If the LERF/ETF wishes to receive a waste with a new constituent of concern, or a previously approved constituent at a higher concentration, a characterization study must be submitted to Ecology demonstrating that the ETF can treat the waste to an acceptable level. Of the constituents identified in the LAW effluent, only boron is above the approved concentration. At a minimum, a characterization study of this constituent identifying it as a new constituent of concern will need to be submitted to Ecology for approval. It is not anticipated that obtaining Ecology approval should be an issue. However, once the individual organic analytes have been identified, this screening will need to be reevaluated.

\subsection{LERF RADIOLOGICAL INVENTORY MANAGEMENT}

The LERF is classified as a below Category 3 nuclear facility. Appendix D-1 of the LERF/ETF waste acceptance criteria document (HNF-3172) gives the radionuclide source term levels. For the LAW effluent, at least one radionuclide in every batch exceeds the LERF bounding source. If the LERF source term is exceeded, then a second screening is accomplished by comparing the calculated dose consequences for the LAW effluents to the maximum allowable dose from pool evaporation and spray release accident scenarios of $1.32 \mathrm{rem}$ and $3.5 \mathrm{rem}$, respectively. Of the eight batches, only the LAW effluent generated from Tank AP-107 exceeds the maximum doses and therefore is not acceptable into LERF. Ruthenium-106 (64\% of the dose) and Plutonium $239 / 240(25 \%$ of the dose) were the major dose contributors. 
The LERF could be recategorized as a nuclear facility, however the cost and consequences associated with recategorizing the facility would need to be addressed and is outside the scope of this treatability evaluation.

\subsection{ETF RADIONUCLIDE INVENTORY MANAGEMENT}

The ETF is classified as below Category 3 nuclear facility. To maintain this designation, the authorization basis for ETF requires that the radionuclide inventory will not exceed the DOE Standard 1027-92 Hazard Category 3 sum-of-fractions threshold of 1.0. Radionuclide inventory control at ETF is accomplished by characterizing feed streams for radionuclide inventory and calculating a maximum allowable feed batch volume that can be present at ETF. Once the ETF has treated the maximum allowable feed batch volume, the facility must remove radionuclide inventory by shipping solid waste out of the facility.

The calculated maximum allowable feed batch volumes of the LAW effluents range from 122,000 gallons to 346,000 gallons, as given in Table 4-1. With these batch volumes, and an annual average LAW feed rate of 9 gpm, ETF should have sufficient capacity to handle the LAW waste. This can be accomplished by the large surge capacity available in the LERF basins and by the ETF evaporator having excess capacity to treat these batches, allowing downtime for shipment of the final waste form as given below for each of the different approaches.

Option 1 - At a minimum, shipments to IDF would range from 1 shipment every two days to two shipments every two weeks, depending on whether the chloride/fluoride concentration is $10,000 \mathrm{ppm}$ or $40,000 \mathrm{ppm}$ (Section 5.0). This frequency accounts for the five day cure time for the blocks. For the purpose of this evaluation, a shipment is defined as ten 3-cubic feet solidified blocks.

Option 2 - At a minimum, tanker shipments of evaporator brine to Tank Farms would range from 1,500 gallons every two days to 3,000 gallons every two weeks, depending on whether the chloride/fluoride concentration is $10,000 \mathrm{ppm}$ or $40,000 \mathrm{ppm}$ (Section 5.0).

Option 3 - Evaporator brine is a continuous feed to Tank Farms, or at a minimum of 1,500 gallons every two days to 3,000 gallons every two weeks, depending on whether the chloride/fluoride concentration is $10,000 \mathrm{ppm}$ or $40,000 \mathrm{ppm}$ (Section 5.0).

Table 4-1 summarizes the major radionuclide contributors to the maximum batch volume.

Table 4-1. Major Radionuclide Contributors to Maximum Batch Volume

\begin{tabular}{|l|c|c|c|c|c|c|c|c|}
\hline & AP-104 & AP-102 & AP-101 & AP-103 & AP-105 & AP-108 & AP-107 & AN-104 \\
\hline $\begin{array}{l}\text { Maximum Batch } \\
\text { Volume (gallons) }\end{array}$ & 252,000 & 223,000 & 221,000 & 150,000 & 195,000 & 253,000 & 122,000 & 346,000 \\
\hline Strontium-90 & $35 \%$ & $9 \%$ & $20 \%$ & $32 \%$ & $33 \%$ & $24 \%$ & $23 \%$ & $35 \%$ \\
\hline Ruthenium-106 & & & $22 \%$ & & & & $42 \%$ & \\
\hline Iodine-129 & $48 \%$ & $76 \%$ & $39 \%$ & $51 \%$ & $52 \%$ & $60 \%$ & $21 \%$ & $44 \%$ \\
\hline
\end{tabular}




\subsection{RADIOACTIVE AIR EMISSIONS}

The LERF and ETF radioactive air emissions are regulated under WAC 246-247. The facilities are permitted for radioactive air emissions through the Washington Department of Health (WDOH) approval of a Notice of Constructions (NOC) that is incorporated into the Hanford Site Operating Permit. The approval includes a curie limit called a "potential-to-emit", which is calculated as a fraction of the radionuclide quantity at the facility. The WDOH approval assumes strontium-90, cesium-137, and plutonium-239/240 are the only radionuclides that contribute over $10 \%$ of the dose. For the LAW effluent, the radionuclide content is within the potential-to-emit; however, at a minimum, notification to $\mathrm{WDOH}$ is required since the technetium-99 will contribute over $10 \%$ of the allowable dose. WDOH often imposes a requirement to sample constituents that contribute over $10 \%$ of the allowable dose. If so, the ETF stack sampler would need to me modified to sample for technetium-99. Such a modification is not expected to have a significant impact on the facility cost or operation.

For Options $1 \& 2$, the existing NOC would need to be expanded to include any new emission sources and if a new ventilation system is installed, stack sampling equipment would be required.

The current NOC and WDOH approval for LERF/ETF assumes iodine-129 is in the liquid-phase. One concern is processing LAW effluent at low $\mathrm{pH}$ (i.e., acidic) will convert the iodine-129 to a gas, increasing its potential-to-emit. If iodine- 129 were to volatilize, notification to WDOH would be required because the iodine would contribute over $10 \%$ of the allowable dose and iodine would adsorb on the activated carbon absorbers in the ETF vessel off-gas requiring frequent change-outs of the activated carbon. Table 4-2 summarizes the carbon change-out frequency and cost. It appears that by bypassing the ETF evaporator feed/distillate heat exchanger, as discussed in Section 5.3, the LAW effluent can be processed at a high $\mathrm{pH}$ (i.e., caustic range) where iodine- 129 will not volatilize and will remain in the evaporator brine.

Table 4-2. Activated Carbon Change-out Frequency and Cost

\begin{tabular}{|c|c|c|c|c|c|c|c|c|c|}
\hline \multirow[b]{2}{*}{$\begin{array}{l}\text { Feed } \\
\text { Tank } \\
\text { Batch }\end{array}$} & \multirow[b]{2}{*}{$\begin{array}{l}\text { Volume of } \\
\text { LAW Feed } \\
\text { (gallons) }\end{array}$} & \multicolumn{3}{|c|}{ lodine-129 } & \multirow{2}{*}{$\begin{array}{c}\text { Total } \\
\text { carbon } \\
\text { required } \\
\text { (unabated) } \\
(\mathrm{kg})\end{array}$} & \multirow[b]{2}{*}{$\begin{array}{l}\text { Changeouts } \\
\text { per batch }\end{array}$} & \multirow[b]{2}{*}{$\begin{array}{l}\text { Curies per } \\
\text { changeout }\end{array}$} & \multirow[b]{2}{*}{$\begin{array}{l}\text { Gallons of } \\
\text { feed per } \\
\text { changeout }\end{array}$} & \multirow[b]{2}{*}{$\begin{array}{c}\text { Cost per } \\
\text { batch }\end{array}$} \\
\hline & & $\mathrm{Ci} / \mathrm{L}$ & $\mathrm{Ci}$ & grams & & & & & \\
\hline AP-104 & $2,932,551$ & $2.41 \mathrm{E}-08$ & $2.68 \mathrm{E}-01$ & 1511 & 1511 & 20 & $1.36 \mathrm{E}-02$ & 149,393 & $\$ 216.000$ \\
\hline AP-102 & $2,962,138$ & $4.31 \mathrm{E}-08$ & $4.83 \mathrm{E}-01$ & 2730 & 2730 & 35 & $1.36 \mathrm{E}-02$ & 83,535 & $\$ 390,000$ \\
\hline AP-101 & $2,915,644$ & $2.25 \mathrm{E}-08$ & $2.48 \mathrm{E}-01$ & 1403 & 1403 & 18 & 1.36E-02 & 160,017 & $\$ 200,000$ \\
\hline AP-103 & $2,972,441$ & $4.31 \mathrm{E}-08$ & 4.85E-01 & 2740 & 2740 & 36 & $1.36 \mathrm{E}-02$ & 83,535 & $\$ 391,000$ \\
\hline AP-105 & $2,971,384$ & $3.37 \mathrm{E}-08$ & $3.79 \mathrm{E}-01$ & 2142 & 2142 & 28 & $1.36 \mathrm{E}-02$ & 106,836 & $\$ 306,000$ \\
\hline AP-108 & $2,968,478$ & $2.99 \mathrm{E}-08$ & $3.36 \mathrm{E}-01$ & 1898 & 1898 & 25 & $1.36 \mathrm{E}-02$ & 120,414 & $\$ 271,000$ \\
\hline AP-107 & $2,960,817$ & $2.13 \mathrm{E}-08$ & $2.39 \mathrm{E}-01$ & 1349 & 1349 & 18 & 1.36E-02 & 169,032 & $\$ 193,000$ \\
\hline AN-104 & $2,929,909$ & 1.62E-08 & $1.80 \mathrm{E}-01$ & 1015 & 1015 & 13 & $1.36 \mathrm{E}-02$ & 222,245 & $\$ 145,000$ \\
\hline
\end{tabular}

\subsection{NONRADIOACTIVE AIR EMISSIONS}

Nonradioactive air emissions from the LERF and ETF are regulated under WAC 173-400 and 173-460 and are permitted by Ecology approval of a Notice of Construction (NOC). The approval order allows the ETF to treat waste streams containing toxic air pollutants and identifies specific pollutants that are approved for treatment. The constituents that have been identified in 
the LAW effluent forecast are within the current NOC; however, once the individual organic analytes have been identified, this screening will need to be re-evaluated. Processing the LAW effluent at a high $\mathrm{pH}$ (caustic range) will result in off-gassing of the ammonia, however, the ammonia emission concentration will be below the allowable small quantity emission rate.

\subsection{PACKAGING REQUIREMENTS}

Waste shipments must meet certain US Department of Transportation (DOT) requirements depending on the total radionuclide curie content of each shipment. The projected ETF evaporator brine for each LAW effluent batch was compared to the $\mathrm{A}_{2}$ values in Table of $A_{1}$ and $A_{2}$ Values for Radionuclides of 49 CFR 173.435. Summarized in Table 4-3 is the maximum shipping volume for each of the batches to stay below an $\mathrm{A}_{2}$ quantity. If a shipment exceeds an $\mathrm{A}_{2}$ quantity then specification packaging is required. In addition, $49 \mathrm{CFR} 173.441$ dose rate limits must be met, however, modeling dose rates were not performed for this treatability evaluation.

Table 4-3: Maximum Shipment Volumes (in gallons)

\begin{tabular}{|l|c|c|c|c|c|c|c|c|}
\hline & AP-104 & AP-102 & AP-101 & AP-103 & AP-105 & AP-108 & AP-107 & AN-104 \\
\hline $\begin{array}{l}\text { Brine at } \\
\begin{array}{l}10,000 \mathrm{ppm} \\
\text { chloride/fluoride }\end{array}\end{array}$ & 6,300 & 8,600 & 1,600 & 4,000 & 7,300 & 7,100 & 640 & 10,000 \\
\hline $\begin{array}{l}\text { Brine at } \\
40,000 \mathrm{ppm} \\
\text { chloride//fluoride }\end{array}$ & 1,600 & 2,200 & 420 & 1,000 & 1,800 & 1,800 & 160 & 2,600 \\
\hline
\end{tabular}

For Option 1, a solidified block, which is considered a package, would be below an $\mathrm{A}_{2}$ quantity since the volume of the brine per package is 150 gallons. For Option 2, a tanker shipment of brine to Tank Farms could not exceed the volumes given in Table 4-3 in order to stayh below and $\mathrm{A}_{2}$ quantity.

\subsection{DESIGN ENVELOPE}

The ETF consists of a series of process units that are configured to provide treatment for contaminants that might be present in aqueous wastes generated on the Hanford Site. The main treatment train includes those process units that destroy or remove dangerous and radioactive constituents from the aqueous waste. The unit operations of the main treatment train include $\mathrm{pH}$ adjustment, filtration, ultraviolet light mediated peroxide oxidation (UV/OX), degasification, reverse osmosis (RO), and mixed-bed ion exchange. Those constituents rejected from the main treatment train are concentrated and dried into a powder in the secondary treatment train (STT) via an evaporator and thin film dryer. The new solidification treatment unit required for Option 1 (Section 5.3.6) would supplement/replace the thin-film dryer. Provided in Figure 5-1 is a flow diagram of the existing ETF process. 
Figure 5-1. ETF Process Diagram

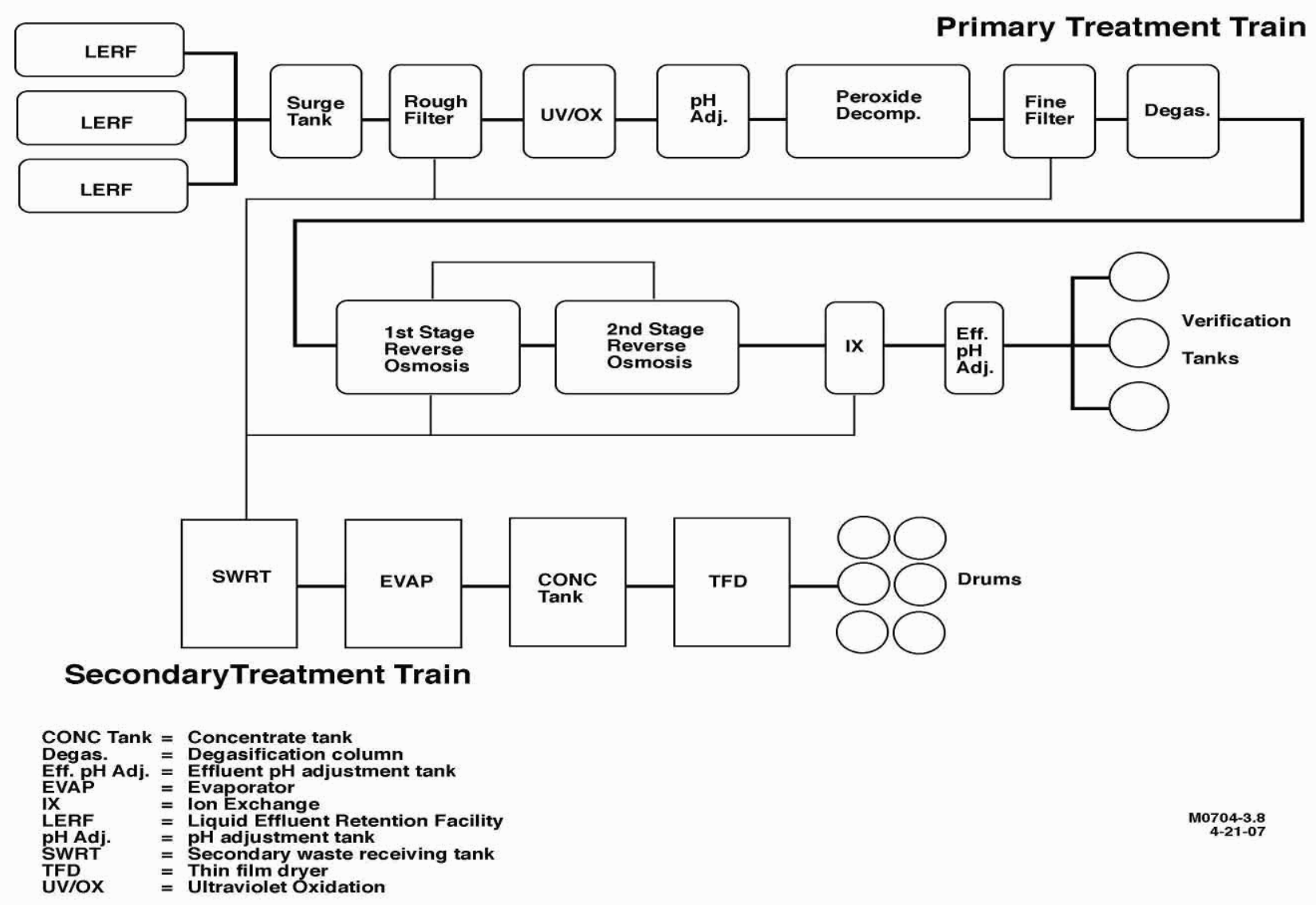

\section{$5.1 \quad$ SUSPENDED SOLIDS}

All feeds are required to be filtered through a 5-micron (nominal) filter before receipt in the LERF or at ETF. Additional filtration could be required if a significant amount of suspended solids remain after the 5-micron filtration.

\subsection{ORGANICS}

Organic destruction rates for the ETF UV/OX unit have been established through actual operating experience and pilot plant testing. The total organic carbon (TOC) levels in the LAW effluent are below what has historically been seen in the 242-A process condensate that the ETF has successfully treated. There should be no issues with treating the organics in the effluent. Once the individual organic analytes have been identified reevaluation will be necessary. 


\subsection{DISSOLVED SOLIDS}

The concentration and nature of dissolved solids in a waste stream have a significant impact upon the LERF/ETF systems. The primary areas of concern include scaling of unit operations and compatibility with materials of construction. The composition of the LAW effluent makes it extremely difficult to process directly through the ETF MTT. Based on the analysis of the LAW effluent it is recommended that it first be processed through the evaporator, and the evaporator distillate then processed through the MTT.

Following is a discussion of the specific parameters that drive the decision to modify the ETF flowsheet by sending the LAW effluent directly to the evaporator rather than through the normal path into the MTT.

\subsubsection{Chloride, Fluoride And Pitting Corrosion}

The tanks and piping in the MTT are composed almost entirely of 304 stainless steel (SS). The levels of chloride/fluoride in the LAW effluent will cause pitting corrosion in 304SS at the $\mathrm{pH}$ levels normally seen in the ETF MTT. Although raising the $\mathrm{pH}$ could mitigate some of the potential for pitting corrosion, it is not possible to do this as it would severely impact unit operations in the MTT, such as carbon dioxide degasification and RO.

\subsubsection{Degasification of Carbon Dioxide}

Carbonates exhibit very low solubility and would present a scaling problem in the RO. The presence of high levels of carbonates and bicarbonates in the feed would require the stream $\mathrm{pH}$ to be lowered to approximately $4.0-5.0$ so that the carbonate and bicarbonate could be converted to dissolved carbon dioxide gas and stripped out of the feed by the degasification column. However, in this $\mathrm{pH}$ range the I-129 in solution would also be converted from a dissolved solid to a dissolved gas and be removed from the stream by the degasification column. The I-129 would then be captured by the activated carbon beds in the Vessel Off Gas (VOG) system. The high levels of I-129 would necessitate frequent change-out of the carbon beds as discussed in Section 4.6. The high maintenance and operating costs of doing this make it very undesirable to operate in this manner.

\subsubsection{Scaling in the RO}

To avoid scaling of the RO membrane surface, the operation of the unit is controlled so solubility limits are not exceeded. The existing brackish water membranes used in the RO units at the ETF have an upper feed limit of 0.5 weight percent dissolved solids. Based on the LAW effluent, the average total solids are approximately 0.3 weight percent. However, the presence of relatively high levels of silica and aluminum make it likely that scaling of the RO membranes with aluminum silicate will occur. Currently available RO scale inhibitor chemicals would be incapable of preventing scaling of aluminum silicate on the RO membranes. Other sparingly soluble salts such as calcium fluoride, calcium carbonate, magnesium ammonium phosphate and lead carbonate would also present potential scaling problems in the RO. 


\subsubsection{Effect of Oxidizing Materials on RO membranes}

RO membranes degrade when exposed to strong oxidizers. Iron in the plus three valence state is particularly damaging to RO membrane surfaces. The manufacturer of the thin-film polyamide membranes in the RO, recommends exposing the membranes to no more than 0.05 ppm of iron with a plus three valence in the feed. The LAW effluent averages $7.9 \mathrm{ppm}$ of dissolved iron. Even though no specific data is available on the particular valence state of the dissolved iron, it is reasonable to assume that a significant portion is in the plus three valence and would therefore be harmful to the RO membranes.

\subsubsection{Evaporator Operation}

Extensive ETF operating experience indicates that the evaporator distillate will be low in dissolved solids and should be processed very efficiently through the MTT. The current feed envelope does not contain organics. If relatively volatile organic species are present in the feed that ETF receives it is possible that more frequent change-out of the Vessel Off-Gas (VOG) carbon adsorption beds will be required. The change-out frequency will depend on the volatility and amount of organics present in the feed. Based on the LAW effluent forecast, no modifications should be required to the MTT or VOG for processing of this feed.

\subsubsection{Evaporator Scaling}

In normal operation the feed would flow through the feed/distillate heat exchanger where the distillate would be used to preheat the feed and then the heated feed would flow into the evaporator vessel. High levels of carbonate, aluminum, silica, and fluoride are a cause for concern in regards to operation of the evaporator. These species are near saturation in the incoming feed and are likely to precipitate out as the solution is heated in the feed preheater and concentrated in the evaporator. The main species of concern are calcium fluoride, magnesium fluoride, calcium carbonate, aluminum silicate, calcium silicate, magnesium silicate and possibly other double or triple salts. Calcium carbonate exhibits inverse solubility with temperature, i.e. it becomes less soluble at higher temperatures, which makes it particularly susceptible to plating out on heat exchange surfaces. The $\mathrm{pH}$ of the solution could be decreased to convert the carbonate and bicarbonate to dissolved carbon dioxide gas, but this would also convert the iodine-129 to the dissolved gas form, causing it to off-gas of the VOG and load the VOG activated carbon beds. Per the previous discussion on MTT degasification column operation this is undesirable due to the large increase in operating and maintenance costs.

Silicate compounds also have a tendency to plate out on heat exchange transfer surfaces and could cause significant reductions in evaporator efficiency. Silicate scales can be very difficult to remove by chemical cleaning and might require shutdown of the evaporator in order to perform mechanical cleaning and removal of the scale. This could result in significant processing delays and concurrent increase in maintenance costs. It is hoped that the high fluid velocities through the evaporator heat exchanger will prevent significant scaling from occurring on the heat exchange surfaces but this will only be demonstrated through operating experience.

Silica scaling has been experienced in the feed/distillate heat exchanger during previous ETF campaigns on feed with high silica content. The primary component of the scale was magnesium 
silicate that was removed after extensive cleaning with a $1 \%$ solution of tetrasodium ethylenediaminetetraacetic acid (EDTA). In this case it is likely that aluminum silicate would scale the heat exchanger. Aluminum silicate is a particularly difficult scale to clean and remove. The low velocities and long residence time in the feed/distillate heat exchanger make this piece of equipment particularly susceptible to scaling. For this reason the evaporator feed will bypass the feed/distillate heat exchanger during normal operation on this feed stream. Cooling water will be connected to the feed/distillate heat exchanger in order to cool the distillate from approximately $215^{\circ} \mathrm{F}$ to $100^{\circ} \mathrm{F}$ before it is transferred to the surge tank for processing in the MTT. Engineering analysis indicates that the existing cooling water system is sufficiently sized to handle this additional load with minimal modification.

\subsubsection{Evaporator Brine Chloride, Fluoride, and Pitting Corrosion}

The levels of chloride/fluoride in the feed stream will cause pitting corrosion to occur in the 304SS pipe and Secondary Waste Receiver Tanks (SWRTs). In a previous operating campaign, levels of 500 - 600 ppm chloride in SWRT-A resulted in extensive chloride pitting corrosion of

the tank wall. For this reason it will be necessary to replace the SWRTs and all associated piping that come into contact with the LAW effluent with more corrosion resistant materials. At a minimum 316L SS is recommended for the piping and 316L SS or fiberglass reinforced plastic (FRP) for the SWRTs. Given in Ficgure C-1 is the proposed location for the new tanks.

A corrosion analysis performed in 1998 (Anantatmula, 1998) indicated that levels of up to $40,000 \mathrm{ppm}$ of chloride could be successfully processed in the evaporator without causing excessive corrosion of the Inconel evaporator. Chloride and fluoride exhibit very similar effects in regards to corrosion so fluoride will be assumed to behave the same as chloride for the purpose of this evaluation. Further analysis would have to be performed to confirm that a chloride/fluoride level greater than $40,000 \mathrm{ppm}$ would not damage the inconel evaporator. Based on this existing analysis the concentration of chloride plus fluoride will be limited to $40,000 \mathrm{ppm}$ in the evaporator.

Evaporator brine chloride levels in excess of $10,000 \mathrm{ppm}$ will result in excessive pitting corrosion in the existing 316L SS concentrate receiver tanks (CTs) and piping. For the options where the brine chloride is greater than $10,000 \mathrm{ppm}$ it will be necessary to replace the CTs and all associated piping with more corrosion resistant materials in order to enhance operational longevity (Figure C-1). Inconel is recommended for the piping and inconel or FRP for the tanks.

\subsubsection{Disposition of ETF Evaporator Brine}

Provided in Table 5-1 is the ETF generated secondary waste volume for the three different approaches. 
Table 5-1. ETF Generated Secondary Waste Volumes

\begin{tabular}{|c|c|c|c|c|c|c|c|c|c|}
\hline & & AP-104 & AP-102 & AP-101 & AP-103 & AP-105 & AP-108 & AP-107 & AN-104 \\
\hline \multirow{2}{*}{$\begin{array}{l}\text { Total gallons of } \\
\text { evaporator brine } \\
\text { generated } \\
\text { (Approaches } \\
\text { 2\&3) }\end{array}$} & $\begin{array}{l}\text { Brine @ 10,000 ppm } \\
\text { Chloride/Fluoride }\end{array}$ & 230,000 & 260,000 & 130,000 & 250,000 & 330,000 & 210,000 & 140,000 & 330,000 \\
\hline & $\begin{array}{l}\text { Brine @ 40,000 ppm } \\
\text { Chloride/Fluoride }\end{array}$ & 58,000 & 67,000 & 33,000 & 63,000 & 83,000 & 54,000 & 35,000 & 87,000 \\
\hline \multirow{2}{*}{$\begin{array}{l}\text { Total number of } \\
\text { 3-cubic solidified } \\
\text { blocks } \\
\text { generated } \\
\text { (Approach 1) }\end{array}$} & $\begin{array}{l}\text { Brine @ 10,000 ppm } \\
\text { Chloride/Fluoride }\end{array}$ & 1,500 & 1,700 & 860 & 1,600 & 2,200 & 1,400 & 930 & 2,200 \\
\hline & $\begin{array}{l}\text { Brine @ 40,000 ppm } \\
\text { Chloride/Fluoride }\end{array}$ & 390 & 450 & 220 & 420 & 550 & 360 & 230 & 580 \\
\hline
\end{tabular}

Option 1 - Process at ETF for Final Disposal

The LAW effluent matrix (e.g., high nitrates and carbonates) is not suitable for producing a secondary waste in a powder, thus requiring the thin-film dryer to be replaced. If the evaporator brine is to be treated at ETF it will require construction of a treatment unit that would solidify the evaporator brine and storage building to cure waste before it can be sent to IDF for disposal. Refer to Ficure C-2 for proposed location of the solidification treatment unit. For the purposes of this treatability evaluation, it is assumed that the solid waste disposal site for the Resource Conservation and Recovery Act (RCRA) designated grout blocks generated by the ETF during the treatment of the LAW effluent is the IDF. A design for the construction of a new solidification treatment unit at the ETF is $90 \%$ complete. Because of increase in costs, the project became a line-item. The Critical Decision-0 for the solidification treatment unit (i.e., Mission Need Statement) has been sent to DOE-RL but has not yet been approved. The draft Critical Decision-1 (i.e., alternatives study) is expected to be submitted to DOE-RL in fiscal year 2009. Once these documents have been approved a definitive schedule for construction of the solidification treatment unit will be developed.

Some preliminary testing of brine solidification has been completed on current waste streams processed through the ETF. Further testing would be necessary to establish the raw material mix (e.g., Portland cement, lime, fly ash, etc.,) for the LAW brine. During the testing it will be necessary to measure chromium leachability to determine if the land disposal restriction (LDR) treatment standard for chromium is met and the testing of getters that may be required to stabilize radionuclides if above the IDF acceptance criteria (e.g., technetium-99, iodine-129). One major concern is whether grout solidification is an acceptable waste form for stabilization of technetium-99 and iodine-129 for final disposal at IDF. Table 5-2 gives the estimated number of block generated along with curie content for each of the batches. The estimated total chromium levels in the brine are given in Table 5-3.

Option 2 - Recycle ETF Evaporator Brine to Tank Farms via Tanker Truck

One approach for treatment of the ETF evaporator brine is to transport it to Tank Farms via tanker truck where it will be off-loaded into an underground tank. This approach would require construction of a separate tanker loading facility to the east of the ETF (Figure C-2). The new facility would be a building approximately 75 feet by 100 feet with a confinement heating, ventilation, and air conditioning (HVAC) system. Building would be capable of holding a tanker and tractor, and tanks and equipment for a solids removal and handling system. The solids 
removal system would be located in a separate room in order to provide containment of the radioactive solids.

The equipment in the building would consist of:

- A tank to receive evaporator brine from the ETF concentrate tanks. The tank would be constructed of FRP or inconel.

- $\quad$ An agitator for the brine receiving tank.

- A pump and piping system to move the brine from the receipt tank to the solids removal system. The wetted parts of the pump and piping would be constructed of inconel.

- A solids removal and handling system, most likely a filter press. The wetted parts of the pump and piping would be constructed of inconel.

- A conveyed drum system to receive the solids from the filter press.

- $\quad$ A tank to receive the liquid effluent from the solids removal system. The tank would be constructed of FRP or inconel.

- A pump and piping system to transfer from the effluent tank to a tanker. The wetted parts of the pump and piping would be constructed of inconel.

- New tanker(s) from corrosion resistant material such as inconel or hastelloy.

Approach 3 - Recycle ETF Evaporator Brine to Tank Farms via New Pipeline

This approach requires a new pipeline from the ETF to Tank Farms that meets all the current requirements that the existing Tank Farms pipelines meet (double encasement, leak detection, etc.). It is assumed that this pipeline will run from the ETF to the $\mathrm{SN}-701$ pipeline near $242-\mathrm{A}$ evaporator (Figure C-2). This would require approximately 6,000 feet of new pipe. 
RPP-RPT-37924, Rev. 0

Table 5-2. Curies per Block of Solidified Waste

\begin{tabular}{|c|c|c|c|c|c|c|c|c|c|c|c|c|c|c|c|c|}
\hline & \multicolumn{2}{|c|}{ AP-104 } & \multicolumn{2}{|c|}{ AP-102 } & \multicolumn{2}{|c|}{ AP-101 } & \multicolumn{2}{|c|}{ AP-103 } & \multicolumn{2}{|c|}{ AP-105 } & \multicolumn{2}{|c|}{ AP-108 } & \multicolumn{2}{|c|}{ AP-107 } & \multicolumn{2}{|c|}{ AN-104 } \\
\hline & Curie & block & Curie & block & Curie & block & Curie & /block & Curie & block & Curie & block & Curie & block & Curies & block \\
\hline & $\begin{array}{c}\text { Brine } \\
10,000 \\
\text { ppm } \\
\text { Chloride } \\
\text { and } \\
\text { Fluoride } \\
\end{array}$ & $\begin{array}{c}\text { Brine } \\
40,000 \\
\text { ppm } \\
\text { Chloride } \\
\text { and } \\
\text { Fluoride } \\
\end{array}$ & $\begin{array}{c}\text { Brine } \\
10,000 \\
\text { ppm } \\
\text { Chloride } \\
\text { and } \\
\text { Fluoride }\end{array}$ & $\begin{array}{c}\text { Brine } \\
40,000 \\
\text { ppm } \\
\text { Chloride } \\
\text { and } \\
\text { Fluoride }\end{array}$ & $\begin{array}{c}\text { Brine } \\
10,000 \\
\text { ppm } \\
\text { Chloride } \\
\text { and } \\
\text { Fluoride }\end{array}$ & $\begin{array}{c}\text { Brine } \\
40,000 \\
\text { ppm } \\
\text { Chloride } \\
\text { and } \\
\text { Fluoride }\end{array}$ & $\begin{array}{c}\text { Brine } \\
10,000 \\
\text { ppm } \\
\text { Chloride } \\
\text { and } \\
\text { Fluoride } \\
\end{array}$ & $\begin{array}{c}\text { Brine } \\
40,000 \\
\text { ppm } \\
\text { Chloride } \\
\text { and } \\
\text { Fluoride } \\
\end{array}$ & $\begin{array}{c}\text { Brine } \\
10,000 \\
\text { ppm } \\
\text { Chloride } \\
\text { and } \\
\text { Fluoride }\end{array}$ & $\begin{array}{c}\text { Brine } \\
40,000 \\
\text { ppm } \\
\text { Chloride } \\
\text { and } \\
\text { Fluoride } \\
\end{array}$ & $\begin{array}{c}\text { Brine } \\
10,000 \\
\text { ppm } \\
\text { Chloride } \\
\text { and } \\
\text { Fluoride } \\
\end{array}$ & $\begin{array}{c}\text { Brine } \\
40,000 \\
\text { ppm } \\
\text { Chloride } \\
\text { and } \\
\text { Fluoride } \\
\end{array}$ & $\begin{array}{c}\text { Brine } \\
10,000 \\
\text { ppm } \\
\text { Chloride } \\
\text { and } \\
\text { Fluoride } \\
\end{array}$ & $\begin{array}{c}\text { Brine } \\
40,000 \\
\text { ppm } \\
\text { Chloride } \\
\text { and } \\
\text { Fluoride }\end{array}$ & $\begin{array}{c}\text { Brine } \\
10,000 \\
\text { ppm } \\
\text { Chloride } \\
\text { and } \\
\text { Fluoride } \\
\end{array}$ & $\begin{array}{c}\text { Brine } \\
40,000 \\
\text { ppm } \\
\text { Chloride } \\
\text { and } \\
\text { Fluoride }\end{array}$ \\
\hline $\begin{array}{l}\text { Projected total } \\
\text { number of } 3^{\prime *} 3^{\prime *} 3^{\prime} \\
\text { blocks }\end{array}$ & 1,500 & 390 & 1,700 & 450 & 860 & 220 & 1,600 & 420 & 2,200 & 550 & 1,400 & 360 & 930 & 230 & 2,200 & 580 \\
\hline Tritium & $7.4 \mathrm{E}-03$ & $2.9 \mathrm{E}-02$ & $5.1 \mathrm{E}-02$ & $2.0 \mathrm{E}-01$ & $3.8 \mathrm{E}-01$ & $1.5 \mathrm{E}+00$ & $1.5 \mathrm{E}-01$ & $5.8 \mathrm{E}-01$ & $2.6 \mathrm{E}-02$ & $1.0 \mathrm{E}-01$ & $6.5 \mathrm{E}-02$ & $2.6 \mathrm{E}-01$ & $3.8 \mathrm{E}-01$ & $1.5 \mathrm{E}+00$ & $1.7 \mathrm{E}-02$ & $6.6 \mathrm{E}-02$ \\
\hline Carbon-14 & $3.8 \mathrm{E}-03$ & $1.5 \mathrm{E}-02$ & $6.7 \mathrm{E}-03$ & $2.6 \mathrm{E}-02$ & $2.0 \mathrm{E}-02$ & $7.8 \mathrm{E}-02$ & $1.6 \mathrm{E}-02$ & $6.3 \mathrm{E}-02$ & $4.5 \mathrm{E}-03$ & $1.8 \mathrm{E}-02$ & $6.9 \mathrm{E}-03$ & 2.7E-02 & 1.6E-02 & $6.4 \mathrm{E}-02$ & $5.3 \mathrm{E}-03$ & $2.0 \mathrm{E}-02$ \\
\hline Cobalt- 60 & $1.6 \mathrm{E}-04$ & $6.4 \mathrm{E}-04$ & $8.4 \mathrm{E}-05$ & $3.3 \mathrm{E}-04$ & $2.5 \mathrm{E}-04$ & $9.5 \mathrm{E}-04$ & $2.2 \mathrm{E}-04$ & $8.5 \mathrm{E}-04$ & 1.2E-04 & $4.7 \mathrm{E}-04$ & $9.9 \mathrm{E}-05$ & $3.9 \mathrm{E}-04$ & $4.0 \mathrm{E}-04$ & $1.6 \mathrm{E}-03$ & $1.4 \mathrm{E}-06$ & $5.5 \mathrm{E}-06$ \\
\hline Selenium-79 & $6.0 \mathrm{E}-04$ & $2.4 \mathrm{E}-03$ & 1.3E-03 & $5.2 \mathrm{E}-03$ & 1.1E-03 & 4.4E-03 & $1.0 \mathrm{E}-03$ & $3.9 \mathrm{E}-03$ & 1.2E-03 & $4.9 \mathrm{E}-03$ & $1.1 \mathrm{E}-03$ & $4.2 \mathrm{E}-03$ & $1.3 \mathrm{E}-03$ & 5.3E-03 & 4.7E-04 & 1.8E-03 \\
\hline Strontium-90 & $3.4 \mathrm{E}-02$ & 1.3E-01 & 8.7E-03 & $3.4 \mathrm{E}-02$ & $3.8 \mathrm{E}-02$ & 1.5E-01 & $4.9 \mathrm{E}-02$ & $1.9 \mathrm{E}-01$ & $3.0 \mathrm{E}-02$ & 1.2E-01 & $2.5 \mathrm{E}-02$ & $9.8 \mathrm{E}-02$ & $7.6 \mathrm{E}-02$ & $3.0 \mathrm{E}-01$ & 1.7E-02 & $6.5 \mathrm{E}-02$ \\
\hline Technetium-99 & $2.8 \mathrm{E}-01$ & $1.1 \mathrm{E}+00$ & $2.5 \mathrm{E}-01$ & $9.8 \mathrm{E}-01$ & $4.8 \mathrm{E}-01$ & $1.8 \mathrm{E}+00$ & $3.4 \mathrm{E}-01$ & $1.3 \mathrm{E}+00$ & $2.5 \mathrm{E}-01$ & $1.0 \mathrm{E}+00$ & $2.6 \mathrm{E}-01$ & $1.0 \mathrm{E}+00$ & $6.0 \mathrm{E}-01$ & $2.4 \mathrm{E}+00$ & $2.3 \mathrm{E}-01$ & $8.8 \mathrm{E}-01$ \\
\hline Ruthenium-106 & $2.0 \mathrm{E}-07$ & $7.9 \mathrm{E}-07$ & $1.1 \mathrm{E}-07$ & $4.4 \mathrm{E}-07$ & $2.7 \mathrm{E}-01$ & $1.1 \mathrm{E}+00$ & $1.8 \mathrm{E}-07$ & $6.9 \mathrm{E}-07$ & $7.4 \mathrm{E}-03$ & $2.9 \mathrm{E}-02$ & $8.3 \mathrm{E}-07$ & $3.3 \mathrm{E}-06$ & $8.9 \mathrm{E}-01$ & $3.5 \mathrm{E}+00$ & $5.9 \mathrm{E}-06$ & $2.2 \mathrm{E}-05$ \\
\hline lodine-129 & $1.8 \mathrm{E}-04$ & $6.9 \mathrm{E}-04$ & $2.8 \mathrm{E}-04$ & 1.1E-03 & $2.9 \mathrm{E}-04$ & 1.1E-03 & $2.9 \mathrm{E}-04$ & 1.1E-03 & 1.7E-04 & $6.9 \mathrm{E}-04$ & $2.4 \mathrm{E}-04$ & $9.3 \mathrm{E}-04$ & $2.6 \mathrm{E}-04$ & $1.0 \mathrm{E}-03$ & $8.1 \mathrm{E}-05$ & 3.1E-04 \\
\hline Cesium-134 & $3.9 \mathrm{E}-07$ & $1.5 \mathrm{E}-06$ & $2.2 \mathrm{E}-08$ & 8.6E-08 & $9.6 \mathrm{E}-06$ & 3.7E-05 & $1.5 \mathrm{E}-07$ & $5.8 \mathrm{E}-07$ & $3.1 \mathrm{E}-07$ & $1.2 \mathrm{E}-06$ & $6.4 \mathrm{E}-07$ & $2.5 \mathrm{E}-06$ & $1.3 \mathrm{E}-05$ & $5.2 \mathrm{E}-05$ & $1.3 \mathrm{E}-07$ & 4.9E-07 \\
\hline Europium-154 & $2.0 \mathrm{E}-04$ & 7.7E-04 & 7.0E-04 & 2.7E-03 & $9.4 \mathrm{E}-04$ & 3.7E-03 & $3.2 \mathrm{E}-04$ & $1.2 \mathrm{E}-03$ & 7.7E-04 & $3.0 \mathrm{E}-03$ & $3.7 \mathrm{E}-04$ & $1.5 \mathrm{E}-03$ & $1.5 \mathrm{E}-03$ & $6.1 \mathrm{E}-03$ & $7.6 \mathrm{E}-11$ & $2.9 \mathrm{E}-10$ \\
\hline Europium-155 & $4.9 \mathrm{E}-04$ & 1.9E-03 & $3.9 \mathrm{E}-04$ & $1.5 \mathrm{E}-03$ & 1.6E-03 & $6.3 \mathrm{E}-03$ & $4.2 \mathrm{E}-04$ & $1.6 \mathrm{E}-03$ & $6.7 \mathrm{E}-04$ & $2.7 \mathrm{E}-03$ & $4.0 \mathrm{E}-04$ & 1.6E-03 & $2.6 \mathrm{E}-03$ & $1.0 \mathrm{E}-02$ & $2.9 \mathrm{E}-11$ & 1.1E-10 \\
\hline Uranium-232 & $7.9 \mathrm{E}-08$ & $3.1 \mathrm{E}-07$ & 1.4E-07 & $5.6 \mathrm{E}-07$ & $6.2 \mathrm{E}-08$ & $2.4 \mathrm{E}-07$ & $7.8 \mathrm{E}-08$ & $3.0 \mathrm{E}-07$ & $2.1 \mathrm{E}-08$ & $8.2 \mathrm{E}-08$ & $9.2 \mathrm{E}-08$ & $3.6 \mathrm{E}-07$ & $4.5 \mathrm{E}-08$ & $1.8 \mathrm{E}-07$ & $1.9 \mathrm{E}-09$ & 7.5E-09 \\
\hline Uranium-233 & $5.5 \mathrm{E}-07$ & $2.1 \mathrm{E}-06$ & $6.0 \mathrm{E}-07$ & $2.4 \mathrm{E}-06$ & $7.9 \mathrm{E}-07$ & $3.1 \mathrm{E}-06$ & $3.3 \mathrm{E}-07$ & $1.3 \mathrm{E}-06$ & $9.1 \mathrm{E}-08$ & $3.6 \mathrm{E}-07$ & $3.8 \mathrm{E}-07$ & $1.5 \mathrm{E}-06$ & $6.5 \mathrm{E}-07$ & $2.6 \mathrm{E}-06$ & $1.2 \mathrm{E}-07$ & 4.6E-07 \\
\hline Uranium-234 & $3.0 \mathrm{E}-07$ & 1.2E-06 & 1.1E-07 & 4.4E-07 & $5.4 \mathrm{E}-07$ & 2.1E-06 & $2.4 \mathrm{E}-07$ & 9.3E-07 & $3.0 \mathrm{E}-08$ & 1.2E-07 & 2.7E-07 & $1.0 \mathrm{E}-06$ & $5.2 \mathrm{E}-07$ & 2.1E-06 & $8.5 \mathrm{E}-08$ & $3.2 \mathrm{E}-07$ \\
\hline Uranium-235 & $1.1 \mathrm{E}-08$ & 4.5E-08 & 4.4E-09 & 1.7E-08 & $2.0 \mathrm{E}-08$ & 7.9E-08 & $1.0 \mathrm{E}-08$ & $4.0 \mathrm{E}-08$ & 1.2E-09 & 4.9E-09 & $1.0 \mathrm{E}-08$ & 4.1E-08 & $2.1 \mathrm{E}-08$ & 8.4E-08 & $3.3 \mathrm{E}-09$ & 1.3E-08 \\
\hline Uranium-236 & $1.3 \mathrm{E}-08$ & $5.3 \mathrm{E}-08$ & $3.6 \mathrm{E}-09$ & 1.4E-08 & 4.4E-08 & 1.7E-07 & $6.7 \mathrm{E}-09$ & $2.6 \mathrm{E}-08$ & 1.1E-09 & 4.3E-09 & 1.7E-08 & $6.5 \mathrm{E}-08$ & $2.5 \mathrm{E}-08$ & $9.9 \mathrm{E}-08$ & $5.7 \mathrm{E}-09$ & $2.2 \mathrm{E}-08$ \\
\hline Uranium-238 & $3.2 \mathrm{E}-07$ & $1.3 \mathrm{E}-06$ & 1.0E-07 & $3.9 \mathrm{E}-07$ & 4.1E-07 & 1.6E-06 & $2.4 \mathrm{E}-07$ & $9.5 \mathrm{E}-07$ & 2.7E-08 & $1.1 \mathrm{E}-07$ & $2.1 \mathrm{E}-07$ & $8.1 \mathrm{E}-07$ & 4.4E-07 & $1.8 \mathrm{E}-06$ & $6.6 \mathrm{E}-08$ & $2.5 \mathrm{E}-07$ \\
\hline Neptunium-237 & $1.3 \mathrm{E}-06$ & 4.9E-06 & 1.1E-05 & 4.2E-05 & $9.5 \mathrm{E}-06$ & 3.7E-05 & 1.1E-06 & 4.4E-06 & 8.4E-06 & 3.3E-05 & $1.3 \mathrm{E}-06$ & $4.9 \mathrm{E}-06$ & $8.6 \mathrm{E}-06$ & $3.4 \mathrm{E}-05$ & 1.7E-07 & 6.4E-07 \\
\hline Plutonium-238 & $3.1 \mathrm{E}-06$ & $1.2 \mathrm{E}-05$ & $1.8 \mathrm{E}-07$ & $7.1 \mathrm{E}-07$ & $5.9 \mathrm{E}-06$ & $2.3 \mathrm{E}-05$ & $4.4 \mathrm{E}-06$ & 1.7E-05 & 2.4E-07 & $9.6 \mathrm{E}-07$ & $6.1 \mathrm{E}-07$ & $2.4 \mathrm{E}-06$ & 1.7E-05 & $6.8 \mathrm{E}-05$ & $9.2 \mathrm{E}-08$ & $3.5 \mathrm{E}-07$ \\
\hline Plutonium-239 & $1.6 \mathrm{E}-05$ & $6.3 \mathrm{E}-05$ & $6.9 \mathrm{E}-06$ & $2.7 \mathrm{E}-05$ & $8.1 \mathrm{E}-05$ & $3.2 \mathrm{E}-04$ & $3.2 \mathrm{E}-05$ & $1.2 \mathrm{E}-04$ & 4.7E-06 & $1.9 \mathrm{E}-05$ & $9.9 \mathrm{E}-06$ & $3.9 \mathrm{E}-05$ & $1.9 \mathrm{E}-04$ & 7.4E-04 & $1.3 \mathrm{E}-06$ & $4.8 \mathrm{E}-06$ \\
\hline Plutonium-240 & $2.0 \mathrm{E}-05$ & $7.9 \mathrm{E}-05$ & 8.6E-06 & $3.4 \mathrm{E}-05$ & 1.4E-04 & 5.4E-04 & $3.9 E-05$ & $1.5 \mathrm{E}-04$ & $6.9 \mathrm{E}-06$ & 2.7E-05 & $1.4 \mathrm{E}-05$ & $5.4 \mathrm{E}-05$ & $3.6 \mathrm{E}-04$ & 1.4E-03 & $2.4 \mathrm{E}-06$ & 9.2E-06 \\
\hline Plutonium-241 & $1.9 \mathrm{E}-05$ & $7.3 \mathrm{E}-05$ & $8.3 \mathrm{E}-06$ & 3.3E-05 & $3.9 \mathrm{E}-04$ & $1.5 \mathrm{E}-03$ & $3.9 \mathrm{E}-05$ & $1.5 \mathrm{E}-04$ & 1.4E-05 & $5.6 \mathrm{E}-05$ & $2.4 \mathrm{E}-05$ & 9.3E-05 & $1.2 \mathrm{E}-03$ & $4.8 \mathrm{E}-03$ & $5.8 \mathrm{E}-06$ & $2.2 \mathrm{E}-05$ \\
\hline Amercium-241 & $9.6 \mathrm{E}-05$ & $3.8 \mathrm{E}-04$ & $7.5 \mathrm{E}-05$ & $2.9 \mathrm{E}-04$ & $5.2 \mathrm{E}-05$ & $2.0 \mathrm{E}-04$ & $3.0 \mathrm{E}-04$ & $1.2 \mathrm{E}-03$ & $6.8 \mathrm{E}-05$ & $2.7 \mathrm{E}-04$ & $9.0 \mathrm{E}-05$ & $3.5 \mathrm{E}-04$ & $6.3 \mathrm{E}-05$ & $2.5 \mathrm{E}-04$ & $4.0 \mathrm{E}-05$ & $1.5 \mathrm{E}-04$ \\
\hline Curium-243 & $5.9 \mathrm{E}-07$ & $2.3 \mathrm{E}-06$ & 1.6E-08 & $6.3 \mathrm{E}-08$ & $5.9 \mathrm{E}-08$ & $2.3 \mathrm{E}-07$ & $3.6 \mathrm{E}-07$ & $1.4 \mathrm{E}-06$ & $2.3 \mathrm{E}-08$ & $9.3 \mathrm{E}-08$ & $3.1 \mathrm{E}-08$ & $1.2 \mathrm{E}-07$ & $2.3 \mathrm{E}-08$ & $9.1 \mathrm{E}-08$ & $2.3 \mathrm{E}-09$ & $8.8 \mathrm{E}-09$ \\
\hline Curium-244 & $1.4 \mathrm{E}-05$ & 5.4E-05 & 2.3E-07 & $9.1 \mathrm{E}-07$ & 1.3E-06 & $5.2 \mathrm{E}-06$ & $7.8 \mathrm{E}-06$ & $3.1 \mathrm{E}-05$ & $4.0 \mathrm{E}-07$ & $1.6 \mathrm{E}-06$ & $5.2 \mathrm{E}-07$ & $2.0 \mathrm{E}-06$ & $5.0 \mathrm{E}-07$ & $2.0 \mathrm{E}-06$ & $5.4 \mathrm{E}-08$ & 2.1E-07 \\
\hline
\end{tabular}


RPP-RPT-37924, Rev. 0

Table 5-3. ETF Evaporator Brine Total Chromium Concentration (in ppm)

\begin{tabular}{|c|c|c|c|c|c|c|c|c|}
\hline & AP-104 & AP-102 & AP-101 & AP-103 & AP- 105 & AP-108 & AP-107 & AN-104 \\
\hline $\begin{array}{l}\text { Brine at } \\
10,000 \mathrm{ppm} \\
\text { chloride/fluoride }\end{array}$ & 120 & 90 & 270 & 100 & 40 & 130 & 310 & 50 \\
\hline $\begin{array}{l}\text { Brine at } \\
40,000 \mathrm{ppm} \\
\text { chloride/fluoride }\end{array}$ & 460 & 370 & 1,000 & 400 & 160 & 510 & 1,200 & 170 \\
\hline
\end{tabular}

\subsection{CONCLUSIONS AND RISKS}

FH could accept the LAW effluent at LERF/ETF based on the high level evaluation that was completed, with the exception of the LAW effluent generated from the treatment of Tank AP-107 waste which exceeds the LERF safety basis. This acceptance is contingent on the necessary permit modification and facility modifications being competed. Due to processing rate restriction with treating the LAW effluent, the ETF would not have the capacity to continue treating pump while receiving and treating the LAW effluent.

A complete list of necessary ETF equipment modifications for the three options is given in Appendix B. For the purposes of this treatability evaluation, it was assumed that the individual organics and applied waste codes (plus D007 for chromium) will be similar to those in the 242-A process condensate that ETF has successfully treated.

\subsection{ETF SAFETY BASIS RESTRICTIVE BATCH VOLUMES}

The ETF maximum allowable batch volumes for LAW effluents would range from 150,000 to 346,000 gallons, depending on which LAW effluent batch is being treated (Table 4-1). These volumes were calculated based on maximum facility radiological inventory allowed within the ETF safety basis. With these batch volumes, and an annual average LAW feed rate of 9 gpm, ETF should have sufficient capacity to handle the LAW waste. This can be accomplished by the large surge capacity available in the LERF basins and by the ETF evaporator having excess capacity to treat these batches, allowing downtime for shipment of the final waste form as given below for each of the different approaches.

Option 1 - At a minimum, shipments to IDF would range from one shipment every two days to two shipments every two weeks, depending on whether the chloride/fluoride concentration is $10,000 \mathrm{ppm}$ or $40,000 \mathrm{ppm}$ (Section 5.0). This frequency accounts for the five day cure time for the blocks. For the purpose of this evaluation, a shipment is defined as ten 3-cubic feet solidified blocks.

Option 2 - At a minimum, tanker shipments of evaporator brine to Tank Farms would range from 1,500 gallons every two days to 3,000 gallons every two weeks, depending on whether the chloride/fluoride concentration is $10,000 \mathrm{ppm}$ or $40,000 \mathrm{ppm}$ (Section 5.0). 
Option 3 - Evaporator brine is a continuous feed to Tank Farms, or at a minimum of 1,500 gallons every two days to 3,000 gallons every two weeks, depending on whether the chloride/fluoride concentration is $10,000 \mathrm{ppm}$ or $40,000 \mathrm{ppm}$ (Section 5.0).

\subsection{MODIFICATIONS TO ADDRESS CORROSION/SCALING OF ETF UNIT OPERATIONS/PIPING}

Common for all Options - The two primary concerns with treating the LAW effluent through the ETF common for all three options is compatibility with the materials of construction and fouling of some equipment. At a minimum, the two evaporator feed tanks and all associated piping that comes in contact with the LAW effluent would need to be repolaced with more corrosion resistant materials. Equipment fouling can easily overcome by routing LAW effluent directly to the evaporator, as was planned for bulk vitrification effluents. Additionally, the existing cooling water system would be extended to cool the evaporator distillate.

For waste minimization, replacing the two evaporator brine receiving tanks and associated piping with corrosion resistant materials would allow the brine to be concentrated further resulting in a 75 percent reduction in secondary waste that would either be sent back to Tank Farm or IDF depending on the final option chosen.

\subsection{ACCEPTABLE WASTE FORM FOR DISPOSAL AT IDF}

Option 1 - Some preliminary testing of brine solidification has been completed on current waste streams processed through the ETF. Further testing would be necessary to establish the raw material mix (e.g., Portland cement, lime, fly ash, etc.,) for the LAW brine. During the testing it will be necessary to measure chromium leachability to determine if the LDR treatment standard for chromium is met and the testing of getters that may be required to stabilize radionuclides if above the IDF acceptance criteria (e.g., technetium-99, iodine-129). One major concern is whether grout solidification is an acceptable waste form for stabilization of technetium- 99 and iodine-129 for final disposal at IDF.

\subsection{EXCEEDENCE OF AN A QUANTITY}

If a shipment exceeds an $\mathrm{A}_{2}$ quantity then specification packaging is required. In addition, 49 CFR 173.441 dose rate limits must be meet, however, modeling of dose rates were not performed for this treatability evaluation. Summarized in Table 4-3 is the maximum packaging volume for each of the batches to stay below an $\mathrm{A}_{2}$ quantity. For a chloride/fluoride limit of $10,000 \mathrm{ppm}$, the maximum package volume to stay below an $\mathrm{A}_{2}$ quantity ranges from 1600 gallons to 10,000 gallons. For a chloride/fluoride limit of $40,000 \mathrm{ppm}$, the maximum package volume to stay below an $A_{2}$ quantity ranges from 420 gallons to 2,600 gallons.

Option 1 - A solidified block, which is considered a package, would be below an $\mathrm{A}_{2}$ quantity since the volume of brine per package is 150 gallons.

Option 2 - A tanker shipment of brine to Tank Farms could not exceed the volumes given in Table 4-3 in order to stay below an $\mathrm{A}_{2}$ quantity. 


\subsection{ADDITIONAL MODIFICATIONS FOR DISPOSITION OF EVAPORATOR BRINE}

Option 1 - This option would require a treatment unit that would solidify the evaporator brine into blocks and storage building to cure blocks before they can be sent to IDF for disposal. A design for the construction of a new solidification treatment unit at the ETF is $90 \%$ complete. Because of increase in costs, the project became a line-item. The Critical Decision- 0 for the solidification treatment unit (i.e., mission need statement) has been sent to DOE-RL but has not yet been approved. The draft Critical Decision-1 (i.e., alternatives study) is expected to be submitted to DOE-RL in fiscal year 2009. Once these documents have been approved a definitive schedule for the construction of the solidification treatment unit will be developed.

Option 2 - This option would require construction of a separate tanker loading facility to the east of the ETF. The new facility would be a building approximately 75 feet by 100 feet with a confinement HVAC system. Building would be capable of holding a tanker and tractor, and tanks and equipment for a solids removal and handling system. The solids removal system would be located in a separate room in order to provide containment of the radioactive solids. Procurement of new tanker(s) made of corrosion resistant material such as inconel or hastelloy, would also be required.

Option $\underline{3}$ - This option requires a new pipeline from the ETF to Tank Farms that meets all the current requirements that the existing Tank Farms pipelines meet (double encasement, leak detection, etc.). It is assumed that this pipeline will run from the ETF to the SN-701 pipeline near 242-A evaporator. This would require approximately 6,000 feet of new pipe.

\subsection{REFERENCES}

Anantatmula, R. P., Lockheed Martin Hanford, to R.J. Nicklas, Waste Management Federal Services of Hanford, Impact of Processing Solutions with High Chloride Concentration on Corrosion of Effluent Treatment Facility Construction Materials, Letter 74711-98RPA-019, dated April 15, 1998.

Aromi, E. S., Waste Management Federal Services of Hanford to T. K. Teynor, U.S. Department of Energy, Richland Operations Office, Liquid Effluent Retention Facility/Effluent Treatment Facility Treatability Envelope, Letter WMH-9758688, dated September 29, 1997.

HNF-3172, Liquid Waste Processing Facilities Waste Acceptance Criteria, Rev. 1, March, 2001, Flour Hanford, Richland, Washington. 
RPP-RPT-37924, Rev. 0

APPENDIX A

\section{LAW Effluent Forecast}


RPP-RPT-37924, Rev. 0

\section{${ }^{\mathrm{A}} \mathrm{E}_{\mathrm{M} \text { Consulting }}$}

April 14, 2008

Letter \# AEM 075

R. A. Burk

Bechtel National Inc.

3000 George Washington Way

Richland, WA 99352

SUBJECT: Analyze and Predict Early LAW Secondary Waste Streams - Task Order no. 14

Dear Mr. Burk:

A E M Consulting, LLC has completed the preliminary analysis of the secondary waste stream for the first eight campaigns of Early LAW. The methodology and results of the analysis are discussed below.

\section{Methodology:}

The tank inventories for the first eight campaigns were provided in SVF-1484 Interim

Pretreatment System DST Feed Calculations. These inventories were fed through a simplified early LAW flowsheet to estimate the concentrations of secondary waste from the LAW facility. The simplified flowsheet proceeded with the following steps;

1. The feed was adjusted to $179 \mathrm{~kg} / \mathrm{hr} \mathrm{Na}$ basis which is equivalent to approximately 30 MTD at approximately $19 \mathrm{wt} \% \mathrm{Na}_{2} \mathrm{O}$.

2. The feed was diluted to $6 \mathrm{M} \mathrm{Na}$.

3. The Cs- 137 was removed to the limit of $1.68 \mathrm{E}-05 \mathrm{Ci} / \mathrm{mole} \mathrm{Na}$ in the feed (BNI CCN 155899). The percentage of C-137 removed was also applied to the Cs-134.

4. Glass formers were added based on a recipe provided by Rod Gimpel (email to GL Dunford 1/6/2008).

5. The LAW melter, Submerged Bed Scrubber (SBS), and Wet Electrostatic Precipitator (WESP) decontamination factors (DF) were applied to the simulated feed/glass former solution to estimate the concentration of condensates. The DF's used were the modified DF's provided from MCR-07-0037/38 (and email input from R. Chen of BNI).

6. WESP water addition was estimated using daily averages discussed in 24590-LAW3YD-LOP-00001 System Description for LAW Primary Offgas Process (LOP) and LAW Secondary Offgas/Vessel Vent Process (LVP) Systems.

7. Caustic Scrubber condensate make-up was estimated using an average of three AES tier model runs (Verification runs, Case 1,2 and $4 ; 12 / 2006$ ). 


\section{Results:}

The combined condensate stream concentrations projected from tank inventories for the first eight campaigns are shown in Table 1 and 2 , and the complete results are provided electronically. The combined SBS, WESP, and caustic scrubber condensate streams were compared to $\mathrm{LERF} / \mathrm{ETF}$ acceptance criteria which is summarized in the attached tables and discussed below.

\section{Radiological:}

The radiological limits listed in HNF-3172, Liquid Waste Processing Facilities Waste Acceptance Criteria, Rev. 2 \& 3 are compared against the combined condensate streams of the first eight campaigns in Table 1 . The limits between revision 2 and 3 changed for $134 \mathrm{Cs}, 137 \mathrm{Cs}$, and $239 / 240 \mathrm{Pu}$. No data was available for $144 \mathrm{Ce}$ and $94 \mathrm{Nb}$.

- The limit for 99Tc and $241 \mathrm{Am}$ were consistently exceeded for all of the eight of the campaigns. The $99 \mathrm{Tc}$ exceeded the limit by an average of $136 \%$ and the $241 \mathrm{Am}$ exceeded the limit by an average of $880 \%$.

- The limit for 106Ru was exceeded for campaigns 3 (AP-104), 5 (AP-105), 7 (AP-107), and 8 (AN-104). Campaigns 3,5, and 7 exceeded the 106Ru limit by four to five orders of magnitude. The source tanks for these campaigns contain higher levels of 106Ru resulting in higher levels in the secondary waste stream.

- The 69Se limit was exceeded in campaigns 2 (AP-102) and 5 (AP-105).

- The $240 \mathrm{Pu}$ and $241 \mathrm{Pu}$ limits were exceeded in campaigns 7 (AP-107) and 3 (AP-101 only 241Pu).

- $14 \mathrm{C}$ concentration in the $4^{\text {th }}$ campaign (AP-103) exceeded the limit.

\section{Non-Rad. Results:}

The LERF/ETF waste acceptance criteria for non-radioactive constituents are not as straight forward as the radiological limits. The limits given in Table 2 were derived from a combination of guidelines in WMH-9758688, Liquid Effluent Retention Facility/Effluent Treatment Facility Treatability Envelope, Sept. 1997 and HNF-3172, Liquid Waste Processing Facilities Waste Acceptance Criteria, Rev. 3, Nov. 2005. The first column in Table 2 is a summary of the highest value for each constituent from the four flowhseets (Table F-1, WNH-9758688) currently developed to treat aqueous waste at the ETF. These flowsheets comprise the current design envelope for ETF. The second column in Table 3 is the highest value from any of the regulatory envelopes listed in WMH-9758688. Some constituents were not listed in the design envelope table, in which case the highest value from either the Final Delisting table (Table C-1) or the State Waste Discharge Permit levels (Tables D-1 \& D-2) table was used. Additional limits from HNF-3172 are listed in the third column of Table 3. These are the operational envelope guidelines for compatibility with ETF material of construction.

Several constituent concentrations were higher than the current regulatory ETF treatability envelope for each campaign. These constituents are; $\mathrm{Al}, \mathrm{B}, \mathrm{Cl}, \mathrm{F}, \mathrm{Cr}, \mathrm{K}, \mathrm{Na}, \mathrm{NO}_{2}$, and $\mathrm{PO}_{4}(\mathrm{Zn}$ exceeded the design envelope only). All of the operational envelope limits from HNF-3172 were met. A few constituents listed in WNH-9758688 were not included in the feed data (e.g. Ag, As, $\mathrm{Ba}, \mathrm{CN}, \mathrm{Se}$, etc..) and hence are not included in table 2. 
From this preliminary analysis it appears that the secondary waste stream from early LAW will likely exceed some of the existing ETF limits. These preliminary estimates are conservative and with better more detailed flowsheet modeling a more refined estimate may reduce the number of constituents which exceed the ETF limits.

If you require additional information, I can be reached at 509-554-7683.

Sincerely,

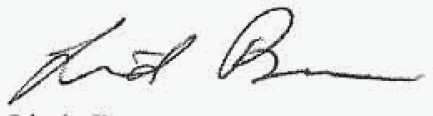

Linda Bergmann

Senior Engineer

Attachment

LB:

cc: Scott Saunders 
RPP-RPT-37924, Rev. 0

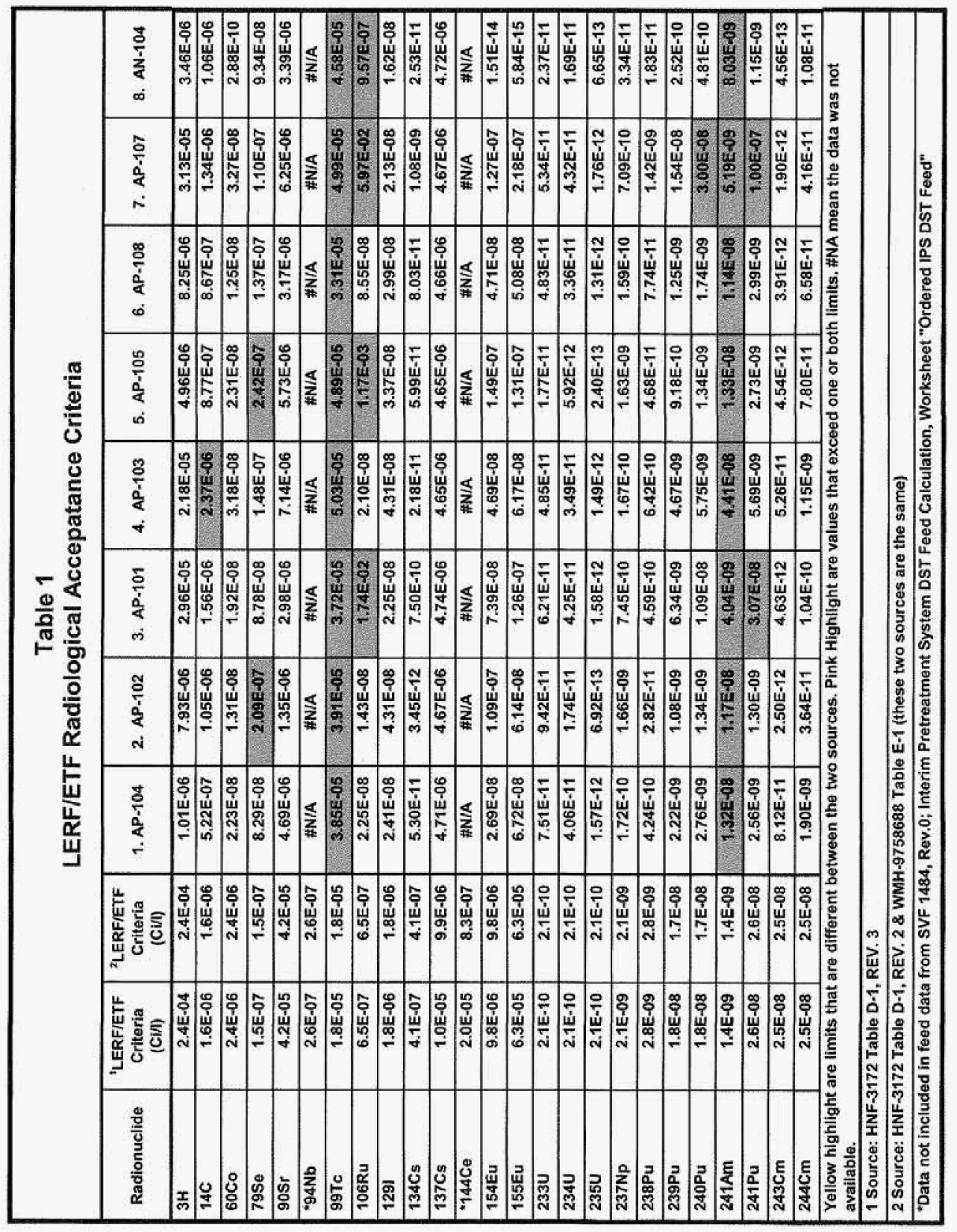




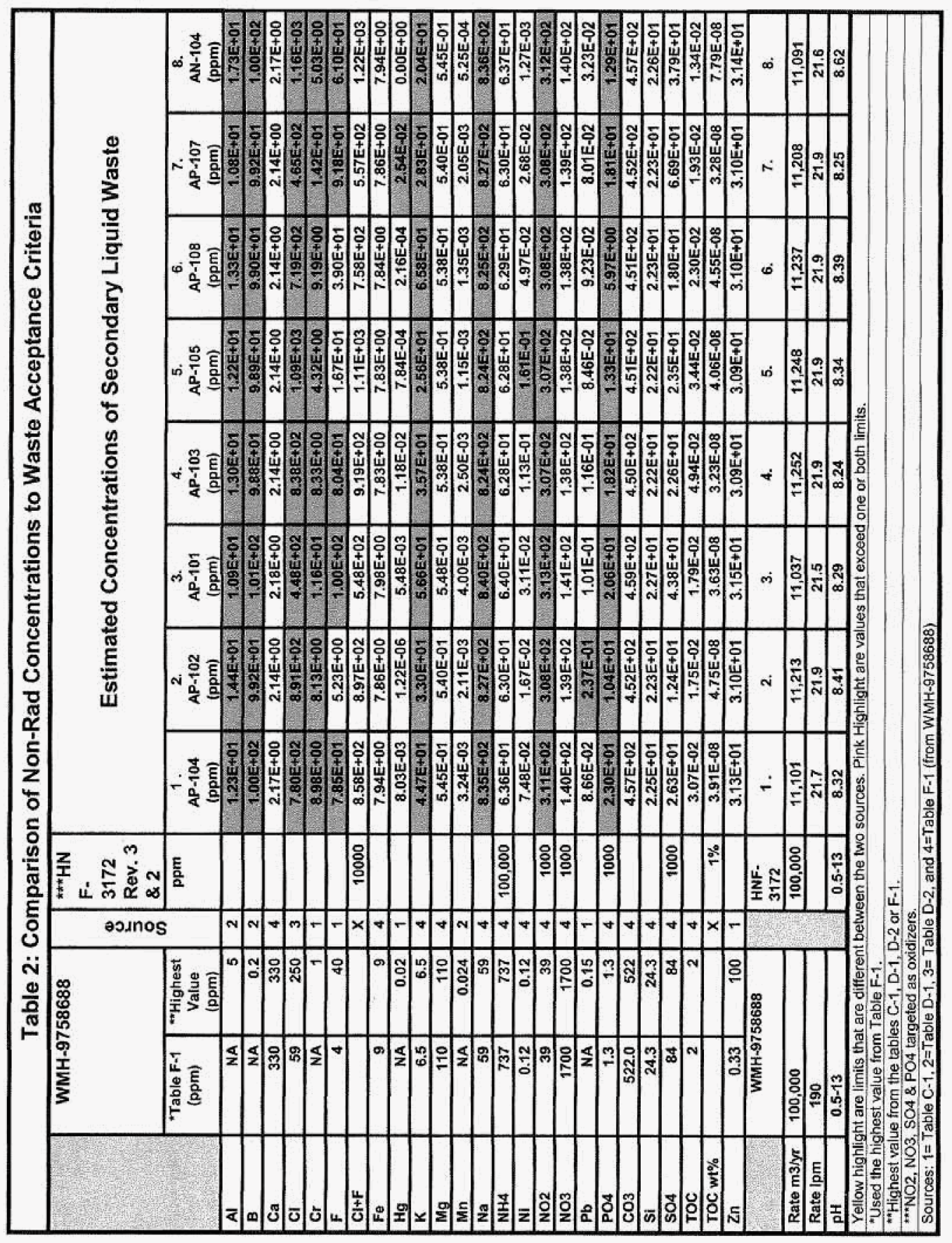


RPP-RPT-37924, Rev. 0

APPENDIX B

\section{ETF EQUIPMENT MODIFICATION LIST}


RPP-RPT-37924, Rev. 0

\section{REQUIRED ETF MODIFICATIONS}

\section{Required Modifications in All Approaches for Less than 10,000 ppm Chloride/Fluoride in Evaporator Brine}

LERF to SWRT transfer piping:

- $\quad 300$ feet of 3"316L SS pipe.

- 3 bank influent filter skid constructed of 316L SS or similar corrosion resistant material. The filter skid will be capable of operation at 150 psig and 200 gallons per minute with replaceable filter cartridges.

SWRT, pumps and recirculation and transfer piping:

- $\quad$ Two 20,000 Secondary Waste Receiver Tanks fabricated from 316L SS or FRP. These tanks will be placed in the existing ETF drum storage room.

- $\quad$ Associated level, pressure, $\mathrm{pH}$, etc. instrumentation.

- $\quad$ Two new pumps fabricated from 316L SS. Pumps will be capable of flowing 180 gpm at 350 feet of TDH. These pumps will be placed in the existing ETF drum storage room.

- $\quad 200$ feet of 3" and 50 feet of 4"316L SS recirculation piping for SWRT.

- $\quad 200$ feet of 1"316L SS pipe from SWRT to evaporator.

- $\quad$ Small $(\sim 50$ gallon) day tank constructed of HDPE, metering pump, instrumentation and 50 feet of $1 / 2 " 316 \mathrm{~L}$ SS transfer tubing. Day tank, metering pump and tubing will be placed in existing ETF drum storage room.

- 100 feet of 1 "304 SS piping from existing verification water system to new day tank.

Utility Connections to SWRT

- 100 feet of $3 / 4$ "' Carpenter Alloy 20 for $4 \%$ acid piping

- $\quad 100$ feet of $3 / 4 " 304$ SS for $4 \%$ caustic piping

- $\quad 100$ feet of 6" CPVC piping to Vessel Off-Gas (VOG)

- $\quad 100$ feet of 1 "304 SS verification water piping

- $\quad 100$ feet of 2" 304 SS piping from Sump 1

- $\quad 100$ feet of $1 " 304$ SS to sump 1

- $\quad 100$ feet of 3" 304 SS piping from Sump 2 
- $\quad 100$ feet of 1 " $304 \mathrm{SS}$ piping from $1^{\text {st }} \mathrm{RO}$

Cooling Water to Evaporator Feed/Distillate Heat Exchanger:

- $\quad 100$ feet of 1-1/2"304 SS pipe for connection (supply and return) of cooling water system to feed/distillate heat exchanger.

Additional Modifications in all Approaches for Greater than 10,000 ppm Chloride/Fluoride in Evaporator Brine

Evaporator Recirculation Pump:

- Axial flow pump with wetted parts built of Inconel. Pump is $75 \mathrm{hp}, 6,000 \mathrm{gpm}$ at 20 feet TDH.

Concentrate Tanks, pumps, recirculation and transfer piping:

- Two 5,000 gallon Concentrate Tanks fabricated from Inconel or FRP. These tanks will be placed in the existing ETF drum storage room.

- $\quad$ Two 2 HP Agitators (one for each tank).

- $\quad$ Associated level, pressure, $\mathrm{pH}$, specific gravity, etc. instrumentation.

- Two new pumps with wetted parts constructed of Inconel. Pumps will be capable of $35 \mathrm{gpm}$ at 125 feet TDH. These pumps will be placed in the existing ETF drum storage room.

- 100 feet of 1-1/2" Inconel recirculation piping for CT.

Utility Connections to Concentrate Tanks:

- 100 feet of $3 / 4$ " Carpenter Alloy 20 for $4 \%$ acid piping

- 100 feet of $3 / 4 " 304 \mathrm{SS}$ for $4 \%$ caustic piping

- 100 feet of $3 / 4 " 304 \mathrm{SS}$ for $50 \%$ caustic piping

- $\quad 100$ feet of 2" CPVC piping to Vessel Off-Gas (VOG)

- 100 feet of 1 " 304 SS verification water piping

- $\quad 100$ feet of 2 "Inconel pipe to sump 1.

\section{Additional Modifications for Option 1 - Process at ETF for Final Disposal}

\section{Solidification Treatment Unit}

- Installation of new treatment unit for solidification of brine feed from CTs. Per CD-0 the estimated total cost is $\$ 14,100,000$. 
- Design and construction of storage building for curing cement blocks. Per the project CDR the estimated cost is $\$ 600,000$.

Additional Modifications for Option 2 - Recycle ETF Evaporator Brine to Tank Farms via Tanker Truck.

New Tanker(s):

- $\quad$ Fabricate new tanker(s) from corrosion resistant material such as Inconel, Hastelloy or FRP.

Tanker Load-out Facility (similar to Tank Farms 204-AR facility)

- $\quad$ Construct new building physically large enough to hold tanker ( 55 feet long and 15 feet wide) and provide confinement. Building will have to be constructed with secondary containment large enough to hold tanker contents. Assume a building footprint of 100 feet by 75 feet.

- $\quad$ Confinement HVAC system for tanker load-out building.

- 1,000 feet of $1-1 / 2 \%$ Inconel pipe.

- Two 5,000 gallon FRP or Inconel tanks.

- $\quad$ Associated level, pressure, $\mathrm{pH}$, specific gravity, etc. instrumentation.

- $\quad$ One $2 \mathrm{hp}$ agitator for one of the tanks.

- 2 pumps with wetted parts constructed of Inconel, capable of flowing $100 \mathrm{gpm}$ at 100 feet TDH.

- $\quad$ Filter Press solids removal system (not a filter skid) to remove solids from brine.

- $\quad$ Drum handling system to accept solids from filter press.

- $\quad$ Separate confinement room or glovebox in the building to hold the filter press and drum handling system.

Additional Modifications for Option 3 - Recycle ETF Evaporator Brine to Tank Farms via New Pipeline

- 5,000 feet of 2" double encased pipe line to Tank Farms line SN-700. Tie in to $\mathrm{SN}-700$ Near 242-A evaporator.

- $\quad$ Transfer pump with wetted parts constructed of Inconel, capable of 50 gpm at 500 feet $\mathrm{TDH}$. 
RPP-RPT-37924, Rev. 0

APPENDIX C

PROPOSED LOCATION OF OPTIONS 
Figure C-1. Proposed Location of New Tanks Applicable to All Three Options

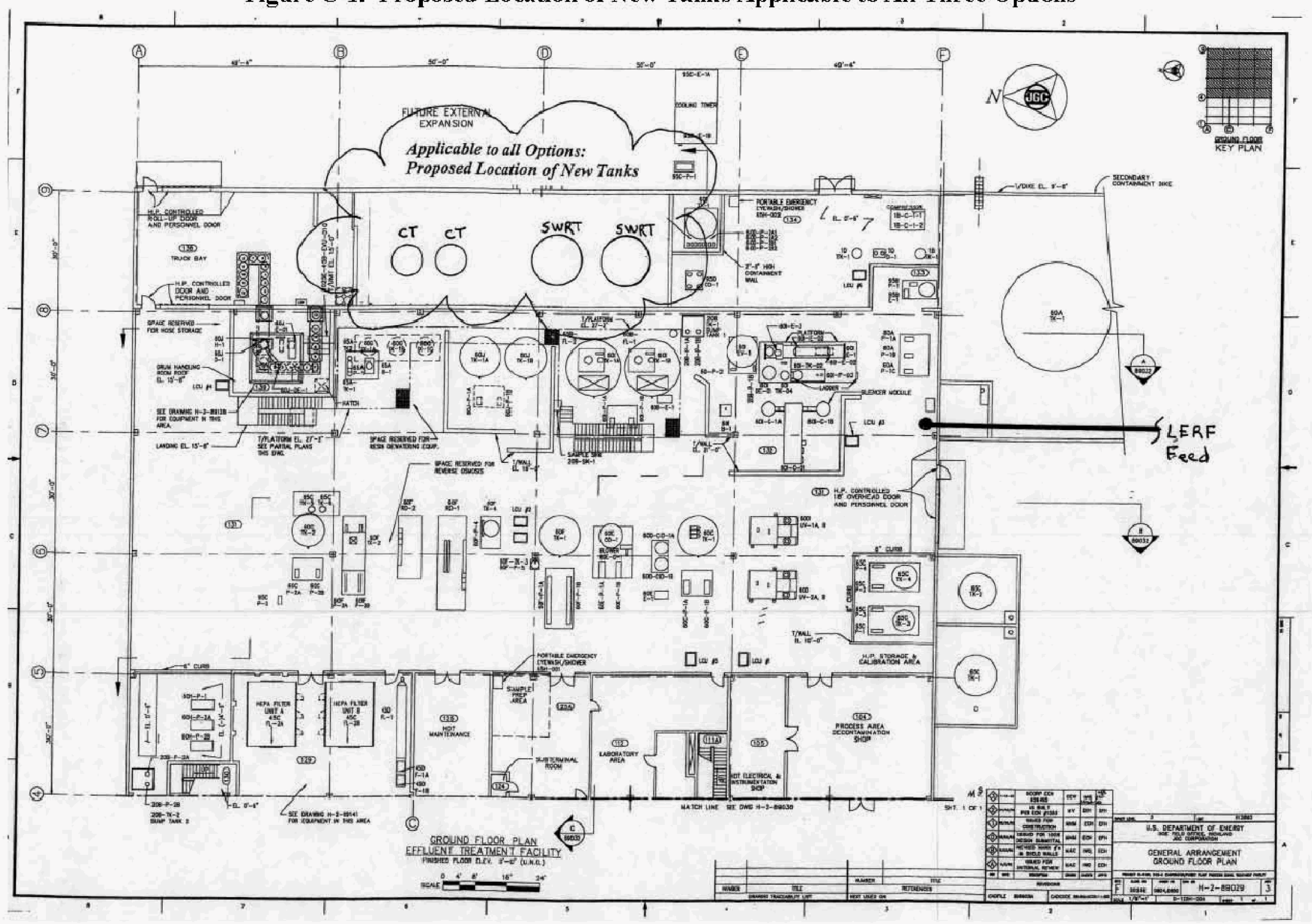


RPP-RPT-37924, Rev. 0

Figure C-2. Prop osed L ocation of New Tanks Applicable to All Three Options

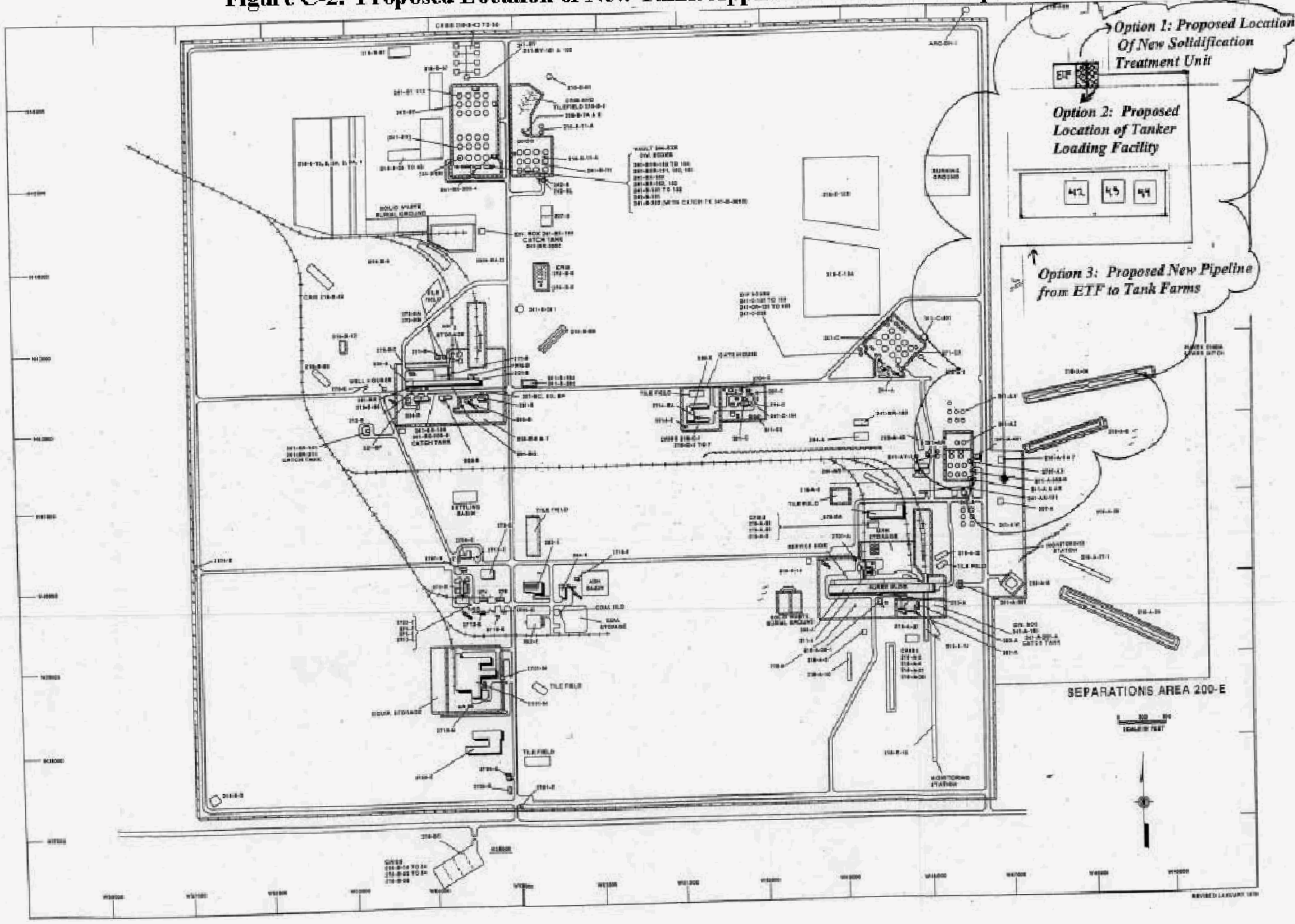


RPP-RPT-37924, Rev. 0

\section{APPENDIX E. INTERIM PRETREATMENT SYSTEM SECONDARY WASTE STUDY - RECYCLE STREAM TO 242-A}

\section{$\underline{\text { Purpose }}$}

Evaluation of Concentrating IPS/LAW Vitrification Dilute Secondary Waste Stream in 242-A Evaporator

\section{2-A System Description}

The 242-A Evaporator has been in service since 1977. It is a forced-circulation vacuum evaporator with a capacity of $26 \mathrm{kgal}$. The vessel and piping are $304 \mathrm{~L}$ stainless steel. Distribution piping to and from Tank Farms is carbon steel.

The 242-A Evaporator typically operates one to two campaigns per year. Campaigns are typically one week to one month. Feed is staged for sampling and analysis (typically 4 months). Candidate feed is transferred to the feed tank (AW-102). Currently the only way to introduce feed is through AW-102.

Current facility limits are $40-80$ torr for processing and up to $150^{\circ} \mathrm{F}$. Processing rates are up to $115 \mathrm{gpm}$ feed and a maximum effective boiloff rate of $38 \mathrm{gpm}$. A typical residence time in the system is 10 hours. Typically the waste volume reduction (WVR) is limited to $50 \%$ or less in a single pass because of minimum slurry flow requirements. Waste that requires further volume reduction is recycled for multiple passes. The overhead vapor is condensed and routed to the LERF for eventual processing through the 200 Area Effluent Treatment Facility. A portion of the condensate is recycled within 242-A for deentrainment pad sprays and pump seal water to reduce raw water usage. Pump seal water drains back to AW-102 ( 2 gpm).

\section{2-A Planned Use and Operating Life}

The 242-A Evaporator plays a key role in the Tank Farms mission. HNF-SD-WM-SP-012, Tank Farm Contractor Operation And Utilization Plan, Table 3-4 projects 46 campaigns over the Tank Farms mission. Recent discussions have proposed operating the facility through 2035 or even 2045 (Wagner 2008). Based on those estimates, the facility is only about halfway through its operating life. In the near term, approximately one campaign is planned per year through 2015 with significant facility upgrades planned through 2018. At this level of use, there is available capacity to support the secondary waste mission. However, the timing of the mission will have to be coordinated with the scheduled maintenance and upgrades.

The 2007 Integrity Assessment (RPP-RPT-33306) indicated that the minimum remaining life of the facility was greater than 20 years. The next integrity assessment is due in 2017 . 
$\underline{\text { Stream Description }}$

The stream considered for evaporation at 242-A is the dilute aqueous recycle stream from the LAW vitrification plant, operating on feed from the IPS. Processes resulting in secondary waste include the submerged bed scrubber and wet electrostatic precipitator. The nominal recycle stream flow rate is $8 \mathrm{gpm}$, and the total volume is $12 \mathrm{Mgal}$. A volume of up to $3 \mathrm{Mgal}$ per year is anticipated. Feed tanks for IPS and early LAW are AP-104, AP-102, AP-101, AP-103, AP-105, AP-108, AP-107 and AN-104. The secondary waste stream compositions were prepared by AEM Consulting (AEM 075). Secondary waste stream compositions from the eight feed tanks are given in the reference. The average chemical composition of secondary waste from all eight tanks is presented in Table 1, along with calculated concentrations at $90 \%$ and 95\% WVR and several other comparisons.

\begin{tabular}{|c|c|c|c|c|c|c|c|}
\hline $\begin{array}{c}\text { Consti- } \\
\text { tuent }\end{array}$ & $\begin{array}{c}\text { Molecular } \\
\text { Weight } \\
\text { (g/mol) }\end{array}$ & $\begin{array}{c}\text { Average } \\
\text { ppm } \\
(\mu \mathrm{g} / \mathbf{m L})\end{array}$ & $\begin{array}{c}\text { Average } \\
\mathrm{mol} / \mathrm{L} \\
\end{array}$ & $\begin{array}{l}\% \text { of } \\
\text { total } \\
\text { moles }\end{array}$ & $\begin{array}{c}\text { Average } \\
\mu \mathrm{g} / \mathrm{mL} \text {, } \\
90 \% \\
\text { WVR } \\
\end{array}$ & $\begin{array}{c}\text { Average } \\
\boldsymbol{\mu} g / \mathrm{mL} \\
95 \% \\
\text { WVR } \\
\end{array}$ & $\begin{array}{c}\text { Maximum/ } \\
\text { Average }\end{array}$ \\
\hline $\mathrm{Al}$ & 27 & 13 & $4.8 \mathrm{E}-04$ & 0.01 & 130 & 261 & 1.33 \\
\hline B & 10.8 & 100 & $9.2 \mathrm{E}-03$ & 0.10 & 995 & 1991 & 1.01 \\
\hline $\mathrm{Ca}$ & 40 & 2 & $5.4 \mathrm{E}-05$ & 0.00 & 22 & 43 & 1.01 \\
\hline $\mathrm{Cl}$ & 35.5 & 799 & $2.3 \mathrm{E}-02$ & 0.24 & 7991 & 15982 & 1.45 \\
\hline $\mathrm{Cr}$ & 52 & 9 & 1.7E-04 & 0.00 & 87 & 175 & 1.63 \\
\hline $\mathrm{F}$ & 19 & 59 & $3.1 \mathrm{E}-03$ & 0.03 & 591 & 1182 & 1.69 \\
\hline $\mathrm{Fe}$ & 56 & 8 & $1.4 \mathrm{E}-04$ & 0.00 & 79 & 158 & 1.01 \\
\hline $\mathrm{Hg}$ & 201 & 0 & $3.2 \mathrm{E}-08$ & 0.00 & 0 & 0 & 3.93 \\
\hline $\mathrm{K}$ & 39 & 39 & $9.9 \mathrm{E}-04$ & 0.01 & 388 & 775 & 1.70 \\
\hline $\mathrm{Mg}$ & 24.3 & 1 & $2.2 \mathrm{E}-05$ & 0.00 & 5 & 11 & 1.01 \\
\hline $\mathrm{Mn}$ & 55 & 0 & $3.8 \mathrm{E}-08$ & 0.00 & 0 & 0 & 1.89 \\
\hline $\mathrm{Na}$ & 23 & 830 & $3.6 \mathrm{E}-02$ & 0.38 & 8300 & 16599 & 1.01 \\
\hline NH4 & 18 & 63 & $3.5 \mathrm{E}-03$ & 0.04 & 632 & 1265 & 1.01 \\
\hline $\mathrm{Ni}$ & 58.7 & 0 & $1.0 \mathrm{E}-06$ & 0.00 & 1 & 1 & 2.72 \\
\hline $\mathrm{NO} 2$ & 46 & 309 & $6.7 \mathrm{E}-03$ & 0.07 & 3094 & 6188 & 1.01 \\
\hline $\mathrm{NO} 3$ & 62 & 139 & $2.2 \mathrm{E}-03$ & 0.02 & 1391 & 2781 & 1.01 \\
\hline $\mathrm{Pb}$ & 207 & 0 & $5.0 \mathrm{E}-07$ & 0.00 & 1 & 2 & 2.28 \\
\hline PO4 & 95 & 15 & $1.6 \mathrm{E}-04$ & 0.00 & 153 & 306 & 1.50 \\
\hline $\mathrm{CO} 3$ & 60 & 454 & 7.6E-03 & 0.08 & 4536 & 9072 & 1.01 \\
\hline $\mathrm{Si}$ & 28 & 22 & $8.0 \mathrm{E}-04$ & 0.01 & 224 & 448 & 1.01 \\
\hline
\end{tabular}


RPP-RPT-37924, Rev. 0

\begin{tabular}{|c|c|c|c|c|c|c|c|}
\hline $\mathrm{SO} 4$ & 96 & 31 & $3.3 \mathrm{E}-04$ & 0.00 & 314 & 628 & 2.13 \\
\hline TOC & 12 & 0 & $2.1 \mathrm{E}-06$ & 0.00 & 0 & 1 & 1.92 \\
\hline $\mathrm{Zn}$ & 65.4 & 31 & $4.8 \mathrm{E}-04$ & 0.01 & 311 & 623 & 1.01 \\
\hline \multicolumn{8}{|l|}{ Notes: } \\
\hline \multicolumn{8}{|c|}{$\begin{array}{l}\text { Average ppm and maximum/average derived from Table } 2 \text { of Letter AEM } 075 \text { (AEM 2008) from the stream } \\
\text { compositions resulting from treatment of the } 8 \text { feed tanks. }\end{array}$} \\
\hline \multicolumn{8}{|c|}{ A $90 \%$ WVR is equivalent to a $10 \mathrm{x}$ increase in concentration, and a $90 \%$ WVR to an increase of $20 \mathrm{x}$. } \\
\hline
\end{tabular}

\section{Discussion of chemical constituents and their behavior during and after evaporation}

The major chemical constituents of this liquid stream are (ranked by mole fraction) sodium, chloride, boron, carbonate, nitrite, ammonia, fluoride, and nitrate. A qualitative discussion of the potential issues associated with evaporation of the waste stream based on the chemical composition is presented below.

Aluminum, calcium, chromium, iron, magnesium, manganese, nickel, silicon and zinc are all present at relatively low concentrations. These metals could all be involved in scale-forming and precipitation, especially aluminum and silicon, which can form aluminosilicates, such as, cancrinite, sodalite, and zeolite.

Boron is elevated in this recycle stream relative the typical levels in tank waste. Boron is present in the borosilicate glass frit. A concentration of $1000 \mathrm{ppm}(\mu \mathrm{g} / \mathrm{mL})$ is projected at $90 \%$ volume reduction, and $2000 \mathrm{ppm}$ at $95 \% \mathrm{WVR}$. A search of tank data in the Tank Waste Information Network System (TWINS) indicates that only the U-200 tanks had liquid samples at concentrations above $1000 \mu \mathrm{g} / \mathrm{mL}$. The concentration of liquid from the U-200s ranged from 300 to $2700 \mu \mathrm{g} / \mathrm{mL}$. It is not known why the boron level in the U-200 tanks would be so high. Solids results for the U-200 tanks were not elevated in boron. Literature solubility data for boron in high $\mathrm{pH}$ solution was not readily available. A concentration of $2000 \mu \mathrm{g} / \mathrm{mL}$ may or may not be reasonable. Additional information on the expected solubility of boron in high $\mathrm{pH}$ tank waste is needed. However, even if all of the boron precipitated, the solids volume would not be excessive.

Chloride and fluoride (and other halides, such as iodide) are semi-volatile in the melters and captured in off-gas treatment. Thus, they are elevated in this stream relative to other constituents. These anions are corrosive, and the elevated levels relative to other constituents requires further evaluation, even after accounting for the addition of corrosion inhibiters (nitrite and hydroxide).

Chloride is soluble in water up to about $5 \mathrm{M}(177,000 \mu \mathrm{g} / \mathrm{mL} \mathrm{Cl})$. The highest DST Cl measurement in the Tank Waste Information System Network is $25,800 \mu \mathrm{g} / \mathrm{mL}(0.73 \mathrm{M}) . \mathrm{Cl}$ is likely soluble well above $1 \mathrm{M}$ even in concentrated tank waste. The average $\mathrm{Cl}$ in $\mathrm{AP}$ farm (from the Best Basis Inventory) ranges up to $0.2 \mathrm{M}$. At $95 \% \mathrm{WVR}$, the average $\mathrm{Cl}$ in the secondary waste stream will be approximately $0.5 \mathrm{M}$. The Tank Waste Information Network System and the Best Basis Inventory data are accessible on the Hanford Intranet.

Fluoride will largely remain in solution at the relatively low concentrations projected in Table 1. However, this cation readily forms the double salts sodium fluoride phosphate and sodium 
fluoride sulfate in the tanks. A small amount of precipitation is likely as the stream is concentrated.

Lead and mercury are extremely low. The stream has virtually no organic carbon, so dimethyl mercury is not a concern.

Sodium and potassium are highly soluble cations. Nitrate and especially nitrite are highly soluble. Phosphate and sulfate are also soluble at the very low levels present in the stream, even after concentration. However, small amounts of sodium fluoride phosphate and sodium fluoride sulfate may form as this stream is concentrated.

Carbonate concentrations projected in the evaporated stream are below levels where significant precipitation would be expected. At $95 \%$ WVR the average concentration is less than $0.2 \mathrm{M}$, well within the solubility range for carbonate in tank waste (as seen in RPP-RPT-29165, Figure 3).

Ammonia is volatile, and will largely partition to the vapor in $242-\mathrm{A}$, and be re-condensed in the process condensate.

Feed stream variability is not excessive for the constituents of greatest interest (Cl). Therefore, evaluating average compositions is reasonable.

\section{$\underline{\text { WVR Potential }}$}

One report from Savannah River indicates that a concentration approaching $90 \%$ had been achieved on a similar recycle stream (WSRC-TR-2001-00330). From inspection of the data at a $90 \%$ and $95 \% \mathrm{WVR}$, the chemical concentrations remain quite low. All results appear to be within typical DST supernatant compositions except for boron and chloride. Based on Tank Farms and 242-A experience, a WVR of between 90 and $95 \%$ should be achieved from this stream with minimal solids formation $(<5 \mathrm{vol} \%)$. The solids formed would be expected to be aluminosilicate minerals, sodium fluoride phosphate and sodium fluoride sulfate, some boron compounds and possibly sodium carbonate. The solids formed should not be problematic for processing and transport, other than concerns about scale formation with the aluminosilicates.

A $90 \%$ WVR would reduce the volume of the stream from $12 \mathrm{Mgal}$ to $1.2 \mathrm{Mgal}$, and a $95 \%$ WVR would reduce the volume to $0.6 \mathrm{Mgal}$. Further WVR might be achieved by mixing the concentrated slurry with other tank waste streams. At 90 to $95 \% \mathrm{WVR}$, almost the entire stream volume (close to $3 \mathrm{Mgal}$ per year) must be evaporated. This would be a significant increase in 242-A processing time and steam usage. Recent operating history (since 2004) has been 1-2 campaigns per year and up to approximately 1 Mgal evaporated.

Based on a reported stream SpG of $1.02,90 \%$ volume reduction would result in a slurry SpG of $1.22 \mathrm{SpG}$, and a $95 \% \mathrm{WVR}$ would correspond to over $1.4 \mathrm{SpG}$. However, a 95\% WVR (concentration ratio of 20) for the average feed results in only $0.7 \mathrm{M}$ for $\mathrm{Na}$ and a $\mathrm{Cl}$ concentration of just $0.5 \mathrm{M}$. $\mathrm{NaCl}$ solubility in water is approximately 5-6 $\mathrm{M}$ with a SpG of nearly 1.3. Therefore, the starting SpG is likely well under 1.01 based on the stream data presented. 


\section{Evaluation of Radionuclide Concentrations}

Radionuclides will partition almost exclusively to the slurry, except for tritium, which is in the water. As with chloride and fluoride, some radionuclides (such as, ${ }^{99} \mathrm{Tc}$ and ${ }^{129} \mathrm{I}$ ) are concentrated in this recycle stream relative to the radionuclides that typically dominate doses incurred from handling and processing tank waste (such as, ${ }^{137} \mathrm{Cs},{ }^{90} \mathrm{Sr}, \mathrm{Pu}$ and $\mathrm{U}$ isotopes, which are almost completely retained in the glass). This will not affect processing at 242-A, but may be a concern in further treatment and eventual disposal of the concentrate (slurry).

Table 2 presents the maximum radionuclide compositions in the secondary waste stream (from Table 1 of AEM 2008 letter). Concentrated stream compositions are compared to a recent 242-A feed composition (from tank AP-104, one of the feeds for Campaign 07-01/07-02).

Radionuclide concentrations in the recent 242-A feed exceed radionuclide concentrations in the secondary waste stream, even assuming that the secondary waste stream is concentrated by a factor of 100. Therefore, the secondary waste stream will be far below all facility limits for radionuclides.

Table 2. Comparison of Secondary Waste Stream Radionuclides to a Recent 242-A Feed Stream.

\begin{tabular}{|c|c|c|c|c|}
\hline Radionuclide & $\begin{array}{c}\text { Maximum } \\
\text { Composition } \\
\text { Ci } / \mathrm{L}\end{array}$ & $\begin{array}{c}\text { Concentrated } \\
\text { (WVR: } \\
99 \%) \mathrm{Ci} / \mathrm{L}\end{array}$ & $\begin{array}{c}\text { 07-02 Campaign } \\
\text { Feed (AP-104) } \\
\text { Ci/L }\end{array}$ & $\begin{array}{c}\text { Ratio, } \\
\text { Concentrated } \\
\text { Recycle/AP-104 }\end{array}$ \\
\hline $3 \mathrm{H}$ & $3.13 \mathrm{E}-05$ & $3.13 \mathrm{E}-05$ & 4.87E-04 & $6.42 \mathrm{E}-02$ \\
\hline $14 \mathrm{C}$ & $2.37 \mathrm{E}-06$ & $2.37 \mathrm{E}-04$ & $6.57 \mathrm{E}-01$ & $3.61 \mathrm{E}-04$ \\
\hline $60 \mathrm{Co}$ & $3.27 \mathrm{E}-08$ & $3.27 \mathrm{E}-06$ & $7.69 \mathrm{E}+00$ & $4.25 \mathrm{E}-07$ \\
\hline $79 \mathrm{Se}$ & $2.42 \mathrm{E}-07$ & $2.42 \mathrm{E}-05$ & $8.08 \mathrm{E}-01$ & $3.00 \mathrm{E}-05$ \\
\hline $90 \mathrm{Sr}$ & 7.14E-06 & $7.14 \mathrm{E}-04$ & $1.69 \mathrm{E}+03$ & 4.23E-07 \\
\hline $99 \mathrm{Tc}$ & $5.03 \mathrm{E}-05$ & $5.03 \mathrm{E}-03$ & $1.90 \mathrm{E}+02$ & $2.64 \mathrm{E}-05$ \\
\hline $106 \mathrm{Ru}$ & 0.0597 & $5.97 \mathrm{E}+00$ & $2.43 \mathrm{E}+02$ & $2.46 \mathrm{E}-02$ \\
\hline 129I & 4.31E-08 & 4.31E-06 & $1.41 \mathrm{E}-01$ & $3.06 \mathrm{E}-05$ \\
\hline $134 \mathrm{Cs}$ & $1.08 \mathrm{E}-09$ & $1.08 \mathrm{E}-07$ & $1.23 \mathrm{E}+01$ & $8.74 \mathrm{E}-09$ \\
\hline $137 \mathrm{Cs}$ & 4.74E-06 & 4.74E-04 & $1.87 \mathrm{E}+05$ & $2.53 \mathrm{E}-09$ \\
\hline $154 \mathrm{Eu}$ & $1.49 \mathrm{E}-07$ & $1.49 \mathrm{E}-05$ & $4.64 \mathrm{E}+00$ & $3.20 \mathrm{E}-06$ \\
\hline $155 \mathrm{Eu}$ & $2.18 \mathrm{E}-07$ & $2.18 \mathrm{E}-05$ & $2.57 \mathrm{E}+01$ & $8.49 \mathrm{E}-07$ \\
\hline $233 \mathrm{U}$ & $9.42 \mathrm{E}-11$ & $9.42 \mathrm{E}-09$ & $1.69 \mathrm{E}-01$ & $5.57 \mathrm{E}-08$ \\
\hline $234 \mathrm{U}$ & 4.32E-11 & 4.32E-09 & - & - \\
\hline $235 \mathrm{U}$ & $1.76 \mathrm{E}-12$ & $1.76 \mathrm{E}-10$ & $1.97 \mathrm{E}-04$ & 8.93E-07 \\
\hline $237 \mathrm{~Np}$ & $1.66 \mathrm{E}-09$ & $1.66 \mathrm{E}-07$ & $6.51 \mathrm{E}-03$ & $2.55 \mathrm{E}-05$ \\
\hline $238 \mathrm{Pu}$ & $1.42 \mathrm{E}-09$ & $1.42 \mathrm{E}-07$ & $1.34 \mathrm{E}+00$ & $1.06 \mathrm{E}-07$ \\
\hline $239 \mathrm{Pu}$ & $1.54 \mathrm{E}-08$ & $1.54 \mathrm{E}-06$ & $1.74 \mathrm{E}+00$ & $8.83 \mathrm{E}-07$ \\
\hline
\end{tabular}


RPP-RPT-37924, Rev. 0

\begin{tabular}{|c|r|r|r|r|}
\hline $240 \mathrm{Pu}$ & $3.00 \mathrm{E}-08$ & $3.00 \mathrm{E}-06$ & $1.74 \mathrm{E}+00$ & $1.72 \mathrm{E}-06$ \\
\hline $241 \mathrm{Am}$ & $4.41 \mathrm{E}-08$ & $4.41 \mathrm{E}-06$ & $2.31 \mathrm{E}+01$ & $1.91 \mathrm{E}-07$ \\
\hline $241 \mathrm{Pu}$ & $1.00 \mathrm{E}-07$ & $1.00 \mathrm{E}-05$ & $7.13 \mathrm{E}+01$ & $1.41 \mathrm{E}-07$ \\
\hline $243 \mathrm{Cm}$ & $8.12 \mathrm{E}-11$ & $8.12 \mathrm{E}-09$ & $2.47 \mathrm{E}+00$ & $3.29 \mathrm{E}-09$ \\
\hline $244 \mathrm{Cm}$ & $1.90 \mathrm{E}-09$ & $1.90 \mathrm{E}-07$ & $2.47 \mathrm{E}+00$ & $7.69 \mathrm{E}-08$ \\
\hline $\begin{array}{l}\text { Notes: The maximum (for an individual feed tank) secondary waste stream compositions from Table 1 of } \\
\text { AEM 2008 were used. }\end{array}$ \\
$\begin{array}{l}\text { A conservatively high 99\% WVR was assumed for analysis. This is equivalent to concentrating the stream } \\
\text { by } 100 \text { times. } \\
\text { Tritium does not concentrate (it is associated with water). } \\
\text { The AP-104 feed (Campaign 07-02) is provided for comparison (from SVF-1315). } \\
\text { The ratio compares the concentrated secondary waste (99\% WVR) to the recent AP-104 feed, } \\
\text { demonstrating that the new stream will be below currently acceptable levels for all radionuclides. }\end{array}$ \\
\hline
\end{tabular}

\section{$\underline{\text { Processing Issues }}$}

Typically the maximum WVR for a single pass through 242-A is 50\%. A higher WVR would make continuous processing difficult. Approximately 4 passes are required to achieve a WVR of 90 to $95 \%$.

This means that dedicated storage space is needed to stage the slurry for recycle to the AW-102 feed tank. In the FY07 242-A campaign, AW-102 was used simultaneously as the feed and slurry tank to concentrate a dilute feed. However, this practice is not recommended as solids accumulation in AW-102 will limit flexibility (decrease the available volume for feed and possibly cover the bottom of the air lift circulators used for supernatant mixing).

The most reasonable choice for a DST to store partially concentrated slurry would be the first feed tank emptied and sent to IPS and LAW vitrification (AP-104). However, other secondary waste streams (such as, the cesium eluant from IPS ion exchange) may also require DST storage space. Mixing the LAW secondary waste stream with a high-cesium stream would limit the overall WVR because of Cs-137 concentration limits at 242-A.

\section{New Facilities for Secondary Waste Accumulation and Feed Qualification}

Since it is unlikely that sufficient DST space will be available for staging the recycle stream for feed to 242-A, feed accumulation and storage space is needed. 242-A will run intermittently, and feed batch qualification will take several months (currently 4 months minimum). The expected accumulation rate is $250 \mathrm{kgal}$ per month.

For feed accumulation and staging for 242-A, a new facility consisting of two basins (750 $1,000 \mathrm{kgal}$ each) is proposed. The basins will be similar to the LERF basins, which are operated as surface impoundments. The LERF basins have $7.8 \mathrm{Mgal}$ operating capacity apiece.

The LERF basins are described in the Hanford Facility RCRA Permit, Operating Unit 3, Chapter 4, Section 4.5 (http://www7.rl.gov/rapidweb/ENVPRO-RCRA/index.cfm?PageNum=129): 
The LERF consists of three lined surface impoundments (basins) with a design operating capacity of 29.5 million liters each. The maximum capacity of each basin is 34 million liters. The dimensions of each basin at the anchor wall are approximately 103 meters by 85 meters. The typical top dimensions of the wetted area are approximately 89 meters by 71 meters, while the bottom dimensions are approximately 57 by 38 meters. Total depth from the top of the dike to the bottom of the basin is approximately 7 meters. The typical finished basin bottoms lie at about 4 meters below the initial grade and 175 meters above sea level. The dikes separating the basins have a typical height of 3 meters and typical top width of 11.6 meters around the perimeter of the impoundments.

For estimating purposes, the proposed feed basins are scale versions of LERF basins. A 50\% reduction in all dimensions $(\mathrm{LxWxH})$ results in $1 / 8$ scale overall, which would result in basins of just under $1 \mathrm{Mgal}$ each. Converting LERF dimensions described above to feet and dividing by two, the associated dimensions of the proposed basins are:

- $\quad$ The dimensions of each basin at the anchor wall are approximately $169 \mathrm{ft}$ by 139 $\mathrm{ft}$.

- The typical top dimensions of the wetted area are approximately $146 \mathrm{ft}$ by $116 \mathrm{ft}$.

- $\quad$ The bottom dimensions are approximately 94 by $62 \mathrm{ft}$.

- Total depth from the top of the dike to the bottom of the basin is approximately 11 $\mathrm{ft}$.

- $\quad$ The typical finished basin bottoms lie at about $7 \mathrm{ft}$ below the initial grade.

- $\quad$ The dike separating the basins has a height of $5 \mathrm{ft}$ and typical top width of $19 \mathrm{ft}$ around the perimeter of the impoundments.

The RCRA permit provides the following details regarding the double-liner and leachate collection system:

The LERF employs a double-composite liner system with a leachate detection, collection, and removal system between the primary and secondary liners. Each basin is constructed with an upper or primary liner consisting of a high-density polyethylene geomembrane laid over a bentonite carpet liner. The lower or secondary liner in each basin is a composite of a geomembrane laid over a layer of soil/bentonite admixture with a hydraulic conductivity less than 10-7 centimeters per second. The synthetic liners extend up the dike wall to a concrete anchor wall that surrounds the basin at the top of the dike. A batten system bolts the layers in place to the anchor wall.

Each basin contains a lined sump, with two risers, one for a submersible pump and the other for level detection. The basins are covered with a floating low density polyethylene liner. Each basin will also be equipped with a submersible pump for transferring aqueous waste out of the basin and a piping/distribution system capable of routing waste to the other basin or over to the SN-700 (or alternatively, SN-701) transfer line. Two lines and two connections to the transfer line are needed [a total of $\sim 400 \mathrm{~m}(1300 \mathrm{ft})$ of pipe]. Spool pieces are acceptable if the project has a lifetime of less than 5 years. Otherwise, a valve pit is required. Plastic or fiberglass double-contained pipe similar to the 242-A PC-5000 line will be adequate.

\section{Chemical addition building}


Hydroxide and nitrite addition is needed prior to sending this stream to the DSTs. A $20 \mathrm{ft}$ by 20 $\mathrm{ft}$ butler building for the $\mathrm{NaOH} / \mathrm{NaNO} 2$ addition system will be required. It will include chemical makeup tanks ( 2 tanks each at 3,000 gal. refilled twice a year), metering pumps $(0-1$ gpm) and inline instrumentation. For purposes of cost estimating, assume an in-line baffled motionless mixer system in the pipeline going back to SN-700, with downstream in-line instrumentation to verify chemical additions.

Approximately 15,000 gal of $8 \mathrm{M} \mathrm{NaOH}$ would need to be added to buffer the entire secondary waste stream $(\sim 12 \mathrm{Mgal})$ to meet the minimum Tank Farms requirements of $0.01 \mathrm{M} \mathrm{OH}$. For planning purposes, 1.5 to 2 times this amount should be used (up to 30,000 gal). Tank waste chemistry requirements are documented in HNF-SD-WM-TSR-006, Tank Farms Technical Safety Requirements, Administrative Control 5.16.

For nitrite, a minimum of $0.011 \mathrm{M}$ is required for dilute waste. Therefore, a similar volume of nitrite would be needed (30,000 gal of $8 \mathrm{M}$ for the entire mission). This level of chemical addition would make the added $\mathrm{NO}_{2}$ and $\mathrm{OH}$ nearly as concentrated as $\mathrm{Cl}$, the most concentrated anion in the stream, and it would approximately double the $\mathrm{Na}$ in the stream.

\section{Discussion of corrosion issues}

Halides are concentrated in this recycle stream relative to existing tank wastes. Although actual chloride and fluoride concentrations will not exceed levels seen in concentrated DST liquids, the $\mathrm{NaOH}$ and $\mathrm{NaNO} 2$ buffers will not be nearly as concentrated as in that found in tank wastes with significant chloride.

For example, the minimum corrosion inhibitor levels of $0.10 \mathrm{M} \mathrm{OH}$ and $0.011 \mathrm{M} \mathrm{NO}_{2}$ apply to dilute waste (where the $\mathrm{NO}_{3}$ is below $1 \mathrm{M}$ ). However, the high chloride concentrations observed in DST liquid samples have generally occurred in concentrated wastes $\left(\mathrm{NO}_{3}>3 \mathrm{M}\right)$. In concentrated wastes, the minimum $\mathrm{OH}$ molarity required is $0.3 \mathrm{M}$ (30 times the level in dilute waste), and the combined $\mathrm{OH}$ and $\mathrm{NO}_{2}$ inhibitor concentrations must exceed $1.2 \mathrm{M}$ (approximately 60 times the level required in dilute waste). The basis document for the corrosion limits (SD-WM-TI-150) does not specify the limits at which chloride was evaluated in corrosion testing. Therefore, this stream is outside of the typical envelope of tank waste compositions, and should be evaluated to ensure that excessive DST corrosion will not occur.

A Savannah River chloride evaluation, WSRC-TR-94-0250, indicated that "corrosive anions act independently, not additively... Pitting corrosion is prevented when the highest nitrite concentration required by any corrosive anion is present in the waste." Based on this, the concentrated waste corrosion limits might be applied to this stream following evaporation. This would require adding at least 3 times as much hydroxide and nitrite as described in the section above.

242-A does not have specific corrosion limits, but relies upon the DST limits (feed and slurry are in compliance with the DST limits). This stream is also raises concerns about 242-A corrosion. Comments regarding Grade 304 stainless steel were extracted from www.axom.com, "Subject to pitting and crevice corrosion in warm chloride environments, and to stress corrosion cracking above about $60^{\circ} \mathrm{C}$. Considered resistant to potable water with up to about $200 \mathrm{mg} / \mathrm{L}$ chlorides at ambient temperatures, reducing to about $150 \mathrm{mg} / \mathrm{L}$ at $60^{\circ} \mathrm{C}$." The current maximum $242-\mathrm{A}$ 
processing temperature is $150^{\circ} \mathrm{F}$ or $65^{\circ} \mathrm{C}$. However, the typical operating temperature is about $130^{\circ} \mathrm{F}$ or $54{ }^{\circ} \mathrm{C}$. Therefore, pitting corrosion is the likely concern.

The $\mathrm{Cl}$ in this stream will be up to $20,000 \mathrm{mg} / \mathrm{L}$ (equivalent units to $\mu \mathrm{g} / \mathrm{mL}$ ) when the stream is concentrated, which is about 100 times the level of concern in water. The stream will be buffered with hydroxide and nitrite, but the inhibitor levels will be much lower than the levels in tank waste with similar chloride concentrations. Therefore, at a minimum, research and development work may be necessary to ensure compatibility of this stream with the 242-A Evaporator. Newer waste evaporators (such as, ETF and the proposed WTP evaporator) are designed with more exotic alloys (Inconel and Incaloy $^{7}$ ), largely because of chloride corrosion concerns.

\section{Dissolution of potential scale}

Although the aluminum and silicon concentrations in the recycle stream data are not elevated, planning for potential deposition of scale in 242-A is prudent. Evaporation of a melter recycle stream at Savannah River resulted in precipitation of aluminosilicate minerals. The forcedcirculation design of 242-A should limit scaling relative to what was experienced at Savannah River. If scaling occurs, it would be expected in the vessel below the deentrainment pads, including the recirculation loop, and reboiler. Scaling on and above the pads is not expected as the pads are continuously pulsed with water or recycled condensate sprays.

Scale might be evident by increased dose rates after draining and flushing, although the radionuclide content of this stream is very low. Scaling will most likely be indicated by decreased performance of the reboiler (higher temperature difference indicating more resistance to heat transfer). Savannah River used two batches of up to $1.5 \mathrm{M}$ nitric acid to dissolve $350 \mathrm{~kg}$ of scale (WSRC-TR-2001-00412). More concentrated acid could be procured and then diluted with water.

De-scaling activities are estimated to take one to two weeks and consist of charging the system with acid and filling to the minimum operating level $(23,500 \mathrm{gal})$; recirculating and heating with steam (under vacuum) for 2 days; reducing the level (by evaporation) to the minimum $(23,500$ gal) and adding concentrated $(19 \mathrm{M})$ caustic sufficient to raise the $\mathrm{pH}$ above 12 . A concentrated caustic volume of approximately 2000 gal would be necessary. Since the upper operating level is 25,500 gal, the caustic might need to be added in two batches. Sampling might be required to confirm that the buffered solution is suitable for release to Tank Farms.

Technical issues to be addressed prior to adding chemicals include modifications to the DSA and criticality safety documentation. Physical plant changes would be minimal. Chemicals could be delivered by hose from a pressurized tanker truck, or added to the decontamination tank (TK-E-104) and pumped into the vessel. This would require reinstalling spool pieces that were removed after chemical additions in 1985.

SD-WM-TI-206, Reboiler Fouling Study was performed in 1985. However, this was focused on dissolution of double-shell slurry solids rather than aluminosilicates, and may not be relevant. Chemical flushes of the evaporator system have been performed, including citric acid and nitric

\footnotetext{
${ }^{7}$ Inconel and Incoloy are registered trademarks of Special Metals Corporation, New Hartford, New York.
} 
acid (SD-WM-PE-027). Piping was modified to recirculate acid from the slurry pump back to the top of the vessel and onto the deentrainer pads for dissolution of scale on the pads (hard water deposits). The acid was neutralized with caustic before dumping to AW-102. As stated above, scaling on the pads is less likely than scaling below the waterline.

\section{Evaluation of Risks}

The 242-A Evaporator is essential to the Tank Farms mission. Previously identified mission risks include that 242-A is an aging facility, and that 242-A is a single-point failure facility (TFC-PLN-039). Actions taken to mitigate risks include periodic upgrades (such as the ongoing ventilation and Monitoring and Control System upgrades) and maintaining a qualified and trained staff. Additional upgrades (such as, water supply, steam and electrical systems) will be necessary at some point during the extended mission. The worst-case impact for a 242 -A singlepoint failure is a 5-year impact to the retrieval and WTP processing schedule $(\$ 4.6$ billion cost impact), plus $\$ 100$ million for a replacement facility.

Processing of the LAW secondary waste stream at 242-A increases risks to the plant. The stream has a higher concentration of chloride (relative to other waste constituents) than historical tank waste streams. Chloride is a major cause of corrosion in 304L stainless steel (which is the material of construction for 242-A). In addition, the recycle stream contains a small fraction of refractory elements, of which aluminum and silicon are a special concern. Aluminosilicates are likely to form scale in the 242-A system and possibly in distribution piping. Scale can affect processing and maintenance by reducing heat transfer rates and increasing dose rates. As aluminosilicate minerals are difficult to dissolve, acid dissolution may be necessary.

The feed staging facility (proposed basins) may be classified as a Hazard Category 3 facility, which would require developing and maintaining an authorized safety basis.

A surface impoundment may not be appropriate or may trigger groundwater monitoring requirements which would increase the cost. Above-ground tanks might ultimately be more appropriate in this application.

Processing of this stream would require modification of RCRA permit. A revised sampling strategy (periodic feed stream samples rather than batch evaluation) would provide more flexibility and could reduce the storage tank volume needed. A revision to the Air Operating Permit might also be necessary prior to processing this stream. Revisiting these documents might result in elimination of grandfathered facility equipment (single-wall slurry line penetrations and limited stack monitoring equipment) resulting in additional facility upgrades.

\section{$\underline{\text { References }}$}

AEM 075, 2008, "Analyze and Predict Secondary Waste Streams and Compare to Acceptance Criteria - Task Order no. 14-Task Scope (BCP-06-03273) subpart 3," (letter from Linda Bergmann to R. A. Burk, Bechtel National, April 14), AEM Consulting, Richland, WA. azom.com, April 28, 2008, "Stainless Steel - Grade 304", http:/www.azom.com/details.asp?ArticleID $=965$.

Hanford Facility RCRA Permit, 2008, Operating Unit 3, Chapter 4, State of Washington Department of Ecology, Olympia, WA. 
RPP-RPT-37924, Rev. 0

HNF-SD-WM-SP-012, 2007, Tank Farm Contractor Operation And Utilization Plan, Rev. 6, CH2M HILL Hanford Group, Inc., Richland, WA.

HNF-SD-WM-TSR-006, 2008, Tank Farms Technical Safety Requirements, Administrative Control 5.16, "Corrosion Mitigation Controls," Rev. 5D,

RPP-RPT-29165, 2006, Evaluation of Solids in 241-AP-108 from 242-A Evaporator Campaigns 04-01 and 05-01, Rev. 0, CH2M HILL Hanford Group, Inc., Richland, WA.

RPP-RPT-33306, 2008, IQRPE Integrity Assessment Report for the 242-A Evaporator Tank System, Rev. 0A, CH2M HILL Hanford Group, Inc., Richland, WA.

SD-WM-PE-027, The 242-A Evaporator/Crystallizer FY 1985 Campaign 85-4 Post-Run Document, Rockwell Hanford Operations, Richland, WA.

SD-WM-TI-150, 1984, Technical Basis For Waste Tank Corrosion Specifications, Rockwell Hanford Operations, Richland, WA.

SD-WM-TI-206, 1985, Reboiler Fouling Study, Rockwell Hanford Operations, Richland, WA.

SVF-1315, 2007, Spreadsheet Supporting 242-A Evaporator Campaign 07-01/07-02 Process Control Plan, CH2M HILL Hanford Group, Inc., Richland, WA.

TFC-PLN-039, 2006, Risk Management Plan, CH2M HILL Hanford Group, Inc., Richland, WA.

Tank Waste Information System Network (TWINS), accessed May 6, 2008, http://twins.pnl.gov/twinsdata/forms/datamenu.htm.

Wagner, V. L., 2008, personal communication, May 12, CH2M HILL Hanford Group, Inc., Richland, WA.

WSRC-TR-94-0250, 2005, Recommended Nitrite Limits for Chloride and Sulfate in ESP Slurries, Rev. 1, Westinghouse Savannah River Company, Aiken, SC.

WSRC-TR-2001-00330, Results of Aluminosilicate Formation Testing, Westinghouse Savannah River Company, Aiken, SC.

WSRC-TR-2001-00412, Results of Chemical Cleaning the 242-16H (2H) Evaporator at the Savannah River Site, Westinghouse Savannah River Company, Aiken, SC. 
RPP-RPT-37924, Rev. 0

\section{APPENDIX F. INTERIM PRETREATMENT SYSTEM SECONDARY WASTE EVAPORATOR}

\subsection{INTRODUCTION}

The Interim Pretreatment System is evaluating alternatives for treating the secondary waste from the WTP LAW Vitrification facility, which consists of the submerged bed scrubber solution and the caustic scrubber solution. The estimated volumetric generation rate for these combined secondary waste streams is 21.6 to 21.9 liters per minute ${ }^{8}$. Treatment alternatives for the secondary waste solutions that are being evaluated include, 1) treatment at the 200 Area Effluent Treatment Facility (ETF), 2) recycle of evaporator bottoms from the ETF to the double-shell tank system, 3) evaporation using the existing 242-A Evaporator, 4) evaporation using a new evaporator system, and 5) removal of ${ }^{99} \mathrm{Tc}$ by ion exchange in a new vault style facility..

The alternative discussed in this section is evaporation of the WTP LAW Vitrification Facility secondary waste solutions using a new evaporator system, referred to as the Secondary Waste Evaporator (SWE) system. The concentrate from SWE system will be transferred to the doubleshell tank system for interim storage and eventual processing in the WTP Pretreatment Facility. The condensate from the SWE system will be transferred to the ETF for treatment and disposal. The SWE system could also be used to concentrate the pretreated LAW solution prior to transfer to the LAW Vitrification Facility. However, this alternative was not evaluated in detail since the composition of the pretreated LAW and the secondary waste solutions would be altered and material balances were not prepared for this alternative by WTP personnel.

The SWE is similar to the Treated Low Activity Waste (LAW) Evaporation Process (TLP system) in the WTP Pretreatment Facility. The major differences are the feeds to be processed by each system. The TLP system is designed to increase the concentration of the pretreated LAW prior to transfer to the LAW vitrification facility and concentrate the SBS condensate recycled from the LAW vitrification facility. The TLP system is designed for processing 10 to $38 \mathrm{gpm}$ of dilute feeds ${ }^{9}$. The SWE system could also perform these functions or may only process the SBS and caustic scrubber solutions.

Given the short duration of this engineering study, it will be assumed that the capacity and materials of construction for the SWE system will be the same as for the TLP system. The SWE system equipment description and capacity is taken from the design media prepared for the TLP system, with the capacity of support vessels recalculated to support the IPS system.

\footnotetext{
8 "Analyze and Predict Early LAW Secondary Waste Streams - Task Order no. 14", Letter \# AEM 075 dated April 14, 2008 from L. Bergman to R. A. Burk, Bechtel National Inc., AEM Consulting, 2417 Mark Avenue, Richland Washington

${ }^{9}$ 24590-PTF-3PS-MEVV-TP001, rev. 2, 2005, River Protection Project-Waste Treatment Plant Engineering Specification for Forced Circulation Vacuum Evaporator System, Bechtel National Inc., Richland Washington
} 
RPP-RPT-37924, Rev. 0

\subsection{PROCESS DESCRIPTION}

The SWE system concentrates the secondary waste solutions from the LAW Vitrification Facility. Some suspended solids are anticipated in the SBS recycle streams to the evaporator. Based on the TLP system description ${ }^{10}$, under normal operating conditions the suspended solids will not exceed $3.4 \mathrm{wt} \%$. The evaporator product concentration is limited to the saturation regions associated with sodium compounds.

The SWE system utilizes a continuous, forced-circulation, vacuum evaporation system to concentrate LAW secondary waste solutions. The concentrate is sent to one of two concentrate storage vessels (SWE-VSL-00003A/B), which collect the concentrate pending sampling, analyses, and transfer to double-shell tank system. The SWE system also provides lag storage capability for the LAW secondary waste solutions. The description of the SWE evaporation system is separated into the following subsections - receipt vessels, evaporator, evaporator overhead equipment, condensate vessel, and system checks.

\subsection{EQUIPMENT DESCRIPTION}

\subsection{RECEIPT VESSELS}

The two LAW secondary waste solutions receipt vessels (SWE-VSL-00001A/B), each with a batch volume of 28,000 gallons (total capacity 36,600 gallons each), receive LAW secondary waste solutions at an average rate of 22-lpm. LAW secondary waste solutions are transferred from the LAW vitrification facility to the SWE facility through existing pipeline SN-701, which is installed within an underground trench (see Section 0). Following a transfer, the line is flushed with water. The transfer pipeline is coaxial to detect and contain any leaks. The leak detection system is designed to meet three requirements - containment and detection of liquid, ability to pressure test for pipe integrity, and the capability to flush any waste from the containment system within 24 hours.

The capacity of the SBS condensate and caustic scrubber collect vessels in the LAW Vitrification Facility are 16,000 and 10,000-gallons, respectively. The contents of these vessels are transferred from once every 24-hours to once every 48-hours to one of the SWE LAW secondary waste solutions receipt vessels. The transfer frequency depends on the concentration of the pretreated LAW solution fed and operating parameters of the LAW melter offgas system. The average volumetric flowrate of the combined secondary waste is an estimated $22-1 \mathrm{pm}^{11}$. The two LAW secondary waste solutions receipt vessels have been sized to each receive the contents of the SBS condensate and caustic scrubber collection vessels plus a pipeline flush of 2,000gallons (see Appendix A).

\footnotetext{
${ }^{10}$ 24590-PTF-3YD-TLP-00001, Rev 0, September 11, 2002, System Description for Treated LAW Evaporation Process (TLP), Waste Treatment Plant, Bechtel, Richland Washington.

11 "Analyze and Predict Early LAW Secondary Waste Streams - Task Order no. 14", Letter \# AEM 075 dated April 14, 2008 from L. Bergman to R. A. Burk, Bechtel National Inc., AEM Consulting, 2417 Mark Avenue, Richland Washington
} 
The receipt vessels will alternate duty. One vessel receives LAW secondary waste solutions and adds $5 \mathrm{M}$ caustic $(\mathrm{NaOH})$ to adjust the $\mathrm{pH}$ as needed. A remote sampling device is used to sample for $\mathrm{pH}$ and determine adjustments necessary. The second vessel will feed the evaporator system using variable-speed feed pumps (SWE-PMP-00005A/B) which are controlled by level indication in the evaporator separator vessel. The vessels will switch duties as needed to keep a continuous feed flow to the evaporator.

Each vessel is equipped with blade-style mixers that blend and maintain solids suspension in the waste. Both vessels are also equipped with temperature, density, and level instrumentation for process monitoring. The two receipt vessels (SWE-VSL-00001A/B) will overflow to a lined sump in the SWE process building. If required, the vessel heel volumes are emptied with emptying ejectors which are external to the vessel. For purposes of decontamination, each vessel is equipped with wash rings.

\subsection{EVAPORATOR}

The feed into the treated SWE evaporator is at the suction side of the recirculation pump (SWE-PMP-00001). The LAW secondary waste solutions is transferred from one of two vessels (SWE-VSL-00001A/B) using the variable-speed pumps (SWE-PMP-00005A/B). These pumps have a design capacity of $70 \mathrm{gpm}^{12}$ and a nominal operating rate of $\sim 13 \mathrm{gpm}$.

The recirculation pump (SWE-PMP-00001) moves the liquor through the evaporator recirculation loop maintaining a high flow rate $(\sim 11,000$-gpm $)$ through the reboiler ${ }^{13}$. The liquor is pumped through the reboiler (SWE-RBLR-00001) which affects a small temperature rise in the fluid. The reboiler has a process design duty of $\sim 1.835 \mathrm{E}+07 \mathrm{BTU} / \mathrm{hr}^{14}$. Re-circulating liquor is prevented from boiling in the reboiler tubes by maintaining sufficient hydrostatic head to increase the boiling point above the temperature of the bulk liquor in the separator vessel. Low pressure steam, modulated via a flow controller, is used to heat the feed liquor to the selected system boil-off rate. Low pressure steam, available at $40 \mathrm{psig}$ and $286^{\circ} \mathrm{F}$, is supplied from a packaged boiler system.

The heated waste is then discharged to the separator vessel (SWE-SEP-00001) ${ }^{15}$. When the re-circulating liquor reaches the separator vessel, flash evaporation occurs due to a reduced pressure in the vessel. The liquid continues to flash, separating the vapor and liquid streams. The liquid stream re-circulates in this closed loop while the vapor stream enters the primary condenser.

\footnotetext{
12 24590-PTF-MPD-TLP-00009, revision 1, December 27, 2005, Mechanical Data Sheet ASME/ANSI General Centrifugal Pump - Feed Pump for Treated LAW Evaporator System, Waste Treatment Plant, Bechtel, Richland Washington

${ }^{13}$ 24590-PTF-MPD-TLP-00007, revision 1, December 27, 2005, Mechanical Data Sheet API 610 Axial Flow Pump - Recirculation Pump for Treated LAW Evaporator System, Waste Treatment Plant, Bechtel, Richland Washington ${ }^{14}$ 24590-PTF-MED-RBLR-00001, March 24, 2004, Mechanical Data Sheet Shell and Tube Heat ExchangerTreated LAW Evaporator Reboiler, Waste Treatment Plant, Bechtel, Richland Washington ${ }^{15}$ 24590-PTF-MVD-TLP-00005, revision 4, March 28, 2007, Mechanical Data Sheet: Vessel - Treated LAW Evaporator Separator Vessel TLP-SEP-00001, Waste Treatment Plant, Bechtel, Richland Washington
} 
The pressure in the separator vessel is maintained at $\sim 1 \mathrm{psia}(\sim 27.7 \mathrm{WC})$ by a vacuum system which pulls a vacuum through the primary condenser. This reduced pressure lowers the boiling point of the bulk liquor to about $122^{\circ} \mathrm{F}$. If the pressure in the separator vessel changes, the air inbleed is adjusted to change the vapor withdrawal rate from the separator vessel. This modulation of the air-bleed maintains a uniform pressure and boiling point in the separator vessel. Vacuum control air is withdrawn from the process vessel ventilation.

The overhead vapor produced in the separator vessel is superheated by $\sim 24^{\circ} \mathrm{F}$ due to the boiling point rise through the reboiler. The overhead vapor is passed through a set of demister pads for deentrainment purposes. The demister pads are sprayed with process condensate from the condensate vessel to de-superheat the vapor and ensure that the demister pads are always wetted completely to mitigate solids formation, plugging and scrubbing of aerosols.

The SWE evaporator will concentrate the waste to a maximum specific gravity of $\sim 1.45$ to be consistent with the 242-A Evaporator process limits. Concentrate is removed from the treated LAW evaporator at the lowest point on the suction side of the recirculation pump using the variable-speed evaporator concentrate pumps (SWE-PMP-00011A/B). The concentrate pumps have a process design rate of $\sim 50 \mathrm{gpm}^{16}$. The speed of the evaporator concentrate pumps is controlled by the density indicator within the separator vessel. The SWE evaporation system will achieve steady-state when the feed and concentrate rates remain constant. The concentrate storage vessels (SWE-VSL-00003A/B) store the concentrate prior to sampling, analyses, and transfer to double-shell tank system.

\subsection{PRIMARY CONDENSER}

The de-entrained vapor and non-condensable gases enter the SWE evaporator primary condenser (SWE-COND-00001). The primary condenser is designed to provide condensation of process vapors generated by evaporation of the waste. This minimizes vapor carry-over by noncondensable gases to the vacuum ejectors. Condensate is gravity drained to the evaporator condensate vessel (SWE-VSL-00002). A seal loop and dip-leg submergence will maintain drain hydraulics adjusting for the pressure gradient in the condenser system. The condensate can also be diverted back to the separator vessel for reflux operation.

The process design rates for the primary condenser is a cooling duty of $\sim 1.71 \mathrm{E}+07 \mathrm{BTU} / \mathrm{hr}$ and a cooling water volume requirement of $\sim 1,300 \mathrm{gpm}^{17}$. The cooling water (raw water) is supplied at a mean pressure of $60 \mathrm{psig}$ and maximum inlet temperature of $75^{\circ} \mathrm{F}$. The cooling water discharge line is monitored in the SWE system for radioactivity, flow and temperature.

\footnotetext{
${ }^{16}$ 24590-PTF-MPD-TLP-00008, revision 1, December 27, 2005, Mechanical Data Sheet ASME/ANSI General Centrifugal Pump - Concentrate Pump for Treated LAW Evaporator System, Waste Treatment Plant, Bechtel, Richland Washington

${ }^{17}$ 24590-PTF-MED-TLP-00001, revision 1, April 5, 2005, Mechanical Data Sheet Shell and Tube Heat Exchanger - Treated LAW Primary Condenser, Waste Treatment Plant, Bechtel, Richland Washington
} 
RPP-RPT-37924, Rev. 0

\subsection{EJECTORS, INTER-CONDENSER AND AFTER-CONDENSER}

Steam motivated ejectors generate the vacuum enabling boiling at approximately $122^{\circ} \mathrm{F}$. The first ejector uses high pressure steam (125 psig) to pull a vacuum off the primary condenser thereby creating the vacuum for removing the steam and non-condensable gases from the evaporator system. The ejector discharges its steam and the non-condensable gases to the SWE evaporator inter-condenser (SWE-COND-00003) ${ }^{18}$ which condenses these gases. The condensate drains from the inter-condenser to the condensate vessel (SWE-VSL-00002).

A second ejector draws the non-condensable gases from the inter-condenser augmenting the function of the first ejector. The second ejector discharges its steam and the non-condensable gases to the SWE evaporator after-condenser (SWE-COND-00002) ${ }^{19}$, which condenses steam from the second ejector. The after-condenser condensate also drains to the condensate vessel.

The steam duty required for the ejectors is $\sim 1500 \mathrm{lb} / \mathrm{hr}$. The vessel vent system draws the noncondensable gases from the after-condenser through the treated LAW evaporator demister (SWE-DMST-00001) $^{20}$. This vessel contains demister pads to remove any water entrained in the non-condensable gases. The water from the demister drains to the condensate vessel.

\subsection{CONDENSATE VESSELS}

Condensate from the condensers and demister all drain to a common condensate collection vessel, SWE-VSL-00002 $2^{21}$. As the condensate vessel fills, the condensate pump $(\mathrm{SWE}-\mathrm{PMP}-00002 \mathrm{~A} / \mathrm{B})^{22}$ re-circulates condensate continuously back to the vessel with a portion recycled to the separator vessel for spraying the de-entrainment pads. When the condensate vessel is filled to its high level set-point, the condensate is directed to the clean condensate vessels (SWE-VSL-00006A/B/C). If the condensate vessel requires makeup water to maintain the dip-leg liquid seal in the vessel, it is supplied from SWE-VSL-00006A/B/C.

The condensate draining from the primary condenser is monitored for radioactivity. The radiation monitor is located close to the condenser condensate outlet to allow a time lag before any contaminated condensate can reach the condensate vessel. This minimizes the possibility that contaminated condensate can be transferred to clean condensate vessels and the Liquid Effluent Retention Facility/200 Area ETF. In the event that the radiation monitor detects high activity, the evaporator is placed into a reflux state and the condensate vessel is isolated so that a sample may be retrieved. A remote sampling point is located on the discharge side of the

\footnotetext{
${ }^{18}$ 24590-PTF-MED-TLP-00002, revision 2, April 5, 2005, Mechanical Data Sheet Shell and Tube Heat Exchanger - Treated LAW Evaporator Inter-Condenser, Waste Treatment Plant, Bechtel, Richland Washington

19 24590-PTF-MED-TLP-00003, revision 1, April 5, 2005, Mechanical Data Sheet Shell and Tube Heat Exchanger

- Treated LAW Evaporator After-Condenser, Waste Treatment Plant, Bechtel, Richland Washington

${ }^{20}$ 24590-PTF-MV-TLP-DMST-00001, June 12, 2002, Mechanical Data Sheet: Vessel - Treated LAW Evaporator

Demister TLP-DMST-00001, Waste Treatment Plant, Bechtel, Richland Washington

${ }^{21}$ 24590-PTF-MVD-TLP-00004, May 27, 2007, Mechanical Data Sheet: Vessel - Treated LAW Evaporator Condensate Vessel TLP-VSL-00002, Waste Treatment Plant, Bechtel, Richland Washington

22 24590-PTF-MPD-TLP-00010, revision 1, December 27, 2005, Mechanical Data Sheet ASME/ANSI General Centrifugal Pump - Treated LAW Evaporator Process Condensate Pump, Waste Treatment Plant, Bechtel, Richland Washington
} 
condensate pump. If the condensate is contaminated, it is manually redirected to the SWE secondary waste solutions receipt vessels (SWE-VSL-00001A/B).

\subsection{SECONDARY WASTE RETURN PIPELINE FROM WTP}

The WTP could use either pipeline SN-700 or SN-701 to return secondary wastes from the LAW Vitrification Facility to the SWE system. Pipelines SN-700 and SN-701 are in the same trench and are about the same length. These pipelines have not been used. It is assumed one of these pipelines would be used to transfer pretreated LAW (SN-700) to the WTP LAW Vitrification facility while the other (SN-701) is used to transfer the secondary waste. Each is a coaxial pipeline consisting of an inner 3-inch diameter pipe (code M-9) and an outer 6-inch diameter pipe (code M-26a) encasement. Drawing H-14-10490123, sheets 1 through 9 depict the 3-inch diameter pipeline SN-701 from the 241-AP-02D pump pit to the WTP site.

While the site location has not been selected, it is assumed for cost estimating purposes that the secondary waste evaporator system is located on the north side of $4^{\text {th }}$ Street, east of the 207-A retention basins at coordinates N 136136, E 575800. Pipeline SN-701 traverses west to east along the south side of this proposed location for the SWE system. It is assumed that pipeline $\mathrm{SN}-701$ is severed and two new 100- $\mathrm{ft}$ segments (200- $\mathrm{ft}$ total) of coaxial pipeline are installed in a trench from both segments of pipeline SN-701 to the SWE system location. A new concrete epoxy coated pit will contain the terminus of the new pipeline segments for connection to the SWE system. Two new jumpers will be installed in this pit to connect the two new segments of coaxial pipeline to the SWE system. The $200-\mathrm{ft}$ of new coaxial pipeline will consist of an inner 3-inch diameter pipe (code M-9) and an outer 6-inch diameter pipe (code M-26a) encasement; same as the existing SN-701 pipeline. After the SWE system has completed it mission, the two segments of the SN-701 pipeline can be reconnected for service from the 241-AP-02D pump pit to the WTP site. Alternatively, valves installed in jumpers could be used to either connect pipeline SN-701 to the SWE system or the WTP.

\subsection{PROCESS CONDENSATE PIPELINE TO LIQUID EFFLUENT RETENTION FACILITY (LERF)}

Condensate from the clean condensate vessels (SWE-VSL-00006A/B/C) is transferred through a direct-buried coaxial pipeline to the existing LERF basins in the 200-East Area. The coaxial pipeline from vessels SWE-VSL-00006A/B consists of an inner 3-inch diameter fiberglass reinforced epoxy resin (FRER) pipe and an outer 6-inch diameter FRER pipe (both pipe code $\mathrm{M}-17)$. The pipeline is equipped with a leak detection system similar to that installed as part of Project W-5 $19^{24}$.

The condensate pipeline from the secondary waste evaporator system will connect to the existing 3 -inch diameter condensate pipeline for use by the WTP (pipeline 3"-WTP-002-M17) at

\footnotetext{
${ }^{23}$ H-14-104901 sheet 1, revision 1, 2003, Piping Support Plan 3" SN-701-M9, U.S. Department of Energy Richland Operations Office, Richland Washington

${ }^{24}$ H-2-830108, revision 1, 2001, W-519 Site / Utility Systems Leak Detection Details, U.S. Department of Energy

Richland Operations Office, Richland Washington
} 
coordinates N 136136, E 575800, which is shown on drawing H-2-830095 25 . The 3"WTP-002-M17 pipeline connects to the existing underground pipeline from the 242-A Evaporator to the LERF basins, as shown on drawing H-2-830093 ${ }^{26}$. A Y-pipeline connection with valves will be installed along with a fiberglass encasement man-way to access these valves, similar to that shown on H-2-830102, sheet 2, detail 4. The Y-pipeline connection will enable connection/isolation of the condensate pipeline from the secondary waste evaporator system and the future condensate pipeline from the WTP to the 3"-WTP-002-M17 pipeline.

While the site location has not been selected, it is assumed for cost estimating purposes that the secondary waste evaporator system is located on the north side of $4^{\text {th }}$ Street, east of the 207-A retention basins at coordinates N 136136, E 575800. An estimated 600 feet of direct buried coaxial pipeline will need to be installed from this site location to join with the 3"-WTP-002M17 pipeline at coordinates N 136136, E 575800.

\subsection{STEAM CONDENSATE AND COOLING WATER DISPOSAL}

The cooling water from the three condensers and the steam condensate is discharged via an underground pipeline to the Treat Effluent Disposal Facility (TEDF). The cooling water/steam condensate pipeline from the SWE system will connect to the existing Line J pipeline for use by the WTP at approximately coordinates N 136136, E 575800, which is shown on drawing $\mathrm{H}-2-830095^{27}$. This is the same location as the 3"-WTP-002-M17 pipeline connection for the process condensate (see Section 0).

The Line J pipeline connects to the existing underground Line $\mathrm{H}$ pipeline for TEDF waste streams, as shown on drawing H-2-830102, sheet 3 , detail $9^{28}$ and $\mathrm{H}-2-140342$, sheet $1^{29}$. The Line J pipeline is a direct buried 8-inch DN200 PVC pipe (AWWA C900 pipe code P-1) and is not encased. A Y-pipeline connection with valves will be installed along with a fiberglass encasement man-way to access these valves, similar to that shown on H-2-830102, sheet 2, detail 4. The Y-pipeline connection will enable connection/isolation of the pipeline from the SWE system and the future condensate pipeline from the WTP to the Line J pipeline.

While the site location has not been selected, it is assumed for cost estimating purposes that the secondary waste evaporator system is located on the north side of $4^{\text {th }}$ Street, east of the 207-A retention basins at coordinates N 135550, E 575800. An estimated 600 feet of direct-buried 8inch DN200 PVC pipe will need to be installed from this site location to join with the Line J pipeline at coordinates N 136136, E 575800. The same excavation will be used to install the process condensate (LERF) and steam condensate/cooling water (TEDF) pipelines.

\footnotetext{
${ }^{25} \mathrm{H}-2-830095$, revision 2, 2001, W-519 Site / Utility Systems Plan and Profile STA $0+800$ to STA $1+200$, U.S. Department of Energy Richland Operations Office, Richland Washington

${ }^{26}$ H-2-830093, revision 1, 2001, W-519 Site / Utility Systems Title Sheet, Dwg List \& General Notes, U.S. Department of Energy Richland Operations Office, Richland Washington

${ }^{27} \mathrm{H}-2-830095$, revision 2, 2001, W-519 Site / Utility Systems Plan and Profile STA $0+800$ to STA $1+200$, U.S. Department of Energy Richland Operations Office, Richland Washington

${ }^{28}$ H-2-830102, sheet 3, revision 1, 2001, W-519 Site / Utility Systems Piping Sections \& Details, U.S. Department of Energy Richland Operations Office, Richland Washington

${ }^{29} \mathrm{H}-2-140342$, sheet 1, revision 2, Civil Line H STA 0+00 to STA 32+23, U.S. Department of Energy Richland Operations Office, Richland Washington
} 


\subsection{CHILLED WATER SUPPLY}

A closed-loop chilled water system supplies water to the SWE building ventilation system at an estimated 200-gpm, based on the chilled water supply to the 242-A Evaporator building ventilation system ${ }^{30}$.

\subsection{MATERIAL BALANCE}

The composition of the candidate LAW solutions to the IPS was estimated in SVF-1484, IPS DST Feed Calc. WTP project personnel used this estimated IPS feed compositions to estimate the composition of the secondary waste solution generated from processing these candidate feeds ${ }^{31}$. The estimated compositions of the secondary waste solutions were then fed to an evaporation simulation to estimate the composition of the evaporator bottoms (concentrate) and overheads (condensate), as detailed in Appendix B. Tables B-7 through B-10 in Appendix B provided the estimated compositions of the condensate and concentrate streams generated from processing the WTP secondary waste solutions in the SWE system.

\subsection{VESSEL SIZING AND ASSUMPTIONS}

Table F-1 summarizes the size and materials of construction for the major equipment of the SWE system. The SWE system equipment and vessels materials of construction, dimensions, and capacities are taken from the design media prepared for the TLP system, with the exception of the capacities for the LAW secondary waste solutions receipt vessels (SWE-VSL-00001A/B), concentrate vessels (SWE-VSL-00003A/B), and clean condensate vessels (SWE-VSL-00006A/B/C). The capacities of these vessels were recalculated based on assumptions for the Interim Pretreatment System. The major changes in assumptions are the TLP system uses pulse-jet mixing whereas the IPS will use mechanical agitators, resonance time for sample analyses, and vessel working capacity, as listed in Table F-2. These assumptions are based on best engineering practices and will be validated during further design activities for the Interim Pretreatment System.

The capacity for each LAW secondary waste solutions receipt vessel (SWE-VSL-00001A/B) is based on receiving the entire inventories of submerged bed scrubber solution, the caustic scrubber solution and the flush volume for the transfer pipeline from the WTP LAW Vitrification facility to the proposed IPS site. The combined volume of these three streams is 28,000 gallons. Using the vessel sizing assumptions in Table F-2, the total volume of each LAW secondary waste solutions receipt vessel is $\sim 36,600$ gallons.

The capacity of each concentrate vessel (SWE-VSL-00003A/B) is based on receiving concentrate for 24-hours and the vessel sizing assumptions in Table F-2. As shown in Appendix $\mathrm{B}$, Table B-9, the volumetric generation rate of concentrate is approximately $1.5 \mathrm{Lpm}$. The

\footnotetext{
${ }^{30} \mathrm{H}-2-830594$, rev. 0, 2007, 242-A Evaporator HVAC Chilled Water P \& ID, U. S. Department of Energy Office of River Protection, Richland Washington

31 "Analyze and Predict Early LAW Secondary Waste Streams - Task Order no. 14", Letter \# AEM 075 dated April 14, 2008 from L. Bergman to R. A. Burk, Bechtel National Inc., AEM Consulting, 2417 Mark Avenue, Richland Washington
} 
operating volume and total capacity of each concentrate vessel is therefore 570 -gallons and 750 gallons.

Three clean condensate vessels (SWE-VSL-00006A/B/C) are utilized in the secondary waste evaporator system. One vessel is normally being filled with clean condensate, the second vessel is being sampled / analyzed, and the third vessel is transferring its contents to the LERF basins. These three vessels are sized to receive the condensate flowrate of an estimated $241 \mathrm{pm}$ for a 24hour period, using the assumption in Table F-2. The average condensate flowrate is calculated in Appendix B, Table B-3.

\subsection{FACILITY ARRANGEMENT}

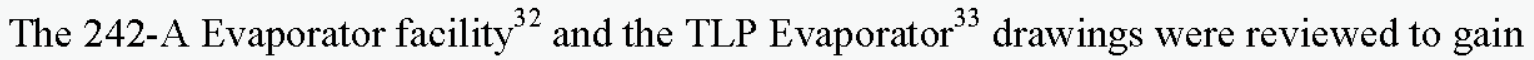
insight into potential arrangement of process equipment for the SWE system. Based on review of these drawings, a preliminary arrangement of the SWE system was selected, as shown in. The dimensions of the 242-A Evaporator building were generally used, with the exception of the process equipment area width and length was increased from $24 \mathrm{ft}(\mathrm{W})$ to $33 \mathrm{ft}(\mathrm{W})$ and $75 \mathrm{ft}(\mathrm{L})$ to $118 \mathrm{ft}$ (L) to incorporate the Secondary Waste Solutions Receipt Vessels within the SWE system building. The 242-A Evaporator building does not contain similar vessels and uses a doubleshell tank as the feed vessel. The area from the control room, motor control centers, change rooms was also enlarged from approximately $42 \mathrm{ft}(\mathrm{W}) \times 36 \mathrm{ft}(\mathrm{L}) \times 11 \mathrm{ft}(\mathrm{H})$ for the $242-\mathrm{A}$ Evaporator building to $75 \mathrm{ft}(\mathrm{W}) \times 118 \mathrm{ft}(\mathrm{L}) \times 12 \mathrm{ft}(\mathrm{H})$ for the SWE system. This change was made to remedy the congestion experienced in these areas within the 242-A Evaporator building. Similarly, the area of the Aqueous Make-up/HVAC systems was enlarged from approximately $25 \mathrm{ft}(\mathrm{W}) \times 50 \mathrm{ft}(\mathrm{L}) \times 47 \mathrm{ft}(\mathrm{H})$ for the 242 -A Evaporator building to $25 \mathrm{ft}(\mathrm{W}) \times 93 \mathrm{ft}(\mathrm{L}) \times 47 \mathrm{ft}(\mathrm{H})$ for the SWE system to remedy congestion in this area as well.

Additionally, the SWE system includes an exterior storage location and a reinforced concrete basin for containment of the three Clean Condensate Vessels. The 242-A Evaporator, which does not include clean condensate vessels, discharges to the LERF basins.

\footnotetext{
${ }^{32}$ H-2-69269, revision 1, 1976, Architectural ${ }^{\text {st }}$ Floor Plan - 242-A; H-2-69270, revision 2, 1977, Architectural $2^{\text {nd }}$ Floor Plan - 242-A; H-2-69271, revision 1, 1976, Architectural Floor Plan - 242-A, H-2-69272, revision 2, 19776, Architectural Elevations \& Sections - 242-A, U. S. Atomic Energy Commission Richland Operations Office, Richland Washington

33 24590-PTF-3PS-MEVV-TP001, rev. 2, 2005, River Protection Project-Waste Treatment Plant Engineering Specification for Forced Circulation Vacuum Evaporator System, Bechtel National Inc., Richland Washington
} 
Figure F-1. Preliminary Concept for Secondary Waste Evaporator Building Arrangement.

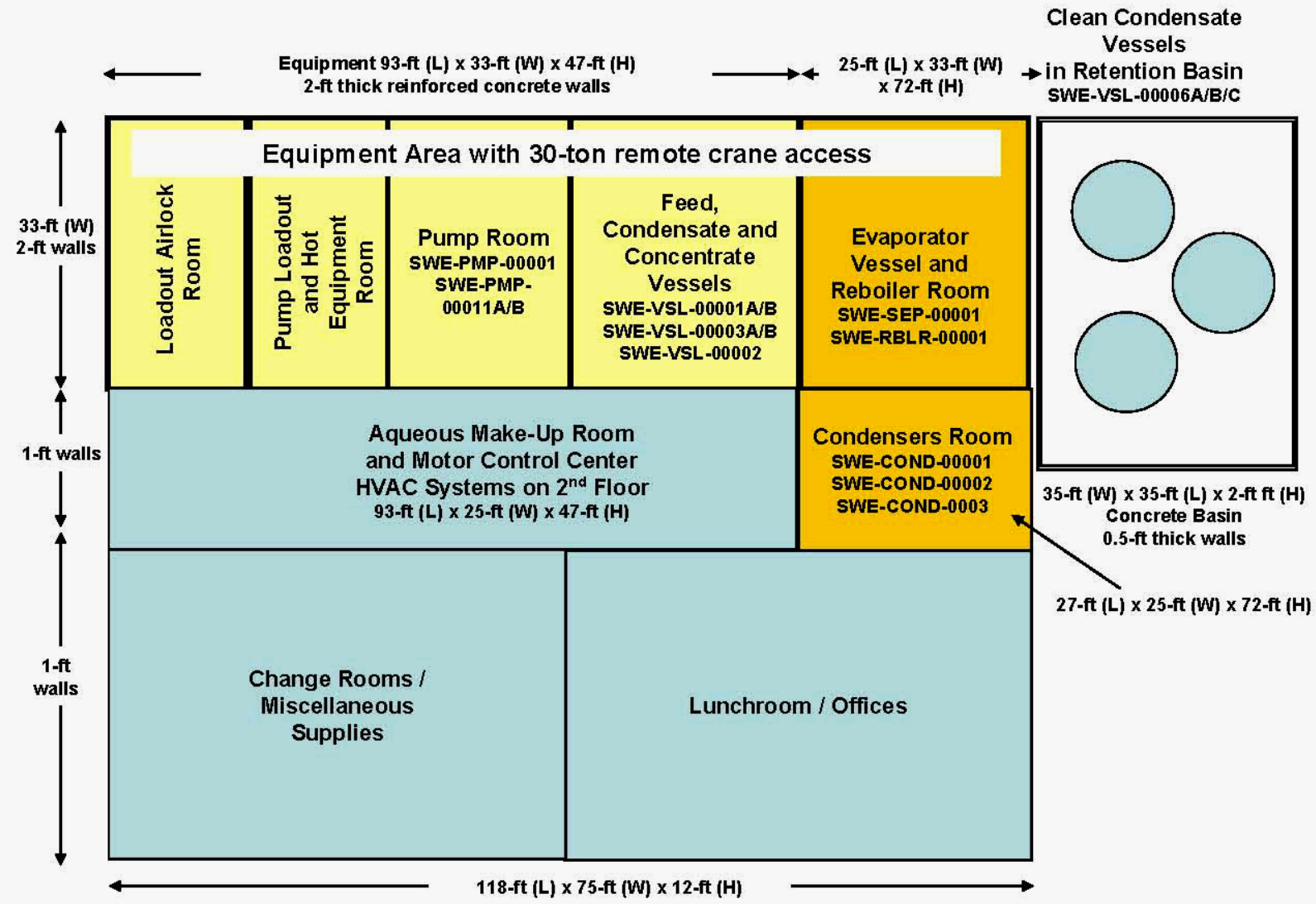


RPP-RPT-37924, Rev. 0

Table F-1. SWE Process Equipment Summary - ASME VIII Division I Vessels.

\begin{tabular}{|c|c|c|c|c|c|}
\hline Name & Description & Dimensions & Capacity & $\begin{array}{l}\text { Materials of } \\
\text { Construction }\end{array}$ & Reference \\
\hline $\begin{array}{l}\text { SWE-VSL- } \\
00001 \mathrm{~A} / \mathrm{B}\end{array}$ & $\begin{array}{l}\text { (2) Secondary } \\
\text { Waste Solutions } \\
\text { Receipt Vessels }\end{array}$ & $\begin{array}{c}\text { 176-inch ID } \\
\text { 350-inch height } \\
5 / 8 \text {-inch thick } \\
\text { shell and top head } \\
1 / 2 \text {-inch thick } \\
\text { bottom head }\end{array}$ & $\begin{array}{c}\text { Maximum } \\
\text { operating } \\
\text { volume: } 28,000- \\
\text { gal each } \\
\text { Total volume: } \\
36,600 \text {-gal each }\end{array}$ & 304L SS & $\begin{array}{c}\text { Table } \\
\text { assumptions. }\end{array}$ \\
\hline $\begin{array}{l}\text { SWE-VSL- } \\
00003 \mathrm{~A} / \mathrm{B}\end{array}$ & $\begin{array}{l}\text { (2) Concentrate } \\
\text { Vessels }\end{array}$ & $\begin{array}{c}\text { 48-inch ID } \\
96 \text {-inch height } \\
5 / 8 \text {-inch thick } \\
\text { shell and top head } \\
1 / 2 \text {-inch thick } \\
\text { bottom head }\end{array}$ & $\begin{array}{c}\text { Maximum } \\
\text { operating } \\
\text { volume: } 570 \text {-gal } \\
\text { each } \\
\text { Total volume: } \\
750 \text {-gal each }\end{array}$ & & $\begin{array}{c}\text { 1.5-lpm of clean } \\
\text { condensate (see } \\
\text { Table B-9) and } \\
\text { Table } \\
\text { assumptions. }\end{array}$ \\
\hline $\begin{array}{c}\text { SWE-PMP- } \\
00005 \mathrm{~A} / \mathrm{B}\end{array}$ & $\begin{array}{l}\text { Variable-speed } \\
\text { feed pumps to } \\
\text { suction side of the } \\
\text { SWE Evaporator } \\
\text { recirc. pump }\end{array}$ & $\mathrm{N} / \mathrm{A}$ & 70-gpm & $316 \mathrm{SS}$ & $\begin{array}{l}\text { 24590-PTF- } \\
\text { MPD-TLP- } \\
00009\end{array}$ \\
\hline $\begin{array}{l}\text { SWE-PMP- } \\
00001\end{array}$ & $\begin{array}{l}\text { SWE evaporator is } \\
\text { at the suction side } \\
\text { of the recirc. } \\
\text { pump }\end{array}$ & $\mathrm{N} / \mathrm{A}$ & 11,000-gpm & $\begin{array}{c}\text { Incoloy } 25- \\
6 \% \mathrm{Mo}\end{array}$ & $\begin{array}{l}\text { 24590-PTF- } \\
\text { MPD-TLP- } \\
00007\end{array}$ \\
\hline $\begin{array}{c}\text { SWE-RBLR- } \\
00001\end{array}$ & $\begin{array}{l}\text { SWE Evaporator } \\
\text { Reboiler }\end{array}$ & $\begin{array}{c}72 \times 72 \times 180 \text {-inch } \\
72 \text {-inch ID shell } \\
822 \text { tubes, } 1.5- \\
\text { inch OD } \\
\text { heat exchanger } \\
\text { with } 2582 \text { - } \mathrm{ft}^{2} \text { of } \\
\text { surface area }\end{array}$ & $\begin{array}{c}1.835 \mathrm{E}+07 \\
\mathrm{BTU} / \mathrm{hr}\end{array}$ & $\begin{array}{c}\text { 304L SS } \\
\text { (shell) } \\
\text { Alloy G-30 } \\
\text { seamless for } \\
\text { tubes }\end{array}$ & $\begin{array}{l}\text { 24590-PTF- } \\
\text { MED-TLP- } \\
\text { P0004 }\end{array}$ \\
\hline $\begin{array}{l}\text { SWE-SEP- } \\
00001\end{array}$ & $\begin{array}{l}\text { SWE Evaporator } \\
\text { Separator Vessel }\end{array}$ & $\begin{array}{c}\text { Diameter } \\
\text { Upper Section: } \\
7.5-\mathrm{ft} \\
\text { Lower Section: } \\
11.5-\mathrm{ft} \\
\text { Height: } 33-\mathrm{ft} \\
10.75 \text {-inch } \\
\text { Includes two } \\
\text { demister pads and } \\
\text { three bubble cap } \\
\text { trays }\end{array}$ & $\begin{array}{l}\text { Max. Operating } \\
\text { Volume: } 3,341- \\
\quad \text { gal } \\
\text { Total Volume: } \\
\text { 13,359-gal }\end{array}$ & $304 \mathrm{SS}$ & $\begin{array}{c}\text { 24590-PTF- } \\
\text { MVD-TLP- } \\
00005 \\
\text { 24590-QL- } \\
\text { POA-MEVV- } \\
\text { 00001-02-00079 } \\
\text { rev. 0B }\end{array}$ \\
\hline $\begin{array}{c}\text { SWE-DMST- } \\
00001\end{array}$ & Offgas Demister & N/A & N/A & 304L SS & $\begin{array}{c}\text { 24590-PTF- } \\
\text { MV-TLP- } \\
\text { DMST-00001 }\end{array}$ \\
\hline $\begin{array}{c}\text { SWE- } \\
\text { PMP-00011A/B }\end{array}$ & $\begin{array}{l}\text { Variable-speed } \\
\text { evaporator } \\
\text { concentrate pumps }\end{array}$ & N/A & 50-gpm & $316 \mathrm{SS}$ & $\begin{array}{l}\text { 24590-PTF- } \\
\text { MPD-TLP- } \\
00008\end{array}$ \\
\hline
\end{tabular}


RPP-RPT-37924, Rev. 0

\begin{tabular}{|c|c|c|c|c|c|}
\hline Name & Description & Dimensions & Capacity & $\begin{array}{c}\text { Materials of } \\
\text { Construction } \\
\end{array}$ & Reference \\
\hline $\begin{array}{c}\text { SWE-COND- } \\
00001\end{array}$ & $\begin{array}{l}\text { SWE Evaporator } \\
\text { Primary } \\
\text { Condenser }\end{array}$ & $\begin{array}{c}115.75 \times 68 \times 263- \\
\text { inch } \\
57-\text { inch ID shell } \\
1,157 \text { tubes, } 1- \\
\text { inch OD } \\
\text { 8-Pass heat } \\
\text { exchanger with } \\
3795-\mathrm{ft}^{2} \text { of surface } \\
\text { area }\end{array}$ & $\begin{array}{c}1.71 \mathrm{E}+07 \\
\mathrm{BTU} / \mathrm{hr} \\
1,300 \text {-gpm water } \\
\text { supply at } 75^{\circ} \mathrm{F} \\
\text { and } 60 \mathrm{psia}\end{array}$ & $316 \mathrm{SS}$ & $\begin{array}{l}\text { 24590-PTF- } \\
\text { MED-TLP- } \\
00001\end{array}$ \\
\hline $\begin{array}{l}\text { SWE-COND- } \\
00003\end{array}$ & $\begin{array}{l}\text { SWE Evaporator } \\
\text { Inter-Condenser }\end{array}$ & $\begin{array}{c}20 \times 12.625 \times 85- \\
\text { inch } \\
8 \text {-inch OD shell } \\
43 \text { tubes, } 0.75- \\
\text { inch OD } \\
\text { heat exchanger } \\
\text { with } 50.7-\mathrm{ft}^{2} \text { of } \\
\text { surface area }\end{array}$ & $\begin{array}{c}4.36 \mathrm{E}+05 \\
\mathrm{BTU} / \mathrm{hr} \\
65 \text {-gpm water } \\
\text { supply at } 75^{\circ} \mathrm{F} \\
60 \text {-psia }\end{array}$ & $316 \mathrm{SS}$ & $\begin{array}{l}\text { 24590-PTF- } \\
\text { MED-TLP- } \\
00002\end{array}$ \\
\hline $\begin{array}{c}\text { SWE-COND- } \\
00002\end{array}$ & $\begin{array}{l}\text { SWE Evaporator } \\
\text { After-Condenser }\end{array}$ & $\begin{array}{c}18 \times 10.75 \times 69- \\
\text { inch } \\
6 \text {-inch OD shell } \\
19 \text { tubes, } 0.75- \\
\text { inch OD } \\
\text { heat exchanger } \\
\text { with } 14.9-\mathrm{ft}^{2} \text { of } \\
\text { surface area }\end{array}$ & $\begin{array}{c}1.68 \mathrm{E}+05 \\
\mathrm{BTU} / \mathrm{hr} \\
30 \text {-gpm water } \\
\text { supply at } 75^{\circ} \mathrm{F} \\
60 \text {-psia }\end{array}$ & $316 \mathrm{SS}$ & $\begin{array}{l}\text { 24590-PTF- } \\
\text { MED-TLP- } \\
00003\end{array}$ \\
\hline $\begin{array}{c}\text { SWE-VSL- } \\
00002\end{array}$ & $\begin{array}{c}\text { Evaporator } \\
\text { Condensate } \\
\text { Vessel }\end{array}$ & $\begin{array}{c}\text { 72-inch ID } \\
\text { 110.69-inch } \\
\text { Height } \\
\\
\text { 5/8-inch thick } \\
\text { shell and top head } \\
1 / 2 \text {-inch thick } \\
\text { bottom head }\end{array}$ & $\begin{array}{c}\text { Max. Operating } \\
\text { Volume: 1,916- } \\
\text { gal } \\
\\
\text { Total Volume: } \\
\text { 2,227-gal }\end{array}$ & 304L SS & $\begin{array}{c}\text { 24590-PTF- } \\
\text { MV-TLP-TLP- } \\
00004\end{array}$ \\
\hline $\begin{array}{c}\text { SWE-PMP- } \\
00002 \mathrm{~A} / \mathrm{B}\end{array}$ & $\begin{array}{l}\text { (2) Condensate } \\
\text { Pumps }\end{array}$ & N/A & 40-gpm & $316 \mathrm{SS}$ & $\begin{array}{l}\text { 24590-PTF- } \\
\text { MPD-TLP- } \\
00010\end{array}$ \\
\hline $\begin{array}{l}\text { SWE-VSL- } \\
00006 \mathrm{~A} / \mathrm{B} / \mathrm{C}\end{array}$ & $\begin{array}{l}\text { (3) Clean } \\
\text { Condensate } \\
\text { Vessels }\end{array}$ & $\begin{array}{c}\text { 122-inch ID } \\
\text { 240-inch height } \\
5 / 8 \text {-inch thick } \\
\text { shell and top head } \\
\text { 1/2-inch thick } \\
\text { bottom head }\end{array}$ & $\begin{array}{c}\text { Maximum } \\
\text { operating } \\
\text { volume: } 9,130- \\
\text { gal each } \\
\text { Total volume: } \\
\text { 11,140-gal each }\end{array}$ & 304L SS & $\begin{array}{c}\text { 24-lpm of clean } \\
\text { condensate (see } \\
\text { Table B-3) and } \\
\text { Table } \\
\text { assumptions. }\end{array}$ \\
\hline $\begin{array}{l}\text { SWE-PMP- } \\
00003 \mathrm{~A} / \mathrm{B} / \mathrm{C}\end{array}$ & $\begin{array}{l}\text { (3) Condensate } \\
\text { Pumps }\end{array}$ & N/A & 50-gpm & $316 \mathrm{SS}$ & \\
\hline
\end{tabular}


Table F-2. Process Vessels Sizing Assumptions.

\begin{tabular}{|c|c|c|}
\hline \multicolumn{2}{|c|}{ Assumption } & Discussion \\
\hline \multicolumn{2}{|c|}{$\begin{array}{l}\text { Normal working volume of vessel is } 85 \text { percent } \\
\text { of the total vessel capacity. }\end{array}$} & $\begin{array}{l}\text { Vessels are allowed to fill to } 85 \text { percent } \\
\text { capacity to provide margin against } \\
\text { inadvertent overfilling and loss of } \\
\text { process solutions to cell floor. }\end{array}$ \\
\hline \multicolumn{2}{|c|}{$\begin{array}{l}\text { An allowance of } 25 \text { percent volume is provided } \\
\text { in vessels where neutralization reactions occur. }\end{array}$} & $\begin{array}{l}\text { Foaming of process solutions can occur } \\
\text { during neutralization. This allowance is } \\
\text { for foam formation and disengagement. }\end{array}$ \\
\hline \multicolumn{2}{|c|}{$\begin{array}{l}10 \text { percent of the vessel capacity is assumed to } \\
\text { be used due to volume displacement by } \\
\text { internal components. }\end{array}$} & $\begin{array}{l}\text { Vessels may be equipment with sensors } \\
\text { (e.g., liquid level and density), pumps, } \\
\text { mixing devices, or other components } \\
\text { that will displace process solution } \\
\text { volume. }\end{array}$ \\
\hline \multicolumn{2}{|c|}{ The vessel height to diameter ratio is 2 . } & $\begin{array}{l}\text { The procurement cost is lower for } \\
\text { vessels with a height to diameter ratio } \\
\text { of } 2 \text {. }\end{array}$ \\
\hline \multicolumn{2}{|c|}{$\begin{array}{l}\text { Line flush volume from WTP LAW } \\
\text { Vitrification Facility to SWE Evaporator LAW } \\
\text { secondary waste solutions receipt vessels }\end{array}$} & 2,000 -gallons \\
\hline \multicolumn{2}{|c|}{$\begin{array}{l}\text { Process solution residence time in vessels used } \\
\text { in SWE system }\end{array}$} & \multirow{5}{*}{$\begin{array}{l}\text { These residence times have been } \\
\text { assigned to provide sufficient sample } \\
\text { analyses turn-around without the need } \\
\text { for process shutdown. } \\
\text { Assumes the Laboratory is operational } \\
\text { 24-hours per day, 7-days a week. }\end{array}$} \\
\hline Vessel & $\begin{array}{c}\text { Capacity / } \\
\text { Residence Time } \\
\text { (hours) } \\
\end{array}$ & \\
\hline $\begin{array}{l}\text { SWE Evaporator LAW } \\
\text { secondary waste solutions } \\
\text { receipt vessels (SWE- } \\
\text { VSL-00001A/B) }\end{array}$ & $\begin{array}{l}\text { Receive entire } \\
\text { contents of WTP } \\
\text { LAW Vitrification } \\
\text { SBS and Caustic } \\
\text { Scrubber Vessels }\end{array}$ & \\
\hline $\begin{array}{l}\text { Concentrate Vessels } \\
\text { SWE-VSL-00003A/B }\end{array}$ & 24 hours each & \\
\hline $\begin{array}{l}\text { Clean Condensate } \\
\text { Vessels (SWE-VSL- } \\
00006 \mathrm{~A} / \mathrm{B} / \mathrm{C}) \\
\end{array}$ & 24 hours each & \\
\hline
\end{tabular}


RPP-RPT-37924, Rev. 0

\subsection{REFERENCES}

24590-PTF-3PS-MEVV-TP0012005, River Protection Project - Waste Treatment Plant Engineering Specification for Forced Circulation Vacuum Evaporator System, , Rev. 2, Bechtel National Inc., Richland WA

24590-PTF-3YD-TLP-00001, 2002, System Description for Treated LAW Evaporation Process (TLP), Rev. 0, Bechtel National Inc. Waste Treatment Plant, Richland WA

24590-QL-POA-MEVV-00001-02-00079 2005, Demister Pad and Bubble Tray Qualification Shipping Condition HEP 1, FEP, and TLP Separator Vessels, Rev. 0B, Framatome ANP Inc., Richland WA

24590-PTF-MED-TLP-00001, 2005, Mechanical Data Sheet Shell and Tube Heat Exchanger, Rev. 1, Bechtel National Inc. Waste Treatment Plant, Richland WA

24590-PTF-MED-TLP-P0002, 2005, Mechanical Data Sheet Shell and Tube Heat Exchanger, Rev. 2, Bechtel National Inc. Waste Treatment Plant, Richland WA

24590-PTF-MED-TLP-P0003, 2005, Mechanical Data Sheet Shell and Tube Heat Exchanger, Rev. 2, Bechtel National Inc. Waste Treatment Plant, Richland WA

24590-PTF-MED-TLP-P0004, 2004, Mechanical Data Sheet Shell and Tube Heat Exchanger, Rev. 0, Bechtel National Inc. Waste Treatment Plant, Richland WA

24590-PTF-MPD-TLP-00001, 2005, Mechanical Systems Data Sheet: ASME/ANSI General Centrifugal Pump, Rev. 1, Bechtel National Inc. Waste Treatment Plant, Richland WA

24590-PTF-MPD-TLP-00007 2005, Mechanical Systems Data Sheet: API610 Axial Flow Pump, Rev. 1, Bechtel National Inc. Waste Treatment Plant, Richland WA

24590-PTF-MPD-TLP-00008, 2005, Mechanical Systems Data Sheet: ASME/ANSI General Centrifugal Pump, Rev. 1, Bechtel National Inc. Waste Treatment Plant, Richland WA

24590-PTF-MPD-TLP-00009, 2005, Mechanical Systems Data Sheet: ASME/ANSI General Centrifugal Pump, Rev. 1, Bechtel National Inc. Waste Treatment Plant, Richland WA

24590-PTF-MV-TLP-DMST-00001, 2002, Mechanical Systems Data Sheet: Vessel, Rev. A, Bechtel National Inc. Waste Treatment Plant, Richland WA

24590-PTF-MVD-TLP-00004, 2004, Mechanical Data Sheet: Vessel, Rev. 1, Bechtel National Inc. Waste Treatment Plant, Richland WA

24590-PTF-MVD-TLP-00005, 2005, Mechanical Data Sheet: Vessel, Rev. 4, Bechtel National Inc. Waste Treatment Plant, Richland WA

SVF-1484, 2008, IPS DST Feed Calculation, CH2M HILL Hanford Group Inc., Richland WA 


\section{Appendix A. Estimation of Pipeline Flush Volume.}

The WTP could use either pipeline SN-700 or SN-701 to return secondary wastes from the LAW Vitrification Facility to the Tank Farms. Pipelines SN-700 and SN-701 are in the same trench and are about the same length. Alternatively, a new pipeline following a similar course and length as SN-700 could be installed.

Drawings H-14-104971 $1^{34}$, sheet 5 and H-14-104900 35 , sheets 1 - 9 depict the 3-inch diameter pipeline SN-700 from the 241-AP-02D pump pit to the WTP site. Pipeline SN-700 is approximately $2,164 \mathrm{ft}$ in length based on these drawings. The WTP would need to connect to SN-700 and extend this pipeline to the LAW Vitrification Facility. Depending on the route selected by the WTP project, the length of the pipeline connecting between SN-700 and the LAW Vitrification facility could be about $2,600 \mathrm{ft}$. The total pipeline length from the AP-02D pump pit to the LAW Vitrification facility would be about $4,764 \mathrm{ft}$. The internal volume of this 3 -inch pipeline is $\sim 233.7$ cubic feet or 1,750 gallons.

$\begin{aligned} \text { Internal Volume }= & \mathrm{L} \times \pi(\mathrm{d} / 2)^{2} \times 7.481 \text { gallons } / \mathrm{ft}^{3} \\ & 4,764 \mathrm{ft} \times 3.14 \times(3-\text { inch } / 2 / 12-\mathrm{inch} / \mathrm{ft})^{2} \times 7.481 \text { gallons } / \mathrm{ft}^{3} \\ & \sim 1,750 \text { gallons }\end{aligned}$

A line flush volume of 2,000 gallons is recommended, which provides some allowance $(\sim 680-\mathrm{ft}$ of 3-inch pipeline) in case pipeline SN-700 is connected from the 241-AP-02D pump pit to another AP Farm tank or the WTP pipeline route is longer than estimated.

\footnotetext{
${ }^{34}$ H-14-104971 sheet 5, revision 2, 2004, Piping Support Plan 3" SN-700-M9, U.S. Department of Energy Richland Operations Office, Richland Washington

${ }^{35}$ H-14-104900 sheet 1, revision 1, 2003, Piping Support Plan 3" SN-700-M9, U.S. Department of Energy Richland Operations Office, Richland Washington
} 


\section{Appendix B. Concentrate and Condensate Composition Estimates.}

\section{B1.0 INTRODUCTION}

The compositions of the concentrate and condensate streams produced from evaporation of the secondary waste solutions are determined assuming the SWE system operates similar to the 242-A Evaporator. The waste volume reduction factor for the secondary waste solutions is first calculated in section B2.0 and then used along with split factors for the 242-A Evaporator to determine the composition of the condensate (Section B3.0). The composition of the concentrate stream (Section B4.0) is calculated using the waste volume reduction factors (Section B2.0) and the split factors for the 242-A Evaporator. The derivation of equations for these calculations and results are presented in the following sections.

\section{B.2 WASTE VOLUME REDUCTION FACTORS}

The waste volume reduction (WVR) factors for the secondary waste solutions processed in the SWE system can be predicted using Equation 1, which was developed for the existing Hanford 242-A Evaporator (HNF-SD-WM-SP-012 Rev. 6, Page A-116) ${ }^{36}$.

Equation 1

$\mathrm{WVR}=\left(\boldsymbol{e} \boldsymbol{r}_{\mathrm{B}}-\boldsymbol{e} \boldsymbol{T}_{\mathrm{F}}\right) /\left(\boldsymbol{e r} \mathbf{r}_{\mathrm{B}}-1\right)$

Where:

$$
\begin{aligned}
& \text { WVR }=\text { Waste Volume Reduction } \\
& \boldsymbol{e}_{\mathrm{B}}=\text { Evaporator set point (bottoms specific gravity) } \\
& \boldsymbol{e}_{\mathrm{F}}=\text { Specific gravity of evaporator feed }
\end{aligned}
$$

The volume of process condensate is assumed to be 1.15 times the waste volume boiled off from the fed to account for seal water and the vacuum system steam jets. This is the same assumption used in modeling the operation of the 242-A Evaporator.

The estimated compositions of the secondary wastes generated at the LAW Vitrification Facility ${ }^{37}$ are provided in Table B-1 and Table B-2. Total waste volume and density are also included in Table B- $1^{38}$.

For the secondary waste solutions, an evaporator set point specific gravity of $1.3 \mathrm{gm} / \mathrm{ml}$ is assumed to minimize the potential for solids formation. The waste volume reduction factors for the secondary waste solutions have been calculated in Table B-3 using Equation 1, the evaporator set point specific gravity of $1.3 \mathrm{gm} / \mathrm{ml}$, and the densities of the secondary waste solutions from Table B-1. Since the evaporator set point specific gravity and the densities of the

\footnotetext{
${ }^{36}$ HNF-SD-WM-SP-012 revision 6, 2007, Tank Farm Contractor Operation and Utilization Plan, CH2MHILL Hanford Group Inc., Richland Washington

37 "Analyze and Predict Early LAW Secondary Waste Streams - Task Order no. 14", Letter \# AEM 075 dated April 14, 2008 from L. Bergman to R. A. Burk, Bechtel National Inc., AEM Consulting, 2417 Mark Avenue, Richland Washington

38 "Analyze and Prediction of Early LAW Secondary Waste Streams", E-mail dated April 23, 2008 from G. Dunford to M. E. Johnson CH2M HILL Hanford Group Inc., AEM Consulting, 2417 Mark Avenue, Richland Washington
} 
secondary waste solutions do not change for each of the feeds, the waste volume reduction factor is $93 \%$ for all of the secondary waste solutions. Also included in Table B-3 is the volumetric generation rate $(\mathrm{Lpm})$ and total volume of the condensate derived from evaporation of these secondary waste solutions.

\begin{tabular}{|c|c|c|c|c|c|c|c|c|}
\hline \multicolumn{9}{|c|}{$\begin{array}{c}\text { Table B-1. Non-radioactive Components in LAW Vitrification } \\
\text { Secondary Waste Stream (ppm). }\end{array}$} \\
\hline Component & \multicolumn{8}{|c|}{ Pretreated LAW Solution Source Tank Processed in WTP LAW Vitrification } \\
\hline & \begin{tabular}{|l|} 
AP-104 \\
\end{tabular} & AP-102 & AP-101 & AP-103 & AP-105 & AP-108 & AP-107 & AN-104 \\
\hline $\mathrm{Al}$ & $1.23 \mathrm{E}+01$ & $1.44 \mathrm{E}+01$ & $1.09 \mathrm{E}+01$ & $1.30 \mathrm{E}+01$ & $1.22 \mathrm{E}+01$ & $1.33 \mathrm{E}+01$ & $1.08 \mathrm{E}+01$ & $1.73 \mathrm{E}+01$ \\
\hline $\mathrm{B}$ & $1.00 \mathrm{E}+02$ & $9.92 \mathrm{E}+01$ & $1.01 \mathrm{E}+02$ & $9.88 \mathrm{E}+01$ & $9.89 \mathrm{E}+01$ & $9.90 \mathrm{E}+01$ & $9.92 \mathrm{E}+01$ & $1.00 \mathrm{E}+02$ \\
\hline $\mathrm{Ca}$ & $2.17 \mathrm{E}+00$ & $2.14 \mathrm{E}+00$ & $2.18 \mathrm{E}+00$ & $2.14 \mathrm{E}+00$ & $2.14 \mathrm{E}+00$ & $2.14 \mathrm{E}+00$ & $2.14 \mathrm{E}+00$ & $2.17 \mathrm{E}+00$ \\
\hline $\mathrm{Cl}$ & $7.80 \mathrm{E}+02$ & $8.91 \mathrm{E}+02$ & $4.48 \mathrm{E}+02$ & $8.38 \mathrm{E}+02$ & $1.09 \mathrm{E}+03$ & $7.19 \mathrm{E}+02$ & $4.65 \mathrm{E}+02$ & $1.16 \mathrm{E}+03$ \\
\hline $\mathrm{Cr}$ & $8.98 \mathrm{E}+00$ & $8.13 \mathrm{E}+00$ & $1.16 \mathrm{E}+01$ & & $4.32 \mathrm{E}+00$ & $9.19 \mathrm{E}+00$ & $1.42 \mathrm{E}+01$ & \\
\hline $\mathrm{F}$ & $7.85 \mathrm{E}+01$ & $5.23 \mathrm{E}+00$ & $1.00 \mathrm{E}+02$ & $8.04 \mathrm{E}+01$ & $1.67 \mathrm{E}+01$ & $3.90 \mathrm{E}+01$ & $9.18 \mathrm{E}+01$ & $6.10 \mathrm{E}+01$ \\
\hline $\mathrm{Fe}$ & $7.94 \mathrm{E}+00$ & $7.86 \mathrm{E}+00$ & $7.98 \mathrm{E}+00$ & $7.83 \mathrm{E}+00$ & $7.83 \mathrm{E}+00$ & $7.84 \mathrm{E}+00$ & $7.86 \mathrm{E}+00$ & $7.94 \mathrm{E}+00$ \\
\hline $\mathrm{Hg}$ & $8.03 \mathrm{E}-03$ & $1.22 \mathrm{E}-06$ & $5.48 \mathrm{E}-03$ & $1.18 \mathrm{E}-02$ & $7.84 \mathrm{E}-04$ & $2.16 \mathrm{E}-04$ & $2.54 \mathrm{E}-02$ & $0.00 \mathrm{E}+00$ \\
\hline $\mathrm{K}$ & $4.47 \mathrm{E}+01$ & $3.30 \mathrm{E}+01$ & $5.66 \mathrm{E}+01$ & $3.57 \mathrm{E}+01$ & $2.56 \mathrm{E}+01$ & $6.58 \mathrm{E}+01$ & $2.83 \mathrm{E}+01$ & $2.04 \mathrm{E}+01$ \\
\hline $\mathrm{Mg}$ & $5.45 \mathrm{E}-01$ & $5.40 \mathrm{E}-01$ & $5.48 \mathrm{E}-01$ & $5.38 \mathrm{E}-01$ & $5.38 \mathrm{E}-01$ & $5.38 \mathrm{E}-01$ & $5.40 \mathrm{E}-01$ & $5.45 \mathrm{E}-01$ \\
\hline $\mathrm{Mn}$ & $3.24 \mathrm{E}-03$ & $2.11 \mathrm{E}-03$ & $4.00 \mathrm{E}-03$ & $2.50 \mathrm{E}-03$ & $1.15 \mathrm{E}-03$ & $1.35 \mathrm{E}-03$ & $2.05 \mathrm{E}-03$ & $5.25 \mathrm{E}-04$ \\
\hline $\mathrm{Na}$ & $8.35 \mathrm{E}+02$ & $8.27 \mathrm{E}+02$ & $8.40 \mathrm{E}+02$ & $8.24 \mathrm{E}+02$ & $8.24 \mathrm{E}+02$ & $8.25 \mathrm{E}+02$ & $8.27 \mathrm{E}+02$ & $8.36 \mathrm{E}+02$ \\
\hline $\mathrm{NH} 4$ & $6.36 \mathrm{E}+01$ & $6.30 \mathrm{E}+01$ & $6.40 \mathrm{E}+01$ & $6.28 \mathrm{E}+01$ & $6.28 \mathrm{E}+01$ & $6.29 \mathrm{E}+01$ & $6.30 \mathrm{E}+01$ & $6.37 \mathrm{E}+01$ \\
\hline $\mathrm{Ni}$ & $7.48 \mathrm{E}-02$ & $1.67 \mathrm{E}-02$ & $3.11 \mathrm{E}-02$ & $1.13 \mathrm{E}-01$ & $1.61 \mathrm{E}-01$ & $4.97 \mathrm{E}-02$ & $2.68 \mathrm{E}-02$ & $1.27 \mathrm{E}-03$ \\
\hline NO2 & $3.11 \mathrm{E}+02$ & $3.08 \mathrm{E}+02$ & $3.13 \mathrm{E}+02$ & $3.07 \mathrm{E}+02$ & $3.07 \mathrm{E}+02$ & $3.08 \mathrm{E}+02$ & $3.08 \mathrm{E}+02$ & $3.12 \mathrm{E}+02$ \\
\hline $\mathrm{NO3}$ & $1.40 \mathrm{E}+02$ & $1.39 \mathrm{E}+02$ & $1.41 \mathrm{E}+02$ & $1.38 \mathrm{E}+02$ & $1.38 \mathrm{E}+02$ & $1.38 \mathrm{E}+02$ & $1.39 \mathrm{E}+02$ & $1.40 \mathrm{E}+02$ \\
\hline $\mathrm{Pb}$ & $8.66 \mathrm{E}-02$ & $2.37 \mathrm{E}-01$ & $1.01 \mathrm{E}-01$ & $1.16 \mathrm{E}-01$ & $8.46 \mathrm{E}-02$ & $9.23 \mathrm{E}-02$ & $8.01 \mathrm{E}-02$ & $3.23 \mathrm{E}-02$ \\
\hline PO4 & $2.30 \mathrm{E}+01$ & $1.04 \mathrm{E}+01$ & $2.06 \mathrm{E}+01$ & $1.82 \mathrm{E}+01$ & $1.33 \mathrm{E}+01$ & $5.97 \mathrm{E}+00$ & $1.81 \mathrm{E}+01$ & $1.29 \mathrm{E}+01$ \\
\hline $\mathrm{CO} 3$ & $4.57 \mathrm{E}+02$ & $4.52 \mathrm{E}+02$ & $4.59 \mathrm{E}+02$ & $4.50 \mathrm{E}+02$ & $4.51 \mathrm{E}+02$ & $4.51 \mathrm{E}+02$ & $4.52 \mathrm{E}+02$ & $4.57 \mathrm{E}+02$ \\
\hline $\mathrm{Si}$ & $2.25 \mathrm{E}+01$ & $2.23 \mathrm{E}+01$ & $2.27 \mathrm{E}+01$ & $2.22 \mathrm{E}+01$ & $2.22 \mathrm{E}+01$ & $2.23 \mathrm{E}+01$ & $2.23 \mathrm{E}+01$ & $2.26 \mathrm{E}+01$ \\
\hline SO4 & $2.63 \mathrm{E}+01$ & $1.24 \mathrm{E}+01$ & $4.38 \mathrm{E}+01$ & $2.26 \mathrm{E}+01$ & $2.35 \mathrm{E}+01$ & $1.80 \mathrm{E}+01$ & $6.69 \mathrm{E}+01$ & $3.79 \mathrm{E}+01$ \\
\hline TOC & $3.07 \mathrm{E}-02$ & $1.75 \mathrm{E}-02$ & $1.79 \mathrm{E}-02$ & $4.94 \mathrm{E}-02$ & $3.44 \mathrm{E}-02$ & $2.30 \mathrm{E}-02$ & $1.93 \mathrm{E}-02$ & $1.34 \mathrm{E}-02$ \\
\hline $\mathrm{Zn}$ & $3.13 \mathrm{E}+01$ & $3.10 \mathrm{E}+01$ & $3.15 \mathrm{E}+01$ & $3.09 \mathrm{E}+01$ & $3.09 \mathrm{E}+01$ & $3.10 \mathrm{E}+01$ & $3.10 \mathrm{E}+01$ & $3.14 \mathrm{E}+01$ \\
\hline Rate $\mathrm{m} 3 / \mathrm{yr}$ & 11101 & 11213 & 11037 & 11252 & 11248 & 11237 & 11208 & 11091 \\
\hline Rate lpm & 21.7 & 21.9 & 21.5 & 21.9 & 21.9 & 21.9 & 21.9 & 21.6 \\
\hline $\mathrm{pH}$ & 8.32 & 8.41 & 8.29 & 8.24 & 8.34 & 8.39 & 8.25 & 8.62 \\
\hline $\begin{array}{l}\text { Density } \\
\mathrm{gm} / \mathrm{ml}\end{array}$ & 1.02 & 1.02 & 1.02 & 1.02 & 1.02 & 1.02 & 1.02 & 1.02 \\
\hline $\begin{array}{l}\text { Volume } \\
\text { (kL) }\end{array}$ & $5.34 \mathrm{E}+03$ & $5.44 \mathrm{E}+03$ & $5.98 \mathrm{E} \quad 03$ & $6.10 \mathrm{E}+03$ & $5.95 \mathrm{E}+03$ & $6.62 \mathrm{E}+03$ & $5.73 \mathrm{E}+03$ & $5.55 \mathrm{E}+03$ \\
\hline
\end{tabular}


RPP-RPT-37924, Rev. 0

\begin{tabular}{|c|c|c|c|c|c|c|c|c|}
\hline \multicolumn{9}{|c|}{$\begin{array}{c}\text { Table B-2. Radioactive Components in LAW Vitrification } \\
\text { Secondary Waste Stream }(\mathrm{Ci} / \mathrm{L}) \text {. }\end{array}$} \\
\hline & \multicolumn{8}{|c|}{ Pretreated LAW Solution Source Tank Processed in WTP LAW Vitrification } \\
\hline & AP-104 & AP-102 & AP-101 & AP-103 & AP-105 & AP-108 & AP-107 & AN-104 \\
\hline $3 \mathrm{H}$ & $1.01 \mathrm{E}-06$ & $7.93 \mathrm{E}-06$ & $2.96 \mathrm{E}-05$ & $2.18 \mathrm{E}-05$ & $4.96 \mathrm{E}-06$ & $8.25 \mathrm{E}-06$ & $3.13 \mathrm{E}-05$ & $3.46 \mathrm{E}-06$ \\
\hline $14 \mathrm{C}$ & $5.22 \mathrm{E}-07$ & $1.05 \mathrm{E}-06$ & $1.56 \mathrm{E}-06$ & $2.37 \mathrm{E}-06$ & $8.77 \mathrm{E}-07$ & $8.67 \mathrm{E}-07$ & $1.34 \mathrm{E}-06$ & $1.06 \mathrm{E}-06$ \\
\hline $60 \mathrm{Co}$ & $2.23 \mathrm{E}-08$ & $1.31 \mathrm{E}-08$ & $1.92 \mathrm{E}-08$ & $3.18 \mathrm{E}-08$ & $2.31 \mathrm{E}-08$ & $1.25 \mathrm{E}-08$ & $3.27 \mathrm{E}-08$ & $2.88 \mathrm{E}-10$ \\
\hline $79 \mathrm{Se}$ & $8.29 \mathrm{E}-08$ & $2.09 \mathrm{E}-07$ & $8.78 \mathrm{E}-08$ & $1.48 \mathrm{E}-07$ & $2.42 \mathrm{E}-07$ & $1.37 \mathrm{E}-07$ & $1.10 \mathrm{E}-07$ & $9.34 \mathrm{E}-08$ \\
\hline $90 \mathrm{Sr}$ & $4.69 \mathrm{E}-06$ & $1.35 \mathrm{E}-06$ & $2.98 \mathrm{E}-06$ & $7.14 \mathrm{E}-06$ & $5.73 \mathrm{E}-06$ & $3.17 \mathrm{E}-06$ & $6.25 \mathrm{E}-06$ & $3.39 \mathrm{E}-06$ \\
\hline $94 \mathrm{Nb}$ & N/A & N/A & N/A & N/A & N/A & & N/A & N/A \\
\hline $99 \mathrm{Tc}$ & $3.85 \mathrm{E}-05$ & $3.91 \mathrm{E}-05$ & $3.72 \mathrm{E}-05$ & $5.03 \mathrm{E}-05$ & $4.89 \mathrm{E}-05$ & $3.31 \mathrm{E}-05$ & $4.99 \mathrm{E}-05$ & $4.58 \mathrm{E}-05$ \\
\hline $106 \mathrm{Ru}$ & $2.25 \mathrm{E}-08$ & $1.43 \mathrm{E}-08$ & $1.74 \mathrm{E}-02$ & $2.10 \mathrm{E}-08$ & & & $5.97 \mathrm{E}-02$ & $9.57 \mathrm{E}-07$ \\
\hline $129 \mathrm{I}$ & $2.41 \mathrm{E}-08$ & $\mathrm{E}-08$ & & & & & & $1.62 \mathrm{E}-08$ \\
\hline $134 \mathrm{Cs}$ & $5.30 \mathrm{E}-11$ & $3.45 \mathrm{E}-12$ & $7.50 \mathrm{E}-10$ & $2.18 \mathrm{E}$ & $5.99 \mathrm{E}-11$ & $8.03 \mathrm{E}-11$ & $1.08 \mathrm{E}-09$ & $2.53 \mathrm{E}-11$ \\
\hline $137 \mathrm{Cs}$ & $4.71 \mathrm{E}-06$ & $4.67 \mathrm{E}-06$ & $4.74 \mathrm{E}-06$ & $4.65 \mathrm{E}-06$ & $4.65 \mathrm{E}-06$ & $4.66 \mathrm{E}-06$ & $4.67 \mathrm{E}-06$ & $4.72 \mathrm{E}-06$ \\
\hline $144 \mathrm{Ce}$ & N/A & N/A & N/A & N/A & N/A & $\mathrm{N} / \mathrm{A}$ & N/A & N/A \\
\hline $154 \mathrm{Eu}$ & $2.69 \mathrm{E}-08$ & $1.09 \mathrm{E}-07$ & $7.39 \mathrm{E}-08$ & $4.69 \mathrm{E}-08$ & $1.49 \mathrm{E}-07$ & $4.71 \mathrm{E}-08$ & $1.27 \mathrm{E}-07$ & $1.51 \mathrm{E}-14$ \\
\hline $155 \mathrm{Eu}$ & $6.72 \mathrm{E}-08$ & $6.14 \mathrm{E}-08$ & $1.26 \mathrm{E}-07$ & $6.17 \mathrm{E}-08$ & $1.31 \mathrm{E}-07$ & $5.08 \mathrm{E}-08$ & $2.18 \mathrm{E}-07$ & $5.84 \mathrm{E}-15$ \\
\hline $233 \mathrm{U}$ & $7.51 \mathrm{E}-11$ & $9.42 \mathrm{E}-11$ & $6.21 \mathrm{E}-11$ & $4.85 \mathrm{E}-11$ & $1.77 \mathrm{E}-11$ & $4.83 \mathrm{E}-11$ & $5.34 \mathrm{E}-11$ & $2.37 \mathrm{E}-11$ \\
\hline $234 \mathrm{U}$ & $4.06 \mathrm{E}-11$ & $1.74 \mathrm{E}-11$ & $4.25 \mathrm{E}-11$ & $3.49 \mathrm{E}-11$ & $5.92 \mathrm{E}-12$ & $3.36 \mathrm{E}-11$ & $4.32 \mathrm{E}-11$ & $1.69 \mathrm{E}-11$ \\
\hline $235 \mathrm{U}$ & $1.57 \mathrm{E}-12$ & $6.92 \mathrm{E}-13$ & $1.58 \mathrm{E}-12$ & $1.49 \mathrm{E}-12$ & $2.40 \mathrm{E}-13$ & $1.31 \mathrm{E}-12$ & $1.76 \mathrm{E}-12$ & $6.65 \mathrm{E}-13$ \\
\hline $237 \mathrm{~Np}$ & $1.72 \mathrm{E}-10$ & $1.66 \mathrm{E}-09$ & $7.45 \mathrm{E}-10$ & $1.67 \mathrm{E}-10$ & $1.63 \mathrm{E}-09$ & $1.59 \mathrm{E}-10$ & $7.09 \mathrm{E}-10$ & $3.34 \mathrm{E}-11$ \\
\hline $238 \mathrm{Pu}$ & $4.24 \mathrm{E}-10$ & $2.82 \mathrm{E}-11$ & $4.59 \mathrm{E}-10$ & $6.42 \mathrm{E}-10$ & $4.68 \mathrm{E}-11$ & $7.74 \mathrm{E}-11$ & $1.42 \mathrm{E}-09$ & $1.83 \mathrm{E}-11$ \\
\hline $239 \mathrm{Pu}$ & $2.22 \mathrm{E}-09$ & $1.08 \mathrm{E}-09$ & $6.34 \mathrm{E}-09$ & $4.67 \mathrm{E}-09$ & $9.18 \mathrm{E}-10$ & $1.25 \mathrm{E}-09$ & $1.54 \mathrm{E}-08$ & $2.52 \mathrm{E}-10$ \\
\hline $240 \mathrm{Pu}$ & $2.76 \mathrm{E}-09$ & $1.34 \mathrm{E}-09$ & & & $1.34 \mathrm{E}-09$ & $1.74 \mathrm{E}-09$ & $3.00 \mathrm{E}-08$ & $4.81 \mathrm{E}-10$ \\
\hline $241 \mathrm{Am}$ & $1.32 \mathrm{E}-08$ & $1.17 \mathrm{E}-08$ & & $4.41 \mathrm{E}-08$ & $1.33 \mathrm{E}-08$ & $1.14 \mathrm{E}-08$ & $5.19 \mathrm{E}-09$ & $8.03 \mathrm{E}-09$ \\
\hline $241 \mathrm{Pu}$ & $2.56 \mathrm{E}-09$ & $1.30 \mathrm{E}-09$ & $3.07 \mathrm{E}-08$ & $5.69 \mathrm{E}-09$ & $2.73 \mathrm{E}-09$ & $2.99 \mathrm{E}-09$ & $1.00 \mathrm{E}-07$ & $1.15 \mathrm{E}-09$ \\
\hline $243 \mathrm{Cm}$ & $8.12 \mathrm{E}-11$ & $2.50 \mathrm{E}-12$ & $4.63 \mathrm{E}-12$ & $5.26 \mathrm{E}-11$ & $4.54 \mathrm{E}-12$ & $3.91 \mathrm{E}-12$ & $1.90 \mathrm{E}-12$ & $4.56 \mathrm{E}-13$ \\
\hline $244 \mathrm{Cm}$ & $1.90 \mathrm{E}-09$ & $3.64 \mathrm{E}-11$ & $1.04 \mathrm{E}-10$ & $1.15 \mathrm{E}-09$ & $7.80 \mathrm{E}-11$ & $6.58 \mathrm{E}-11$ & $4.16 \mathrm{E}-11$ & $1.08 \mathrm{E}-11$ \\
\hline
\end{tabular}

\begin{tabular}{|l|c|c|c|c|c|c|c|c|}
\hline \multicolumn{7}{|c|}{ Table B-3. Secondary Waste Solutions Waste Volume Reduction Factors and } \\
Condensate Volumetric Generation Rates. \\
\hline & \multicolumn{7}{|c|}{ Pretreated LAW Solution Source Tank Processed in WTP LAW Vitrification } \\
\hline & AP-104 & AP-102 & AP-101 & AP-103 & AP-15 & AP-108 & AP-107 & AN-104 \\
\hline $\begin{array}{l}\text { Density } \\
\text { (gm/ml) }\end{array}$ & 1.02 & 1.02 & 1.02 & 1.02 & 1.02 & 1.02 & 1.02 & 1.02 \\
\hline WVR & $93 \%$ & $93 \%$ & $93 \%$ & $93 \%$ & $93 \%$ & $93 \%$ & $93 \%$ & $93 \%$ \\
\hline $\begin{array}{l}\text { Condensate } \\
\text { (Lpm) }\end{array}$ & 23.2 & 23.5 & 23.1 & 23.6 & 23.6 & 23.5 & 23.5 & 23.2 \\
\hline $\begin{array}{l}\text { Condensate } \\
\text { (kL) }\end{array}$ & $5.73 \mathrm{E}+03$ & $5.84 \mathrm{E}+03$ & $6.42 \mathrm{E}+03$ & $6.55 \mathrm{E}+03$ & $6.39 \mathrm{E}+03$ & $7.11 \mathrm{E}+03$ & $6.15 \mathrm{E}+03$ & $5.96 \mathrm{E}+03$ \\
\hline
\end{tabular}




\section{B3.0 CONDENSATE COMPOSITION}

The composition of the process condensate from the SWE system is estimated using the same estimation basis as for the 242-A Evaporator. The following calculation determines split factors (SF).

$\mathrm{SF}_{i} \quad=1 /\left[1+\mathrm{Kp}_{i} / 21,579 *((1-\mathrm{WVR}) / \mathrm{WVR})\right]$

Equation 2

Where:

$\mathrm{SF}_{i}=$ split factor for component $i$; the split factor is the mass or activity of component $i$ in the process condensate to the mass or activity of component $i$ in the feed

WVR $=$ Waste Volume Reduction factor

$\mathrm{Kp}_{i}=242-\mathrm{A}$ Evaporator partition coefficients provided in Table A-29 of HNF-SDWM-SP-012 Rev. 6, Pages A-117 thru A-119

$21,579=$ a numerical factor accounting for the $15 \%$ volume increase and for the ratio of the volume of condensate as a vapor to the volume of condensate as a liquid evaluated at 60 torr and $52^{\circ} \mathrm{C}$.

The partition coefficients $\left(\mathrm{Kp}_{i}\right)$ used for the SWE system are summarized in Table B-4. The split factor for component $i\left(\mathrm{SF}_{i}\right)$ is calculated in Tables B-5 and B-6 using Equation 2, the partition coefficients $\left(\mathrm{Kp}_{i}\right)$ from Tables B-3, and the WVR from Table B-4.

\begin{tabular}{|c|c|}
\hline \multicolumn{2}{|c|}{ Table B-4. Partitioning Coefficients from HNF-SD-WM- } \\
SP-012, Rev. 6.
\end{tabular}


Table B-4. Partitioning Coefficients from HNF-SD-WMSP-012, Rev. 6.

\begin{tabular}{|c|c|}
\hline Component & $\mathbf{K} \mathbf{p}_{i}$ \\
\hline $234 \mathrm{U}$ & $1.00 \mathrm{E}+07$ \\
\hline $235 \mathrm{U}$ & $1.00 \mathrm{E}+07$ \\
\hline $237 \mathrm{~Np}$ & $3.70 \mathrm{E}+10$ \\
\hline $238 \mathrm{Pu}$ & $3.70 \mathrm{E}+10$ \\
\hline $239 \mathrm{Pu}$ & $3.70 \mathrm{E}+10$ \\
\hline $240 \mathrm{Pu}$ & $1.00 \mathrm{E}+07$ \\
\hline $241 \mathrm{Am}$ & $1.40 \mathrm{E}+10$ \\
\hline $241 \mathrm{Pu}$ & $1.00 \mathrm{E}+07$ \\
\hline $243 \mathrm{Cm}$ & $1.00 \mathrm{E}+07$ \\
\hline $244 \mathrm{Cm}$ & $1.00 \mathrm{E}+07$ \\
\hline $\mathrm{Al}$ & $1.50 \mathrm{E}+07$ \\
\hline $\mathrm{B}$ & $1.00 \mathrm{E}+07$ \\
\hline $\mathrm{Ca}$ & $1.00 \mathrm{E}+07$ \\
\hline $\mathrm{Cl}$ & $5.20 \mathrm{E}+06$ \\
\hline $\mathrm{Cr}$ & $3.50 \mathrm{E}+08$ \\
\hline $\mathrm{F}$ & $2.40 \mathrm{E}+08$ \\
\hline $\mathrm{Fe}$ & $1.00 \mathrm{E}+07$ \\
\hline $\mathrm{Hg}$ & $1.00 \mathrm{E}+07$ \\
\hline $\mathrm{K}$ & $1.00 \mathrm{E}+07$ \\
\hline $\mathrm{Mg}$ & $1.00 \mathrm{E}+07$ \\
\hline $\mathrm{Mn}$ & $1.00 \mathrm{E}+07$ \\
\hline $\mathrm{Na}$ & $3.00 \mathrm{E}+08$ \\
\hline $\mathrm{NH} 4$ & $1.10 \mathrm{E}+03$ \\
\hline $\mathrm{Ni}$ & $1.00 \mathrm{E}+07$ \\
\hline $\mathrm{NO} 2$ & $2.40 \mathrm{E}+07$ \\
\hline $\mathrm{NO} 3$ & $5.70 \mathrm{E}+06$ \\
\hline $\mathrm{Pb}$ & $3.00 \mathrm{E}+05$ \\
\hline PO4 & $1.00 \mathrm{E}+07$ \\
\hline $\mathrm{CO} 3$ & $1.00 \mathrm{E}+07$ \\
\hline $\mathrm{Si}$ & $1.00 \mathrm{E}+07$ \\
\hline $\mathrm{SO} 4$ & $1.40 \mathrm{E}+07$ \\
\hline TOC & $1.00 \mathrm{E}+07$ \\
\hline $\mathrm{Zn}$ & $1.00 \mathrm{E}+07$ \\
\hline
\end{tabular}




\begin{tabular}{|c|c|c|c|c|c|c|c|c|c|}
\hline & & \multicolumn{8}{|c|}{ Pretreated LAW Solution Source Tank Processed in WTP LAW Vitrification } \\
\hline & & AP-104 & AP-102 & AP-101 & AP-103 & AP-15 & AP-108 & AP-107 & AN-104 \\
\hline Component & $\mathbf{K} \mathbf{p}_{\mathbf{i}}$ & $\mathbf{S F}_{\mathbf{i}}$ & $\mathbf{S F}_{\mathbf{i}}$ & $\mathbf{S F}_{\mathrm{i}}$ & $\mathbf{S F}_{\mathbf{i}}$ & $\mathbf{S F}_{\mathbf{i}}$ & $\mathbf{S F}_{\mathbf{i}}$ & $\mathbf{S F}_{\mathbf{i}}$ & $\mathbf{S F}_{\mathbf{i}}$ \\
\hline $\mathrm{Al}$ & $1.50 \mathrm{E}+07$ & 0.0197428 & 0.0197428 & 0.0197428 & 0.0197428 & 0.0197428 & 0.0197428 & 0.0197428 & 0.0197428 \\
\hline $\mathrm{B}$ & $1.00 \mathrm{E}+07$ & 0.0293247 & 0.0293247 & 0.0293247 & 0.0293247 & 0.0293247 & 0.0293247 & 0.0293247 & 0.0293247 \\
\hline $\mathrm{Ca}$ & $1.00 \mathrm{E}+07$ & 0.0293247 & 0.0293247 & \begin{tabular}{|l|}
0.0293247 \\
\end{tabular} & \begin{tabular}{|l|}
0.0293247 \\
\end{tabular} & \begin{tabular}{|l|}
0.0293247 \\
\end{tabular} & \begin{tabular}{|l}
0.0293247 \\
\end{tabular} & 0.0293247 & 0.0293247 \\
\hline $\mathrm{Cl}$ & \begin{tabular}{|l|}
$5.20 \mathrm{E}+06$ \\
\end{tabular} & \begin{tabular}{|l|}
0.0549073 \\
\end{tabular} & 0.0549073 & \begin{tabular}{|l|}
0.0549073 \\
\end{tabular} & \begin{tabular}{|l|}
0.0549073 \\
\end{tabular} & \begin{tabular}{|l|}
0.0549073 \\
\end{tabular} & \begin{tabular}{|l|}
0.0549073 \\
\end{tabular} & \begin{tabular}{|l|}
0.0549073 \\
\end{tabular} & 549073 \\
\hline $\mathrm{Cr}$ & $3.50 \mathrm{E}+08$ & 0.0008624 & 0.0008624 & 0.0008624 & 0.00 & \begin{tabular}{|l|}
0.0008624 \\
\end{tabular} & 0.0008624 & 0.0008624 & 624 \\
\hline $\mathrm{F}$ & $2.40 \mathrm{E}+08$ & 0.0012572 & 0.0012572 & 0.0012572 & 0.0012572 & \begin{tabular}{|l|}
0.0012572 \\
\end{tabular} & 0.0012572 & 0.0012572 & 0.0012572 \\
\hline $\mathrm{Fe}$ & $1.00 \mathrm{E}+07$ & 0.0293247 & 0.0293247 & \begin{tabular}{|l|}
0.0293247 \\
\end{tabular} & \begin{tabular}{|l|}
0.0293247 \\
\end{tabular} & \begin{tabular}{|l|}
0.0293247 \\
\end{tabular} & \begin{tabular}{|l|}
0.0293247 \\
\end{tabular} & 0.0293247 & 0.0293247 \\
\hline $\mathrm{Hg}$ & $1.00 \mathrm{E}+07$ & 0.0293247 & 0.0293247 & 0.0293247 & & & 93247 & & \\
\hline $\mathrm{K}$ & $1.00 \mathrm{E}+07$ & 0.0293247 & 0.0293247 & \begin{tabular}{|l|}
0.0293247 \\
\end{tabular} & \begin{tabular}{|l|}
0.0293247 \\
\end{tabular} & \begin{tabular}{|l|}
0.0293247 \\
\end{tabular} & \begin{tabular}{|l|}
0.0293247 \\
\end{tabular} & 0.0293247 & 0.0293247 \\
\hline $\mathrm{Mg}$ & \begin{tabular}{|l|}
$1.00 \mathrm{E}+07$ \\
\end{tabular} & 0.029 & 0.0293247 & 0.02 & 0.02 & 0.02 & 0.02 & 0.0 & \\
\hline $\mathrm{Mn}$ & $1.00 \mathrm{E}+07$ & 0.0293247 & 0.0293247 & 0.0293247 & 0.0293247 & \begin{tabular}{|l|}
0.0293247 \\
\end{tabular} & 0.0293247 & 0.0293247 & 0.0293247 \\
\hline $\mathrm{Na}$ & $3.00 \mathrm{E}+08$ & 0.001006 & 0.001006 & 0.001006 & 0.001006 & \begin{tabular}{|l|}
0.001006 \\
\end{tabular} & 0.001006 & 0.001006 & 0.001006 \\
\hline NH4 & \begin{tabular}{|l}
$1.10 \mathrm{E}+03$ \\
\end{tabular} & \begin{tabular}{|l|}
0.9963721 \\
\end{tabular} & 0.9963721 & 0.9 & 0.9 & & & 0.9 & 0.9963721 \\
\hline $\mathrm{Ni}$ & $1.00 \mathrm{E}+07$ & 0.0293247 & 0.0293247 & \begin{tabular}{|l|}
0.0293247 \\
\end{tabular} & \begin{tabular}{|l|}
0.0293247 \\
\end{tabular} & \begin{tabular}{|l|}
0.0293247 \\
\end{tabular} & \begin{tabular}{|l|}
0.0293247 \\
\end{tabular} & 0.0293247 & 0.0293247 \\
\hline $\mathrm{NO} 2$ & \begin{tabular}{|l}
$2.40 \mathrm{E}+07$ \\
\end{tabular} & 0.012 & 0.0124313 & \begin{tabular}{|c|}
0.0124313 \\
\end{tabular} & 0.0124313 & \begin{tabular}{|l|}
0.0124313 \\
\end{tabular} & \begin{tabular}{|l|}
0.0124313 \\
\end{tabular} & 0.0124313 & 0.0124313 \\
\hline $\mathrm{NO} 3$ & $5.70 \mathrm{E}+06$ & 0.0503333 & 0.0503333 & 0.0503333 & 0.0503333 & \begin{tabular}{|l|}
0.0503333 \\
\end{tabular} & 0.0503333 & 0.0503333 & 0.0503333 \\
\hline $\mathrm{Pb}$ & $3.00 \mathrm{E}+05$ & 0.5017489 & 0.5017489 & \begin{tabular}{|l|}
0.5017489 \\
\end{tabular} & 0.5017489 & \begin{tabular}{|l|}
0.5017489 \\
\end{tabular} & \begin{tabular}{|l|}
0.5017489 \\
\end{tabular} & 0.5017489 & 0.5017489 \\
\hline $\mathrm{PO} 4$ & $1.00 \mathrm{E}+07$ & 0.0293247 & 0.0293247 & 0.0293247 & \begin{tabular}{|l|}
0.0293247 \\
\end{tabular} & \begin{tabular}{|l|}
0.0293247 \\
\end{tabular} & 0.0293247 & 0.0293247 & 0.0293247 \\
\hline $\mathrm{CO} 3$ & $1.00 \mathrm{E}+07$ & 0.0293247 & 0.0293247 & 0.0293247 & \begin{tabular}{|l|}
0.0293247 \\
\end{tabular} & \begin{tabular}{|l|}
0.0293247 \\
\end{tabular} & \begin{tabular}{|l}
0.0293247 \\
\end{tabular} & 0.0293247 & 0.0293247 \\
\hline $\mathrm{Si}$ & \begin{tabular}{|l|}
$1.00 \mathrm{E}+07$ \\
\end{tabular} & 0.0293247 & 0.0293247 & 0.0293247 & 0.0293247 & \begin{tabular}{|l|}
0.0293247 \\
\end{tabular} & \begin{tabular}{|l}
0.0293247 \\
\end{tabular} & 0.0293247 & 0.0293247 \\
\hline $\mathrm{SO} 4$ & $1.40 \mathrm{E}+07$ & 0.0211232 & 0.0211232 & 0.0211232 & 0.0211232 & 0.0211232 & 0.0211232 & 0.0211232 & 0.0211232 \\
\hline TOC & $1.00 \mathrm{E}+07$ & 0.0293247 & 0.0293247 & 0.0293247 & 0.0293247 & \begin{tabular}{|l|}
0.0293247 \\
\end{tabular} & 0.0293247 & 0.0293247 & 0.0293247 \\
\hline $\mathrm{Zn}$ & \begin{tabular}{|l|}
$1.00 \mathrm{E}+07$ \\
\end{tabular} & \begin{tabular}{|l}
0.0293247 \\
\end{tabular} & 0.0293247 & \begin{tabular}{|l|}
0.0293247 \\
\end{tabular} & \begin{tabular}{|l|}
0.0293247 \\
\end{tabular} & \begin{tabular}{|l|}
0.0293247 \\
\end{tabular} & \begin{tabular}{|l|}
0.0293247 \\
\end{tabular} & 0.0293247 & 0.0293247 \\
\hline
\end{tabular}




\begin{tabular}{|c|c|c|c|c|c|c|c|c|c|}
\hline \multicolumn{10}{|c|}{ Table B-6. Secondary Waste Split Factors - Radionuclides. } \\
\hline & & \multicolumn{8}{|c|}{ Pretreated LAW Solution Source Tank Processed in WTP LAW Vitrification } \\
\hline & & AP-104 & AP-102 & AP-101 & AP-103 & AP-15 & AP-108 & AP-107 & AN-104 \\
\hline & $\mathbf{K} \mathbf{p}_{\mathbf{i}}$ & $\mathbf{S F}_{\mathbf{i}}$ & $\mathbf{S F}_{\mathbf{i}}$ & $\mathbf{S F}_{\mathbf{i}}$ & $\mathbf{S F}_{\mathrm{i}}$ & $\mathbf{S F}_{\mathbf{i}}$ & $\mathbf{S F}_{\mathbf{i}}$ & $\mathbf{S F}_{\mathbf{i}}$ & $\mathbf{S F}_{\mathbf{i}}$ \\
\hline $3 \mathrm{H}$ & $\begin{array}{c}\text { same as } \\
\text { WVR }\end{array}$ & 0.93 & 0.93 & 0.93 & 0.93 & 0.93 & 0.93 & 0.93 & 0.93 \\
\hline $14 \mathrm{C}$ & $1.00 \mathrm{E}+07$ & 0.0293247 & 0.0293247 & 0.0293247 & 0.0293247 & 0.0293247 & 0.0293247 & 0.0293247 & 0.0293247 \\
\hline $60 \mathrm{Co}$ & $7.00 \mathrm{E}+10$ & $4.316 \mathrm{E}-06$ & $4.316 \mathrm{E}-06$ & $4.316 \mathrm{E}-06$ & $4.316 \mathrm{E}-06$ & $4.316 \mathrm{E}-06$ & $4.316 \mathrm{E}-06$ & $4.316 \mathrm{E}-06$ & 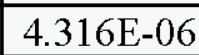 \\
\hline $79 \mathrm{Se}$ & $1.00 \mathrm{E}+07$ & 0.0293247 & 0.0293247 & 0.0293247 & 0.0293247 & 0.0293247 & 0.0293247 & 0.0293247 & 0.0293247 \\
\hline $90 \mathrm{Sr}$ & $2.30 \mathrm{E}+09$ & 0.0001313 & 0.0001313 & 0.0001313 & 0.0001313 & 0.0001313 & 0.0001313 & 0.0001313 & 0.0001313 \\
\hline \multicolumn{10}{|l|}{$* 94 \mathrm{Nb}$} \\
\hline $99 \mathrm{Tc}$ & $1.10 \mathrm{E}+11$ & $2.746 \mathrm{E}-06$ & \begin{tabular}{|l|}
$2.746 \mathrm{E}-06$ \\
\end{tabular} & \begin{tabular}{|l|}
$2.746 \mathrm{E}-06$ \\
\end{tabular} & \begin{tabular}{|l|}
$2.746 \mathrm{E}-06$ \\
\end{tabular} & \begin{tabular}{|l|}
$2.746 \mathrm{E}-06$ \\
\end{tabular} & \begin{tabular}{|l|}
$2.746 \mathrm{E}-06$ \\
\end{tabular} & \begin{tabular}{|l|}
$2.746 \mathrm{E}-06$ \\
\end{tabular} & \begin{tabular}{|l}
$2.746 \mathrm{E}-06$ \\
\end{tabular} \\
\hline $106 \mathrm{Ru}$ & $6.70 \mathrm{E}+07$ & 0.0044888 & 0.0044888 & 0.0044888 & 0.0044888 & 0.0044888 & 0.0044888 & 0.0044888 & 0.0044888 \\
\hline $129 \mathrm{I}$ & $4.00 \mathrm{E}+08$ & 0.0007547 & 0.0007547 & 0.0007547 & 0.0007547 & 0.0007547 & 0.0007547 & 0.0007547 & 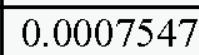 \\
\hline $134 \mathrm{Cs}$ & $1.00 \mathrm{E}+07$ & 0.0293247 & 0.0293247 & 0.0293247 & 0.0293247 & 0.0293247 & 0.0293247 & 0.0293247 & 0.0293247 \\
\hline $137 \mathrm{Cs}$ & $9.30 \mathrm{E}+11$ & $3.248 \mathrm{E}-07$ & \begin{tabular}{|c|}
$3.248 \mathrm{E}-07$ \\
\end{tabular} & $3.248 \mathrm{E}-07$ & $3.248 \mathrm{E}-07$ & $3.248 \mathrm{E}-07$ & $3.248 \mathrm{E}-07$ & $3.248 \mathrm{E}-07$ & 3.2 \\
\hline \multicolumn{10}{|l|}{$* 144 \mathrm{Ce}$} \\
\hline $154 \mathrm{Eu}$ & $1.00 \mathrm{E}+07$ & 0.0293247 & 0.0293247 & 0.0293247 & 0.0293247 & 0.0293247 & 0.0293247 & 0.0293247 & \begin{tabular}{|l|}
0.0293247 \\
\end{tabular} \\
\hline $155 \mathrm{Eu}$ & $1.00 \mathrm{E}+07$ & 0.0293247 & \begin{tabular}{|l}
0.0293247 \\
\end{tabular} & 0.0293 & 0.0293 & 0.0293247 & 0.0293247 & 0.0293247 & \begin{tabular}{|l}
0.0293247 \\
\end{tabular} \\
\hline $233 \mathrm{U}$ & $1.00 \mathrm{E}+07$ & 0.0293247 & 0.0293247 & 0.0293247 & 0.0293247 & 0.0293247 & 0.0293247 & 0.0293247 & 0.0293247 \\
\hline $234 \mathrm{U}$ & $1.00 \mathrm{E}+07$ & 0.0293247 & \begin{tabular}{|l}
0.0293247 \\
\end{tabular} & \begin{tabular}{|l}
0.0293247 \\
\end{tabular} & $\mid 0.0293247$ & $\mid 0.0293247$ & 0.0293247 & $\mid 0.0293247$ & \begin{tabular}{|l}
0.0293247 \\
\end{tabular} \\
\hline $235 \mathrm{U}$ & $1.00 \mathrm{E}+07$ & 0.0293247 & \begin{tabular}{|l|}
0.0293247 \\
\end{tabular} & 0.0293247 & 0.0293247 & 0.0293247 & 0.0293247 & 0.0293247 & 0.0293247 \\
\hline $237 \mathrm{~Np}$ & $3.70 \mathrm{E}+10$ & $8.165 \mathrm{E}-06$ & $8.165 \mathrm{E}-06$ & $8.165 \mathrm{E}-06$ & $8.165 \mathrm{E}-06$ & $8.165 \mathrm{E}-06$ & $8.165 \mathrm{E}-06$ & $8.165 \mathrm{E}-06$ & $8.165 \mathrm{E}-06$ \\
\hline $238 \mathrm{Pu}$ & $3.70 \mathrm{E}+10$ & $8.165 \mathrm{E}-06$ & \begin{tabular}{|c|c|}
$8.165 \mathrm{E}-06$ \\
\end{tabular} & $8.165 \mathrm{E}-06$ & $8.165 \mathrm{E}-06$ & $8.165 \mathrm{E}-06$ & $8.165 \mathrm{E}-06$ & $8.165 \mathrm{E}-06$ & \begin{tabular}{|l}
$8.165 \mathrm{E}-06$ \\
\end{tabular} \\
\hline $239 \mathrm{Pu}$ & $3.70 \mathrm{E}+10$ & $8.165 \mathrm{E}-06$ & \begin{tabular}{|l|}
$8.165 \mathrm{E}-06$ \\
\end{tabular} & \begin{tabular}{|l|}
$8.165 \mathrm{E}-06$ \\
\end{tabular} & \begin{tabular}{|l|}
$8.165 \mathrm{E}-06$ \\
\end{tabular} & \begin{tabular}{|l|}
$8.165 \mathrm{E}-06$ \\
\end{tabular} & \begin{tabular}{|l|}
$8.165 \mathrm{E}-06$ \\
\end{tabular} & \begin{tabular}{|l|}
$8.165 \mathrm{E}-06$ \\
\end{tabular} & \begin{tabular}{|l|}
$8.165 \mathrm{E}-06$ \\
\end{tabular} \\
\hline $240 \mathrm{Pu}$ & $1.00 \mathrm{E}+07$ & 0.0293247 & \begin{tabular}{|l}
0.0293247 \\
\end{tabular} & $\mid 0.0293247$ & 0.0293247 & 0.0293247 & 0.0293247 & 0.0293247 & \begin{tabular}{|l}
0.0293247 \\
\end{tabular} \\
\hline $241 \mathrm{Am}$ & $1.40 \mathrm{E}+10$ & $2.158 \mathrm{E}-05$ & \begin{tabular}{|c|}
$2.158 \mathrm{E}-05$ \\
\end{tabular} & $2.158 \mathrm{E}-05$ & $2.158 \mathrm{E}-05$ & $2.158 \mathrm{E}-05$ & $2.158 \mathrm{E}-05$ & $2.158 \mathrm{E}-05$ & 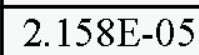 \\
\hline $241 \mathrm{Pu}$ & $1.00 \mathrm{E}+07$ & 0.0293247 & 0.0293247 & 0.0293247 & 0.0293247 & 0.0293247 & 0.0293247 & 0.0293247 & \begin{tabular}{|l|}
0.0293247 \\
\end{tabular} \\
\hline $243 \mathrm{Cm}$ & $1.00 \mathrm{E}+07$ & 0.0293247 & \begin{tabular}{|l}
0.0293247 \\
\end{tabular} & 0.0293247 & 0.0293247 & 0.0293247 & 0.0293247 & 0.0293247 & 0.0293247 \\
\hline $244 \mathrm{Cm}$ & $1.00 \mathrm{E}+07$ & 0.0293247 & \begin{tabular}{|l}
0.0293247 \\
\end{tabular} & 0.0293247 & 0.0293247 & 0.0293247 & 0.0293247 & 0.0293247 & 0.0293247 \\
\hline
\end{tabular}


The mass or activity of component $i$ in the process condensate can then be calculated from the split factor $\left(\mathrm{SF}_{i}\right)$ as follows:

$\mathrm{SF}_{i} *\left(\operatorname{mass}_{i}\right)_{\text {feed }}=\left(\operatorname{mass}_{i}\right)_{\text {condensate }}$

Equation 3a

$\mathrm{SF}_{i} *\left(\operatorname{activity}_{i}\right)_{\text {feed }}=\left(\operatorname{activity}_{i}\right)_{\text {condensate }}$

Equation $3 b$

Where:

$$
\begin{aligned}
& \left(\operatorname{mass}_{i}\right)_{\text {feed }}=\left(\mathrm{gm}_{i} / \mathrm{L}\right)_{\text {feed }} * \text { volume feed } \\
& \left(\mathrm{gm}_{i} / \mathrm{L}\right)_{\text {feed }}=\left(\mathrm{ppm}_{i}\right)_{\text {feed }} *(1 \mathrm{E}-06 \mathrm{gm} / \mathrm{ppm}) *(1 \mathrm{E}+03 \mathrm{ml} / \mathrm{L}) * e_{\text {feed }} \\
& \text { volume }_{\text {condensate }}=\mathrm{WVR} * \text { volume }_{\text {feed }} * 1.15 \\
& \left(\operatorname{mass}_{i}\right)_{\text {condensate }}=\text { volume condensate } *\left(\mathrm{gm}_{i} / \mathrm{L}\right) \text { condensate }
\end{aligned}
$$

Equation $4 \mathrm{a}$

Equation $4 b$

Equation 5

Equation 6

Substituting Equation 3a into Equation 6 and solving for concentration of component $i$ in the process condensate yields Equation 7:

$\left[\mathrm{SF}_{i} *\left(\operatorname{mass}_{i}\right)_{\text {feed }}\right] /$ volume condensate $=\left(\mathrm{gm}_{i} / \mathrm{L}\right)_{\text {condensate }}$

Equation 7

Substituting Equation 5 into Equation 7 and solving yields Equation 8:

$\left[\mathrm{SF}_{i} *\left(\operatorname{mass}_{i}\right)_{\text {feed }}\right] /\left[\mathrm{WVR} *\right.$ volume $\left._{\text {feed }} * 1.15\right]=\left(\mathrm{gm}_{i} / \mathrm{L}\right)_{\text {condensate }}$

Equation 8

Substituting Equation 4a into Equation 8 and solving yields Equation 9:

$\left[\mathrm{SF}_{i} *\left(\mathrm{gm}_{i} / \mathrm{L}\right)_{\text {feed }}\right] /[\mathrm{WVR} * 1.15]=\left(\mathrm{gm}_{i} / \mathrm{L}\right)_{\text {condensate }}$

Equation 9

Substituting Equation $4 \mathrm{~b}$ into Equation 9 and solving yields Equation 10:

$\left[\mathrm{SF}_{i} *\left(\mathrm{ppm}_{i}\right)_{\text {feed }} * \boldsymbol{e r}_{\text {feed }}\right] /\left[\mathrm{WVR} * 1.15 * \boldsymbol{e r}_{\text {cond. }}\right]=\left(\mathrm{ppm}_{i}\right)$ cond.

Equation 10

Assuming the density of the condensate ( $\boldsymbol{e r}_{\text {cond. }}$ ) is $1 \mathrm{gm} / \mathrm{ml}$ and using the density of the feeds

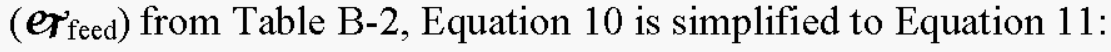

$\left[\mathrm{SF}_{i} *\left(\mathrm{ppm}_{i}\right)_{\text {feed }} * 1.02\right] /[\mathrm{WVR} * 1.15]=\left(\mathrm{ppm}_{i}\right)$ cond

Equation 11 
Similarly, the above equations can be solved to determine the activity of component $i$ in the process condensate yielding Equation 12:

$\left[\mathrm{SF}_{i} *(\mathrm{Ci} / \mathrm{L})_{i}\right.$ feed $\left.* 1.02\right] /[\mathrm{WVR} * 1.15]=\mathrm{Ci} / \mathrm{L}_{i}$ cond

Equation 12

Equations 11 and 12 have been used along with the mass (Table B-1) or activity (Table B-2) of component $i$ in the feed, the waste volume reduction factors (Table B-3), and the split factor for component $i$ (Tables B-5 and B-6) to solve for the mass or activity of component $i$ in the condensate in Tables B-7 and B-8.

\begin{tabular}{|c|c|c|c|c|c|c|c|c|}
\hline & AP-104 & AP-102 & AP-101 & AP-103 & AP-15 & AP-108 & AP-107 & $\overline{A N-104}$ \\
\hline $\mathrm{Al}$ & $2.30 \mathrm{E}-01$ & $2.69 \mathrm{E}-01$ & $2.04 \mathrm{E}-01$ & $2.45 \mathrm{E}-01$ & 2.29E-01 & $2.50 \mathrm{E}-01$ & 2.03E-01 & $3.25 \mathrm{E}-01$ \\
\hline $\mathrm{B}$ & $2.79 \mathrm{E}+00$ & $2.76 \mathrm{E}+00$ & $2.81 \mathrm{E}+00$ & $2.75 \mathrm{E}+00$ & $2.76 \mathrm{E}+00$ & $2.76 \mathrm{E}+00$ & $2.77 \mathrm{E}+00$ & $2.79 \mathrm{E}+00$ \\
\hline $\mathrm{Ca}$ & $6.04 \mathrm{E}-02$ & $5.98 \mathrm{E}-02$ & $6.07 \mathrm{E}-02$ & $5.96 \mathrm{E}-02$ & $5.97 \mathrm{E}-02$ & $5.96 \mathrm{E}-02$ & $5.98 \mathrm{E}-02$ & $6.04 \mathrm{E}-02$ \\
\hline $\mathrm{Cl}$ & $4.07 \mathrm{E}+01$ & $4.65 \mathrm{E}+01$ & $2.34 \mathrm{E}+01$ & $4.37 \mathrm{E}+01$ & $5.69 \mathrm{E}+01$ & $3.75 \mathrm{E}+01$ & $2.43 \mathrm{E}+01$ & $6.06 \mathrm{E}+01$ \\
\hline $\mathrm{Cr}$ & $7.36 \mathrm{E}-03$ & $6.67 \mathrm{E}-03$ & $9.54 \mathrm{E}-03$ & $6.82 \mathrm{E}-03$ & $3.54 \mathrm{E}-03$ & $7.53 \mathrm{E}-03$ & $1.17 \mathrm{E}-02$ & $4.12 \mathrm{E}-03$ \\
\hline $\mathrm{F}$ & $9.38 \mathrm{E}-02$ & $6.25 \mathrm{E}-03$ & $1.19 \mathrm{E}-01$ & $9.60 \mathrm{E}-02$ & $2.00 \mathrm{E}-02$ & $4.66 \mathrm{E}-02$ & $1.10 \mathrm{E}-01$ & $7.29 \mathrm{E}-02$ \\
\hline $\mathrm{Fe}$ & $2.21 \mathrm{E}-01$ & $2.19 \mathrm{E}-01$ & $2.22 \mathrm{E}-01$ & $2.18 \mathrm{E}-01$ & $2.18 \mathrm{E}-01$ & $2.19 \mathrm{E}-01$ & $2.19 \mathrm{E}-01$ & $2.21 \mathrm{E}-01$ \\
\hline $\mathrm{Hg}$ & $2.24 \mathrm{E}-04$ & $3.40 \mathrm{E}-08$ & $1.53 \mathrm{E}-04$ & $3.29 \mathrm{E}-04$ & $2.19 \mathrm{E}-05$ & $6.02 \mathrm{E}-06$ & $7.09 \mathrm{E}-04$ & $0.00 \mathrm{E}+00$ \\
\hline $\mathrm{K}$ & $1.25 \mathrm{E}+00$ & $9.19 \mathrm{E}-01$ & $1.58 \mathrm{E}+00$ & $9.95 \mathrm{E}-01$ & $7.15 \mathrm{E}-01$ & $1.83 \mathrm{E}+00$ & $7.89 \mathrm{E}-01$ & $5.69 \mathrm{E}-01$ \\
\hline $\mathrm{Mg}$ & $1.52 \mathrm{E}-02$ & $1.50 \mathrm{E}-02$ & $1.53 \mathrm{E}-02$ & $1.50 \mathrm{E}-02$ & $1.50 \mathrm{E}-02$ & $1.50 \mathrm{E}-02$ & $1.50 \mathrm{E}-02$ & $1.52 \mathrm{E}-02$ \\
\hline $\mathrm{Mn}$ & $9.03 \mathrm{E}-05$ & $5.89 \mathrm{E}-05$ & $1.11 \mathrm{E}-04$ & $6.97 \mathrm{E}-05$ & $3.22 \mathrm{E}-05$ & $3.75 \mathrm{E}-05$ & $5.70 \mathrm{E}-05$ & $1.46 \mathrm{E}-05$ \\
\hline $\mathrm{Na}$ & $7.99 \mathrm{E}-01$ & $7.91 \mathrm{E}-01$ & $8.03 \mathrm{E}-01$ & $7.88 \mathrm{E}-01$ & $7.88 \mathrm{E}-01$ & $7.89 \mathrm{E}-01$ & $7.91 \mathrm{E}-01$ & $7.99 \mathrm{E}-01$ \\
\hline$\overline{\mathrm{NH} 4}$ & $6.03 \mathrm{E}+01$ & $5.97 \mathrm{E}+01$ & $6.06 \mathrm{E}+01$ & $5.95 \mathrm{E}+01$ & $5.95 \mathrm{E}+01$ & $5.95 \mathrm{E}+01$ & $5.97 \mathrm{E}+01$ & $6.03 \mathrm{E}+01$ \\
\hline $\mathrm{Ni}$ & $2.09 \mathrm{E}-03$ & $4.65 \mathrm{E}-04$ & $8.67 \mathrm{E}-04$ & $3.15 \mathrm{E}-03$ & $4.49 \mathrm{E}-03$ & $1.39 \mathrm{E}-03$ & $7.47 \mathrm{E}-04$ & $3.54 \mathrm{E}-05$ \\
\hline NO2 & $3.68 \mathrm{E}+00$ & $3.64 \mathrm{E}+00$ & $3.70 \mathrm{E}+00$ & $3.63 \mathrm{E}+00$ & $3.63 \mathrm{E}+00$ & $3.63 \mathrm{E}+00$ & $3.64 \mathrm{E}+00$ & $3.68 \mathrm{E}+00$ \\
\hline $\mathrm{NO3}$ & $6.70 \mathrm{E}+00$ & $6.63 \mathrm{E}+00$ & $6.74 \mathrm{E}+00$ & $6.60 \mathrm{E}+00$ & $6.61 \mathrm{E}+00$ & $6.61 \mathrm{E}+00$ & $6.63 \mathrm{E}+00$ & $6.70 \mathrm{E}+00$ \\
\hline $\mathrm{Pb}$ & $4.13 \mathrm{E}-02$ & $1.13 \mathrm{E}-01$ & $4.81 \mathrm{E}-02$ & $5.52 \mathrm{E}-02$ & $4.04 \mathrm{E}-02$ & $4.40 \mathrm{E}-02$ & $3.82 \mathrm{E}-02$ & $1.54 \mathrm{E}-02$ \\
\hline PO4 & $6.41 \mathrm{E}-01$ & $2.89 \mathrm{E}-01$ & $5.74 \mathrm{E}-01$ & $5.06 \mathrm{E}-01$ & $3.69 \mathrm{E}-01$ & $1.66 \mathrm{E}-01$ & $5.03 \mathrm{E}-01$ & $3.61 \mathrm{E}-01$ \\
\hline $\mathrm{CO} 3$ & $1.27 \mathrm{E}+01$ & $1.26 \mathrm{E}+01$ & $1.28 \mathrm{E}+01$ & $1.26 \mathrm{E}+01$ & $1.26 \mathrm{E}+01$ & $1.26 \mathrm{E}+01$ & $1.26 \mathrm{E}+01$ & $1.27 \mathrm{E}+01$ \\
\hline $\mathrm{Si}$ & $6.28 \mathrm{E}-01$ & $6.22 \mathrm{E}-01$ & $6.32 \mathrm{E}-01$ & $6.20 \mathrm{E}-01$ & $6.20 \mathrm{E}-01$ & $6.20 \mathrm{E}-01$ & $6.22 \mathrm{E}-01$ & $6.29 \mathrm{E}-01$ \\
\hline $\mathrm{SO} 4$ & $5.28 \mathrm{E}-01$ & $2.48 \mathrm{E}-01$ & $8.80 \mathrm{E}-01$ & $4.53 \mathrm{E}-01$ & $4.72 \mathrm{E}-01$ & $3.60 \mathrm{E}-01$ & $1.34 \mathrm{E}+00$ & $7.60 \mathrm{E}-01$ \\
\hline TOC & $8.55 \mathrm{E}-04$ & $4.88 \mathrm{E}-04$ & $4.99 \mathrm{E}-04$ & $1.38 \mathrm{E}-03$ & $9.57 \mathrm{E}-04$ & $6.40 \mathrm{E}-04$ & $5.38 \mathrm{E}-04$ & $3.73 \mathrm{E}-04$ \\
\hline $\mathrm{Zn}$ & $8.73 \mathrm{E}-01$ & $8.65 \mathrm{E}-01$ & $8.78 \mathrm{E}-01$ & $8.62 \mathrm{E}-01$ & $8.62 \mathrm{E}-01$ & $8.63 \mathrm{E}-01$ & $8.65 \mathrm{E}-01$ & $8.74 \mathrm{E}-01$ \\
\hline
\end{tabular}




\begin{tabular}{|c|c|c|c|c|c|c|c|c|}
\hline \multicolumn{9}{|c|}{ Table B-8. Condensate Composition - Radionuclides (Ci/L). } \\
\hline & AP-104 & AP-102 & AP-101 & AP-103 & AP-15 & AP-108 & AP-107 & $\mathrm{AN}-104$ \\
\hline $3 \mathrm{H}$ & $9.00 \mathrm{E}-07$ & $7.03 \mathrm{E}-06$ & $2.63 \mathrm{E}-05$ & $1.93 \mathrm{E}-05$ & $4.40 \mathrm{E}-06$ & $7.31 \mathrm{E}-06$ & $2.78 \mathrm{E}-05$ & $3.07 \mathrm{E}-06$ \\
\hline $14 \mathrm{C}$ & $1.45 \mathrm{E}-08$ & $2.91 \mathrm{E}-08$ & $4.34 \mathrm{E}-08$ & $6.60 \mathrm{E}-08$ & $2.44 \mathrm{E}-08$ & $2.42 \mathrm{E}-08$ & $3.73 \mathrm{E}-08$ & $2.96 \mathrm{E}-08$ \\
\hline $60 \mathrm{Co}$ & $9.15 \mathrm{E}-14$ & $5.37 \mathrm{E}-14$ & $7.89 \mathrm{E}-14$ & $1.30 \mathrm{E}-13$ & $9.46 \mathrm{E}-14$ & $5.14 \mathrm{E}-14$ & $1.34 \mathrm{E}-13$ & $1.18 \mathrm{E}-15$ \\
\hline $79 \mathrm{Se}$ & $2.31 \mathrm{E}-09$ & $5.84 \mathrm{E}-09$ & $2.45 \mathrm{E}-09$ & $4.13 \mathrm{E}-09$ & $6.75 \mathrm{E}-09$ & $3.83 \mathrm{E}-09$ & $3.06 \mathrm{E}-09$ & $2.60 \mathrm{E}-09$ \\
\hline $90 \mathrm{Sr}$ & $5.85 \mathrm{E}-10$ & $1.69 \mathrm{E}-10$ & $3.72 \mathrm{E}-10$ & $8.91 \mathrm{E}-10$ & $7.15 \mathrm{E}-10$ & $3.96 \mathrm{E}-10$ & $7.80 \mathrm{E}-10$ & $4.24 \mathrm{E}-10$ \\
\hline $99 \mathrm{Tc}$ & $1.00 \mathrm{E}-10$ & $1.02 \mathrm{E}-10$ & $9.71 \mathrm{E}-11$ & $1.31 \mathrm{E}-10$ & $1.27 \mathrm{E}-10$ & $8.63 \mathrm{E}-11$ & $1.30 \mathrm{E}-10$ & $1.19 \mathrm{E}-10$ \\
\hline $106 \mathrm{Ru}$ & $9.59 \mathrm{E}-11$ & $6.10 \mathrm{E}-11$ & $7.43 \mathrm{E}-05$ & $8.97 \mathrm{E}-11$ & $4.97 \mathrm{E}-06$ & $3.65 \mathrm{E}-10$ & $2.55 \mathrm{E}-04$ & $4.08 \mathrm{E}-09$ \\
\hline 129I & $1.73 \mathrm{E}-11$ & $3.09 \mathrm{E}-11$ & 1.6 & 3.05 & $2.42 \mathrm{E}$ & 2.1 & $1.53 \mathrm{E}-11$ & $1.16 \mathrm{E}-11$ \\
\hline $134 \mathrm{Cs}$ & $1.48 \mathrm{E}-12$ & $9.60 \mathrm{E}-14$ & $2.09 \mathrm{E}-11$ & & $1.67 \mathrm{E}-12$ & 2.2 & $3.00 \mathrm{E}-11$ & $7.06 \mathrm{E}-13$ \\
\hline $137 \mathrm{Cs}$ & $1.46 \mathrm{E}-12$ & $1.44 \mathrm{E}-12$ & $1.46 \mathrm{E}-12$ & $1.44 \mathrm{E}-12$ & $1.44 \mathrm{E}-12$ & $1.44 \mathrm{E}-12$ & $1.44 \mathrm{E}-12$ & $1.46 \mathrm{E}-12$ \\
\hline $154 \mathrm{Eu}$ & $7.50 \mathrm{E}-10$ & $3.04 \mathrm{E}-09$ & $2.06 \mathrm{E}-09$ & $1.31 \mathrm{E}-09$ & $4.14 \mathrm{E}-09$ & $1.31 \mathrm{E}-09$ & $3.54 \mathrm{E}-09$ & $4.22 \mathrm{E}-16$ \\
\hline $155 \mathrm{Eu}$ & $1.87 \mathrm{E}-09$ & $1.71 \mathrm{E}-09$ & $3.51 \mathrm{E}-09$ & $1.72 \mathrm{E}-09$ & $3.66 \mathrm{E}-09$ & $1.42 \mathrm{E}-09$ & $6.08 \mathrm{E}-09$ & $1.63 \mathrm{E}-16$ \\
\hline $233 \mathrm{U}$ & $2.09 \mathrm{E}-12$ & $2.63 \mathrm{E}-12$ & $1.73 \mathrm{E}-12$ & $1.35 \mathrm{E}-12$ & $4.95 \mathrm{E}-13$ & $1.35 \mathrm{E}-12$ & $1.49 \mathrm{E}-12$ & $6.61 \mathrm{E}-13$ \\
\hline $234 \mathrm{U}$ & $1.13 \mathrm{E}-12$ & $4.86 \mathrm{E}-13$ & $1.18 \mathrm{E}-12$ & $9.73 \mathrm{E}-13$ & $1.65 \mathrm{E}-13$ & $9.36 \mathrm{E}-13$ & $1.20 \mathrm{E}-12$ & $4.70 \mathrm{E}-13$ \\
\hline $235 \mathrm{U}$ & $4.37 \mathrm{E}-14$ & $1.93 \mathrm{E}-14$ & $4.39 \mathrm{E}-14$ & $4.16 \mathrm{E}-14$ & $6.70 \mathrm{E}-15$ & $3.65 \mathrm{E}-14$ & $4.89 \mathrm{E}-14$ & $1.85 \mathrm{E}-14$ \\
\hline $237 \mathrm{~Np}$ & $1.34 \mathrm{E}-15$ & $1.29 \mathrm{E}-14$ & $5.78 \mathrm{E}-15$ & $1.30 \mathrm{E}-15$ & $1.26 \mathrm{E}-14$ & $1.23 \mathrm{E}-15$ & $5.50 \mathrm{E}-15$ & $2.59 \mathrm{E}-16$ \\
\hline $238 \mathrm{Pu}$ & $3.29 \mathrm{E}-15$ & $2.19 \mathrm{E}-16$ & $3.56 \mathrm{E}-15$ & $4.98 \mathrm{E}-15$ & $3.63 \mathrm{E}-16$ & $6.00 \mathrm{E}-16$ & $1.10 \mathrm{E}-14$ & $1.42 \mathrm{E}-16$ \\
\hline $239 \mathrm{Pu}$ & $1.72 \mathrm{E}-14$ & $8.39 \mathrm{E}-15$ & $4.92 \mathrm{E}-14$ & $3.62 \mathrm{E}-14$ & 7.12E-15 & $9.67 \mathrm{E}-15$ & $1.19 \mathrm{E}-13$ & $1.96 \mathrm{E}-15$ \\
\hline $240 \mathrm{Pu}$ & $7.68 \mathrm{E}-11$ & $3.74 \mathrm{E}-11$ & $3.03 \mathrm{E}-10$ & $1.60 \mathrm{E}-10$ & $3.73 \mathrm{E}-11$ & $4.84 \mathrm{E}-11$ & $8.35 \mathrm{E}-10$ & $1.34 \mathrm{E}-11$ \\
\hline $241 \mathrm{Am}$ & $2.70 \mathrm{E}-13$ & $2.41 \mathrm{E}-13$ & $8.29 \mathrm{E}-14$ & $9.05 \mathrm{E}-13$ & $2.72 \mathrm{E}-13$ & $2.33 \mathrm{E}-13$ & $1.06 \mathrm{E}-13$ & $1.65 \mathrm{E}-13$ \\
\hline $241 \mathrm{Pu}$ & $7.14 \mathrm{E}-11$ & $3.62 \mathrm{E}-11$ & $8.56 \mathrm{E}-10$ & $1.58 \mathrm{E}-10$ & $7.62 \mathrm{E}-11$ & $8.35 \mathrm{E}-11$ & $2.79 \mathrm{E}-09$ & $3.21 \mathrm{E}-11$ \\
\hline $243 \mathrm{Cm}$ & $2.26 \mathrm{E}-12$ & $6.98 \mathrm{E}-14$ & $1.29 \mathrm{E}-13$ & $1.47 \mathrm{E}-12$ & $1.27 \mathrm{E}-13$ & $1.09 \mathrm{E}-13$ & $5.31 \mathrm{E}-14$ & $1.27 \mathrm{E}-14$ \\
\hline $244 \mathrm{Cm}$ & $5.30 \mathrm{E}-11$ & $1.01 \mathrm{E}-12$ & $2.90 \mathrm{E}-12$ & $3.21 \mathrm{E}-11$ & $2.17 \mathrm{E}-12$ & $1.83 \mathrm{E}-12$ & $1.16 \mathrm{E}-12$ & $3.00 \mathrm{E}-13$ \\
\hline
\end{tabular}

\section{B4.0 CONCENTRATE COMPOSITION}

The concentration of component $i$ in concentrate produced in the SWE system is the mass of component $i$ divided by the volume of the concentrate as expressed by Equation 13. The mass of component $i$ in the concentrate can be determined by subtracting the mass of component $i$ in the process condensate from the mass of component $i$ in the feed to the SWE system as expressed by Equation 14. The volume of the concentrate is determined using Equation 15 and the waste volume reduction factor for the feed (Table B-3).

Equation 13

Component $_{i}(\mathrm{gm} / \mathrm{L})=\left[\operatorname{mass}_{i} /\right.$ volume $_{\text {concentrate }}$

Equation 14

$\left[\operatorname{mass}_{i}\right]_{\text {concentrate }}=\left[\operatorname{mass}_{i}\right]_{\text {feed }}-\left[\operatorname{mass}_{i}\right]_{\text {condensate }}$

Equation $15 \mathrm{a}$

volume $_{\text {concentrate }}=(1-\mathrm{WVR}) *$ volume $_{\text {feed }}$

Equation $15 b$

volume $_{\text {feed }}=$ volume $_{\text {concentrate }} /(1-\mathrm{WVR})$

Substituting Equation 3) into Equation 15 and rearranging yields Equation 16:

$\left[\operatorname{mass}_{i}\right]_{\text {concentrate }}=\left[\operatorname{mass}_{i}\right]_{\text {feed }} *\left(1-\mathrm{SF}_{i}\right)$ 
Substituting Equation 4a into Equation 16 yields Equation 17:

$\left[\text { mass }_{i}\right]_{\text {concentrate }}=\left[\left(\mathrm{gm}_{i} / \mathrm{L}\right)_{\text {feed }} *\right.$ volume feed $] *\left(1-\mathrm{SF}_{i}\right)$

Equation 17

Substituting Equation $4 \mathrm{~b}$ into Equation 17 yields Equation 18:

Equation 18

$\left[\operatorname{mass}_{i}\right]_{\mathrm{concentrate}}=\left[\left(\mathrm{ppm}_{i}\right)_{\text {feed }} *(1 \mathrm{E}-06 \mathrm{gm} / \mathrm{ppm}) *(1 \mathrm{E}+03 \mathrm{ml} / \mathrm{L}) * \boldsymbol{e r}_{\text {feed }} *\right.$ volume feed $] *\left(1-\mathrm{SF}_{i}\right)$

Substituting Equation 15b into Equation 18 and rearranging yields Equation 19:

$\left[\operatorname{mass}_{i} / \text { volume }\right]_{\text {concentrate }}=\left[\left(\mathrm{ppm}_{i}\right)_{\text {feed }} * 1 \mathrm{E}-03 * \boldsymbol{e r}_{\text {feed }} *\left(1-\mathrm{SF}_{i}\right) /(1-\mathrm{WVR})\right.$

Similarly, the above equations can be solved to determine the concentration of radionuclide component $i$ in the concentrate yielding Equation 20:

$\left[\text { activity }_{i} / \text { volume }\right]_{\text {concentrate }}=\left[\left(\mathrm{ppm}_{i}\right)_{\text {feed }} * 1 \mathrm{E}-03 * \boldsymbol{e}_{\text {feed }} *\left(1-\mathrm{SF}_{i}\right) /(1-\mathrm{WVR})\right.$

Table B-9 provides the concentration of component $i$ in the concentrate based on Equation 19, the SWE system feed (Table B-1), the separation factors (Table B-5), and the waste volume reduction factors (Table B-3). Table B-10 provides the concentration of radionuclide component $i$ in the concentrate based on Equation 20, the SWE system feed (Table B-2), the separation factors (Table B-5), and the waste volume reduction factors (Table B-3). 
RPP-RPT-37924, Rev. 0

\begin{tabular}{|c|c|c|c|c|c|c|c|c|}
\hline \multicolumn{9}{|c|}{ Table B-9. Concentrate Composition - Analytes (gm/L). } \\
\hline & AP-104 & AP-102 & AP-101 & AP-103 & AP-15 & AP-108 & AP-107 & $\mathrm{AN}-104$ \\
\hline $\mathrm{Al}$ & $1.84 \mathrm{E}-01$ & $2.15 \mathrm{E}-01$ & $1.63 \mathrm{E}-01$ & $1.96 \mathrm{E}-01$ & $1.83 \mathrm{E}-01$ & $2.00 \mathrm{E}-01$ & $1.62 \mathrm{E}-01$ & $2.60 \mathrm{E}-01$ \\
\hline $\bar{B}$ & $1.49 \mathrm{E}+00$ & $1.47 \mathrm{E}+00$ & $1.50 \mathrm{E}+00$ & $1.47 \mathrm{E}+00$ & $1.47 \mathrm{E}+00$ & $1.47 \mathrm{E}+00$ & $1.47 \mathrm{E}+00$ & $1.49 \mathrm{E}+00$ \\
\hline $\mathrm{Ca}$ & $3.22 \mathrm{E}-02$ & $3.18 \mathrm{E}-02$ & $3.24 \mathrm{E}-02$ & $3.18 \mathrm{E}-02$ & $3.18 \mathrm{E}-02$ & $3.18 \mathrm{E}-02$ & $3.19 \mathrm{E}-02$ & $3.22 \mathrm{E}-02$ \\
\hline $\mathrm{Cl}$ & $1.13 \mathrm{E}+01$ & $1.29 \mathrm{E}+01$ & $6.48 \mathrm{E}+00$ & $1.21 \mathrm{E}+01$ & $1.58 \mathrm{E}+01$ & $1.04 \mathrm{E}+01$ & $6.73 \mathrm{E}+00$ & $1.68 \mathrm{E}+01$ \\
\hline $\mathrm{Cr}$ & $1.37 \mathrm{E}-01$ & $1.24 \mathrm{E}-01$ & $1.78 \mathrm{E}-01$ & $1.27 \mathrm{E}-01$ & $6.60 \mathrm{E}-02$ & $1.41 \mathrm{E}-01$ & $2.17 \mathrm{E}-01$ & $7.69 \mathrm{E}-02$ \\
\hline $\mathrm{F}$ & $1.20 \mathrm{E}+00$ & $8.00 \mathrm{E}-02$ & $1.53 \mathrm{E}+00$ & $1.23 \mathrm{E}+00$ & $2.55 \mathrm{E}-01$ & $5.96 \mathrm{E}-01$ & $1.40 \mathrm{E}+00$ & $9.33 \mathrm{E}-01$ \\
\hline $\mathrm{Fe}$ & $1.18 \mathrm{E}-01$ & $1.17 \mathrm{E}-01$ & $1.19 \mathrm{E}-01$ & $1.16 \mathrm{E}-01$ & $1.16 \mathrm{E}-01$ & $1.16 \mathrm{E}-01$ & $1.17 \mathrm{E}-01$ & $1.18 \mathrm{E}-01$ \\
\hline $\mathrm{Hg}$ & $1.19 \mathrm{E}-04$ & $1.81 \mathrm{E}-08$ & $8.14 \mathrm{E}-05$ & $1.75 \mathrm{E}-04$ & $1.16 \mathrm{E}-05$ & $3.21 \mathrm{E}-06$ & $3.78 \mathrm{E}-04$ & $0.00 \mathrm{E}+00$ \\
\hline $\mathrm{K}$ & $6.64 \mathrm{E}-01$ & $4.90 \mathrm{E}-01$ & $8.41 \mathrm{E}-01$ & $5.30 \mathrm{E}-01$ & $3.81 \mathrm{E}-01$ & $9.77 \mathrm{E}-01$ & $4.21 \mathrm{E}-01$ & $3.03 \mathrm{E}-01$ \\
\hline $\mathrm{Mg}$ & $8.09 \mathrm{E}-03$ & $8.01 \mathrm{E}-03$ & $8.14 \mathrm{E}-03$ & $7.98 \mathrm{E}-03$ & $7.99 \mathrm{E}-03$ & $8.00 \mathrm{E}-03$ & \begin{tabular}{|c|}
$8.02 \mathrm{E}-03$ \\
\end{tabular} & $8.10 \mathrm{E}-03$ \\
\hline $\mathrm{Mn}$ & $4.81 \mathrm{E}-05$ & $3.14 \mathrm{E}-05$ & $5.94 \mathrm{E}-05$ & $3.71 \mathrm{E}-05$ & $1.72 \mathrm{E}-05$ & $2.00 \mathrm{E}-05$ & $3.04 \mathrm{E}-05$ & $7.80 \mathrm{E}-06$ \\
\hline$\overline{\mathrm{Na}}$ & $1.28 \mathrm{E}+01$ & $1.26 \mathrm{E}+01$ & $1.28 \mathrm{E}+01$ & $1.26 \mathrm{E}+01$ & $1.26 \mathrm{E}+01$ & $1.26 \mathrm{E}+01$ & $1.26 \mathrm{E}+01$ & $1.28 \mathrm{E}+01$ \\
\hline $\mathrm{NH} 4$ & $3.53 \mathrm{E}-03$ & $3.50 \mathrm{E}-03$ & $3.55 \mathrm{E}-03$ & $3.49 \mathrm{E}-03$ & $3.49 \mathrm{E}-03$ & $3.49 \mathrm{E}-03$ & $3.50 \mathrm{E}-03$ & $3.54 \mathrm{E}-03$ \\
\hline $\mathrm{Ni}$ & $1.11 \mathrm{E}-03$ & $2.48 \mathrm{E}-04$ & $4.62 \mathrm{E}-04$ & $1.68 \mathrm{E}-03$ & $2.39 \mathrm{E}-03$ & $7.39 \mathrm{E}-04$ & $3.98 \mathrm{E}-04$ & $1.89 \mathrm{E}-05$ \\
\hline $\mathrm{NO} 2$ & $4.70 \mathrm{E}+00$ & $4.66 \mathrm{E}+00$ & $4.73 \mathrm{E}+00$ & $4.64 \mathrm{E}+00$ & $4.64 \mathrm{E}+00$ & $4.65 \mathrm{E}+00$ & $4.66 \mathrm{E}+00$ & $4.71 \mathrm{E}+00$ \\
\hline $\mathrm{NO} 3$ & $2.03 \mathrm{E}+00$ & $2.01 \mathrm{E}+00$ & $2.05 \mathrm{E}+00$ & $2.01 \mathrm{E}+00$ & $2.01 \mathrm{E}+00$ & $2.01 \mathrm{E}+00$ & $2.01 \mathrm{E}+00$ & $2.04 \mathrm{E}+00$ \\
\hline $\mathrm{Pb}$ & $6.60 \mathrm{E}-04$ & $1.81 \mathrm{E}-03$ & $7.69 \mathrm{E}-04$ & $8.82 \mathrm{E}-04$ & $6.45 \mathrm{E}-04$ & $7.04 \mathrm{E}-04$ & $6.11 \mathrm{E}-04$ & $2.46 \mathrm{E}-04$ \\
\hline PO4 & $3.42 \mathrm{E}-01$ & $1.54 \mathrm{E}-01$ & $3.06 \mathrm{E}-01$ & $2.70 \mathrm{E}-01$ & $1.97 \mathrm{E}-01$ & $8.87 \mathrm{E}-02$ & $2.68 \mathrm{E}-01$ & $1.92 \mathrm{E}-01$ \\
\hline $\mathrm{CO} 3$ & $6.78 \mathrm{E}+00$ & $6.71 \mathrm{E}+00$ & $6.82 \mathrm{E}+00$ & $6.69 \mathrm{E}+00$ & $6.69 \mathrm{E}+00$ & $6.70 \mathrm{E}+00$ & $6.72 \mathrm{E}+00$ & $6.79 \mathrm{E}+00$ \\
\hline $\mathrm{Si}$ & $3.35 \mathrm{E}-01$ & $3.31 \mathrm{E}-01$ & & 3.3 & $3.30 \mathrm{E}-01$ & 3.3 & $3.31 \mathrm{E}-01$ & $3.35 \mathrm{E}-01$ \\
\hline SO4 & $3.94 \mathrm{E}-01$ & $1.85 \mathrm{E}-01$ & $6.56 \mathrm{E}-01$ & 3.38 & $3.52 \mathrm{E}-01$ & $2.69 \mathrm{E}-01$ & $1.00 \mathrm{E}+00$ & $5.67 \mathrm{E}-01$ \\
\hline TOC & $4.56 \mathrm{E}-04$ & $2.60 \mathrm{E}-04$ & $2.66 \mathrm{E}-04$ & $7.33 \mathrm{E}-04$ & $5.10 \mathrm{E}-04$ & $3.41 \mathrm{E}-04$ & $2.87 \mathrm{E}-04$ & $1.99 \mathrm{E}-04$ \\
\hline $\mathrm{Zn}$ & $4.65 \mathrm{E}-01$ & $4.61 \mathrm{E}-01$ & $4.68 \mathrm{E}-01$ & $4.59 \mathrm{E}-01$ & $4.59 \mathrm{E}-01$ & $4.60 \mathrm{E}-01$ & $4.61 \mathrm{E}-01$ & $4.66 \mathrm{E}-01$ \\
\hline $\mathrm{Lpm}$ & 1.44 & 1.46 & 1.44 & 1.46 & 1.46 & 1.46 & 1.46 & 1.44 \\
\hline Volume $(\mathrm{kL})$ & $3.56 \mathrm{E}+02$ & $3.63 \mathrm{E}+02$ & $3.99 \mathrm{E}+02$ & $4.07 \mathrm{E}+02$ & $3.97 \mathrm{E}+02$ & $4.41 \mathrm{E}+02$ & $3.82 \mathrm{E}+02$ & $3.70 \mathrm{E}+02$ \\
\hline
\end{tabular}


RPP-RPT-37924, Rev. 0

\begin{tabular}{|c|c|c|c|c|c|c|c|c|}
\hline \multicolumn{9}{|c|}{ Table B-10. Concentrate Composition - Radionuclides (Ci/L). } \\
\hline & $\mathrm{AP}-104$ & $\mathrm{AP}-102$ & $\mathrm{AP}-101$ & $\mathrm{AP}-103$ & $\mathrm{AP}-15$ & $\mathrm{AP}-108$ & $\mathrm{AP}-107$ & AN-104 \\
\hline $3 \mathrm{H}$ & $1.03 \mathrm{E}-09$ & $8.08 \mathrm{E}-09$ & $3.02 \mathrm{E}-08$ & $2.22 \mathrm{E}-08$ & $5.06 \mathrm{E}-09$ & $8.41 \mathrm{E}-09$ & $3.19 \mathrm{E}-08$ & $3.53 \mathrm{E}-09$ \\
\hline $14 \mathrm{C}$ & $7.75 \mathrm{E}-09$ & $1.55 \mathrm{E}-08$ & $2.31 \mathrm{E}-08$ & $3.52 \mathrm{E}-08$ & $1.30 \mathrm{E}-08$ & $1.29 \mathrm{E}-08$ & $1.99 \mathrm{E}-08$ & $1.58 \mathrm{E}-08$ \\
\hline $60 \mathrm{Co}$ & $3.41 \mathrm{E}-10$ & $2.00 \mathrm{E}-10$ & $2.94 \mathrm{E}-10$ & $4.87 \mathrm{E}-10$ & $3.53 \mathrm{E}-10$ & $1.92 \mathrm{E}-10$ & $5.00 \mathrm{E}-10$ & $4.40 \mathrm{E}-12$ \\
\hline $79 \mathrm{Se}$ & $1.23 \mathrm{E}-09$ & $3.11 \mathrm{E}-09$ & $1.30 \mathrm{E}-09$ & $2.20 \mathrm{E}-09$ & $3.60 \mathrm{E}-09$ & $2.04 \mathrm{E}-09$ & $1.63 \mathrm{E}-09$ & $1.39 \mathrm{E}-09$ \\
\hline $90 \mathrm{Sr}$ & $7.17 \mathrm{E}-08$ & $2.07 \mathrm{E}-08$ & $4.56 \mathrm{E}-08$ & $1.09 \mathrm{E}-07$ & $8.77 \mathrm{E}-08$ & $4.86 \mathrm{E}-08$ & $9.56 \mathrm{E}-08$ & $5.19 \mathrm{E}-08$ \\
\hline $99 \mathrm{Tc}$ & $5.88 \mathrm{E}-07$ & $5.98 \mathrm{E}-07$ & $5.69 \mathrm{E}-07$ & $7.69 \mathrm{E}-07$ & $7.47 \mathrm{E}-07$ & $5.06 \mathrm{E}-07$ & $7.64 \mathrm{E}-07$ & $7.00 \mathrm{E}-07$ \\
\hline $106 \mathrm{Ru}$ & $3.42 \mathrm{E}-10$ & $2.18 \mathrm{E}-10$ & $2.65 \mathrm{E}-04$ & $3.20 \mathrm{E}-10$ & $1.78 \mathrm{E}-05$ & $1.30 \mathrm{E}-09$ & $9.10 \mathrm{E}-04$ & $1.46 \mathrm{E}-08$ \\
\hline $129 \mathrm{I}$ & $3.69 \mathrm{E}-10$ & $6.59 \mathrm{E}-10$ & $3.44 \mathrm{E}-10$ & $6.59 \mathrm{E}-10$ & $5.15 \mathrm{E}-10$ & $4.58 \mathrm{E}-10$ & $3.26 \mathrm{E}-10$ & $2.48 \mathrm{E}-10$ \\
\hline $134 \mathrm{Cs}$ & $7.86 \mathrm{E}-13$ & $5.12 \mathrm{E}-14$ & $1.11 \mathrm{E}-11$ & $3.24 \mathrm{E}-13$ & $8.90 \mathrm{E}-13$ & $1.19 \mathrm{E}-12$ & $1.60 \mathrm{E}-11$ & $3.76 \mathrm{E}-13$ \\
\hline $137 \mathrm{Cs}$ & $7.21 \mathrm{E}-08$ & $7.14 \mathrm{E}-08$ & & & $7.12 \mathrm{E}-08$ & & $7.14 \mathrm{E}-08$ & $7.22 \mathrm{E}-08$ \\
\hline $154 \mathrm{Eu}$ & $3.99 \mathrm{E}-10$ & $1.62 \mathrm{E}-09$ & 1.1 & -10 & $2.21 \mathrm{E}-09$ & $6.99 \mathrm{E}-10$ & $1.89 \mathrm{E}-09$ & $2.25 \mathrm{E}-16$ \\
\hline $155 \mathrm{Eu}$ & $9.98 \mathrm{E}-10$ & $9.12 \mathrm{E}-10$ & 1.8 & $\overline{E-10}$ & $1.95 \mathrm{E}-09$ & 7.5 & $3.24 \mathrm{E}-09$ & $8.67 \mathrm{E}-17$ \\
\hline $233 \mathrm{U}$ & $1.12 \mathrm{E}-12$ & $1.40 \mathrm{E}-12$ & $9.23 \mathrm{E}-13$ & $7.21 \mathrm{E}-13$ & $2.64 \mathrm{E}-13$ & $7.17 \mathrm{E}-13$ & $7.93 \mathrm{E}-13$ & $3.52 \mathrm{E}-13$ \\
\hline $234 \mathrm{U}$ & $6.04 \mathrm{E}-13$ & $2.59 \mathrm{E}-13$ & $6.31 \mathrm{E}-13$ & $5.19 \mathrm{E}-13$ & $8.80 \mathrm{E}-14$ & $4.99 \mathrm{E}-13$ & $6.41 \mathrm{E}-13$ & $2.50 \mathrm{E}-13$ \\
\hline $235 \mathrm{U}$ & $2.33 \mathrm{E}-14$ & $1.03 \mathrm{E}-14$ & $2.34 \mathrm{E}-14$ & $2.22 \mathrm{E}-14$ & $3.57 \mathrm{E}-15$ & $1.95 \mathrm{E}-14$ & $2.61 \mathrm{E}-14$ & $9.88 \mathrm{E}-15$ \\
\hline $237 \mathrm{~Np}$ & $2.63 \mathrm{E}-12$ & $2.54 \mathrm{E}-11$ & $1.14 \mathrm{E}-11$ & $2.56 \mathrm{E}-12$ & $2.49 \mathrm{E}-11$ & $2.43 \mathrm{E}-12$ & $1.08 \mathrm{E}-11$ & $5.11 \mathrm{E}-13$ \\
\hline $238 \mathrm{Pu}$ & $6.49 \mathrm{E}-12$ & $4.31 \mathrm{E}-13$ & $7.03 \mathrm{E}-12$ & $9.82 \mathrm{E}-12$ & $7.16 \mathrm{E}-13$ & $1.18 \mathrm{E}-12$ & $2.17 \mathrm{E}-11$ & $2.80 \mathrm{E}-13$ \\
\hline $239 \mathrm{Pu}$ & $3.39 \mathrm{E}-11$ & $1.65 \mathrm{E}-11$ & $9.70 \mathrm{E}-11$ & $7.14 \mathrm{E}-11$ & $1.40 \mathrm{E}-11$ & $1.91 \mathrm{E}-11$ & $2.35 \mathrm{E}-10$ & $3.86 \mathrm{E}-12$ \\
\hline $240 \mathrm{Pu}$ & $4.09 \mathrm{E}-11$ & $1.99 \mathrm{E}-11$ & $1.61 \mathrm{E}-10$ & $8.54 \mathrm{E}-11$ & $1.99 \mathrm{E}-11$ & $2.58 \mathrm{E}-11$ & $4.45 \mathrm{E}-10$ & $7.15 \mathrm{E}-12$ \\
\hline $241 \mathrm{Am}$ & $2.02 \mathrm{E}-10$ & $1.80 \mathrm{E}-10$ & $6.18 \mathrm{E}-11$ & $6.75 \mathrm{E}-10$ & $2.03 \mathrm{E}-10$ & $1.74 \mathrm{E}-10$ & $7.94 \mathrm{E}-11$ & $1.23 \mathrm{E}-10$ \\
\hline $241 \mathrm{Pu}$ & $3.80 \mathrm{E}-11$ & $1.93 \mathrm{E}-11$ & $4.56 \mathrm{E}-10$ & $8.44 \mathrm{E}-11$ & $4.06 \mathrm{E}-11$ & $4.45 \mathrm{E}-11$ & $1.49 \mathrm{E}-09$ & $1.71 \mathrm{E}-11$ \\
\hline $243 \mathrm{Cm}$ & $1.21 \mathrm{E}-12$ & $3.72 \mathrm{E}-14$ & $6.88 \mathrm{E}-14$ & $7.81 \mathrm{E}-13$ & $6.75 \mathrm{E}-14$ & $5.81 \mathrm{E}-14$ & $2.83 \mathrm{E}-14$ & $6.77 \mathrm{E}-15$ \\
\hline $244 \mathrm{Cm}$ & $2.82 \mathrm{E}-11$ & $5.40 \mathrm{E}-13$ & $1.55 \mathrm{E}-12$ & $1.71 \mathrm{E}-11$ & $1.16 \mathrm{E}-12$ & $9.78 \mathrm{E}-13$ & $6.17 \mathrm{E}-13$ & $1.60 \mathrm{E}-13$ \\
\hline
\end{tabular}




\section{APPENDIX G. COST}

Cost estimates were prepared for mitigating approaches to assist in a quantitative approach comparison. Cost estimates for Approach 6, potential feed selections from the Tank Farm baseline, are shown in Section G1.0. Rough-order-of magnitude cost estimates were prepared for the remaining mitigating approaches are shown in Sections G2 through G14. The cost estimates are provided in detail here and summarized in Section 7.0.

\section{G1.0 POTENTIAL FEED SELECTIONS}

Costs for retrieval of waste from all tanks are included in the Tank Farm baseline. None of the potential IPS feed tanks is currently planned for retrieval between 2014 and 2019. Therefore, the costs estimates of the three tank groups, High, Mid and Low ${ }^{99} \mathrm{Tc}$, are compared on an equal basis. The cost estimates represent the incremental cost burden during the FY2014 through FY2019 time frame to support IPS operations; even though they are all baseline costs in the future. The cost estimates below are for Approach 6, potential feed selections.

Baseline cost estimates for retrieval of waste in High ${ }^{99} \mathrm{Tc}$ Feed Tanks, DSTs, total \$22,926 thousand dollars as shown in Table G-1. Supernatants in the DSTs other than AN-104 will be pumped using existing transfer pumps and require no incremental cost for IPS operations. The other seven DSTs include AP-101, AP-102, AP-103, AP-104, AP-105, AP-107 and AP-108.

Baseline cost estimates for retrieval of waste in Mid ${ }^{99} \mathrm{Tc}$ Feed Tanks, sound SSTs in close proximity to DSTs, total $\$ 267,813$ thousand dollars as shown in Table G-2. These tanks include 11 SSTs and 2 DSTs in 200-West area which are already connected with hose-in-hose transfer lines.

Baseline cost estimates for retrieval of waste in Low ${ }^{99} \mathrm{Tc}$ Feed Tanks, sound and assumed leaker SSTs some distance to the nearest DSTs, total $\$ 417,956$ thousand dollars as shown in Table G-3. These costs include 16 SSTs and a Waste Receiver Facility in 200-East area which is required to enable transfer of waste the long distance the East area DST farms.

\section{Table G-1. Cost of High ${ }^{99}$ Tc Feed Tanks.}

WBS Lvl 6

5.08.03.07.04.02

5.08 .03 .07 .04 .03

5.08.03.07.04.04

5.08 .03 .07 .04 .01

5.08 .03 .07 .04 .02

5.08 .03 .07 .04 .05

5.08 .03 .07 .04 .04

5.08 .03 .07 .04 .05

5.08.03.07.04.02

\section{Activity Name}

AN-104 Technical Evaluation/Design Update

AN-104 Retrieval System Equipment Procurement

AN-104 Retrieval System Construction

AN-104 Retrieval System Project Management

AN-104 Retrieval System Engineering/Inspection

AN-104 Startup/Test Retrieval Sys (less Mixers)

AN-104 Install Mixer Pumps

AN-104 Startup and Test Mixer Pumps

AN-104 Retr Sys Engineering/Inspection (MP)

\section{Thousands of Dollars}

$\$ 487$

$\$ 4,287$

$\$ 8,294$

$\$ 3,447$

$\$ 2,806$

$\$ 1,893$

$\$ 978$

$\$ 704$

$\$ 30$

$\$ 22,926$ 


\section{Table G-2. Cost of Mid ${ }^{99 T c}$ Feed Tanks.}

\section{WBS Lvl 6}

5.08 .07 .01 .03 .01

5.08 .07 .01 .03 .02

5.08 .07 .01 .03 .02

5.08 .07 .01 .03 .03

5.08 .07 .01 .03 .04

5.08 .07 .01 .03 .05

5.08 .07 .01 .03 .06

5.08.07.01.03.06

5.08.07.01.03.07

5.08.07.01.03.08

5.08.07.01.03.09

5.08.07.01.03.09

5.08.07.01.03.09

5.08.07.01.03.09

5.08 .07 .01 .05 .01

5.08 .07 .01 .05 .02

5.08 .07 .01 .05 .02

5.08 .07 .01 .05 .03

5.08 .07 .01 .05 .04

5.08 .07 .01 .05 .05

5.08 .07 .01 .05 .06

5.08 .07 .01 .05 .06

5.08 .07 .01 .05 .07

5.08 .07 .01 .05 .08

5.08.07.01.05.09

5.08.07.01.05.09

5.08.07.01.05.09

5.08.07.01.05.09

5.08 .07 .01 .06 .01

5.08 .07 .01 .06 .02

5.08 .07 .01 .06 .02

5.08 .07 .01 .06 .03

5.08.07.01.06.04

5.08 .07 .01 .06 .05

5.08 .07 .01 .06 .06

5.08 .07 .01 .06 .06

5.08 .07 .01 .06 .07

5.08.07.01.06.08

\section{Activity Name}

S-103 Retrieval Project Management

S-103 Retrieval Design

S-103 Engineering Support

S-103 Retrieval Procurement

S-103 Retrieval System Installation

S-103 Retrieval Startup and Readiness

S-103 Retrieval Operations (MS)

S-103 Retrieval - Equipment Removal for

Sampling

S-103 Post-Retrieval Sampling \& Analysis

S-103 Retrieval Data Report

S-103 Hard Heel Rmvl Procurement

S-103 Hard Heel Rmvl Design \& Engineering

Support

S-103 Hard Heel Rmvl Installation

S-103 Hard Heel Rmvl Operations

S-105 Retrieval Project Management

S-105 Retrieval Design

S-105 Engineering Support

S-105 Retrieval Procurement

S-105 Retrieval System Installation

S-105 Retrieval Startup and Readiness

S-105 Retrieval Operations (MS) (78)

S-105 Retrieval - Equipment Removal for

Sampling

S-105 Post-Retrieval Sampling \& Analysis

S-105 Retrieval Data Report

S-105 Hard Heel Rmvl Procurement

S-105 Hard Heel Rmvl Design \& Engineering

Support

S-105 Hard Heel Rmvl Installation

S-105 Hard Heel Rmvl Operations

S-106 Retrieval Project Management

S-106 Retrieval Design

S-106 Engineering Support

S-106 Retrieval Procurement

S-106 Retrieval System Installation

S-106 Retrieval Startup and Readiness

S-106 Retrieval Operations (MS)

S-106 Retrieval - Equipment Removal for

Sampling

S-106 Post-Retrieval Sampling \& Analysis

S-106 Retrieval Data Report

\section{Thousands of \\ Dollars}

$\$ 2,627$

$\$ 472$

$\$ 1,179$

$\$ 1,860$

$\$ 4,061$

$\$ 736$

$\$ 234$

$\$ 2,965$

$\$ 599$

$\$ 148$

$\$ 1,088$

$\$ 816$

$\$ 1,464$

$\$ 1,481$

$\$ 3,504$

$\$ 472$

$\$ 1,179$

$\$ 1,860$

$\$ 4,061$

$\$ 736$

$\$ 6,708$

$\$ 234$

$\$ 599$

$\$ 148$

$\$ 1,088$

$\$ 816$

$\$ 1,464$

$\$ 1,481$

$\$ 2,904$

$\$ 472$

$\$ 1,179$

$\$ 1,860$

$\$ 4,061$

$\$ 736$

$\$ 4,147$

$\$ 234$

$\$ 599$

$\$ 148$ 
RPP-RPT-37924, Rev. 0

WBS Lvl 6

5.08.07.01.06.09

5.08.07.01.06.09

5.08.07.01.06.09

5.08.07.01.06.09

5.08.07.01.08.01

5.08 .07 .01 .08 .02

5.08 .07 .01 .08 .02

5.08 .07 .01 .08 .03

5.08.07.01.08.04

5.08 .07 .01 .08 .05

5.08 .07 .01 .08 .06

5.08 .07 .01 .08 .06

5.08.07.01.08.07

5.08.07.01.08.08

5.08.07.01.08.09

5.08.07.01.08.09

5.08.07.01.08.09

5.08.07.01.08.09

5.08 .07 .01 .09 .01

5.08 .07 .01 .09 .02

5.08 .07 .01 .09 .02

5.08 .07 .01 .09 .03

5.08 .07 .01 .09 .04

5.08 .07 .01 .09 .05

5.08 .07 .01 .09 .06

5.08.07.01.09.06

5.08.07.01.09.07

5.08 .07 .01 .09 .08

5.08.07.01.09.09

5.08 .07 .01 .09 .09

5.08.07.01.09.09

5.08.07.01.09.09

5.08.07.01.11.01

5.08.07.01.11.02

5.08.07.01.11.02

5.08.07.01.11.03

5.08 .07 .01 .11 .04

5.08 .07 .01 .11 .05

5.08 .07 .01 .11 .06

5.08 .07 .01 .11 .06

\section{Activity Name}

S-106 Hard Heel Rmvl Procurement

S-106 Hard Heel Rmvl Design \& Engineering

Support

S-106 Hard Heel Rmvl Installation

S-106 Hard Heel Rmvl Operations

S-108 Retrieval Project Management

S-108 Retrieval Design

S-108 Engineering Support

S-108 Retrieval Procurement

S-108 Retrieval System Installation

S-108 Retrieval Startup and Readiness

S-108 Retrieval Operations (MS)

S-108 Retrieval - Equipment Removal for

Sampling

S-108 Post-Retrieval Sampling \& Analysis

S-108 Retrieval Data Report

S-108 Hard Heel Rmvl Procurement

S-108 Hard Heel Rmvl Design \& Engineering

Support

S-108 Hard Heel Rmvl Installation

S-108 Hard Heel Rmvl Operations

S-109 Retrieval Project Management

S-109 Retrieval Design

S-109 Engineering Support

S-109 Retrieval Procurement

S-109 Retrieval System Installation

S-109 Retrieval Startup and Readiness

S-109 Retrieval Operations (MS)

S-109 Retrieval - Equipment Removal for Sampling

S-109 Post-Retrieval Sampling \& Analysis

S-109 Retrieval Data Report

S-109 Hard Heel Rmvl Procurement

S-109 Hard Heel Rmvl Design \& Engineering

Support

S-109 Hard Heel Rmvl Installation

S-109 Hard Heel Rmvl Operations

S-111 Retrieval Project Management

S-111 Retrieval Design

S-111 Engineering Support

S-111 Retrieval Procurement

S-111 Retrieval System Installation

S-111 Retrieval Startup and Readiness

S-111 Retrieval Operations (MS)

S-111 Retrieval - Equipment Removal for

Sampling
Thousands of

Dollars

$\$ 1,088$

$\$ 816$

$\$ 1,464$

$\$ 1,481$

$\$ 3,024$

$\$ 472$

$\$ 1,179$

$\$ 1,860$

$\$ 4,061$

$\$ 736$

$\$ 4,660$

$\$ 234$

$\$ 599$

$\$ 148$

$\$ 1,088$

$\$ 816$

$\$ 1,464$

$\$ 1,481$

$\$ 2,566$

$\$ 472$

$\$ 1,179$

$\$ 1,860$

$\$ 4,061$

$\$ 736$

$\$ 2,706$

$\$ 234$

$\$ 599$

$\$ 148$

$\$ 1,088$

$\$ 816$

$\$ 1,464$

$\$ 1,481$

$\$ 2,848$

$\$ 472$

$\$ 1,179$

$\$ 1,860$

$\$ 4,061$

$\$ 736$

$\$ 3,910$

$\$ 234$ 
RPP-RPT-37924, Rev. 0

\section{WBS Lvl 6}

5.08.07.01.11.07

5.08 .07 .01 .11 .08

5.08.07.01.11.09

5.08.07.01.11.09

5.08.07.01.11.09

5.08.07.01.11.09

5.08.07.01.13.01

5.08 .07 .01 .13 .02

5.08 .07 .01 .13 .03

5.08 .07 .01 .13 .04

5.08 .07 .01 .13 .04

5.08 .07 .01 .13 .05

5.08 .07 .01 .13 .06

5.08.07.01.14.08

5.08 .07 .06 .02 .01

5.08 .07 .06 .02 .02

5.08.07.06.02.02

5.08 .07 .06 .02 .03

5.08 .07 .06 .02 .04

5.08 .07 .06 .02 .05

5.08 .07 .06 .02 .06

5.08 .07 .06 .02 .06

5.08 .07 .06 .02 .07

5.08 .07 .06 .02 .08

5.08.07.06.02.09

5.08.07.06.02.09

5.08.07.06.02.09

5.08.07.06.02.09

5.08 .07 .06 .03 .01

5.08 .07 .06 .03 .02

5.08 .07 .06 .03 .02

5.08 .07 .06 .03 .03

5.08.07.06.03.04

5.08 .07 .06 .03 .05

5.08 .07 .06 .03 .06

5.08.07.06.03.06

5.08.07.06.03.07

5.08.07.06.03.08

5.08.07.06.03.09

5.08.07.06.03.09

5.08.07.06.03.09
Activity Name

S-111 Post-Retrieval Sampling \& Analysis

S-111 Retrieval Data Report

S-111 Hard Heel Rmvl Procurement

S-111 Hard Heel Rmvl Design \& Engineering

Support

S-111 Hard Heel Rmvl Installation

S-111 Hard Heel Rmvl Operations

S Farm Infrastructure Project Mgmt

S Farm Infrastructure Final Design

S Farm Infrastructure Procurement

S Farm Infrastructure Construction - FY06

S Farm Infrastructure Construction

S Farm Infrastructure Startup/Readiness

S Farm Infrastructure Equipment Removal

Replace S-A to SY-101 HIHTL

U-102 Retrieval Project Management

U-102 Retrieval Design

U-102 Engineering Support

U-102 Retrieval Procurement

U-102 Retrieval System Installation

U-102 Retrieval Startup and Readiness

U-102 Retrieval Operations (MS)

U-102 Retrieval - Equipment Removal for

Sampling

U-102 Post-Retrieval Sampling \& Analysis

U-102 Retrieval Data Report

U-102 Hard Heel Rmvl Procurement

U-102 Hard Heel Rmvl Design \& Engineering

Support

U-102 Hard Heel Rmvl Installation

U-102 Hard Heel Rmvl Operations

U-103 Retrieval Project Management

U-103 Retrieval Design

U-103 Engineering Support

U-103 Retrieval Procurement

U-103 Retrieval System Installation

U-103 Retrieval Startup and Readiness

U-103 Retrieval Operations (MS)

U-103 Retrieval - Equipment Removal for

Sampling

U-103 Post-Retrieval Sampling \& Analysis

U-103 Retrieval Data Report

U-103 Hard Heel Rmvl Procurement

U-103 Hard Heel Rmvl Design \& Engineering

Support

U-103 Hard Heel Rmvl Installation
Thousands of

Dollars

$\$ 599$

$\$ 148$

$\$ 1,088$

$\$ 816$

$\$ 1,464$

$\$ 1,481$

$\$ 715$

$\$ 1,398$

$\$ 2,659$

$\$ 184$

$\$ 2,375$

$\$ 331$

$\$ 257$

$\$ 1,134$

$\$ 3,021$

$\$ 813$

$\$ 1,484$

$\$ 2,251$

$\$ 4,093$

$\$ 736$

$\$ 4,648$

$\$ 234$

$\$ 599$

$\$ 185$

$\$ 1,088$

$\$ 816$

$\$ 1,464$

$\$ 1,481$

$\$ 3,192$

$\$ 472$

$\$ 1,179$

$\$ 1,860$

$\$ 4,061$

$\$ 736$

$\$ 5,376$

$\$ 234$

$\$ 599$

$\$ 148$

$\$ 1,088$

$\$ 816$

$\$ 1,464$ 
RPP-RPT-37924, Rev. 0

\section{WBS Lvl 6}

5.08.07.06.03.09

5.08.07.06.07.11

5.08.07.06.07.11

5.08.07.06.07.13

5.08 .07 .06 .07 .15

5.08 .07 .06 .07 .15

5.08.07.06.07.15

5.08.07.06.07.19

5.08.07.06.07.24

5.08 .07 .06 .07 .25

5.08 .07 .06 .07 .26

5.08 .07 .06 .07 .27

5.08.07.06.07.27

5.08 .07 .06 .07 .27

5.08.07.06.07.27

5.08.07.06.08.01

5.08 .07 .06 .08 .02

5.08 .07 .06 .08 .02

5.08 .07 .06 .08 .03

5.08.07.06.08.04

5.08 .07 .06 .08 .05

5.08 .07 .06 .08 .06

5.08 .07 .06 .08 .06

5.08 .07 .06 .08 .07

5.08 .07 .06 .08 .08

5.08.07.06.08.09

5.08.07.06.08.09

5.08.07.06.08.09

5.08 .07 .06 .08 .09

5.08 .07 .06 .09 .01

5.08 .07 .06 .09 .02

5.08 .07 .06 .09 .02

5.08 .07 .06 .09 .03

5.08.07.06.09.04

5.08 .07 .06 .09 .05

5.08 .07 .06 .09 .06

5.08.07.06.09.06

5.08.07.06.09.07

5.08 .07 .06 .09 .08

5.08.07.06.09.09

5.08.07.06.09.09
Activity Name

U-103 Hard Heel Rmvl Operations

U-107 Retrieval Design

U-107 Engineering Support

U-107 Retrieval System Installation

U-107 Retrieval Startup \& Readiness

U-107 Retrieval Operations (MS)

U-107 Retrieval - Equipment Removal for

Sampling

U-107 Retrieval Project Management

U-107 Retrieval Equipment Procurement

U-107 Post-Retrieval Sampling \& Analysis

U-107 Retrieval Data Report

U-107 Hard Heel Rmvl Procurement

U-107 Hard Heel Rmvl Design \& Engineering

Support

U-107 Hard Heel Rmvl Installation

U-107 Hard Heel Rmvl Operations

U-108 Retrieval Project Management

U-108 Retrieval Design

U-108 Engineering Support

U-108 Retrieval Procurement

U-108 Retrieval System Installation

U-108 Retrieval Startup and Readiness

U-108 Retrieval Operations (MS)

U-108 Retrieval - Equipment Removal for

Sampling

U-108 Post-Retrieval Sampling \& Analysis

U-108 Retrieval Data Report

U-108 Hard Heel Rmvl Procurement

U-108 Hard Heel Rmvl Design \& Engineering

Support

U-108 Hard Heel Rmvl Installation

U-108 Hard Heel Rmvl Operations

U-109 Retrieval Project Management

U-109 Retrieval Design

U-109 Engineering Support

U-109 Retrieval Procurement

U-109 Retrieval System Installation

U-109 Retrieval Startup and Readiness

U-109 Retrieval Operations (MS)

U-109 Retrieval - Equipment Removal for

Sampling

U-109 Post-Retrieval Sampling \& Analysis

U-109 Retrieval Data Report

U-109 Hard Heel Rmvl Procurement

U-109 Hard Heel Rmvl Design \& Engineering
Thousands of

Dollars

$\$ 1,481$

$\$ 472$

$\$ 1,179$

$\$ 4,061$

$\$ 736$

$\$ 4,388$

$\$ 234$

$\$ 2,961$

$\$ 1,860$

$\$ 599$

$\$ 148$

$\$ 1,088$

$\$ 816$

$\$ 1,464$

$\$ 1,481$

$\$ 3,226$

$\$ 472$

$\$ 1,179$

$\$ 1,860$

$\$ 4,061$

$\$ 736$

$\$ 5,522$

$\$ 234$

$\$ 599$

$\$ 148$

$\$ 1,088$

$\$ 816$

$\$ 1,464$

$\$ 1,481$

$\$ 3,173$

$\$ 472$

$\$ 1,179$

$\$ 1,860$

$\$ 4,061$

$\$ 736$

$\$ 5,295$

$\$ 234$

$\$ 599$

$\$ 148$

$\$ 1,088$

$\$ 816$ 
WBS Lvl 6

5.08 .07 .06 .09 .09
5.08 .07 .06 .09 .09
5.08 .07 .06 .17 .01
5.08 .07 .06 .17 .02
5.08 .07 .06 .17 .03
5.08 .07 .06 .17 .04
5.08 .07 .06 .17 .05
5.08 .07 .06 .17 .07
5.08 .09 .01 .01 .05
5.08 .09 .01 .02 .05

WBS Lvl 6

5.08 .05 .07 .01 .01

5.08.06.03.01.01

5.08 .06 .03 .01 .02

5.08 .06 .03 .01 .02

5.08 .06 .03 .01 .03

5.08 .06 .03 .01 .04

5.08 .06 .03 .01 .05

5.08.06.03.01.06

5.08 .06 .03 .01 .06

5.08 .06 .03 .01 .07

5.08.06.03.01.08

5.08.06.03.02.01

5.08 .06 .03 .02 .02

5.08 .06 .03 .02 .02

5.08 .06 .03 .02 .03

5.08 .06 .03 .02 .04

5.08 .06 .03 .02 .05

5.08 .06 .03 .02 .06

5.08 .06 .03 .02 .06

5.08.06.03.02.07

5.08 .06 .03 .02 .08

5.08 .06 .03 .03 .01

5.08 .06 .03 .03 .02

5.08 .06 .03 .03 .02

5.08 .06 .03 .03 .03

5.08.06.03.03.04

\section{Activity Name}

Support

U-109 Hard Heel Rmvl Installation

U-109 Hard Heel Rmvl Operations

U Farm Infrastructure Project Mgmt

U Farm Infrastructure Final Design

U Farm Infrastructure Procurement

U Farm Infrastructure Construction

U Farm Infrastructure Startup/Readiness

U Farm Infrastructure Equipment Removal

SY-101 Hard Heel Retrieval

SY-102 Hard Heel Retrieval
Thousands of

Dollars

$\$ 1,464$

$\$ 1,481$

$\$ 715$

$\$ 1,398$

$\$ 2,659$

$\$ 2,375$

$\$ 331$

$\$ 257$

$\$ 5,513$

$\$ 5,513$

Total

$\$ 267,813$

\section{Table G-3. Cost of Low ${ }^{99}$ Te Feed Tanks.}

\section{Activity Name}

Waste Receiver Facility Dsn/Const - (B-

Complex)

B-101 Retrieval Project Management

B-101 Retrieval Design

B-101 Engineering Support

B-101 Retrieval Procurement

B-101 Retrieval System Installation

B-101 Retrieval Startup and Readiness

B-101 Retrieval Operations (MRS)

B-101 Retrieval - Equipment Removal for

Sampling

B-101 Post-Retrieval Sampling \& Analysis

B-101 Retrieval Data Report

B-102 Retrieval Project Management

B-102 Retrieval Design

B-102 Engineering Support

B-102 Retrieval Procurement

B-102 Retrieval System Installation

B-102 Retrieval Startup and Readiness

B-102 Retrieval Operations (MS)

B-102 Retrieval - Equipment Removal for

Sampling

B-102 Post-Retrieval Sampling \& Analysis

B-102 Retrieval Data Report

B-103 Retrieval Project Management

B-103 Retrieval Design

B-103 Engineering Support

B-103 Retrieval Procurement

B-103 Retrieval System Installation
Thousands of

Dollars

$\$ 95,998$

$\$ 2,466$

$\$ 1,389$

$\$ 1,613$

$\$ 6,440$

$\$ 6,013$

$\$ 674$

$\$ 1,889$

$\$ 234$

$\$ 599$

$\$ 185$

$\$ 2,012$

$\$ 813$

$\$ 1,484$

$\$ 2,251$

$\$ 4,093$

$\$ 736$

$\$ 1,842$

$\$ 234$

$\$ 599$

$\$ 185$

$\$ 2,408$

$\$ 760$

$\$ 1,313$

$\$ 5,022$

$\$ 5,934$ 


\section{WBS Lvl 6}

5.08 .06 .03 .03 .05

5.08 .06 .03 .03 .06

5.08 .06 .03 .03 .06

5.08 .06 .03 .03 .07

5.08 .06 .03 .03 .08

5.08 .06 .03 .05 .01

5.08 .06 .03 .05 .02

5.08 .06 .03 .05 .02

5.08 .06 .03 .05 .03

5.08 .06 .03 .05 .04

5.08 .06 .03 .05 .05

5.08 .06 .03 .05 .06

5.08 .06 .03 .05 .06

5.08 .06 .03 .05 .07

5.08 .06 .03 .05 .08

5.08 .06 .03 .08 .01

5.08.06.03.08.02

5.08 .06 .03 .08 .02

5.08 .06 .03 .08 .03

5.08.06.03.08.04

5.08 .06 .03 .08 .05

5.08 .06 .03 .08 .06

5.08 .06 .03 .08 .06

5.08.06.03.08.07

5.08.06.03.08.08

5.08 .06 .03 .08 .09

5.08.06.03.08.09

5.08.06.03.08.09

5.08 .06 .03 .08 .09

5.08 .06 .03 .09 .01

5.08 .06 .03 .09 .02

5.08.06.03.09.02

5.08 .06 .03 .09 .03

5.08 .06 .03 .09 .04

5.08 .06 .03 .09 .05

5.08 .06 .03 .09 .06

5.08.06.03.09.06

5.08 .06 .03 .09 .07

5.08 .06 .03 .09 .08

5.08 .06 .03 .09 .09

5.08.06.03.09.09
Activity Name

B-103 Retrieval Startup and Readiness

B-103 Retrieval Operations (MRS)

B-103 Retrieval - Equipment Removal for

Sampling

B-103 Post-Retrieval Sampling \& Analysis

B-103 Retrieval Data Report

B-105 Retrieval Project Management

B-105 Retrieval Design

B-105 Engineering Support

B-105 Retrieval Procurement

B-105 Retrieval System Installation

B-105 Retrieval Startup and Readiness

B-105 Retrieval Operations (MRS)

B-105 Retrieval - Equipment Removal for

Sampling

B-105 Post-Retrieval Sampling \& Analysis

B-105 Retrieval Data Report

B-108 Retrieval Project Management

B-108 Retrieval Design

B-108 Engineering Support

B-108 Retrieval Procurement

B-108 Retrieval System Installation

B-108 Retrieval Startup and Readiness

B-108 Retrieval Operations (MS)

B-108 Retrieval - Equipment Removal for

Sampling

B-108 Post-Retrieval Sampling \& Analysis

B-108 Retrieval Data Report

B-108 Hard Heel Rmvl Procurement

B-108 Hard Heel Rmvl Design \& Engineering

Support

B-108 Hard Heel Rmvl Installation

B-108 Hard Heel Rmvl Operations

B-109 Retrieval Project Management

B-109 Retrieval Design

B-109 Engineering Support

B-109 Retrieval Procurement

B-109 Retrieval System Installation

B-109 Retrieval Startup and Readiness

B-109 Retrieval Operations (MS)

B-109 Retrieval - Equipment Removal for

Sampling

B-109 Post-Retrieval Sampling \& Analysis

B-109 Retrieval Data Report

B-109 Hard Heel Rmvl Procurement

B-109 Hard Heel Rmvl Design \& Engineering
Thousands of

Dollars

$\$ 674$

$\$ 1,603$

$\$ 234$

$\$ 599$

$\$ 148$

$\$ 2,706$

$\$ 760$

$\$ 1,313$

$\$ 5,022$

$\$ 5,934$

$\$ 674$

$\$ 2,866$

$\$ 234$

$\$ 599$

$\$ 148$

$\$ 2,445$

$\$ 472$

$\$ 1,179$

$\$ 1,860$

$\$ 4,061$

$\$ 736$

$\$ 2,187$

$\$ 234$

$\$ 599$

$\$ 148$

$\$ 1,088$

$\$ 816$

$\$ 1,464$

$\$ 1,481$

$\$ 2,486$

$\$ 472$

$\$ 1,179$

$\$ 1,860$

$\$ 4,061$

$\$ 736$

$\$ 2,366$

$\$ 234$

$\$ 599$

$\$ 148$

$\$ 1,088$

$\$ 816$ 
WBS Lvl 6

Activity Name

Support

5.08.06.03.09.09

5.08.06.03.09.09

5.08 .06 .03 .17 .01

5.08.06.03.17.02

5.08 .06 .03 .17 .03

5.08 .06 .03 .17 .04

5.08.06.03.17.05

5.08.06.03.17.06

5.08 .06 .05 .01 .01

5.08 .06 .05 .01 .02

5.08 .06 .05 .01 .02

5.08 .06 .05 .01 .03

5.08 .06 .05 .01 .04

5.08 .06 .05 .01 .05

5.08.06.05.01.06

5.08 .06 .05 .01 .06

5.08.06.05.01.07

5.08.06.05.01.08

5.08.06.05.01.09

5.08.06.05.01.09

5.08.06.05.01.09

5.08.06.05.01.09

5.08 .06 .05 .02 .01

5.08 .06 .05 .02 .02

5.08 .06 .05 .02 .02

5.08 .06 .05 .02 .03

5.08 .06 .05 .02 .04

5.08 .06 .05 .02 .05

5.08 .06 .05 .02 .06

5.08 .06 .05 .02 .06

5.08.06.05.02.07

5.08 .06 .05 .02 .08

5.08 .06 .05 .03 .01

5.08 .06 .05 .03 .02

5.08 .06 .05 .03 .02

5.08 .06 .05 .03 .03

5.08 .06 .05 .03 .04

5.08 .06 .05 .03 .05

5.08 .06 .05 .03 .06

5.08 .06 .05 .03 .06

5.08.06.05.03.07

BY-101 Retrieval Design

BY-101 Engineering Support

BY-101 Retrieval Procurement

Sampling

BY-101 Retrieval Data Report

Support

BY-102 Retrieval Design

BY-102 Engineering Support

BY-102 Retrieval Procurement

Sampling

BY-102 Retrieval Data Report

BY-103 Retrieval Design

BY-103 Engineering Support

BY-103 Retrieval Procurement

Sampling
B-109 Hard Heel Rmvl Installation

Thousands of

Dollars

B-109 Hard Heel Rmvl Operations

B Farm Infrastructure Project Mgmt

B Farm Infrastructure Final Design

B Farm Infrastructure Procurement

B Farm Infrastructure Construction

B Farm Infrastructure Startup/Readiness

B Farm Infrastructure Equipment Removal

BY-101 Retrieval Project Management

BY-101 Retrieval System Installation

BY-101 Retrieval Startup and Readiness

BY-101 Retrieval Operations (MS)

BY-101 Retrieval - Equipment Removal for

BY-101 Post-Retrieval Sampling \& Analysis

BY-101 Hard Heel Rmvl Procurement

BY-101 Hard Heel Rmvl Design \& Engineering

BY-101 Hard Heel Rmvl Installation

BY-101 Hard Heel Rmvl Operations

BY-102 Retrieval Project Management

BY-102 Retrieval System Installation

BY-102 Retrieval Startup and Readiness

BY-102 Retrieval Operations (MS)

BY-102 Retrieval - Equipment Removal for

BY-102 Post-Retrieval Sampling \& Analysis

BY-103 Retrieval Project Management

BY-103 Retrieval System Installation

BY-103 Retrieval Startup and Readiness

BY-103 Retrieval Operations (MRS)

BY-103 Retrieval - Equipment Removal for

BY-103 Post-Retrieval Sampling \& Analysis
$\$ 1,464$

$\$ 1,481$

$\$ 715$

$\$ 1,398$

$\$ 2,659$

$\$ 2,375$

$\$ 331$

$\$ 257$

$\$ 2,796$

$\$ 813$

$\$ 1,484$

$\$ 2,251$

$\$ 4,093$

$\$ 736$

$\$ 3,688$

$\$ 234$

$\$ 599$

$\$ 185$

$\$ 1,088$

$\$ 816$

$\$ 1,464$

$\$ 1,481$

$\$ 2,339$

$\$ 472$

$\$ 1,179$

$\$ 1,860$

$\$ 4,061$

$\$ 736$

$\$ 3,197$

$\$ 234$

$\$ 599$

$\$ 148$

$\$ 2,856$

$\$ 1,389$

$\$ 1,613$

$\$ 6,440$

$\$ 6,013$

$\$ 674$

$\$ 3,552$

$\$ 234$

$\$ 599$ 
WBS Lvl 6

5.08 .06 .05 .03 .08

5.08 .06 .05 .04 .01

5.08 .06 .05 .04 .02

5.08 .06 .05 .04 .02

5.08 .06 .05 .04 .03

5.08 .06 .05 .04 .04

5.08 .06 .05 .04 .05

5.08 .06 .05 .04 .06

5.08.06.05.04.06

5.08.06.05.04.07

5.08 .06 .05 .04 .08

5.08 .06 .05 .04 .09

5.08.06.05.04.09

5.08 .06 .05 .04 .09

5.08.06.05.04.09

5.08 .06 .05 .05 .01

5.08 .06 .05 .05 .02

5.08 .06 .05 .05 .02

5.08 .06 .05 .05 .03

5.08.06.05.05.04

5.08 .06 .05 .05 .05

5.08 .06 .05 .05 .06

5.08 .06 .05 .05 .06

5.08 .06 .05 .05 .07

5.08.06.05.05.08

5.08 .06 .05 .06 .01

5.08 .06 .05 .06 .02

5.08 .06 .05 .06 .02

5.08 .06 .05 .06 .03

5.08 .06 .05 .06 .04

5.08 .06 .05 .06 .05

5.08 .06 .05 .06 .06

5.08 .06 .05 .06 .06

5.08 .06 .05 .06 .07

5.08 .06 .05 .06 .08

5.08 .06 .05 .07 .01

5.08.06.05.07.02

5.08 .06 .05 .07 .02

5.08 .06 .05 .07 .03

5.08 .06 .05 .07 .04

5.08 .06 .05 .07 .05

5.08 .06 .05 .07 .06
Activity Name

BY-103 Retrieval Data Report

BY-104 Retrieval Project Management

BY-104 Retrieval Design

BY-104 Engineering Support

BY-104 Retrieval Procurement

BY-104 Retrieval System Installation

BY-104 Retrieval Startup and Readiness

BY-104 Retrieval Operations (MS)

BY-104 Retrieval - Equipment Removal for

Sampling

BY-104 Post-Retrieval Sampling \& Analysis

BY-104 Retrieval Data Report

BY-104 Hard Heel Rmvl Procurement

BY-104 Hard Heel Rmvl Design \& Engineering

Support

BY-104 Hard Heel Rmvl Installation

BY-104 Hard Heel Rmvl Operations

BY-105 Retrieval Project Management

BY-105 Retrieval Design

BY-105 Engineering Support

BY-105 Retrieval Procurement

BY-105 Retrieval System Installation

BY-105 Retrieval Startup and Readiness

BY-105 Retrieval Operations (MRS)

BY-105 Retrieval - Equipment Removal for

Sampling

BY-105 Post-Retrieval Sampling \& Analysis

BY-105 Retrieval Data Report

BY-106 Retrieval Project Management

BY-106 Retrieval Design

BY-106 Engineering Support

BY-106 Retrieval Procurement

BY-106 Retrieval System Installation

BY-106 Retrieval Startup and Readiness

BY-106 Retrieval Operations (MRS)

BY-106 Retrieval - Equipment Removal for

Sampling

BY-106 Post-Retrieval Sampling \& Analysis

BY-106 Retrieval Data Report

BY-107 Retrieval Project Management

BY-107 Retrieval Design

BY-107 Engineering Support

BY-107 Retrieval Procurement

BY-107 Retrieval System Installation

BY-107 Retrieval Startup and Readiness

BY-107 Retrieval Operations (MRS)
Thousands of

Dollars

$\$ 185$

$\$ 2,781$

$\$ 472$

$\$ 1,179$

$\$ 1,860$

$\$ 4,061$

$\$ 736$

$\$ 3,623$

$\$ 234$

$\$ 599$

$\$ 148$

$\$ 1,088$

$\$ 816$

$\$ 1,464$

$\$ 1,481$

$\$ 2,948$

$\$ 760$

$\$ 1,313$

$\$ 5,022$

$\$ 5,934$

$\$ 674$

$\$ 3,897$

$\$ 234$

$\$ 599$

$\$ 148$

$\$ 2,924$

$\$ 760$

$\$ 1,313$

$\$ 5,022$

$\$ 5,934$

$\$ 674$

$\$ 3,795$

$\$ 234$

$\$ 599$

$\$ 148$

$\$ 2,683$

$\$ 760$

$\$ 1,313$

$\$ 5,022$

$\$ 5,934$

$\$ 674$

$\$ 2,769$ 


\section{WBS Lvl 6}

5.08.06.05.07.06

5.08.06.05.07.07

5.08 .06 .05 .07 .08

5.08 .06 .05 .10 .01

5.08 .06 .05 .10 .02

5.08 .06 .05 .10 .02

5.08 .06 .05 .10 .03

5.08 .06 .05 .10 .04

5.08 .06 .05 .10 .05

5.08.06.05.10.06

5.08.06.05.10.06

5.08 .06 .05 .10 .07

5.08.06.05.10.08

5.08.06.05.10.09

5.08.06.05.10.09

5.08.06.05.10.09

5.08.06.05.10.09

5.08 .06 .05 .11 .01

5.08 .06 .05 .11 .02

5.08 .06 .05 .11 .02

5.08 .06 .05 .11 .03

5.08 .06 .05 .11 .04

5.08 .06 .05 .11 .05

5.08 .06 .05 .11 .06

5.08.06.05.11.06

5.08.06.05.11.07

5.08 .06 .05 .11 .08

5.08 .06 .05 .12 .01

5.08 .06 .05 .12 .02

5.08 .06 .05 .12 .02

5.08 .06 .05 .12 .03

5.08 .06 .05 .12 .04

5.08 .06 .05 .12 .05

5.08 .06 .05 .12 .06

5.08 .06 .05 .12 .06

5.08 .06 .05 .12 .07

5.08 .06 .05 .12 .08

5.08 .06 .05 .13 .01

5.08 .06 .05 .13 .02

5.08 .06 .05 .13 .03

5.08.06.05.13.04
Activity Name

BY-107 Retrieval - Equipment Removal for Sampling

BY-107 Post-Retrieval Sampling \& Analysis

BY-107 Retrieval Data Report

BY-110 Retrieval Project Management

BY-110 Retrieval Design

BY-110 Engineering Support

BY-110 Retrieval Procurement

BY-110 Retrieval System Installation

BY-110 Retrieval Startup and Readiness

BY-110 Retrieval Operations (MS)

BY-110 Retrieval - Equipment Removal for

Sampling

BY-110 Post-Retrieval Sampling \& Analysis

BY-110 Retrieval Data Report

BY-110 Hard Heel Rmvl Procurement

BY-110 Hard Heel Rmvl Design \& Engineering

Support

BY-110 Hard Heel Rmvl Installation

BY-110 Hard Heel Rmvl Operations

BY-111 Retrieval Project Management

BY-111 Retrieval Design

BY-111 Engineering Support

BY-111 Retrieval Procurement

BY-111 Retrieval System Installation

BY-111 Retrieval Startup and Readiness

BY-111 Retrieval Operations (MS)

BY-111 Retrieval - Equipment Removal for

Sampling

BY-111 Post-Retrieval Sampling \& Analysis

BY-111 Retrieval Data Report

BY-112 Retrieval Project Management

BY-112 Retrieval Design

BY-112 Engineering Support

BY-112 Retrieval Procurement

BY-112 Retrieval System Installation

BY-112 Retrieval Startup and Readiness

BY-112 Retrieval Operations (MS)

BY-112 Retrieval - Equipment Removal for

Sampling

BY-112 Post-Retrieval Sampling \& Analysis

BY-112 Retrieval Data Report

BY Farm Infrastructure Project Mgmt

BY Farm Infrastructure Final Design

BY Farm Infrastructure Procurement

BY Farm Infrastructure Construction
Thousands of

Dollars

$\$ 234$

$\$ 599$

$\$ 148$

$\$ 2,766$

$\$ 472$

$\$ 1,179$

$\$ 1,860$

$\$ 4,061$

$\$ 736$

$\$ 3,559$

$\$ 234$

$\$ 599$

$\$ 148$

$\$ 1,088$

$\$ 816$

$\$ 1,464$

$\$ 1,481$

$\$ 2,367$

$\$ 472$

$\$ 1,179$

$\$ 1,860$

$\$ 4,061$

$\$ 736$

$\$ 3,316$

$\$ 234$

$\$ 599$

$\$ 148$

$\$ 2,348$

$\$ 472$

$\$ 1,179$

$\$ 1,860$

$\$ 4,061$

$\$ 736$

$\$ 3,235$

$\$ 234$

$\$ 599$

$\$ 148$

$\$ 715$

$\$ 1,398$

$\$ 2,659$

$\$ 2,375$ 
WBS Lvl 6

Activity Name

5.08.06.05.13.05 BY Farm Infrastructure Startup/Readiness

5.08.06.05.13.06 BY Farm Infrastructure Equipment Removal
Thousands of

Dollars

$\$ 331$

$\$ 257$

Total

\section{G2.0 ESTIMATING METHODOLOGY}

The technical basis and required facility modifications for each approach is identified in Appendices $\mathrm{B}$ through $\mathrm{F}$ of this report. The cost estimate was developed by quantifying the material, equipment and labor required to implement the systems and facilities identified in the technical basis. The cost for materials, labor hours and rates are based on recent experience with design, procurement and installation of projects currently in process or completed in the recent past at the Tank Farms. The operating costs are estimated as the incremental increase above the current Tank Farms Baseline cost estimate.

The cost estimate is grouped into the following elements for estimating ease and cost summarization:

- $\quad$ Project Management

- Design/Engineering

- Construction

- $\quad$ Start Up

- Operations

- Other Project Costs

- $\quad$ Facility Decommissioning

- $\quad$ Contingency

- Escalation.

The following sections present the basis used to develop the individual elements of the cost estimate. A summary of the cost estimates are shown in Table G-4. 
Table G-4. LAW Secondary Waste Treatment Approach Cost Estimate Summary.

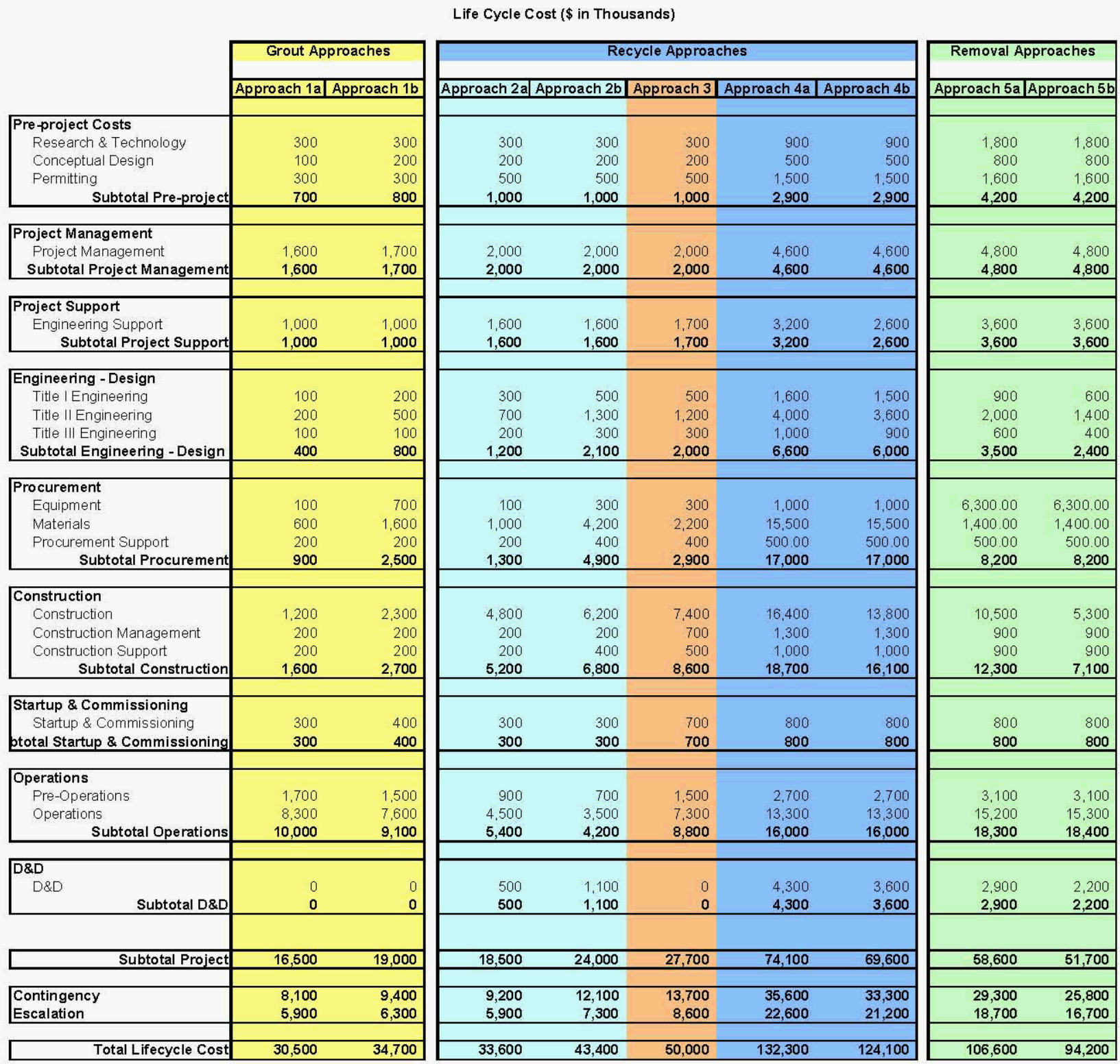

\section{G3.0 KEY ASSUMPTIONS}

The following assumptions were used to complete the estimates:

- The facility modifications and operations of these approaches are not in the current ETF or Tank Farm Baselines.

- $\quad$ Field work at ETF and inside the Tank Farms will be completed using current procedures and practices.

- $\quad$ After startup the facilities will operate on a continuous basis, 24 hours per day, 7 days per week for five years. 
- The design life of the major pieces of operating equipment is longer than the expected years of operations so no equipment replacement costs are included in the cost estimates for operations.

\section{G4.0 PROJECT MANAGEMENT}

Project Management is the incremental increase for the specific project management and project management support required for each approach from the project inception to the start up of the facility. The cost estimates include both the cost of the Hanford Site personnel and subcontracted services. The estimated cost is based on a consistent level of staffing from the beginning of the project through startup. The management costs after startup are included in the operating cost.

The cost estimates do not include any incremental increase to the overall site management.

\section{G5.0 ENGINEERING/DESIGN}

The Engineering/Design includes Title I and Title II Design and Title III Engineering during construction. Engineering/Design also includes Engineering Support which provides the Project Manager with supporting functions such as design reviews and environmental, safety and health support. The basis for the Engineering/Design Cost Estimate is a combination of identifying the labor required to provide the needed support and percentages of construction and material costs from previous experience.

\section{G6.0 PROCUREMENT}

Procurement includes procurement of the major equipment, significant fabricated items and procurement support. The equipment and significant items of fabrication were determined from the available preliminary design information. Prices for equipment and fabricated items were obtained from suppliers and recent construction at the Tank Farms. The cost estimates for procurement support was developed using the staffing for similar activities recently completed at the Tank Farms.

\section{G7.0 CONSTRUCTION}

Construction includes procurement of the minor materials and equipment, field construction, equipment installation, construction management and construction support. The quantities of materials and equipment were determined from the available preliminary design information. Prices for materials and equipment were obtained from equipment suppliers and recent construction at the Tank Farms. Field construction and installation costs are based on recent Tank Farm experience on similar facilities. The cost estimates for procurement support, construction management and construction support were developed using the staffing for similar projects recently completed at the Tank Farms. 


\section{New Evaporator Building Cost for Approaches $4 \mathrm{a}$ and $4 \mathrm{~b}$}

The difference between Approach $4 \mathrm{a}$ and $4 \mathrm{~b}$ is the type of building required to house the process equipment. The building has a footprint that is $118^{\prime}$ by 133 ' or 15,694 square foot. About $56 \%$ of the building square footage has a 12 ' wall height:

- The offices, lunchroom, change rooms, and storage space are in this portion of the building.

- For both Approaches the construction is an industrial metal building or concrete tilt-wall construction.

The remainder of the facility houses the evaporator and process equipment.

- For Approach 4a the estimate is based on the walls constructed of cast in place concrete 1 ' or 2' thick.

- For Approach $4 \mathrm{~b}$ the estimate is based on the masonry walls.

For Approach 4a the building cost is $\$ 7.4$ million which is $45 \%$ of the total construction cost. For Approach $4 \mathrm{~b}$ the building cost is $\$ 4.4$ million which is $32 \%$ of the total construction cost. The remainder of the construction cost is associated with transfer lines, recirculation system and evaporator equipment installation which is the same for both Approaches. For both approaches, the single level space is estimated at $\$ 180$ per square foot. For Approach 4 a the high-bay space is estimated at $\$ 842$ per square foot. For Approach 4a the high-bay space is estimated at $\$ 400$ per square foot.

\section{G8.0 START UP}

The estimated cost of startup is based on the number of systems included in the startup and the complexity of the systems including the number of procedures and the amount of training required. Startup includes both Hanford Site labor and subcontracted services to perform the following tasks:

- Develop, review and approve a plan for the facility/system startup.

- Develop, review and approve an operational readiness review or readiness assessment.

- Develop or revise the operating procedures.

- Develop the needed training material and train the trainer. Operator training is included in the operations.

- Conduct the system tests in accordance with the test plan. 


\section{G9.0 OPERATIONS}

The cost estimate for operations is the incremental cost above the current ETF and Tank Farm baseline operations on an annual basis. The cost estimates are based on one year of training followed by five years of operations. Operations is the incremental increase associated with operating, maintaining and managing the additional systems installed but does not include additional administrative oversight. The specific scope of the operations function includes shift operations personnel other personnel that support shift operations (radiological control, engineers, planners, craft personnel, and necessary supplies and consumables), and sampling and analysis.

The specific scope of the maintenance function includes the activities necessary to maintain operable equipment in a calibrated and functionally tested condition to be compliant with authorization bases, regulatory requirements and to support plant operation. This includes preventive maintenance and calibration work packages, planning, scheduling, and setup of preventive maintenance activities, work package preparation and approval for work. The scope includes labor for the pre-job meetings, performance of preventive maintenance, and postmaintenance testing.

The operating cost for Approach 1a includes $\$ 106,000$ annually for consumables, $\$ 100,000$ for sample analysis, 3 additional people per shift for operating and maintaining the cementation system, and 2 drivers on the day shift for transporting the product to IDF.

The operating cost for Approach $1 \mathrm{~b}$ includes $\$ 40,000$ annually for consumables, $\$ 100,000$ for sample analysis, 3 additional people per shift for operating and maintaining the cementation system and recycle system, and a driver on the day shift for transporting the product to IDF.

\section{Waste Disposal at IDF}

- $\quad$ Approach 1a and $1 \mathrm{~b}$ dispose of cemented waste at IDF.

- The cost estimates include this cost.

- The basis for the disposal cost is:

- $\quad$ IDF operating costs are in the Baseline

- $\quad$ IDF project cost at completion of $\$ 22,381,000$

- $\quad$ IDF has a capacity of 211,000 cubic yards.

- $\quad$ Therefore, a value of $\$ 106.07$ per cubic yard was used as a capacity replacement cost.

- $\quad$ Approach 1a ships $103 \mathrm{ft}^{3}$ blocks (1.11 cy) every 2 days.

- $\quad 183$ shipments per year at $1.11 \mathrm{cy}$ times $\$ 106.07 / \mathrm{cy}=\$ 21,546$ annually. 
- $\quad$ Approach $1 \mathrm{~b}$ ships $103 \mathrm{ft}^{3}$ blocks (1.11 cy) each week.

- $\quad 52$ shipments per year at 1.11 cy times $\$ 106.07 / \mathrm{cy}=\$ 6,122$ annually.

The operating cost for Approach 2a includes $\$ 40,000$ annually for consumables, $\$ 250,000$ for sample analysis, 1 additional person per shift for operating and maintaining the transport load and unload stations, and 2 drivers on the day shift for transporting the brine to the tank farms.

The operating cost for Approach $2 \mathrm{~b}$ includes $\$ 20,000$ annually for consumables, $\$ 250,000$ for sample analysis, and 1 additional person per shift for operating and maintaining the recycle system and transfer line.

The operating cost for Approach 3 provides for the incremental increase for two evaporator campaigns per year above the base operating and maintenance costs and baseline campaigns for the 242-A Evaporator. The operating cost estimate includes $\$ 450,000$ annually for consumables, $\$ 480,000$ for sample analysis, $\$ 75,000$ for subcontracted steam, and the additional personnel to operate and maintaining the evaporator for the additional two campaigns per year.

The operating cost for Approach $4 \mathrm{a}$ and $4 \mathrm{~b}$ are the same. They provide for the operation and maintenance of a new evaporator facility.

The operating cost for Approach 5a and $5 \mathrm{~b}$ are the same. They provide for the operation and maintenance of a new ion exchange system.

\section{G10.0 OTHER PROJECT COSTS}

Other project costs include the cost for preliminary design, process development including pilot testing, environmental permitting for the required modifications and the incremental increase in Tank Farm Contractor fee. The cost estimate is based on recent experience on similar projects at the Tank Farms.

\section{G11.0 FACILITY DECOMMISSIONING}

The estimated cost for facility decommissioning is based on the decommissioning of similar facilities at DOE sites. Decommissioning includes:

- Characterization: The up front scoping and reconnaissance level characterization and the in process characterization requirements.

- Decontamination: The removal of radioactivity decontamination from the facility.

- Decommissioning: The dismantlement and stabilization of piping, ducts, process systems, tanks, etc. The removal of materials, equipment and fixtures within a facility are part of decommissioning.

- Demolition/Disposal: The removal of facilities and systems. Demolition includes loading debris and waste into containers. Facilities are removed to the extent required by the site Closure Plan. 
- Closure: The regulatory paperwork required to achieve closure including any required cap, site grading, planting etc.

- $\quad$ Project Management: The oversight and management of the specific closure task.

\section{G12.0 CONTINGENCY}

In accordance with DOE 430.1-1, Cost Estimating Guide, contingency is the amount budgeted to cover costs that may result from incomplete design, unforeseen and unpredictable conditions or uncertainties. The amount of contingency depends on the status of design, procurement and construction plus the complexity and uncertainty of the component parts of the project.

The overall percentage of contingency included in the estimate is $50 \%$ of Project Management, Engineering/Design, Construction, Startup, Operations Other Project Costs and Facility Decommissioning.

\section{G13.0 ESCALATION}

The cost estimate is based on FY 2008 dollars. An escalation rate of $2.4 \%$ per year compounded is included to adjust the out year estimates.

\section{G14.0 COST ESTIMATE DETAILS}

Details of each cost estimate are provided in Tables G-5 through G-13 for Approaches 1a, 1b, 2a, $2 \mathrm{~b}, 3,4 \mathrm{a}, 4 \mathrm{~b}, 5 \mathrm{a}$, and $5 \mathrm{~b}$, respectively. This section provides cost estimate summary and details for the nine Approaches. For each Approach there is a profile of the funding required by year to complete the Approach followed by the detailed cost estimate. 
RPP-RPT-37924 Rev. 0

Table G-5. Approach 1a Cost Estimate.

Table begins on next page. 
RPP-RPT-37924 Rev. 0

\section{Cost Estimate}

CH2N THLL Title: IPS 2nd Waste Treatment Project Approach 1a Concentrate/Cement at ETF (<10,000 ppm Cl in Brine) Hanford Group, Inc. Estimator: Bob Williamson

\begin{tabular}{|c|c|c|c|c|c|c|c|c|c|c|c|c|}
\hline Description & \begin{tabular}{l|l} 
Sch \\
ID
\end{tabular} & \begin{tabular}{|c|}
$\begin{array}{c}\text { Resource } \\
\text { Code }\end{array}$ \\
\end{tabular} & Quan. & Unit & $\begin{array}{l}\text { Labor } \\
\text { Unit Hrs }\end{array}$ & \begin{tabular}{c|} 
Total \\
Labor Hrs \\
\end{tabular} & \begin{tabular}{c|} 
Labor \\
Rate
\end{tabular} & $\begin{array}{l}\text { Labor } \\
\text { Dollars } \\
\end{array}$ & \begin{tabular}{|l|} 
Material \\
Unit cost \\
\end{tabular} & $\begin{array}{c}\text { Material } \\
\text { Dollars }\end{array}$ & $\begin{array}{c}\text { Equip/Sub } \\
\text { Dollars }\end{array}$ & $\begin{array}{c}\text { Total } \\
\text { Dollars } \\
\end{array}$ \\
\hline \multicolumn{13}{|l|}{ Project Management FY11 } \\
\hline Materials and Supplies & & 10 & 1 & LS & 0 & 0.0 & 1.00 & 0.00 & $10,000.00$ & $10,000.00$ & 0.00 & $10,000.00$ \\
\hline Staff Augmentation Contract & & $2 \mathrm{~N}$ & 1 & LS & 0 & 0.0 & 1.00 & 0.00 & 0.00 & 0.00 & $50,000.00$ & $50,000.00$ \\
\hline Environmental Engineer & & E110-REG & 1 & LS & 360 & 360.0 & 77.14 & $27,771.75$ & 0.00 & 0.00 & 0.00 & $27,771.75$ \\
\hline Quality Control Engineer & & E110-REG & 1 & LS & 360 & 360.0 & 77.14 & $27,771.75$ & 0.00 & 0.00 & 0.00 & $27,771.75$ \\
\hline Safety Engineer & & E120-REG & 1 & LS & 900 & 900.0 & 69.13 & $62,219.35$ & 0.00 & 0.00 & 0.00 & $62,219.35$ \\
\hline Secretaries & & G040-REG & 1 & LS & 900 & 900.0 & 35.47 & $31,925.99$ & 0.00 & 0.00 & 0.00 & $31,925.99$ \\
\hline Project Manager & & M020-REG & 1 & LS & 1800 & $1,800.0$ & 112.40 & $202,314.35$ & 0.00 & 0.00 & 0.00 & $202,314.35$ \\
\hline Project Engineer & & E130-REG & 1 & LS & 1800 & $1,800.0$ & 95.71 & $172,285.23$ & 0.00 & 0.00 & 0.00 & $172,285.23$ \\
\hline Scheduler & & P070-REG & 1 & LS & 900 & 900.0 & 76.59 & $68,929.19$ & 0.00 & 0.00 & 0.00 & $68,929.19$ \\
\hline Estimator & & P070-REG & 1 & LS & 450 & 450.0 & 76.59 & $34,464.60$ & 0.00 & 0.00 & 0.00 & $34,464.60$ \\
\hline Cost Analyst & & P070-REG & 1 & LS & 450 & 450.0 & 76.59 & $34,464.60$ & 0.00 & 0.00 & 0.00 & $34,464.60$ \\
\hline \multicolumn{13}{|l|}{ Project Management FY12 } \\
\hline Materials and Supplies & & 10 & 1 & LS & 0 & 0.0 & 1.00 & 0.00 & $10,000,00$ & $10,000.00$ & 0.00 & $10,000.00$ \\
\hline Staff Augmentation Contract & & $2 \mathrm{~N}$ & 1 & LS & 0 & 0.0 & 1.00 & 0.00 & 0.00 & 0.00 & $50,000.00$ & $50,000.00$ \\
\hline $\begin{array}{l}\text { Environmental Engineer } \\
\text { E }\end{array}$ & & E110-REG & 1 & LS & 360 & 360.0 & 77.14 & $27,771.75$ & 0.00 & 0.00 & 0.00 & $27,771.75$ \\
\hline Quality Control Engineer & & E110-REG & 1 & LS & 360 & 360.0 & 77.14 & $27,771.75$ & 0.00 & 0.00 & 0.00 & $27,771.75$ \\
\hline Safety Engineer & & E120-REG & 1 & LS & 900 & 900.0 & 69.13 & $62,219.35$ & 0.00 & 0.00 & 0.00 & $62,219.35$ \\
\hline Secretaries & & G040-REG & 1 & LS & 900 & 900.0 & 35.47 & $31,925.99$ & 0.00 & 0.00 & 0.00 & $31,925.99$ \\
\hline Project Manager & & M020-REG & 1 & LS & 1800 & $1,800.0$ & 112.40 & $202,314.35$ & 0.00 & 0.00 & 0.00 & $202,314.35$ \\
\hline Project Engineer & & E130-REG & 1 & LS & 1800 & $1,800.0$ & 95.71 & $172,285.23$ & 0.00 & 0.00 & 0.00 & $172,285.23$ \\
\hline $\begin{array}{l}\text { Scheduler } \\
\text { S }\end{array}$ & & P070-REG & 1 & LS & 900 & 900.0 & 76.59 & $68,929.19$ & 0.00 & 0.00 & 0.00 & 68.929 .19 \\
\hline Estimator & & P070-REG & 1 & LS & 450 & 450.0 & 76.59 & $34,464.60$ & 0.00 & 0.00 & 0.00 & $34,464.60$ \\
\hline Cost Analyst & & P070-REG & 1 & LS & 450 & 450.0 & 76.59 & $34,464.60$ & 0.00 & 0.00 & 0.00 & $34,464.60$ \\
\hline \multicolumn{13}{|l|}{ Project Management FY13 } \\
\hline Materials and Supplies & & 10 & 1 & LS & 0 & 0.0 & 1.00 & 0.00 & $2,500.00$ & $2,500.00$ & 0.00 & $2,500.00$ \\
\hline Staff Augmentation Contract & & $2 \mathrm{~N}$ & 1 & LS & 0 & 0.0 & 1.00 & 0.00 & 0.00 & 0.00 & $10,000.00$ & $10,000.00$ \\
\hline Environmental Engineer & & E110-REG & 1 & LS & 90 & 90.0 & 77.14 & 6.942 .94 & 0.00 & 0.00 & 0.00 & $6,942.94$ \\
\hline Quality Control Engineer & & E110-REG & 1 & LS & 90 & 90.0 & 77.14 & $6,942.94$ & 0.00 & 0.00 & 0.00 & $6,942.94$ \\
\hline Safety Engineer & & E120-REG & $i$ & LS & 250 & 250.0 & 69.13 & $17,283.15$ & 0.00 & 0.00 & 0.00 & $17,283.15$ \\
\hline Secretaries & & G040-REG & 1 & LS & 250 & 250.0 & 35.47 & $8,868.33$ & 0.00 & 0.00 & 0.00 & $8,868.33$ \\
\hline Project Manager & & MO20-REG & 1 & LS & 450 & 450.0 & 112.40 & $50,578.59$ & 0.00 & 0.00 & 0.00 & $50,578.59$ \\
\hline Project Engineer & & E130-REG & 1 & LS & 900 & 450.0 & 95.71 & $43,071.31$ & 0.00 & 0.00 & 0.00 & $43,071,31$ \\
\hline Scheduler & & P070-REG & 1 & LS & 250 & 250.0 & 76.59 & $19,147.00$ & 0.00 & 0.00 & 0.00 & $19,147.00$ \\
\hline \multirow{3}{*}{$\begin{array}{l}\text { Estimator } \\
\text { Cost Analyst }\end{array}$} & & P070-REG & 1 & LS & 100 & 100.0 & 76.59 & $7,658.80$ & 0.00 & 0.00 & 0.00 & $7,658.80$ \\
\hline & & P070-REG & 1 & LS & 100 & 100.0 & 76.59 & $7,658.80$ & 0.00 & 0.00 & 0.00 & $7,658.80$ \\
\hline & ement & & & & & $17,870.0$ & & $1,492,445.46$ & & $22,500.00$ & $110,000.00$ & $1,624,945.46$ \\
\hline \multirow{2}{*}{\multicolumn{13}{|c|}{$\begin{array}{l}\text { Engineering } \\
\text { Detail Design - Offsite Engineering Contract }\end{array}$}} \\
\hline & & 21 & 1 & LS & 0 & 0.0 & 1.00 & 0.00 & 0.00 & 0.00 & $100,000.00$ & $100,000.00$ \\
\hline Final Design - Offsite Engineering Contract & & 21 & 1 & LS & 0 & 0.0 & 1.00 & 0.00 & 0.00 & 0.00 & $200,000.00$ & $200,000.00$ \\
\hline Title III Engineering Contract & & 21 & 1 & LS & 0 & 0.0 & 1.00 & 0.00 & 0.00 & 0.00 & $60,000.00$ & $60,000.00$ \\
\hline & eering & & & & & 0.0 & & 0.00 & & 0.00 & $360,000.00$ & $360,000.00$ \\
\hline
\end{tabular}


RPP-RPT-37924 Rev. 0

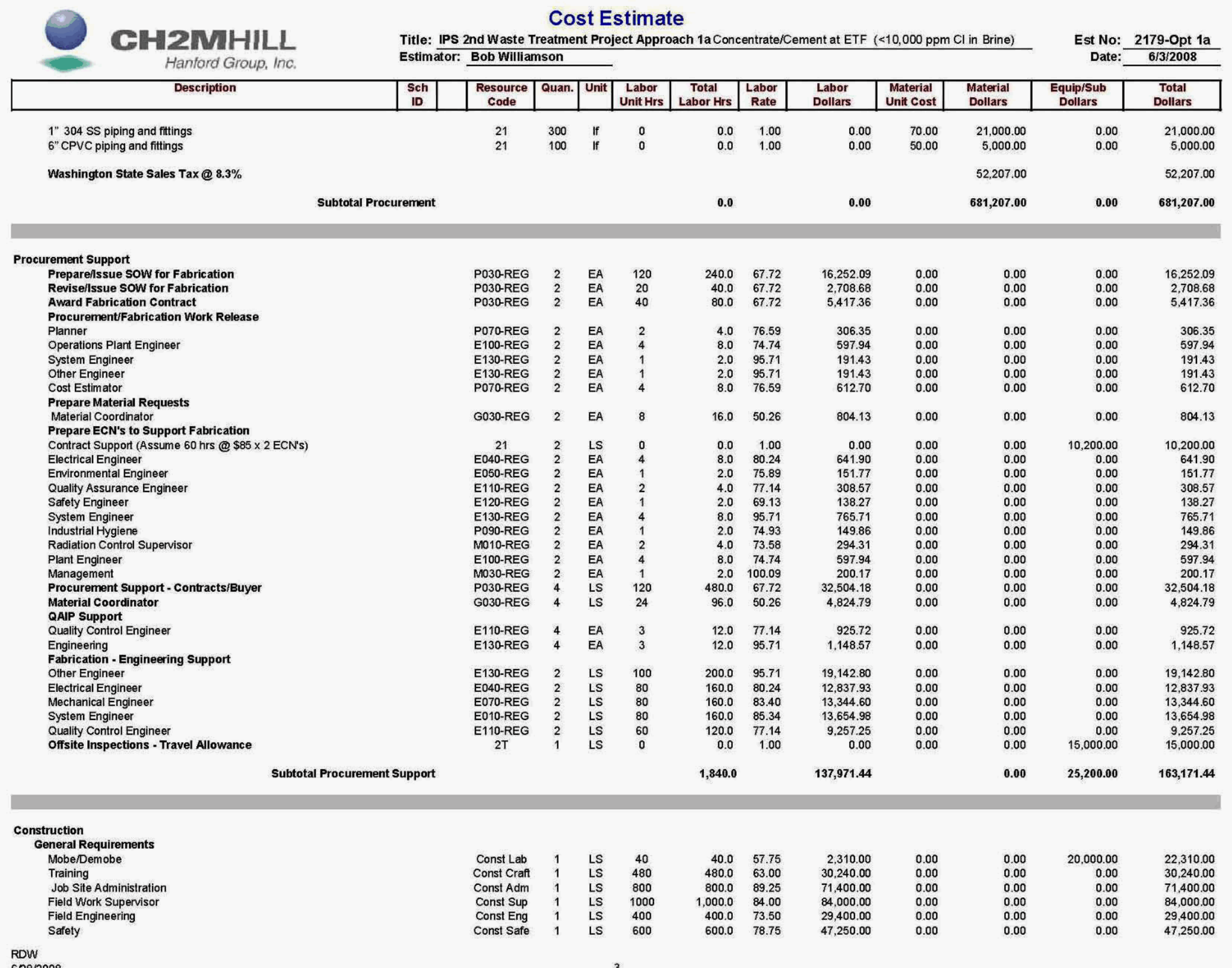


RPP-RPT-37924 Rev. 0

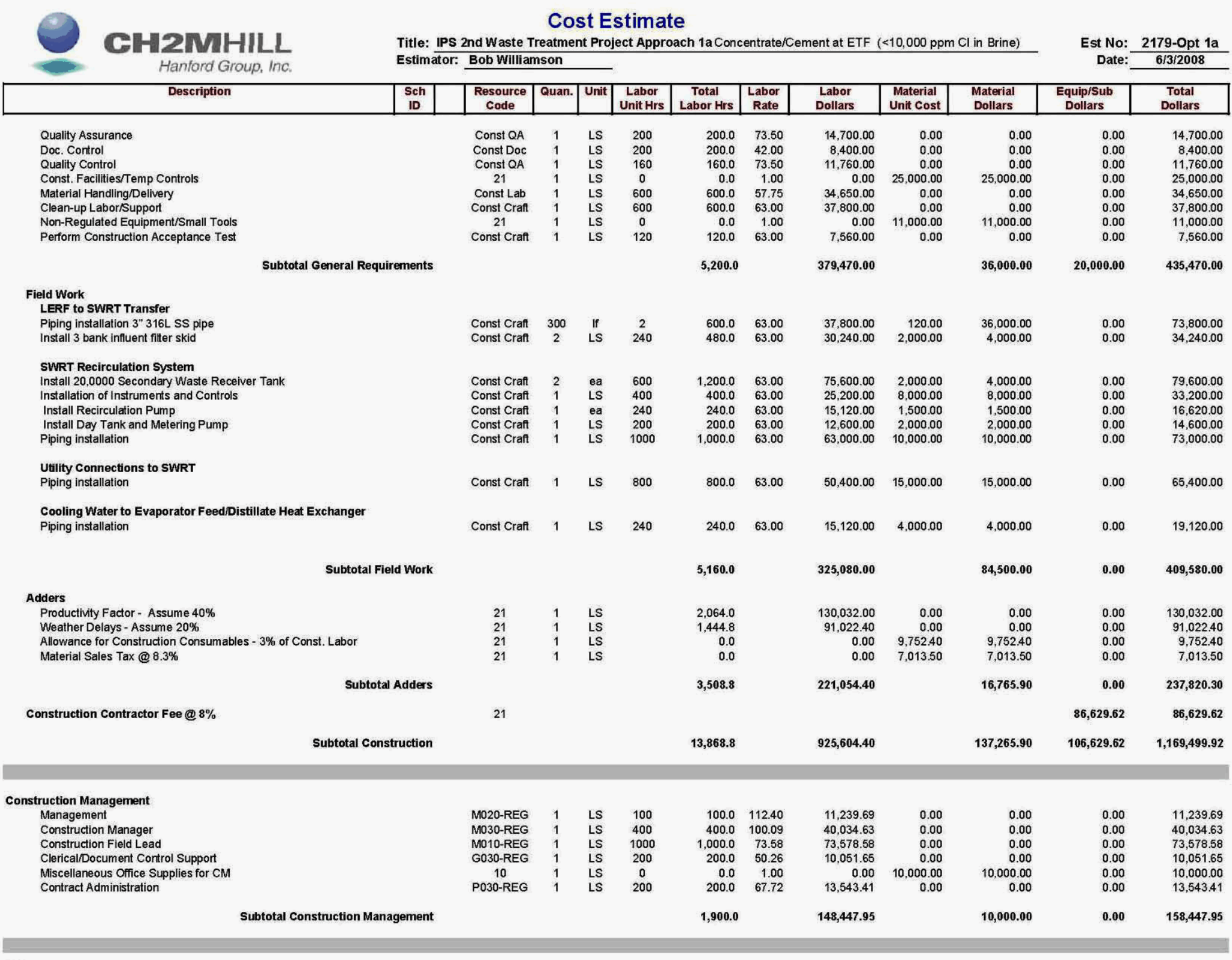


RPP-RPT-37924 Rev. 0

\section{Cost Estimate}

Title: IPS 2nd Waste Treatment Project Approach 1a Concentrate/Cement at ETF $(<10,000 \mathrm{ppm} \mathrm{Cl}$ in Brine $) \quad$ Est No: 2179-Opt 1a Estimator: Bob Williamson Date: $6 / 3 / 2008$

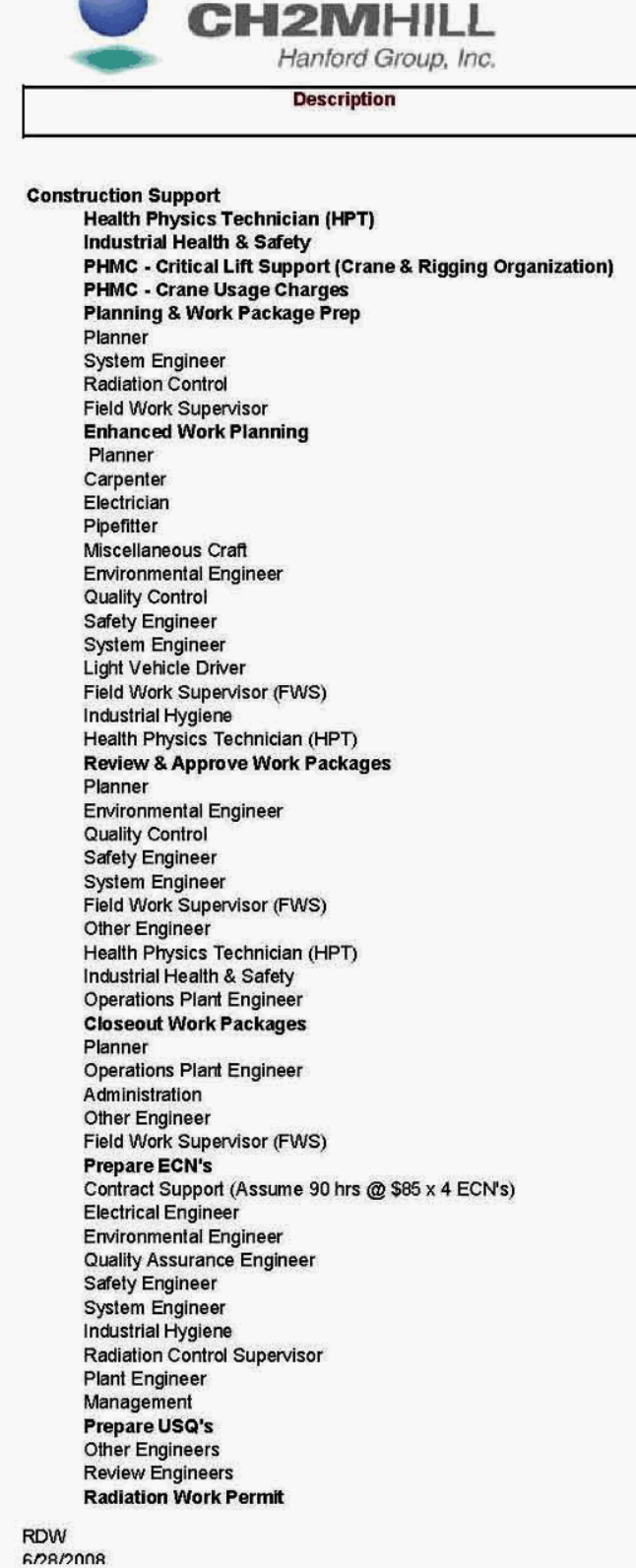

\begin{tabular}{|c|c|c|c|c|c|c|c|c|c|c|}
\hline $\begin{array}{c}\text { Sch } \\
\text { ID }\end{array}$ & $\begin{array}{c}\text { Resource } \\
\text { code }\end{array}$ & Quan. & Unit & $\begin{array}{c}\text { Labor } \\
\text { Unit Hrs }\end{array}$ & $\begin{array}{c}\text { Total } \\
\text { Labor Hrs }\end{array}$ & $\begin{array}{c}\text { Labor } \\
\text { Rate }\end{array}$ & $\begin{array}{c}\text { Labor } \\
\text { Dollars }\end{array}$ & $\begin{array}{c}\text { Material } \\
\text { Unit cost }\end{array}$ & $\begin{array}{c}\text { Material } \\
\text { Dollars }\end{array}$ \\
\hline
\end{tabular}

quip/Su

Total
Dollars

\begin{tabular}{|c|c|c|c|c|c|c|c|c|c|c|}
\hline T050-REG & 1 & LS & 80 & 80.0 & 58.48 & $4,678.33$ & 0.00 & 0.00 & 0.00 & $4,678.33$ \\
\hline T060-REG & 1 & LS & 40 & 40.0 & 57.69 & $2,307.71$ & 0.00 & 0.00 & 0.00 & $2,307.71$ \\
\hline $3 P$ & 1 & LS & 0 & 0.0 & 1.00 & 0.00 & 0.00 & 0.00 & $20,000.00$ & $20,000.00$ \\
\hline $3 P$ & 1 & LS & 0 & 0.0 & 1.00 & 0.00 & 0.00 & 0.00 & $10,000.00$ & $10,000.00$ \\
\hline P070-REG & 1 & EA & 112 & 112.0 & 76.59 & 8.577 .85 & 0.00 & 0.00 & 0.00 & 8.577 .85 \\
\hline E130-REG & 1 & EA & 20 & 20.0 & 95.71 & $1,914.28$ & 0.00 & 0.00 & 0.00 & $1,914.28$ \\
\hline P090-REG & 1 & EA & 20 & 20.0 & 74.93 & $1,498.62$ & 0.00 & 0.00 & 0.00 & $1,498.62$ \\
\hline Mo10-REG & 1 & EA & 20 & 20.0 & 73.58 & 1.471 .57 & 0.00 & 0.00 & 0.00 & 1.471 .57 \\
\hline P070-REG & 1 & $E A$ & 3 & 3.0 & 76.59 & 229.76 & 0.00 & 0.00 & 0.00 & 229.76 \\
\hline CO10-REG & 1 & $E A$ & 3 & 3.0 & 55.84 & 167.51 & 0.00 & 0.00 & 0.00 & 167.51 \\
\hline CO20-REG & 1 & EA & 3 & 3.0 & 61.07 & 183.21 & 0.00 & 0.00 & 0.00 & 183.21 \\
\hline C080-REG & 1 & EA & 3 & 3.0 & 57.11 & 171.32 & 0.00 & 0.00 & 0.00 & 171.32 \\
\hline C120-REG & 1 & $E A$ & 3 & 3.0 & 56.94 & 170.81 & 0.00 & 0.00 & 0.00 & 170.81 \\
\hline E050-REG & 1 & EA & 3 & 3.0 & 75.89 & 227.66 & 0.00 & 0.00 & 0.00 & 227.66 \\
\hline E110-REG & 1 & EA & 3 & 3.0 & 77.14 & 231.43 & 0.00 & 0.00 & 0.00 & 231.43 \\
\hline E120-REG & 1 & EA & 3 & 3.0 & 69.13 & 207.40 & 0.00 & 0.00 & 0.00 & 207.40 \\
\hline E130-REG & 1 & EA & 3 & 3.0 & 95.71 & 287.14 & 0.00 & 0.00 & 0.00 & 287.14 \\
\hline L070-REG & 1 & EA & 3 & 3.0 & 47.91 & 143.73 & 0.00 & 0.00 & 0.00 & 143.73 \\
\hline M010-REG & 1 & EA & 3 & 3.0 & 73.58 & 220.74 & 0.00 & 0.00 & 0.00 & 220.74 \\
\hline P090-REG & 1 & EA & 3 & 3.0 & 74.93 & 224.79 & 0.00 & 0.00 & 0.00 & 224.79 \\
\hline T050-REG & 1 & $\mathrm{EA}$ & 3 & 3.0 & 58.48 & 175.44 & 0.00 & 0.00 & 0.00 & 175.44 \\
\hline P070-REG & 1 & $E A$ & 28 & 28.0 & 76.59 & $2,144.46$ & 0.00 & 0.00 & 0.00 & 2.144 .46 \\
\hline EO50-REG & 1 & EA & 5 & 5.0 & 75.89 & 379.43 & 0.00 & 0.00 & 0.00 & 379.43 \\
\hline E110-REG & 1 & $E A$ & 5 & 5.0 & 77.14 & $\begin{array}{l}385.72 \\
3\end{array}$ & 0.00 & 0.00 & 0.00 & 385.72 \\
\hline E120-REG & 1 & EA & 5 & 5.0 & 69.13 & 345.66 & 0.00 & 0.00 & 0.00 & 345.66 \\
\hline E130-REG & 1 & $E A$ & 10 & 10.0 & 95.71 & 957.14 & 0.00 & 0.00 & 0.00 & 957.14 \\
\hline MO10-REG & 1 & EA & 5 & 5.0 & 73.58 & 367.89 & 0.00 & 0.00 & 0.00 & 367.89 \\
\hline E130-REG & 1 & EA & 5 & 5.0 & 95.71 & 478.57 & 0.00 & 0.00 & 0.00 & 478.57 \\
\hline TO50-REG & 1 & EA & 5 & 5.0 & 58.48 & 292.40 & 0.00 & 0.00 & 0.00 & 292.40 \\
\hline TO60-REG & 1 & EA & 5 & 5.0 & 57.69 & 288.46 & 0.00 & 0.00 & 0.00 & 288.46 \\
\hline E100-REG & 1 & EA & 25 & 25.0 & 74.74 & $1,868.56$ & 0.00 & 0.00 & 0.00 & $1,868.56$ \\
\hline P070-REG & 1 & EA & 12 & 12.0 & 76.59 & 919.06 & 0.00 & 0.00 & 0.00 & 919.06 \\
\hline E100-REG & 1 & EA & 4 & 4.0 & 74.74 & 298.97 & 0.00 & 0.00 & 0.00 & 298.97 \\
\hline G020-REG & 1 & EA & 2 & 2.0 & 33.28 & 66.56 & 0.00 & 0.00 & 0.00 & 66.56 \\
\hline E130-REG & 1 & EA & 4 & 4.0 & 95.71 & 382.86 & 0.00 & 0.00 & 0.00 & 382.86 \\
\hline M010-REG & 1 & EA & 2 & 2.0 & 73.58 & 147.16 & 0.00 & 0.00 & 0.00 & 147.16 \\
\hline 21 & 1 & LS & 0 & 0.0 & 1.00 & 0.00 & 0.00 & 0.00 & $30,600.00$ & $30,600.00$ \\
\hline E040-REG & 1 & EA & 4 & 4.0 & 80.24 & 320.95 & 0.00 & 0.00 & 0.00 & 320.95 \\
\hline E050-REG & 1 & EA & 1 & 1.0 & 75.89 & 75.89 & 0.00 & 0.00 & 0.00 & 75.89 \\
\hline E110-REG & 1 & $E A$ & 2 & 2.0 & 77.14 & 154.29 & 0.00 & 0.00 & 0.00 & 154.29 \\
\hline E120-REG & 1 & EA & 1 & 1.0 & 69.13 & 69.13 & 0.00 & 0.00 & 0.00 & 69.13 \\
\hline E130-REG & 1 & $E A$ & 4 & 4.0 & 95.71 & 382.86 & 0.00 & 0.00 & 0.00 & 382.86 \\
\hline P090-REG & 1 & EA & 1 & 1.0 & 74.93 & 74.93 & 0.00 & 0.00 & 0.00 & 74.93 \\
\hline M010-REG & 1 & EA & 2 & 2.0 & 73.58 & 147.16 & 0.00 & 0.00 & 0.00 & 147.16 \\
\hline E100-REG & 1 & EA & 4 & 4.0 & 74.74 & 298.97 & 0.00 & 0.00 & 0.00 & 298.97 \\
\hline MO30-REG & 1 & $E A$ & 1 & 1.0 & 100.09 & 100.09 & 0.00 & 0.00 & 0.00 & 100.09 \\
\hline E130-REG & 1 & EA & 28 & 28.0 & 95.71 & 267999 & 0.00 & 0.00 & 0.00 & 2.67999 \\
\hline E130-REG & 1 & EA & 9 & 9.0 & 95.71 & 861.43 & 0.00 & 0.00 & 0.00 & 861.43 \\
\hline
\end{tabular}


RPP-RPT-37924 Rev. 0

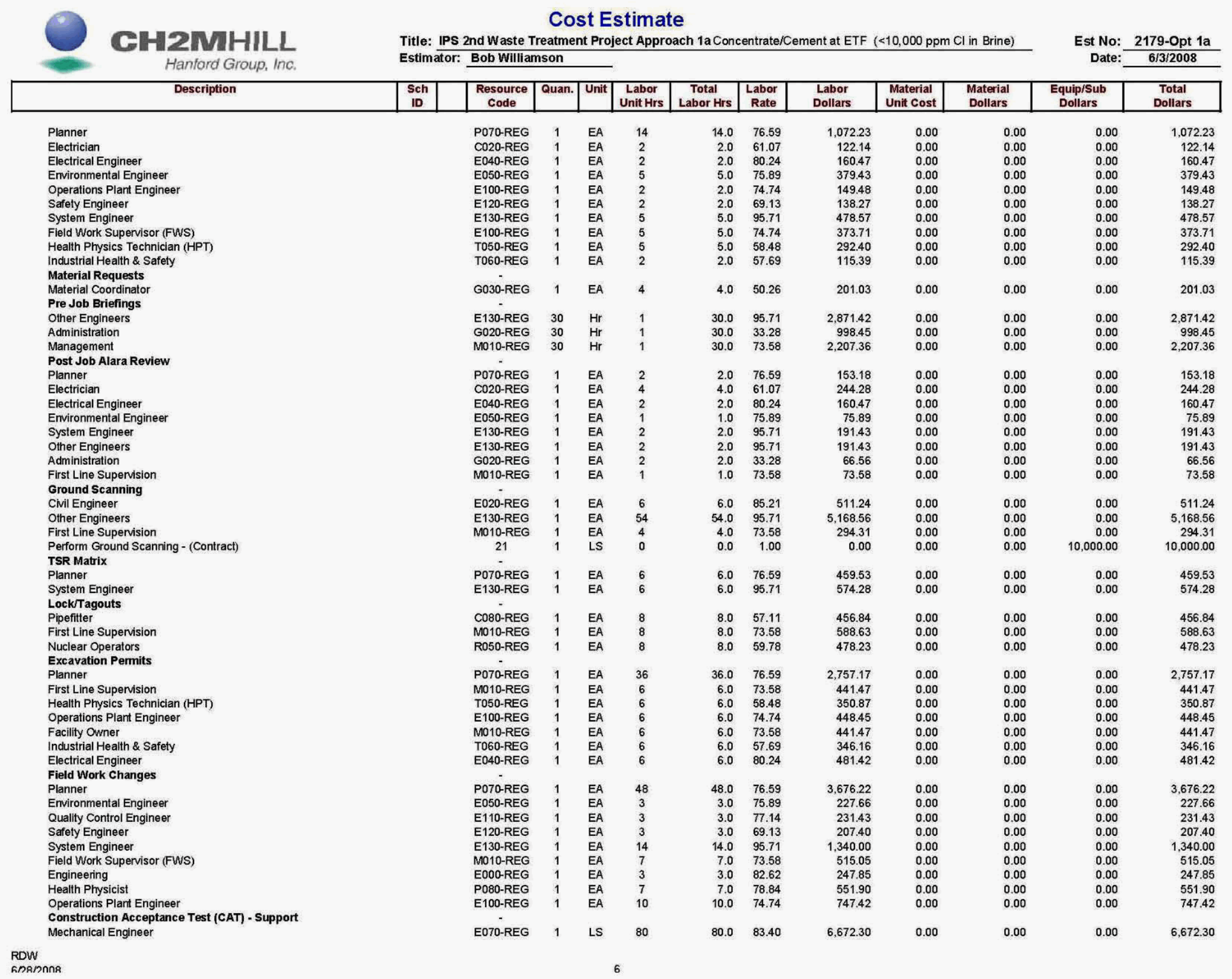


RPP-RPT-37924 Rev. 0

\section{Cost Estimate}

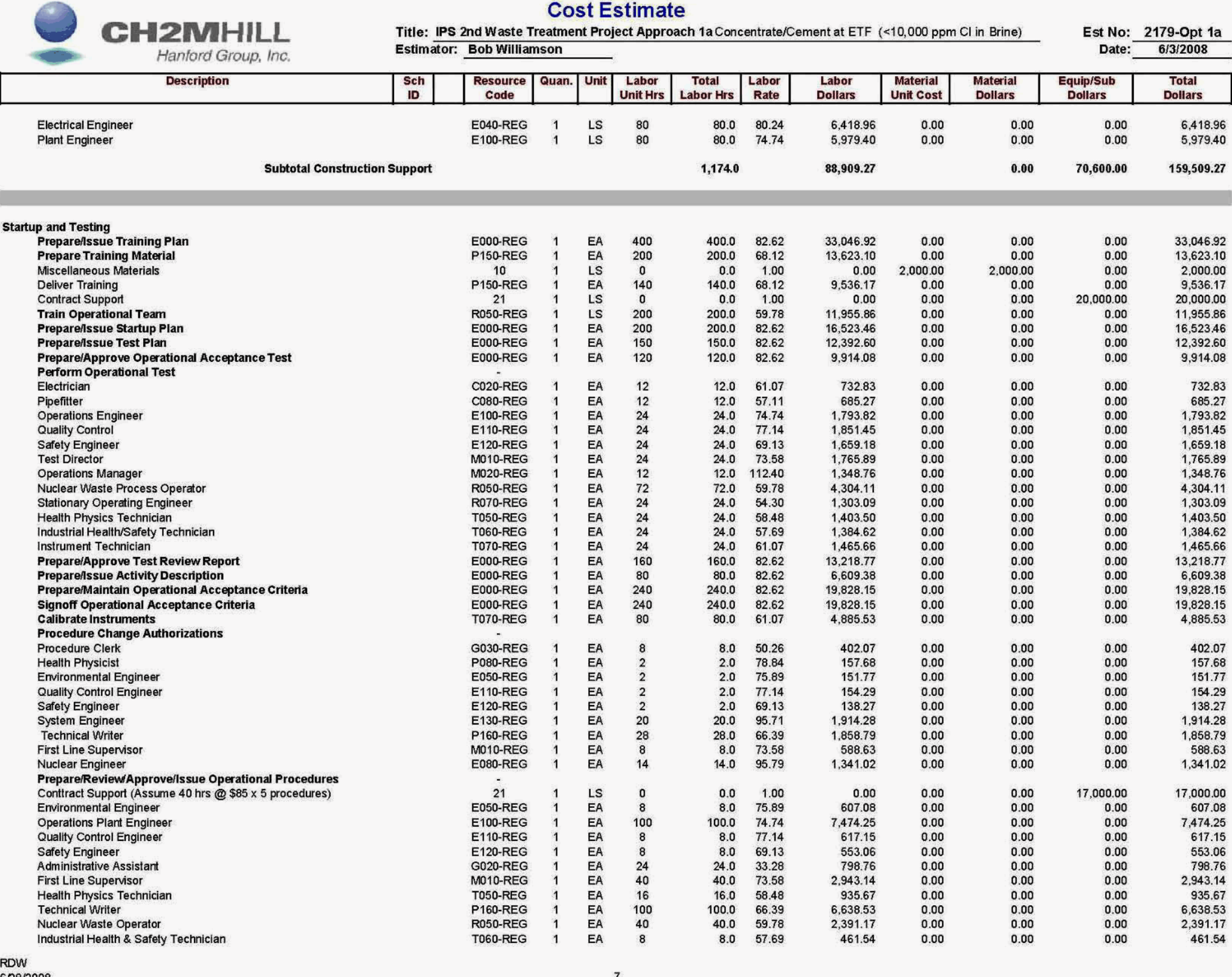


RPP-RPT-37924 Rev. 0

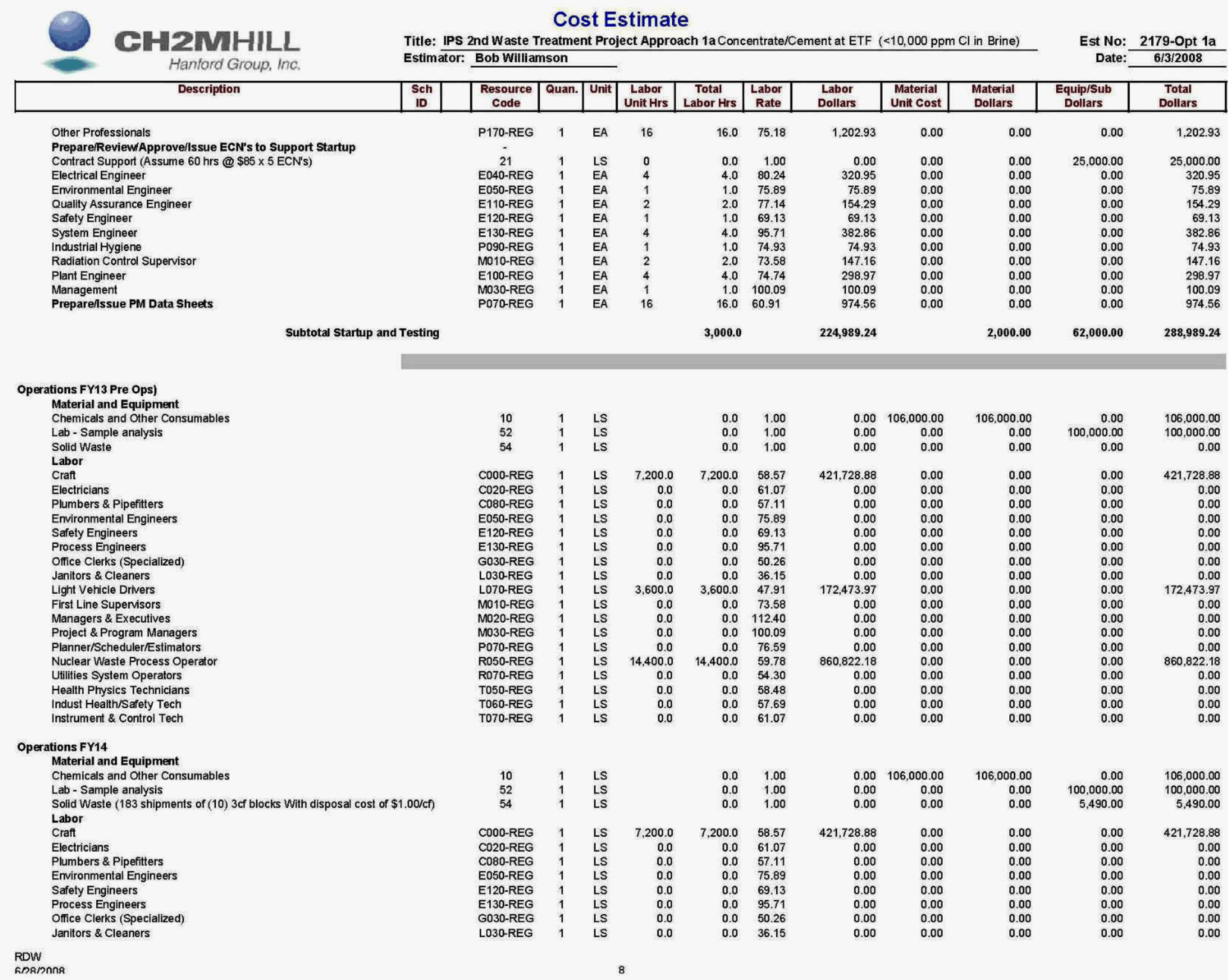


RPP-RPT-37924 Rev. 0

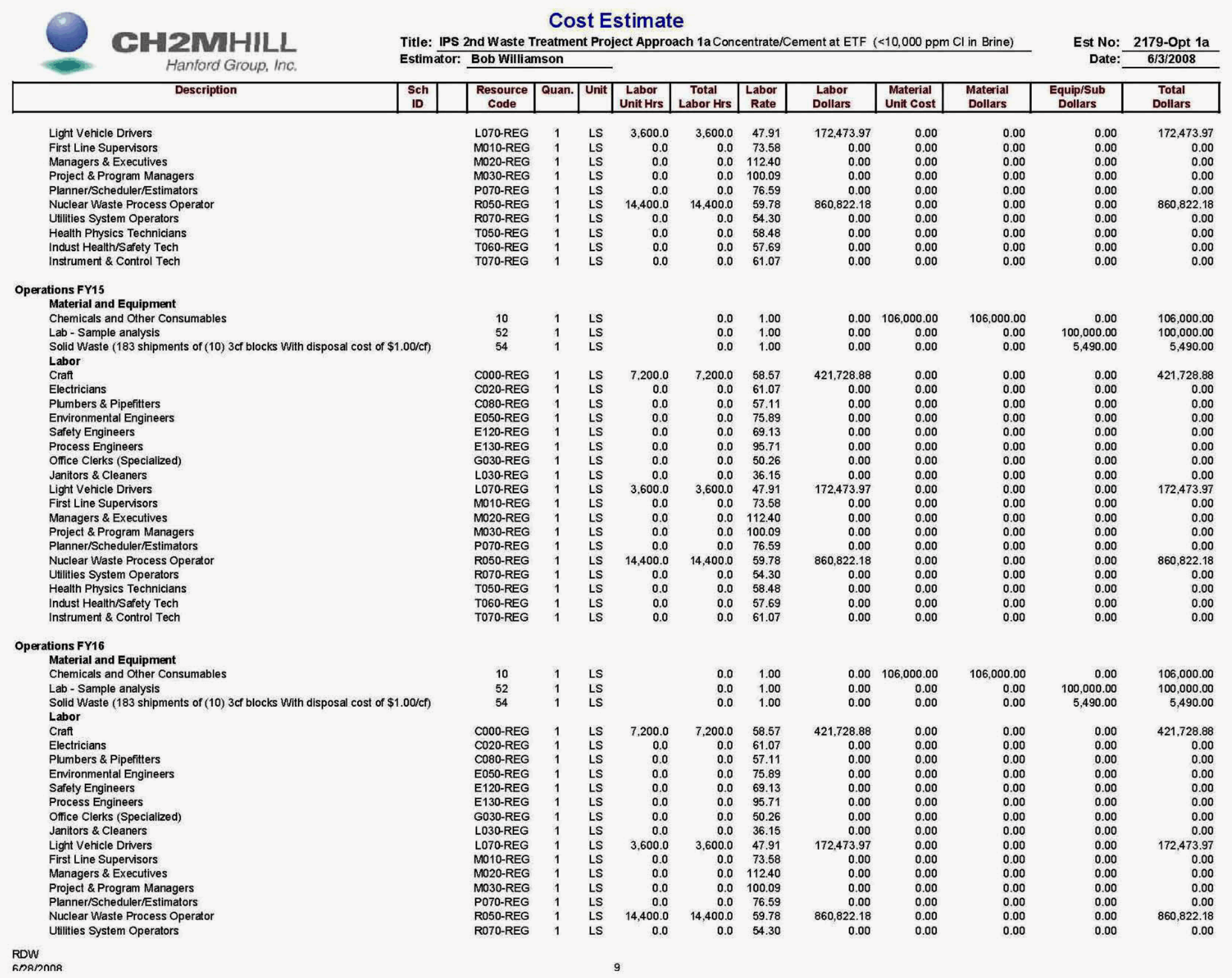


RPP-RPT-37924 Rev. 0

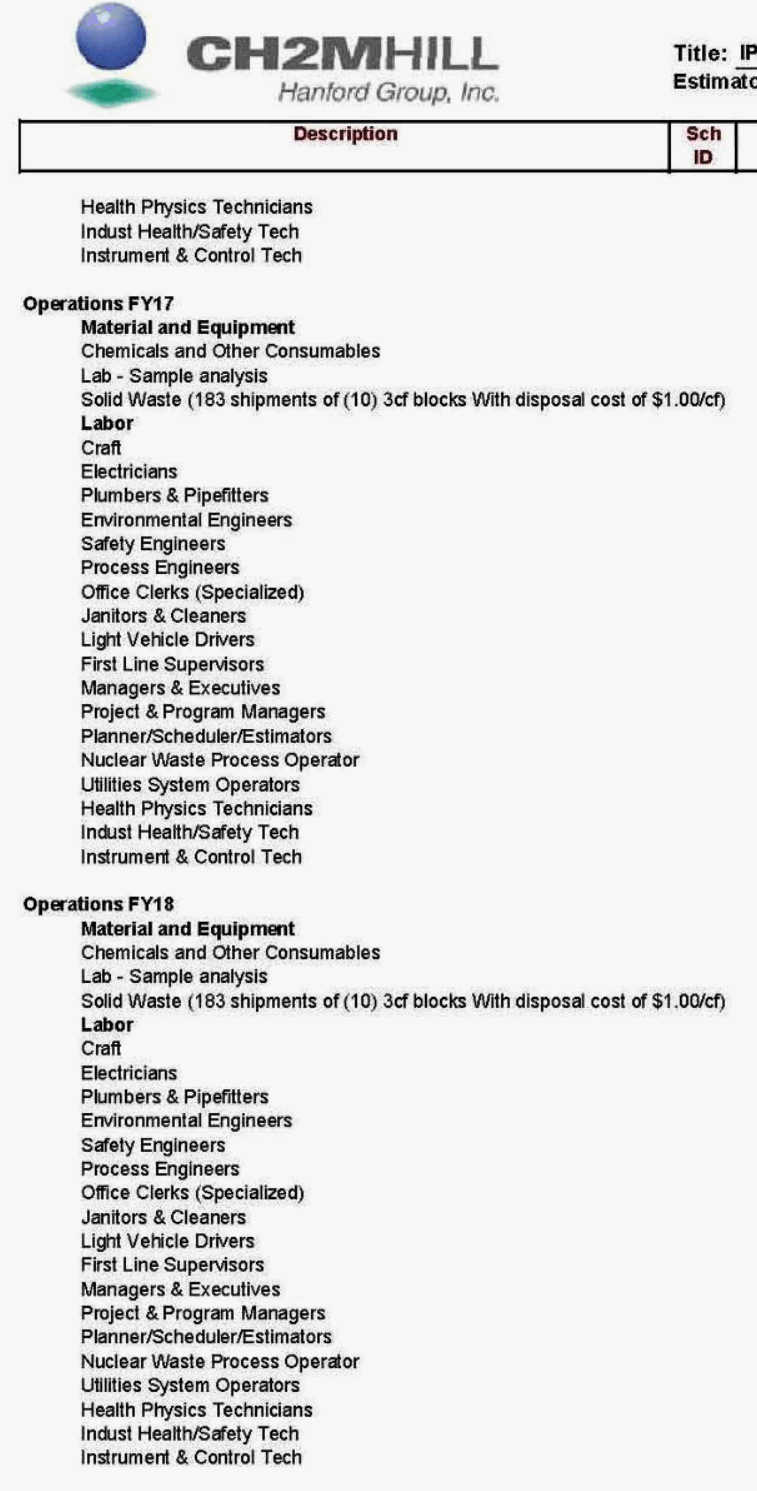

Subtotal Operations

\section{Cost Estimate}

le: IPS 2nd Waste Treatment Project Approach 1a Concentrate/Cement at ETF ( $<10,000 \mathrm{ppm} \mathrm{Cl}$ in Brine) Estimator: Bob Williamson

\begin{tabular}{|c|c|c|c|}
\hline $\begin{array}{c}\text { Resource } \\
\text { Code }\end{array}$ & Quan. & Unit & $\begin{array}{c}\text { Labo } \\
\text { Unit H }\end{array}$ \\
\hline
\end{tabular}

TO50-REG

TO60-REG
T070-REG

$\begin{array}{ll}1 & \text { LS } \\ 1 & \text { LS } \\ & \text { LS }\end{array}$

Labor
Unit Hrs
0.0
0.0
0

\begin{tabular}{|c|c|} 
Total \\
Labor Hrs
\end{tabular}

\begin{tabular}{l|c|c|} 
Hrs & $\begin{array}{c}\text { Labor } \\
\text { Rate }\end{array}$ & \\
\hline
\end{tabular}

Labor
Dollars

\begin{tabular}{|l|l}
\hline bor & $\begin{array}{c}\text { Material } \\
\text { Unit Cost }\end{array}$ \\
\hline
\end{tabular}

$\begin{array}{cc}10 & 1 \\ 52 & 1 \\ 54 & 1 \\ \text { CO00-REG } & 1 \\ \text { C020-REG } & 1 \\ \text { C080-REG } & 1 \\ \text { E050--REG } & 1 \\ \text { E120-REG } & 1 \\ \text { E130-REG } & 1 \\ \text { G030-REG } & 1 \\ \text { L030-REG } & 1 \\ \text { L0070-REG } & 1 \\ \text { MO10-REG } & 1 \\ \text { MO20-REG } & 1 \\ \text { MO0-REG } & 1 \\ \text { P070-REG } & 1 \\ \text { R050-REG } & 1 \\ \text { R070-REG } & 1 \\ \text { T050-REG } & 1 \\ \text { T060-REG } & 1 \\ \text { T070-REG } & 1 \\ & \end{array}$

$\begin{array}{lrrr} & & & \\ \text { LS } & & 0.0 & 1.00 \\ \text { LS } & & 0.0 & 1.00 \\ \text { LS } & & 0.0 & 1.00 \\ & & & \\ \text { LS } & 7.200 .0 & 7.200 .0 & 58.57 \\ \text { LS } & 0.0 & 0.0 & 61.07 \\ \text { LS } & 0.0 & 0.0 & 57.11 \\ \text { LS } & 0.0 & 0.0 & 75.89 \\ \text { LS } & 0.0 & 0.0 & 69.13 \\ \text { LS } & 0.0 & 0.0 & 95.71 \\ \text { LS } & 0.0 & 0.0 & 50.26 \\ \text { LS } & 0.0 & 0.0 & 36.15 \\ \text { LS } & 3,600.0 & 3,600.0 & 47.91 \\ \text { LS } & 0.0 & 0.0 & 73.58 \\ \text { LS } & 0.0 & 0.0 & 112.40 \\ \text { LS } & 0.0 & 0.0 & 100.09 \\ \text { LS } & 0.0 & 0.0 & 76.59 \\ \text { LS } & 14,400.0 & 14,400.0 & 59.78 \\ \text { LS } & 0.0 & 0.0 & 54.30 \\ \text { LS } & 0.0 & 0.0 & 58.48 \\ \text { LS } & 0.0 & 0.0 & 57.69 \\ \text { LS } & 0.0 & 0.0 & 61.07 \\ & & & \end{array}$

$\begin{array}{ccc}10 & 1 & \text { L } \\ 52 & 1 & \text { L } \\ 54 & 1 & \text { LS } \\ \text { CO00-REG } & 1 & \text { L } \\ \text { CO20-REG } & 1 & \text { L } \\ \text { CO80-REG } & 1 & \text { LS } \\ \text { E050-REG } & 1 & \text { L } \\ \text { E120-REG } & 1 & \text { L } \\ \text { E130-REG } & 1 & \text { L } \\ \text { G030-REG } & 1 & \text { L } \\ \text { L030-REG } & 1 & \text { L } \\ \text { L070-REG } & 1 & \text { L } \\ \text { MO10-REG } & 1 & \text { L } \\ \text { MO20-REG } & 1 & \text { L } \\ \text { MO30-REG } & 1 & \text { L } \\ \text { P070-REG } & 1 & \text { L } \\ \text { R050-REG } & 1 & \text { L } \\ \text { R070-REG } & 1 & \text { L } \\ \text { TO50-REG } & 1 & \text { L } \\ \text { TO60-REG } & 1 & \text { L } \\ \text { TO70-REG } & 1 & \text { L } \\ & & \end{array}$

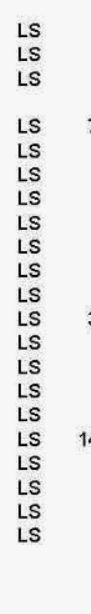
$\begin{array}{ll}0.0 & 1.00 \\ 0.0 & 1.00 \\ 0.0 & 1.00\end{array}$
$\begin{array}{rrr}7.200 .0 & 7.200 .0 & 58.57 \\ 0.0 & 0.0 & 61.07\end{array}$
$\begin{array}{lll}0.0 & 0.0 & 57.11 \\ 0.0 & 0.0 & 75.89\end{array}$

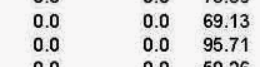
$\begin{array}{rrr}0.0 & 0.0 & 50.26 \\ 0.0 & 0.0 & 36.15 \\ 0 & 0.0\end{array}$
$\begin{array}{rrr}3,600.0 & 3,600.0 & 47.91 \\ 0.0 & 0.0 & 73.58\end{array}$
$\begin{array}{rrrr}0.0 & 0.0 & 73.58 \\ 0.0 & 0.0 & 112.40 \\ 0.0 & 0.0 & 10.09\end{array}$
$\begin{array}{rrrr}0.0 & 0.0 & 100.09 \\ 0.0 & 0.0 & 76.59\end{array}$
$\begin{array}{rrr}14,400.0 & 14,400.0 & 59.78 \\ 0.0 & 0.0 & 54.30 \\ 0.0 & 0.0 & 5.88 \\ 0.0 & 0.0 & 57.69\end{array}$
0.0
0.0

$151,200.0$

$\begin{array}{rr}0.00 & 106,000.00 \\ 0.00 & 0.00 \\ 0.00 & 0.00 \\ & \\ 421.728 .88 & 0.00 \\ 0.00 & 0.00 \\ 0.00 & 0.00 \\ 0.00 & 0.00 \\ 0.00 & 0.00 \\ 0.00 & 0.00 \\ 0.00 & 0.00 \\ 0.00 & 0.00 \\ 72.473 .97 & 0.00 \\ 0.00 & 0.00 \\ 0.00 & 0.00 \\ 0.00 & 0.00 \\ 0.00 & 0.00 \\ 860,822.18 & 0.00 \\ 0.00 & 0.00 \\ 0.00 & 0.00 \\ 0.00 & 0.00 \\ 0.00 & 0.00\end{array}$

$106,000.00$
0.00
0.00
0.00
0.00
0.00
0.00
0.00
0.00
0.00
0.00
0.00
0.00
0.00
0.00
0.00
0.00
0.00
0.00
0.00
0.00

$\begin{array}{rr}000.00 & \\ 0.00 & 100,000.00 \\ 0.00 & 5,490.00 \\ 0.00 & \\ 0.00 & 0.00 \\ 0.00 & 0.00 \\ 0.00 & 0.00 \\ 0.00 & 0.00 \\ 0.00 & 0.00 \\ 0.00 & 0.00 \\ 0.00 & 0.00 \\ 0.00 & 0.00 \\ 0.00 & 0.00 \\ 0.00 & 0.00 \\ 0.00 & 0.00 \\ 0.00 & 0.00 \\ 0.00 & 0.00 \\ 0.00 & 0.00 \\ 0.00 & 0.00 \\ 0.00 & 0.00 \\ 0.00 & 0.00\end{array}$

Est No: 2179-Opt 1a Date: 6/3/2008

Dollars

Total
Dollars

$\begin{array}{rrrrr}0.00 & 106,000.00 & 106,000.00 & 0.00 & 106,000.00 \\ 0.00 & 0.00 & 0.00 & 100,000.00 & 100,000.00 \\ 0.00 & 0.00 & 0.00 & 5,490.00 & 5,490.00 \\ 421,728.88 & 0.00 & 0.00 & 0.00 & 421,728.88 \\ 0.00 & 0.00 & 0.00 & 0.00 & 0.00 \\ 0.00 & 0.00 & 0.00 & 0.00 & 0.00 \\ 0.00 & 0.00 & 0.00 & 0.00 & 0.00 \\ 0.00 & 0.00 & 0.00 & 0.00 & 0.00 \\ 0.00 & 0.00 & 0.00 & 0.00 & 0.00 \\ 0.00 & 0.00 & 0.00 & 0.00 & 0.00 \\ 0.00 & 0.00 & 0.00 & 0.00 & 0.00 \\ 172,473.97 & 0.00 & 0.00 & 0.00 & 172,473.97 \\ 0.00 & 0.00 & 0.00 & 0.00 & 0.00 \\ 0.00 & 0.00 & 0.00 & 0.00 & 0.00 \\ 0.00 & 0.00 & 0.00 & 0.00 & 0.00 \\ 0.00 & 0.00 & 0.00 & 0.00 & 0.00 \\ 860,822.18 & 0.00 & 0.00 & 0.00 & 860,822.18 \\ 0.00 & 0.00 & 0.00 & 0.00 & 0.00 \\ 0.00 & 0.00 & 0.00 & 0.00 & 0.00 \\ 0.00 & 0.00 & 0.00 & 0.00 & 0.00 \\ 0.00 & 0.00 & 0.00 & 0.00 & 0.00 \\ & & & & \\ 3,730,150.17 & & 636,000.00 & 627,450.00 & 9,993,600.17\end{array}$




\begin{tabular}{|c|c|c|c|c|c|c|c|c|c|c|c|c|}
\hline \multirow{2}{*}{$\begin{array}{c}\text { CHIWHILL } \\
\text { Hanford Group, Inc. } \\
\text { Description } \\
\end{array}$} & \multicolumn{10}{|c|}{$\begin{array}{l}\text { Cost Estimate } \\
\text { Title: IPS 2nd Waste Treatment Project Approach 1a Concentrate/Cement at ETF ( }(10,000 \mathrm{ppm} \text { Cl in Brine) }\end{array}$} & \multicolumn{2}{|c|}{$\begin{aligned} \text { Est No: } & \text { 2179-Opt 1a } \\
\text { Date: } & 6 / 3 / 2008\end{aligned}$} \\
\hline & \begin{tabular}{|c|}
$\begin{array}{c}\text { Sch } \\
\text { ID }\end{array}$ \\
\end{tabular} & \begin{tabular}{|c|}
$\begin{array}{c}\text { Resource } \\
\text { Code }\end{array}$ \\
\end{tabular} & \begin{tabular}{|l|} 
Quan. \\
\end{tabular} & Unit & \begin{tabular}{|l|} 
Labor \\
Unit Hrs \\
\end{tabular} & \begin{tabular}{|l|} 
Total \\
Labor Hrs \\
\end{tabular} & \begin{tabular}{|c|c|} 
Labor \\
Rate
\end{tabular} & $\begin{array}{l}\text { Labor } \\
\text { Dollars } \\
\end{array}$ & \begin{tabular}{|l|} 
Material \\
Unit cost \\
\end{tabular} & $\begin{array}{l}\begin{array}{c}\text { Material } \\
\text { Dollars }\end{array} \\
\end{array}$ & $\begin{array}{c}\begin{array}{c}\text { Equip/sub } \\
\text { Dollars }\end{array} \\
\end{array}$ & $\begin{array}{l}\text { Total } \\
\text { Dollars }\end{array}$ \\
\hline $\begin{array}{l}\text { Other Poriject Costs } \\
\text { Preliminary Design } \\
\text { Preliminary Design (Subcontract) }\end{array}$ & & $\begin{array}{l}21 \\
\text { E1130-REG } \\
\text { MO30-REG }\end{array}$ & $\begin{array}{l}1 \\
1 \\
1\end{array}$ & $\begin{array}{l}\text { LS } \\
\text { LS } \\
\text { LS }\end{array}$ & $\begin{array}{c}0 \\
200 \\
200\end{array}$ & $\begin{array}{r}0.0 \\
200.0 \\
200.0\end{array}$ & $\begin{array}{r}1.00 \\
95.71 \\
100.09\end{array}$ & $\begin{array}{r}0.00 \\
19,142.80 \\
20,017.32\end{array}$ & $\begin{array}{l}0.00 \\
0.00 \\
0.00\end{array}$ & $\begin{array}{l}0.00 \\
0.00 \\
0.00\end{array}$ & $\begin{array}{r}50,000.00 \\
0.00 \\
0.00\end{array}$ & $\begin{array}{l}50,000.00 \\
19,142.80 \\
20,017.32\end{array}$ \\
\hline $\begin{array}{l}\text { Development } \\
\text { Lab Scale Tests to Verify Process Conditions } \\
\text { Development Coordination (Engineering Support) } \\
\text { Development Coordination (Project Manager) } \\
\text { Development Coordination (Staff Aug) } \\
\text { Laboratory Analysis }\end{array}$ & & $\begin{array}{c}21 \\
\text { E130-REG } \\
\text { MO30-REG } \\
21 \\
21\end{array}$ & $\begin{array}{l}1 \\
1 \\
1 \\
1 \\
1\end{array}$ & $\begin{array}{l}\text { LS } \\
\text { LS } \\
\text { LS } \\
\text { LS } \\
\text { LS }\end{array}$ & $\begin{array}{l}0 \\
0 \\
0 \\
0 \\
0\end{array}$ & $\begin{array}{l}0.0 \\
0.0 \\
0.0 \\
0.0 \\
0.0\end{array}$ & $\begin{array}{r}1.00 \\
95.71 \\
100.09 \\
1.00 \\
1.00\end{array}$ & $\begin{array}{l}0.00 \\
0.00 \\
0.00 \\
0.00 \\
0.00\end{array}$ & $\begin{array}{l}0.00 \\
0.00 \\
0.00 \\
0.00 \\
0.00\end{array}$ & $\begin{array}{l}0.00 \\
0.00 \\
0.00 \\
0.00 \\
0.00\end{array}$ & $\begin{array}{r}250,000.00 \\
0.00 \\
0.00 \\
0.00 \\
0.00\end{array}$ & $\begin{array}{r}250,000.00 \\
0.00 \\
0.00 \\
0.00 \\
0.00\end{array}$ \\
\hline 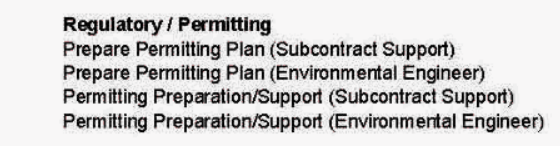 & & $\begin{array}{c}21 \\
\text { E050-REG } \\
21 \\
\text { E050-REG }\end{array}$ & $\begin{array}{l}1 \\
1 \\
1 \\
1\end{array}$ & $\begin{array}{l}\text { LS } \\
\text { LS } \\
\text { LS } \\
\text { LS }\end{array}$ & $\begin{array}{c}0 \\
450 \\
0 \\
900\end{array}$ & $\begin{array}{r}0.0 \\
450.0 \\
0.0 \\
900.0\end{array}$ & $\begin{array}{r}1.00 \\
75.89 \\
1.00 \\
75.89\end{array}$ & $\begin{array}{r}0.00 \\
34,148.45 \\
0.00 \\
68,296.90\end{array}$ & $\begin{array}{r}0.00 \\
0.00 \\
0.00 \\
5,000.00\end{array}$ & $\begin{array}{r}0.00 \\
0.00 \\
0.00 \\
5,000.00\end{array}$ & $\begin{array}{r}50,000.00 \\
0.00 \\
100,000.00 \\
0.00\end{array}$ & $\begin{array}{r}50,000.00 \\
34,148.45 \\
100,000.00 \\
73,296.90\end{array}$ \\
\hline Subtotal ot & ct costs & & & & & $1,750.0$ & & $141,605.47$ & & $5,000.00$ & $450,000.00$ & $596,605.47$ \\
\hline $\begin{array}{l}\text { Facility Decommissioning } \\
\text { characterization } \\
\text { Characterization (Subcontract) } \\
\text { Characterizatiton (Engineering Support) } \\
\text { Characterization (HPT Support) }\end{array}$ & & $\begin{array}{l}21 \\
\text { E130-REG } \\
\text { T050-REG }\end{array}$ & $\begin{array}{l}0 \\
0 \\
0\end{array}$ & $\begin{array}{l}\text { LS } \\
\text { LS } \\
\text { LS }\end{array}$ & $\begin{array}{l}0 \\
0 \\
0\end{array}$ & $\begin{array}{l}0.0 \\
0.0 \\
0.0\end{array}$ & $\begin{array}{l}1.00 \\
95.71 \\
58.48\end{array}$ & $\begin{array}{l}0.00 \\
0.00 \\
0.00\end{array}$ & $\begin{array}{l}0.00 \\
0.00 \\
0.00\end{array}$ & $\begin{array}{l}0.00 \\
0.00 \\
0.00\end{array}$ & $\begin{array}{l}0.00 \\
0.00 \\
0.00\end{array}$ & $\begin{array}{l}0.00 \\
0.00 \\
0.00\end{array}$ \\
\hline $\begin{array}{l}\text { Decontamination } \\
\text { Decontamination (Subcontract Supporr) }\end{array}$ & & 21 & 0 & LS & 0 & 0.0 & 1.00 & 0.00 & 0.00 & 0.00 & 0.00 & 0.00 \\
\hline $\begin{array}{l}\text { Decommissioning } \\
\text { Decommissioning (Subcontrad Support) }\end{array}$ & & 21 & 0 & LS & 0 & 0.0 & 1.00 & 0.00 & 0.00 & 0.00 & 0.00 & 0.00 \\
\hline $\begin{array}{l}\text { Demolition / Disposal } \\
\text { Demolition / Disposal (Subcontract Support) }\end{array}$ & & 21 & 0 & LS & 0 & 0.0 & 1.00 & 0.00 & 0.00 & 0.00 & 0.00 & 0.00 \\
\hline $\begin{array}{l}\text { Closure } \\
\text { Closure Documentation (Subcontract Support) } \\
\text { Closure Documentation (Environmental Engineer) }\end{array}$ & & $\begin{array}{l}21 \\
\text { E050-REG }\end{array}$ & $\begin{array}{l}0 \\
0\end{array}$ & $\begin{array}{l}\text { LS } \\
\text { LS }\end{array}$ & $\begin{array}{l}0 \\
0\end{array}$ & $\begin{array}{l}0.0 \\
0.0\end{array}$ & $\begin{array}{r}1.00 \\
75.89\end{array}$ & $\begin{array}{l}0.00 \\
0.00\end{array}$ & $\begin{array}{l}0.00 \\
0.00\end{array}$ & $\begin{array}{l}0.00 \\
0.00\end{array}$ & $\begin{array}{l}0.00 \\
0.00\end{array}$ & $\begin{array}{l}0.00 \\
0.00\end{array}$ \\
\hline $\begin{array}{l}\text { Project Management } \\
\text { Project Management (Subcontract Support) } \\
\text { Project Management (Project Manager) }\end{array}$ & & $\begin{array}{l}21 \\
\text { E050-REG }\end{array}$ & $\begin{array}{l}0 \\
0\end{array}$ & $\begin{array}{l}\text { LS } \\
\text { LS }\end{array}$ & $\begin{array}{l}0 \\
0\end{array}$ & $\begin{array}{l}0.0 \\
0.0\end{array}$ & $\begin{array}{r}1.00 \\
75.89\end{array}$ & $\begin{array}{l}0.00 \\
0.00\end{array}$ & $\begin{array}{l}0.00 \\
0.00\end{array}$ & $\begin{array}{l}0.00 \\
0.00\end{array}$ & $\begin{array}{l}0.00 \\
0.00\end{array}$ & $\begin{array}{l}0.00 \\
0.00\end{array}$ \\
\hline Subtotal Facility & ssioning & & & & & 0.0 & & 0.00 & & 0.00 & 0.00 & 0.00 \\
\hline $\begin{array}{l}\text { Contingency } \\
\text { Contingency }\end{array}$ & & & & & & & & $6,298,203.96$ & & $754,486.45$ & 1,023,939.81 & $8,076,630.22$ \\
\hline & ingency & & & & & & & $6,298,203.96$ & & $754,486.45$ & $1,023,939.81$ & $8,076,630.22$ \\
\hline
\end{tabular}


RPP-RPT-37924 Rev. 0

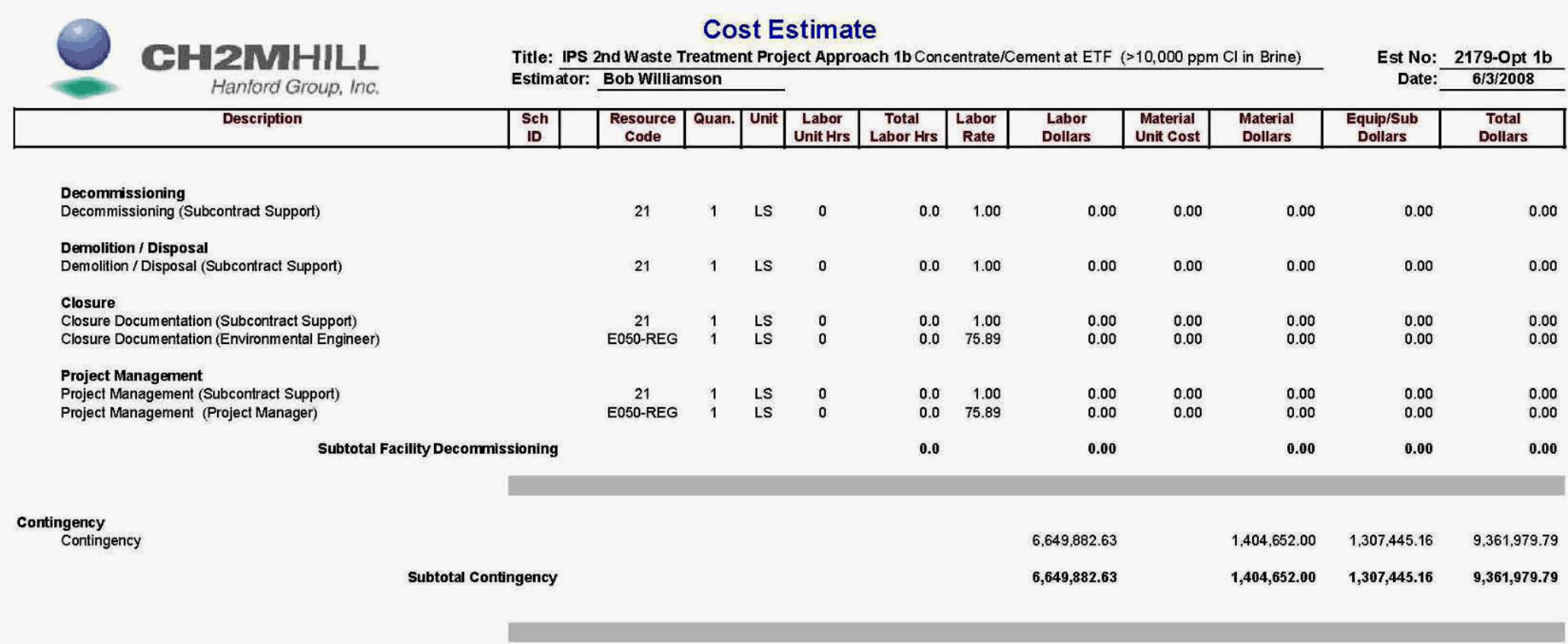


RPP-RPT-37924 Rev. 0

Table G-6. Approach 1 b Cost Estimate.

Table begins on next page. 
RPP-RPT-37924 Rev. 0

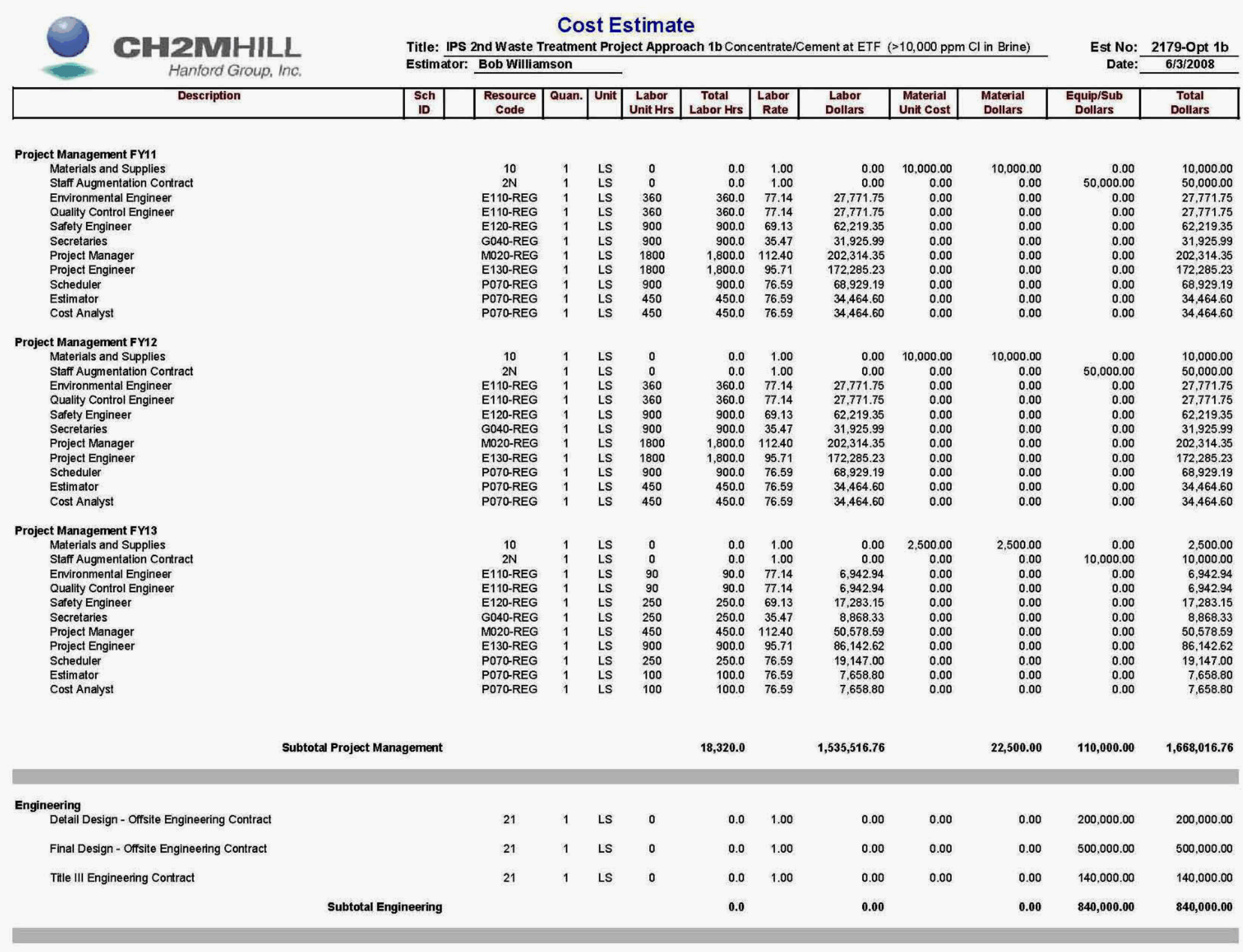


RPP-RPT-37924 Rev. 0

\section{Cost Estimate} CHI2 2 Manford Group, inc

Title: IPS 2nd Waste Treatment Project Approach 1b Concentrate/Cement at ETF ( $>10,000 \mathrm{ppm}$ Cl in Brine)

Est No: 2179-Opt 1b Estimator: Bob Williamson

\begin{tabular}{|c|c|c|c|c|c|c|c|c|c|c|c|c|}
\hline Description & $\begin{array}{l}\text { Sch } \\
\text { ID }\end{array}$ & \begin{tabular}{|c|}
$\begin{array}{c}\text { Resource } \\
\text { Code }\end{array}$ \\
\end{tabular} & Quan. & Unit & \begin{tabular}{|c|}
$\begin{array}{c}\text { Labor } \\
\text { Unit Hrs }\end{array}$ \\
\end{tabular} & \begin{tabular}{|c|} 
Total \\
Labor Hrs \\
\end{tabular} & \begin{tabular}{|l|} 
Labor \\
Rate \\
\end{tabular} & $\begin{array}{l}\text { Labor } \\
\text { Dollars }\end{array}$ & \begin{tabular}{|c|} 
Material \\
Unit cost \\
\end{tabular} & $\begin{array}{c}\text { Material } \\
\text { Dollars }\end{array}$ & $\begin{array}{c}\text { Equip/Sub } \\
\text { Dollars }\end{array}$ & $\begin{array}{c}\text { Total } \\
\text { Dollars } \\
\end{array}$ \\
\hline \multicolumn{13}{|l|}{ Engineering Support FY11 } \\
\hline Process Engineer & & E130-REG & 1 & EA & 1800 & $1,800.0$ & 95.71 & $172,285.23$ & $5,000.00$ & $5,000.00$ & 0.00 & $177,285.23$ \\
\hline \multicolumn{13}{|l|}{ NS \& L Documentation Support } \\
\hline Nuclear Engineer & & E080-REG & 1 & LS & 120 & 120.0 & 95.79 & $11,494.49$ & 0.00 & 0.00 & 0.00 & $11,494.49$ \\
\hline Safety Engineer & & E120-REG & 1 & LS & 120 & 120.0 & 69.13 & $8,295.91$ & 0.00 & 0.00 & 0.00 & $8,295.91$ \\
\hline Health Physicist & & P080-REG & 1 & LS & 120 & 120.0 & 78.84 & $9,461.09$ & 0.00 & 0.00 & 0.00 & $9,461.09$ \\
\hline Environmental Engineer & & E050-REG & 1 & Ls & 120 & 120.0 & 75.89 & $9,106.25$ & 0.00 & 0.00 & 0.00 & $9,106.25$ \\
\hline Contract Support (300 hrs @ \$90/hr) & & 21 & 1 & LS & 0 & 0.0 & 1.00 & 0.00 & 0.00 & 0.00 & $5,000.00$ & $5,000.00$ \\
\hline \multicolumn{13}{|l|}{ Engineering Support FY12 } \\
\hline \multicolumn{13}{|l|}{ Process Engineering Support } \\
\hline Process Engineer & & E130-REG & 1 & EA & 1800 & $1,800.0$ & 95.71 & $172,285.23$ & $5,000.00$ & $5,000.00$ & 0.00 & $177,285.23$ \\
\hline & & 21 & 1 & LS & 0 & 0.0 & 1.00 & 0.00 & 0.00 & 0.00 & $72,000.00$ & $72,000.00$ \\
\hline NS \& L Documentation Support & & E080-REG & 1 & LS & 120 & 120.0 & 95.79 & $11,494.49$ & 0.00 & 0.00 & 0.00 & $11,494.49$ \\
\hline Safety Engineer & & E120-REG & 1 & LS & 120 & 120.0 & 69.13 & $\begin{array}{r}11,454.459 \\
8,295.91\end{array}$ & 0.00 & 0.00 & 0.00 & $8,295.91$ \\
\hline Health Physicist & & P080-REG & 1 & LS & 120 & 120.0 & 78.84 & $9,461.09$ & 0.00 & 0.00 & 0.00 & $9,461.09$ \\
\hline Emvironmental Engineer & & E050-REG & 1 & LS & 120 & 120.0 & 75.89 & $9,106.25$ & 0.00 & 0.00 & 0.00 & $9,106.25$ \\
\hline Contract Support (400 hrs @ \$90/hr) & & 21 & 1 & LS & 0 & 0.0 & 1.00 & 0.00 & 0.00 & 0.00 & $36,000.00$ & $36,000.00$ \\
\hline \multirow{2}{*}{\multicolumn{13}{|c|}{ Engineering Support FY13 }} \\
\hline \multicolumn{10}{|l|}{$\begin{array}{l}\text { Engineering Support FF113 } \\
\text { Process Engineering Support }\end{array}$} & & & \\
\hline Process Engineer & & E130-REG & 1 & EA & 1800 & $1,800.0$ & 95.71 & $172,285.23$ & 5.000 .00 & $5,000.00$ & 0.00 & $177,285.23$ \\
\hline \multicolumn{8}{|l|}{ NS \& L Documentation Support } & 0.00 & 0.00 & 0.00 & $72,000.00$ & $72,000.00$ \\
\hline $\begin{array}{l}\text { NS \&L Documentatiton Support } \\
\text { Nuclear Engineer }\end{array}$ & & E080-REG & 1 & LS & 120 & 120.0 & 95.79 & 11.494 .49 & 0.00 & 0.00 & 0.00 & $11,494,49$ \\
\hline Safety Engineer & & E120-REG & 1 & LS & 120 & 120.0 & 69.13 & $8,295.91$ & 0.00 & 0.00 & 0.00 & $8,295.91$ \\
\hline Health Physicist & & P080-REG & 1 & LS & 120 & 120.0 & 78.84 & $9,461.09$ & 0.00 & 0.00 & 0.00 & $9,461.09$ \\
\hline Emvironmental Engineer & & E050-REG & 1 & LS & 120 & 120.0 & 75.89 & $9,106.25$ & 0.00 & 0.00 & 0.00 & $9,106.25$ \\
\hline Contract Support (400 hrs @ \$90/hr) & & 21 & 1 & LS & 0 & 0.0 & 1.00 & 0.00 & 0.00 & 0.00 & $36,000.00$ & $36,000.00$ \\
\hline Title III Engineering Support During Construction & & E000-REG & 1 & LS & 1800 & $1,800.0$ & 82.62 & $148,711.15$ & 0.00 & 0.00 & 0.00 & $148,711.15$ \\
\hline \multicolumn{3}{|c|}{ Subtotal Engineering Support } & & & & $8,640.0$ & & $780,640.09$ & & $15,000.00$ & $236,000.00$ & $1,031,640.09$ \\
\hline \\
\hline \multicolumn{13}{|l|}{ Material \& Equipment } \\
\hline Recirculation Pumps Inconel & & 10 & 2 & EA & 0 & 0.0 & 1.00 & 0.00 & $50,000.00$ & $100,000.00$ & 0.00 & $100,000.00$ \\
\hline Concentrate Pumps Inconel & & 10 & 2 & EA & 0 & 0.0 & 1.00 & 0.00 & $50,000.00$ & $100,000.00$ & 0.00 & $100,000.00$ \\
\hline Instrun & & 10 & 1 & LS & 0 & 0.0 & 1.00 & 0.00 & $100,000.00$ & $100,000.00$ & 0.00 & $100,000.00$ \\
\hline Recircu & & 10 & 2 & EA & 0 & 0.0 & 1.00 & 0.00 & $50,000.00$ & $100,000,00$ & 0.00 & $100,000.00$ \\
\hline nger Incon & & 10 & 1 & $E A$ & 0 & 0.0 & 1.00 & 0.00 & $80,000.00$ & $80,000.00$ & 0.00 & $80,000.00$ \\
\hline Valves, & & 10 & 1 & EA & 0 & 0.0 & 1.00 & 0.00 & $50,000.00$ & $50,000.00$ & 0.00 & $50,000.00$ \\
\hline Chemical Metering pump & & 10 & 1 & EA & 0 & 0.0 & 1.00 & 0.00 & $15,000.00$ & $15,000.00$ & 0.00 & $15,000.00$ \\
\hline \multicolumn{13}{|l|}{ Fabric } \\
\hline 3 bank influent filter skid Inconel & & 21 & 2 & EA & 0 & 0.0 & 1.00 & 0.00 & $200,000.00$ & $400,000.00$ & 0.00 & $400,000.00$ \\
\hline 20,0000 Secondary Waste Receiver Tanks & & 21 & 2 & EA & 0 & 0.0 & 1.00 & 0.00 & $80,000.00$ & $160,000.00$ & 0.00 & $160,000.00$ \\
\hline 5,0000 Concentrate Tanks Inconel & & 21 & 2 & EA & 0 & 0.0 & 1.00 & 0.00 & $92,000.00$ & $184,000.00$ & 0.00 & $184,000.00$ \\
\hline Mixer (2 HP) Inconel & & 21 & 2 & EA & 0 & 0.0 & 1.00 & 0.00 & $50,000.00$ & $100,000.00$ & 0.00 & $100,000.00$ \\
\hline Day Tank & & 21 & 1 & EA & 0 & 0.0 & 1.00 & 0.00 & $10,000.00$ & $10,000.00$ & 0.00 & $10,000.00$ \\
\hline
\end{tabular}


RPP-RPT-37924 Rev. 0

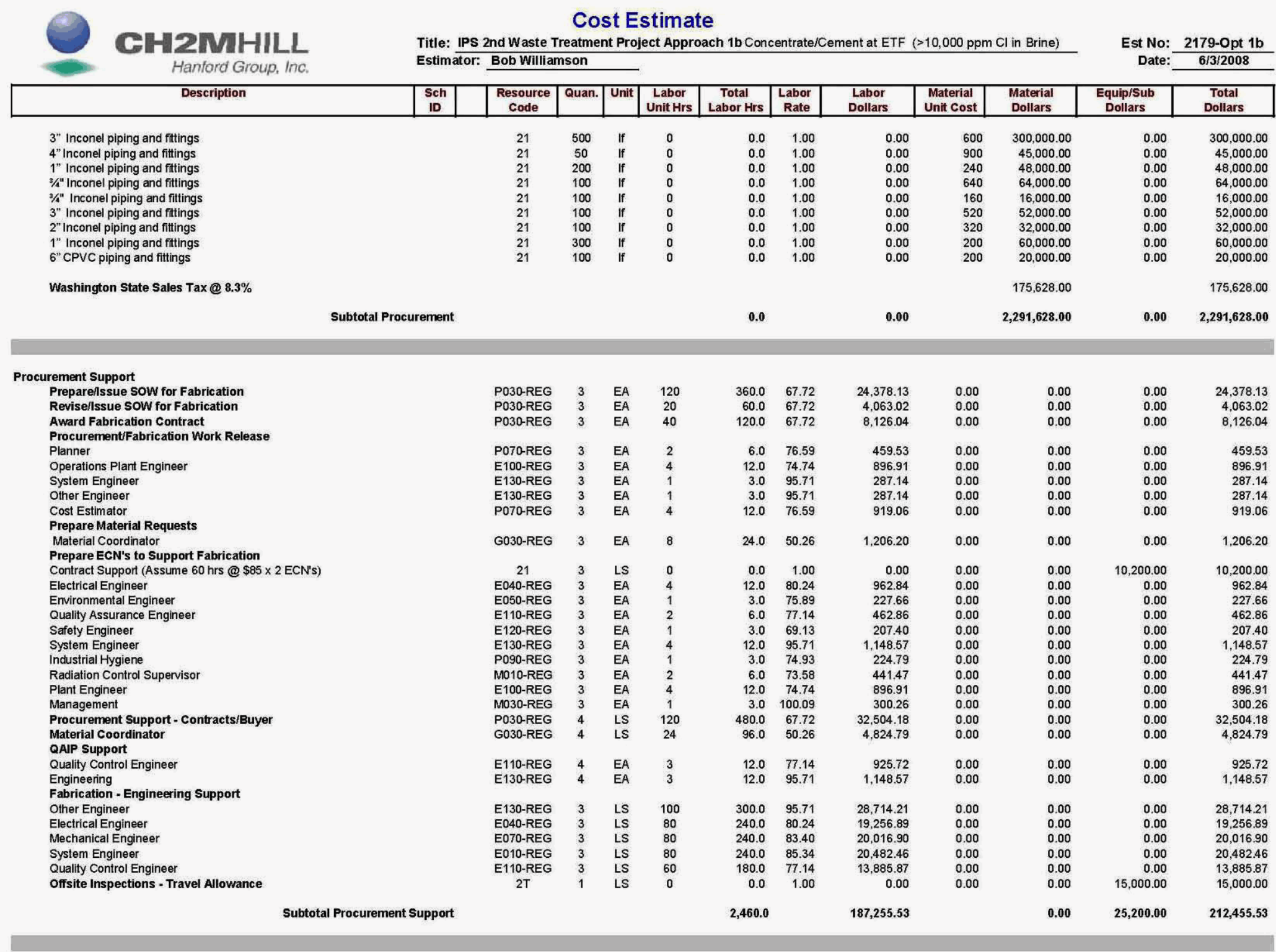

Construction

RDW 
RPP-RPT-37924 Rev. 0

\begin{tabular}{|c|c|c|c|c|c|c|c|c|c|c|c|c|}
\hline \multirow{2}{*}{$\begin{array}{c}\text { CHI2WMHLL } \\
\text { Hanford Group, Inc. } \\
\text { Description } \\
\end{array}$} & \multicolumn{9}{|c|}{$\begin{array}{c}\text { Cost Estimate } \\
\text { Title: IPS 2nd Waste Treatment Project Approach 1b }\end{array}$} & Brine) & \multicolumn{2}{|c|}{$\begin{aligned} \text { Est No: } & 2179-\text { Opt 1b } \\
\text { Date: } & 6 / 3 / 2008\end{aligned}$} \\
\hline & $\begin{array}{l}\text { Sch } \\
\text { ID }\end{array}$ & $\begin{array}{c}\text { Resource } \\
\text { Code }\end{array}$ & Quan. & Unit & \begin{tabular}{|l|} 
Labor \\
Unit Hrs \\
\end{tabular} & \begin{tabular}{|c|} 
Total \\
Labor Hrs \\
\end{tabular} & \begin{tabular}{|c|} 
Labor \\
Rate
\end{tabular} & $\begin{array}{l}\text { Labor } \\
\text { Dollars }\end{array}$ & \begin{tabular}{|l|} 
Material \\
Unit Cost \\
\end{tabular} & $\begin{array}{l}\text { Material } \\
\text { Dollars }\end{array}$ & $\begin{array}{l}\text { Equip/Sub } \\
\text { Dollars }\end{array}$ & $\begin{array}{l}\text { Total } \\
\text { Dollars }\end{array}$ \\
\hline $\begin{array}{l}\text { General Requirements } \\
\text { Mobe/Demobe } \\
\text { Training } \\
\text { Job Site Administratition } \\
\text { Field Work Supervisor } \\
\text { Field Engineering } \\
\text { Safety } \\
\text { Quality Assurance } \\
\text { Doc. Control } \\
\text { Quality Control } \\
\text { Const. Facilities/Temp Controls } \\
\text { Material Handling/Delivery } \\
\text { Clean-up Laborisupport } \\
\text { Non-Regulated Equipment/small Tools } \\
\text { Perform Construction Acceptance Test }\end{array}$ & & 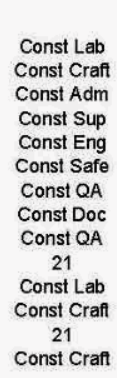 & $\begin{array}{ll}1 & \\
1 & \\
1 & \\
1 \\
1 \\
1 \\
1 \\
1 \\
1 \\
1 \\
1 \\
1 \\
1 \\
1\end{array}$ & $\begin{array}{l}\text { LS } \\
\text { LS } \\
\text { LS } \\
\text { LS } \\
\text { LS } \\
\text { LS } \\
\text { LS } \\
\text { LS } \\
\text { LS } \\
\text { LS } \\
\text { LS } \\
\text { LS } \\
\text { LS }\end{array}$ & $\begin{array}{r}60 \\
720 \\
1200 \\
1500 \\
600 \\
900 \\
300 \\
300 \\
240 \\
0 \\
900 \\
900 \\
0 \\
180\end{array}$ & $\begin{array}{r}60.0 \\
720.0 \\
1,200.0 \\
1,500.0 \\
6000.0 \\
900.0 \\
300.0 \\
300.0 \\
240.0 \\
0.0 \\
900.0 \\
900.0 \\
0.0 \\
180.0\end{array}$ & $\begin{array}{l}57.75 \\
63.00 \\
89.25 \\
84.00 \\
73.50 \\
78.75 \\
73.50 \\
42.00 \\
73.50 \\
1.00 \\
57.75 \\
63.00 \\
1.00 \\
63.00\end{array}$ & 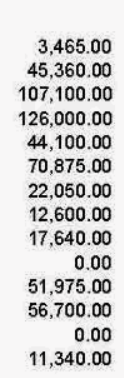 & $\begin{array}{r}0.00 \\
0.00 \\
0.00 \\
0.00 \\
0.00 \\
0.00 \\
0.00 \\
0.00 \\
0.00 \\
25.000 .00 \\
0.00 \\
0.00 \\
17.000 .00 \\
0.00\end{array}$ & $\begin{array}{r}0.00 \\
0.00 \\
0.00 \\
0.00 \\
0.00 \\
0.00 \\
0.00 \\
0.00 \\
0.00 \\
25,000.00 \\
0.00 \\
0.00 \\
17,000.00 \\
0.00\end{array}$ & $\begin{array}{r}20.000 .00 \\
0.00 \\
0.00 \\
0.00 \\
0.00 \\
0.00 \\
0.00 \\
0.00 \\
0.00 \\
0.00 \\
0.00 \\
0.00 \\
0.00 \\
0.00\end{array}$ & 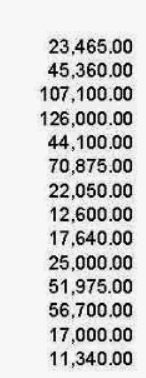 \\
\hline Subtotal General R & irements & & & & & $7,800.0$ & & $569,205.00$ & & $42,000.00$ & $20,000.00$ & $631,205.00$ \\
\hline 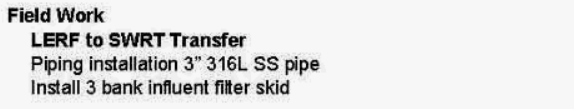 & & $\begin{array}{l}\text { Const Craft } \\
\text { Const Craft }\end{array}$ & $\begin{array}{c}300 \\
2\end{array}$ & If & $\begin{array}{c}2 \\
240\end{array}$ & $\begin{array}{l}600.0 \\
480.0\end{array}$ & $\begin{array}{l}63.00 \\
63.00\end{array}$ & $\begin{array}{l}37,800.00 \\
30,240.00\end{array}$ & $\begin{array}{r}120.00 \\
2,000.00\end{array}$ & $\begin{array}{r}36,000.00 \\
4,000.00\end{array}$ & $\begin{array}{l}0.00 \\
0.00\end{array}$ & $\begin{array}{l}73,800.00 \\
34,240.00\end{array}$ \\
\hline $\begin{array}{l}\text { SWRT Recirculation System } \\
\text { Install 20.0000 Secondary Waste Receiver Tank } \\
\text { Instalalition of Instruments and Controls } \\
\text { Intstal Recirulation Pump } \\
\text { Install Dac Tank and Metering Pump } \\
\text { Piping installatition }\end{array}$ & & $\begin{array}{l}\text { Const Craft } \\
\text { Const Craft } \\
\text { Const Craft } \\
\text { Const Craft } \\
\text { Const Craff }\end{array}$ & $\begin{array}{l}2 \\
1 \\
1 \\
1 \\
1\end{array}$ & $\begin{array}{l}\text { ea } \\
\text { LS } \\
\text { ea } \\
\text { LS } \\
\text { LS }\end{array}$ & $\begin{array}{l}600 \\
400 \\
240 \\
200 \\
1000\end{array}$ & $\begin{array}{r}1,200.0 \\
4400.0 \\
240.0 \\
200.0 \\
1,000.0\end{array}$ & $\begin{array}{l}63.00 \\
63.00 \\
63.00 \\
63.00 \\
63.00\end{array}$ & $\begin{array}{l}75,600.00 \\
25,200.00 \\
15,120.00 \\
12,600.00 \\
63,000.00\end{array}$ & $\begin{array}{r}2,000.00 \\
8.000 .00 \\
1,500.00 \\
2,000.00 \\
10,000.00\end{array}$ & 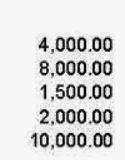 & $\begin{array}{l}0.00 \\
0.00 \\
0.00 \\
0.00 \\
0.00\end{array}$ & $\begin{array}{l}79,600.00 \\
33,200.00 \\
16,620.00 \\
14,600.00 \\
73,000.00\end{array}$ \\
\hline $\begin{array}{l}\text { Utility Connections to SWRT } \\
\text { Piping installation }\end{array}$ & & Const craft & 1 & LS & 800 & 800.0 & 63.00 & $50,400.00$ & $15,000.00$ & $15,000.00$ & 0.00 & $65,400.00$ \\
\hline $\begin{array}{l}\text { Cooling Water to Evaporator Feed Distillate Heat Exchanger } \\
\text { Piping installation }\end{array}$ & & Const Craft & 1 & LS & 240 & 240.0 & 63.00 & $15,120.00$ & $4,000.00$ & $4,000.00$ & 0.00 & $19,120.00$ \\
\hline $\begin{array}{l}\text { SWRT Recirculation System } \\
\text { Install Axial Flow Pump } \\
\text { Instalalition of Instruments and Controls } \\
\text { Install Recirulation Pump } \\
\text { Install Day Tank and Metering Pump } \\
\text { Piping installatition }\end{array}$ & & $\begin{array}{l}\text { Const Craft } \\
\text { Const Craft } \\
\text { Const Craff } \\
\text { Const Craff } \\
\text { Const Craff }\end{array}$ & $\begin{array}{l}2 \\
1 \\
1 \\
1 \\
1\end{array}$ & $\begin{array}{l}\text { ea } \\
\text { LS } \\
\text { ea } \\
\text { LS } \\
\text { LS }\end{array}$ & $\begin{array}{l}400 \\
400 \\
240 \\
200 \\
3000\end{array}$ & $\begin{array}{r}800.0 \\
400.0 \\
240.0 \\
200.0 \\
3,000.0\end{array}$ & $\begin{array}{l}63.00 \\
63.00 \\
63.00 \\
63.00 \\
63.00\end{array}$ & $\begin{array}{r}50.400 .00 \\
25,200.00 \\
15,120.00 \\
12,600.00 \\
189,000.00\end{array}$ & $\begin{array}{r}5.000 .00 \\
8,000.00 \\
1,500.00 \\
2,000.00 \\
10,000.00\end{array}$ & $\begin{array}{r}10,000.00 \\
8,000.00 \\
1,500.00 \\
2,000.00 \\
10,000.00\end{array}$ & $\begin{array}{l}0.00 \\
0.00 \\
0.00 \\
0.00 \\
0.00\end{array}$ & $\begin{array}{l}60,400.00 \\
33.200 .00 \\
16,6200 \\
14,600.00 \\
199,000.00\end{array}$ \\
\hline $\begin{array}{l}\text { Utility Connections to SWRT } \\
\text { Piping installation }\end{array}$ & & Const Craft & 1 & LS & 2400 & $2,400.0$ & 63.00 & 151.200 .00 & $30,000.00$ & 30.000 .00 & 0.00 & $181,200.00$ \\
\hline Subtota & eld Work & & & & & $12,200.0$ & & $768,600.00$ & & $146,000.00$ & 0.00 & $914,600.00$ \\
\hline $\begin{array}{l}\text { Adders } \\
\text { Productivity Factor- Assume 40\% } \\
\text { Weather Delays - Assume } 20 \% \\
\text { Allowance for Construction Consumables - } 3 \% \text { of Const. Labor } \\
\text { Material Sales Tax @ } 8.3 \%\end{array}$ & & $\begin{array}{l}21 \\
21 \\
21 \\
21\end{array}$ & $\begin{array}{l}1 \\
1 \\
1 \\
1\end{array}$ & $\begin{array}{l}\mathrm{LS} \\
\mathrm{LS} \\
\mathrm{LS} \\
\mathrm{LS}\end{array}$ & & $\begin{array}{r}4,880.0 \\
3,416.0 \\
0.0 \\
0.0\end{array}$ & & $\begin{array}{r}307.440 .00 \\
215,208.00 \\
0.00 \\
0.00\end{array}$ & $\begin{array}{r}0.00 \\
0.00 \\
23,05.80 \\
12,118.00\end{array}$ & $\begin{array}{r}0.00 \\
0.00 \\
23,058.00 \\
12,118.00\end{array}$ & $\begin{array}{l}0.00 \\
0.00 \\
0.00 \\
0.00\end{array}$ & $\begin{array}{r}307,440.00 \\
215.208 .00 \\
23.085 .00 \\
12,118.00\end{array}$ \\
\hline & Adders & & & & & $8,296.0$ & & $522,648.00$ & & $35,176.00$ & 0.00 & $557,824.00$ \\
\hline
\end{tabular}


RPP-RPT-37924 Rev. 0

Cost Estimate

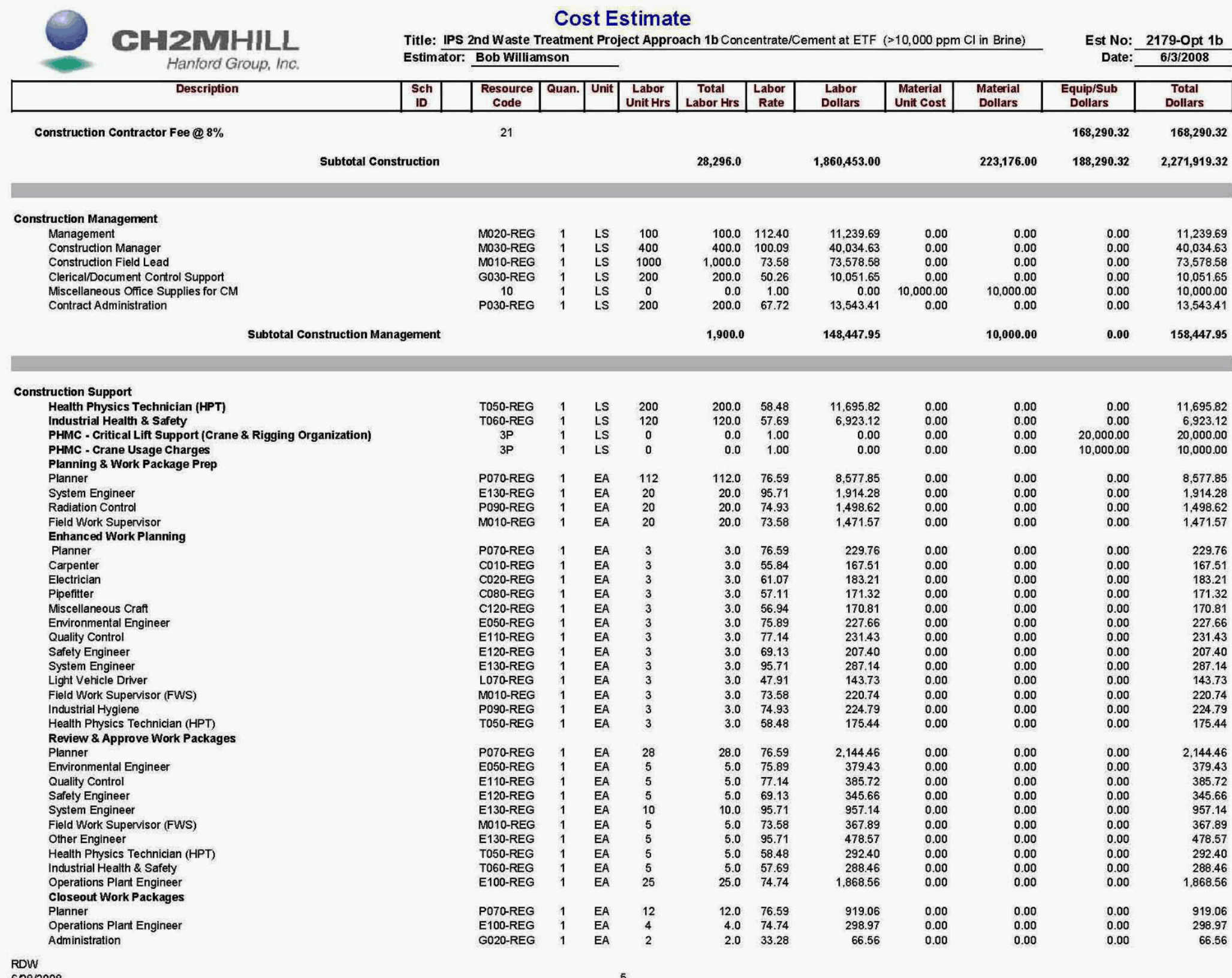


RPP-RPT-37924 Rev. 0

\begin{tabular}{|c|c|c|c|c|c|c|c|c|c|c|c|c|}
\hline CHH2MHHILL & $\begin{array}{l}\text { Title: } \\
\text { Estim }\end{array}$ & $\begin{array}{l}\text { nd Waste T } \\
\text { Bob Willian }\end{array}$ & $\begin{array}{l}\text { Co } \\
\text { reatme } \\
\text { nson } \\
\end{array}$ & $\begin{array}{l}\text { st E } \\
\text { nt Pro }\end{array}$ & $\begin{array}{l}\text { stima } \\
\text { ject Appr }\end{array}$ & ach $1 \mathrm{~b}$ Conc & centrate// & nent at ETF & $(>10,000 \mathrm{ppn}$ & I in Brine) & $\begin{array}{r}\text { Est No: } \\
\text { Date: }\end{array}$ & $\begin{array}{c}2179-0 p t \text { 1b } \\
6 / 3 / 2008 \\
\end{array}$ \\
\hline Description & \begin{tabular}{|l|} 
Sch \\
ID
\end{tabular} & \begin{tabular}{|c|}
$\begin{array}{c}\text { Resource } \\
\text { Code }\end{array}$ \\
\end{tabular} & Quan. & Unit & \begin{tabular}{|l|} 
Labor \\
Unit Hrs
\end{tabular} & \begin{tabular}{|c|} 
Total \\
Labor Hrs \\
\end{tabular} & \begin{tabular}{|c|} 
Labor \\
Rate \\
\end{tabular} & $\begin{array}{l}\text { Labor } \\
\text { Dollars }\end{array}$ & \begin{tabular}{|c|} 
Material \\
Unit Cost \\
\end{tabular} & $\begin{array}{c}\text { Material } \\
\text { Dollars }\end{array}$ & $\begin{array}{c}\text { Equip/Sub } \\
\text { Dollars }\end{array}$ & $\begin{array}{c}\text { Total } \\
\text { Dollars }\end{array}$ \\
\hline Other Engineer & & E130-REG & 1 & EA & 4 & 4.0 & 95.71 & 382.86 & 0.00 & 0.00 & 0.00 & 382.86 \\
\hline $\begin{array}{l}\text { Field Work Supervisor (FWS) } \\
\text { Prepare ECN's }\end{array}$ & & MO10-REG & 1 & EA & 2 & 2.0 & 73.58 & 147.16 & 0.00 & 0.00 & 0.00 & 147.16 \\
\hline Contract Support (Assume 90 hrs @ $\$ 85$ × 4 ECN's) & & 21 & 1 & LS & 0 & 0.0 & 1.00 & 0.00 & 0.00 & 0.00 & $30,600,00$ & $30,600,00$ \\
\hline Electrical Engineer & & E040-REG & 1 & EA & 4 & 4.0 & 80.24 & 320.95 & 0.00 & 0.00 & 0.00 & 320.95 \\
\hline Emvironmental Engineer & & E050-REG & 1 & EA & 1 & 1.0 & 75.89 & 75.89 & 0.00 & 0.00 & 0.00 & 75.89 \\
\hline Quality Assurance Engineer & & E110-REG & 1 & EA & 2 & 2.0 & 77.14 & 154.29 & 0.00 & 0.00 & 0.00 & 154.29 \\
\hline Safety Engineer & & E120-REG & 1 & $\mathrm{EA}$ & 1 & 1.0 & 69.13 & 69.13 & 0.00 & 0.00 & 0.00 & 69.13 \\
\hline System Engineer & & E130-REG & 1 & EA & 4 & 4.0 & 95.71 & 382.86 & 0.00 & 0.00 & 0.00 & 382.86 \\
\hline Industrial Hygiene & & PO90-REG & 1 & EA & 1 & 1.0 & 74.93 & 74.93 & 0.00 & 0.00 & 0.00 & 74.93 \\
\hline Radiation Control Supervisor & & MO10-REG & 1 & EA & 2 & 2.0 & 73.58 & 147.16 & 0.00 & 0.00 & 0.00 & 147.16 \\
\hline Plant Engineer & & E100-REG & 1 & EA & 4 & 4.0 & 74.74 & 298.97 & 0.00 & 0.00 & 0.00 & 298.97 \\
\hline $\begin{array}{l}\text { Management } \\
\text { Prepare USQ's }\end{array}$ & & M030-REG & 1 & EA & 1 & 1.0 & 100.09 & 100.09 & 0.00 & 0.00 & 0.00 & 100.09 \\
\hline $\begin{array}{l}\text { Other Engineers } \\
\text { Ots E }\end{array}$ & & E130-REG & 1 & EA & 28 & 28.0 & 95.71 & $2,679.99$ & 0.00 & 0.00 & 0.00 & $2,679.99$ \\
\hline $\begin{array}{l}\text { Review Engineers } \\
\text { Radiation Work Permit }\end{array}$ & & E130-REG & 1 & EA & 9 & 9.0 & 95.71 & 861.43 & 0.00 & 0.00 & 0.00 & 861.43 \\
\hline $\begin{array}{l}\text { Planner } \\
\text { Plant }\end{array}$ & & P070-REG & 1 & EA & 14 & 14.0 & 76.59 & 1.072 .23 & 0.00 & 0.00 & 0.00 & $1,072.23$ \\
\hline Electrician & & CO20-REG & 1 & $E A$ & 2 & 2.0 & 61.07 & 122.14 & 0.00 & 0.00 & 0.00 & 122.14 \\
\hline Electrical Engineer & & E040-REG & 1 & EA & 2 & 2.0 & 80.24 & 160.47 & 0.00 & 0.00 & 0.00 & 160.47 \\
\hline $\begin{array}{l}\text { Crectronmental Engineer } \\
\text { Emvirant }\end{array}$ & & E050-REG & 1 & EA & 5 & 50 & $\begin{array}{l}75.89 \\
75.24\end{array}$ & $\begin{array}{l}100.41 \\
37943\end{array}$ & 0.00 & 0.00 & 0.00 & 379.43 \\
\hline Operations Plant Engineer & & E100-REG & 1 & EA & 2 & 2.0 & 74.74 & 149.48 & 0.00 & 0.00 & 0.00 & 149.48 \\
\hline Safety Engineer & & E120-REG & 1 & EA & 2 & 2.0 & 69.13 & 138.27 & 0.00 & 0.00 & 0.00 & 138.27 \\
\hline System Engineer & & E130-REG & 1 & EA & 5 & 5.0 & 95.71 & 478.57 & 0.00 & 0.00 & 0.00 & 478.57 \\
\hline Field Work Supervisor (FWS) & & E100-REG & 1 & EA & 5 & 5.0 & 74.74 & 373.71 & 0.00 & 0.00 & 0.00 & 373.71 \\
\hline Health Physics Technician (HPT) & & TO50-REG & 1 & EA & 5 & 5.0 & 58.48 & 292.40 & 0.00 & 0.00 & 0.00 & 292.40 \\
\hline Industrial Health \& Safety & & T060-REG & 1 & EA & 2 & 2.0 & 57.69 & 115.39 & 0.00 & 0.00 & 0.00 & 115.39 \\
\hline $\begin{array}{l}\text { Material Requests } \\
\text { Material C Coordinator } \\
\text { Pre Job Briefings }\end{array}$ & & G030-REG & 1 & EA & 4 & 4.0 & 50.26 & 201.03 & 0.00 & 0.00 & 0.00 & 201.03 \\
\hline Other Engineers & & E130-REG & 30 & $\mathrm{Hr}$ & 1 & 30.0 & 95.71 & $2,871.42$ & 0.00 & 0.00 & 0.00 & $2,871.42$ \\
\hline Administration & & G020-REG & 30 & $\mathrm{Hr}$ & 1 & 30.0 & 33.28 & 998.45 & 0.00 & 0.00 & 0.00 & 998.45 \\
\hline $\begin{array}{l}\text { Management } \\
\text { Post Job Alara Review }\end{array}$ & & M010-REG & 30 & $\mathrm{Hr}$ & 1 & 30.0 & 73.58 & $2,207.36$ & 0.00 & 0.00 & 0.00 & $2,207.36$ \\
\hline $\begin{array}{l}\text { Planner } \\
\text { Plara Keview }\end{array}$ & & P070-REG & 1 & EA & 2 & 2.0 & 76.59 & 153.18 & 0.00 & 0.00 & 0.00 & 153.18 \\
\hline Electrician & & CO20-REG & 1 & EA & 4 & 4.0 & 61.07 & 244.28 & 0.00 & 0.00 & 0.00 & 244.28 \\
\hline Electrical Engineer & & E040-REG & 1 & $E A$ & 2 & 2.0 & 80.24 & 160.47 & 0.00 & 0.00 & 0.00 & 160.47 \\
\hline Emvironmental Engineer & & E050-REG & 1 & EA & 1 & 1.0 & $\begin{array}{l}75.89 \\
75.24\end{array}$ & $\begin{array}{l}100.47 \\
75.89\end{array}$ & 0.00 & 0.00 & 0.00 & $\begin{array}{l}75.89 \\
75.89\end{array}$ \\
\hline $\begin{array}{l}\text { System Engineer } \\
\text { - }\end{array}$ & & E130-REG & 1 & EA & 2 & 2.0 & 95.71 & 191.43 & 0.00 & 0.00 & 0.00 & 191.43 \\
\hline Other Engineers & & E130-REG & 1 & EA & 2 & 2.0 & 95.71 & 191.43 & 0.00 & 0.00 & 0.00 & 191.43 \\
\hline Administration & & GO2O-REG & 1 & EA & 2 & 2.0 & 33.28 & 66.56 & 0.00 & 0.00 & 0.00 & 66.56 \\
\hline $\begin{array}{l}\text { Aaminisirfation } \\
\text { First Line Supervision }\end{array}$ & & MO10-REG & 1 & $\begin{array}{l}E A \\
E A\end{array}$ & $\begin{array}{l}2 \\
1\end{array}$ & 1.0 & 73.58 & 73.58 & 0.00 & 0.00 & 0.00 & 73.58 \\
\hline Ground Scanning & & (1) & & & & & & & & & & \\
\hline Civil Engineer & & E020-REG & 1 & EA & 6 & 6.0 & 85.21 & 511.24 & 0.00 & 0.00 & 0.00 & 511.24 \\
\hline Other Engineers & & E130-REG & 1 & EA & 54 & 54.0 & 95.71 & 5.168 .56 & 0.00 & 0.00 & 0.00 & $5,168.56$ \\
\hline First Line Supenision & & M010-REG & 1 & EA & 4 & 4.0 & 73.58 & 294.31 & 0.00 & 0.00 & 0.00 & 294.31 \\
\hline Perform Ground Scanning - (Contract) & & 21 & 1 & LS & 0 & 0.0 & 1.00 & 0.00 & 0.00 & 0.00 & $10,000.00$ & $10,000.00$ \\
\hline TSR Matrix & & P070-REG & 1 & FA & 6 & 60 & $7659^{\circ}$ & 45953 & 000 & - >00 & 000 & 45953 \\
\hline System Engineer & & E130-REG & 1 & EA & 6 & 6.0 & $\begin{array}{l}65.71 \\
95.71\end{array}$ & $\begin{array}{l}459.53 \\
574.28\end{array}$ & 0.00 & 0.00 & $\begin{array}{l}0.00 \\
0.00\end{array}$ & $\begin{array}{l}459.35 \\
574.28\end{array}$ \\
\hline LockTagouts & & mises & 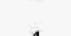 & & 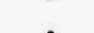 & & & & & & & \\
\hline $\begin{array}{l}\text { Pipefitter } \\
\text { First Line Supenision }\end{array}$ & & $\begin{array}{l}\text { C080-REG } \\
\text { MO10-REG }\end{array}$ & $\begin{array}{l}1 \\
1\end{array}$ & $\begin{array}{l}E A \\
E A\end{array}$ & $\begin{array}{l}8 \\
8\end{array}$ & $\begin{array}{l}8.0 \\
80\end{array}$ & $\begin{array}{l}57.11 \\
73.58\end{array}$ & $\begin{array}{l}456.84 \\
588.63\end{array}$ & $\begin{array}{l}0.00 \\
0.00\end{array}$ & $\begin{array}{l}0.00 \\
0.00\end{array}$ & $\begin{array}{l}0.00 \\
0.00-3-3-1\end{array}$ & $\begin{array}{l}456.84 \\
588.63\end{array}$ \\
\hline Nuclear Operators & & R050-REG & 1 & EA & 8 & 8.0 & 59.78 & 478.23 & 0.00 & 0.00 & 0.00 & 478.23 \\
\hline $\begin{array}{l}\text { Excavation Permits } \\
\text { Planner }\end{array}$ & & P070-REG & 1 & EA & 36 & 36.0 & 76.59 & $2,757.17$ & 0.00 & 0.00 & 0.00 & $2,757.17$ \\
\hline First Line Supervision & & MO10-REG & 1 & EA & 6 & 6.0 & 73.58 & 441.47 & 0.00 & 0.00 & 0.00 & 441.47 \\
\hline & & & & & & & & & & & & \\
\hline
\end{tabular}


RPP-RPT-37924 Rev. 0

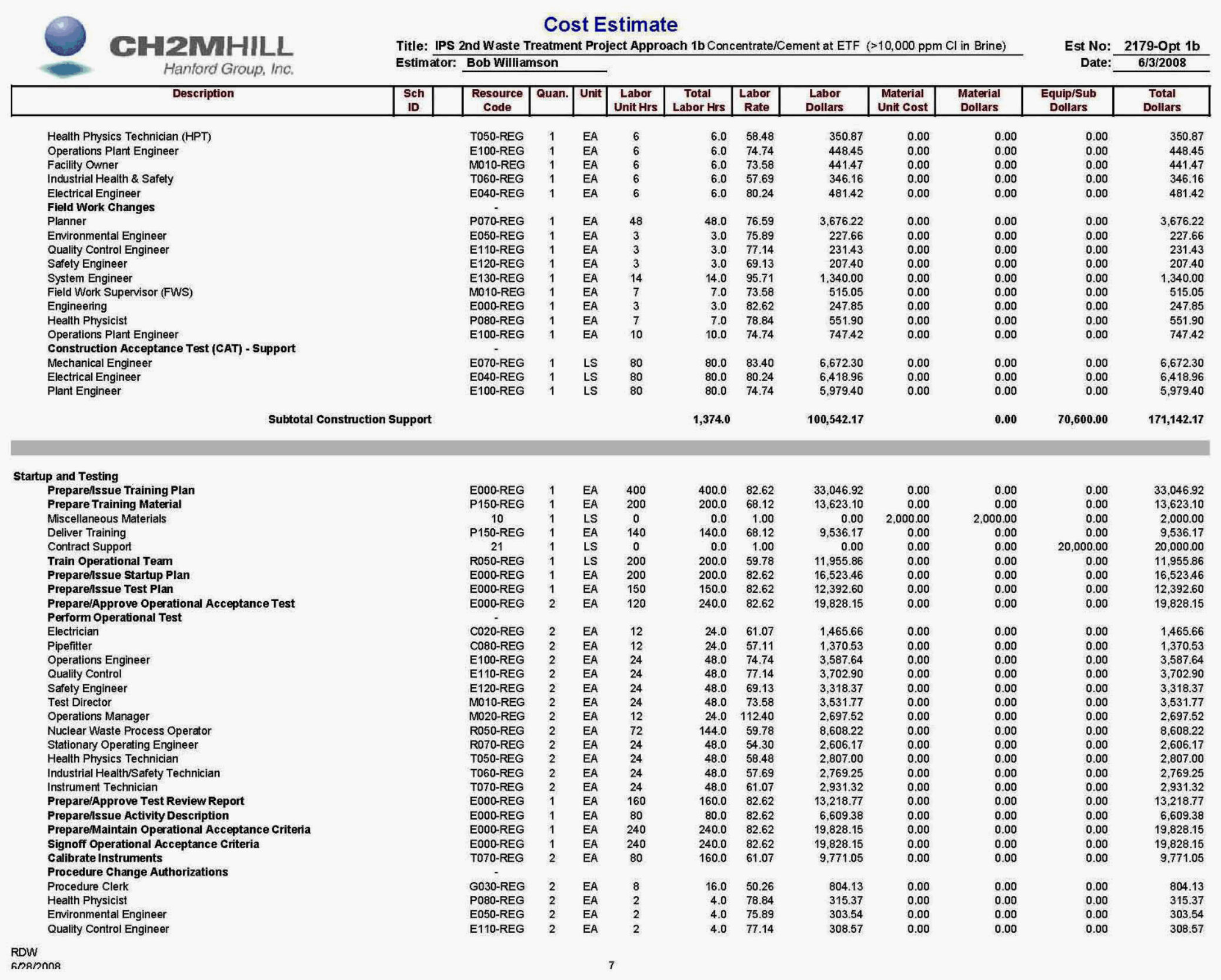


RPP-RPT-37924 Rev. 0

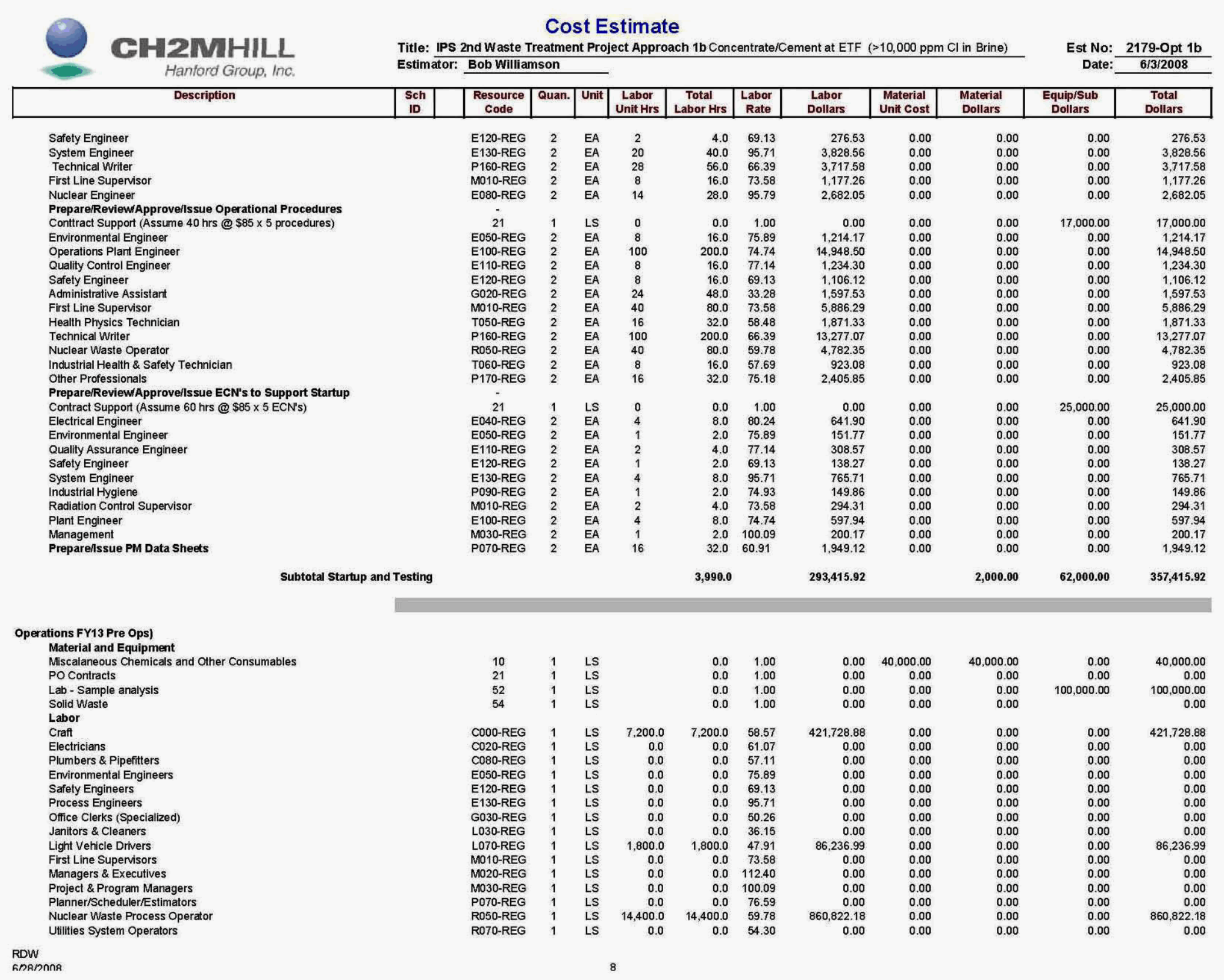


RPP-RPT-37924 Rev. 0

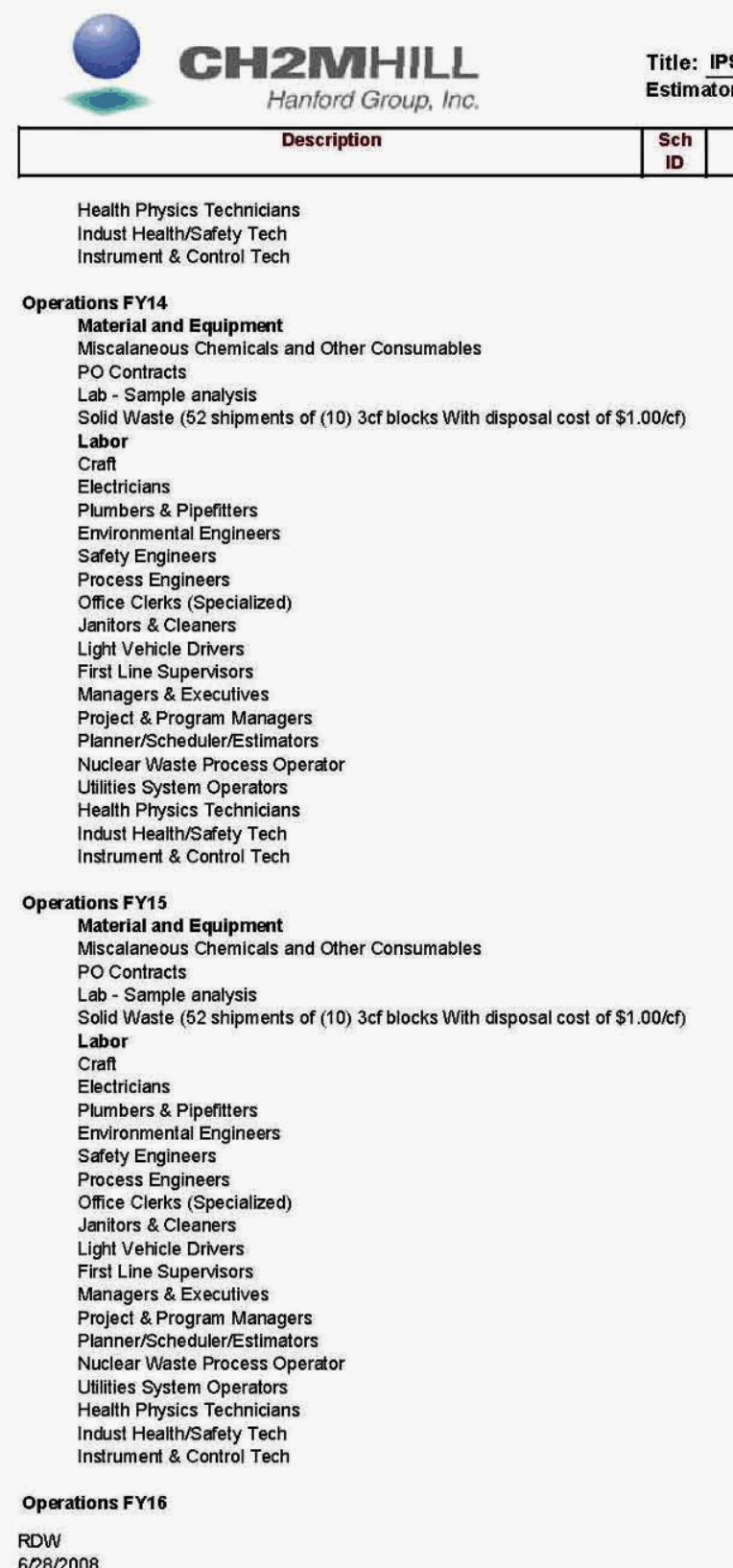

\section{Cost Estimate}

Title: IPS 2nd Waste Treatment Project Approach 1b Concentrate/Cement at ETF ( $>10,000 \mathrm{ppm} \mathrm{Cl} \mathrm{in} \mathrm{Brine)} \quad$ Est No: 2179-0pt 1b

\begin{tabular}{|c|c|c|c|c|c|c|c|c|c|c|c|c|}
\hline $\begin{array}{c}\text { Sch } \\
\text { ID }\end{array}$ & $\begin{array}{c}\text { Resource } \\
\text { Code }\end{array}$ & Quan. & Unit & $\begin{array}{c}\text { Labor } \\
\text { Unit Hrs }\end{array}$ & $\begin{array}{c}\text { Total } \\
\text { Labor Hrs }\end{array}$ & $\begin{array}{c}\text { Labor } \\
\text { Rate }\end{array}$ & $\begin{array}{c}\text { Labor } \\
\text { Dollars }\end{array}$ & $\begin{array}{c}\text { Material } \\
\text { Unit Cost }\end{array}$ & $\begin{array}{c}\text { Material } \\
\text { Dollars }\end{array}$ & $\begin{array}{c}\text { Equip/Sub } \\
\text { Dollars }\end{array}$ & $\begin{array}{c}\text { Total } \\
\text { Dollars }\end{array}$ \\
\hline
\end{tabular}

$\begin{array}{llllll}\text { TO50-REG } & 1 & \text { LS } & 0.0 & 0.0 & 58.48 \\ \text { TO60-REG } & 1 & \text { LS } & 0.0 & 0.0 & 57.69\end{array}$

$\begin{array}{llllll}\text { TO50-REG } & 1 & \text { LS } & 0.0 & 0.0 & 58.48 \\ \text { TO60-REG } & 1 & \text { LS } & 0.0 & 0.0 & 57.69\end{array}$

$0.00 \quad 0.00$

0.00

0.00

$10 \quad 1$ is 10.0

$\begin{array}{ccc}10 & 1 & \text { LS } \\ 21 & 1 & \text { LS } \\ 52 & 1 & \text { LS } \\ 54 & 1 & \text { L } \\ \text { C000-REG } & 1 & \text { L } \\ \text { C020-REG } & 1 & \text { LS } \\ \text { C080-REG } & 1 & \text { L } \\ \text { E050-REG } & 1 & \text { LS } \\ \text { E120-REG } & 1 & \text { LS } \\ \text { E130-REG } & 1 & \text { LS } \\ \text { G030-REG } & 1 & \text { LS } \\ \text { L030-REG } & 1 & \text { LS } \\ \text { L070-REG } & 1 & \text { LS } \\ \text { M010-REG } & 1 & \text { LS } \\ \text { M020-REG } & 1 & \text { LS } \\ \text { M030-REG } & 1 & \text { LS } \\ \text { PO70-REG } & 1 & \text { LS } \\ \text { R050-REG } & 1 & \text { LS } \\ \text { R070-REG } & 1 & \text { LS } \\ \text { TO50-REG } & 1 & \text { TS } \\ \text { TO60-REG } & 1 & \text { TS } \\ \text { T070-REG } & 1 & \\ & & \end{array}$

$\begin{array}{rr}0.0 & 1.00 \\ 0.0 & 1.00 \\ 0.0 & 1.00 \\ 0.0 & 1.00 \\ & \\ 7,200.0 & 58.57 \\ 0.0 & 61.07 \\ 0.0 & 57.11 \\ 0.0 & 75.89 \\ 0.0 & 69.13 \\ 0.0 & 95.71 \\ 0.0 & 50.26 \\ 0.0 & 36.15 \\ 1,800.0 & 47.91 \\ 0.0 & 73.58 \\ 0.0 & 112.40 \\ 0.0 & 100.09 \\ 0.0 & 76.59 \\ 14,400.0 & 59.78 \\ 0.0 & 54.30 \\ 0.0 & 58.48 \\ 0.0 & 57.69 \\ 0.0 & 61.07\end{array}$

$\begin{array}{rr}0.00 & 40,000.00 \\ 0.00 & 0.00 \\ 0.00 & 0.00 \\ 0.00 & 0.00 \\ & \\ 421,728.88 & 0.00 \\ 0.00 & 0.00 \\ 0.00 & 0.00 \\ 0.00 & 0.00 \\ 0.00 & 0.00 \\ 0.00 & 0.00 \\ 0.00 & 0.00 \\ 0.00 & 0.00 \\ 86,236.99 & 0.00 \\ 0.00 & 0.00 \\ 0.00 & 0.00 \\ 0.00 & 0.00 \\ 0.00 & 0.00 \\ 860,822.18 & 0.00 \\ 0.00 & 0.00 \\ 0.00 & 0.00 \\ 0.00 & 0.00 \\ 0.00 & 0.00\end{array}$

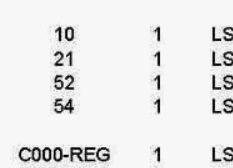

$\begin{array}{lrrr}\text { LS } & & 0.0 & 1.00 \\ \text { LS } & & 0.0 & 1.00 \\ \text { LS } & & 0.0 & 1.00 \\ \text { LS } & & 0.0 & 1.00 \\ \text { LS } & 7,200.0 & 7,200.0 & 58.57\end{array}$

COOO-REG

CO20-REG

E120-REG

G130-REG

G030-REG
LO30-REG

LO70-REG

MO10-REG
MO20-REG

MO30-REG
P070-REG

R050-REG

R070-REG

TO60-REG
T070-REG

$\begin{array}{lrrr}\text { LS } & 7,200.0 & 7,200.0 & 58.57 \\ \text { LS } & 0.0 & 0.0 & 61.07 \\ \text { LS } & 0.0 & 0.0 & 57.11 \\ \text { LS } & 0.0 & 0.0 & 75.89 \\ \text { LS } & 0.0 & 0.0 & 69.13 \\ \text { LS } & 0.0 & 0.0 & 95.71 \\ \text { LS } & 0.0 & 0.0 & 50.26 \\ \text { LS } & 0.0 & 0.0 & 36.15 \\ \text { LS } & 1,800.0 & 1,800.0 & 47.91 \\ \text { LS } & 0.0 & 0.0 & 73.58 \\ \text { LS } & 0.0 & 0.0 & 112.40 \\ \text { LS } & 0.0 & 0.0 & 100.09 \\ \text { LS } & 0.0 & 0.0 & 76.59 \\ \text { LS } & 14,400.0 & 14,400.0 & 59.78 \\ \text { LS } & 0.0 & 0.0 & 54.30 \\ \text { LS } & 0.0 & 0.0 & 58.48 \\ \text { LS } & 0.0 & 0.0 & 57.69 \\ \text { LS } & 0.0 & 0.0 & 61.07\end{array}$

$\begin{array}{rr}0.00 & 40,000.00 \\ 0.00 & 0.00 \\ 0.00 & 0.00 \\ 0.00 & 0.00 \\ 421,728.88 & 0.00 \\ 0.00 & 0.00 \\ 0.00 & 0.00 \\ 0.00 & 0.00 \\ 0.00 & 0.00 \\ 0.00 & 0.00 \\ 0.00 & 0.00 \\ 0.00 & 0.00 \\ 86,236.99 & 0.00 \\ 0.00 & 0.00 \\ 0.00 & 0.00 \\ 0.00 & 0.00 \\ 0.00 & 0.00 \\ 860,822.18 & 0.00 \\ 0.00 & 0.00 \\ 0.00 & 0.00 \\ 0.00 & 0.00 \\ 0.00 & 0.00\end{array}$

$40,000.00$
0.00
0.00
0.00
0.00
0.00
0.00
0.00
0.00
0.00
0.00
0.00
0.00
0.00
0.00
0.00
0.00
0.00
0.00
0.00
0.00
0.00

0.00
0.00

0.00

0.00
0.00
0.00


RPP-RPT-37924 Rev. 0

\section{Cost Estimate}

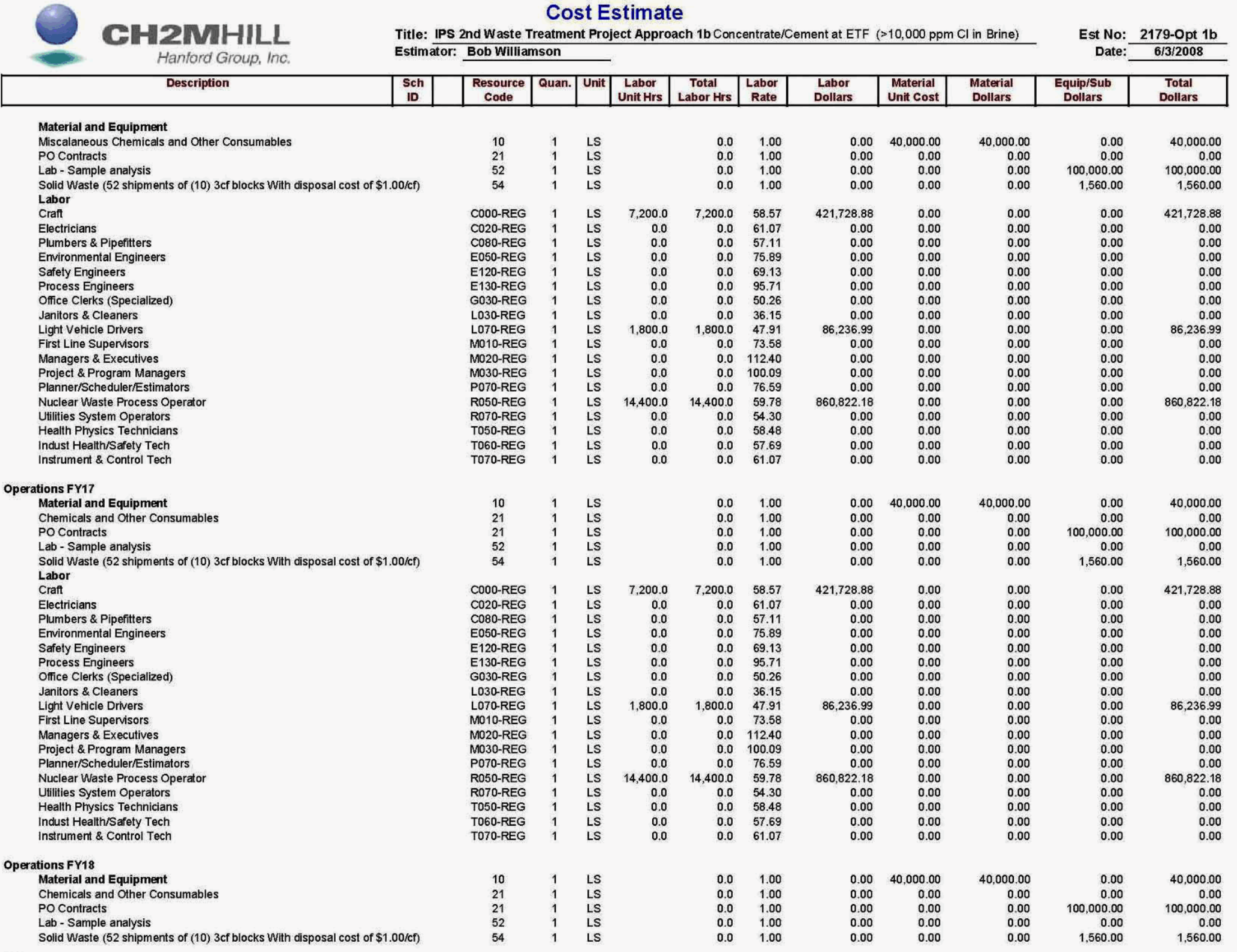


RPP-RPT-37924 Rev. 0

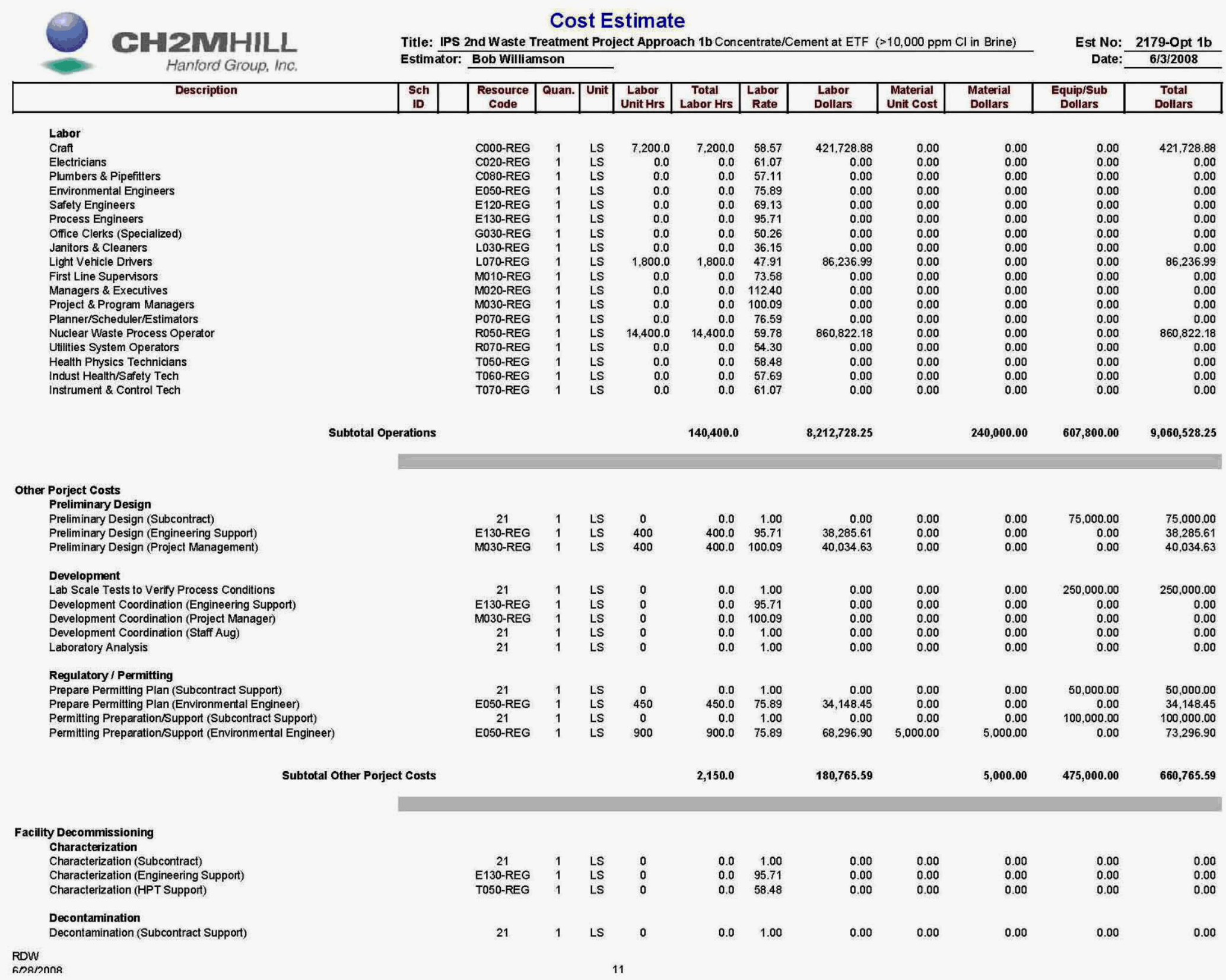


RPP-RPT-37924 Rev. 0

\begin{tabular}{|c|c|c|c|c|c|c|c|c|c|c|c|c|}
\hline \multirow{2}{*}{$\begin{array}{c}\text { CHH2WIHILL } \\
\text { Hanford Group, Ino } \\
\text { Description } \\
\end{array}$} & \multicolumn{10}{|c|}{$\begin{array}{l}\text { Cost Estimate } \\
\text { Title: IPS 2nd Waste Treatment Project Approach 2a (Transfer Brine to TF) } \\
\text { Estimator: Bob Williamson }\end{array}$} & \multicolumn{2}{|c|}{$\begin{array}{rrr}\text { Est No: } & \text { 2179-Opt 2a } \\
\text { Date: } & 5 / 27 / 2008 \\
\end{array}$} \\
\hline & $\begin{array}{c}\text { Sch } \\
\text { ID }\end{array}$ & \begin{tabular}{|c|}
$\begin{array}{c}\text { Resource } \\
\text { Code }\end{array}$ \\
\end{tabular} & Quan. & Unit & \begin{tabular}{|l|} 
Labor \\
Unit Hrs \\
\end{tabular} & \begin{tabular}{|l|} 
Total \\
Labor Hrs \\
\end{tabular} & \begin{tabular}{|l}
$\begin{array}{c}\text { Labor } \\
\text { Rate }\end{array}$ \\
\end{tabular} & $\begin{array}{l}\text { Labor } \\
\text { Dollars }\end{array}$ & \begin{tabular}{|l|} 
Material \\
Unit cost \\
\end{tabular} & $\begin{array}{l}\text { Material } \\
\text { Dollars } \\
\end{array}$ & $\begin{array}{c}\text { Equip/sub } \\
\text { Dollars }\end{array}$ & $\begin{array}{c}\text { Total } \\
\text { Dollars }\end{array}$ \\
\hline $\begin{array}{l}\text { Decommissioning } \\
\text { Decommissioning (Subcontrad Support) }\end{array}$ & & 21 & 1 & LS & 0 & 0.0 & 1.00 & 0.00 & 0.00 & 0.00 & $40,000.00$ & $40,000.00$ \\
\hline $\begin{array}{l}\text { Demolition / Disposal } \\
\text { Demolition / Disposal (Subcontract Support) }\end{array}$ & & 21 & 1 & LS & 0 & 0.0 & 1.00 & 0.00 & 0.00 & 0.00 & $80,000.00$ & $80,000.00$ \\
\hline $\begin{array}{l}\text { Closure } \\
\text { Closure Documentation (Subcontract Suppoor) } \\
\text { Closure Documentation (Evvironmental Engineer) }\end{array}$ & & $\begin{array}{l}21 \\
\text { E050-REG }\end{array}$ & 1 & $\begin{array}{l}\text { LS } \\
\text { LS }\end{array}$ & $\begin{array}{l}0 \\
900\end{array}$ & $\begin{array}{r}0.0 \\
900.0\end{array}$ & $\begin{array}{r}1.00 \\
75.89\end{array}$ & $\begin{array}{r}0.00 \\
68,296.90\end{array}$ & $\begin{array}{l}0.00 \\
0.00\end{array}$ & $\begin{array}{l}0.00 \\
0.00\end{array}$ & $\begin{aligned} \begin{array}{r}100,000.00 \\
0.00\end{array} & \end{aligned}$ & $\begin{array}{r}100,000.00 \\
68,296.90\end{array}$ \\
\hline $\begin{array}{l}\text { Project Management } \\
\text { Project Management (Subcontract Support) } \\
\text { Project Management (Project Manager) }\end{array}$ & & $\begin{array}{l}21 \\
\text { E050-REG }\end{array}$ & $\begin{array}{l}1 \\
1\end{array}$ & $\begin{array}{l}\text { LS } \\
\text { LS }\end{array}$ & $\begin{array}{c}0 \\
450\end{array}$ & $\begin{array}{r}0.0 \\
450.0\end{array}$ & $\begin{array}{r}1.00 \\
75.89\end{array}$ & $\begin{array}{r}0.00 \\
34,148.45\end{array}$ & $\begin{array}{l}0.00 \\
0.00\end{array}$ & $\begin{array}{l}0.00 \\
0.00\end{array}$ & $\begin{array}{r}50,000.00 \\
0.00\end{array}$ & $\begin{array}{l}50,000.00 \\
34.148 .45\end{array}$ \\
\hline Subtotal F & illty Decommissioning & & & & & $2,000.0$ & & $157,212.48$ & & 0.00 & $315,000.00$ & $472,212.48$ \\
\hline $\begin{array}{l}\text { Contingency } \\
\text { Contingency }\end{array}$ & & & & & & & & $5,302,275.08$ & & $1,580,835.40$ & $2,343,214.54$ & $9,226,325.02$ \\
\hline & Subtotal Contingency & & & & & & & $5,302,275.08$ & & $1,580,835.40$ & $2,343,214.54$ & $9,226,325.02$ \\
\hline
\end{tabular}


RPP-RPT-37924 Rev. 0

Table G-7. Approach 2a Cost Estimate.

Table begins on next page. 
RPP-RPT-37924 Rev. 0

\begin{tabular}{|c|c|c|c|c|c|c|c|c|c|c|c|c|}
\hline \multirow{2}{*}{$\underbrace{\substack{\text { Canford Group, Ino } \\
\text { CHH }}}_{\text {Description }}$} & \multicolumn{10}{|c|}{$\begin{array}{l}\text { Cost Estimate } \\
\text { Title: IPS 2nd Waste Treatment Project Approach 2a (Transfer Brine to TF) } \\
\text { Estimator: Bob Williamson }\end{array}$} & \multicolumn{2}{|c|}{$\begin{aligned} \text { Est No: } & \text { 2179-Opt 2a } \\
\text { Date: } & \text { 5/2712008 }\end{aligned}$} \\
\hline & $\begin{array}{l}\text { Sch } \\
\text { ID }\end{array}$ & $\begin{array}{c}\text { Resource } \\
\text { code }\end{array}$ & Quan. & Unit & $\begin{array}{ll}\text { Labor } \\
\text { Unit Hrs } \\
\end{array}$ & \begin{tabular}{c|} 
Total \\
Labor Hrs
\end{tabular} & $\begin{array}{l}\text { Labor } \\
\text { Rate }\end{array}$ & $\begin{array}{l}\text { Labor } \\
\text { Dollars }\end{array}$ & $\begin{array}{l}\text { Material } \\
\text { Unit cost }\end{array}$ & $\begin{array}{l}\text { Material } \\
\text { Dollars }\end{array}$ & $\begin{array}{l}\text { Equip/Sub } \\
\text { Dollars }\end{array}$ & $\begin{array}{c}\text { Total } \\
\text { Dollars }\end{array}$ \\
\hline $\begin{array}{l}\text { oject Management FY11 } \\
\text { Materials and Supplies } \\
\text { Steff Augmentation Contract } \\
\text { Emironmental Engineer } \\
\text { Qualily Control Engineer } \\
\text { Safety Engineer } \\
\text { Secretaries } \\
\text { Project Manager } \\
\text { Project Engineer } \\
\text { Scheduler } \\
\text { Estimator } \\
\text { Cost Analyst }\end{array}$ & & $\begin{array}{c}10 \\
2 N \\
\text { 2N } \\
\text { E110-REG } \\
\text { E110-REG } \\
\text { E120-REG } \\
\text { G040-REG } \\
\text { MO20-REG } \\
\text { E130-REG } \\
\text { PO70REG } \\
\text { P070-REG } \\
\text { P070-REG }\end{array}$ & $\begin{array}{l}1 \\
1 \\
1 \\
1 \\
1 \\
1 \\
1 \\
1 \\
1 \\
1 \\
1 \\
1\end{array}$ & $\begin{array}{l}\text { LS } \\
\text { LS } \\
\text { LS } \\
\text { LS } \\
\text { LS } \\
\text { LS } \\
\text { LS } \\
\text { LS } \\
\text { LS } \\
\text { LS } \\
\text { LS }\end{array}$ & $\begin{array}{c}0 \\
0 \\
360 \\
360 \\
900 \\
900 \\
1800 \\
3600 \\
900 \\
450 \\
450\end{array}$ & $\begin{array}{r}0.0 \\
0.0 \\
360.0 \\
3600 . \\
9000.0 \\
9900.0 \\
1,000.0 \\
3,600.0 \\
900.0 \\
450.0 \\
450.0\end{array}$ & $\begin{array}{r}1.00 \\
1.00 \\
77.14 \\
77.14 \\
69.13 \\
35.47 \\
15.20 \\
95.40 \\
76.59 \\
76.59 \\
76.59\end{array}$ & 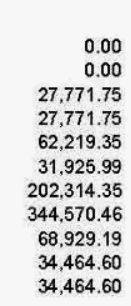 & $\begin{array}{r}10,000.00 \\
0.00 \\
0.00 \\
0.00 \\
0.00 \\
0.00 \\
0.00 \\
0.00 \\
0.00 \\
0.00 \\
0.00\end{array}$ & $\begin{array}{r}10,000.00 \\
0.00 \\
0.00 \\
0.00 \\
0.00 \\
0.00 \\
0.00 \\
0.00 \\
0.00 \\
0.00 \\
0.00\end{array}$ & $\begin{array}{r}0.00 \\
50,000.00 \\
0.00 \\
0.00 \\
0.00 \\
0.00 \\
0.00 \\
0.00 \\
0.00 \\
0.00 \\
0.00\end{array}$ & 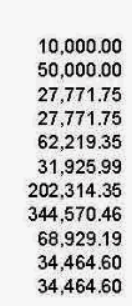 \\
\hline 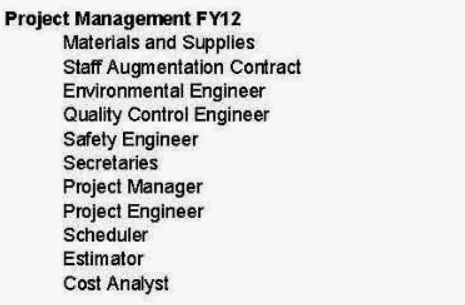 & & 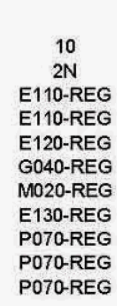 & $\begin{array}{l}1 \\
1 \\
1 \\
1 \\
1 \\
1 \\
1 \\
1 \\
1 \\
1 \\
1 \\
1 \\
1\end{array}$ & $\begin{array}{l}\text { LS } \\
\text { LS } \\
\text { LS } \\
\text { LS } \\
\text { LS } \\
\text { LS } \\
\text { LS } \\
\text { LS } \\
\text { LS } \\
\text { LS } \\
\text { LS }\end{array}$ & $\begin{array}{c}0 \\
0 \\
360 \\
360 \\
900 \\
900 \\
1800 \\
3600 \\
900 \\
450 \\
450\end{array}$ & $\begin{array}{r}0.0 \\
0.0 \\
360.0 \\
360.0 \\
9000.0 \\
9900.0 \\
1,8000.0 \\
3,6000.0 \\
900.0 \\
450.0 \\
450.0\end{array}$ & $\begin{array}{r}1.00 \\
1.00 \\
77.14 \\
77.14 \\
69.13 \\
35.47 \\
112.40 \\
95.71 \\
76.59 \\
76.59 \\
76.59\end{array}$ & 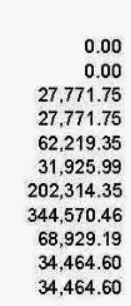 & $\begin{array}{r}10.000 .00 \\
0.00 \\
0.00 \\
0.00 \\
0.00 \\
0.00 \\
0.000 \\
0.00 \\
0.00 \\
0.00 \\
0.00\end{array}$ & $\begin{array}{r}10,000.00 \\
0.00 \\
0.00 \\
0.00 \\
0.00 \\
0.00 \\
0.00 \\
0.00 \\
0.00 \\
0.00 \\
0.00\end{array}$ & $\begin{array}{r}0.00 \\
50,000.00 \\
0.00 \\
0.00 \\
0.00 \\
0.00 \\
0.00 \\
0.00 \\
0.00 \\
0.00 \\
0.00\end{array}$ & 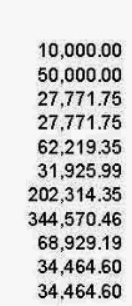 \\
\hline $\begin{array}{l}\text { Project Management FY13 } \\
\text { Materials and Supplies } \\
\text { Staff Augmentation Contract } \\
\text { Evirionmental Engininer } \\
\text { Ouallty Control Engineer } \\
\text { Safetet Engineer } \\
\text { Secretaries } \\
\text { Project Manager } \\
\text { Project Engineer } \\
\text { Scheduler } \\
\text { Estimator } \\
\text { Cost Analyst }\end{array}$ & & 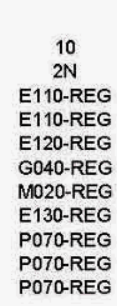 & $\begin{array}{l}1 \\
1 \\
1 \\
1 \\
1 \\
1 \\
1 \\
1 \\
1 \\
1 \\
1 \\
1 \\
1\end{array}$ & $\begin{array}{l}\text { LS } \\
\text { LS } \\
\text { LS } \\
\text { LS } \\
\text { LS } \\
\text { LS } \\
\text { LS } \\
\text { LS } \\
\text { LS } \\
\text { LS } \\
\text { LS }\end{array}$ & $\begin{array}{l}0 \\
0 \\
90 \\
90 \\
250 \\
250 \\
450 \\
900 \\
250 \\
100 \\
100\end{array}$ & $\begin{array}{c}0.0 \\
0.0 \\
90.0 \\
90.0 \\
250.0 \\
250.0 \\
450.0 \\
900.0 \\
250.0 \\
100.0 \\
100.0\end{array}$ & $\begin{array}{r}1.00 \\
1.00 \\
77.14 \\
77.14 \\
69.14 \\
35.47 \\
11.424 \\
9.51 \\
76.59 \\
76.59 \\
76.59\end{array}$ & 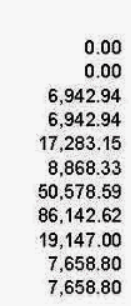 & $\begin{array}{r}2.500 .00 \\
0.00 \\
0.00 \\
0.00 \\
0.00 \\
0.00 \\
0.00 \\
0.00 \\
0.00 \\
0.00 \\
0.00\end{array}$ & $\begin{array}{r}2.500 .00 \\
0.00 \\
0.00 \\
0.00 \\
0.00 \\
0.00 \\
0.00 \\
0.00 \\
0.00 \\
0.00 \\
0.00\end{array}$ & $\begin{array}{r}0.00 \\
10,000.00 \\
0.00 \\
0.00 \\
0.00 \\
0.00 \\
0.00 \\
0.00 \\
0.00 \\
0.00 \\
0.00\end{array}$ & 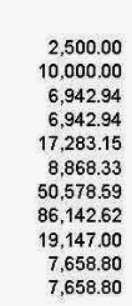 \\
\hline & Subtotal Project Management & & & & & $21,920.0$ & & $1,880,087.23$ & & $22,500.00$ & $110,000.00$ & 2,012,587.23 \\
\hline $\begin{array}{l}\text { neering } \\
\text { Detall Design - Offsite Engineering Contract }\end{array}$ & & 21 & 1 & LS & 0 & 0.0 & 1.00 & 0.00 & 0.00 & 0.00 & $300,000.00$ & $300,000.00$ \\
\hline Final Design - Offsite Engineering Contract & & 21 & 1 & LS & 0 & 0.0 & 1.00 & 0.00 & 0.00 & 0.00 & $700,000.00$ & $700,000.00$ \\
\hline Title III Engineering Contract & & 21 & 1 & LS & 0 & 0.0 & 1.00 & 0.00 & 0.00 & 0.00 & $170,000.00$ & $170,000.00$ \\
\hline & btotal Engineering & & & & & 0.0 & & 0.00 & & 0.00 & $1,170,000.00$ & $1,170,000.00$ \\
\hline
\end{tabular}


RPP-RPT-37924 Rev. 0

\section{Cost Estimate}

Title: IPS 2nd Waste Treatment Project Approach 2a (Transfer Brine to TF)

Est No: 2179-Opt 2a Estimator: Bob Williamson

\begin{tabular}{|c|c|c|c|c|c|c|}
\hline $\begin{array}{c}\text { Sch } \\
\text { ID }\end{array}$ & & $\begin{array}{c}\text { Resource } \\
\text { Code }\end{array}$ & Quan. & Unit & $\begin{array}{c}\text { Labor } \\
\text { Unit Hrs }\end{array}$ & Total \\
\hline
\end{tabular}

\begin{tabular}{|c|c|c|}
\hline Labor & \\
Rate
\end{tabular}

Labor
Dollars

\begin{tabular}{c|c|}
\hline Material \\
Unit cost
\end{tabular}

Material
Dollars

Equip/Su
Dollars

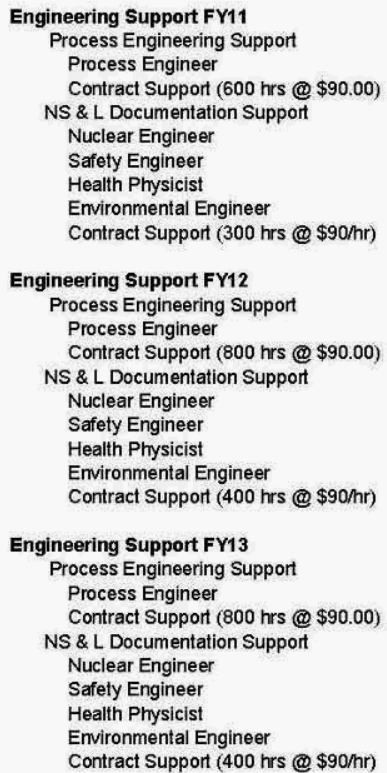

$\begin{array}{cccc}\text { E130-REG } & 1 & \text { EA } & 3600 \\ 21 & 1 & \text { LS } & 0 \\ \text { E080-REG } & 1 & \text { LS } & 300 \\ \text { E120-REG } & 1 & \text { LS } & 300 \\ \text { P080-REG } & 1 & \text { LS } & 100 \\ \text { E050-REG } & 1 & \text { LS } & 100 \\ 21 & 1 & \text { LS } & 0\end{array}$

$\begin{array}{rr}3,600.0 & 95.71 \\ 0.0 & 1.00 \\ 300.0 & 95.79 \\ 300.0 & 69.13 \\ 100.0 & 78.84 \\ 100.0 & 75.89 \\ 0.0 & 1.00\end{array}$

$\begin{array}{rr}344,570.46 & 5,000.00 \\ 0.00 & 0.00 \\ 28,736.23 & 0.00 \\ 20.739 .78 & 0.00 \\ 7.884 .24 & 0.00 \\ 7,588.54 & 0.00 \\ 0.00 & 0.00\end{array}$

\section{$5,000.00$}

0.00
15.000 .00 Dollars

$\begin{array}{cllrrrrrrrr}\text { E130-REG } & 1 & \text { EA } & 3600 & 3,600.0 & 95.71 & 344,570.46 & 5,000.00 & 5,000.00 & 0.00 & 349,570.46 \\ 21 & 1 & \text { LS } & 0 & 0.0 & 1.00 & 0.00 & 0.00 & 0.00 & 72,000.00 & 72,000.00 \\ \text { E080-REG } & 1 & \text { LS } & 300 & 300.0 & 95.79 & 28,736.23 & 0.00 & 0.00 & 0.00 & 28.736 .23 \\ \text { E120-REG } & 1 & \text { LS } & 300 & 300.0 & 69.13 & 20.739 .78 & 0.00 & 0.00 & 0.00 & 20.739 .78 \\ \text { P080-REG } & 1 & \text { LS } & 100 & 100.0 & 78.84 & 7.884 .24 & 0.00 & 0.00 & 0.00 & 7.884 .24 \\ \text { EO50-REG } & 1 & \text { LS } & 100 & 100.0 & 75.89 & 7,588.54 & 0.00 & 0.00 & 0.00 & 7,588.54 \\ 21 & 1 & \text { LS } & 0 & 0.0 & 1.00 & 0.00 & 0.00 & 0.00 & 36,000.00 & 36,000.00\end{array}$

$\begin{array}{ccccrrrrrrr}\text { E130-REG } & 1 & \text { EA } & 3600 & 3,600.0 & 95.71 & 344,570.46 & 5.000 .00 & 5.000 .00 & 0.00 & 349,570.46 \\ 21 & 1 & \text { LS } & 0 & 0.0 & 1.00 & 0.00 & 0.00 & 0.00 & 72,000.00 & 72,000.00 \\ \text { E080-REG } & 1 & \text { LS } & 300 & 300.0 & 95.79 & 28,736.23 & 0.00 & 0.00 & 0.00 & 28.736 .23 \\ \text { E120-REG } & 1 & \text { LS } & 300 & 300.0 & 69.13 & 20,739.78 & 0.00 & 0.00 & 0.00 & 20,739.78 \\ \text { P080-REG } & 1 & \text { LS } & 100 & 100.0 & 78.84 & 7,884.24 & 0.00 & 0.00 & 0.00 & 7,884.24 \\ \text { E050-REG } & 1 & \text { LS } & 100 & 100.0 & 75.89 & 7,588.54 & 0.00 & 0.00 & 0.00 & 7,588.54 \\ 21 & 1 & \text { LS } & 0 & 0.0 & 1.00 & 0.00 & 0.00 & 0.00 & 36,000.00 & 36,000.00 \\ \text { E000-REG } & 1 & \text { LS } & 1800 & 1,800.0 & 82.62 & 148,711.15 & 0.00 & 0.00 & 0.00 & 148,711.15 \\ & & & & 15,000.0 & & \mathbf{1 , 3 7 7 , 2 6 8 . 9 2} & & \mathbf{1 5 , 0 0 0 . 0 0} & \mathbf{2 3 6 , 0 0 0 . 0 0} & \mathbf{1 , 6 2 8 , 2 6 8 . 9 2}\end{array}$

Subtotal Engineering Support

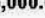

$\begin{array}{lccc}10 & 1 & \text { LS } & 0 \\ 10 & 2 & \text { EA } & 0 \\ & & & \\ 21 & 1 & \text { EA } & 0 \\ 21 & 2 & \text { EA } & 0 \\ 21 & 2 & \text { EA } & 0 \\ 21 & 100 & \text { If } & 0 \\ 21 & 200 & \text { If } & 0 \\ 21 & 100 & \text { If } & 0 \\ 21 & 100 & \text { If } & 0 \\ 21 & 100 & \text { If } & 0\end{array}$

$\begin{array}{ll}0.0 & 1.00 \\ 0.0 & 1.00 \\ & \\ 0.0 & 1.00 \\ 0.0 & 1.00 \\ 0.0 & 1.00 \\ 0.0 & 1.00 \\ 0.0 & 1.00 \\ 0.0 & 1.00 \\ 0.0 & 1.00 \\ 0.0 & 1.00\end{array}$

"CPVC pinng and fittings

Washington State Sales Tax @ 8.3\%

Material \& Equipment Instruments and
Transfer Pumps

\section{Fabrication}

Tanker Truck (1,000 gal Tank, Inconel) Tanks (5,000 gal, Inconel)

" 4 " Carpenter Alloy 20 piping and fittings

$3 / 4$ " 304 SS piping and fittings

2"Inconel piping and fittings

$\begin{array}{rrrrr}0.00 & 1,000.00 & 1,000.00 & 0.00 & 1,000.00 \\ 0.00 & 25,000.00 & 50,000.00 & 0.00 & 50,000.00 \\ & & & & \\ 0.00 & 200,000.00 & 200,000.00 & 0.00 & 200,000.00 \\ 0.00 & 190,000.00 & 380,000.00 & 0.00 & 380,000.00 \\ 0.00 & 50,000.00 & 100,000.00 & 0.00 & 100,000.00 \\ 0.00 & 75.00 & 7,500.00 & 0.00 & 7,500.00 \\ 0.00 & 400.00 & 80,000.00 & 0.00 & 80,000.00 \\ 0.00 & 600.00 & 60,000.00 & 0.00 & 60.000 .00 \\ 0.00 & 500.00 & 50,000.00 & 0.00 & 50,000.00 \\ 0.00 & 20.00 & 2,000.00 & 0.00 & 2,000.00 \\ & & & & \\ & & 77,231.50 & & 77,231.50\end{array}$

$77,231.50$ 
RPP-RPT-37924 Rev. 0

Cost Estimate

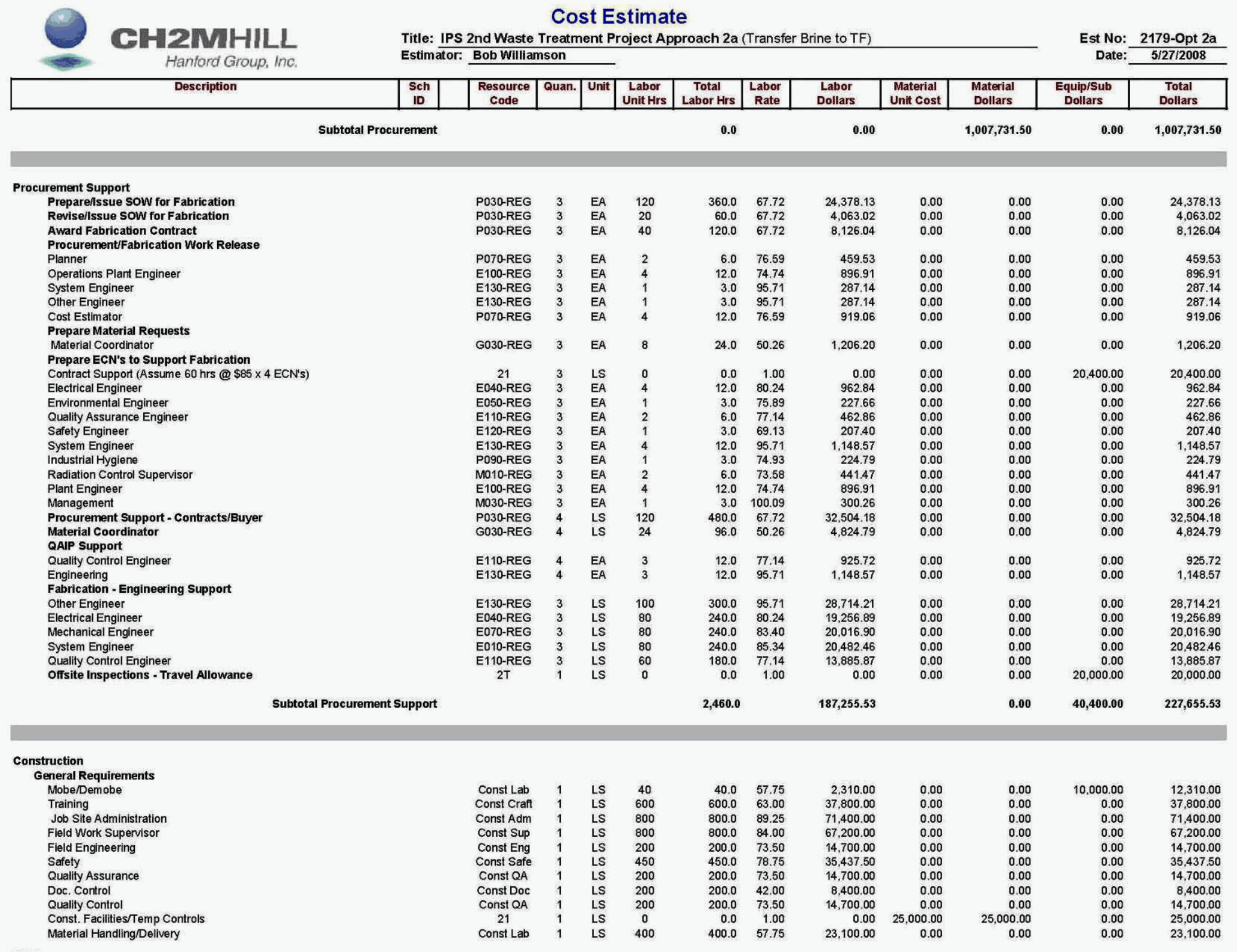

RDW

3 
RPP-RPT-37924 Rev. 0

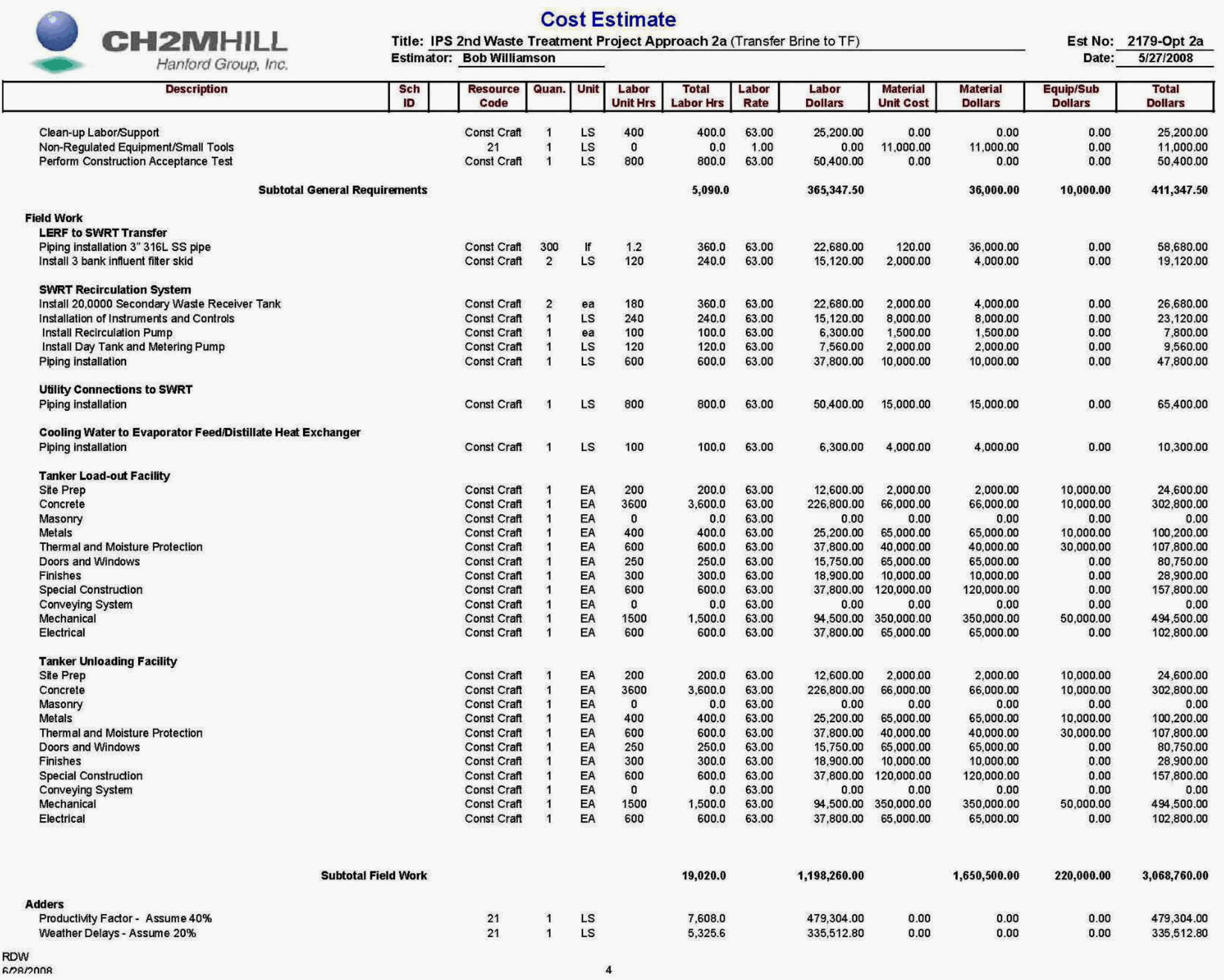


RPP-RPT-37924 Rev. 0

\begin{tabular}{|c|c|c|c|c|c|c|c|c|c|c|c|c|}
\hline \multirow{2}{*}{ 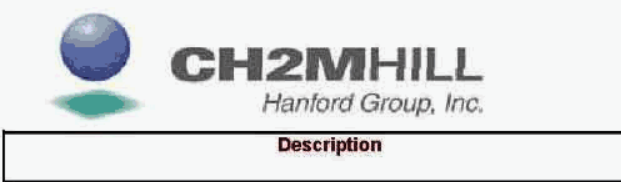 } & \multicolumn{8}{|c|}{$\begin{array}{c}\text { Cost Estimate } \\
\text { Tite. IPs 2ndwaste }\end{array}$} & & & $\begin{array}{l}\text { Est No: } \\
\text { Date: }\end{array}$ & $\frac{2179-O p t ~ 2 a}{5 / 27 / 2008}$ \\
\hline & \begin{tabular}{c|c|} 
Sch \\
ID
\end{tabular} & $\begin{array}{c}\text { Resource } \\
\text { Code }\end{array}$ & Quan. & \begin{tabular}{|l|} 
Unit \\
\end{tabular} & \begin{tabular}{|l} 
Labor \\
Unit Hrs \\
\end{tabular} & \begin{tabular}{|c|} 
Total \\
Labor Hrs \\
\end{tabular} & \begin{tabular}{|c|}
$\begin{array}{c}\text { Labor } \\
\text { Rate }\end{array}$ \\
\end{tabular} & $\begin{array}{l}\text { Labor } \\
\text { Dollars }\end{array}$ & \begin{tabular}{|l|l|} 
Material \\
Unit cost \\
\end{tabular} & $\begin{array}{c}\text { Material } \\
\text { Dollars }\end{array}$ & $\begin{array}{c}\text { Equip/Sub } \\
\text { Dollars }\end{array}$ & $\begin{array}{c}\text { Total } \\
\text { Dollars }\end{array}$ \\
\hline $\begin{array}{l}\text { Allowance for Construction Consumables - } 3 \% \text { of Const. Labor } \\
\text { Material Sales Tax @ } 8.3 \%\end{array}$ & & $\begin{array}{l}21 \\
21\end{array}$ & $\begin{array}{l}1 \\
1\end{array}$ & $\begin{array}{l}\text { LS } \\
\text { LS }\end{array}$ & & $\begin{array}{l}0.0 \\
0.0\end{array}$ & & $\begin{array}{l}0.00 \\
0.00\end{array}$ & $\begin{array}{r}35,947.80 \\
136.991 .50\end{array}$ & $\begin{array}{r}35,947.80 \\
136,991.50\end{array}$ & $\begin{array}{l}0.00 \\
0.00\end{array}$ & $\begin{array}{r}35,947.80 \\
136,991.50\end{array}$ \\
\hline Subt & Adders & & & & & $12,933.6$ & & $814,816.80$ & & $172,939.30$ & 0.00 & $987,756.10$ \\
\hline \multirow[t]{2}{*}{ Construction Contractor Fee @ 8\% } & & 21 & & & & & & & & & $357,429.09$ & $357,429.09$ \\
\hline & struction & & & & & $37,043.6$ & & $2,378,424.30$ & & $1,859,439.30$ & $587,429.09$ & $4,825,292.69$ \\
\hline \multicolumn{13}{|l|}{ Construction Management } \\
\hline Management & & M020-REG & 1 & LS & 100 & 100.0 & 112.40 & $11,239.69$ & 0.00 & 0.00 & 0.00 & 11.239 .69 \\
\hline Construction Manager & & MO 0 -REG & 1 & LS & 900 & 900.0 & 100.09 & $90,077.92$ & 0.00 & 0.00 & 0.00 & $90,077.92$ \\
\hline Construction Field Lead & & MO10-REG & 1 & LS & 900 & 900.0 & 73.58 & $66,220.72$ & 0.00 & 0.00 & 0.00 & $66,220.72$ \\
\hline Clerical/Document Control Support & & G030-REG & 1 & LS & 450 & 450.0 & 50.26 & $22,616.21$ & 0.00 & 0.00 & 0.00 & $22,616.21$ \\
\hline Miscellaneous Office Supplies for CM & & 10 & 1 & LS & 0 & 0.0 & 1.00 & 0.00 & $10,000.00$ & $10,000.00$ & 0.00 & $10,000.00$ \\
\hline Contract Administration & & P030-REG & 1 & LS & 450 & 450.0 & 67.72 & $30,472.67$ & & 0.00 & 0.00 & $30,472.67$ \\
\hline Subtotal Construction N & agement & & & & & $2,800.0$ & & $220,627.21$ & & $10,000.00$ & 0.00 & $230,627.21$ \\
\hline \multicolumn{13}{|l|}{ Construction Support } \\
\hline Health Physics Technician (HPT) & & T050-REG & 1 & LS & 200 & 200.0 & 58.48 & $11,695.82$ & 0.00 & 0.00 & 0.00 & $11,695.82$ \\
\hline Industrial Health \& Safety & & T060-REG & 1 & LS & 100 & 100.0 & 57.69 & $5,769.27$ & 0.00 & 0.00 & 0.00 & $5,769.27$ \\
\hline PHMC - Critical Lift Support (Crane \& Rigging Organization) & & $3 \mathrm{P}$ & 1 & LS & 0 & 0.0 & 1.00 & 0.00 & 0.00 & 0.00 & $20,000.00$ & $20,000.00$ \\
\hline $\begin{array}{l}\text { PHMC - Crane Usage Charges } \\
\text { Planning \& Work Package Prep }\end{array}$ & & $3 P$ & 1 & LS & 0 & 0.0 & 1.00 & 0.00 & 0.00 & 0.00 & $10,000.00$ & $10,000.00$ \\
\hline $\begin{array}{l}\text { Planning \& Work Package Prep } \\
\text { Planner }\end{array}$ & & PO70-REG & 2 & EA & 112 & 224.0 & 76.59 & $17,155.71$ & 0.00 & 0.00 & 0.00 & $17,155.71$ \\
\hline System Engineer & & E130-REG & 2 & EA & 20 & 40.0 & 95.71 & $3,828.56$ & 0.00 & 0.00 & 0.00 & $3,828.56$ \\
\hline Radiation Control & & PO90-REG & 2 & EA & 20 & 40.0 & 74.93 & $2,997.25$ & 0.00 & 0.00 & 0.00 & $2,997.25$ \\
\hline $\begin{array}{l}\text { Field Work Supervisor } \\
\text { Enhanced Work Planning }\end{array}$ & & M010-REG & 2 & EA & 20 & 40.0 & 73.58 & $2,943.14$ & 0.00 & 0.00 & 0.00 & $2,943.14$ \\
\hline $\begin{array}{l}\text { Planner } \\
\text { Plork lanting }\end{array}$ & & P070-REG & 2 & EA & 3 & 6.0 & 76.59 & 459.53 & 0.00 & 0.00 & 0.00 & 459.53 \\
\hline Carpenter & & CO10-REG & 2 & EA & 3 & 6.0 & 55.84 & 335.02 & 0.00 & 0.00 & 0.00 & 335.02 \\
\hline Electrician & & CO20-REG & 2 & EA & 3 & 6.0 & 61.07 & 366.41 & 0.00 & 0.00 & 0.00 & 366.41 \\
\hline Pipefitter & & CO80-REG & 2 & EA & 3 & 6.0 & 57.11 & 342.63 & 0.00 & 0.00 & 0.00 & 342.63 \\
\hline Miscellaneous Craft & & C120-REG & 2 & EA & 3 & 6.0 & 56.94 & 341.63 & 0.00 & 0.00 & 0.00 & 341.63 \\
\hline Emvironmental Engineer & & EO50-REG & 2 & EA & 3 & 6.0 & 75.89 & 455.31 & 0.00 & 0.00 & 0.00 & 455.31 \\
\hline Quality Control & & E110-REG & 2 & EA & 3 & 6.0 & 77.14 & 462.86 & 0.00 & 0.00 & 0.00 & 462.86 \\
\hline Safety Engineer & & E120-REG & 2 & $E A$ & 3 & 6.0 & 69.13 & 414.80 & 0.00 & 0.00 & 0.00 & 414.80 \\
\hline System Engineer & & E130-REG & 2 & $E A$ & 3 & 6.0 & 95.71 & 574.28 & 0.00 & 0.00 & 0.00 & 574.28 \\
\hline Light Vehicle Driver & & L070-REG & 2 & EA & 3 & 6.0 & 47.91 & 287.46 & 0.00 & 0.00 & 0.00 & 287.46 \\
\hline Field Work Supervisor (FWS) & & MO10-REG & 2 & EA & 3 & 6.0 & 73.58 & 441.47 & 0.00 & 0.00 & 0.00 & 441.47 \\
\hline Industrial Hygiene & & PO90-REG & 2 & EA & 3 & 6.0 & 74.93 & 449.59 & 0.00 & 0.00 & 0.00 & 449.59 \\
\hline $\begin{array}{l}\text { Health Physics Technician (HPT) } \\
\text { Review \& Approve Work Packages }\end{array}$ & & T050-REG & 2 & EA & 3 & 6.0 & 58.48 & 350.87 & 0.00 & 0.00 & 0.00 & 350.87 \\
\hline Planner & & P070-REG & 2 & EA & 28 & 56.0 & 76.59 & $4,288.93$ & 0.00 & 0.00 & 0.00 & $4,288.93$ \\
\hline Environmental Engineer & & E050-REG & 2 & $E A$ & 5 & 10.0 & 75.89 & 758.85 & 0.00 & 0.00 & 0.00 & 758.85 \\
\hline $\begin{array}{l}\text { Quality Control } \\
\text { Syinter }\end{array}$ & & E110-REG & 2 & EA & 5 & 10.0 & 77.14 & 771.44 & 0.00 & 0.00 & 0.00 & 771.44 \\
\hline Safety Engineer & & E120-REG & 2 & EA & 5 & 10.0 & 69.13 & 691.33 & 0.00 & 0.00 & 0.00 & 691.33 \\
\hline System Engineer & & E130-REG & 2 & EA & 10 & 20.0 & 95.71 & 1.914 .28 & 0.00 & 0.00 & 0.00 & $1,914.28$ \\
\hline Field Work Supervisor (FWS) & & MO10-REG & 2 & EA & 5 & 10.0 & 73.58 & 735.79 & 0.00 & 0.00 & 0.00 & 735.79 \\
\hline Other Engineer & & E130-REG & 2 & EA & 5 & 10.0 & 95.71 & 957.14 & 0.00 & 0.00 & 0.00 & 957.14 \\
\hline Health Physics Technician (HPT) & & TO50-REG & 2 & EA & 5 & 10.0 & 58.48 & 584.79 & 0.00 & 0.00 & 0.00 & 584.79 \\
\hline Industrial Health \& Safety & & TO60-REG & 2 & EA & 5 & 10.0 & $\begin{array}{l}57.40^{\circ} \\
57.69\end{array}$ & 576.93 & 0.00 & 0.00 & 0.00 & 576.93 \\
\hline RDW & & & & & & & & & & & & \\
\hline
\end{tabular}


RPP-RPT-37924 Rev. 0

Cost Estimate

Title: IPS 2nd Waste Treatment Project Approach 2a (Transfer Brine to TF)

Est No: 2179-Opt 2a \begin{tabular}{|c|c|c|c|c|c|c|}
\hline Sch & & Resource & Quan. & Unit & Labor & Total \\
\hline
\end{tabular}

\begin{tabular}{|c|c|c|c|c|c|c|c|c|c|c|c|c|}
\hline Description & $\begin{array}{l}\text { Sch } \\
\text { ID }\end{array}$ & $\begin{array}{c}\text { Resource } \\
\text { Code }\end{array}$ & Quan. & Unit & \begin{tabular}{|l|} 
Labor \\
Unit Hrs \\
\end{tabular} & \begin{tabular}{c|} 
Total \\
Labor Hrs \\
\end{tabular} & \begin{tabular}{|c|} 
Labor \\
Rate \\
\end{tabular} & $\begin{array}{l}\text { Labor } \\
\text { Dollars }\end{array}$ & $\begin{array}{l}\text { Material } \\
\text { Unit cost } \\
\end{array}$ & $\begin{array}{l}\text { Material } \\
\text { Dollars }\end{array}$ & $\begin{array}{c}\begin{array}{c}\text { Equip/Sub } \\
\text { Dollars }\end{array} \\
\end{array}$ & $\begin{array}{c}\text { Total } \\
\text { Dollars }\end{array}$ \\
\hline $\begin{array}{l}\text { Operations Plant Engineer } \\
\text { Closeout Work Packages }\end{array}$ & & E100-REG & 2 & EA & 25 & 50.0 & 74.74 & $3,737.12$ & 0.00 & 0.00 & 0.00 & $3,737.12$ \\
\hline Planner & & P070-REG & 2 & EA & 12 & 24.0 & 76.59 & $1,838.11$ & 0.00 & 0.00 & 0.00 & $1,838.11$ \\
\hline Operations Plant Engineer & & E100-REG & 2 & EA & 4 & 8.0 & 74.74 & 597.94 & 0.00 & 0.00 & 0.00 & 597.94 \\
\hline Administration & & G020-REG & 2 & EA & 2 & 4.0 & 33.28 & 133.13 & 0.00 & 0.00 & 0.00 & 133.13 \\
\hline Other Engineer & & E130-REG & 2 & EA & 4 & 8.0 & 95.71 & 765.71 & 0.00 & 0.00 & 0.00 & 765.71 \\
\hline $\begin{array}{l}\text { Field Work Supervisor (FWS) } \\
\text { Prepare ECN's }\end{array}$ & & M010-REG & 2 & EA & 2 & 4.0 & 73.58 & 294.31 & 0.00 & 0.00 & 0.00 & 294.31 \\
\hline Contract Support (Assume 90 hrs @ $\$ 85 \times 4$ ECN's) & & 21 & 1 & LS & 0 & 0.0 & 1.00 & 0.00 & 0.00 & 0.00 & $30,600.00$ & $30,600.00$ \\
\hline Electrical Engineer & & E040-REG & 2 & $E A$ & 4 & 8.0 & 80.24 & 641.90 & 0.00 & 0.00 & 0.00 & 641.90 \\
\hline Emvironmental Engineer & & E050-REG & 2 & EA & 1 & 2.0 & 75.89 & 151.77 & 0.00 & 0.00 & 0.00 & 151.77 \\
\hline Quality Assurance Engineer & & E110-REG & 2 & $E A$ & 2 & 4.0 & 77.14 & 308.57 & 0.00 & 0.00 & 0.00 & 308.57 \\
\hline Safety Engineer & & E120-REG & 2 & EA & 1 & 2.0 & 69.13 & 138.27 & 0.00 & 0.00 & 0.00 & 138.27 \\
\hline System Engineer & & E130-REG & 2 & $E A$ & 4 & 8.0 & 95.71 & 765.71 & 0.00 & 0.00 & 0.00 & 765.71 \\
\hline Industrial Hygiene & & PO90-REG & 2 & $E A$ & 1 & 2.0 & 74.93 & 149.86 & 0.00 & 0.00 & 0.00 & 149.86 \\
\hline Radiation Control Supervisor & & MO10-REG & 2 & EA & 2 & 4.0 & 73.58 & 294.31 & 0.00 & 0.00 & 0.00 & 294.31 \\
\hline Plant Engineer & & E100-REG & 2 & EA & 4 & 8.0 & 74.74 & 597.94 & 0.00 & 0.00 & 0.00 & 597.94 \\
\hline Management & & MO3O-REG & 2 & $\mathrm{EA}$ & 1 & 2.0 & 100.09 & 200.17 & 0.00 & 0.00 & 0.00 & 200.17 \\
\hline Prepare USQ's & & E130-REG & 2 & $E A$ & 28 & & 9571 & 535998 & & 0.00 & 0.00 & $5,359.98$ \\
\hline $\begin{array}{l}\text { Other Engineers } \\
\text { Review Engineers }\end{array}$ & & $\begin{array}{l}\text { E130-REG } \\
\text { E130-REG }\end{array}$ & $\begin{array}{l}2 \\
2\end{array}$ & $\begin{array}{l}E A \\
E A\end{array}$ & $\begin{array}{c}28 \\
9\end{array}$ & $\begin{array}{l}56.0 \\
18.0\end{array}$ & $\begin{array}{l}95.71 \\
95.71\end{array}$ & $\begin{array}{l}5,359.98 \\
1,722.85\end{array}$ & $\begin{array}{l}0.00 \\
0.00\end{array}$ & $\begin{array}{l}0.00 \\
0.00\end{array}$ & $\begin{array}{l}0.00 \\
0.00\end{array}$ & $\begin{array}{l}5,359.98 \\
1,722.85\end{array}$ \\
\hline Radiation Work Permit & & - & & & & & & & & & & \\
\hline Planner & & P070-REG & 1 & EA & 14 & 14.0 & 76.59 & $1,072.23$ & 0.00 & 0.00 & 0.00 & $1,072.23$ \\
\hline Electrician & & C020-REG & 1 & EA & 2 & 2.0 & 61.07 & 122.14 & 0.00 & 0.00 & 0.00 & 122.14 \\
\hline Electrical Engineer & & E040-REG & 1 & EA & 2 & 2.0 & 80.24 & 160.47 & 0.00 & 0.00 & 0.00 & 160.47 \\
\hline Environmental Engineer & & EO50-REG & $i$ & $E A$ & 5 & 5.0 & 75.89 & 379.43 & 0.00 & 0.00 & 0.00 & 379.43 \\
\hline Operations Plant Engineer & & E100-REG & 1 & EA & 2 & 2.0 & 74.74 & 149.48 & 0.00 & 0.00 & 0.00 & 149.48 \\
\hline Safety Engineer & & E120-REG & 1 & EA & 2 & 2.0 & 69.13 & 138.27 & 0.00 & 0.00 & 0.00 & 138.27 \\
\hline System Engineer & & E130-REG & 1 & EA & 5 & 5.0 & 95.71 & 478.57 & 0.00 & 0.00 & 0.00 & 478.57 \\
\hline Field Work Supervisor (FWS) & & E100-REG & 1 & EA & 5 & 5.0 & 74.74 & 373.71 & 0.00 & 0.00 & 0.00 & 373.71 \\
\hline Health Physics Technician (HPT) & & TO50-REG & $i$ & $E A$ & 5 & 5.0 & 58.48 & 292.40 & 0.00 & 0.00 & 0.00 & 292.40 \\
\hline Industrial Health \& Safety & & TO60-REG & 1 & EA & 2 & 2.0 & 57.69 & 115.39 & 0.00 & 0.00 & 0.00 & 115.39 \\
\hline Material Requests & & - & & & & & & & & & & \\
\hline Material Coordinator & & G030-REG & 1 & EA & 4 & 4.0 & 50.26 & 201.03 & 0.00 & 0.00 & 0.00 & 201.03 \\
\hline $\begin{array}{l}\text { Pre Job Briefings } \\
\text { Other Engineers }\end{array}$ & & E130-REG & 60 & $\mathrm{Hr}$ & 1 & 60.0 & 95.71 & $5,742.84$ & 0.00 & 0.00 & 0.00 & $5,742.84$ \\
\hline Administration & & G020-REG & 60 & $\mathrm{Hr}$ & 1 & 60.0 & 33.28 & $1,996.91$ & 0.00 & 0.00 & 0.00 & $1,996.91$ \\
\hline Management & & MO10-REG & 60 & $\mathrm{Hr}$ & 1 & 60.0 & 73.58 & $4,414.71$ & 0.00 & 0.00 & 0.00 & $4,414.71$ \\
\hline Post Job Alara Review & & $\therefore-$ & & & & & & & & & & \\
\hline Planner & & PO70-REG & 1 & EA & 2 & 2.0 & 76.59 & 153.18 & 0.00 & 0.00 & 0.00 & 153.18 \\
\hline Electrician & & C020-REG & 1 & EA & 4 & 4.0 & 61.07 & 244.28 & 0.00 & 0.00 & 0.00 & 244.28 \\
\hline Electrical Engineer & & E040-REG & 1 & EA & 2 & 2.0 & 80.24 & 160.47 & 0.00 & 0.00 & 0.00 & 160.47 \\
\hline Environmental Engineer & & EO50-REG & 1 & $E A$ & 1 & 1.0 & 75.89 & 75.89 & 0.00 & 0.00 & 0.00 & 75.89 \\
\hline System Engineer & & E130-REG & 1 & $E A$ & 2 & 2.0 & 95.71 & 191.43 & 0.00 & 0.00 & 0.00 & 191.43 \\
\hline Other Engineers & & E130-REG & 1 & $E A$ & 2 & 2.0 & 95.71 & 191.43 & 0.00 & 0.00 & 0.00 & 191.43 \\
\hline Administration & & G020-REG & 1 & EA & 2 & 2.0 & 33.28 & 66.56 & 0.00 & 0.00 & 0.00 & 66.56 \\
\hline $\begin{array}{l}\text { First Line Supervision } \\
\text { Ground Scanning }\end{array}$ & & MO10-REG & 1 & EA & 1 & 1.0 & 73.58 & 73.58 & 0.00 & 0.00 & 0.00 & 73.58 \\
\hline CVill Engineer & & E020-REG & 2 & EA & 6 & 12.0 & 85.21 & $1,022.49$ & 0.00 & 0.00 & 0.00 & $1,022.49$ \\
\hline Other Engineers & & E130-REG & 2 & EA & 54 & 108.0 & 95.71 & $10,337.11$ & 0.00 & 0.00 & 0.00 & $10,337.11$ \\
\hline First Line Supervision & & MO10-REG & 2 & EA & 4 & 8.0 & 73.58 & 588.63 & 0.00 & 0.00 & 0.00 & 588.63 \\
\hline $\begin{array}{l}\text { Perform Ground Scanning - (Contract) } \\
\text { TSR Matrix }\end{array}$ & & 21 & 1 & LS & 0 & 0.0 & 1.00 & 0.00 & 0.00 & 0.00 & $5,000.00$ & $5,000.00$ \\
\hline Planner & & P070-REG & 1 & EA & 6 & 6.0 & 76.59 & 459.53 & 0.00 & 0.00 & 0.00 & 459.53 \\
\hline System Engineer & & E130-REG & 1 & $E A$ & 6 & 6.0 & 95.71 & 574.28 & 0.00 & 0.00 & 0.00 & 574.28 \\
\hline $\begin{array}{l}\text { Lock/Tagouts } \\
\text { Pipefitter }\end{array}$ & & CO80-REG & 2 & EA & 8 & 16.0 & 57.11 & 913.69 & 0.00 & 0.00 & 0.00 & 913.69 \\
\hline
\end{tabular}

RDW 
RPP-RPT-37924 Rev. 0

Cost Estimate

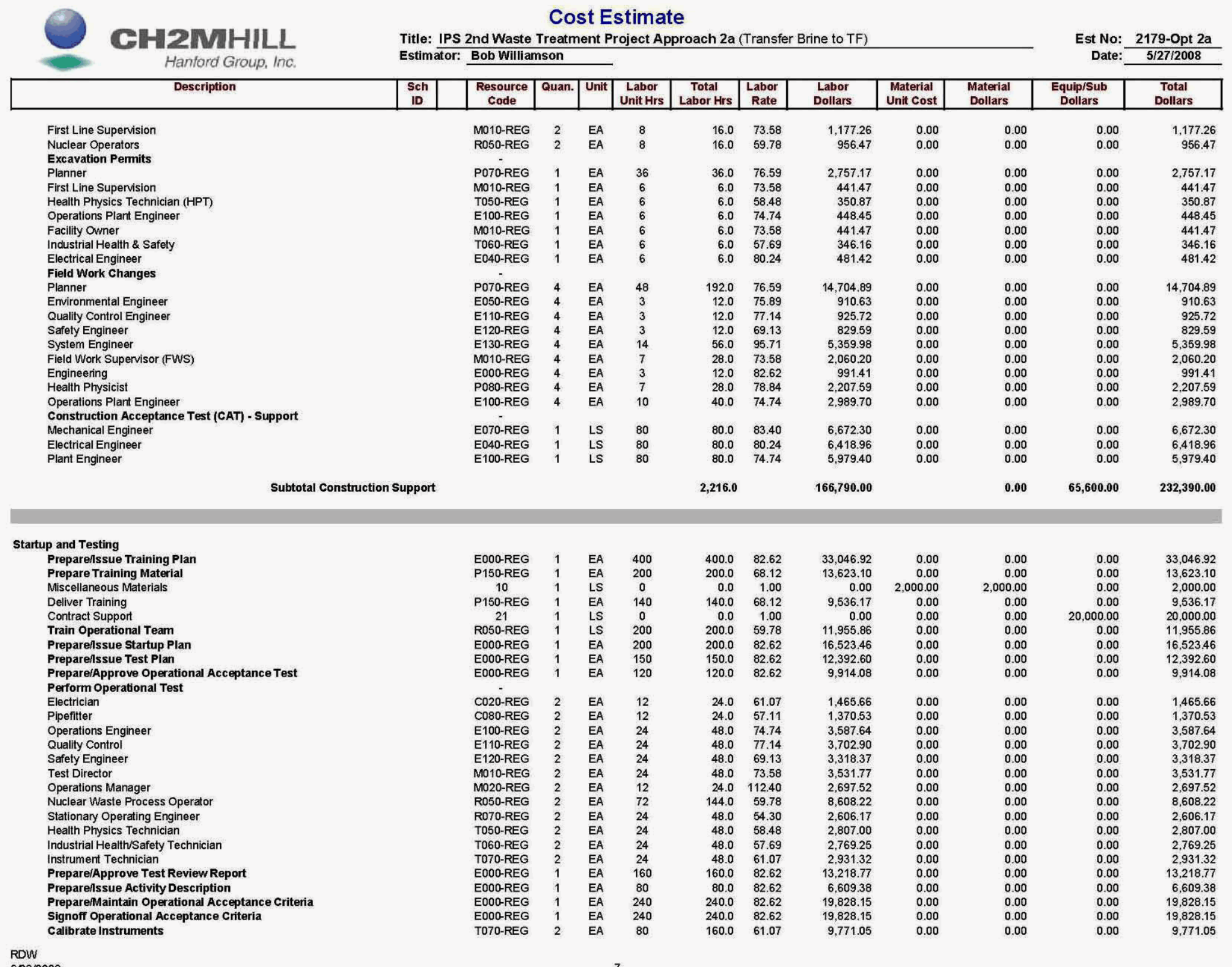


RPP-RPT-37924 Rev. 0

Cost Estimate

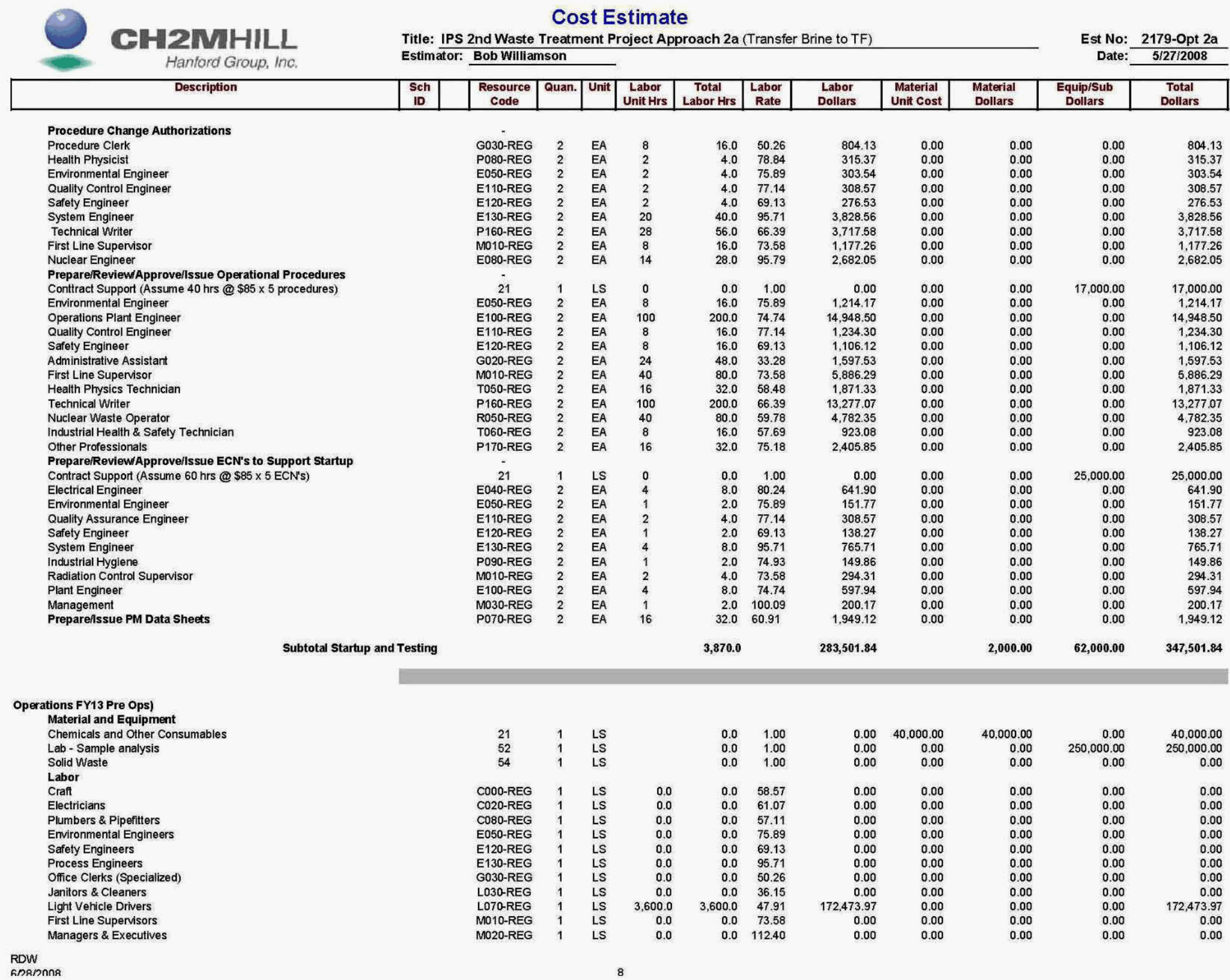


RPP-RPT-37924 Rev. 0

Cost Estimate

Title: IPS 2nd Waste Treatment Project Approach 2a (Transfer Brine to TF)

Est No: 2179-Opt 2a Estimator: Bob Williamson

\begin{tabular}{|c|c|c|c|c|c|c|c|c|c|c|c|c|}
\hline Description & $\begin{array}{l}\text { Sch } \\
\text { ID } \\
\end{array}$ & \begin{tabular}{|c|}
$\begin{array}{c}\text { Resource } \\
\text { Code }\end{array}$ \\
\end{tabular} & Quan. & Unit & \begin{tabular}{|c|} 
Labor \\
Unit Hrs \\
\end{tabular} & \begin{tabular}{c|c|} 
Total \\
Labor Hrs \\
\end{tabular} & \begin{tabular}{|c|} 
Labor \\
Rate \\
\end{tabular} & $\begin{array}{l}\text { Labor } \\
\text { Dollars }\end{array}$ & \begin{tabular}{|l|} 
Material \\
Unit cost \\
\end{tabular} & $\begin{array}{l}\text { Material } \\
\text { Dollars }\end{array}$ & $\begin{array}{c}\text { Equip/Sub } \\
\text { Dollars }\end{array}$ & $\begin{array}{c}\text { Total } \\
\text { Dollars }\end{array}$ \\
\hline Project \& Program Managers & & M030-REG & 1 & LS & 0.0 & 0.0 & 100.09 & 0.00 & 0.00 & 0.00 & 0.00 & 0.00 \\
\hline Planner/Scheduler/Estimators & & P070-REG & 1 & LS & 0.0 & 0.0 & 76.59 & 0.00 & 0.00 & 0.00 & 0.00 & 0.00 \\
\hline Nuclear Waste Process Operator & & R050-REG & 1 & LS & $7,200.0$ & $7,200.0$ & 59.78 & $430,411.09$ & 0.00 & 0.00 & 0.00 & $430,411.09$ \\
\hline Utilities System Operators & & R070-REG & 1 & LS & 0.0 & 0.0 & 54.30 & 0.00 & 0.00 & 0.00 & 0.00 & 0.00 \\
\hline Health Physics Technicians & & TO50-REG & 1 & LS & 0.0 & 0.0 & 58.48 & 0.00 & 0.00 & 0.00 & 0.00 & 0.00 \\
\hline Indust Health/Safety Tech & & T060-REG & 1 & LS & 0.0 & 0.0 & 57.69 & 0.00 & 0.00 & 0.00 & 0.00 & 0.00 \\
\hline Instrument \& Control Tech & & TO70-REG & 1 & LS & 0.0 & 0.0 & 61.07 & 0.00 & 0.00 & 0.00 & 0.00 & 0.00 \\
\hline \multirow{2}{*}{\multicolumn{13}{|c|}{ Operations FY14 }} \\
\hline & & & & & & & & & & & & \\
\hline Chemicals and Other Consumables & & 21 & 1 & LS & & 0.0 & 1.00 & 0.00 & 40.000 .00 & $40,000.00$ & 0.00 & $40,000.00$ \\
\hline Lab - Sample analysis & & 52 & 1 & IS & & 00 & 100 & 000 & 0.00 & 0.00 & $250,000.00$ & 250000.00 \\
\hline Solid Waste & & 54 & 1 & LS & & 0.0 & 1.00 & 0.00 & 0.00 & 0.00 & 0.00 & 0.00 \\
\hline Labor & & & & & & & & & & & & \\
\hline Craft & & COOO-REG & 1 & LS & 0.0 & 0.0 & 58.57 & 0.00 & 0.00 & 0.00 & 0.00 & 0.00 \\
\hline Electricians & & CO20-REG & 1 & LS & 0.0 & 0.0 & 61.07 & 0.00 & 0.00 & 0.00 & 0.00 & 0.00 \\
\hline Plumbers \& Pipefitters & & C080-REG & 1 & LS & 0.0 & 0.0 & 57.11 & 0.00 & 0.00 & 0.00 & 0.00 & 0.00 \\
\hline Emvironmental Engineers & & E050-REG & 1 & LS & 0.0 & 0.0 & 75.89 & 0.00 & 0.00 & 0.00 & 0.00 & 0.00 \\
\hline Safety Engineers & & E120-REG & 1 & LS & 0.0 & 0.0 & 69.13 & 0.00 & 0.00 & 0.00 & 0.00 & 0.00 \\
\hline Process Engineers & & E130-REG & 1 & LS & 0.0 & 0.0 & 95.71 & 0.00 & 0.00 & 0.00 & 0.00 & 0.00 \\
\hline Office Clerks (Specialized) & & G030-REG & 1 & LS & 0.0 & 0.0 & 50.26 & 0.00 & 0.00 & 0.00 & 0.00 & 0.00 \\
\hline Janitors \& Cleaners & & L030-REG & 1 & LS & 0.0 & 0.0 & 36.15 & 0.00 & 0.00 & 0.00 & 0.00 & 0.00 \\
\hline Light Vehicle Drivers & & L070-REG & 1 & LS & $3,600.0$ & $3,600.0$ & 47.91 & $172,473.97$ & 0.00 & 0.00 & 0.00 & $172,473.97$ \\
\hline First Line Supervisors & & MO10-REG & 1 & LS & 0.0 & 0.0 & 73.58 & 0.00 & 0.00 & 0.00 & 0.00 & 0.00 \\
\hline Managers \& Executives & & MO20-REG & 1 & LS & 0.0 & 0.0 & 112.40 & 0.00 & 0.00 & 0.00 & 0.00 & 0.00 \\
\hline Project \& Program Managers & & M030-REG & 1 & LS & 0.0 & 0.0 & 100.09 & 0.00 & 0.00 & 0.00 & 0.00 & 0.00 \\
\hline Planner/Scheduler/Estimators & & P070-REG & 1 & LS & 0.0 & 0.0 & 76.59 & 0.00 & 0.00 & 0.00 & 0.00 & 0.00 \\
\hline Nuclear Waste Process Operator & & R050-REG & 1 & LS & 7.200 .0 & $7,200.0$ & 59.78 & $430,411.09$ & 0.00 & 0.00 & 0.00 & $430,411.09$ \\
\hline Utilitities System Operators & & R070-REG & $i$ & LS & 0.0 & 0.0 & 54.30 & 0.00 & 0.00 & 0.00 & 0.00 & 0.00 \\
\hline Health Physics Technicians & & TO50-REG & 1 & LS & 0.0 & 0.0 & 58.48 & 0.00 & 0.00 & 0.00 & 0.00 & 0.00 \\
\hline Indust Health/Safety Tech & & TO60-REG & 1 & LS & 0.0 & 0.0 & 57.69 & 0.00 & 0.00 & 0.00 & 0.00 & 0.00 \\
\hline Instrument \& Control Tech & & TO70-REG & 1 & LS & 0.0 & 0.0 & 61.07 & 0.00 & 0.00 & 0.00 & 0.00 & 0.00 \\
\hline \multirow{2}{*}{\multicolumn{13}{|c|}{$\begin{array}{l}\text { Operations FY15 } \\
\text { Farial }\end{array}$}} \\
\hline & & & & & & & & & & & & \\
\hline Chemicals and Other Consumables & & 21 & 1 & LS & & 0.0 & 1.00 & 0.00 & $40,000.00$ & $40,000.00$ & 0.00 & $40,000.00$ \\
\hline Lab - Sample analysis & & 52 & 1 & LS & & 0.0 & 1.00 & 0.00 & 0.00 & 0.00 & $250,000.00$ & $250,000.00$ \\
\hline Solid Waste & & 54 & 1 & LS & & 0.0 & 1.00 & 0.00 & 0.00 & 0.00 & 0.00 & 0.00 \\
\hline $\begin{array}{l}\text { Labor } \\
\text { Craft }\end{array}$ & & CMOPREG & 1 & & & & 5857 & - & & 000 & 000 & 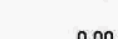 \\
\hline $\begin{array}{l}\text { Craft } \\
\text { Electricians }\end{array}$ & & $\begin{array}{l}\text { COUD-REG } \\
\text { CO20-REG }\end{array}$ & $\frac{1}{1}$ & LS & 0.0 & 0.0 & $\begin{array}{l}58.07 \\
61.07\end{array}$ & 0.00 & 0.00 & 0.00 & 0.00 & 0.00 \\
\hline Plumbers \& Pipefitters & & & 1 & LS & 0.0 & 0.0 & 57.11 & 0.00 & 0.00 & 0.00 & 0.00 & 0.00 \\
\hline Environmental Engineers & & E050-REG & 1 & LS & 0.0 & 0.0 & 75.89 & 0.00 & 0.00 & 0.00 & 0.00 & 0.00 \\
\hline Safety Engineers & & E120-REG & 1 & LS & 0.0 & 0.0 & 69.13 & 0.00 & 0.00 & 0.00 & 0.00 & 0.00 \\
\hline Process Engineers & & E130-REG & 1 & LS & 0.0 & 0.0 & 95.71 & 0.00 & 0.00 & 0.00 & 0.00 & 0.00 \\
\hline Office Clerks (Specialized) & & G030-REG & 1 & LS & 0.0 & 0.0 & 50.26 & 0.00 & 0.00 & 0.00 & 0.00 & 0.00 \\
\hline Janitors \& Cleaners & & L030-REG & 1 & LS & 0.0 & 0.0 & 36.15 & 0.00 & 0.00 & 0.00 & 0.00 & 0.00 \\
\hline Light Vehicle Drivers & & L070-REG & 1 & LS & $3,600.0$ & $3,600.0$ & 47.91 & $172,473.97$ & 0.00 & 0.00 & 0.00 & $172,473.97$ \\
\hline First Line Supervisors & & MO10-REG & 1 & LS & 0.0 & 0.0 & 73.58 & 0.00 & 0.00 & 0.00 & 0.00 & 0.00 \\
\hline Managers \& Executives & & MO20-REG & 1 & LS & 0.0 & 0.0 & 112.40 & 0.00 & 0.00 & 0.00 & 0.00 & 0.00 \\
\hline Project \& Program Managers & & M030-REG & 1 & LS & 0.0 & 0.0 & 100.09 & 0.00 & 0.00 & 0.00 & 0.00 & 0.00 \\
\hline Planner/Scheduler/Estimators & & P070-REG & 1 & LS & 0.0 & 0.0 & 76.59 & 0.00 & 0.00 & 0.00 & 0.00 & 0.00 \\
\hline Nuclear Waste Process Operator & & R050-REG & 1 & LS & $7,200.0$ & $7,200.0$ & 59.78 & $430,411.09$ & 0.00 & 0.00 & 0.00 & $430,411.09$ \\
\hline Utilities System Operators & & R070-REG & 1 & LS & 0.0 & 0.0 & 54.30 & 0.00 & 0.00 & 0.00 & 0.00 & 0.00 \\
\hline Health Physics Technicians & & TO50-REG & 1 & LS & 0.0 & 0.0 & 58.48 & 0.00 & 0.00 & 0.00 & 0.00 & 0.00 \\
\hline Indust Health/Safety Tech & & T060-REG & 1 & LS & 0.0 & 0.0 & 57.69 & 0.00 & 0.00 & 0.00 & 0.00 & 0.00 \\
\hline Instrument \& Control Tech & & T070-REG & 1 & LS & 0.0 & 0.0 & 61.07 & 0.00 & 0.00 & 0.00 & 0.00 & 0.00 \\
\hline
\end{tabular}


RPP-RPT-37924 Rev. 0

\section{Cost Estimate}

Title: IPS 2nd Waste Treatment Project Approach 2a (Transfer Brine to TF)

Est No: 2179-Opt 2a Estimator: Bob Williamson

Date: 5/27/2008

Hanford Group, inc

\begin{tabular}{|c|c|c|c|c|c|c|}
\hline $\begin{array}{c}\text { Sch } \\
\text { ID }\end{array}$ & $\begin{array}{c}\text { Resource } \\
\text { code }\end{array}$ & Quan. & Unit & $\begin{array}{c}\text { Labor } \\
\text { Unit Hrs }\end{array}$ & $\begin{array}{c}\text { Total } \\
\text { Labor HIS }\end{array}$ \\
\hline
\end{tabular}

$\left[\begin{array}{c}\text { Labor } \\ \text { Rate }\end{array}\right]$

Labor
Dollars

Material
Unit Cost

Material

Equip/Sub

Total
Dollars

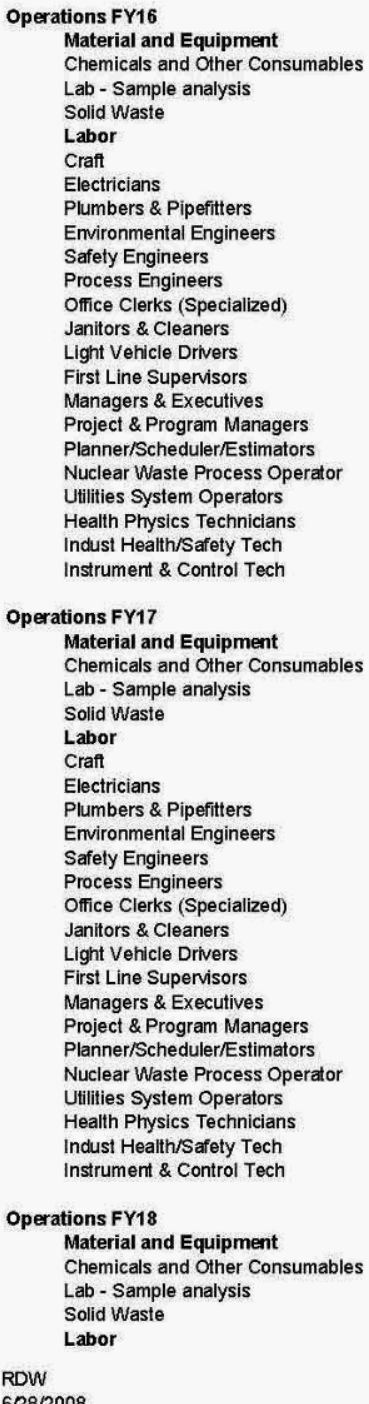

$\begin{array}{ccccrc}21 & 1 & \text { LS } & & 0.0 & 1.00 \\ 52 & 1 & \text { LS } & & 0.0 & 1.00 \\ 54 & 1 & \text { LS } & & 0.0 & 1.00 \\ \text { C000-REG } & 1 & \text { LS } & 0.0 & 0.0 & 58.57 \\ \text { CO20-REG } & 1 & \text { LS } & 0.0 & 0.0 & 61.07 \\ \text { C080-REG } & 1 & \text { LS } & 0.0 & 0.0 & 57.11 \\ \text { E05-REG } & 1 & \text { LS } & 0.0 & 0.0 & 75.89 \\ \text { E120-REG } & 1 & \text { LS } & 0.0 & 0.0 & 69.13 \\ \text { E130-REG } & 1 & \text { LS } & 0.0 & 0.0 & 95.71 \\ \text { G030-REG } & 1 & \text { LS } & 0.0 & 0.0 & 50.26 \\ \text { LO30-REG } & 1 & \text { LS } & 0.0 & 0.0 & 36.15 \\ \text { L070-REG } & 1 & \text { LS } & 3,600.0 & 3,600.0 & 47.91 \\ \text { MO10-REG } & 1 & \text { LS } & 0.0 & 0.0 & 73.58 \\ \text { MO20-REG } & 1 & \text { LS } & 0.0 & 0.0 & 112.40 \\ \text { MO30-REG } & 1 & \text { LS } & 0.0 & 0.0 & 10.09 \\ \text { P070-REG } & 1 & \text { LS } & 0.0 & 0.0 & 76.59 \\ \text { RO50-REG } & 1 & \text { LS } & 7.200 .0 & 7.200 .0 & 59.78 \\ \text { R070-REG } & 1 & \text { LS } & 0.0 & 0.0 & 54.30 \\ \text { TO50-REG } & 1 & \text { LS } & 0.0 & 0.0 & 58.48 \\ \text { TO60-REG } & 1 & \text { LS } & 0.0 & 0.0 & 57.69 \\ \text { TO70-REG } & 1 & \text { LS } & 0.0 & 0.0 & 61.07\end{array}$

$\begin{array}{rr}0.00 & 40,000.00 \\ 0.00 & 0.00 \\ 0.00 & 0.00 \\ & \\ 0.00 & 0.00 \\ 0.00 & 0.00 \\ 0.00 & 0.00 \\ 0.00 & 0.00 \\ 0.00 & 0.00 \\ 0.00 & 0.00 \\ 0.00 & 0.00 \\ 0.00 & 0.00 \\ 172,473.97 & 0.00 \\ 0.00 & 0.00 \\ 0.00 & 0.00 \\ 0.00 & 0.00 \\ 0.00 & 0.00 \\ 430.411 .09 & 0.00 \\ 0.00 & 0.00 \\ 0.00 & 0.00 \\ 0.00 & 0.00 \\ 0.00 & 0.00\end{array}$

$40,000.00$
0.00
0.00
0.00
0.00
0.00
0.00
0.00
0.00
0.00
0.00
0.00
0.00
0.00
0.00
0.00
0.00
0.00
0.00
0.00
0.00

0.00
$250,000.00$

$40,000.00$

$\begin{array}{lllll}21 & 1 & \text { LS } & 0.0 & 1.00\end{array}$

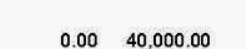

$40,000.00$

0.000 .00

$40,000.00$
$250,000.00$

$\begin{array}{lllll}54 & 1 & \text { LS } & 0.0 & 1.00 \\ 54 & 0.0 & 1.00\end{array}$

$\begin{array}{rr}0.00 & 40,0000 \\ 0.00 & 0.00 \\ 0.00 & 0.00 \\ 0.00 & 0.00\end{array}$

0.00

0.00

0.00

$\begin{array}{llllll}\text { CO0O-REG } & 1 & \text { LS } & 0.0 & 0.0 & 58.57 \\ \text { CO20-REG } & 1 & \text { LS } & 0.0 & 0.0 & 61.07\end{array}$

$\begin{array}{llllll}\text { CO20-REG } & 1 & \text { LS } & 0.0 & 0.0 & 61.07 \\ \text { CO80-REG } & 1 & \text { LS } & 0.0 & 0.0 & 57.11 \\ \text { E050-REG } & 1 & \text { LS } & 0.0 & 0.0 & 75.89\end{array}$

E120-REG

G030-REG

LO30-REG

MO10-REG

MO20-REG

MO30-REG

R050-REG

R070-REG
TO50-REG

TO60-REG

$\begin{array}{ll}0.00 & 0.00 \\ 0.00 & 0.00 \\ 0.00 & 0.00 \\ 0.00 & 0.00\end{array}$

0.00
0.00
0.00

0.00
0.00
0.00
0.00

0.00
0.00

0.00
0.00
0.00

0.00
0.00

0.00

0.00
0.00
0.00
0.00

0.00
0.00
0.00

0.00
0.00

0.00
0.00
0.00

0.00
0.00

0.00

0.00

$\begin{array}{lll}21 & 1 & \text { LS } \\ 52 & 1 & \text { LS } \\ 54 & 1 & \text { LS }\end{array}$

$\begin{array}{ll}0.0 & 1.00 \\ 0.0 & 1.00 \\ 0.0 & 1.00\end{array}$

$\begin{array}{lr}0.00 & 40,000.00 \\ 0.00 & 0.00 \\ 0.00 & 0.00\end{array}$

$40,000.00$
0.00

0.00
$250,000.00$

$40,000.00$
$250,000.00$ 0.00 
RPP-RPT-37924 Rev. 0

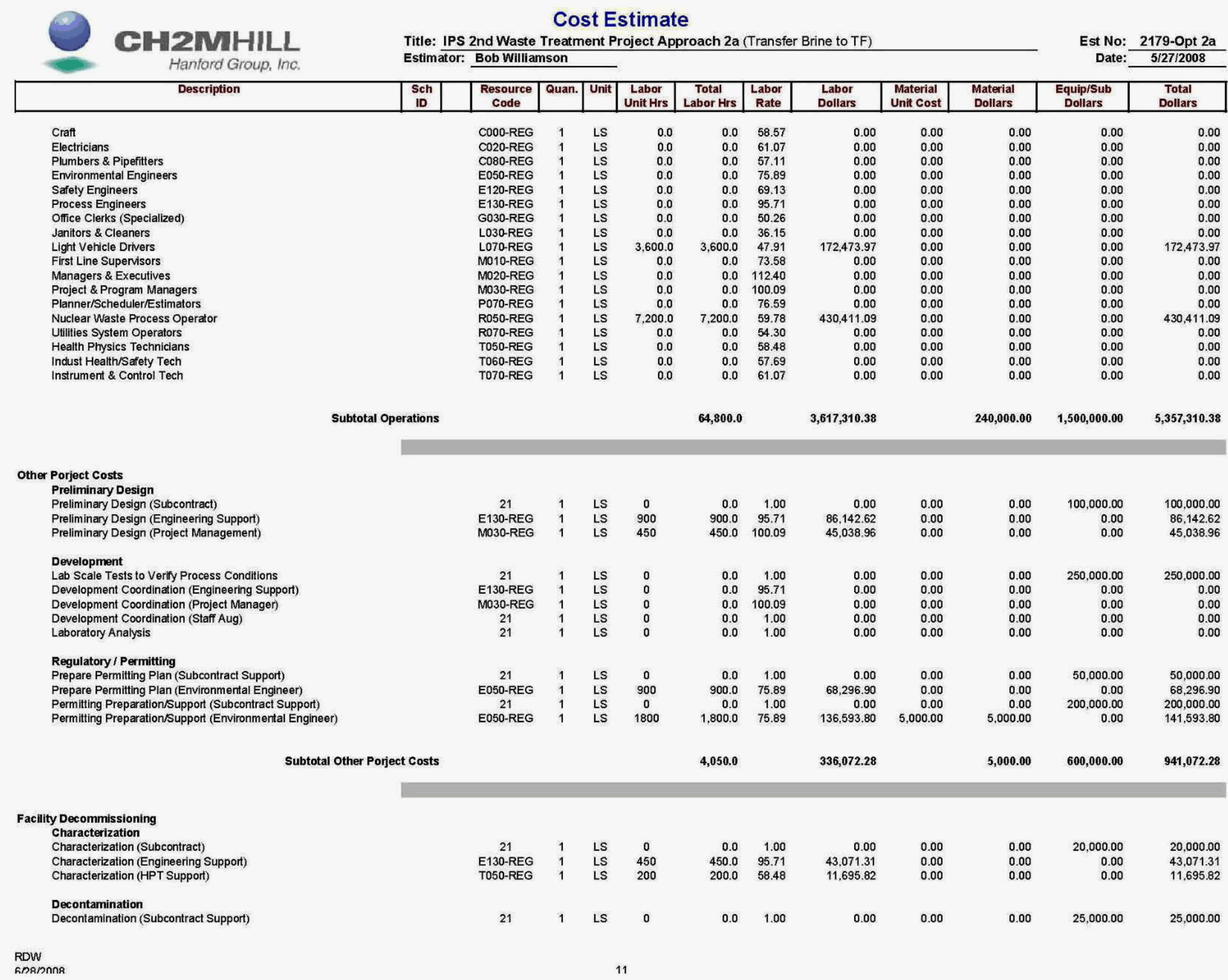


RPP-RPT-37924 Rev. 0

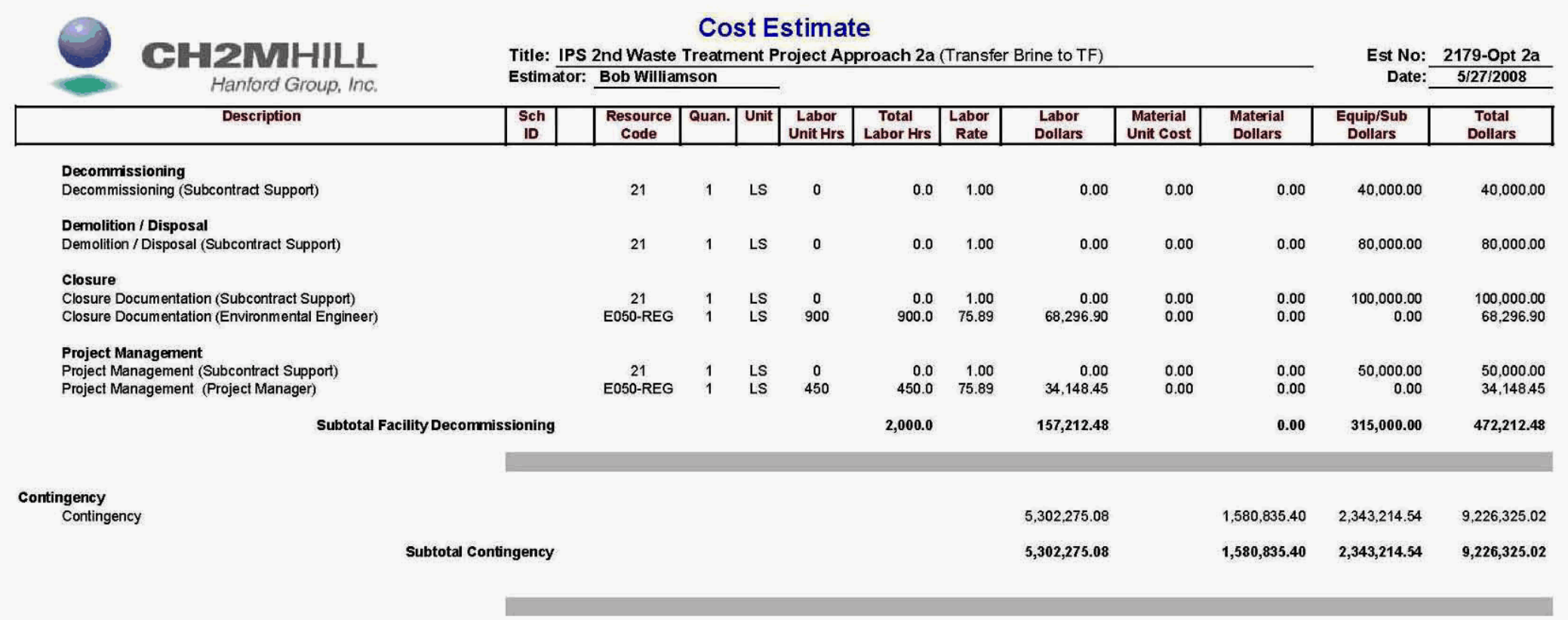


RPP-RPT-37924 Rev. 0

Table G-8. Approach 2 b Cost Estimate.

Table begins on next page. 
RPP-RPT-37924 Rev. 0

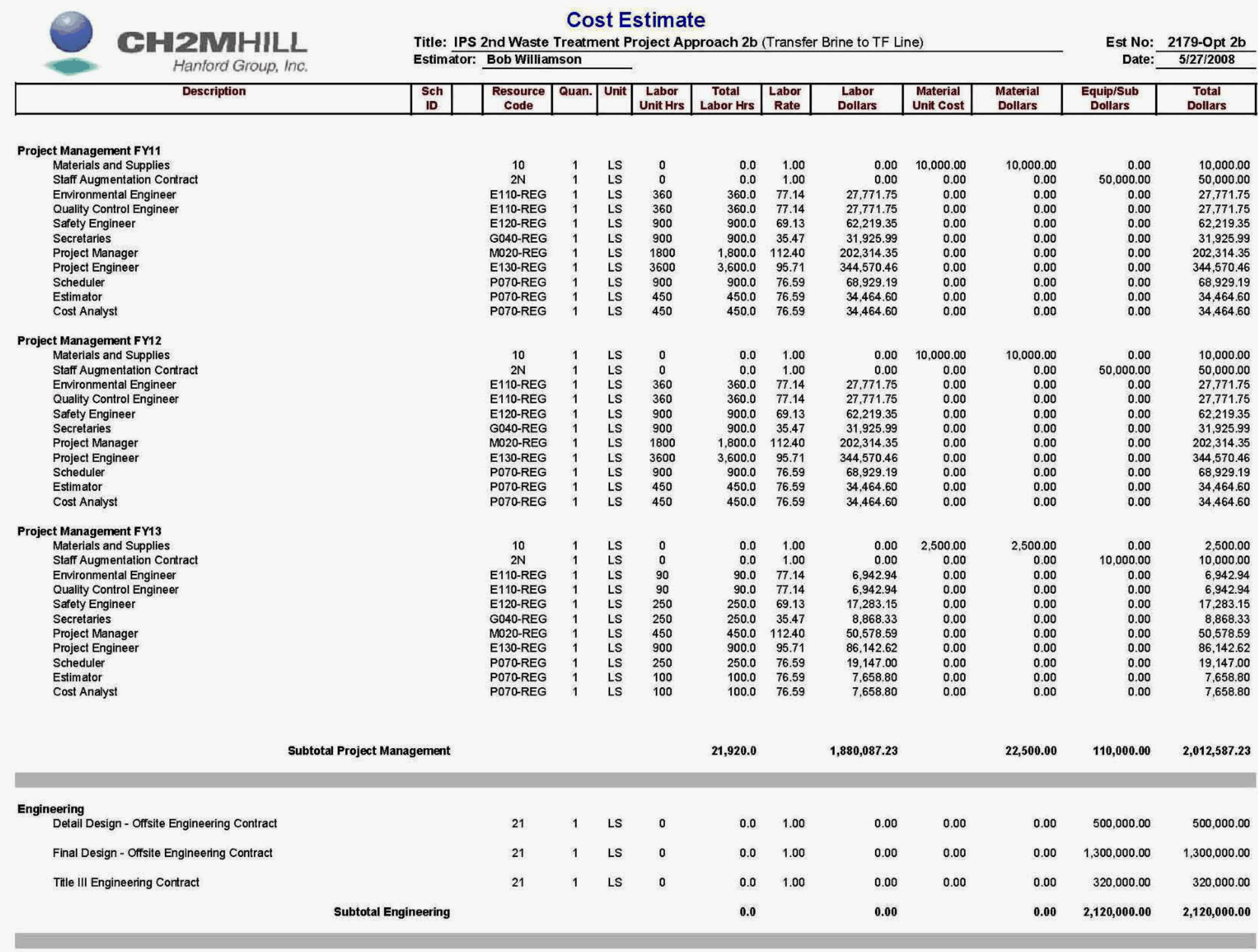


RPP-RPT-37924 Rev. 0

\section{Cost Estimate}

Title: IPS 2nd Waste Treatment Project Approach 2b (Transfer Brine to TF Line)

Est No: 2179-Opt 2b Estimator: Bob Williamson

\begin{tabular}{|c|c|c|c|c|c|c|c|c|c|c|c|}
\hline $\begin{array}{c}\text { Sch } \\
\text { ID }\end{array}$ & $\begin{array}{c}\text { Resource } \\
\text { Code }\end{array}$ & Quan. & Unit & $\begin{array}{c}\text { Labor } \\
\text { Unit Hrs }\end{array}$ & $\begin{array}{c}\text { Total } \\
\text { Labor Hrs }\end{array}$ & $\begin{array}{c}\text { Labor } \\
\text { Rate }\end{array}$ & $\begin{array}{c}\text { Labor } \\
\text { Dollars }\end{array}$ & $\begin{array}{c}\text { Material } \\
\text { Unit Cost }\end{array}$ & $\begin{array}{c}\text { Material } \\
\text { Dollars }\end{array}$ & $\begin{array}{c}\text { Equip/Sub } \\
\text { Dollars }\end{array}$ & $\begin{array}{c}\text { Total } \\
\text { Dollars }\end{array}$ \\
\hline
\end{tabular}

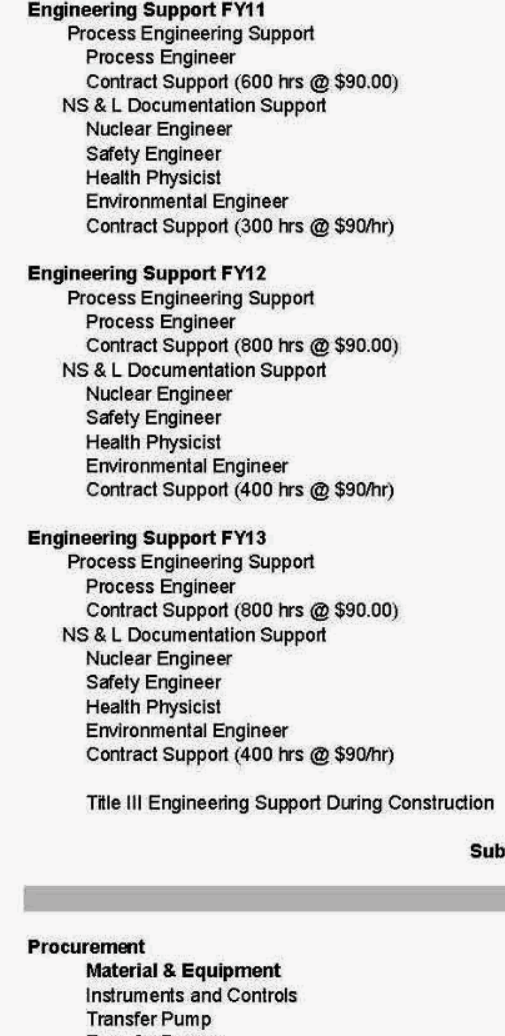

\section{Procurement}

Material \& Equipment

Instruments and
Transfer Pump
Tons

Subtotal Engineering Support

$\begin{array}{cccc}\begin{array}{c}\text { E130-REG } \\ 21\end{array} & 1 & \text { EA } & 3600 \\ \text { E080-REG } & 1 & \text { LS } & 0 \\ \text { E120-REG } & 1 & \text { LS } & 300 \\ \text { P080-REG } & 1 & \text { LS } & 100 \\ \text { E050-REG } & 1 & \text { LS } & 100 \\ 21 & 1 & \text { LS } & 0\end{array}$

$\begin{array}{rr}3,600.0 & 95.71 \\ 0.0 & 1.00 \\ 300.0 & 95.79 \\ 300.0 & 69.13 \\ 100.0 & 78.84 \\ 100.0 & 75.89 \\ 0.0 & 1.00\end{array}$

$\begin{array}{rr}344,570.46 & 5,000.00 \\ 0.00 & 0.00 \\ & \\ 28,736.23 & 0.00 \\ 20,739.78 & 0.00 \\ 7,884.24 & 0.00 \\ 7.588 .54 & 0.00 \\ 0.00 & 0.00\end{array}$

\section{$5,000.00$}

0.00
$15,000.00$

$349,570.46$

$\begin{array}{cccc}\text { E130-REG } & 1 & \text { EA } & 3600 \\ 21 & 1 & \text { LS } & 0\end{array}$

$\begin{array}{rr}3,600.0 & 95.71 \\ 0.0 & 1.00\end{array}$

$\begin{array}{rr}344,570.46 & 5,000.00 \\ 0.00 & 0.00 \\ & \\ 28,736.23 & 0.00 \\ 20.739 .78 & 0.00 \\ 7,884.24 & 0.00 \\ 7,588.54 & 0.00 \\ 0.00 & 0.00\end{array}$

E080-REG

LS 300

D80-REG

$\begin{array}{ll}300.0 & 95.79 \\ 300.0 & 69.13\end{array}$

$\begin{array}{ll}300.0 & 69.13 \\ 100.0 & 78.84\end{array}$

$\begin{array}{rr}100.0 & 78.84 \\ 100.0 & 75.89 \\ 0.0 & 1.00\end{array}$

0.0

0.00

$\begin{array}{cccc}\text { E130-REG } & 1 & \text { EA } & 3600 \\ 21 & 1 & \text { LS } & 0\end{array}$

$3,600.0 \quad 95.71$

$\begin{array}{rr}344,570.46 & 5.000 .00 \\ 0.00 & 0.00\end{array}$

5.000 .00

0.00

$\begin{array}{llllrrrr}\text { EO80-REG } & 1 & \text { LS } & 300 & 300.0 & 95.79 & 28,736.23 & 0.00 \\ \text { E120-REG } & 1 & \text { LS } & 300 & 300.0 & 69.13 & 20.739 .78 & 0.00 \\ \text { P080-REG } & 1 & \text { LS } & 100 & 100.0 & 78.84 & 7.884 .24 & 0.00\end{array}$

$\begin{array}{lllllll}\text { PO80-REG } & 1 & \text { LS } & 100 & 100.0 & 78.84 & 7,884.24 \\ \text { E050-REG } & 1 & \text { LS } & 100 & 100.0 & 75.89 & 7.58 .54\end{array}$

$\begin{array}{cccc}\text { E050-REG } & 1 & \text { LS } & 100 \\ 21 & 1 & \text { LS } & 0\end{array}$

E000-REG 1 LS 1800

$1,377,268.92$

$5,000.00$
0.00
0.00
0.00
0.00
0.00
0.00

5.000 .00
0.00
0.00
0.00
0.00
0.00
0.00

0.00
$72,000.00$

$349,570.46$

$72,000.00$

$\begin{array}{lr}0.00 & 28.736 .23 \\ 0.00 & 20.73978\end{array}$

$0.00 \quad 7.884 .24$

$\begin{array}{rr}0.00 & 7,588.54 \\ 36,000.00 & 36,000.00\end{array}$

$\begin{array}{rr}0.00 & 349,570.46 \\ 72,000.00 & 72,000.00\end{array}$

$\begin{array}{lr}0.00 & 28,736.23 \\ 0.00 & 20.739 .78\end{array}$

$0.00 \quad 7,884.24$

$\begin{array}{rr}0.00 & 7,588.54 \\ 36,000.00 & 36,000.00\end{array}$

$0.00 \quad 148,711.15$

$15,000.00 \quad 236,000.00 \quad 1,628,268.92$

$\begin{array}{cccc}10 & 1 & \text { LS } & 0 \\ 10 & 1 & \text { EA } & 0 \\ 10 & 2 & \text { EA } & 0 \\ & & & \\ 21 & 6000 & \text { If } & 0 \\ 21 & 1 & \text { LS } & 0 \\ 21 & 2 & \text { EA } & 0 \\ 21 & 2 & \text { EA } & 0 \\ 21 & 100 & \text { If } & 0 \\ 21 & 200 & \text { If } & 0 \\ 21 & 100 & \text { If } & 0 \\ 21 & 100 & \text { If } & 0 \\ 21 & 100 & \text { If } & 0\end{array}$

$\begin{array}{ll}0.0 & 1.00 \\ 0.0 & 1.00 \\ 0.0 & 1.00 \\ & \\ 0.0 & 1.00 \\ 0.0 & 1.00 \\ 0.0 & 1.00 \\ 0.0 & 1.00 \\ 0.0 & 1.00 \\ 0.0 & 1.00 \\ 0.0 & 1.00 \\ 0.0 & 1.00 \\ 0.0 & 1.00\end{array}$

$\begin{array}{rrr}0.00 & 100,000.00 & 100,000.00 \\ 0.00 & 150,000.00 & 150,000.00 \\ 0.00 & 25,000.00 & 50,000.00 \\ & & \\ & & \\ 0.00 & 450.00 & 2,700,000.00 \\ 0.00 & 500,000.00 & 500,000.00 \\ 0.00 & 190,000.00 & 380,000.00 \\ 0.00 & 50,000.00 & 100,000.00 \\ 0.00 & 75.00 & 7,500.00 \\ 0.00 & 400.00 & 80,000.00 \\ 0.00 & 600.00 & 60,000.00 \\ 0.00 & 500.00 & 50,000.00 \\ 0.00 & 20.00 & 2,000.00\end{array}$

$\begin{array}{lr}0.00 & 100,000.00 \\ 0.00 & 150,000.00 \\ 0.00 & 50,000.00 \\ & \\ & \\ 0.00 & 2,700,000.00 \\ 0.00 & 500,000.00 \\ 0.00 & 380,000.00 \\ 0.00 & 100,000.00 \\ 0.00 & 7,500.00 \\ 0.00 & 80,000.00 \\ 0.00 & 60,000.00 \\ 0.00 & 50,000.00 \\ 0.00 & 2,000.00\end{array}$

RDW 
RPP-RPT-37924 Rev. 0

\section{Cost Estimate}

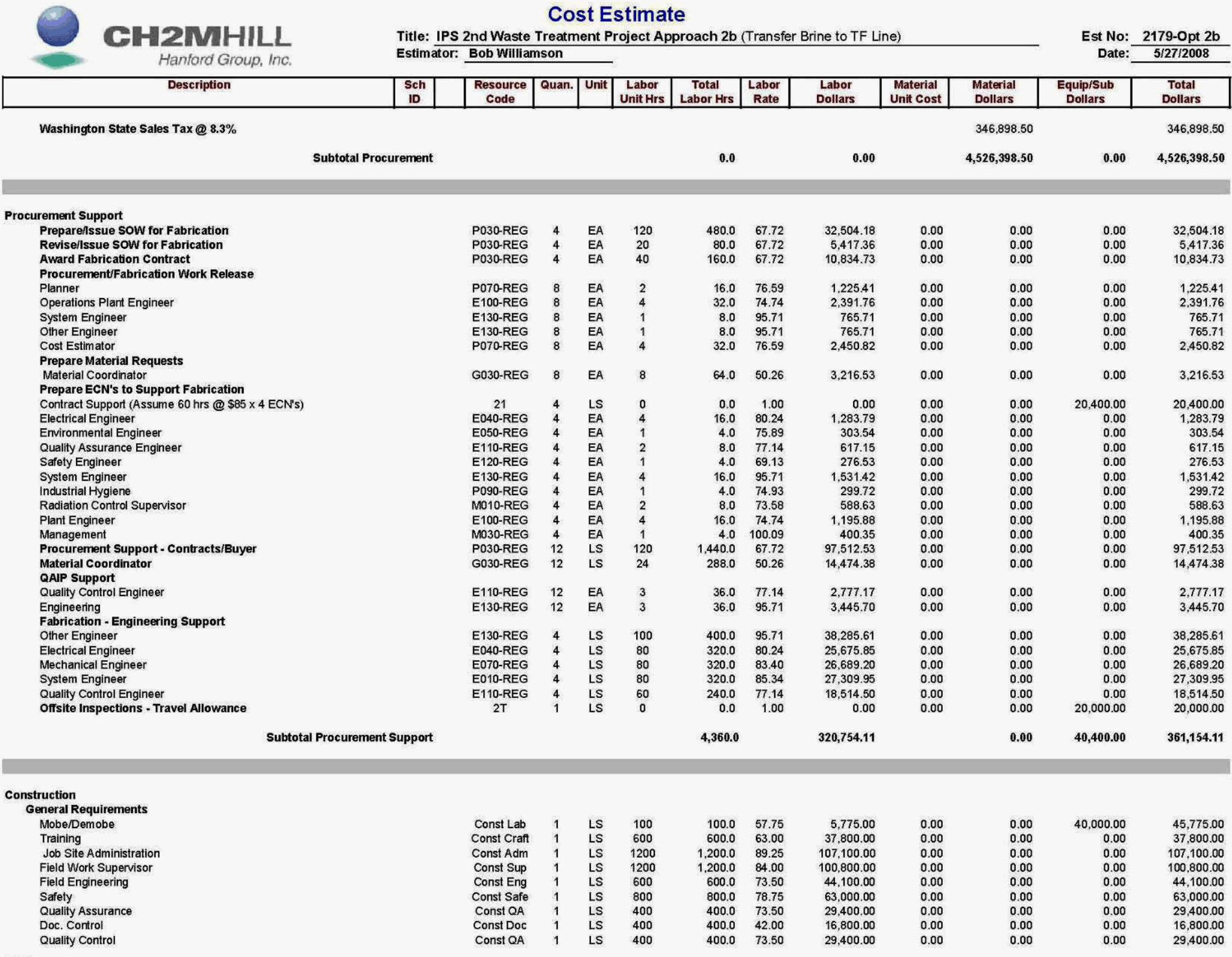


RPP-RPT-37924 Rev. 0

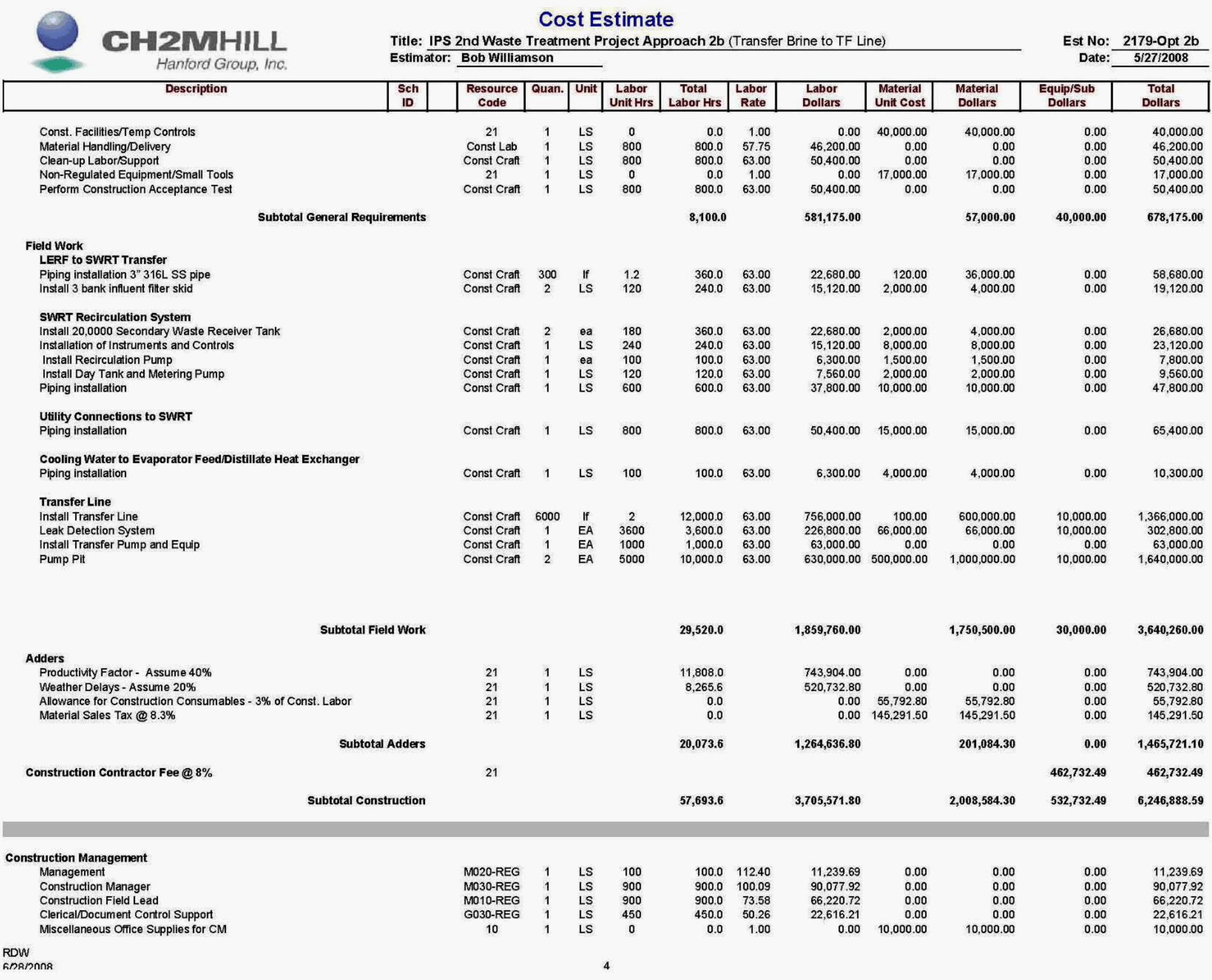


RPP-RPT-37924 Rev. 0

Cost Estimate

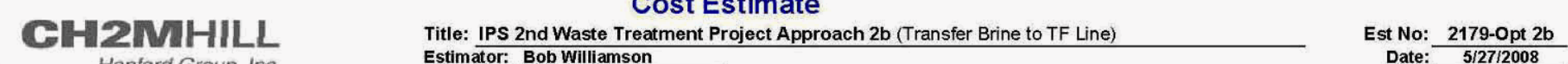

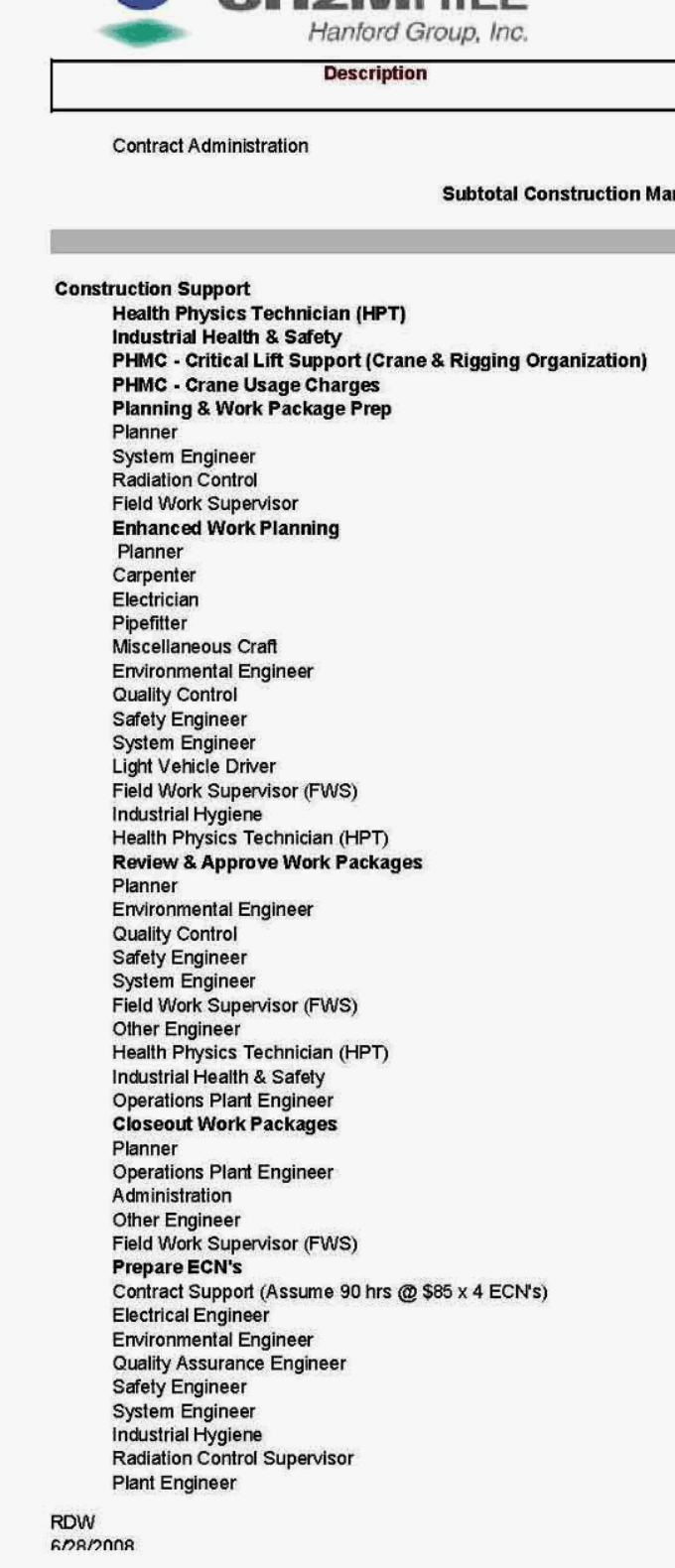

\begin{tabular}{|c|c|c|c|c|c|c|c|c|c|c|c|}
\hline $\begin{array}{c}\text { Sch } \\
\text { ID }\end{array}$ & $\begin{array}{c}\text { Resource } \\
\text { Code }\end{array}$ & Quan. & Unit & $\begin{array}{c}\text { Labor } \\
\text { Unit Hrs }\end{array}$ & $\begin{array}{c}\text { Total } \\
\text { Labor Hrs }\end{array}$ & $\begin{array}{c}\text { Labor } \\
\text { Rate }\end{array}$ & $\begin{array}{c}\text { Labor } \\
\text { Dollars }\end{array}$ & $\begin{array}{c}\text { Material } \\
\text { Unit Cost }\end{array}$ & $\begin{array}{c}\text { Material } \\
\text { Dollars }\end{array}$ & $\begin{array}{c}\text { Equip/Sub } \\
\text { Dollars }\end{array}$ & $\begin{array}{c}\text { Total } \\
\text { Dollars }\end{array}$ \\
\hline
\end{tabular}

\begin{tabular}{|c|c|c|c|c|c|c|c|c|c|c|}
\hline T050-REG & 1 & LS & 200 & 200.0 & 58.48 & $11,695.82$ & 0.00 & 0.00 & 0.00 & $11,695.82$ \\
\hline T060-REG & 1 & LS & 100 & 100.0 & 57.69 & $5,769.27$ & 0.00 & 0.00 & 0.00 & $5,769.27$ \\
\hline $3 \mathrm{P}$ & 1 & LS & 0 & 0.0 & 1.00 & 0.00 & 0.00 & 0.00 & $20,000.00$ & $20,000.00$ \\
\hline $3 P$ & 1 & LS & 0 & 0.0 & 1.00 & 0.00 & 0.00 & 0.00 & $10,000.00$ & $10,000.00$ \\
\hline P070-REG & 5 & $E A$ & 112 & 560.0 & 76.59 & $42,889.27$ & 0.00 & 0.00 & 0.00 & $42,889.27$ \\
\hline E130-REG & 5 & EA & 20 & 100.0 & 95.71 & $9,571.40$ & 0.00 & 0.00 & 0.00 & $9,571.40$ \\
\hline P090-REG & 5 & EA & 20 & 100.0 & 74.93 & $7,493.12$ & 0.00 & 0.00 & 0.00 & $7,493.12$ \\
\hline M010-REG & 5 & EA & 20 & 100.0 & 73.58 & $7,357.86$ & 0.00 & 0.00 & 0.00 & $7,357.86$ \\
\hline P070-REG & 5 & $E A$ & 3 & 15.0 & 76.59 & $1,148.82$ & 0.00 & 0.00 & 0.00 & $1,148.82$ \\
\hline C010-REG & 5 & $E A$ & 3 & 15.0 & 55.84 & 837.55 & 0.00 & 0.00 & 0.00 & 837.55 \\
\hline C020-REG & 5 & EA & 3 & 15.0 & 61.07 & 916.04 & 0.00 & 0.00 & 0.00 & 916.04 \\
\hline C080-REG & 5 & $E A$ & 3 & 15.0 & 57.11 & 856.58 & 0.00 & 0.00 & 0.00 & 856.58 \\
\hline C120-REG & 5 & EA & 3 & 15.0 & 56.94 & 854.07 & 0.00 & 0.00 & 0.00 & 854.07 \\
\hline E050-REG & 5 & EA & 3 & 15.0 & 75.89 & $1,138.28$ & 0.00 & 0.00 & 0.00 & $1,138.28$ \\
\hline E110-REG & 5 & EA & 3 & 15.0 & 77.14 & $1,157.16$ & 0.00 & 0.00 & 0.00 & $1,157.16$ \\
\hline E120-REG & 5 & $E A$ & 3 & 15.0 & 69.13 & $1,036.99$ & 0.00 & 0.00 & 0.00 & $1,036.99$ \\
\hline E130-REG & 5 & EA & 3 & 15.0 & 95.71 & $1,435.71$ & 0.00 & 0.00 & 0.00 & $1,435.71$ \\
\hline L070-REG & 5 & EA & 3 & 15.0 & 47.91 & 718.64 & 0.00 & 0.00 & 0.00 & 718.64 \\
\hline MO10-REG & 5 & EA & 3 & 15.0 & 73.58 & $1,103.68$ & 0.00 & 0.00 & 0.00 & $1,103.68$ \\
\hline P090-REG & 5 & EA & 3 & 15.0 & 74.93 & $1,123.97$ & 0.00 & 0.00 & 0.00 & $1,123.97$ \\
\hline T050-REG & 5 & $E A$ & 3 & 15.0 & 58.48 & 877.19 & 0.00 & 0.00 & 0.00 & 877.19 \\
\hline P070-REG & 5 & EA & 28 & 140.0 & 76.59 & $10,722.32$ & 0.00 & 0.00 & 0.00 & $10,722.32$ \\
\hline E050-REG & 5 & EA & 5 & 25.0 & 75.89 & $1,897.14$ & 0.00 & 0.00 & 0.00 & $1,897.14$ \\
\hline E110-REG & 5 & EA & 5 & 25.0 & 77.14 & $1,928.59$ & 0.00 & 0.00 & 0.00 & $1,928.59$ \\
\hline E120-REG & 5 & $E A$ & 5 & 25.0 & 69.13 & $1,728.32$ & 0.00 & 0.00 & 0.00 & $1,728.32$ \\
\hline E130-REG & 5 & EA & 10 & 50.0 & 95.71 & $4,785.70$ & 0.00 & 0.00 & 0.00 & 4.785 .70 \\
\hline MO10-REG & 5 & EA & 5 & 25.0 & 73.58 & $1,839.46$ & 0.00 & 0.00 & 0.00 & $1,839.46$ \\
\hline E130-REG & 5 & EA & 5 & 25.0 & 95.71 & $2,392.85$ & 0.00 & 0.00 & 0.00 & $2,392.85$ \\
\hline TO50-REG & 5 & EA & 5 & 25.0 & 58.48 & $1,461.98$ & 0.00 & 0.00 & 0.00 & $1,461.98$ \\
\hline T060-REG & 5 & $E A$ & 5 & 25.0 & 57.69 & $1,442.32$ & 0.00 & 0.00 & 0.00 & $1,442.32$ \\
\hline E100-REG & 5 & $\mathrm{EA}$ & 25 & 125.0 & 74.74 & $9,342.81$ & 0.00 & 0.00 & 0.00 & $9,342.81$ \\
\hline P070-REG & 5 & $E A$ & 12 & 60.0 & 76.59 & $4,595.28$ & 0.00 & 0.00 & 0.00 & $4,595.28$ \\
\hline E100-REG & 5 & EA & 4 & 20.0 & 74.74 & $1,494.85$ & 0.00 & 0.00 & 0.00 & $1,494.85$ \\
\hline G020-REG & 5 & $E A$ & 2 & 10.0 & 33.28 & 332.82 & 0.00 & 0.00 & 0.00 & 332.82 \\
\hline E130-REG & 5 & EA & 4 & 20.0 & 95.71 & $1,914.28$ & 0.00 & 0.00 & 0.00 & $1,914.28$ \\
\hline MO10-REG & 5 & EA & 2 & 10.0 & 73.58 & 735.79 & 0.00 & 0.00 & 0.00 & 735.79 \\
\hline 21 & 1 & LS & 0 & 0.0 & 1.00 & 0.00 & 0.00 & 0.00 & $30,600.00$ & $30,600.00$ \\
\hline E040-REG & 5 & EA & 4 & 20.0 & 80.24 & $1,604.74$ & 0.00 & 0.00 & 0.00 & $1,604.74$ \\
\hline E050-REG & 5 & $E A$ & 1 & 5.0 & 75.89 & 379.43 & 0.00 & 0.00 & 0.00 & 379.43 \\
\hline E110-REG & 5 & $E A$ & 2 & 10.0 & 77.14 & 771.44 & 0.00 & 0.00 & 0.00 & 771.44 \\
\hline E120-REG & 5 & EA & 1 & 5.0 & 69.13 & 345.66 & 0.00 & 0.00 & 0.00 & 345.66 \\
\hline E130-REG & 5 & EA & 4 & 20.0 & 95.71 & $1,914.28$ & 0.00 & 0.00 & 0.00 & $1,914.28$ \\
\hline PO90-REG & 5 & EA & 1 & 5.0 & 74.93 & 374.66 & 0.00 & 0.00 & 0.00 & 374.66 \\
\hline MO10-REG & 5 & EA & 2 & 10.0 & 73.58 & 735.79 & 0.00 & 0.00 & 0.00 & 735.79 \\
\hline E100-REG & 5 & EA & 4 & 20.0 & 74.74 & $1,494.85$ & 0.00 & 0.00 & 0.00 & $1,494.85$ \\
\hline
\end{tabular}


RPP-RPT-37924 Rev. 0

\begin{tabular}{|c|c|c|c|c|c|c|c|c|c|c|c|c|}
\hline \multirow{2}{*}{$\begin{array}{c}\text { CHI2WMHLL } \\
\text { Hanford Group, Inc. } \\
\text { Description } \\
\end{array}$} & \multicolumn{10}{|c|}{$\begin{array}{l}\text { Cost Estimate } \\
\text { Title: IPS 2nd Waste Treatment Project Approach 2b (Transfer Brine to TF Line) } \\
\text { Estimator: Bob Williamson }\end{array}$} & \multicolumn{2}{|c|}{$\begin{array}{rlrl}\text { Est No: } & 2179-\text { Opt 2b } \\
\text { Date: } & 5 / 27 / 2008 \\
\end{array}$} \\
\hline & $\begin{array}{l}\text { Sch } \\
\text { ID }\end{array}$ & \begin{tabular}{|c|}
$\begin{array}{c}\text { Resource } \\
\text { code }\end{array}$ \\
\end{tabular} & Quan. & Unit & \begin{tabular}{|l} 
Labor \\
Unit Hrs \\
\end{tabular} & \begin{tabular}{|l|} 
Total \\
Labor Hrs \\
\end{tabular} & \begin{tabular}{|c|} 
Labor \\
Rate \\
\end{tabular} & $\begin{array}{l}\text { Labor } \\
\text { Dollars } \\
\end{array}$ & \begin{tabular}{|l|} 
Material \\
Unit cost \\
\end{tabular} & $\begin{array}{l}\text { Material } \\
\text { Dollars }\end{array}$ & $\begin{array}{c}\begin{array}{c}\text { Equip/Sub } \\
\text { Dollars }\end{array} \\
\end{array}$ & $\begin{array}{l}\text { Total } \\
\text { Dollars }\end{array}$ \\
\hline $\begin{array}{l}\text { Management } \\
\text { Prepare USQ's }\end{array}$ & & MO30-REG & 5 & EA & 1 & 5.0 & 100.09 & 500.43 & 0.00 & 0.00 & 0.00 & 500.43 \\
\hline $\begin{array}{l}\text { Other Engineers } \\
\text { Review Engineers } \\
\text { Radiation Work Permit }\end{array}$ & & $\begin{array}{l}\text { E130-REG } \\
\text { E130-REG }\end{array}$ & $\begin{array}{l}5 \\
5\end{array}$ & $\begin{array}{l}E A \\
E A\end{array}$ & $\stackrel{28}{9}$ & $\begin{array}{r}140.0 \\
45.0\end{array}$ & $\begin{array}{l}95.71 \\
95.71\end{array}$ & $\begin{array}{l}13,399.96 \\
4,307.13\end{array}$ & $\begin{array}{l}0.00 \\
0.00\end{array}$ & $\begin{array}{l}0.00 \\
0.00\end{array}$ & $\begin{array}{l}0.00 \\
0.00\end{array}$ & $\begin{array}{r}13,399.96 \\
4,307.13\end{array}$ \\
\hline \multirow{2}{*}{\multicolumn{2}{|c|}{$\begin{array}{l}\text { Planner } \\
\text { Electrician }\end{array}$}} & PO70-REG & 1 & EA & 14 & 14.0 & 76.59 & $1,072.23$ & 0.00 & 0.00 & 0.00 & $1,072.23$ \\
\hline & & $\begin{array}{l}\text { Co20-REG } \\
\text { E040REG }\end{array}$ & $i_{1}^{1}$ & $\begin{array}{l}E A \\
E A\end{array}$ & 2 & $\begin{array}{l}2.0 \\
2.0\end{array}$ & $\begin{array}{l}61.07 \\
80.24\end{array}$ & $\begin{array}{l}122.14 \\
160.47\end{array}-2$ & $\begin{array}{l}0.00 \\
0.00\end{array}$ & $\begin{array}{l}0.00 \\
0.00\end{array}$ & $\begin{array}{l}0.00 \\
0.00\end{array}$ & 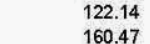 \\
\hline \multicolumn{2}{|l|}{$\begin{array}{l}\text { Electrical Engineer } \\
\text { Emvironmental Engineer }\end{array}$} & EO50-REG & 1 & $E A$ & 5 & 5.0 & 75.89 & $\begin{array}{l}160.41 \\
379.43\end{array}$ & 0.00 & 0.00 & 0.00 & $\begin{array}{l}7100.49 \\
379.43\end{array}$ \\
\hline \multirow{2}{*}{\multicolumn{2}{|c|}{$\begin{array}{l}\text { Operations Plant Engineer } \\
\text { Safety Engineer }\end{array}$}} & E100-REG & 1 & EA & 2 & 2.0 & 74.74 & $\begin{array}{l}149.48 \\
12027\end{array}$ & 0.00 & 0.00 & 0.00 & 149.48 \\
\hline \multirow{2}{*}{\multicolumn{2}{|c|}{$\begin{array}{l}\text { System Engineer } \\
\text { Field Work Superisor (FWS) }\end{array}$}} & $\begin{array}{l}\text { E120-REG } \\
\text { E130-REG }\end{array}$ & 1 & $\begin{array}{c}E A \\
E A\end{array}$ & $\frac{2}{5}$ & $\begin{array}{l}2.0 \\
5.0\end{array}$ & $\begin{array}{l}69.13 \\
95.71\end{array}$ & $\begin{array}{l}138.27 \\
47857\end{array}$ & 0.00 & 0.00 & 0.00 & $\begin{array}{l}138.27 \\
478.57\end{array}$ \\
\hline & & $\begin{array}{l}\text { E130-REG } \\
\text { E100-REG }\end{array}$ & $\frac{1}{1}$ & $\begin{array}{l}E A \\
E A\end{array}$ & $\begin{array}{l}5 \\
5\end{array}$ & 5.0 & 74.74 & $\begin{array}{l}4 / 8.5 f \\
373.71\end{array}$ & 0.00 & 0.00 & 0.00 & $\begin{array}{l}\begin{array}{l}478.57 \\
373.71\end{array}-10 \\
0\end{array}$ \\
\hline \multirow{2}{*}{\multicolumn{2}{|c|}{$\begin{array}{l}\text { Health Physics Technician (HPT) } \\
\text { Industrial Health \& Safety }\end{array}$}} & TO50-REG & 1 & $E A$ & 5 & 5.0 & $\begin{array}{l}74.44 \\
58.48\end{array}$ & 292.40 & 0.00 & 0.00 & 0.00 & 292.40 \\
\hline & & TO60-REG & 1 & EA & 2 & 2.0 & 57.69 & 115.39 & 0.00 & 0.00 & 0.00 & 115.39 \\
\hline \multicolumn{2}{|l|}{$\begin{array}{l}\text { Material Requests } \\
\text { Material Coordinator }\end{array}$} & G030-REG & 1 & EA & 4 & 4.0 & 50.26 & 201.03 & 0.00 & 0.00 & 0.00 & 201.03 \\
\hline \multicolumn{2}{|l|}{$\begin{array}{l}\text { Pre Job Briefings } \\
\text { Other Engineers } \\
\text { Administration }\end{array}$} & $\begin{array}{l}\text { E130-REG } \\
\text { G020-REG }\end{array}$ & $\begin{array}{l}200 \\
200\end{array}$ & $\begin{array}{l}\mathrm{Hr} \\
\mathrm{Hr}\end{array}$ & $\begin{array}{l}1 \\
1\end{array}$ & $\begin{array}{l}200.0 \\
200.0\end{array}$ & $\begin{array}{l}95.71 \\
33.28\end{array}$ & $\begin{array}{r}19.142 .80 \\
655636\end{array}$ & $\begin{array}{l}0.00 \\
0.00\end{array}$ & $\begin{array}{l}0.00 \\
0.00\end{array}$ & $\begin{array}{l}0.00 \\
0.00\end{array}$ & $\begin{array}{l}19,142.80 \\
6.656 .36\end{array}$ \\
\hline \multicolumn{2}{|l|}{$\begin{array}{l}\text { Management } \\
\text { Post Job Alara Review }\end{array}$} & MO10-REG & 200 & $\mathrm{Hr}$ & 1 & 200.0 & $\begin{array}{l}73.58 \\
73.58\end{array}$ & $\begin{array}{l}14,715.72 \\
19.50\end{array}$ & 0.00 & 0.00 & 0.00 & $\begin{aligned} 14.715 .72 \\
\end{aligned}$ \\
\hline & P070-REG & 1 & EA & 2 & 2.0 & 76.59 & 153.18 & 0.00 & 0.00 & 0.00 & 153.18 \\
\hline & & CO20-REG & 1 & EA & 4 & 4.0 & 61.07 & 244.28 & 0.00 & - & 0.00 & 244.28 \\
\hline \multicolumn{2}{|l|}{$\begin{array}{l}\text { Electrician } \\
\text { Electrical Engineer } \\
\text { Evwironmental Engineer }\end{array}$} & $\begin{array}{l}\text { E040-REG } \\
\text { E050REG }\end{array}$ & $\begin{array}{l}1 \\
1\end{array}$ & $\begin{array}{c}E A \\
E A\end{array}$ & ${ }_{1}^{2}$ & $\begin{array}{l}2.0 \\
1.0\end{array}$ & $\begin{array}{l}80.24 \\
75.89\end{array}$ & $\begin{array}{r}160.47 \\
75.89\end{array}$ & $\begin{array}{l}0.00 \\
0.00\end{array}$ & $\begin{array}{l}0.00 \\
0.00\end{array}$ & $\begin{array}{l}0.00 \\
0.00\end{array}$ & $\begin{array}{l}160.47 \\
77.89\end{array}$ \\
\hline \multicolumn{2}{|l|}{ System Engineer } & $\begin{array}{l}\text { E130-REG } \\
\text { E130 }\end{array}$ & 1 & EA & 2 & 2.0 & 95.71 & 191.43 & 0.00 & 0.00 & 0.00 & 191.43 \\
\hline \multicolumn{2}{|l|}{$\begin{array}{l}\text { Other Engineers } \\
\text { Administration }\end{array}$} & $\begin{array}{l}\text { E130-REG } \\
\text { GP00-RFG }\end{array}$ & 1 & $\begin{array}{c}E A \\
E A\end{array}$ & 2 & 2.0 & $\begin{array}{l}95.71 \\
3328\end{array}$ & $\begin{array}{r}191.43 \\
6656\end{array}$ & 0.00 & 0. & 0.00 & $\begin{array}{r}191.43 \\
6656\end{array}$ \\
\hline \multicolumn{2}{|l|}{$\begin{array}{l}\text { First Line Supenisision } \\
\text { artund SSannion }\end{array}$} & $\begin{array}{l}\text { G020-REG } \\
\text { MO10-REG }\end{array}$ & 1 & $\begin{array}{l}E A \\
E A\end{array}$ & ${ }_{1}^{2}$ & $\begin{array}{l}2.0 \\
1.0\end{array}$ & $\begin{array}{l}33.28 \\
73.58\end{array}$ & $\begin{array}{l}6.6 .56 \\
73.58\end{array}$ & $\begin{array}{l}0.00 \\
0.00\end{array}$ & $\begin{array}{l}0.00 \\
0.00\end{array}$ & $\begin{array}{l}0.00 \\
0.00\end{array}$ & $\begin{array}{l}66.56 \\
73.58\end{array}$ \\
\hline & E020-REG & & EA & 6 & 12.0 & 85.21 & $1,022.49$ & 0.00 & 0.00 & 0.00 & $1,022.49$ \\
\hline & $\begin{array}{l}\text { Other Engineers } \\
\text { First Line Supenision }\end{array}$ & E130-REG & 2 & EA & 54 & 108.0 & 95.71 & 10,337.11 & 0.00 & & 0.00 & 10,337.11 \\
\hline \multicolumn{2}{|l|}{$\begin{array}{l}\text { Perform Ground Scanning - (Contract) } \\
\text { TSR Matrix }\end{array}$} & $\begin{array}{l}\text { Mo10-REG } \\
21\end{array}$ & $\begin{array}{l}2 \\
1\end{array}$ & $\begin{array}{l}\text { EA } \\
\text { LS }\end{array}$ & $\begin{array}{l}4 \\
0\end{array}$ & $\begin{array}{l}8.0 \\
0.0\end{array}$ & $\begin{array}{r}73.58 \\
1.00\end{array}$ & $\begin{array}{r}588.63 \\
0.00\end{array}$ & $\begin{array}{l}0.00 \\
0.00\end{array}$ & $\begin{array}{l}0.00 \\
0.00\end{array}$ & $\begin{array}{r}0.00 \\
5,000.00\end{array}$ & $\begin{array}{r}588.63 \\
5,000.00\end{array}$ \\
\hline \multirow{2}{*}{$\begin{array}{l}\text { Planner } \\
\text { System Engineer } \\
\text { LockTagouts }\end{array}$} & & POTO-REG & 1 & EA & 6 & $\begin{array}{l}6.0 \\
6.0\end{array}$ & 76.59 & $\begin{array}{l}459.53 \\
574.28\end{array}$ & $\begin{array}{l}0.00 \\
0.00\end{array}$ & 0.00 & 0.00 & 459.53 \\
\hline & & & & & & & & & & & & \\
\hline $\begin{array}{l}\text { Pipefititer } \\
\text { First Lin Supenision } \\
\text { Nuclear Operators }\end{array}$ & & $\begin{array}{l}\text { Co80-REG } \\
\text { MO10-REG } \\
\text { Ro50-REG }\end{array}$ & $\begin{array}{l}2 \\
2 \\
2\end{array}$ & $\begin{array}{l}E A \\
E A \\
E A\end{array}$ & $\begin{array}{l}8 \\
8 \\
8\end{array}$ & $\begin{array}{l}\begin{array}{l}16.0 \\
16.0 \\
16.0\end{array} \\
16.0\end{array}$ & $\begin{array}{l}57.11 \\
73.58 \\
59.78\end{array}$ & $\begin{array}{l}913.69 \\
1,177.26 \\
956.47\end{array}$ & $\begin{array}{l}0.00 \\
0.00 \\
0.00\end{array}$ & $\begin{array}{l}0.00 \\
0.00 \\
0.00\end{array}$ & $\begin{array}{l}0.00 \\
0.00 \\
0.00\end{array}$ & $\begin{array}{r}9931.69 \\
1,177.26 \\
956.47\end{array}$ \\
\hline $\begin{array}{l}\text { Excavation Permits } \\
\text { Planner }\end{array}$ & & PR7R-REG & & EA & 36 & 36.0 & 76.59 & 2757.17 & 0.00 & 000 & 600 & \\
\hline 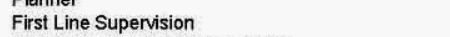 & & MO10-REG & 1 & $E A$ & 6 & 6.0 & 73.58 & 441.47 & 0.00 & 000 & 0.00 & $\begin{array}{l}2,257.17 \\
441.47\end{array}$ \\
\hline Technician (HPT) & & TO50-REG & 1 & EA & 6 & 6.0 & 58.48 & 350.87 & 0.00 & $0 . c$ & 0.00 & 350.87 \\
\hline $\begin{array}{l}\text { Operation } \\
\text { Facality }\end{array}$ & & $\begin{array}{l}\text { E100-REG } \\
\text { M10-REG }\end{array}$ & 1 & $\begin{array}{l}E A \\
E A\end{array}$ & ${ }_{6}^{6}$ & $\begin{array}{l}6.0 \\
6.0\end{array}$ & $\begin{array}{l}74.74 \\
73.58\end{array}$ & $\begin{array}{l}448.45 \\
44147\end{array}$ & 0 & & 00 & 448.45 \\
\hline $\begin{array}{l}\begin{array}{l}\text { Facilily o } \\
\text { Industrial }\end{array} \\
\end{array}$ & & $\begin{array}{l}\text { M010-REG } \\
\text { TO60-REG }\end{array}$ & 1 & FA & 6 & 6.0 & $\begin{array}{l}10.36 \\
57.69\end{array}$ & $\begin{array}{l}441.47 \\
346.16\end{array}$ & 0.000 & & 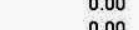 & $\begin{array}{l}441.47 \\
447\end{array}$ \\
\hline $\begin{array}{l}\text { Industrial Hearth } \\
\text { Electrical Engine }\end{array}$ & & $\begin{array}{l}\text { llob0-REG } \\
\text { E040-REG }\end{array}$ & 1 & EA & 6 & 6.0 & 80.24 & $\begin{array}{l}3461.42 \\
481.16\end{array}$ & 0.00 & $\begin{array}{l}0.00 \\
0.00\end{array}$ & $\begin{array}{l}0.00 \\
0.00\end{array}$ & $\begin{array}{l}3461.16 \\
481.42\end{array}$ \\
\hline $\begin{array}{l}\text { Field Work Changes } \\
\text { Planner }\end{array}$ & & PO70-REG & & & 48 & & & 29.409 .79 & 0.00 & 0.00 & 0.00 & 29.409 .79 \\
\hline Emvironmental Engineer & & E050-REG & 8 & $E A$ & 3 & 24.0 & 75.89 & 1.821 .25 & 0.00 & 0.00 & 0.00 & 1.821 .25 \\
\hline $\begin{array}{l}\text { Quality Control Engineer } \\
\text { Sffety Ennipeor }\end{array}$ & & $\begin{array}{l}\text { E110-REG } \\
\text { F120-PFG }\end{array}$ & 8 & EA & 3 & 24.0 & 77.14 & $\begin{array}{l}1.851 .45 \\
156918\end{array}$ & 0.00 & 0.00 & 0.00 & $1,851.45$ \\
\hline $\begin{array}{l}\text { Safety Engineer } \\
\text { System Engineer }\end{array}$ & & $\begin{array}{l}\text { E120-REG } \\
\text { Fi30-REG }\end{array}$ & 8 & $\begin{array}{l}E A \\
E A\end{array}$ & ${ }_{14}^{3}$ & $\begin{array}{r}24.0 \\
11100\end{array}-10$ & 69.13 & $\begin{array}{c}1,659.18 \\
10,199.97\end{array}$ & 0.00 & 0.00 & 0.00 & $\begin{array}{l}1,659.18 \\
107997\end{array}$ \\
\hline Field Work Supervisor (FWS) & & MO10-REG & 8 & $E A$ & $\begin{array}{l}14 \\
7\end{array}$ & 56.0 & 73.58 & $4,120.40$ & 0.00 & 0.00 & 0.00 & $\begin{array}{r}4,120.40 \\
\end{array}$ \\
\hline & & & & & & & & & & & & \\
\hline
\end{tabular}


RPP-RPT-37924 Rev. 0

Cost Estimate

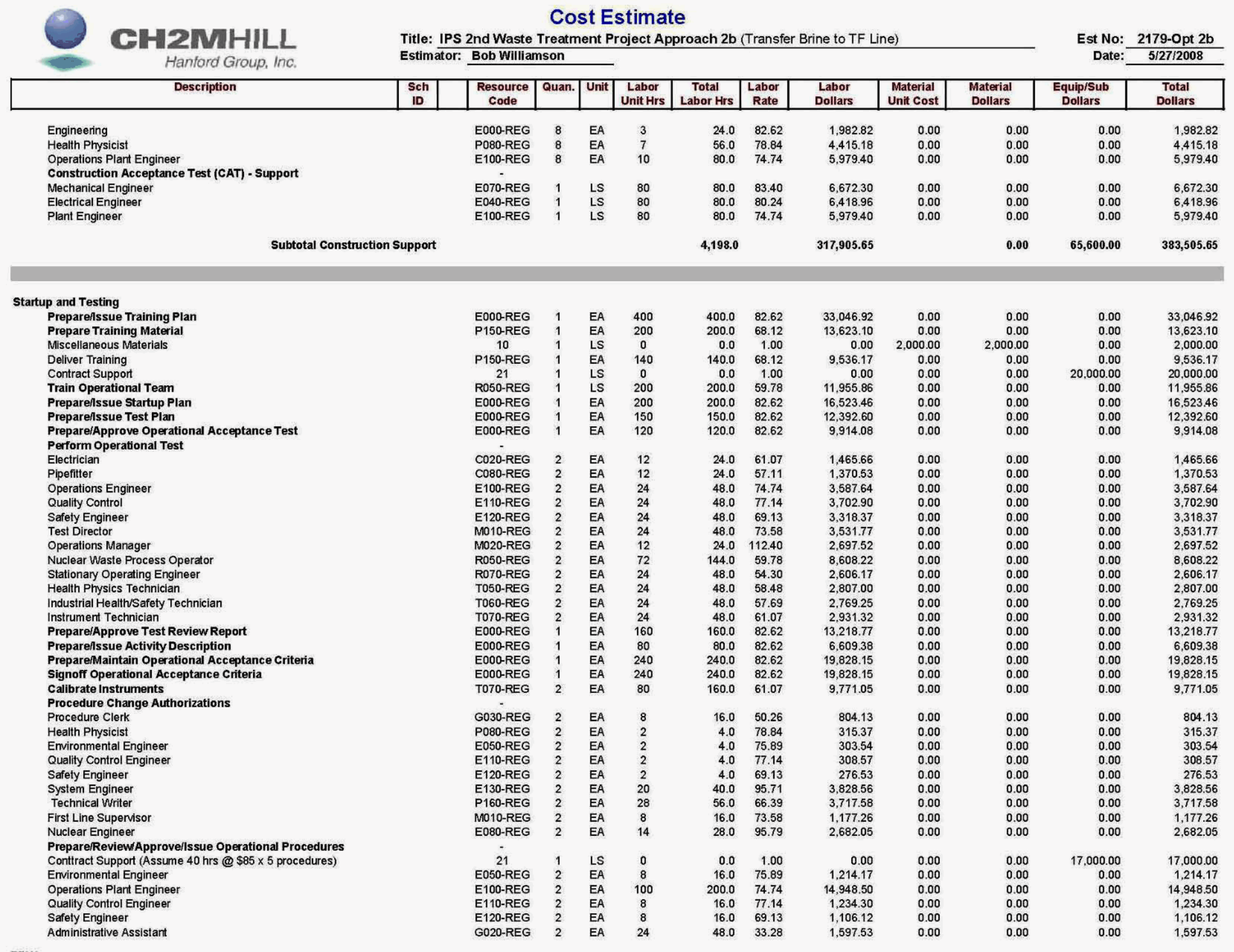


RPP-RPT-37924 Rev. 0

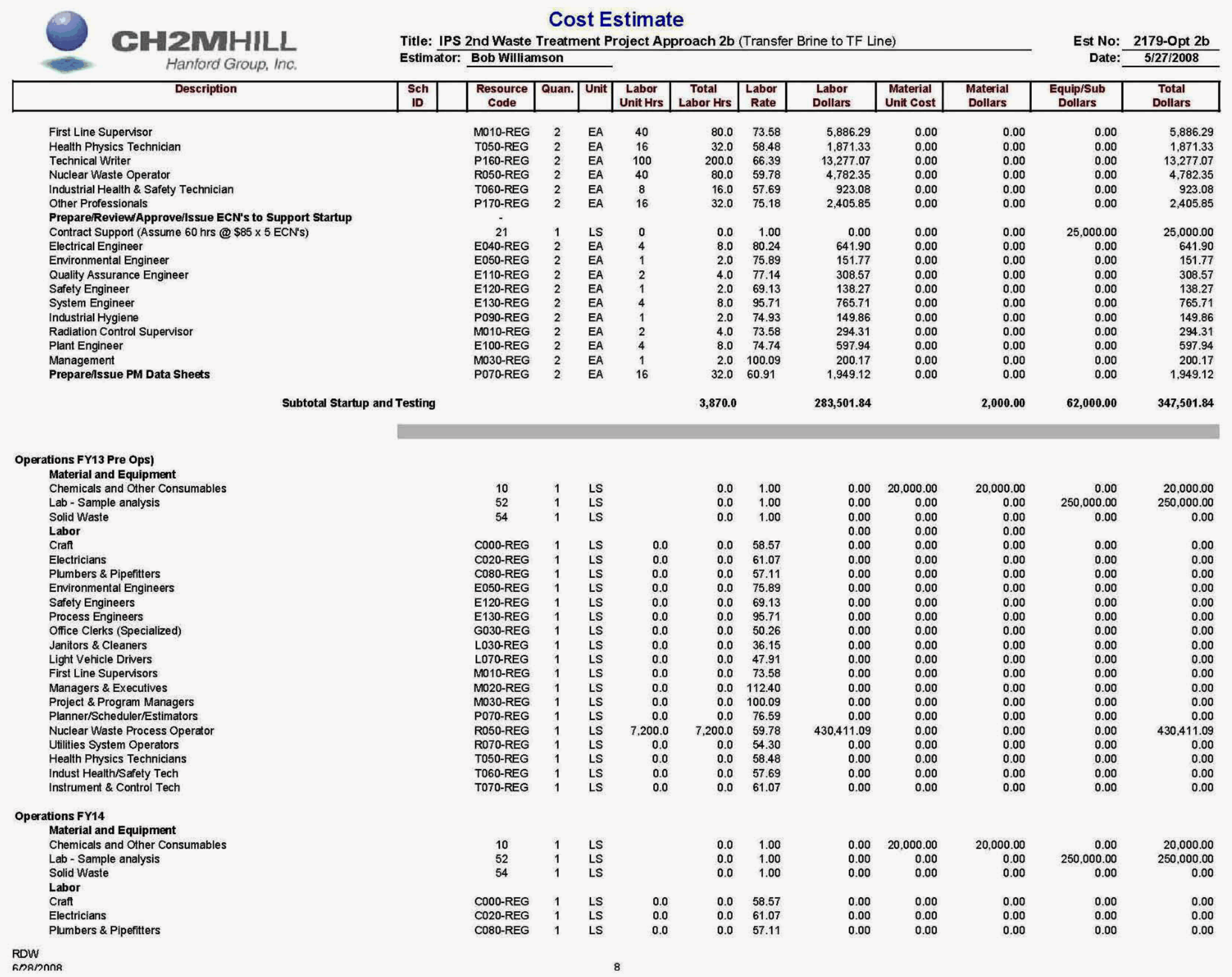


RPP-RPT-37924 Rev. 0

Cost Estimate

Title: IPS 2nd Waste Treatment Project Approach 2b (Transfer Brine to TF Line)

Est No: 2179-Opt 2b Estimator: Bob Williamson

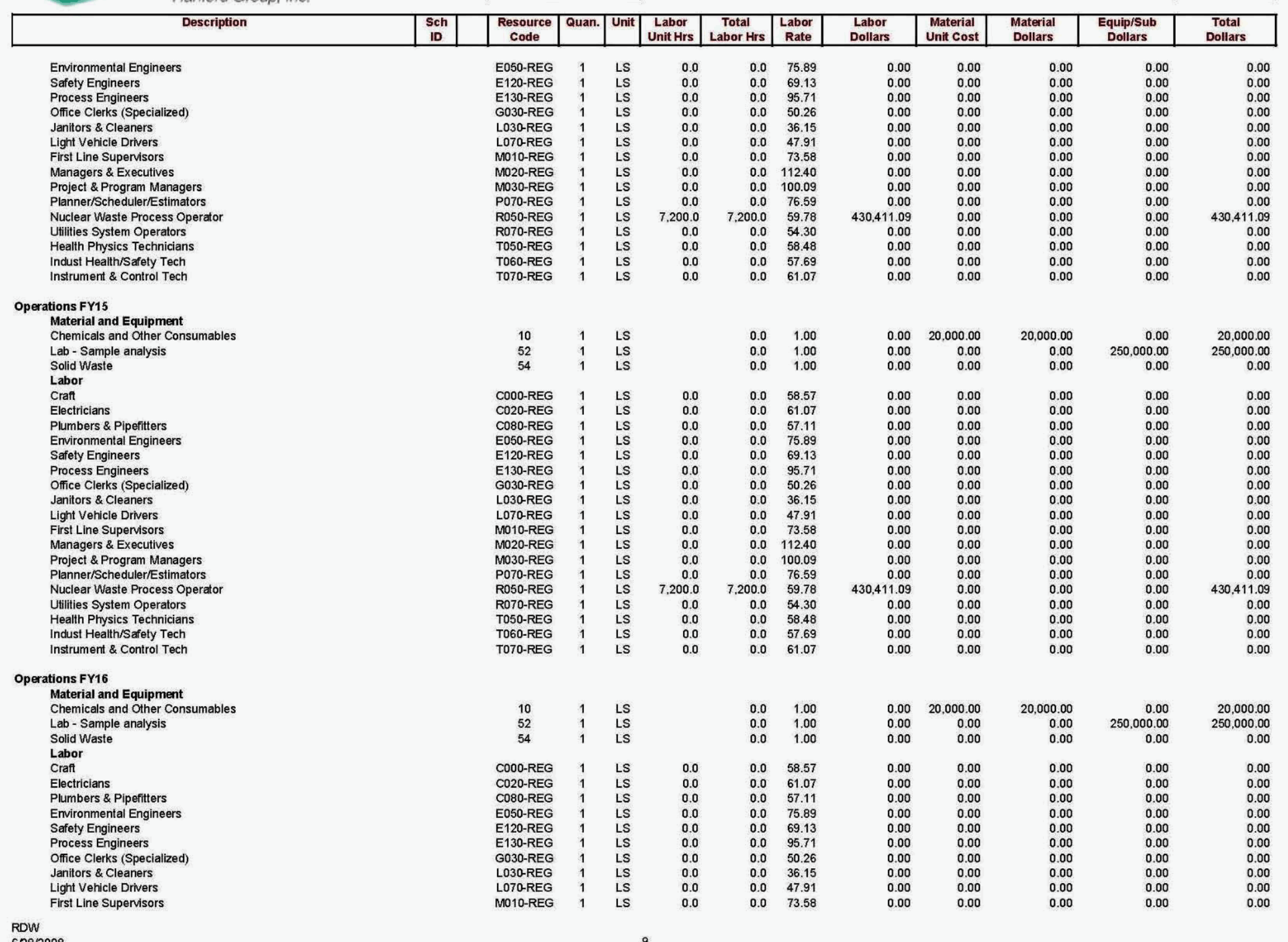


RPP-RPT-37924 Rev. 0

Cost Estimate

Title: IPS 2nd Waste Treatment Project Approach 2b (Transfer Brine to TF Line)

Est No: 2179-Opt 2b

\begin{tabular}{|c|c|c|c|c|c|c|c|c|c|c|c|c|}
\hline Description & $\begin{array}{l}\text { Sch } \\
\text { ID }\end{array}$ & $\begin{array}{c}\text { Resource } \\
\text { Code }\end{array}$ & Quan. & Unit & \begin{tabular}{|l|} 
Labor \\
Unit Hrs \\
\end{tabular} & $\begin{array}{c}\text { Total } \\
\text { Labor Hrs }\end{array}$ & $\begin{array}{c}\text { Labor } \\
\text { Rate }\end{array}$ & $\begin{array}{l}\text { Labor } \\
\text { Dollars }\end{array}$ & $\begin{array}{l}\text { Material } \\
\text { Unit Cost }\end{array}$ & $\begin{array}{c}\text { Material } \\
\text { Dollars } \\
\end{array}$ & $\begin{array}{c}\begin{array}{c}\text { Equip/Sub } \\
\text { Dollars }\end{array} \\
\end{array}$ & $\begin{array}{c}\text { Total } \\
\text { Dollars }\end{array}$ \\
\hline Managers \& Executives & & MO20-REG & 1 & LS & 0.0 & 0.0 & 112.40 & 0.00 & 0.00 & 0.00 & 0.00 & 0.00 \\
\hline Project \& Program Managers & & MO30-REG & 1 & LS & 0.0 & 0.0 & 100.09 & 0.00 & 0.00 & 0.00 & 0.00 & 0.00 \\
\hline Planner/Scheduler/Estimators & & PO70-REG & 1 & LS & 0.0 & 0.0 & 76.59 & 0.00 & 0.00 & 0.00 & 0.00 & 0.00 \\
\hline Nuclear Waste Process Operator & & R050-REG & 1 & LS & $7,200.0$ & $7,200.0$ & 59.78 & $430,411.09$ & 0.00 & 0.00 & 0.00 & $430,411.09$ \\
\hline Utilities System Operators & & R070-REG & 1 & LS & 0.0 & 0.0 & 54.30 & 0.00 & 0.00 & 0.00 & 0.00 & 0.00 \\
\hline Health Physics Technicians & & TO50-REG & 1 & LS & 0.0 & 0.0 & 58.48 & 0.00 & 0.00 & 0.00 & 0.00 & 0.00 \\
\hline Indust Health/Safety Tech & & TO60-REG & 1 & LS & 0.0 & 0.0 & 57.69 & 0.00 & 0.00 & 0.00 & 0.00 & 0.00 \\
\hline Instrument \& Control Tech & & TO70-REG & 1 & LS & 0.0 & 0.0 & 61.07 & 0.00 & 0.00 & 0.00 & 0.00 & 0.00 \\
\hline \multirow{2}{*}{\multicolumn{13}{|c|}{ Operations FY17 }} \\
\hline Material and Equipment & & & & & & & & & & & & \\
\hline Chemicals and Other Consumables & & 10 & 1 & LS & & 0.0 & 1.00 & 0.00 & $20,000.00$ & $20,000.00$ & 0.00 & $20,000.00$ \\
\hline Lab - Sample analysis & & 52 & 1 & LS & & 0.0 & 1.00 & 0.00 & 0.00 & 0.00 & $250,000.00$ & $250,000.00$ \\
\hline Solid Waste & & 54 & 1 & LS & & 0.0 & 1.00 & 0.00 & 0.00 & 0.00 & 0.00 & 0.00 \\
\hline Labor & & & & & & & & & & & & \\
\hline Craft & & CO00-REG & 1 & LS & 0.0 & 0.0 & 58.57 & 0.00 & 0.00 & 0.00 & 0.00 & 0.00 \\
\hline Electricians & & C020-REG & 1 & LS & 0.0 & 0.0 & 61.07 & 0.00 & 0.00 & 0.00 & 0.00 & 0.00 \\
\hline Plumbers \& Pipefitters & & CO80-REG & 1 & LS & 0.0 & 0.0 & 57.11 & 0.00 & 0.00 & 0.00 & 0.00 & 0.00 \\
\hline Emvironmental Engineers & & E050-REG & 1 & LS & 0.0 & 0.0 & 75.89 & 0.00 & 0.00 & 0.00 & 0.00 & 0.00 \\
\hline Safety Engineers & & E120-REG & 1 & LS & 0.0 & 0.0 & 69.13 & 0.00 & 0.00 & 0.00 & 0.00 & 0.00 \\
\hline Process Engineers & & E130-REG & 1 & LS & 0.0 & 0.0 & 95.71 & 0.00 & 0.00 & 0.00 & 0.00 & 0.00 \\
\hline Office Clerks (Specialized) & & $\begin{array}{l}\text { GO30-REG } \\
\text { Gous }\end{array}$ & 1 & LS & 0.0 & 0.0 & 50.26 & 0.00 & 0.00 & 0.00 & 0.00 & 0.00 \\
\hline Janitors \& Cleaners & & LO30-REG & 1 & LS & 0.0 & 0.0 & 36.15 & 0.00 & 0.00 & 0.00 & 0.00 & 0.00 \\
\hline Light Vehicle Drivers & & L070-REG & 1 & LS & 0.0 & 0.0 & 47.91 & 0.00 & 0.00 & 0.00 & 0.00 & 0.00 \\
\hline First Line Supervisors & & MO10-REG & 1 & LS & 0.0 & 0.0 & 73.58 & 0.00 & 0.00 & 0.00 & 0.00 & 0.00 \\
\hline Managers \& Executives & & MO20-REG & 1 & LS & 0.0 & 0.0 & 112.40 & 0.00 & 0.00 & 0.00 & 0.00 & 0.00 \\
\hline Project \& Program Managers & & MO30-REG & 1 & LS & 0.0 & 0.0 & 100.09 & 0.00 & 0.00 & 0.00 & 0.00 & 0.00 \\
\hline Planner/Scheduler/Estimators & & PO70-REG & 1 & LS & 0.0 & 0.0 & 76.59 & 0.00 & 0.00 & 0.00 & 0.00 & 0.00 \\
\hline Nuclear Waste Process Operator & & RO50-REG & 1 & LS & $7,200.0$ & $7,200.0$ & 59.78 & $430,411.09$ & 0.00 & 0.00 & 0.00 & $430,411.09$ \\
\hline Utilities System Operators & & R070-REG & 1 & LS & 0.0 & 0.0 & 54.30 & 0.00 & 0.00 & 0.00 & 0.00 & 0.00 \\
\hline Health Physics Technicians & & TO50-REG & 1 & LS & 0.0 & 0.0 & 58.48 & 0.00 & 0.00 & 0.00 & 0.00 & 0.00 \\
\hline Indust Health/Safety Tech & & TO60-REG & 1 & LS & 0.0 & 0.0 & 57.69 & 0.00 & 0.00 & 0.00 & 0.00 & 0.00 \\
\hline Instrument \& Control Tech & & TO70-REG & 1 & LS & 0.0 & 0.0 & 61.07 & 0.00 & 0.00 & 0.00 & 0.00 & 0.00 \\
\hline \multicolumn{13}{|l|}{ Operations FY18 } \\
\hline Material and Equipment & & 10 & 1 & LS & & 0.0 & 1.00 & 0.00 & $20,000.00$ & $20,000.00$ & 0.00 & $20,000.00$ \\
\hline Chemicals and Other Consumables & & 21 & 1 & LS & & 0.0 & 1.00 & 0.00 & 0.00 & 0.00 & 0.00 & 0.00 \\
\hline $\begin{array}{l}\text { Lab - Sample analysis } \\
\text { S }\end{array}$ & & 52 & 1 & LS & & 0.0 & 1.00 & 0.00 & 0.00 & 0.00 & $250,000.00$ & $250,000.00$ \\
\hline Solid Waste & & 54 & 1 & LS & & 0.0 & 1.00 & 0.00 & 0.00 & 0.00 & 0.00 & 0.00 \\
\hline \multicolumn{13}{|l|}{$\begin{array}{l}\text { Solia or } \\
\text { Lasie }\end{array}$} \\
\hline Craft & & COOO-REG & 1 & LS & 0.0 & 0.0 & 58.57 & 0.00 & 0.00 & 0.00 & 0.00 & 0.00 \\
\hline Electricians & & C020-REG & 1 & LS & 0.0 & 0.0 & 61.07 & 0.00 & 0.00 & 0.00 & 0.00 & 0.00 \\
\hline Plumbers \& Pipefitters & & CO80-REG & 1 & LS & 0.0 & 0.0 & 57.11 & 0.00 & 0.00 & 0.00 & 0.00 & 0.00 \\
\hline 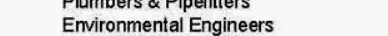 & & E050-REG & 1 & LS & 0.0 & 0.0 & 75.89 & 0.00 & 0.00 & 0.00 & 0.00 & 0.00 \\
\hline Safety Engineers & & E120-REG & 1 & LS & 0.0 & 0.0 & 69.13 & 0.00 & 0.00 & 0.00 & 0.00 & 0.00 \\
\hline Process Engineers & & E130-REG & 1 & LS & 0.0 & 0.0 & 95.71 & 0.00 & 0.00 & 0.00 & 0.00 & 0.00 \\
\hline Office Clerks (Specialized) & & G030-REG & 1 & LS & 0.0 & 0.0 & 50.26 & 0.00 & 0.00 & 0.00 & 0.00 & 0.00 \\
\hline Janitors \& Cleaners & & L030-REG & 1 & LS & 0.0 & 0.0 & 36.15 & 0.00 & 0.00 & 0.00 & 0.00 & 0.00 \\
\hline Light Vehicle Drivers & & LO70-REG & 1 & LS & 0.0 & 0.0 & 47.91 & 0.00 & 0.00 & 0.00 & 0.00 & 0.00 \\
\hline First Line Supenvisors & & MO10-REG & 1 & LS & 0.0 & 0.0 & 73.58 & 0.00 & 0.00 & 0.00 & 0.00 & 0.00 \\
\hline Managers \& Executives & & MO20-REG & 1 & LS & 0.0 & 0.0 & 112.40 & 0.00 & 0.00 & 0.00 & 0.00 & 0.00 \\
\hline Project \& Program Managers & & MO30-REG & 1 & LS & 0.0 & 0.0 & 100.09 & 0.00 & 0.00 & 0.00 & 0.00 & 0.00 \\
\hline Planner/Scheduler/Estimators & & PO70-REG & 1 & LS & 0.0 & 0.0 & 76.59 & 0.00 & 0.00 & 0.00 & 0.00 & 0.00 \\
\hline Nuclear Waste Process Operator & & R050-REG & 1 & LS & $7,200.0$ & $7,200.0$ & 59.78 & $430,411.09$ & 0.00 & 0.00 & 0.00 & $430,411.09$ \\
\hline Utilitities System Operators & & R070-REG & 1 & LS & 0.0 & 0.0 & 54.30 & 0.00 & 0.00 & 0.00 & 0.00 & 0.00 \\
\hline Health Physics Technicians & & TO50-REG & 1 & LS & 0.0 & 0.0 & 58.48 & 0.00 & 0.00 & 0.00 & 0.00 & 0.00 \\
\hline Indust Health/Safety Tech & & TO60-REG & 1 & LS & 0.0 & 0.0 & 57.69 & 0.00 & 0.00 & 0.00 & 0.00 & 0.00 \\
\hline
\end{tabular}


RPP-RPT-37924 Rev. 0

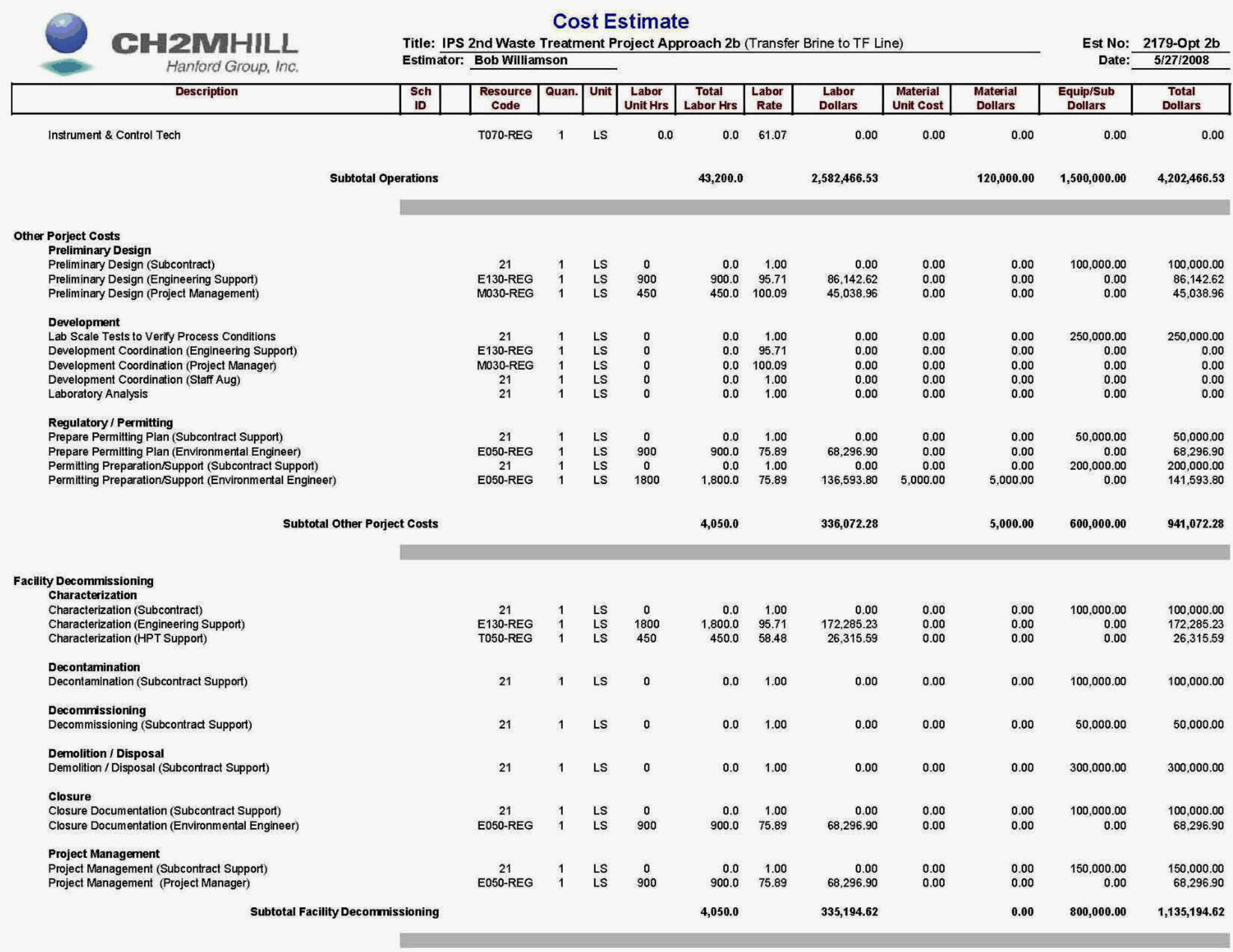


RPP-RPT-37924 Rev. 0

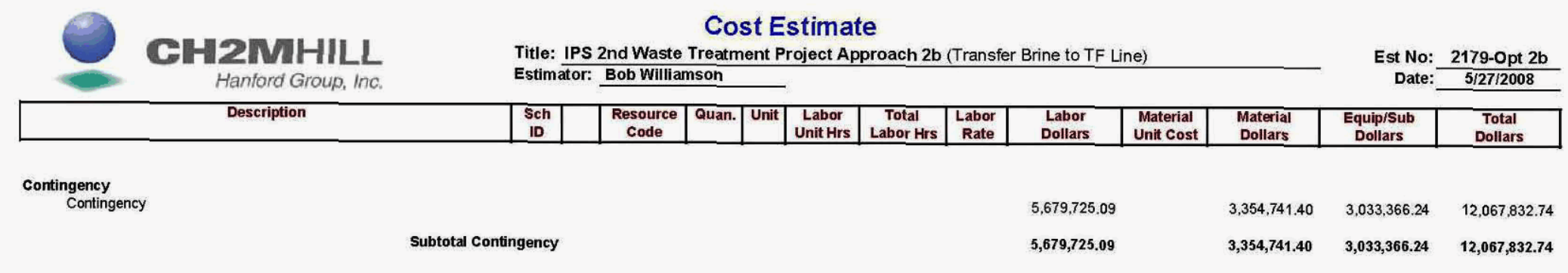


RPP-RPT-37924 Rev. 0

Table G-9. Approach 3 Cost Estimate.

Table begins on next page. 
RPP-RPT-37924 Rev. 0

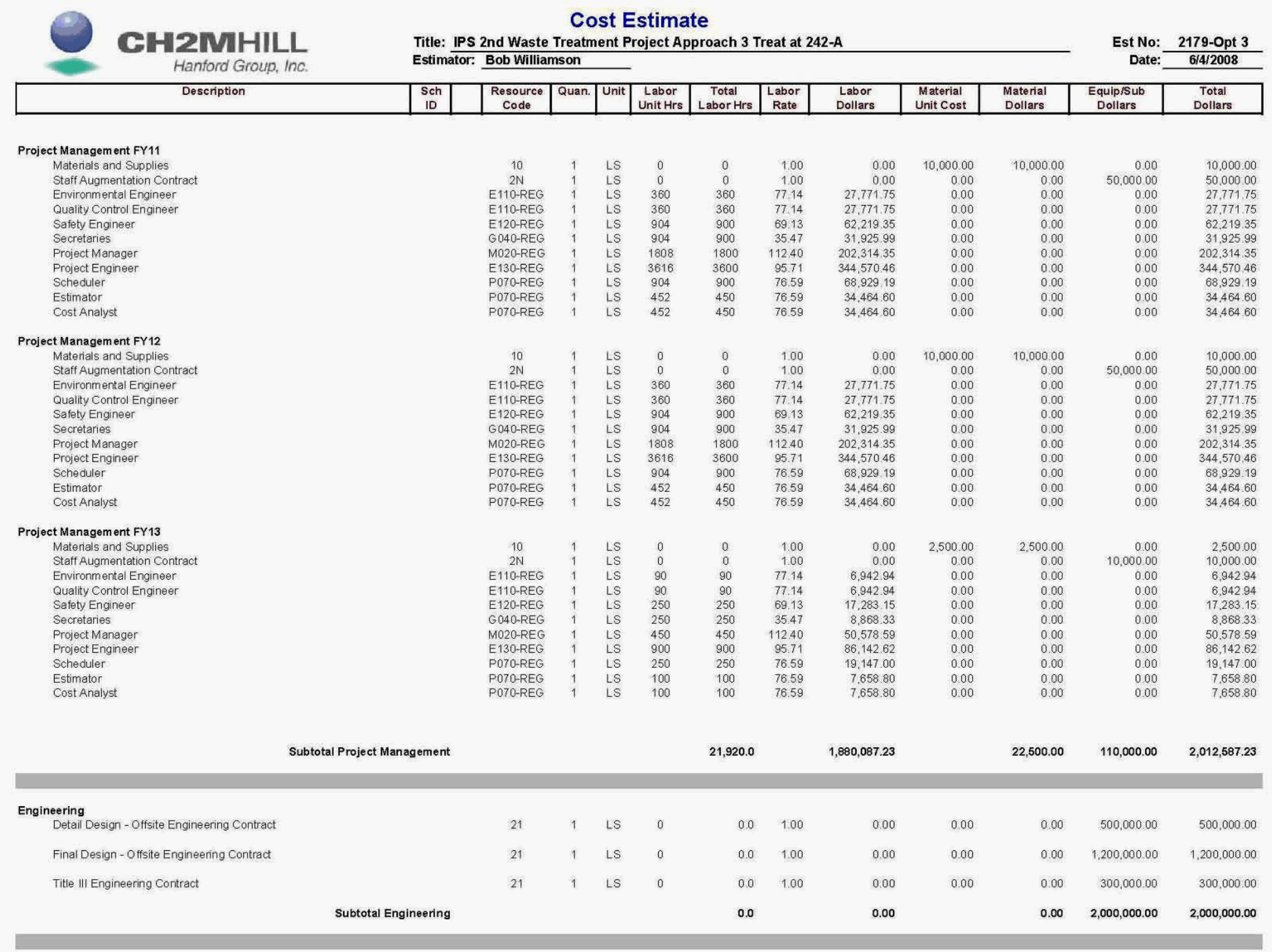

Engineering Support FY11

RDW 
RPP-RPT-37924 Rev. 0

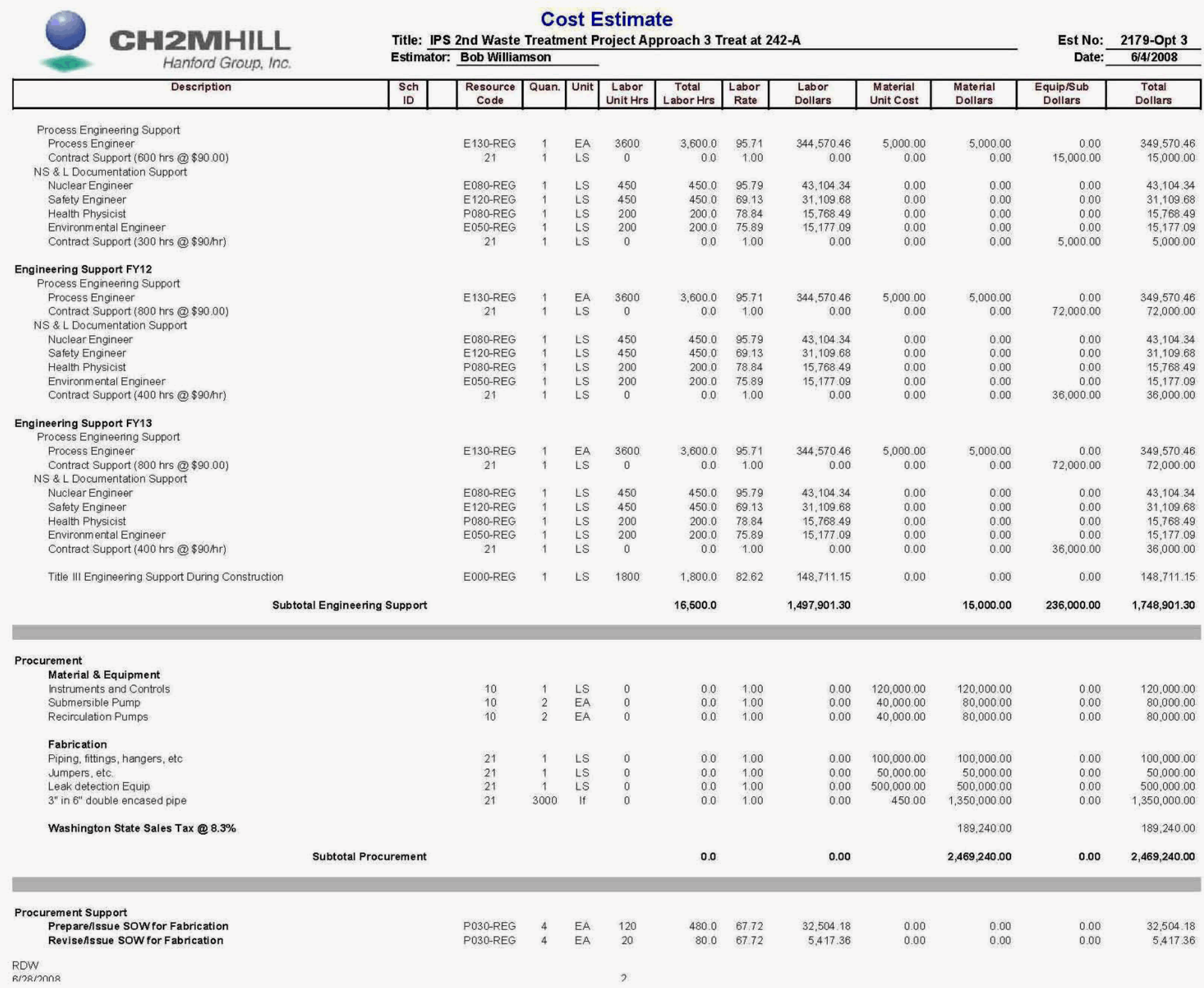


RPP-RPT-37924 Rev. 0

\begin{tabular}{|c|c|c|c|c|c|c|c|c|c|c|c|c|}
\hline \multirow{2}{*}{$\underset{\frac{\text { Canford Group, Inc. }}{\text { Description }}}{\infty}$} & \multicolumn{10}{|c|}{$\begin{array}{l}\text { Cost Estimate } \\
\text { Title: IPS 2nd Waste Treatment Project Approach } 3 \text { Treat at 242-A } \\
\text { Estimator: Bob Williamson }\end{array}$} & $\begin{array}{l}\text { Est No: } \\
\text { Date: }\end{array}$ & $\begin{array}{c}\text { 2179-Opt } 3 \\
6 / 4 / 2008 \\
\end{array}$ \\
\hline & \begin{tabular}{|c|} 
Sch \\
ID \\
\end{tabular} & $\begin{array}{c}\begin{array}{c}\text { Resource } \\
\text { Code }\end{array} \\
\end{array}$ & Quan. & Unit & $\begin{array}{l}\text { Labor } \\
\text { Unit Hrs }\end{array}$ & \begin{tabular}{|c|} 
Total \\
Labor Hrs \\
\end{tabular} & $\begin{array}{c}\text { Labor } \\
\text { Rate } \\
\end{array}$ & $\begin{array}{l}\text { Labor } \\
\text { Dollars }\end{array}$ & $\begin{array}{l}\text { Material } \\
\text { Unit cost } \\
\end{array}$ & $\begin{array}{l}\text { Material } \\
\text { Dollars }\end{array}$ & $\begin{array}{c}\text { Equip/Sub } \\
\text { Dollars }\end{array}$ & $\begin{array}{l}\text { Total } \\
\text { Dollars }\end{array}$ \\
\hline \multicolumn{2}{|l|}{$\begin{array}{l}\text { Award Fabrication Contract } \\
\text { ProcurementF Fabrication Work Release }\end{array}$} & P030-REG & 4 & EA & 40 & 160.0 & 67.72 & 10.834 .73 & 0.00 & 0.00 & 0.00 & 10.834 .73 \\
\hline \multicolumn{2}{|l|}{$\begin{array}{l}\text { Planner } \\
\text { Operations Plant Engineer }\end{array}$} & P070-REG & 8 & EA & 2 & 16.0 & 76.59 & 1.225 .41 & 0.00 & 0.00 & 0.00 & 1.225 .41 \\
\hline \multirow{2}{*}{\multicolumn{2}{|c|}{$\begin{array}{l}\text { Operations Plant Engineer } \\
\text { System Engineer }\end{array}$}} & E100-REG & 8 & EA & 4 & 320 & 74.74 & 2,39176 & 0.00 & 0.00 & 0.00 & 2.39176 \\
\hline & & E130-REG & 8 & EA & 1 & 8.0 & 95.71 & 76571 & 0.00 & 0.00 & 0.00 & 765.71 \\
\hline \multicolumn{2}{|l|}{$\begin{array}{l}\text { Other Enineer } \\
\text { Cost Estimator }\end{array}$} & E130-REG & 8 & EA & 1 & 8.0 & 95.71 & 765.71 & 0.00 & 0.00 & 0.00 & 765.71 \\
\hline \multicolumn{13}{|l|}{$\begin{array}{l}\text { Cost Estimator } \\
\text { Prepare Material Requests }\end{array}$} \\
\hline & G030-REG & 8 & EA & 8 & 64.0 & 50,26 & 3.216 .53 & 0.00 & 0.00 & 0.00 & 3.216 .53 \\
\hline & $\begin{array}{l}\text { Prepare ECN's to Support Fabrication } \\
\text { Contract Support (Assume60 hrs @ } \$ 85 \times 4 \text { ECN's) }\end{array}$ & & 4 & 18 & 0 & & & & 000 & 000 & & 2040000 \\
\hline \multicolumn{2}{|l|}{$\begin{array}{l}\text { Clectract Sulpopolt Engineer } \\
\text { Essume } 60 \mathrm{hrs} @ \$ 85 \times 4 \text { ECN's) }\end{array}$} & $\begin{array}{l}21 \\
\text { E040-REG } \\
\end{array}$ & $\begin{array}{l}4 \\
4\end{array}$ & EA & 4 & 16.0 & $\begin{array}{l}1.00 \\
80.24\end{array}$ & $\begin{array}{r}0.00 \\
1.28379\end{array}$ & 0.00 & 0.00 & $\begin{array}{r}20,400.00 \\
0.00\end{array}$ & $\begin{array}{r}20.400000 \\
1.283 .79\end{array}$ \\
\hline \multirow{2}{*}{\multicolumn{2}{|c|}{$\begin{array}{l}\text { Environmental Engineer } \\
\text { Quality Assurance Engineer }\end{array}$}} & E050-REG & 4 & $E A$ & 1 & 4.0 & 75.89 & 30354 & 0.00 & 0.00 & 0.00 & 303,54 \\
\hline & & E110-REG & 4 & EA & 2 & 80 & 77.14 & 617.15 & 0.00 & 0.00 & 0.00 & 617.15 \\
\hline \multicolumn{2}{|l|}{ Safety Engineer } & E120-REG & 4 & EA & 1 & 4.0 & 69.13 & 276.53 & 0.00 & 0.00 & 0.00 & 276.53 \\
\hline \multirow{2}{*}{\multicolumn{2}{|c|}{$\begin{array}{l}\text { System Engineer } \\
\text { Industrial Hygiene }\end{array}$}} & E130-REG & 4 & EA & 4 & 16.0 & 95.71 & $1,531.42$ & 0.00 & 0.00 & 0.00 & 1.531 .42 \\
\hline & & PO90-REG & 4 & EA & 1 & 4.0 & 74.93 & 299.72 & 0.00 & 0.00 & 0.00 & 299.72 \\
\hline \multicolumn{2}{|l|}{ Radiation Control Supenvisor } & M010-REG & 4 & EA & 2 & 8.0 & 73.58 & 588.63 & 0.00 & 0.00 & 0.00 & 588.63 \\
\hline \multirow{2}{*}{\multicolumn{2}{|c|}{$\begin{array}{l}\text { Plant Engineer } \\
\text { Management }\end{array}$}} & E100-REG & 4 & EA & 4 & 16.0 & 74.74 & 1.195 .88 & 0.00 & 0.00 & 0.00 & $1,195,88$ \\
\hline & & M030-REG & 4 & EA & 1 & 40 & 100.09 & 40035 & 0.00 & 0.00 & 0.00 & 400.35 \\
\hline \multicolumn{2}{|l|}{ Procurement Support - Contracts/Buyer } & PO30-REG & 12 & LS & 120 & 1.440 .0 & 67.72 & $97,512.53$ & 0.00 & 0.00 & 0.00 & 97.512 .53 \\
\hline $\begin{array}{l}\text { Material Coordinator } \\
\text { QAIP Support }\end{array}$ & & G030-REG & 12 & LS & 24 & 288.0 & 50.26 & $14,474.38$ & 0.00 & 0.00 & 0.00 & $14,474.38$ \\
\hline Quality Control Engineer & & E110-REG & 12 & EA & 3 & 36.0 & 77.14 & $2,777.17$ & 0.00 & 0.00 & 0.00 & $2,777.17$ \\
\hline $\begin{array}{l}\text { Engineering } \\
\text { Fabrication - Engineering Support }\end{array}$ & & E130-REG & 12 & EA & 3 & 36.0 & 95.71 & $3,445.70$ & 0.00 & 0.00 & 0.00 & $3,445.70$ \\
\hline Other Engineer & & E130-REG & 4 & LS & 100 & 400.0 & 95.71 & $38,285.61$ & 0.00 & 0.00 & 0.00 & 38.285 .61 \\
\hline Electrical Engineer & & E040-REG & 4 & LS & 80 & 320.0 & 80.24 & $25,675.85$ & 0.00 & 0.00 & 0.00 & $25,675,85$ \\
\hline Mechanical Engineer & & E070-REG & 4 & LS & 80 & 320.0 & 83.40 & $26,689.20$ & 0.00 & 0.00 & 0.00 & $26,689.20$ \\
\hline System Engineer & & E010-REG & 4 & LS & 80 & 320.0 & 85.34 & $27,309.95$ & .00 & 0.00 & 0.00 & 27.309 .95 \\
\hline Quality Control Engineer & & E110-REG & 4 & LS & 60 & 240.0 & 77.14 & $18,514.50$ & 0.00 & 0.00 & 0.00 & 18.514 .50 \\
\hline Offsite Inspections - Travel Allowance & & $2 \mathrm{~T}$ & 1 & LS & 0 & 0.0 & 1.00 & 0.00 & 0.00 & 0.00 & $20,000.00$ & $20,000.00$ \\
\hline Subtote & Support & & & & & $4,360.0$ & & $320,754.11$ & & 0.00 & $40,400.00$ & $361,154.11$ \\
\hline $\begin{array}{l}\text { Construction } \\
\text { General Requirements }\end{array}$ & & & & & & & & & & & & \\
\hline Mobe/Demobe & & Const Lab & 1 & LS & 150 & 150.0 & 57.75 & 8.662 .50 & 0.00 & 0.00 & $20,000.00$ & 28.662 .50 \\
\hline Training & & Const Craft & 1 & LS & 1800 & 1,8000 & 63.00 & $113,400.00$ & 0.00 & & & 113.400 .00 \\
\hline Job Site Administration & & Const Adm & 1 & LS & 2250 & 2.250 .0 & 89.25 & $200,812.50$ & 0.00 & 0.00 & 0.00 & $200,812.50$ \\
\hline Field Work Supervisor & & Const Sup & 1 & LS & 3000 & $3,000.0$ & 84.00 & $252,000,00$ & 0.00 & 0.00 & 0.00 & $252,000.00$ \\
\hline Field Engineering & & Const Eng & 1 & LS & 900 & 900.0 & 73.50 & 66.1 & 0.00 & & 0.00 & 66.150 .00 \\
\hline Safety & & Const Safe & 1 & LS & 1200 & $1,200.0$ & 78.75 & 94.500 .00 & 0.00 & 0.00 & 0.00 & 94.500 .00 \\
\hline Quality Assurance & & Const $\mathrm{QA}$ & 1 & LS & 600 & 600.0 & 73.50 & $44,100.00$ & 0.00 & 0.00 & 0.00 & $44,100.00$ \\
\hline Doc Control & & Const Doc & 1 & LS & 450 & 450.0 & 42.00 & & 0.00 & 0.00 & 0.00 & 18.900 .00 \\
\hline Quality Control & & Const $Q A$ & 1 & LS & 450 & 450.0 & 73,50 & 33.075 .00 & 0.00 & 0.00 & 0.00 & $33,075.00$ \\
\hline Const. Facilties/Temp Controls & & 21 & 1 & LS & 0 & 0.0 & 1.00 & 0.00 & $25,000,00$ & $25,000.00$ & 0.00 & $25,000,00$ \\
\hline Material Handling/Delivery & & Const Lab & 1 & LS & 750 & 750.0 & 57.75 & $43,312.50$ & & 0.00 & 0.00 & 43.312 .50 \\
\hline Clean-up Labor/Support & & Const Craft & 1 & LS & 750 & 750.0 & 63.00 & 47.250 .00 & 0.00 & 0.00 & & 47.250 .00 \\
\hline Non-Regulated Equipment/Small Tools & & 21 & 1 & LS & 0 & 0.0 & 1.00 & 0.00 & $29,000,00$ & $29,000.00$ & 0.00 & 29.000 .00 \\
\hline Perform Construction Acceptance Test & & Const Craft & 1 & LS & 900 & 900.0 & 63.00 & $56,700.00$ & 0.00 & 0.00 & 0.00 & $56,700,00$ \\
\hline Subtotal & irements & & & & & $13,200.0$ & & $978,862.50$ & & $54,000.00$ & $20,000.00$ & $1,052,862.50$ \\
\hline $\begin{array}{l}\text { Field Work } \\
\text { Feed Accumulation and Storage Space }\end{array}$ & & & & & & & & & & & & \\
\hline Piping installation $3^{\prime \prime}$ in 6" double encased pipe & & Const Craft & 3000 & If & 2 & 6.000 .0 & 63.00 & $378,000.00$ & 100.00 & $300,000.00$ & 0.00 & 678.000 .00 \\
\hline F/2R/ & & & & & 3 & & & & & & & \\
\hline
\end{tabular}


RPP-RPT-37924 Rev. 0

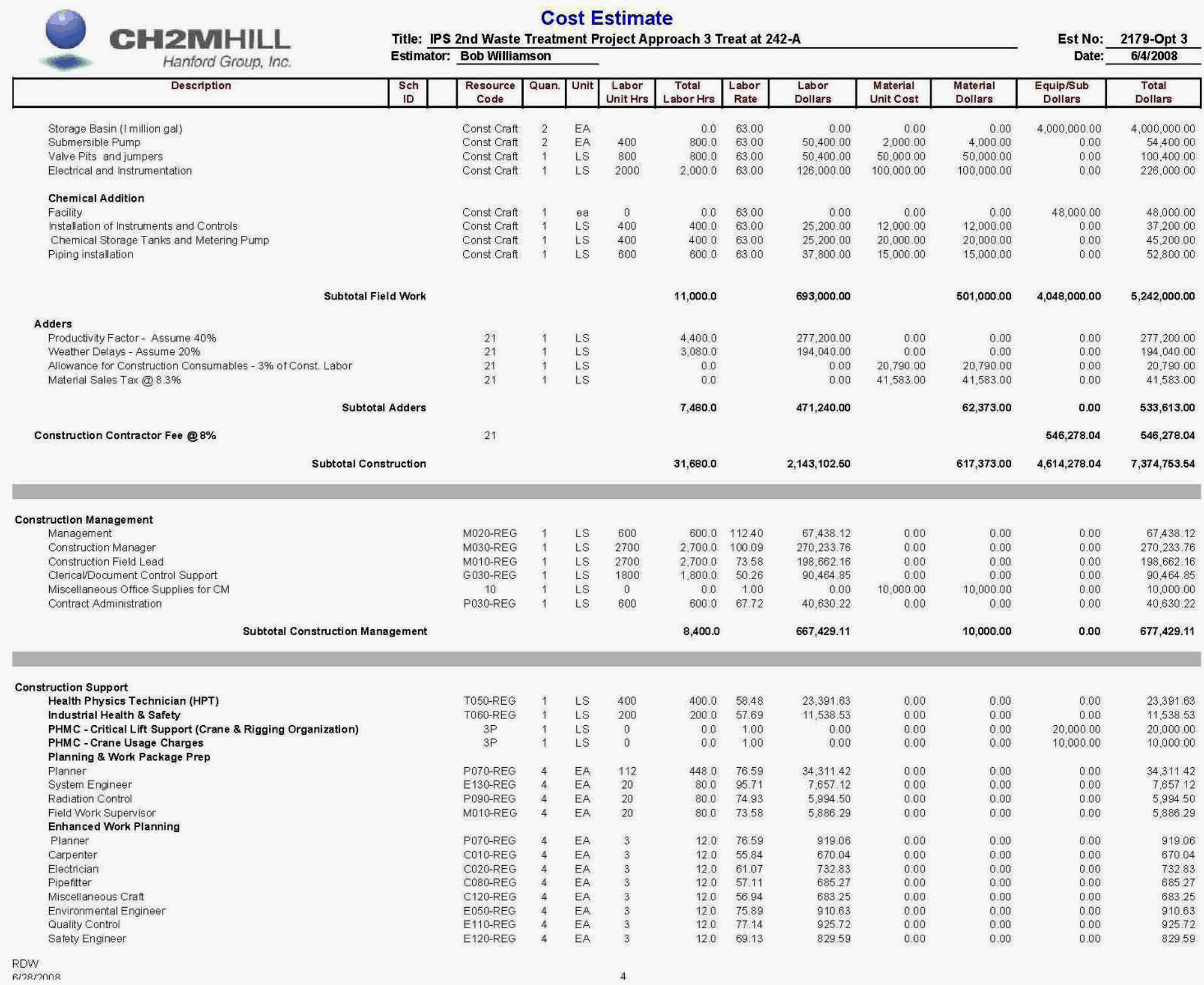


RPP-RPT-37924 Rev. 0

\begin{tabular}{|c|c|c|c|c|c|c|c|c|c|c|c|c|}
\hline \multirow{2}{*}{$\underbrace{}_{\substack{\text { Hanford Group, inc. } \\
\text { Description }}}$} & \multicolumn{10}{|c|}{$\begin{array}{l}\text { Cost Estimate } \\
\text { Title: IPS 2nd Waste Treatment Project Approach } 3 \text { Treat at 242-A } \\
\text { Estimator: Bob Williamson }\end{array}$} & \multicolumn{2}{|c|}{$\begin{aligned} \text { Est No: } & 2179-\mathrm{Opt} 3 \\
\text { Date: } & =6 / 4 / 2008\end{aligned}$} \\
\hline & $\begin{array}{l}\text { Sch } \\
\text { ID }\end{array}$ & \begin{tabular}{|c|}
$\begin{array}{c}\text { Resource } \\
\text { code }\end{array}$ \\
\end{tabular} & Quan. & Unit & $\begin{array}{l}\text { Labor } \\
\text { Unit Hrs }\end{array}$ & \begin{tabular}{c|} 
Total \\
Labor Hrs \\
\end{tabular} & $\begin{array}{l}\text { Labor } \\
\text { Rate }\end{array}$ & $\begin{array}{l}\text { Labor } \\
\text { Dollars }\end{array}$ & $\begin{array}{l}\text { Material } \\
\text { Unit Cost }\end{array}$ & $\begin{array}{l}\text { Material } \\
\text { Dollars }\end{array}$ & $\begin{array}{c}\text { Equip/sub } \\
\text { Dollars }\end{array}$ & $\begin{array}{l}\text { Total } \\
\text { Dollars }\end{array}$ \\
\hline System Engineer & & E130-REG & 4 & EA & 3 & & & 1.148 .57 & & & & \\
\hline $\begin{array}{l}\text { Light Vehicle Driver } \\
\text { Field Work Supenvisi (FWS }\end{array}$ & & $\begin{array}{l}\text { LO70-REG } \\
\text { M010-REG }\end{array}$ & $\begin{array}{l}4 \\
4\end{array}$ & $\begin{array}{l}E A \\
E A\end{array}$ & ${ }_{3}^{3}$ & $\begin{array}{l}12.0 \\
120\end{array}$ & $\begin{array}{l}47.91 \\
7358\end{array}$ & $\begin{array}{l}57491 \\
8894\end{array}$ & 0.00 & 0.00 & $\begin{array}{l}0.00 \\
0.00\end{array}$ & $\begin{array}{l}574.91 \\
8894\end{array}$ \\
\hline 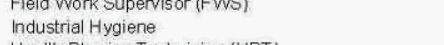 & & $\begin{array}{l}\text { PO90-REG } \\
\text { POTEG }\end{array}$ & $\begin{array}{l}4 \\
4\end{array}$ & $\begin{array}{l}E A \\
E A\end{array}$ & $\begin{array}{l}3 \\
3\end{array}$ & 12.0 & $\begin{array}{r}73.58 \\
74.93\end{array}$ & $\begin{array}{l}892.94 \\
899.17\end{array}$ & 0.00 & 0.00 & 0.00 & $\begin{array}{l}892.94 \\
899.17\end{array}$ \\
\hline $\begin{array}{l}\text { Health Physics Technician (HPT) } \\
\text { Review \& Approve Work Packag }\end{array}$ & & TO50-REG & 4 & EA & 3 & 12.0 & & 701.75 & & & 0.00 & \\
\hline $\begin{array}{l}\text { Planer } \\
\text { Panpore }\end{array}$ & & PO70-REG & 4 & EA & 28 & 112.0 & 76.59 & 8.577 .85 & 0.00 & 0.00 & 0.00 & 8.577 .85 \\
\hline $\begin{array}{l}\text { Enviromentatal Engineer } \\
\text { Quality Control }\end{array}$ & & $\begin{array}{l}\text { E050-REG } \\
\text { FE10PEG }\end{array}$ & $\begin{array}{l}4 \\
4\end{array}$ & $\begin{array}{l}E A \\
E A \\
E A\end{array}-1-1$ & 5 & 20.0 & $\begin{array}{r}75.89 \\
7714\end{array}$ & $\begin{array}{l}1,517.71 \\
155287\end{array}$ & 0.00 & 0.00 & 0.00 & 1.51771 \\
\hline Safety Engineer & & E120-REG & $\begin{array}{l}4 \\
4\end{array}$ & $E A$ & 5 & $\begin{array}{l}20.0 \\
20.0\end{array}$ & 69.13 & 1.382 .65 & 0.00 & 0.00 & 0.00 & $\begin{array}{l}1.54287 \\
1.382 .65\end{array}$ \\
\hline $\begin{array}{l}\text { System Engineer } \\
\text { Field Work Supenvisor IFWS) }\end{array}$ & & E130-REG & 4 & EA & 10 & 40.0 & $\begin{array}{r}95.71 \\
7358\end{array}$ & $\begin{array}{l}3.828 .56 \\
147.57\end{array}$ & 0.00 & 0.00 & 0.00 & 3.82856 \\
\hline $\begin{array}{l}\text { Field Work Supervisor (FWS) } \\
\text { Other Engineer }\end{array}$ & & $\begin{array}{l}\text { M MUUU-REG } \\
\text { E130-REG }\end{array}$ & $\begin{array}{l}4 \\
4\end{array}$ & $\begin{array}{l}E A \\
E A \\
E A\end{array}$ & 5 & 20.0 & $\begin{array}{l}73.58 \\
9571\end{array}$ & $\begin{array}{l}1.4157 \\
191428\end{array}$ & 0.00 & 0.00 & 000 & $\begin{array}{l}1.47157 \\
191428 \\
2\end{array}$ \\
\hline Health Physics Technician (HPT) & & TO50-REG & $\begin{array}{l}4 \\
4\end{array}$ & EA & $\begin{array}{l}5 \\
5\end{array}$ & $\begin{array}{l}20.0 \\
20.0\end{array}$ & $\begin{array}{l}95.71 \\
58.48\end{array}$ & $\begin{array}{l}1.1942 .28 \\
1.169 .58\end{array}$ & $\begin{array}{l}0.00 \\
0.00\end{array}$ & $\begin{array}{l}0.00 \\
0.00\end{array}$ & $\begin{array}{l}0.00 \\
0.00\end{array}$ & $\begin{array}{l}1.91428 \\
1.16958\end{array}-\mathrm{l}$ \\
\hline $\begin{array}{l}\text { Industrial Heath \& Safety } \\
\text { Operations Plant Engineer }\end{array}$ & & $\begin{array}{l}\text { TO60-REG } \\
\text { E100-REG }\end{array}$ & $\begin{array}{l}4 \\
4\end{array}$ & $\begin{array}{l}E A \\
E A\end{array}$ & $\begin{array}{c}5 \\
25\end{array}$ & $\begin{array}{r}20.0 \\
100.0\end{array}$ & $\begin{array}{l}57.69 \\
74.74\end{array}$ & $\begin{array}{l}1.153 .85 \\
7.474 .25\end{array}$ & $\begin{array}{l}0.00 \\
0.00\end{array}$ & $\begin{array}{l}0.00 \\
0.00\end{array}$ & $\begin{array}{l}0.00 \\
0.00\end{array}$ & $\begin{array}{l}1.15385 \\
747425\end{array}$ \\
\hline $\begin{array}{l}\text { Closeout Work Packages } \\
\text { Planner }\end{array}$ & & PO70-PEG & & & & & & & & & & \\
\hline Operations Plant Engineer & & $\begin{array}{l}\text { E E100REEG } \\
\text { E REF }\end{array}$ & $\begin{array}{l}4 \\
4\end{array}$ & $\begin{array}{l}\text { EA } \\
\text { EA }\end{array}$ & $\frac{12}{4}$ & $\begin{array}{l}48.0 \\
16.0\end{array}$ & $\begin{array}{r}76.59 \\
74.74\end{array}$ & 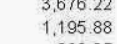 & 0.00 & 0.00 & $\begin{array}{l}0.00 \\
0.00\end{array}$ & 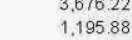 \\
\hline $\begin{array}{l}\text { Administration } \\
\text { Other Enoinear }\end{array}$ & & $\begin{array}{l}\text { G020-REG } \\
\text { E130PEG }\end{array}$ & 4 & $\begin{array}{l}E A \\
\text { EA } \\
\text { EA }\end{array}$ & 2 & 8.0 & 33.28 & $\begin{array}{r}26625 \\
153142 \\
\end{array}$ & 0.00 & 0.00 & 0.00 & 26625 \\
\hline $\begin{array}{l}\text { Oother Engneer } \\
\text { Field Work Supenisoor (FWS) }\end{array}$ & & $\begin{array}{l}\text { E130-REG } \\
\text { MO10-REG }\end{array}$ & $\begin{array}{l}4 \\
4\end{array}$ & $\begin{array}{l}\text { EA } \\
\text { EA }\end{array}$ & $\begin{array}{l}4 \\
2\end{array}$ & $\begin{aligned} 16.0 \\
8.0\end{aligned}$ & $\begin{array}{l}95.71 \\
73.58\end{array}$ & $\begin{array}{l}1.53142 \\
588.63\end{array}$ & $\begin{array}{l}0.000 \\
0.00\end{array}$ & $\begin{array}{l}0.00 \\
0.00\end{array}$ & $\begin{array}{l}0.00 \\
0.00\end{array}$ & $\begin{array}{l}1.53142 \\
588.63\end{array}$ \\
\hline $\begin{array}{l}\text { Prepare ECN's } \\
\text { Contrac Support (Assume } 90 \text { hrs @ } \$ 85 \times 4 \text { ECN's) }\end{array}$ & & & 1 & LS & 0 & & 1.00 & & 0.00 & & $30,600.00$ & $30,600.00$ \\
\hline Electrical Engineer & & EO40-REG & 4 & EA & 4 & 16.0 & 80.24 & 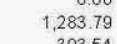 & 0.00 & 0.00 & & $\begin{array}{r}1,283.79 \\
1,237\end{array}$ \\
\hline $\begin{array}{l}\text { Environtmental Engineer } \\
\text { Ougatitu Assurance Enoineer }\end{array}$ & & $\begin{array}{l}\text { E050-REG } \\
\text { E } 110-R E G\end{array}$ & ${ }_{4}^{4}$ & $\begin{array}{l}E A \\
E A\end{array}$ & $\frac{1}{2}$ & $\begin{array}{l}40 \\
80\end{array}$ & $\begin{array}{l}75.89 \\
7714\end{array}$ & $\begin{array}{l}30354 \\
61715\end{array}$ & 0.00 & 0.00 & 0.00 & $\begin{array}{l}303.54 \\
6\end{array}$ \\
\hline $\begin{array}{l}\text { lualiti Assurancere Engineer } \\
\text { Safety Engineer }\end{array}$ & & $\begin{array}{l}\text { E1100REG } \\
\text { E120-REG }\end{array}$ & $\begin{array}{l}4 \\
4\end{array}$ & $\begin{array}{l}E A \\
E A \\
E A\end{array}$ & $\begin{array}{l}2 \\
1\end{array}$ & $\begin{array}{l}80 \\
40\end{array}$ & 69.13 & $\begin{array}{l}67715 \\
27653\end{array}$ & $\begin{array}{l}0.000 \\
0.00\end{array}$ & $\begin{array}{l}0.000 \\
0.00\end{array}$ & $\begin{array}{l}0.000 \\
0.00\end{array}$ & $\begin{array}{l}677.15 \\
27653\end{array}$ \\
\hline System Engineer & & E130-REG & ${ }_{4}^{4}$ & $E A$ & 4 & 160 & 9571 & 1.531 .42 & 0.00 & 0.00 & 0.00 & $\begin{array}{r}1.531 .42 \\
1.52\end{array}$ \\
\hline Industrial Hygiene & & PO90-REG & 4 & EA & 1 & 40 & 74.93 & 299.72 & 0.00 & 0.00 & 0.00 & 299.72 \\
\hline Radiation Control Supenisor & & MO10-REG & 4 & EA & ${ }^{2}$ & 8.0 & 73.58 & 588.63 & 0.00 & 0.00 & 0.00 & 588.63 \\
\hline $\begin{array}{l}\text { Plant Engininer } \\
\text { Management }\end{array}$ & & $\begin{array}{l}\text { E1000-REG } \\
\text { MO30-REG }\end{array}$ & $\begin{array}{l}4 \\
4\end{array}$ & $\begin{array}{l}\text { EA } \\
\text { EA }\end{array}$ & ${ }_{1}^{4}$ & $\begin{array}{r}16.0 \\
4.0\end{array}$ & $\begin{array}{r}74.74 \\
100.09 \\
\end{array}$ & $\begin{aligned} \begin{array}{r}1.495 .88 \\
40035\end{array} & \end{aligned}$ & $\begin{array}{l}0.00 \\
0.00\end{array}$ & $\begin{array}{l}0.00 \\
0.00\end{array}$ & $\begin{array}{l}0.00 \\
0.00\end{array}$ & $\begin{array}{r}1.195 .88 \\
400.35\end{array}$ \\
\hline Prepare USQ's & & F130-REG & & & & & & 10710.97 & & & & \\
\hline $\begin{array}{l}\text { Revivew Eneniners } \\
\text { Revist }\end{array}$ & & E130-REG & 4 & $E A$ & 9 & 36.0 & 95.71 & 3.445 .70 & 0.00 & 0.00 & 0.00 & 3,44570 \\
\hline $\begin{array}{l}\text { Planner } \\
\text { Fectrichan }\end{array}$ & & PO70-REG & 5 & EA & 14 & 70.0 & 76.59 & 5.361 .16 & 0.00 & 0.00 & 0.00 & 5.361 .16 \\
\hline $\begin{array}{l}\text { Electrician } \\
\text { Electrical Engineer }\end{array}$ & & $\begin{array}{l}\text { CO2020-REG } \\
\text { E040-REG }\end{array}$ & $\begin{array}{l}5 \\
5\end{array}$ & $\begin{array}{l}E A \\
E A\end{array}$ & ${ }_{2}^{2}$ & $\begin{array}{l}10.0 \\
10.0\end{array}$ & $\begin{array}{l}61.07 \\
8024\end{array}$ & $\begin{array}{l}610.69 \\
802.37\end{array}$ & & & 10 & $\begin{array}{l}610.69 \\
80237\end{array}$ \\
\hline Environmental Engineer & & E050-REG & 5 & $E A$ & 5 & 25.0 & 75.89 & 1.897 .14 & 0.00 & & 0.00 & $1,897.14$ \\
\hline $\begin{array}{l}\text { Operations Plant Engineer } \\
\text { Saffy Froiner }\end{array}$ & & E100-REG & 5 & EA & 2 & 10.0 & 74.74 & 74742 & 0.00 & 0.00 & 0.00 & 74742 \\
\hline $\begin{array}{l}\text { Saffte Engine } \\
\text { System Engin }\end{array}$ & & $\begin{array}{l}\text { E120-REG } \\
\text { E130REG }\end{array}$ & $\begin{array}{l}5 \\
5\end{array}$ & $\begin{array}{l}E A \\
E A \\
E A\end{array}$ & ${ }_{5}^{2}$ & 250 & $\begin{array}{l}69.13 \\
9571\end{array}$ & $\begin{array}{r}699133 \\
239285 \\
235\end{array}$ & $\begin{array}{l}0.00 \\
0.00\end{array}$ & 0.00 & 0.000 & $\begin{array}{r}691.33 \\
239285\end{array}$ \\
\hline $\begin{array}{l}\text { Sylemenomi } \\
\text { Field Work Sul }\end{array}$ & & E100-REG & 5 & $E A$ & 5 & 25.0 & 74.74 & 1.868 .56 & 0.00 & 0.00 & 0.00 & $\begin{array}{l}2.398 .85 \\
1.86856\end{array}$ \\
\hline Health Physics & & TO50-REG & 5 & EA & 5 & 25.0 & 58.48 & $1,461.98$ & 0.0 & 0.00 & 10 & 1.46198 \\
\hline $\begin{array}{l}\text { Industrial Heatif } \\
\text { Material Reque }\end{array}$ & & T060-REG & 5 & EA & 2 & 10.0 & 57.69 & 576.93 & 0.00 & 0.00 & & 576.93 \\
\hline Matenial Coordinator & & G030-REG & 5 & EA & 4 & 20.0 & 50.26 & $1,005.16$ & 0.00 & 0.00 & 0.00 & $1,005.16$ \\
\hline $\begin{array}{l}\text { rere Job Briefings } \\
\text { Other Engineers }\end{array}$ & & E130-REG & 120 & $\mathrm{Hr}$ & 1 & 120.0 & 95.71 & $11,485.68$ & 0.00 & & & \\
\hline Administr: & & G020-REG & 120 & $\mathrm{Hr}$ & 1 & 120.0 & 33.28 & $3,993.82$ & 0.00 & 0.00 & 0.00 & 3.993 .82 \\
\hline Manage & & Mo10-F & 120 & $\mathrm{Hr}$ & 1 & 120.0 & 73 & $8,829.43$ & 0.00 & 0.00 & 10 & 8.829 .43 \\
\hline $\begin{array}{l}\text { Post Job A lara Review } \\
\text { Planner }\end{array}$ & & P070-REG & 3 & EA & $2^{2}$ & & 76.59 & 459.53 & 0.00 & 00 & .00 & 459.53 \\
\hline Electrician & & $\mathrm{C} 020$ & 3 & EA & 4 & & & & 0.00 & & 00 & \\
\hline $\begin{array}{l}\text { Electrical Engineer } \\
\text { Environmenta| }\end{array}$ & & 6 & 3 & EA & ${ }^{2}$ & $\begin{array}{l}60 \\
30\end{array}$ & 80.24 & $\begin{array}{l}48142 \\
227.66\end{array}$ & 0.00 & 0.00 & to & $\begin{array}{l}481.42 \\
2766\end{array}$ \\
\hline System Engineer & & E130-REG & 3 & EA & 2 & 6.0 & 9571 & 574.28 & 0.00 & 0.00 & 0.00 & 574.28 \\
\hline & & & & & & & & & & & & \\
\hline
\end{tabular}


RPP-RPT-37924 Rev. 0

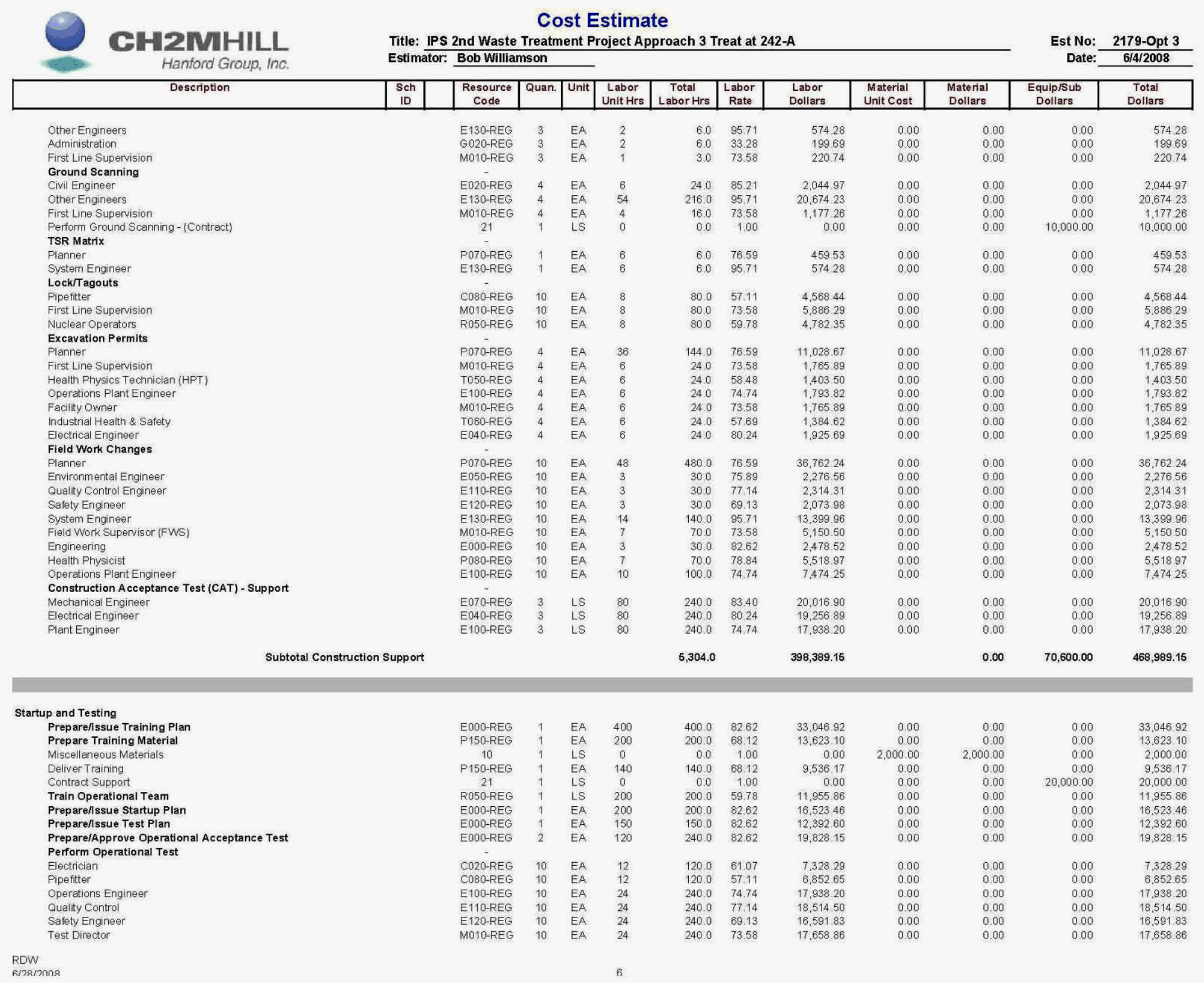


RPP-RPT-37924 Rev. 0

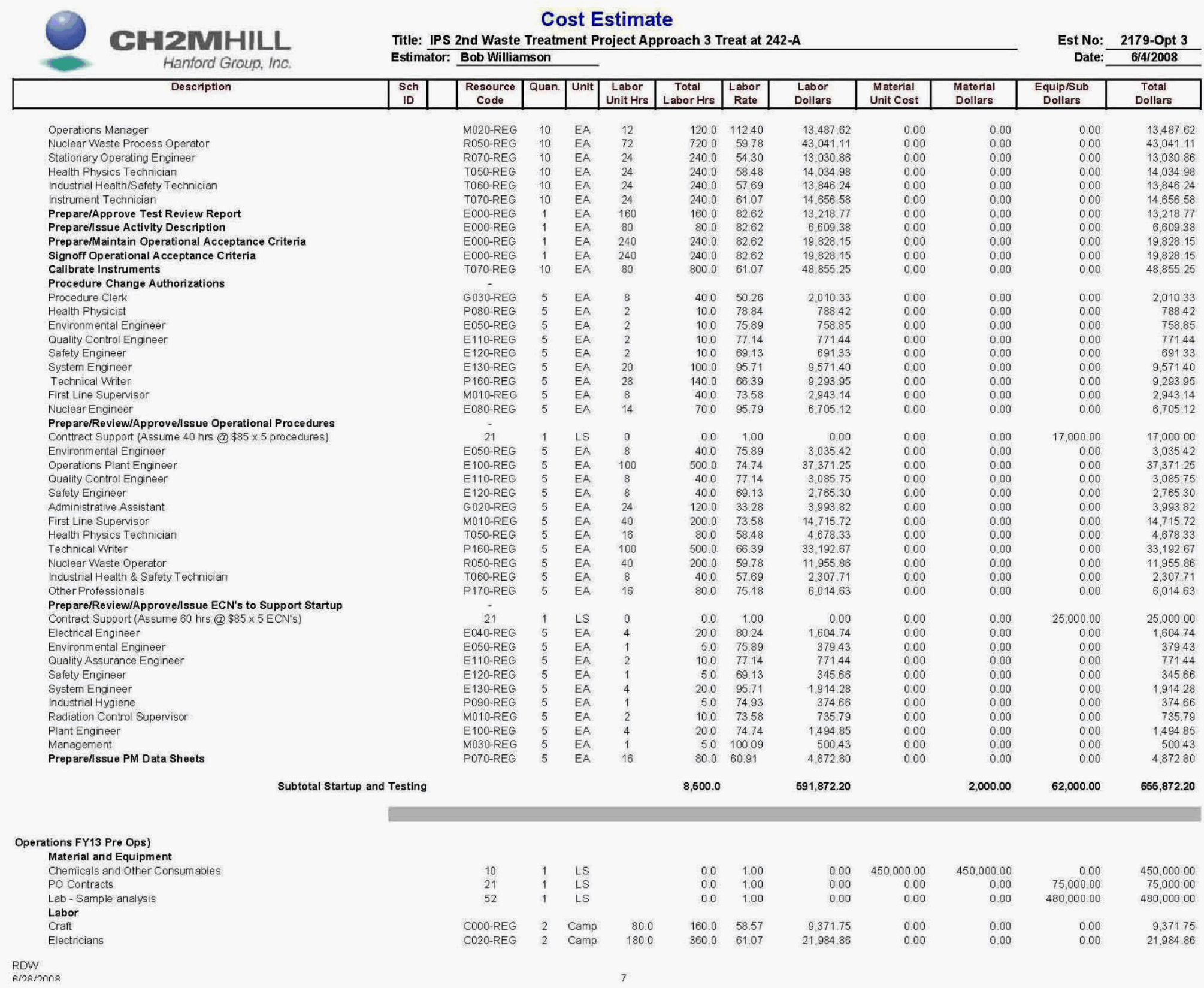


RPP-RPT-37924 Rev. 0

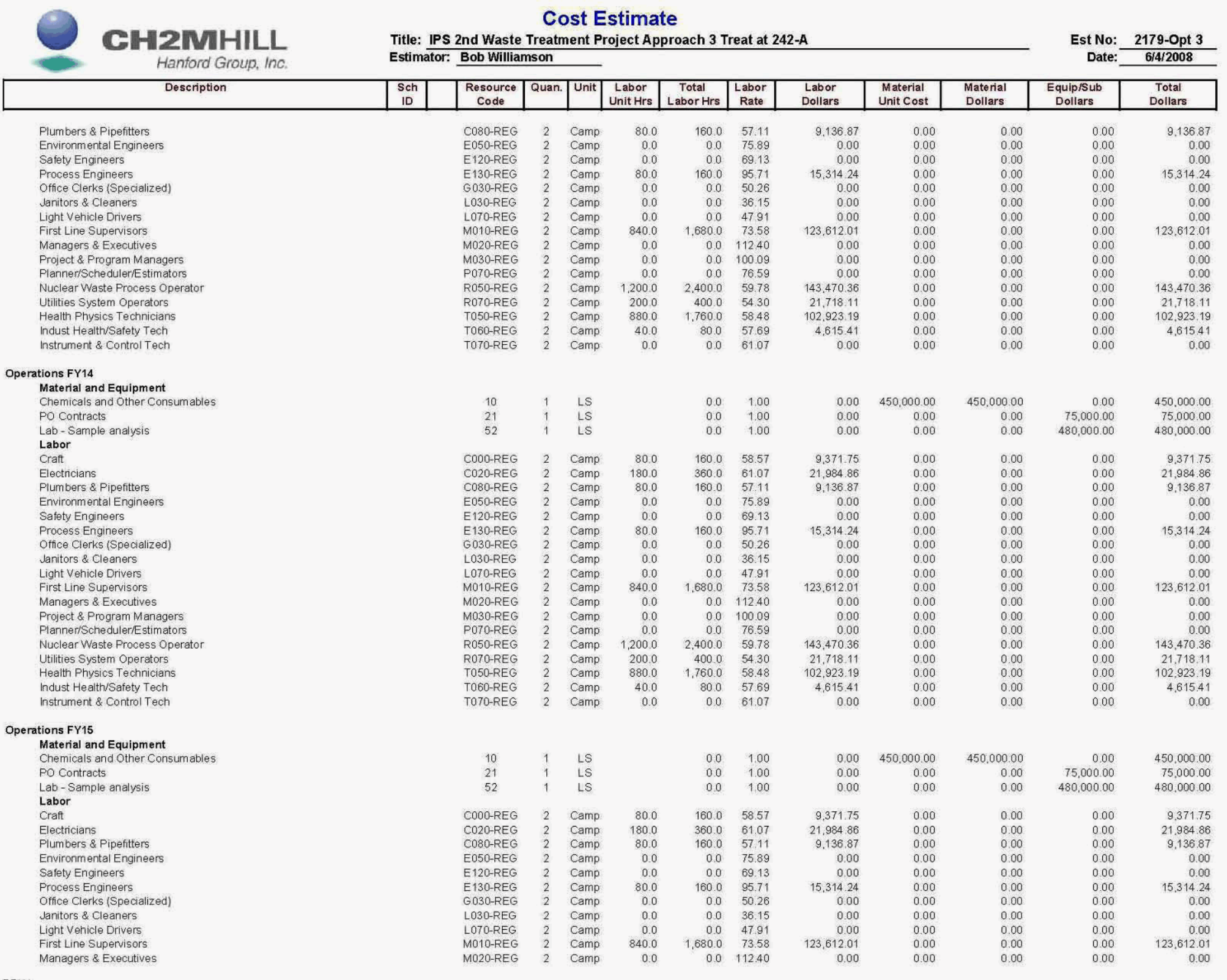


RPP-RPT-37924 Rev. 0

\begin{tabular}{|c|c|c|c|c|c|c|c|c|c|c|c|c|}
\hline \multirow[b]{2}{*}{\begin{tabular}{|l|} 
Description \\
\end{tabular}} & \multicolumn{10}{|c|}{$\begin{array}{l}\text { Cost Estimate } \\
\text { Title: IPS 2nd Waste Treatment Project Approach } 3 \text { Treat at 242-A }\end{array}$} & $\begin{array}{l}\text { Est No: } \\
\text { Date: }\end{array}$ & $\frac{2179-0 p t 3}{6 / 4 / 2008}$ \\
\hline & $\begin{array}{l}\text { Sch } \\
\text { ID }\end{array}$ & $\begin{array}{c}\text { Resource } \\
\text { Code }\end{array}$ & Quan. & Unit & \begin{tabular}{|l|} 
Labor \\
Unit Hrs \\
\end{tabular} & \begin{tabular}{|l} 
Total \\
Labor Hrs \\
\end{tabular} & $\begin{array}{c}\text { Labor } \\
\text { Rate }\end{array}$ & $\begin{array}{l}\text { Labor } \\
\text { Dollars }\end{array}$ & $\begin{array}{l}\text { Material } \\
\text { Unit Cost }\end{array}$ & $\begin{array}{l}\text { Material } \\
\text { Dollars }\end{array}$ & $\begin{array}{l}\text { Equip/sub } \\
\text { Dollars }\end{array}$ & $\begin{array}{c}\text { Total } \\
\text { Dollars }\end{array}$ \\
\hline $\begin{array}{l}\text { Project \& Program Managers } \\
\text { Planner/Scheduler/Estimators } \\
\text { Nuclear Waste Process Operator } \\
\text { Utilties System Operators } \\
\text { Heatth Physics Technicians } \\
\text { Indust Health/Safety Tech } \\
\text { Instrument \& Control Tech }\end{array}$ & & $\begin{array}{l}\text { MO30-REG } \\
\text { P070-REG } \\
\text { R050-REG } \\
\text { R070-REG } \\
\text { TO50-REG } \\
\text { TO60-REG } \\
\text { TO70-REG }\end{array}$ & $\begin{array}{l}2 \\
2 \\
2 \\
2 \\
2 \\
2 \\
2\end{array}$ & $\begin{array}{l}\text { Camp } \\
\text { Camp } \\
\text { Camp } \\
\text { Camp } \\
\text { Camp } \\
\text { Camp } \\
\text { Camp }\end{array}$ & $\begin{array}{r}0.0 \\
0.0 \\
1.200 .0 \\
200.0 \\
880.0 \\
40.0 \\
0.0\end{array}$ & $\begin{array}{r}0.0 \\
0.0 \\
2,400.0 \\
400.0 \\
1,760.0 \\
80.0 \\
0.0\end{array}$ & $\begin{array}{r}100.09 \\
76.59 \\
59.78 \\
54.30 \\
58.48 \\
5.69 \\
61.07\end{array}$ & $\begin{array}{r}0.00 \\
0.00 \\
143.470 .36 \\
21.718 .11 \\
102.923 .19 \\
4.615 .41 \\
0.00\end{array}$ & $\begin{array}{l}0.00 \\
0.00 \\
0.00 \\
0.00 \\
0.00 \\
0.00 \\
0.00\end{array}$ & $\begin{array}{l}0.00 \\
0.00 \\
0.00 \\
0.00 \\
0.00 \\
0.00 \\
0.00\end{array}$ & $\begin{array}{l}0.00 \\
0.00 \\
0.00 \\
0.00 \\
0.00 \\
0.00 \\
0.00\end{array}$ & $\begin{array}{r}0.00 \\
0.00 \\
143,470.36 \\
21.718 .11 \\
102.923 .19 \\
4.615 .41 \\
0.00\end{array}$ \\
\hline $\begin{array}{l}\text { Operations FY16 } \\
\text { Material and Equipment }\end{array}$ & & & & & & & & & & & & \\
\hline $\begin{array}{l}\text { Chemicals and Other Consumables } \\
\text { PO Contracts } \\
\text { Lab - Sample analysis }\end{array}$ & & $\begin{array}{l}10 \\
21 \\
52\end{array}$ & $\begin{array}{l}1 \\
1 \\
1\end{array}$ & $\begin{array}{l}\text { LS } \\
\text { LS } \\
\text { LS }\end{array}$ & & $\begin{array}{l}0.0 \\
0.0 \\
0.0\end{array}$ & $\begin{array}{l}1.00 \\
1.00 \\
1.00\end{array}$ & $\begin{array}{l}0.00 \\
0.00 \\
0.00\end{array}$ & $\begin{array}{r}450,000.00 \\
0.00 \\
0.00\end{array}$ & $\begin{array}{r}450,000.00 \\
0.00 \\
0.00\end{array}$ & $\begin{array}{r}0.00 \\
75,000.00 \\
480,000.00\end{array}$ & $\begin{array}{r}450,000.00 \\
75,000.00 \\
480,000,00\end{array}$ \\
\hline Labor & & & & & & & & & & & & \\
\hline Craft & & COOO-REG & 2 & Camp & 800 & 1600 & 5857 & 937175 & 000 & 0.00 & 0.00 & 937175 \\
\hline Electricians & & C020-REG & 2 & Camp & 180.0 & 360.0 & 61.07 & $21,984.86$ & 0.00 & 0.00 & 0.00 & $21,984,86$ \\
\hline Plumbers \& Pipefitters & & COBOREG & 2 & Camp & 80.0 & 160.0 & $\begin{array}{l}57.11 \\
5710\end{array}$ & $\begin{array}{r}21,0404.00 \\
9,136.87\end{array}$ & 0.00 & 0.00 & 0.00 & 9.136 .87 \\
\hline Environmental Engineers & & E050-REG & 2 & Camp & 0.0 & 0.0 & 75.89 & 0.00 & 0.00 & 0.00 & 0.00 & 0.00 \\
\hline 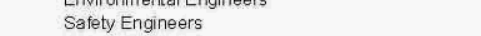 & & E120-REG & 2 & Camp & 0.0 & 0.0 & 69.13 & 0.00 & 0.00 & 0.00 & 0.00 & 0.00 \\
\hline Process Engineers & & E130-REG & 2 & Camp & 80.0 & 160.0 & 95.71 & $15,314.24$ & 0.00 & 0.00 & 0.00 & 15.314 .24 \\
\hline Office Clerks (Specialized) & & GO3O-REG & 2 & Camp & 0.0 & 0.0 & 50.26 & 0.00 & 0.00 & 0.00 & 0.00 & 0.00 \\
\hline Janitors \& Cleaners & & LO30-REG & 2 & Camp & 0.0 & 0.0 & 36.15 & 0.00 & 0.00 & 0.00 & 0.00 & 0.00 \\
\hline Light Vehicle Drivers & & LOTO-REG & 2 & Camp & 0.0 & 0.0 & 47.91 & 0.00 & 0.00 & 0.00 & 0.00 & 0.00 \\
\hline First Line Supenvisors & & MO10-REG & 2 & Camp & 840.0 & 1.680 .0 & 73.58 & $123,612.01$ & 0.00 & 0.00 & 0.00 & $123,612.01$ \\
\hline Managers \& Executives & & MO2O-REG & 2 & Camp & 0.0 & 0.0 & 112.40 & 0.00 & 0.00 & 0.00 & 0.00 & 0.00 \\
\hline Project \& Program Managers & & MO30-REG & 2 & Camp & 0.0 & 0.0 & 100.09 & 0.00 & 0.00 & 0.00 & 0.00 & 0.00 \\
\hline Planner/ScheduleriEstimators & & PO70-REG & 2 & Camp & 0.0 & 0.0 & 76.59 & 0.00 & 0.00 & 0.00 & 0.00 & 0.00 \\
\hline Nuclear Waste Process Operator & & R050-REG & 2 & Camp & $1,200.0$ & $2,400.0$ & 59.78 & $143,470.36$ & 0.00 & 0.00 & 0.00 & $143,470.36$ \\
\hline Utilities System Operators & & R070-REG & 2 & Camp & 200.0 & 400.0 & 54.30 & 21.718 .11 & 0.00 & 0.00 & 0.00 & $21,718.11$ \\
\hline Health Physics Technicians & & TO50-REG & 2 & Camp & 880.0 & $1,760.0$ & 58.48 & $102,923.19$ & 0.00 & 0.00 & 0.00 & $102,923.19$ \\
\hline Indust Health/Safety Tech & & TO60-REG & 2 & Camp & 40.0 & 80.0 & 57.69 & 4.615 .41 & 0.00 & 0.00 & 0.00 & 4.615 .41 \\
\hline Instrument \& Control Tech & & TO70-REG & 2 & Camp & 0.0 & 0.0 & 61.07 & 0.00 & 0.00 & 0.00 & 0.00 & 0.00 \\
\hline $\begin{array}{l}\text { Operations FY17 } \\
\text { Material and Equipment }\end{array}$ & & & & & & & & & & & & \\
\hline Chemicals and Other Consumables & & 10 & 1 & LS & & 0.0 & 1.00 & 0.00 & $450,000.00$ & 450.000 .00 & 0.00 & $450,000.00$ \\
\hline PO Contracts & & 21 & 1 & LS & & 0.0 & 1.00 & 0.00 & 0.00 & 0.00 & $75,000.00$ & $75,000,00$ \\
\hline Lab - Sample analysis & & 52 & 1 & LS & & 0.0 & 1.00 & 0.00 & 0.00 & 0.00 & $480,000.00$ & 480.000 .00 \\
\hline $\begin{array}{l}\text { Labor } \\
\text { Craft }\end{array}$ & & COOO-REG & 2 & Camp & 80.0 & 160.0 & 5857 & 937175 & 0.00 & 0.00 & 000 & 937175 > $>3$ \\
\hline Electricians & & CO20-REG & 2 & Camp & 180.0 & 360.0 & 61.07 & $21,984.86$ & 0.00 & 0.00 & 0.00 & 21.984 .86 \\
\hline Plumbers \& Pipefitters & & CO80-REG & 2 & Camp & 80.0 & 160.0 & 57.11 & 9.136 .87 & 0.00 & 0.00 & 0.00 & 9.136 .87 \\
\hline Environmental Engineers & & E050-REG & 2 & Camp & 0.0 & 0.0 & 75.89 & 0.00 & 0.00 & 0.00 & 0.00 & 0.00 \\
\hline Safety Engineers & & E120-REG & 2 & Camp & 0.0 & 0.0 & 69.13 & 0.00 & 0.00 & 0.00 & 0.00 & \\
\hline Process Engineers & & E130-REG & 2 & Camp & 80.0 & 160.0 & 9571 & $15,314.24$ & 0.00 & 0.00 & 0.00 & 15.314 .24 \\
\hline Office Clerks (Specialized) & & G030-REG & 2 & Camp & 0.0 & 0.0 & 50.26 & 0.00 & 0.00 & 0.00 & 0.00 & 0.00 \\
\hline Janitors \& Cleaners & & LOSO-REG & 2 & Camp & 0.0 & 0.0 & 36.15 & 0.00 & 0.00 & 0.00 & 0.00 & 0.00 \\
\hline Light Vehicle Drivers & & LOTO-REG & 2 & Camp & 0.0 & 0.0 & 47.91 & 0.00 & 0.00 & 0.00 & 0.00 & 0.00 \\
\hline First Line Supervisors & & MO10-REG & 2 & Camp & 840.0 & $1,680.0$ & 73.58 & $123,612.01$ & 0.00 & 0.00 & 0.00 & $123,612.01$ \\
\hline Managers \& Executives & & MO20-REG & 2 & Camp & 0.0 & 0.0 & 112.40 & 0.00 & 0.00 & 0.00 & 0.00 & 0.00 \\
\hline Project \& Program Managers & & MO30-REG & 2 & Camp & 0.0 & 0.0 & 100.09 & 0.00 & 0.00 & 0.00 & 0.00 & 0.00 \\
\hline Planner/SchedulerEstimators & & P070-REG & 2 & Camp & 0.0 & 0.0 & 76.59 & 0.00 & 0.00 & 0.00 & 0.00 & 0.00 \\
\hline Nuclear Waste Process Operator & & R050-REG & 2 & Camp & 1.200 .0 & 2.400 .0 & 59.78 & 143.470 .36 & 0.00 & 0.00 & 0.00 & $143,470.36$ \\
\hline Utilities System Operators & & R070-REG & 2 & Camp & 200.0 & 400.0 & 54.30 & $21,718.11$ & 0.00 & 0.00 & 0.00 & $21,718.11$ \\
\hline Health Physics Technicians & & T050-REG & 2 & Camp & 880.0 & $1,760.0$ & 58.48 & $102,923.19$ & 0.00 & 0.00 & 0.00 & 102.923 .19 \\
\hline Indust Health/Safety Tech & & TO60-REG & 2 & Camp & 40.0 & 80.0 & 57.69 & 4.615 .41 & 0.00 & 0.00 & 0.00 & 4.615 .41 \\
\hline Instrument \& Control Tech & & TO70-REG & 2 & Camp & 0.0 & 0.0 & 61.07 & 0.00 & 0.00 & 0.00 & 0.00 & 0.00 \\
\hline
\end{tabular}

RDW 
RPP-RPT-37924 Rev. 0

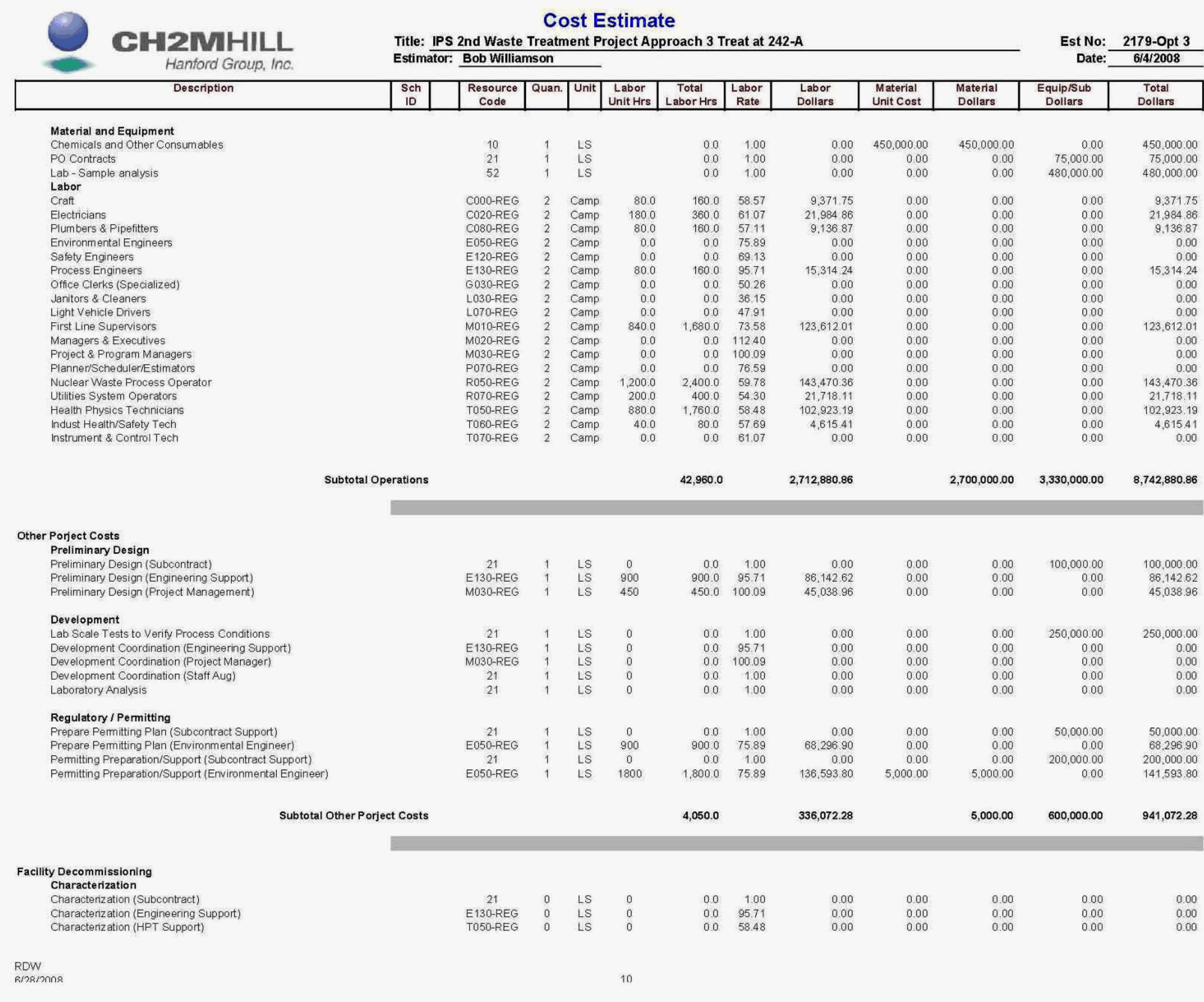


RPP-RPT-37924 Rev. 0

\begin{tabular}{|c|c|c|c|c|c|c|c|c|c|c|c|c|}
\hline CH2 2 Hanford Group, Inc. & & \multicolumn{9}{|c|}{$\begin{array}{l}\text { Title: IPS 2nd Waste Treatment Project Approach } 3 \text { Treat at 242-A } \\
\text { Estimator: } \underline{\text { Bob Williamson }}\end{array}$} & \multicolumn{2}{|c|}{$\begin{aligned} & \text { Est No: } \text { 2179-Opt } 3 \\
& \text { Date: } 6 / 4 / 2008 \\
&\end{aligned}$} \\
\hline \multicolumn{2}{|l|}{ Description } & \begin{tabular}{|c|}
$\begin{array}{c}\text { Resource } \\
\text { Code }\end{array}$ \\
\end{tabular} & Quan. & Unit & \begin{tabular}{|l} 
Labor \\
Unit Hrs \\
\end{tabular} & \begin{tabular}{|l|} 
Total \\
Labor Hrs \\
\end{tabular} & \begin{tabular}{|l}
$\begin{array}{c}\text { Labor } \\
\text { Rate }\end{array}$ \\
\end{tabular} & $\begin{array}{l}\text { Labor } \\
\text { Dollars } \\
\end{array}$ & $\begin{array}{l}\text { Material } \\
\text { Unitc cost } \\
\end{array}$ & $\begin{array}{l}\text { Material } \\
\text { Dollars }\end{array}$ & $\begin{array}{l}\text { Equip/Sub } \\
\text { Dollars }\end{array}$ & $\begin{array}{c}\text { Total } \\
\text { Dollars }\end{array}$ \\
\hline \multicolumn{2}{|l|}{$\begin{array}{l}\text { Decontamination } \\
\text { Decontamination (Subcontract Support) }\end{array}$} & 21 & 0 & LS & 0 & 0.0 & 1.00 & 0.00 & 0.00 & 0.00 & 0.00 & 0.00 \\
\hline \multicolumn{2}{|l|}{$\begin{array}{l}\text { Decommmissioning } \\
\text { Decommissioning (Subcontract Support) }\end{array}$} & 21 & 0 & LS & 0 & 0.0 & 1.00 & 0.00 & 0.00 & 0.00 & 0.00 & 0.00 \\
\hline \multicolumn{2}{|l|}{$\begin{array}{l}\text { Dem ilition / Disposal } \\
\text { Demolition / Disposal (Subcontract Support) }\end{array}$} & 21 & 0 & LS & 0 & 0.0 & 1.00 & 0.00 & 0.00 & 0.00 & 0.00 & 0.00 \\
\hline \multicolumn{2}{|l|}{$\begin{array}{l}\text { Closure } \\
\text { Closure Documentation (Subcontract Support) } \\
\text { Closure Documentation (Environmental Engineer) }\end{array}$} & E050-REG & $\begin{array}{l}0 \\
0\end{array}$ & $\begin{array}{l}\text { LS } \\
\text { LS }\end{array}$ & 0 & $\begin{array}{l}0.0 \\
0.0\end{array}$ & $\begin{array}{r}1.00 \\
75.89\end{array}$ & $\begin{array}{l}0.00 \\
0.00\end{array}$ & $\begin{array}{l}0.00 \\
0.00\end{array}$ & $\begin{array}{l}0.00 \\
0.00\end{array}$ & $\begin{array}{l}0.00 \\
0.00\end{array}$ & $\begin{array}{l}0.00 \\
0.00\end{array}$ \\
\hline \multicolumn{2}{|l|}{$\begin{array}{l}\text { Project Management } \\
\text { Project Management (Subcontract Support) } \\
\text { Project Management (Project Manager) }\end{array}$} & E050-REG & $\begin{array}{l}0 \\
0\end{array}$ & $\begin{array}{l}L S \\
L S\end{array}$ & $\begin{array}{l}0 \\
0\end{array}$ & $\begin{array}{l}0.0 \\
0.0\end{array}$ & $\begin{array}{r}1.00 \\
75.89\end{array}$ & $\begin{array}{l}0.00 \\
0.00\end{array}$ & $\begin{array}{l}0.00 \\
0.00\end{array}$ & $\begin{array}{l}0.00 \\
0.00\end{array}$ & $\begin{array}{l}0.00 \\
0.00\end{array}$ & $\begin{array}{l}0.00 \\
0.00\end{array}$ \\
\hline \multicolumn{2}{|c|}{ Subtotal Facility Decommissioning } & & & & & 0.0 & & 0.00 & & 0.00 & 0.00 & 0.00 \\
\hline \multirow[t]{2}{*}{$\begin{array}{l}\text { Contingency } \\
\text { Contingency }\end{array}$} & & & & & & & & $5,274,244,37$ & & $2,920,556.50$ & $5,531,639.02$ & $13,726,439.89$ \\
\hline & Subtotal Contingency & & & & & & & $5,274,244.37$ & & $2,920,556.50$ & $5,531,639.02$ & $13,726,439.89$ \\
\hline
\end{tabular}


RPP-RPT-37924 Rev. 0

Table G-10. Approach 4a Cost Estimate.

Table begins on next page. 
RPP-RPT-37924 Rev. 0

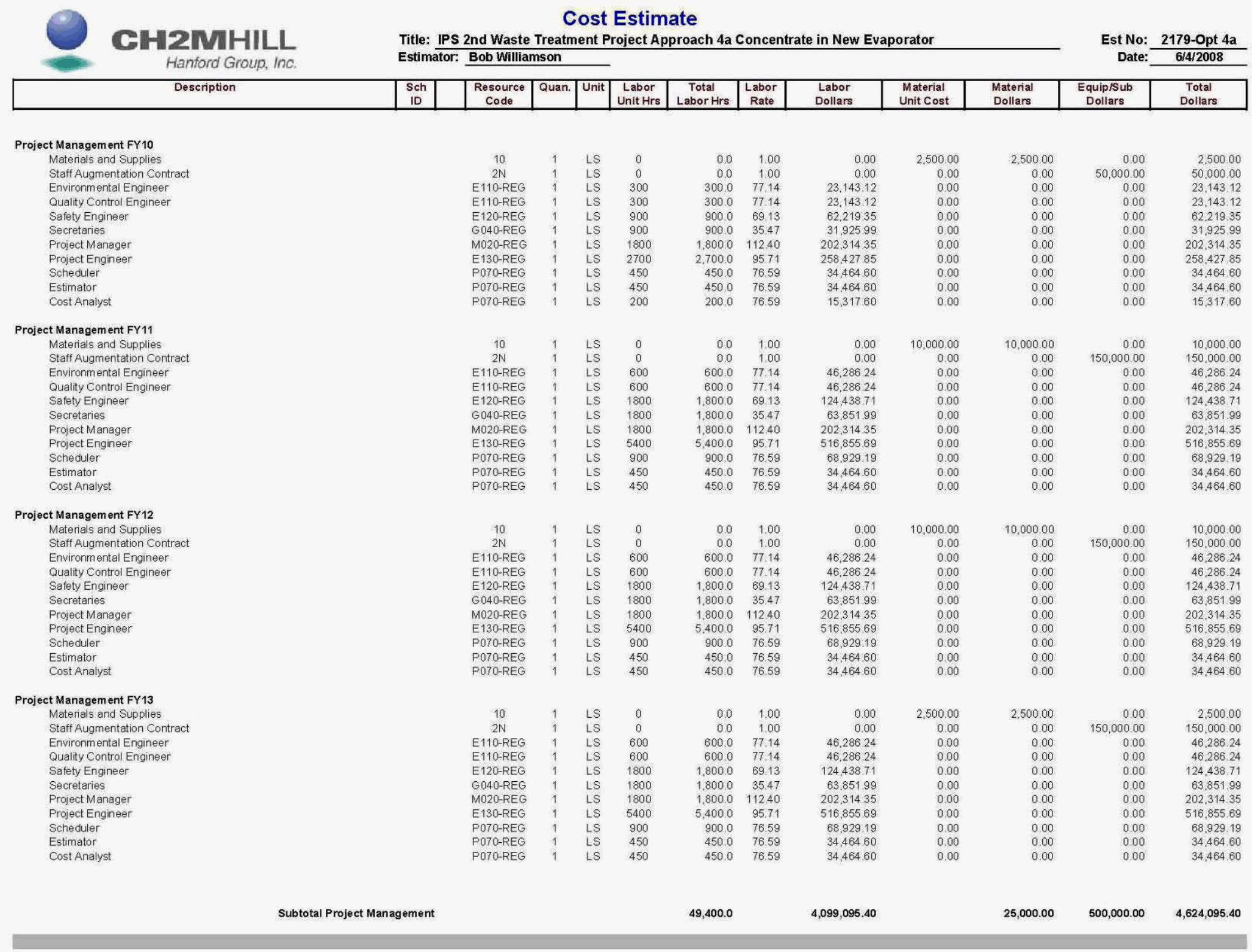


RPP-RPT-37924 Rev. 0

\begin{tabular}{|c|c|c|c|c|c|c|c|c|c|c|c|c|}
\hline \multirow[b]{2}{*}{\begin{tabular}{|l|} 
Description \\
\end{tabular}} & \multicolumn{10}{|c|}{$\begin{array}{c}\text { Cost Estimate } \\
\text { Title: IPS 2nd Waste Treatment Project Approach 4a Co }\end{array}$} & $\begin{array}{l}\text { Est No: } \\
\text { Date: }\end{array}$ & $\frac{2179-0 p t 4 a}{6 / 4 / 2008}$ \\
\hline & \begin{tabular}{c|c|} 
sch \\
ID
\end{tabular} & \begin{tabular}{|c|}
$\begin{array}{c}\text { Resource } \\
\text { Code }\end{array}$ \\
\end{tabular} & Quan. & Unit & \begin{tabular}{|l|} 
Labor \\
Unit Hrs \\
\end{tabular} & \begin{tabular}{c|} 
Total \\
Labor Hrs \\
\end{tabular} & \begin{tabular}{|l|l|}
$\begin{array}{c}\text { Labor } \\
\text { Rate }\end{array}$ \\
\end{tabular} & $\begin{array}{l}\text { Labor } \\
\text { Dollars } \\
\end{array}$ & $\begin{array}{l}\text { Material } \\
\text { Unit Cost }\end{array}$ & $\begin{array}{l}\text { Material } \\
\text { Dollars }\end{array}$ & $\begin{array}{l}\text { Equip/sub } \\
\text { Dollars }\end{array}$ & $\begin{array}{l}\text { Total } \\
\text { Dotlars }\end{array}$ \\
\hline Engineering & & 21 & 1 & LS & 0 & 0.0 & 1.00 & 0.00 & 0.00 & 0.00 & $1,600,000.00$ & $1,600,000,00$ \\
\hline Final Design - Offsite Engineening Contract & & 21 & 1 & LS & 0 & 0.0 & 1.00 & 0.00 & 0.00 & 0.00 & $4,000,000.00$ & $4,000,000,00$ \\
\hline \multirow[t]{2}{*}{ Title III Engineering Contract } & & 21 & 1 & LS & 0 & 0.0 & 1.00 & 0.00 & 0.00 & 0.00 & $990,000.00$ & $990,000.00$ \\
\hline & Subtotal Engineering & & & & & 0.0 & & 0.00 & & 0.00 & $6,590,000.00$ & $6,590,000.00$ \\
\hline \multicolumn{13}{|l|}{$\begin{array}{l}\text { Engineering Support FY10 } \\
\text { Process Engineening Support }\end{array}$} \\
\hline Process Engineer & & E130-REG & 1 & EA & 4200 & 4.200 .0 & 95.71 & $401,998.87$ & $5,000.00$ & $5,000.00$ & 0.00 & $406,998.87$ \\
\hline Contract Support (600 hrs @ \$90.00) & & 21 & 1 & LS & 0 & 0.0 & 1.00 & 0.00 & 0.00 & 0.00 & $15,000.00$ & $15,000,00$ \\
\hline NS \& L Documentation Support & & FOROREF & t & 10 & 30 & (200 & $0570-2-1$ & & & & & 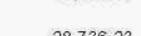 \\
\hline $\begin{array}{l}\text { Nuclear Engineer } \\
\text { Safety Engineer }\end{array}$ & & E120-REG & $\frac{1}{1}$ & LS & 900 & 9000 & $\begin{array}{l}95.19 \\
69.13\end{array}$ & $\begin{array}{l}28.736 .23 \\
62.21935\end{array}$ & $\begin{array}{l}0.00 \\
0.00\end{array}$ & 0.00 & 0.00 & $\begin{array}{l}28,736.23 \\
6221935\end{array}$ \\
\hline $\begin{array}{l}\text { Health Physicist } \\
\text { Hest }\end{array}$ & & P080-REG & 1 & LS & 300 & 300.0 & 78.84 & $23,652.73$ & 0.00 & 0.00 & 0.00 & $\begin{array}{l}02,219.30 \\
23.652 .73\end{array}$ \\
\hline Environmental Engineer & & E050-REG & 1 & LS & 300 & 300.0 & 75.89 & 22.765 .63 & 0.00 & 0.00 & 0.00 & $22,765.63$ \\
\hline Contract Support (300 hrs@\$90hr) & & 21 & 1 & LS & 0 & 0.0 & 1.00 & 0.00 & 0.00 & 0.00 & $5,000.00$ & $5,000.00$ \\
\hline \multicolumn{13}{|l|}{$\begin{array}{l}\text { Engineering Support FY11 } \\
\text { Process Engineering Support }\end{array}$} \\
\hline Process Engineer & & E130-REG & 1 & EA & 4200 & $4,200.0$ & 95.71 & $401,998.87$ & $5,000.00$ & 5.000 .00 & 0.00 & 406.998 .87 \\
\hline \multirow{2}{*}{\multicolumn{13}{|c|}{ NS \& L Documentation Support }} \\
\hline & & & & & & & & & & & & \\
\hline $\begin{array}{l}\text { Nuclear Engineer } \\
\text {. }\end{array}$ & & E080-REG & 1 & LS & 600 & 600.0 & 95.79 & $57,472.45$ & 0.00 & 0.00 & 0.00 & 57.472 .45 \\
\hline $\begin{array}{l}\text { Safety Engineer } \\
\text { Helth Physict }\end{array}$ & & E12UREG & 1 & LS & 1800 & $1,800.0$ & 69.13 & $124,438.71$ & 0.00 & 0.00 & 0.00 & $124,438.71$ \\
\hline Health Physicist & & PUDUREG & 1 & LS & 600 & 600.0 & 78.84 & $47,305,46$ & 0.00 & 0.00 & 0.00 & $47,305.46$ \\
\hline $\begin{array}{l}\text { Environmental Engineer } \\
\text { Contract Support ( } 300 \text { hrs @\$90hr) }\end{array}$ & & $\begin{array}{l}\text { E050REG } \\
21\end{array}$ & $\frac{1}{1}$ & $\begin{array}{l}\text { LS } \\
\text { LS }\end{array}$ & $\begin{array}{c}600 \\
0\end{array}$ & $\begin{array}{r}600.0 \\
0.0\end{array}$ & $\begin{array}{r}75.89 \\
1.00\end{array}$ & $\begin{array}{r}45.531 .27 \\
0.00\end{array}$ & $\begin{array}{l}0.00 \\
0.00\end{array}$ & $\begin{array}{l}0.00 \\
0.00\end{array}$ & $\begin{array}{r}0.00 \\
500000\end{array}$ & $\begin{array}{r}45,531.27 \\
5,000,00\end{array}$ \\
\hline \multicolumn{13}{|l|}{$\begin{array}{l}\text { Engineering Support FY12 } \\
\text { Process Engineenng Support }\end{array}$} \\
\hline Process Engineer & & E130-REG & 1 & EA & 4200 & $4,200.0$ & 95.71 & $401,998.87$ & $5,000.00$ & $5,000.00$ & 0.00 & $406,998.87$ \\
\hline $\begin{array}{l}\text { Contract Support (800 hrs @ } \$ 90.00) \\
\text { ) }\end{array}$ & & 21 & 1 & LS & $a$ & 0.0 & 1.00 & 0.00 & 0.00 & 0.00 & $72,000.00$ & 72.000 .00 \\
\hline $\begin{array}{l}\text { NS \& L Documentation Support } \\
\text { Nuclear Engineer }\end{array}$ & & E080-REG & 1 & LS & 600 & 6000 & 9579 & 57.47245 & 0.00 & 0.00 & 0.00 & 5747245 \\
\hline Safety Engineer & & E120-REG & 1 & LS & 1800 & $1,800.0$ & 69.13 & $124,438.71$ & 0.00 & 0.00 & 0.00 & $124,438.71$ \\
\hline Health Physicist & & P080-REG & 1 & LS & 600 & 600.0 & 78.84 & $47,305,46$ & 0.00 & 0.00 & 0.00 & $47,305.46$ \\
\hline Environmental Engineer & & E050-REG & 1 & LS & 600 & 600.0 & 75.89 & $45,531.27$ & 0.00 & 0.00 & 0.00 & 45.531 .27 \\
\hline Contract Support (400 hrs@\$90hr) & & 21 & 1 & LS & 0 & 0.0 & 1.00 & 0.00 & 0.00 & 0.00 & $36,000.00$ & $36,000.00$ \\
\hline \multicolumn{13}{|l|}{$\begin{array}{l}\text { Engineering Support FY13 } \\
\text { Process Engineering Support }\end{array}$} \\
\hline Process Engineer & & E130-REG & 1 & EA & 4200 & 4.200 .0 & 95.71 & $401,998.87$ & 5.000 .00 & 5.000 .00 & $\begin{array}{r}0.00 \\
72000\end{array}$ & $406,998.87$ \\
\hline NS \& L Documentation Support & & 21 & & & 0 & & 1.00 & 0.00 & 0.00 & 0.00 & & $72,000.00$ \\
\hline Nuclear Engineer & & E080-REG & 1 & LS & 600 & 600.0 & 95.79 & 57.47245 & 0.00 & 0.00 & 0.00 & $57,472.45$ \\
\hline Safety Engineer & & E120-REG & 1 & LS & 1800 & $1,800.0$ & 69.13 & $124,438.71$ & 0.00 & 0.00 & 0.00 & $124,438.71$ \\
\hline Health Physicist & & P080-REG & 1 & LS & 600 & 600.0 & 78.84 & $47,305,46$ & 0.00 & 0.00 & 0.00 & $47,305.46$ \\
\hline $\begin{array}{l}\text { Environmental Engineer } \\
\text { Contract Support }(400 \mathrm{hrs} @ \$ 90 \mathrm{hr})\end{array}$ & & E050-REG & 1 & LS & $\begin{array}{c}600 \\
0\end{array}$ & $\begin{array}{r}600.0 \\
0.0\end{array}$ & 75.89 & $\begin{array}{r}45,531.27 \\
0.00\end{array}$ & 0.00 & 0.00 & $\begin{array}{r}0.00 \\
360000\end{array}$ & $\begin{array}{l}45.531 .27 \\
3600\end{array}$ \\
\hline Title III Engineering Support During Construction & & E000-REG & 1 & LS & 4200 & 4.200 .0 & 82.62 & $346,992.67$ & 0.00 & 0.00 & 0.00 & $346,992.67$ \\
\hline su & Ineering Support & & & & & $33,600.0$ & & $2,916,605.76$ & & $0,000.00$ & $256,000.00$ & $3,192,605.76$ \\
\hline
\end{tabular}


RPP-RPT-37924 Rev. 0

Cost Estimate

Title: IPS 2nd Waste Treatment Project Approach 4a Concentrate in New Evaporator

Est No: 2179-Opt 4a anford Group, inc Estimator: Bob Williamson

\begin{tabular}{|c|c|c|c|c|c|c|c|c|c|c|c|c|c|}
\hline Description & $\begin{array}{c}\text { Sch } \\
\text { ID }\end{array}$ & $\begin{array}{c}\text { Resource } \\
\text { Code }\end{array}$ & Quan. & Unit & $\begin{array}{c}\text { Labor } \\
\text { Unit Hrs }\end{array}$ & $\begin{array}{c}\text { Total } \\
\text { Labor Hrs }\end{array}$ & $\begin{array}{c}\text { Labor } \\
\text { Rate }\end{array}$ & $\begin{array}{c}\text { Labor } \\
\text { Dollars }\end{array}$ & $\begin{array}{c}\text { Material } \\
\text { Unit Cost }\end{array}$ & $\begin{array}{c}\text { Material } \\
\text { Dollars }\end{array}$ & $\begin{array}{c}\text { Equip/Sub } \\
\text { Dollars }\end{array}$ & $\begin{array}{c}\text { Total } \\
\text { Dollars }\end{array}$ \\
\hline
\end{tabular}
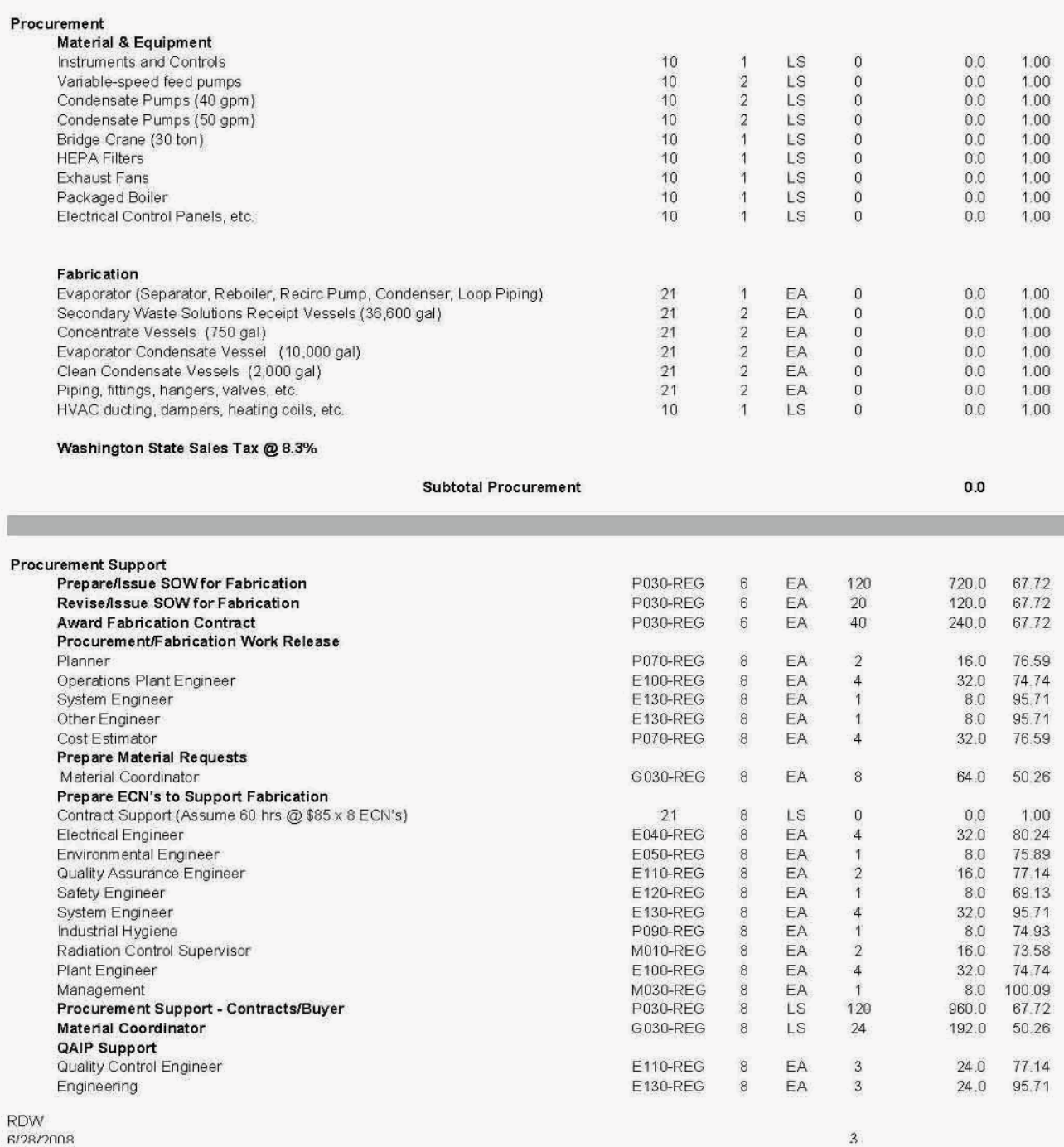

$\begin{array}{rr}0.00 & 40.000 .00 \\ 0.00 & 100,000.00 \\ 0.00 & 30.000 .00 \\ 0.00 & 40.000 .00 \\ 0.00 & 80.000 .00 \\ 0.00 & 280.000 .00 \\ 0.00 & 60.000 .00 \\ 0.00 & 60.000 .00 \\ 0.00 & 100.000 .00\end{array}$

$\begin{array}{rrr}40,000.00 & 0.00 & 40.000 .00 \\ 200,000.00 & 1.00 & 200.001 .00 \\ 60.000 .00 & 2.00 & 60.002 .00 \\ 80.000 .00 & 3.00 & 80.003 .00 \\ 80,000.00 & 4.00 & 80.004 .00 \\ 280,000.00 & 4.00 & 280,004.00 \\ 60.000 .00 & 4.00 & 60.004 .00 \\ 60,000.00 & 4.00 & 60.004 .00 \\ 100.000 .00 & 4.00 & 100.004 .00\end{array}$

$\begin{array}{llll}21 & 1 & \text { EA } & 0 \\ 21 & 2 & \text { EA } & 0 \\ 21 & 2 & \text { EA } & 0 \\ 21 & 2 & \text { EA } & 0 \\ 21 & 2 & \text { EA } & 0 \\ 21 & 2 & \text { EA } & 0 \\ 10 & 1 & \text { LS } & 0\end{array}$

$\begin{array}{ll}0.0 & 1.00 \\ 0.0 & 1.00 \\ 0.0 & 1.00 \\ 0.0 & 1.00 \\ 0.0 & 1.00 \\ 0.0 & 1.00 \\ 0.0 & 1.00\end{array}$

$\begin{array}{lr}0.00 & 12,700,000.00 \\ 0.00 & 130,000.00 \\ 0.00 & 5.000 .00 \\ 0.00 & 60.000 .00 \\ 0.00 & 18,000.00 \\ 0.00 & 350,000.00 \\ 0.00 & 500,000.00\end{array}$

$12,700,000.00$
$260,000.00$
$10,000.00$
$120,000.00$
$36,000.00$
$700,000.00$ $700,000,00$
$500,000.00$

$1,268,738.00$

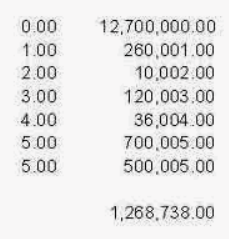

0.0

0.00

$16,554,738.00$

\begin{tabular}{|c|c|c|c|c|c|c|c|c|c|c|}
\hline P030-REG & 6 & EA & 120 & 720,0 & 67.72 & $\begin{array}{r}48,756.27 \\
8\end{array}$ & 0.00 & 0.00 & 0.00 & $\begin{array}{r}48.756 .27 \\
812.27\end{array}$ \\
\hline & 6 & EA & 20 & 120.0 & 67.72 & $8,126.04$ & 0.00 & 0.00 & 0.00 & \\
\hline P030-REG & 6 & EA & 40 & 240.0 & 67.72 & $16,252.09$ & 0.00 & 0.00 & 0.00 & 16.252 .09 \\
\hline P070-REG & 8 & EA & 2 & 16.0 & 76.59 & $1,225.41$ & 0.00 & 0.00 & 0.00 & $1,225.41$ \\
\hline E100-REG & 8 & EA & 4 & 32.0 & 74.74 & 2,39176 & 0.00 & 0.00 & 0.00 & 2,39176 \\
\hline E130-REG & 8 & EA & 1 & 80 & 9571 & 76571 & 000 & 0.00 & 000 & 76571 \\
\hline E130-REG & 8 & EA & 1 & 8.0 & 95.71 & 765.71 & 0.00 & 0.00 & 0.00 & 765.71 \\
\hline PO70-REG & 8 & $\mathrm{EA}$ & 4 & 32.0 & 76.59 & $2,450.82$ & 0.00 & 0.00 & 0.00 & $2,450.82$ \\
\hline G030-REG & 8 & EA & 8 & 64.0 & 50.26 & $3,216.53$ & 0.00 & 0.00 & 0.00 & 3.216 .53 \\
\hline 21 & 8 & LS & 0 & 0.0 & 1.00 & 0.00 & 0.00 & 0.00 & $40,800.00$ & 40.800 .00 \\
\hline E040-REG & 8 & EA & 4 & 32.0 & 80.24 & $2,567.59$ & 0.00 & 0.00 & 0.00 & $2,567.59$ \\
\hline E050-REG & 8 & EA & 1 & 8.0 & 75.89 & 607.08 & 0.00 & 0.00 & 0.00 & 607.08 \\
\hline E110-REG & 8 & EA & 2 & 16.0 & 77.14 & $1.234,30$ & 0.00 & 0.00 & 0.00 & $1,234.30$ \\
\hline E120-REG & 8 & EA & 1 & 80 & 69.13 & 553.06 & 0.00 & 0.00 & 0.00 & 553.06 \\
\hline E130-REG & 8 & EA & 4 & 32.0 & 9571 & 3.062 .85 & 0.00 & 0.00 & 0.00 & 306285 \\
\hline P090-REG & 8 & $E A$ & 1 & 80 & 7493 & 599.45 & 0.00 & 0.00 & 0.00 & 59945 \\
\hline M010-REG & 8 & EA & 2 & 16.0 & 7358 & 1.177 .26 & 0.00 & 0.00 & 0.00 & $1,177,26$ \\
\hline E100-REG & 8 & EA & 4 & 32.0 & 74.74 & 239176 & 0.00 & 0.00 & 0.00 & $2,391.76$ \\
\hline M030-REG & 8 & EA & 1 & 80 & 100.09 & 800.69 & 0.00 & 0.00 & 0.00 & 800.69 \\
\hline P030-REG & 8 & LS & 120 & 960.0 & 67.72 & 65,00836 & 0.00 & 0.00 & 0.00 & $65,008.36$ \\
\hline G030-REG & 8 & LS & 24 & 192.0 & 50.26 & 9.649 .58 & 0.00 & 0.00 & 0.00 & $9,649.58$ \\
\hline & 8 & & 3 & & & & 0.00 & 0.00 & 0.00 & \\
\hline E130-RE & 8 & EA & 3 & 24.0 & 95.71 & $2,297.14$ & 0.00 & 0.00 & 0.00 & 2,297 . \\
\hline
\end{tabular}


RPP-RPT-37924 Rev. 0

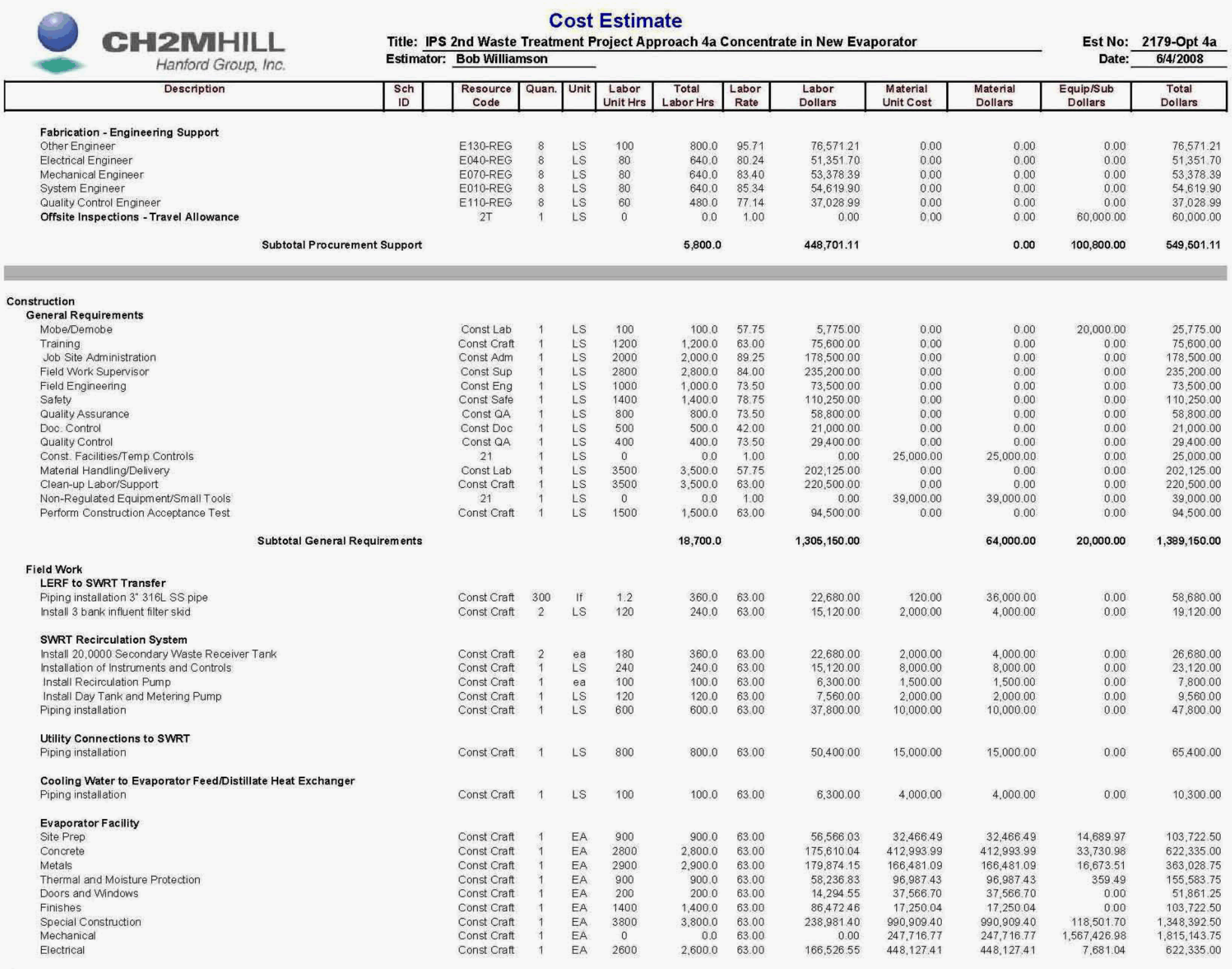


RPP-RPT-37924 Rev. 0

\begin{tabular}{|c|c|c|c|c|c|c|c|c|c|c|c|c|}
\hline \multirow{2}{*}{$\frac{\underbrace{2}_{\text {Hanford Group, Inc }} \text { Cescription }}{\text { DHHLL }}$} & \multicolumn{9}{|c|}{ Cost Estimate } & & $\begin{array}{l}\text { Est No: } \\
\text { Date:- }\end{array}$ & $\frac{2179-0 p t 4 a}{6 / 4 / 2008}$ \\
\hline & $\begin{array}{l}\text { Sch } \\
\text { ID }\end{array}$ & \begin{tabular}{|c|}
$\begin{array}{c}\text { Resource } \\
\text { Code }\end{array}$ \\
\end{tabular} & Quan. & Unit & \begin{tabular}{|l|} 
Labor \\
Unit Hrs \\
\end{tabular} & \begin{tabular}{c|} 
Total \\
Labor Hrs \\
\end{tabular} & $\begin{array}{c}\text { Labor } \\
\text { Rate }\end{array}$ & $\begin{array}{l}\text { Labor } \\
\text { Dollars } \\
\end{array}$ & $\begin{array}{l}\text { Material } \\
\text { Unit Cost } \\
\end{array}$ & $\begin{array}{l}\text { Material } \\
\text { Dollars }\end{array}$ & $\begin{array}{c}\begin{array}{c}\text { Equip/sub } \\
\text { Dollars }\end{array} \\
\end{array}$ & $\begin{array}{c}\text { Total } \\
\text { Dollars }\end{array}$ \\
\hline \multicolumn{13}{|l|}{ Other Construction } \\
\hline $\begin{array}{l}\text { Evaporator Installation } \\
\text { Evaporator Supply Air and Exhaust System }\end{array}$ & & $\begin{array}{l}\text { Const Craft } \\
\text { Const Craft }\end{array}$ & $\frac{1}{1}$ & $\begin{array}{l}E A \\
E A\end{array}$ & $\begin{array}{l}25000 \\
23000\end{array}$ & $\begin{array}{l}25,0000 \\
230000\end{array}$ & $\begin{array}{l}6300 \\
6300\end{array}$ & $\begin{array}{l}1,575,000.00 \\
1449000,00\end{array}$ & $\begin{array}{l}800,000,00 \\
500,000,00\end{array}$ & $\begin{array}{l}800,000,00 \\
50000000\end{array}$ & 0.00 & $\begin{array}{l}2,375,000,00 \\
1,949,000,00\end{array}$ \\
\hline Feed and Condensate System Installation & & Const Craft & 1 & EA & 12000 & $12,000.0$ & 63.00 & $756,000,00$ & $280,000.00$ & $280,000.00$ & 0.00 & $1,036,000.00$ \\
\hline Electrical and Control System Installation & & Const Craft & 1 & EA & 8000 & 8.000 .0 & 63.00 & $504,000.00$ & 160.000 .00 & $160,000,00$ & 0.00 & $664,000.00$ \\
\hline Condensate Retention Basin & & Const Craft & 1 & EA & 0 & 0.0 & 63.00 & 0.00 & 0.00 & 0.00 & $25,000.00$ & 25.000 .00 \\
\hline Subtotal & Id Work & & & & & $86,420.0$ & & $5,444,522.01$ & & $4,274,999.32$ & $1,784,063.67$ & $11,503,585.00$ \\
\hline \multicolumn{13}{|l|}{ Adders } \\
\hline Productivity Factor - Assume $20 \%$ & & 21 & 1 & LS & & $17,284.0$ & & $1,088,904,40$ & 0.00 & 0.00 & 0.00 & $1,088,904,40$ \\
\hline Weather Delays - Assume $10 \%$ & & 21 & 1 & LS & & $10,370.4$ & & $653,342,64$ & 0.00 & 0.00 & 0.00 & $653,342.64$ \\
\hline Allowance for Construction Consumables - $3 \%$ of Const Labor & & 21 & 1 & LS & & 0.0 & & 0.00 & $163,335.66$ & $163,335.66$ & 0.00 & $163,335.66$ \\
\hline Material Sales Tax@8.3\% & & 21 & 1 & LS & & 0.0 & & 0.00 & $354,824,94$ & 354.824 .94 & 0.00 & 354.824 .94 \\
\hline Subt & IAdders & & & & & $27,654.4$ & & $1,742,247.04$ & & $518,160.60$ & 0.00 & $2,260,407.65$ \\
\hline \multirow[t]{2}{*}{ Construction Contractor Fee @ $8 \%$} & & 21 & & & & & & & & & $1,212,251.41$ & $1,212,251.41$ \\
\hline & itruction & & & & & $132,774.4$ & & $8,491,919.06$ & & $4,857,159.92$ & $3,016,315.08$ & $16,365,394.06$ \\
\hline \multicolumn{13}{|l|}{ Construction Management } \\
\hline Management & & M020-REG & 1 & LS & 1800 & 1.800 .0 & 112.40 & $202,314.35$ & 0.00 & 0.00 & 0.00 & $202,314,35$ \\
\hline Construction Manager & & MO30-REG & 1 & LS & 5400 & 5.400 .0 & 100.09 & 540.467 .53 & 0.00 & 0.00 & 0.00 & 540.467 .53 \\
\hline Construction Field Lead & & MO10-REG & 1 & LS & 5400 & 5.400 .0 & 73.58 & $397,324.32$ & 0.00 & 0.00 & 0.00 & 397.324 .32 \\
\hline ClericalDocument Control Support & & G030-REG & 1 & LS & 900 & 900.0 & 50.26 & $45,232,42$ & 0.00 & 0.00 & 0.00 & $45,232.42$ \\
\hline Miscellaneous Office Supplies for CM & & 10 & 1 & LS & 0 & 0.0 & 1.00 & & $50,000.00$ & $50,000.00$ & 0.00 & $50,000.00$ \\
\hline Contract Administration & & P030-REG & 1 & LS & 900 & 900.0 & 67.72 & $60,945.33$ & 0.00 & 0.00 & 0.00 & $60,945.33$ \\
\hline Subtotal Construction N & agement & & & & & $14,400.0$ & & $1,246,283.96$ & & $50,000.00$ & 0.00 & $1,296,283.96$ \\
\hline \multicolumn{13}{|l|}{ Construction Support } \\
\hline Health Physics Technician (HPT) & & T050-REG & 1 & LS & 600 & 600.0 & 58.48 & $35,087.45$ & 0.00 & 0.00 & 0.00 & 35.087 .45 \\
\hline Industrial Health \& Safety & & TO60-REG & 1 & LS & 400 & 400.0 & 57.69 & 23.077 .06 & 0.00 & 0.00 & 0.00 & $23,077.06$ \\
\hline PHMC - Critical Lift Support (Crane \& Rigging Organization) & & $3 \mathrm{P}$ & 1 & LS & 0 & 0.0 & 1.00 & 0.00 & 0.00 & 0.00 & $20,000.00$ & $20,000.00$ \\
\hline $\begin{array}{l}\text { PHMC - Crane Usage Charges } \\
\text { Planning \& Work Package Prep }\end{array}$ & & $3 \mathrm{P}$ & 1 & LS & 0 & 0.0 & 1.00 & 0.00 & 0.00 & 0.00 & $10,000.00$ & $10,000.00$ \\
\hline $\begin{array}{l}\text { Planning \& Work Package Prep } \\
\text { Planner }\end{array}$ & & P070-REG & 10 & EA & 112 & 1.120 .0 & 76.59 & $85,778.55$ & 0.00 & 0.00 & 0.00 & 85.778 .55 \\
\hline System Engineer & & E130-REG & 10 & EA & 20 & 200.0 & 95.71 & $19,142.80$ & 0.00 & 0.00 & 0.00 & 19.142 .80 \\
\hline Radiation Control & & P090-REG & 10 & EA & 20 & 200.0 & 74.93 & $14,986.25$ & 0.00 & 0.00 & 0.00 & $14,986.25$ \\
\hline \multirow{2}{*}{\multicolumn{13}{|c|}{ Enhanced Work Planning }} \\
\hline & & & & & & & & & & & & \\
\hline Planner & & P070-REG & 10 & EA & 3 & 30.0 & 76.59 & 2.297 .64 & 0.00 & 0.00 & 0.00 & $2,297.64$ \\
\hline Carpen & & Co10-REG & 10 & EA & 3 & 30.0 & 55. & 1.67 & 0.00 & 0.00 & 0.00 & $1.675,10$ \\
\hline Electric & & CO20-REG & 10 & EA & 3 & 30.0 & 61. & 1,83 & 0.00 & 0.00 & 0.00 & 1.832 .07 \\
\hline Pipefitter & & CO80-REG & 10 & EA & 3 & 30.0 & 57.11 & 1,71 & 0.00 & 0.00 & 0.00 & 1.713 .16 \\
\hline Miscellaneous Craft & & C120-R & 10 & EA & 3 & 30.0 & 56.94 & 1,70 & 0.00 & 0.00 & 0.00 & 1.708 .13 \\
\hline Environmental Engineer & & E050-F & 10 & EA & 3 & 30.0 & 75 & 2,27 & 0.00 & 0.00 & 0.00 & 2.276 .56 \\
\hline Quality Con & & E110-REG & 10 & EA & 3 & 30.0 & 77.14 & 2,31 & 0.00 & 0.00 & 0.00 & $2,314,31$ \\
\hline Safety $E$ & & E120-REG & 10 & EA & 3 & 30.0 & 69. & $2,073.98$ & 0.00 & 0.00 & 0.00 & $2,073.98$ \\
\hline System Engineer & & E130-REG & 10 & EA & 3 & 30.0 & 95.71 & 2,87 & 0.00 & 0.00 & 0.00 & 2,87142 \\
\hline Light Vehicle Driver & & L070-REG & 10 & EA & 3 & 30.0 & 47.91 & 1.437 .28 & 0.00 & 0.00 & 0.00 & 1,43728 \\
\hline Field Work Supervisor (FWS) & & M010-REG & 10 & EA & 3 & 30.0 & 73.58 & $2,207.36$ & 0.00 & 0,00 & 0.00 & $2,207.36$ \\
\hline $\begin{array}{l}\text { RDW } \\
\text { K/28/7nn } 2\end{array}$ & & & & & 5 & & & & & & & \\
\hline
\end{tabular}


RPP-RPT-37924 Rev. 0

Cost Estimate

Title: IPS 2nd Waste Treatment Project Approach 4a Concentrate in New Evaporator $\quad$ Est No: 2179-Opt 4a

Estimator: Bob Williamson $\quad$ Date: $\frac{2179-0 p t / 4 a}{6 / 2008}$

\begin{tabular}{|c|c|c|c|c|c|c|c|c|c|c|c|c|}
\hline Description & $\begin{array}{l}\text { Sch } \\
\text { ID } \\
\end{array}$ & \begin{tabular}{|c}
$\begin{array}{c}\text { Resource } \\
\text { Code }\end{array}$ \\
\end{tabular} & Quan. & Unit & \begin{tabular}{|l|} 
Labor \\
Unit Hrs \\
\end{tabular} & $\begin{array}{c}\text { Total } \\
\text { Labor Hrs }\end{array}$ & \begin{tabular}{|c|} 
Labor \\
Rate \\
\end{tabular} & $\begin{array}{l}\text { Labor } \\
\text { Dollars }\end{array}$ & $\begin{array}{l}\text { Material } \\
\text { Unit cost }\end{array}$ & $\begin{array}{l}\text { Material } \\
\text { Dollars }\end{array}$ & $\begin{array}{c}\text { Equip/sub } \\
\text { Dollars }\end{array}$ & $\begin{array}{c}\text { Total } \\
\text { Dollars }\end{array}$ \\
\hline Industrial Hygiene & & PO90-REG & 10 & EA & 3 & 30.0 & 74.93 & $2,247.94$ & 0.00 & 0.00 & 0.00 & $2,247.94$ \\
\hline \multirow{2}{*}{\multicolumn{13}{|c|}{ Review \& Approve Work Packages }} \\
\hline & & & & & & & & & & & & \\
\hline Planner & & P070-REG & 10 & EA & 28 & 280.0 & 76.59 & $21,444.64$ & 0.00 & 0.00 & 0.00 & $21,444,64$ \\
\hline Environmental Engineer & & E050-REG & 10 & EA & 5 & 50.0 & 75.89 & 3.794 .27 & 0.00 & 0.00 & 0.00 & $\begin{array}{r}3.794 .27 \\
\end{array}$ \\
\hline Quality Control & & E110-REG & 10 & EA & 5 & 50.0 & 77.14 & 3.857 .19 & 0.00 & 0.00 & 0.00 & 3.857 .19 \\
\hline Safety Engineer & & E120-REG & 10 & EA & 5 & 50.0 & 6913 & $3,456.63$ & 0.00 & 0.00 & 0.00 & 3.456 .63 \\
\hline System Engineer & & E130-REG & 10 & EA & 10 & 100.0 & 9571 & 9.571 .40 & 0.00 & 0.00 & 0.00 & 9.57140 \\
\hline Field Work Supervisor (FWS) & & MO10-REG & 10 & EA & 5 & 50.0 & 7358 & 3.678 .93 & 0.00 & 0.00 & 0.00 & 3.678 .93 \\
\hline Other Engineer & & E130-REG & 10 & EA & 5 & 50.0 & 9571 & $4,785.70$ & 0,00 & 0.00 & 0.00 & $4,785.70$ \\
\hline Health Physics Technician (HPT) & & TO50-REG & 10 & EA & 5 & 50.0 & 58.48 & 2.923 .95 & 0.00 & 0.00 & 0.00 & 2.923 .95 \\
\hline Industrial Health \& Safety & & TO60-REG & 10 & EA & 5 & 50.0 & 57.69 & $2,884.63$ & 0.00 & 0.00 & 0.00 & 2.884 .63 \\
\hline Operations Plant Engineer & & E100-REG & 10 & EA & 25 & 250.0 & 74.74 & $18,685,62$ & 0.00 & 0.00 & 0.00 & $18,685.62$ \\
\hline $\begin{array}{l}\text { Closeout Work Packages } \\
\text { Planner }\end{array}$ & & P070-REG & 10 & EA & 12 & 1200 & 7659 & 9.190 .56 & 0.00 & 000 & 0.00 & 9,19056 \\
\hline Operations Plant Engineer & & E100-REG & 10 & EA & 4 & 40.0 & 74.74 & $2,989.70$ & 0.00 & 0.00 & 0.00 & 2.989 .70 \\
\hline Administration & & G020-REG & 10 & EA & 2 & 20.0 & 33.28 & 665.64 & 0.00 & 0.00 & 0.00 & 665.64 \\
\hline Other Engineer & & E130-REG & 10 & EA & 4 & 40.0 & 95.71 & 3.828 .56 & 0.00 & 0.00 & 0.00 & 3.828 .56 \\
\hline \multirow{2}{*}{\multicolumn{13}{|c|}{$\begin{array}{l}\text { Prepare ECN's } \\
\text { P }\end{array}$}} \\
\hline & & & & & & & & & & & & \\
\hline Contract Support (Assume 90 hrs @ $\$ 85 \times 4$ ECN's) & & 21 & 1 & LS & 0 & 0.0 & 1.00 & 0.00 & 0.00 & 0.00 & $30,600.00$ & $30,600.00$ \\
\hline Electrical Engineer & & E040-REG & 10 & EA & 4 & 40.0 & 80.24 & $3,209.48$ & 0.00 & 0.00 & 0.00 & $3,209,48$ \\
\hline Environmental Engineer & & E050-REG & 10 & EA & 1 & 10.0 & 75.89 & 758.85 & 0.00 & 0.00 & 0.00 & 758.85 \\
\hline Quality Assurance Engineer & & E110-REG & 10 & EA & 2 & 20.0 & 77.14 & 1.542 .87 & 0.00 & 0.00 & 0.00 & 1.542 .87 \\
\hline Safety Engineer & & E120-REG & 10 & EA & 1 & 10.0 & 69.13 & 691.33 & 0.00 & 0.00 & 0.00 & 691.33 \\
\hline System Engineer & & E130-REG & 10 & EA & 4 & 40.0 & 95.71 & $3,828.56$ & 0.00 & 0.00 & 0.00 & 3.828 .56 \\
\hline Industrial Hygiene & & P090-REG & 10 & EA & 1 & 10.0 & 74.93 & 749.31 & 0.00 & 0.00 & 0.00 & 749.31 \\
\hline Radiation Control Supervisor & & M010-REG & 10 & EA & 2 & 20.0 & 73.58 & 1.471 .57 & 0.00 & 0.00 & 0.00 & 1.471 .57 \\
\hline Plant Engineer & & E100-REG & 10 & EA & 4 & 40.0 & 74.74 & $2,989.70$ & 0.00 & 0.00 & 0.00 & 2.989 .70 \\
\hline \multirow{2}{*}{\multicolumn{13}{|c|}{ Prepare USQ's }} \\
\hline & & E130-REG & 4 & EA & 28 & & & & & & & \\
\hline $\begin{array}{l}\text { Review Engineers } \\
\text { Rers }\end{array}$ & & E130-REG & $\begin{array}{l}4 \\
4\end{array}$ & $E A$ & 9 & 36.0 & 95.71 & 3.445 .70 & 0.00 & 0.00 & 0.00 & 3.445 .70 \\
\hline \multicolumn{13}{|l|}{ Radiation Work Permit } \\
\hline $\begin{array}{l}\text { Planner } \\
\text { Electrician }\end{array}$ & & $\begin{array}{l}\text { P070-REG } \\
\text { CO20REG }\end{array}$ & $\begin{array}{l}5 \\
5\end{array}$ & $\begin{array}{l}\text { EA } \\
\text { EA }\end{array}$ & ${ }_{2}^{14}$ & $\begin{array}{l}70.0 \\
100\end{array}$ & $\begin{array}{l}76.59 \\
6107\end{array}$ & $\begin{array}{r}5,361,16 \\
610.69\end{array}$ & $\begin{array}{l}0.00 \\
0.00\end{array}$ & $\begin{array}{l}0.00 \\
0.00\end{array}$ & $\begin{array}{l}0.00 \\
0.00\end{array}$ & $\begin{array}{r}5,361.16 \\
61069\end{array}$ \\
\hline $\begin{array}{l}\text { Electncian } \\
\text { Electrical Engineer }\end{array}$ & & EO40-REG & 5 & EA & 2 & 10.0 & 80.24 & 802.37 & 0.00 & 0.00 & 0.00 & 802.37 \\
\hline Environmental Engineer & & EO50-REG & 5 & EA & 5 & 25.0 & 75.89 & $\begin{array}{r}802.31 \\
189714\end{array}$ & 0.00 & 0.00 & 0.00 & $\begin{array}{l}002.31 \\
1.897 .14\end{array}$ \\
\hline $\begin{array}{l}\text { Environtrenturl } \\
\text { Operations Plant Engineer }\end{array}$ & & E100-REG & 5 & EA & 2 & 100 & 74.74 & $\begin{array}{r}1.097 .14 \\
74742\end{array}$ & 0.00 & 0.00 & 0.00 & $\begin{array}{l}1.89714 \\
74742\end{array}$ \\
\hline Safety Engineer & & E120-REG & 5 & EA & 2 & 100 & 69.13 & $\begin{array}{r}117.42 \\
69133\end{array}$ & 0.00 & 0.00 & 0.00 & 69133 \\
\hline Sustem Enoineer & & E130-REG & 5 & EA & 5 & 250 & 9571 & 239285 & 0.00 & 0.00 & 0,00 & 239285 \\
\hline Field Work Supenvisor (FWS) & & E100-REG & 5 & $E A$ & 5 & 25.0 & 7474 & 1.868 .56 & 0.00 & 0.00 & 000 & $\begin{array}{l}2.392 .05 \\
186856\end{array}$ \\
\hline Health Physics Technician (HPT) & & TO50-REG & 5 & EA & 5 & 25.0 & 5848 & 1,46198 & 0.00 & 0.00 & 0.00 & 1.461 .98 \\
\hline \multirow{2}{*}{\multicolumn{13}{|c|}{$\begin{array}{l}\text { Industrial Health \& Safety } \\
\text { Material Requests }\end{array}$}} \\
\hline & & & & & & & & & & & & \\
\hline $\begin{array}{l}\text { Material Coordinator } \\
\text { Pre Job Briefings }\end{array}$ & & G030-REG & 5 & EA & 4 & 20.0 & 50.26 & $1,005.16$ & 0.00 & 0.00 & 0.00 & $1,005.16$ \\
\hline $\begin{array}{l}\text { Pre Job Briefings } \\
\text { Other Ennineers }\end{array}$ & & E130-REG & 600 & $\mathrm{Hr}$ & 1 & 6000 & 9571 & 5742841 & 0.00 & 0,00 & 000 & 5742841 \\
\hline Administration & & G020-REG & 600 & $\mathrm{Hr}$ & 1 & 600.0 & 33.28 & 19.969 .08 & 0.00 & 0.00 & 0.00 & 19.969 .08 \\
\hline Management & & MO10-REG & 600 & $\mathrm{Hr}$ & 1 & 600.0 & 73.58 & $44,147.15$ & 0.00 & 0.00 & 0.00 & $44,147.15$ \\
\hline \multicolumn{13}{|l|}{ Post Job Alara Review } \\
\hline $\begin{array}{l}\text { Planner } \\
\text { Electrician }\end{array}$ & & CO20-REG & 3 & EA & 4 & 120 & 6107 & 73283 & 0.00 & 0.00 & 0.00 & $\begin{array}{l}459.53 \\
73283\end{array}$ \\
\hline Electrical Engineer & & E040-REG & 3 & EA & $\begin{array}{l}4 \\
2\end{array}$ & 60 & 80.24 & 481.42 & 0.00 & 0.00 & 0.00 & 481.42 \\
\hline Environmental Engineer & & E050-REG & 3 & EA & 1 & 3.0 & 75.89 & 227.66 & 0.00 & 0.00 & 0.00 & 227.66 \\
\hline System Engineer & & E130-REG & 3 & EA & 2 & 60 & 95.71 & 574.28 & 0.00 & 0.00 & 0.00 & 574.28 \\
\hline Other Engineers & & E130-REG & 3 & EA & 2 & 6.0 & 9571 & 574.28 & 0.00 & 0.00 & 0.00 & 574.28 \\
\hline Administration & & G020-REG & 3 & EA & 2 & 6.0 & 33.28 & 199.69 & 0.00 & 0.00 & 0.00 & 199.69 \\
\hline First Line Suponision & & MO10-REG & 3 & FA & 1 & 30 & 7358 & 2074 & 0.000 & 000 & 000 & 20074 \\
\hline
\end{tabular}


RPP-RPT-37924 Rev. 0

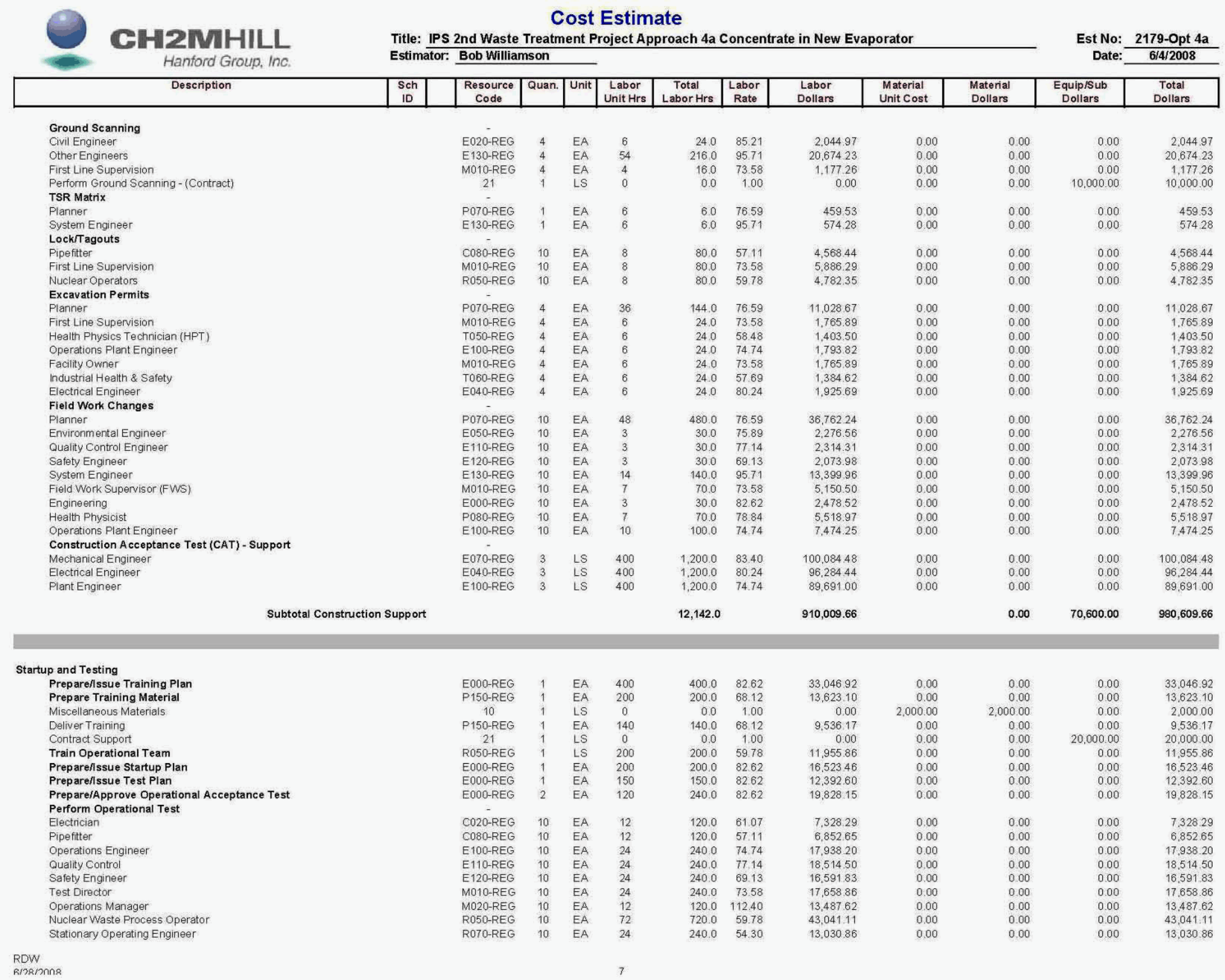


RPP-RPT-37924 Rev. 0

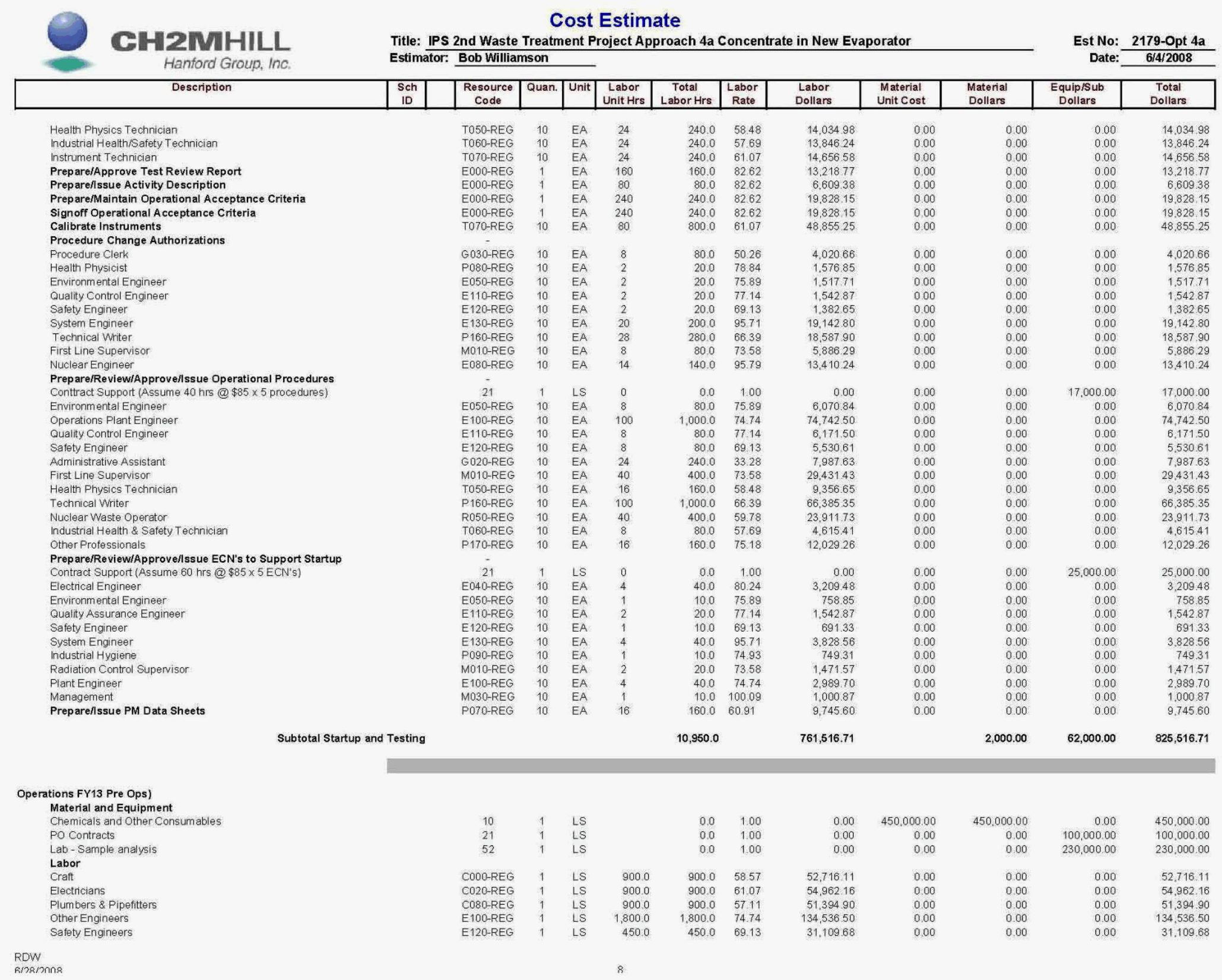


RPP-RPT-37924 Rev. 0

\begin{tabular}{|c|c|c|c|c|c|c|c|c|c|c|c|c|}
\hline \multirow{2}{*}{$\frac{\substack{\text { CHanford Group, Inc. } \\
\text { Description }}}{\underbrace{2}}$} & \multicolumn{10}{|c|}{$\begin{array}{l}\text { Cost Estimate } \\
\text { Title: IPS 2nd Waste Treatment Project Approach 4a Concentrate in New Evaporator } \\
\text { Estimator: Bob Williamson }\end{array}$} & \multicolumn{2}{|c|}{$\begin{aligned} \text { Est No: } & \text { 2179-Opt 4a } \\
\text { Date: } & \frac{64 / 2008}{1}\end{aligned}$} \\
\hline & \begin{tabular}{|l|l|} 
Sch \\
10
\end{tabular} & $\begin{array}{ll}\begin{array}{c}\text { Resource } \\
\text { Code }\end{array} \\
\end{array}$ & Quan. & Unit & $\begin{array}{ll}\text { Labor } \\
\text { Unit Hus }\end{array}$ & $\begin{array}{ll}\text { Total } \\
\end{array}$ & \begin{tabular}{|l|} 
Labor \\
Rate
\end{tabular} & $\begin{array}{l}\text { Labor } \\
\text { Dollars }\end{array}$ & $\begin{array}{l}\text { Material } \\
\text { Unit Cost }\end{array}$ & $\begin{array}{l}\text { Material } \\
\text { Dollars }\end{array}$ & $\begin{array}{l}\text { Equip/sub } \\
\text { Dolys }\end{array}$ & $\begin{array}{l}\text { Total } \\
\text { Dollars }\end{array}$ \\
\hline 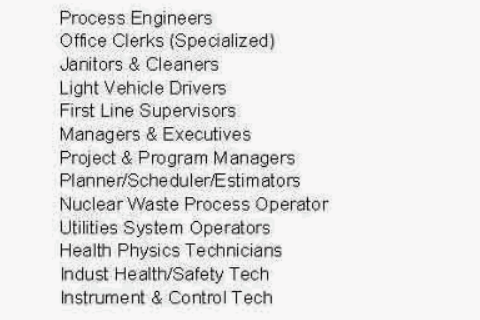 & & 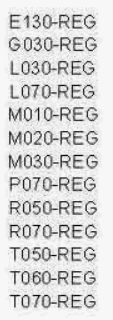 & $\begin{array}{ll} & \\
1 & \\
1 & \\
1 \\
1 \\
1 \\
1 \\
1 \\
1 \\
1 \\
1 \\
1 \\
1 \\
1\end{array}$ & $\begin{array}{l}\text { LS } \\
\text { LS } \\
\text { LS } \\
\text { LS } \\
\text { LS } \\
\text { LS } \\
\text { LS } \\
\text { LS } \\
\text { LS } \\
\text { LS } \\
\text { LS }\end{array}$ & $\begin{array}{r}900.0 \\
250.0 \\
0.0 \\
450.0 \\
1,800.0 \\
1,800.0 \\
250.0 \\
1,800.0 \\
10,8000.0 \\
1,000.0 \\
2,600.0 \\
900.0 \\
450.0\end{array}$ & $\begin{array}{r}900.0 \\
250.0 \\
0.0 \\
450.0 \\
1,8000 \\
1,8000 \\
250.0 \\
1,800.0 \\
10,8000 \\
1.000 .0 \\
2,6000 \\
900.0 \\
450.0\end{array}$ & $\begin{array}{l}95.71 \\
50.26 \\
36.15 \\
47.91 \\
73.58 \\
112.40 \\
100.09 \\
76.59 \\
59.78 \\
54.30 \\
58.48 \\
57.69 \\
61.07\end{array}$ & 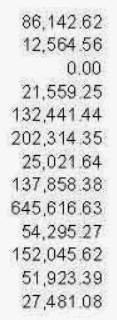 & $\begin{array}{l}0.00 \\
0.00 \\
0.00 \\
0.00 \\
0.000 \\
0.00 \\
0.000 \\
0.000 \\
0.00 \\
0.000 \\
0.00 \\
0.00 \\
0.00\end{array}$ & $\begin{array}{l}0.00 \\
0.00 \\
0.00 \\
0.00 \\
0.00 \\
0.00 \\
0.00 \\
0.00 \\
0.00 \\
0.00 \\
0.00 \\
0.00 \\
0.00\end{array}$ & $\begin{array}{l}0.00 \\
0.00 \\
0.00 \\
0.00 \\
0.00 \\
0.00 \\
0.00 \\
0.00 \\
0.00 \\
0.00 \\
0.00 \\
0.00 \\
0.00\end{array}$ & $\begin{array}{r}86.142 .62 \\
12.564 .56 \\
0.00 \\
21.559 .25 \\
132.44 .44 \\
202.31 .43 \\
25.021 .64 \\
137.258 .38 \\
645.616 .63 \\
54.253 .27 \\
152.045 .62 \\
51.923 .39 \\
27.481 .08\end{array}$ \\
\hline Operations FY14 & & & & & & & & & & & & \\
\hline 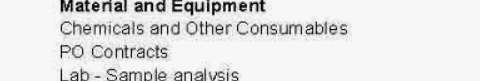 & & $\begin{array}{l}10 \\
21 \\
52\end{array}$ & $\frac{1}{1}$ & $\begin{array}{l}\text { LS } \\
\text { LS }\end{array}$ & & $\begin{array}{l}0.0 \\
0.0 \\
0.0\end{array}$ & $\begin{array}{l}1.00 \\
1.00 \\
1.00\end{array}$ & $\begin{array}{l}0.00 \\
0.00\end{array}$ & $\begin{array}{r}450.000 .00 \\
0.00\end{array}$ & $\begin{array}{r}450,000.00 \\
0.00\end{array}$ & $\begin{array}{r}0.00 \\
100,000.00\end{array}$ & $\begin{array}{l}450,000.00 \\
100,000.00\end{array}$ \\
\hline 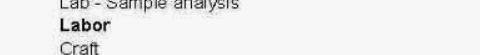 & & C000-REG & & & & & & & & & & \\
\hline $\begin{array}{l}\text { Electicians } \\
\text { Pumbers \& Pipefitters } \\
\text { Other Enginears }\end{array}$ & & $\begin{array}{l}\text { Co20-REG } \\
\text { Co80-REG } \\
\text { E100-REG }\end{array}$ & & $\begin{array}{l}\text { LS } \\
\text { LS } \\
\text { LS }\end{array}$ & $\begin{array}{r}900.0 \\
900.0 \\
1800.0\end{array}$ & $\begin{array}{r}990.0 \\
90.0 \\
1.800 .0\end{array}$ & $\begin{array}{l}51.07 \\
57.11 \\
74.74\end{array}$ & $\begin{array}{l}52,962.17 \\
51.349 \\
54.3490 \\
134.536 .50\end{array}$ & $\begin{array}{l}0.00 \\
0.00 \\
0.00 \\
0.00\end{array}$ & $\begin{array}{l}0.00 \\
0.00 \\
0.00\end{array}$ & $\begin{array}{l}0.00 \\
0.00 \\
0.00\end{array}$ & 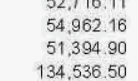 \\
\hline $\begin{array}{l}\text { Satety Engininers } \\
\text { Procoss }\end{array}$ & & E120-REG & 1 & Ls & 450.0 & 450.0 & 69.13 & $31,109.68$ & 0.00 & 0.00 & 0.00 & $31,109.68$ \\
\hline $\begin{array}{l}\text { Processs Engineers } \\
\text { Office Clerks (Spe cialized) }\end{array}$ & & $\begin{array}{l}\text { E130-REG } \\
\text { GO30REG }\end{array}$ & $\frac{1}{1}$ & $\begin{array}{l}L S \\
L S\end{array}$ & $\begin{array}{l}900.0 \\
250.0\end{array}$ & $\begin{array}{l}900.0 \\
250.0\end{array}$ & $\begin{array}{l}95.71 \\
50.26\end{array}$ & $\begin{array}{l}86,14262.62 \\
12,56456\end{array}$ & 0.00 & $\begin{array}{l}0.00 \\
0.00\end{array}$ & 0.00 & $\begin{array}{l}86.142 .62 \\
1256456\end{array}$ \\
\hline Janitors \& Cleane & & LO30-REG & 1 & LS & 0.0 & 0.0 & 36.15 & $\begin{array}{r}0.00 \\
2155025\end{array}$ & D & 0.00 & 0.00 & $\begin{aligned} 0.00 \\
0150.25\end{aligned}$ \\
\hline $\begin{array}{l}\text { Light Veticle Dirivers } \\
\text { First Une Supervisors }\end{array}$ & & $\begin{array}{l}\text { LO70-REG } \\
\text { MO10REG }\end{array}$ & 1 & $\begin{array}{l}\text { LS } \\
\text { LS }\end{array}$ & $\begin{array}{c}450.0 \\
1800.0\end{array}$ & $\begin{array}{l}450.0 \\
18000\end{array}$ & $\begin{array}{l}47.91 \\
73.58\end{array}$ & $\begin{array}{r}21.559 .25 \\
1324444\end{array}$ & 0.00 & 0.00 & 0.00 & 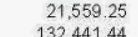 \\
\hline es & & MO20-REG & 1 & LS & $1,800.0$ & $1,800.0$ & 112.50 & $\begin{array}{r}302,444.44 \\
202,314,35\end{array}$ & & 0.00 & 0.00 & $202,314.35$ \\
\hline $\begin{array}{l}\text { Project \& } \\
\text { Plopors }\end{array}$ & & $\begin{array}{l}\text { MO30-REG } \\
\text { PNOPEG }\end{array}$ & 1 & LS & 250.0 & 250.0 & 100.09 & $\begin{array}{r}25,02164 \\
1378538\end{array}$ & & & 0.00 & $\begin{array}{r}25.021 .64 \\
137.8538\end{array}$ \\
\hline $\begin{array}{l}\text { Plannerer/SchedulerEstimators } \\
\text { Nuctear Waste Process OOerator }\end{array}$ & & $\begin{array}{l}\text { P070-REG } \\
\text { R050REG }\end{array}$ & $\begin{array}{l}1 \\
1\end{array}$ & $\begin{array}{l}\text { LS } \\
\text { LS } P\end{array}$ & $\begin{array}{r}1,800.0 \\
10800.0\end{array}$ & $\begin{array}{r}1,8000.0 \\
10,000.0\end{array}$ & $\begin{array}{l}76.59 \\
5978\end{array}$ & $\begin{array}{l}137.858 .38 \\
64561663\end{array}$ & 0,0 & 0.00 & 0.00 & $\begin{array}{l}137.858 .38 \\
645616.63\end{array}$ \\
\hline $\begin{array}{l}\text { Utilties S } \\
\text { Utents }\end{array}$ & & RO70-REG & 1 & ts & 1,0000 & 1.000 .0 & 54.30 & $54,295.27$ & 0.00 & 0.00 & 0.00 & 54.295 .27 \\
\hline 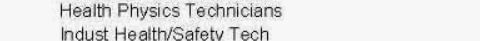 & & $G$ & 1 & LS & 2.500 .0 & $2,600.0$ & 58.48 & $\begin{array}{r}152,045.62 \\
510220\end{array}$ & & & & $152,045.62$ \\
\hline $\begin{array}{l}\text { Indust Heath } \\
\text { Instrumentety \& Control Tech }\end{array}$ & & $\begin{array}{l}\text { To60-REG } \\
\text { TO70-REG }\end{array}$ & $\begin{array}{l}1 \\
1\end{array}$ & ${ }_{\text {LS }}$ & $\begin{array}{l}900.0 \\
450.0\end{array}$ & $\begin{array}{l}9000.0 \\
450.0\end{array}$ & 61.07 & $\begin{array}{l}571923339 \\
27,481.08\end{array}$ & $\begin{array}{l}0.00 \\
0.00\end{array}$ & $\begin{array}{l}0.00 \\
0.00\end{array}$ & $\begin{array}{l}0.00 \\
0.00\end{array}$ & $\begin{array}{l}51,2323.39 \\
27.481 .08\end{array}$ \\
\hline erations $F Y$ & & & & & & & & & & & & \\
\hline er consumables & & 10 & 1 & LS & & 0.0 & 1.00 & 0.00 & $450,000.00$ & $450,000.00$ & & 450.000 .00 \\
\hline Po Contracts & & 21 & 1 & LS & & 0.0 & 1.00 & 0.00 & $m_{0}$ & 0.00 & $100,000.00$ & $100,000.00$ \\
\hline Sample analysis & & 52 & 1 & LS & & 0.0 & 1.00 & 0.00 & 0.00 & 0.00 & $230,000.00$ & 230.000 .00 \\
\hline Cre & & CO00-REG & 1 & LS & 9000.0 & 9000 & 58.57 & $52,716.11$ & 0.00 & 0.00 & 0.00 & $52,716.11$ \\
\hline fitters & & $\begin{array}{l}\text { Co00-REG } \\
\text { Co80-REG }\end{array}$ & & $\begin{array}{l}\text { LS } \\
\text { LS }\end{array}$ & $\begin{array}{l}990.0 \\
900.0\end{array}$ & $\begin{array}{l}900.0 \\
900.0\end{array}$ & $\begin{array}{l}61.07 \\
57.11\end{array}$ & $\begin{array}{l}54 . \\
51 .\end{array}$ & & & 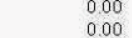 & $\begin{array}{l}54,9 \\
513\end{array}$ \\
\hline & & E100-REG & & LS & 1.800 .0 & $\begin{array}{l}1.800 .0 \\
1,800\end{array}$ & 74.74 & $134,536.50$ & & & 10 & $\begin{array}{r}334,536.50 \\
\end{array}$ \\
\hline sa & & E120-REG & & LS & 450.0 & 450.0 & 6913 & 31,10 & & & 0 & 31.109.68 \\
\hline alized) & & $\begin{array}{l}\text { E130-REG } \\
\text { G000-REG }\end{array}$ & $\begin{array}{l}1 \\
1\end{array}$ & $\begin{array}{l}\text { LS } \\
\text { LS }\end{array}$ & $\begin{array}{l}900.0 \\
250.0\end{array}$ & $\begin{array}{l}900.0 \\
250.0\end{array}$ & $\begin{array}{l}9571 \\
50.26\end{array}$ & $\begin{array}{l}86.142 .62 \\
1.255456\end{array}$ & & $\begin{array}{l}0.0 \\
0.0\end{array}$ & 00 & $\begin{array}{l}86.142 .62 \\
12.565 .56\end{array}$ \\
\hline Janitors \& Clean & & LO30-REG & $i$ & LS & 0.0 & 0.0 & 3615 & 0.00 & 0.00 & 0.00 & 0.00 & 0.00 \\
\hline (anich Dor & & 70-REG & 1 & LS & 450.0 & 450.0 & 47.91 & 21.55925 & 0 & 0.0 & 0.00 & $21,559.25$ \\
\hline ss & & M010-REG & 1 & LS & $\begin{array}{l}1,800.0 \\
1800\end{array}$ & $\begin{array}{l}1,800.0 \\
18000\end{array}$ & 73. & $\begin{array}{l}132,441.44 \\
20231425\end{array}$ & 0.00 & 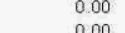 & 0.00 & $132,441.44$ \\
\hline utives & & $\begin{array}{l}\text { M020-REG } \\
\text { M20RE }\end{array}$ & 1 & ts & $\begin{array}{l}1,800.0 \\
2500\end{array}$ & 200 & 1200 & $\begin{array}{l}202,34.35 \\
250204\end{array}$ & 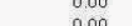 & 0.0 & 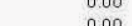 & 202.314 .35 \\
\hline anneris & & 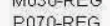 & 1 & Ls & 18000 & 18000 & 76 & $\begin{array}{l}1644 \\
838\end{array}$ & & & 年 & 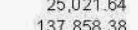 \\
\hline Nuclear Waste Procoess & & RO50-REG & 1 & LS & 10.800 .0 & 10.8000 & 59.78 & $\begin{array}{l}645.616 .63 \\
6463\end{array}$ & 0.00 & 0.00 & 0.00 & $\begin{array}{l}645.616 .63 \\
6453\end{array}$ \\
\hline
\end{tabular}


RPP-RPT-37924 Rev. 0

Cost Estimate

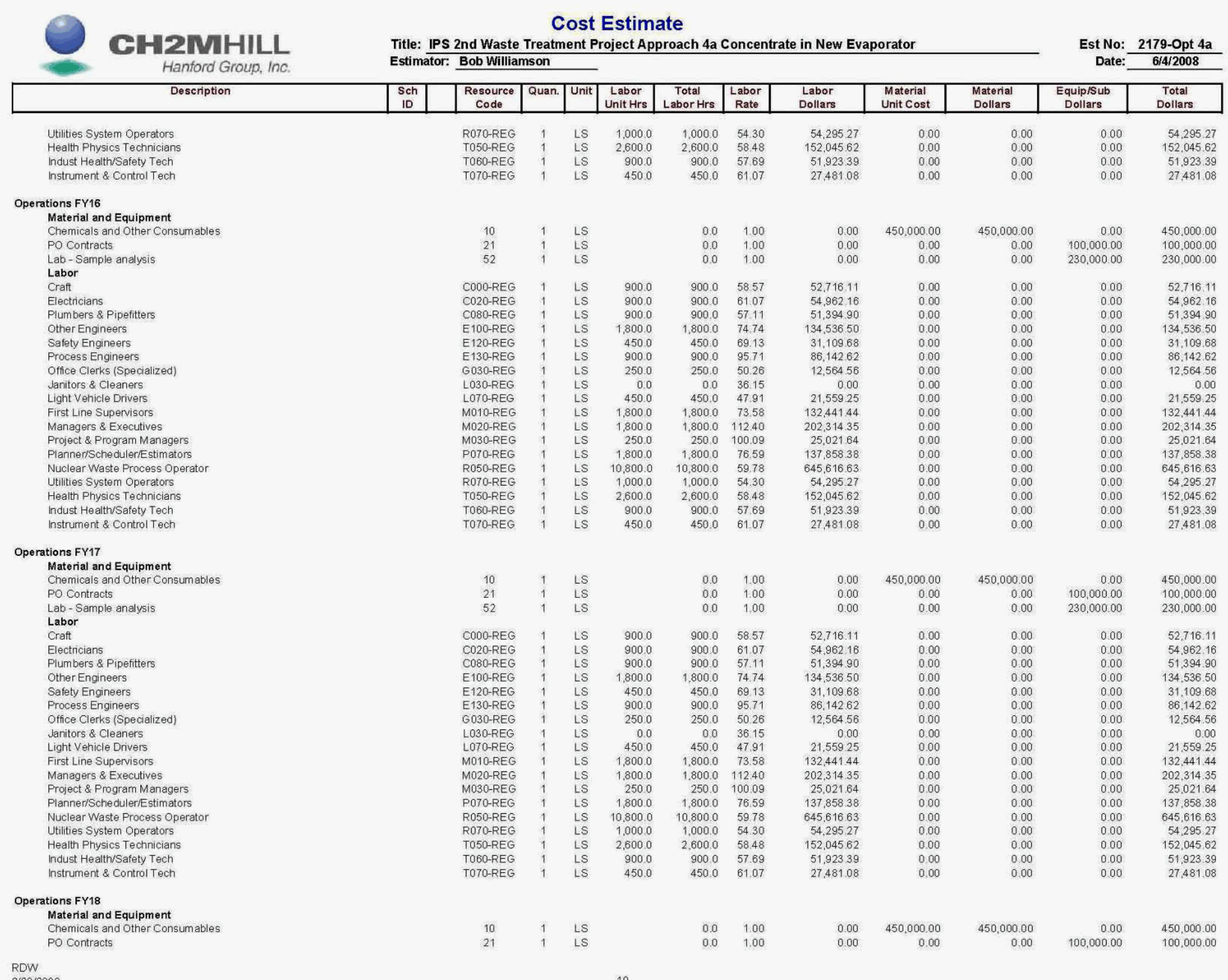


RPP-RPT-37924 Rev. 0

\begin{tabular}{|c|c|c|c|c|c|c|c|c|c|c|c|c|}
\hline CHIII 2 Hanford Group, Inc. & $\begin{array}{l}\text { Title: } \\
\text { Estima }\end{array}$ & $\begin{array}{l}\text { 2nd Waste } \\
\text { Bob Williar }\end{array}$ & $\begin{array}{l}\text { Treatm } \\
\text { nson }\end{array}$ & ent $P$ & $\begin{array}{l}\text { Estime } \\
\text { roject App }\end{array}$ & $\begin{array}{l}\text { ate } \\
\text { proach } 4 a \mathrm{C}\end{array}$ & Concent & in New Eve & orator & & $\begin{array}{l}\text { Est No: } \\
\text { Date: }\end{array}$ & $\begin{array}{c}2179-0 p t 4 a \\
6 / 4 / 2008\end{array}$ \\
\hline Description & \begin{tabular}{|c|} 
Sch \\
ID \\
\end{tabular} & \begin{tabular}{|c|}
$\begin{array}{c}\text { Resource } \\
\text { Code }\end{array}$ \\
\end{tabular} & \begin{tabular}{|l|} 
Quan. \\
\end{tabular} & \begin{tabular}{|l|} 
Unit \\
\end{tabular} & \begin{tabular}{l|l|} 
Labor \\
Unit Hrs \\
\end{tabular} & \begin{tabular}{c|} 
Total \\
Labor Hrs \\
\end{tabular} & $\begin{array}{c}\text { Labor } \\
\text { Rate } \\
\end{array}$ & $\begin{array}{l}\text { Labor } \\
\text { Dollars }\end{array}$ & $\begin{array}{l}\text { Material } \\
\text { Unit Cost } \\
\end{array}$ & $\begin{array}{l}\text { Material } \\
\text { Dollars } \\
\end{array}$ & $\begin{array}{c}\text { Equip/sub } \\
\text { Dollars }\end{array}$ & $\begin{array}{l}\text { Total } \\
\text { Dollars }\end{array}$ \\
\hline Lab-Sample analysis & & 52 & 1 & LS & & 0.0 & 1.00 & 0.00 & 0.00 & 0.00 & $230,000.00$ & $230,000.00$ \\
\hline Craft & & CO00-REG & 1 & LS & 900.0 & 900.0 & 58.57 & $52,716.11$ & 0.00 & 0.00 & 0.00 & $52,716.11$ \\
\hline Electricians & & C020-REG & 1 & LS & 900.0 & 900.0 & 61.07 & $54,962.16$ & 0.00 & 0. & 0.00 & $54,962,16$ \\
\hline Plumbers \& Pipefitters & & C080-REG & 1 & LS & 900.0 & 900.0 & 57.11 & $51,394.90$ & 0.00 & 0.00 & 0.00 & $51,394.90$ \\
\hline Other Engineers & & E100-REG & 1 & LS & $1,800.0$ & $1,800.0$ & 74.74 & 134,53650 & 0.00 & 0.00 & 0.00 & $134,536,50$ \\
\hline Safety Engineers & & E120-REG & 1 & LS & 450.0 & 450.0 & 6913 & $31,109.68$ & 0.00 & 0,00 & 0.00 & 31.109 .68 \\
\hline Process Engineers & & E130-REG & 1 & LS & 900.0 & 900.0 & 9571 & 86.142 .62 & 0.00 & 0.00 & 00 & $86,142.62$ \\
\hline Office Clerks (Specialized) & & G030-REG & 1 & LS & 250.0 & 250.0 & 50.26 & 12,56456 & 0 & ) & 0 & $12,564.56$ \\
\hline Janitors \& Cleaners & & LO30-REG & 1 & LS & 0.0 & 0.0 & 36.15 & 0.00 & & ) & 0.00 & \\
\hline Light Vehicle Drivers & & L070-REG & 1 & LS & 450.0 & 450.0 & 47.91 & 21.559 .25 & & ) & 0.00 & 21.559 .25 \\
\hline First Line Supervisors & & M010-REG & 1 & LS & 1.800 .0 & 1.800 .0 & 73.58 & $132,441,44$ & & p & 0.00 & 132.441 .44 \\
\hline Managers \& Executives & & MO20-REG & 1 & LS & $1,800.0$ & $1,800.0$ & 112.40 & $202,314,35$ & & D & 0.00 & $202,314,35$ \\
\hline Project \& Program Managers & & M030-REG & 1 & LS & 250.0 & 250.0 & 100.09 & 25.021 .64 & & & 0.00 & 25.021 .64 \\
\hline Planner/Sche duler/Estimators & & P070-REG & 1 & LS & $1,800.0$ & 1.800 .0 & 76.59 & $137,858.38$ & & 0.00 & 0.00 & 137.858 .38 \\
\hline Nuclear Waste Process Operator & & R050-REG & 1 & LS & $10,800.0$ & $10,800.0$ & 59.78 & 645.616 .63 & & 0.00 & 0.00 & 645.616 .63 \\
\hline Utilities System Operators & & R070-REG & 1 & LS & 1.000 .0 & 1.000 .0 & 54.30 & 54.295 .27 & & 0.00 & 0.00 & 54.295 .27 \\
\hline Health Physics Technicians & & T050-REG & 1 & LS & $2,600.0$ & $2,600.0$ & 58.48 & $152,045.62$ & & 0.00 & 0.00 & $152,045,62$ \\
\hline $\begin{array}{l}\text { Indust Health/Safety Tech } \\
\text { Instrument \& Control Tech }\end{array}$ & & $\begin{array}{l}\text { T060-REG } \\
\text { T070-REG }\end{array}$ & ${ }_{1}^{1}$ & $\begin{array}{l}\text { LS } \\
\text { LS }\end{array}$ & $\begin{array}{l}900.0 \\
450.0\end{array}$ & $\begin{array}{l}900.0 \\
450.0\end{array}$ & $\begin{array}{l}57.69 \\
61.07\end{array}$ & $\begin{array}{l}51,923.39 \\
27,481.08\end{array}$ & 0.00 & $\begin{array}{l}0.00 \\
0.00\end{array}$ & $\begin{array}{l}0.00 \\
0.00\end{array}$ & $\begin{array}{l}51.923 .39 \\
27.481 .08\end{array}$ \\
\hline & erations & & & & & $167,700.0$ & & $11,243,901.42$ & & $2,700,000.00$ & $1,980,000.00$ & $15,923,901.42$ \\
\hline her Porject Costs & & & & & & & & & & & & \\
\hline her Porject Costs & & & & & & & & & & & & \\
\hline $\begin{array}{l}\text { Prelimir } \\
\text { PPelimin }\end{array}$ & & & & & & & & & & & & \\
\hline Preliminary Design (Subcontra & & 21 & 1 & LS & 0 & 0.0 & 1.00 & 0.00 & 0.00 & 0.00 & $250,000.00$ & $250,000.00$ \\
\hline Preliminary Design (Engineering Support) & & E130-REG & 1 & LS & 1800 & 1.800 .0 & 95.71 & $172,285.23$ & 0.00 & 0.00 & 0.00 & $172,285.23$ \\
\hline Preliminary Design (Project Management) & & M030-REG & 1 & LS & 900 & 900.0 & 100.09 & $90,077.92$ & 0.00 & 0.00 & 0.00 & $90,077.92$ \\
\hline Develo & & & & & & & & & & & & \\
\hline ts to Ve & & 21 & 1 & LS & 0 & 0.0 & 1.00 & 0.00 & 0.00 & 0.00 & $300,000.00$ & $300,000.00$ \\
\hline Develop & & E130-REG & 1 & LS & 1800 & 1.800 .0 & 95.71 & $172,285.23$ & & & 0.00 & 172.285 .23 \\
\hline Develo & & M030-REG & 1 & LS & 900 & 900.0 & 100.09 & $90,077.92$ & 0 & & 00 & $90,077.92$ \\
\hline Develop & & 21 & 1 & LS & 0 & 0.0 & 1.00 & 0.00 & & 0.00 & 100.000 .00 & $100,000.00$ \\
\hline Laboratory Analysis & & 21 & 1 & LS & 0 & 0.0 & 1.00 & 0.00 & 0.00 & 0.00 & $250,000.00$ & $250,000.00$ \\
\hline Regu & & & & & & & & & & & & \\
\hline Prepar & & 21 & 1 & LS & 0 & 0.0 & 1.00 & 0.00 & 0.00 & 0.00 & $50,000.00$ & $50,000.00$ \\
\hline Prepar & & E050-REG & 1 & LS & 900 & 900.0 & 75.89 & $68,296.90$ & 0 & 0.00 & 0.00 & $68,296.90$ \\
\hline Permitt & & 21 & 1 & LS & 0 & 0.0 & 1.00 & 0.00 & 0 & & $200,000.00$ & $200,000.00$ \\
\hline Permitting Preparation/Support (Environmental Engineer) & & E050-REG & 1 & LS & 1800 & $1,800.0$ & 75.89 & $136,593,80$ & $5,000.00$ & 5.000 .00 & 10 & 141.593 .80 \\
\hline AirPern & & 21 & 1 & LS & 0 & 0.0 & 0.00 & 0.00 & 0.00 & 0.00 & $150,000.00$ & $150,000.00$ \\
\hline Air $\mathrm{Pe}$ & & E130 & 1 & LS & 1808 & 1.808 .0 & 80. & 144.820 .80 & & & & 144. \\
\hline Develop/Review/Approve RCRA Part B Permit & & 21 & 1 & LS & 0 & 0.0 & 0.00 & 0.00 & 0. & 0.00 & $500,000.00$ & $500,000.00$ \\
\hline Develop/Review/Approve RCRA Part B Permit & & E130 & 1 & LS & 3616 & $3,616.0$ & 80.10 & $289,641.60$ & 0.00 & 0.00 & 0.00 & $289,641,60$ \\
\hline Subtotal o & et costs & & & & & $13,524.0$ & & $1,164,079.41$ & & $5,000.00$ & $1,800,000.00$ & $2,969,079.41$ \\
\hline $\begin{array}{l}\text { cility De } \\
\text { Cha }\end{array}$ & & & & & & & & & & & & \\
\hline Charactenzation (Sub & & 21 & 1 & LS & 0 & 0.0 & 1.00 & 0.00 & 0.00 & 0.0 & $250,000.00$ & $250,000.00$ \\
\hline Characterization & & E130-REG & 1 & LS & 4000 & 4.000 .0 & 95.71 & $382,856.07$ & 0.00 & 0.00 & 0.00 & 382.85 \\
\hline
\end{tabular}
RDW 
RPP-RPT-37924 Rev. 0

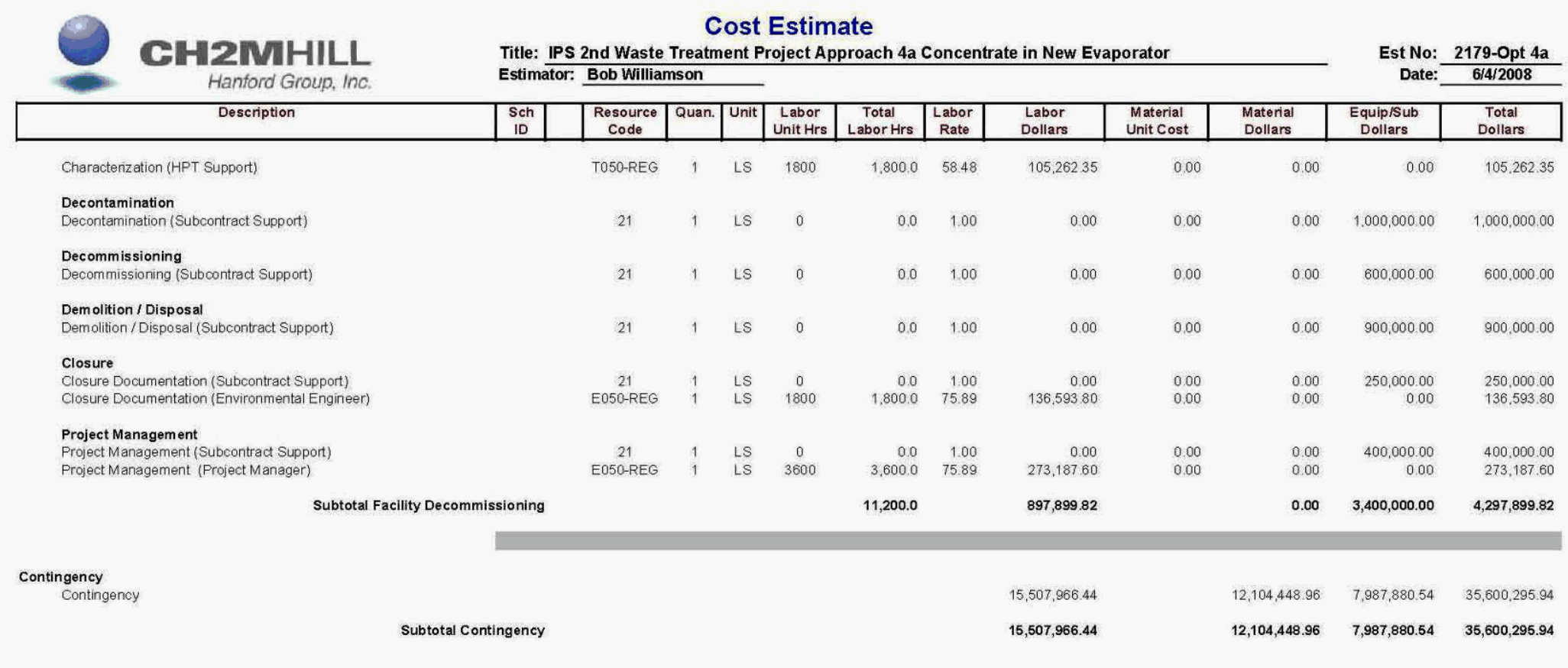


RPP-RPT-37924 Rev. 0

Table G-11. Approach 4b Cost Estimate.

Table begins on next page. 
RPP-RPT-37924 Rev. 0

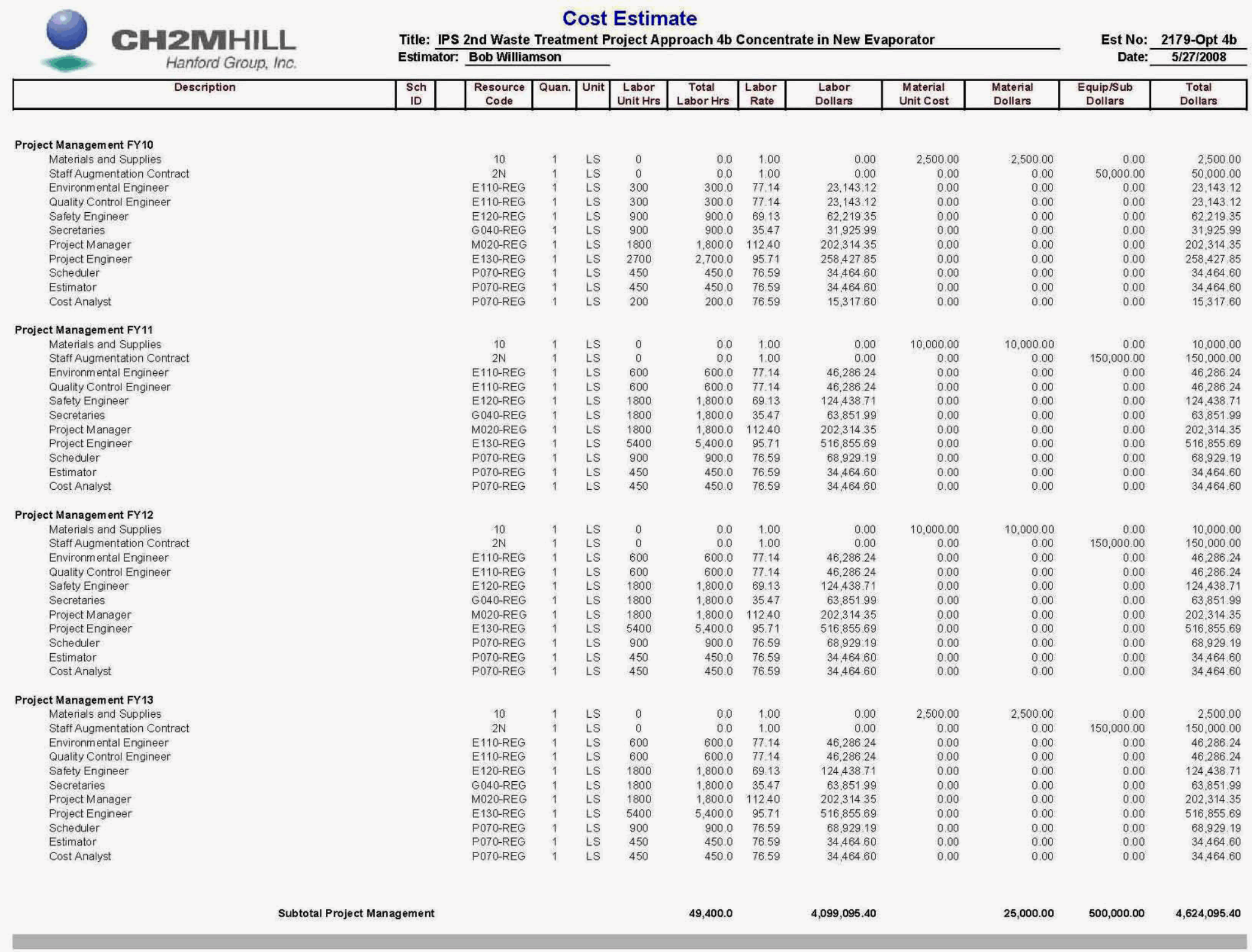


RPP-RPT-37924 Rev. 0

\begin{tabular}{|c|c|c|c|c|c|c|c|c|c|c|c|c|}
\hline \multirow{2}{*}{$\begin{array}{c}\text { CHanford Group, Inc. } \\
\text { Description } \\
\end{array}$} & \multicolumn{10}{|c|}{$\begin{array}{c}\text { Cost Estimate } \\
\end{array}$} & \multicolumn{2}{|c|}{$\begin{aligned} \text { Est No: } & 2179-\text { Opt } 4 b \\
\text { Date: } & 5 / 27 / 2008\end{aligned}$} \\
\hline & $\begin{array}{c}\text { Sch } \\
\text { ID }\end{array}$ & $\begin{array}{c}\text { Resource } \\
\text { Code }\end{array}$ & Quan. & Unit & \begin{tabular}{|l|} 
Labor \\
Unit Hrs \\
\end{tabular} & \begin{tabular}{|l|l|} 
Total \\
Labor Hrs \\
\end{tabular} & $\begin{array}{c}\text { Labor } \\
\text { Rate }\end{array}$ & $\begin{array}{l}\text { Labor } \\
\text { Dollars } \\
\end{array}$ & $\begin{array}{l}\text { Material } \\
\text { Unit Cost }\end{array}$ & $\begin{array}{l}\text { Material } \\
\text { Dollars }\end{array}$ & $\begin{array}{l}\text { Equip/Sub } \\
\text { Dollars }\end{array}$ & $\begin{array}{c}\text { Total } \\
\text { Dollars } \\
\end{array}$ \\
\hline Engineering & & 21 & 1 & LS & 0 & 0.0 & 1.00 & 0.00 & 0.00 & 0.00 & $1,500,000.00$ & $1,500,000.00$ \\
\hline Final Design - Offsite Engineening Contract & & 21 & 1 & LS & 0 & 0.0 & 1.00 & 0.00 & 0.00 & 0.00 & $3.600,000.00$ & $3.600,000,00$ \\
\hline \multirow[t]{2}{*}{ Title III Engineering Contract } & & 21 & 1 & LS & 0 & 0.0 & 1.00 & 0.00 & 0.00 & 0.00 & $910,000.00$ & $910,000.00$ \\
\hline & Subtotal Engineering & & & & & 0.0 & & 0.00 & & 0.00 & $6,010,000.00$ & $6,010,000.00$ \\
\hline \multicolumn{13}{|l|}{$\begin{array}{l}\text { Engineering Support FY10 } \\
\text { Process Engineening Support }\end{array}$} \\
\hline $\begin{array}{l}\text { Process Engineer } \\
\text { Contract Support (600 hrs @ } \$ 90.00 \text { ) }\end{array}$ & & E130-REG & 1 & $\begin{array}{l}\text { EA } \\
\text { LS }\end{array}$ & $\begin{array}{c}4200 \\
0\end{array}$ & $\begin{array}{r}4.200 .0 \\
0.0\end{array}$ & $\begin{array}{r}95.71 \\
100\end{array}$ & $\begin{array}{r}401,998.87 \\
0.00\end{array}$ & $5,000.00$ & $5,000.00$ & $\begin{array}{r}0.00 \\
1500000\end{array}$ & $\begin{array}{r}406,998.87 \\
15000,00\end{array}$ \\
\hline NS \& L Documentation Support & & & & & & & 1.00 & 0.00 & & & & \\
\hline $\begin{array}{l}\text { Nuclear Engineer } \\
\text { Safety Enoineer }\end{array}$ & & $\begin{array}{l}\text { E080-REG } \\
\text { F120-REG }\end{array}$ & 1 & $\begin{array}{l}\text { LS } \\
\text { LS }\end{array}$ & $\begin{array}{l}300 \\
900\end{array}$ & $\begin{array}{l}300.0 \\
9000\end{array}$ & $\begin{array}{l}95.79 \\
69.13\end{array}$ & $\begin{array}{l}28,736.23 \\
62,21935\end{array}$ & $\begin{array}{l}0.00 \\
0.00\end{array}$ & $\begin{array}{l}0.00 \\
0.00\end{array}$ & $\begin{array}{l}0.00 \\
0.00\end{array}$ & $\begin{array}{l}28.736 .23 \\
62.21935\end{array}$ \\
\hline Health Physicist & & $\begin{array}{l}\text { ENDOREG } \\
\text { POB-REG }\end{array}$ & 1 & LS & 300 & 300.0 & 78.84 & $\begin{array}{l}23,2713.35 \\
23,652.73\end{array}$ & 0.00 & 0.00 & 0.00 & $\begin{array}{l}0,2,219.35 \\
23,652.73\end{array}$ \\
\hline Environmental Engineer & & E050-REG & 1 & LS & 300 & 300.0 & 75.89 & $22,765.63$ & 0.00 & 0.00 & 0.00 & $22,765.63$ \\
\hline Contract Support (300 hrs@\$90/hr) & & 21 & 1 & LS & 0 & 0.0 & 1.00 & 0.00 & 0.00 & 0.00 & $5,000.00$ & $5,000.00$ \\
\hline \multicolumn{13}{|l|}{$\begin{array}{l}\text { Engineering Support FY11 } \\
\text { Procoss Engineering Support }\end{array}$} \\
\hline $\begin{array}{l}\text { Process Engineer } \\
\text { Contract Support } 600 \text { hrs } @ \$ 9000)\end{array}$ & & E130-REG & 1 & $\begin{array}{l}\text { EA } \\
\text { LS }\end{array}$ & 4200 & $\begin{aligned} 4,200.0 \\
00\end{aligned}$ & $\begin{array}{r}95.71 \\
100\end{array}$ & $\begin{array}{r}401,998.87 \\
0.00\end{array}$ & $\begin{array}{r}5,000.00 \\
0.00\end{array}$ & $\begin{array}{r}5.000 .00 \\
0.00\end{array}$ & $\begin{array}{r}0.00 \\
15000.00\end{array}$ & $\begin{array}{r}406,998.87 \\
15,00000\end{array}$ \\
\hline \multicolumn{13}{|l|}{ NS \& L Documentation Support } \\
\hline $\begin{array}{l}\text { Nuclear Engineer } \\
\text { Satety Encineer }\end{array}$ & & $\begin{array}{l}\text { E080-REG } \\
\text { E120-PGG }\end{array}$ & 1 & LS & 300 & 300.0 & $\begin{array}{r}95.79 \\
6913\end{array}$ & $\begin{array}{l}28,736.23 \\
6221935\end{array}$ & 0.00 & 0.00 & 0.00 & $\begin{array}{l}28.736 .23 \\
62.21935\end{array}$ \\
\hline Health Physicist & & PO8OREG & 1 & LS & 300 & 300.0 & 78.84 & $23,652.73$ & 0.00 & 0.00 & 0.00 & $23,652.73$ \\
\hline Environmental Engineer & & E050-REG & 1 & LS & 300 & 300.0 & 75.89 & $22,765.63$ & 0.00 & & 0.00 & 22.765 .63 \\
\hline Contract Support (300 hrs @\$90/hr) & & 21 & 1 & LS & 0 & 0.0 & 1.00 & 0.00 & 0.00 & 0.00 & $5,000.00$ & $5,000.00$ \\
\hline \multicolumn{13}{|l|}{$\begin{array}{l}\text { Engineering Support FY12 } \\
\text { Process Engineenng Support }\end{array}$} \\
\hline Process Engineer & & E130-REG & 1 & EA & 4200 & $4,200.0$ & 95.71 & $401,998.87$ & $5,000.00$ & $5,000.00$ & $\begin{array}{r}0.00 \\
1500000\end{array}$ & $406,998.87$ \\
\hline \multicolumn{13}{|l|}{$\begin{array}{l}\text { NS \& L Do Doumentation Support } \\
\text { Not }\end{array}$} \\
\hline 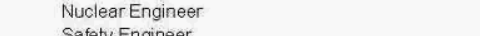 & & E080-REG & 1 & LS & 300 & 300.0 & 95.79 & $28,736.23$ & 0.00 & 0.00 & 0.00 & 28.736 .23 \\
\hline $\begin{array}{l}\text { Safety Engineer } \\
\text { Health Physists }\end{array}$ & & $\begin{array}{l}\text { E120-REG } \\
P 080-R E G\end{array}$ & 1 & LS & $\begin{array}{l}9000 \\
300\end{array}$ & $\begin{array}{r}900.0 \\
3300\end{array}-1-2$ & $\begin{array}{l}69.13 \\
78.84\end{array}$ & $\begin{array}{l}62.21935 \\
2352.73\end{array}$ & 0.00 & $\begin{array}{l}0.00 \\
0.00\end{array}$ & $\begin{array}{l}0.00 \\
0.00\end{array}-3-3-3$ & $\begin{array}{l}62,219.35 \\
2365273\end{array}$ \\
\hline Environmental Engineer & & E050-REG & 1 & LS & 300 & 300.0 & 75.89 & $22,765.63$ & 0.00 & 0.00 & 0.00 & 22.765 .63 \\
\hline Contract Support (300 hrs@\$90hr) & & 21 & 1 & LS & 0 & 0.0 & 1.00 & 0.00 & 0.00 & 0.00 & 5.000 .00 & 5.000 .00 \\
\hline \multicolumn{13}{|l|}{ Engineering Support FY13 } \\
\hline Process Engineer & & E130-REG & 1 & EA & 4200 & 4.200 .0 & 9571 & $401,998.87$ & 5.000 .00 & 5.000 .00 & 0.00 & $406,998.87$ \\
\hline Contract Support (600 hrs @\$90.00) & & 21 & 1 & LS & 0 & 0.0 & 1.00 & 0.00 & 0.00 & 0.00 & $15,000.00$ & $15,000.00$ \\
\hline \multicolumn{12}{|l|}{ NS \& L Documentation Support } & \\
\hline $\begin{array}{l}\text { Nuclear Engineer } \\
\text { Safety Engineer }\end{array}$ & & $\begin{array}{l}\text { E080-REG } \\
\text { E120-REG }\end{array}$ & 1 & LS & 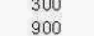 & $\begin{array}{l}300.0 \\
900.0\end{array}$ & $\begin{array}{r}95.79 \\
69.13\end{array}$ & $\begin{array}{l}28,73623 \\
62.21935\end{array}$ & $\begin{array}{l}0.00 \\
0.00\end{array}$ & $\begin{array}{l}0.00 \\
0.00\end{array}$ & $\begin{array}{l}0.00 \\
0.00\end{array}$ & $\begin{array}{l}28,736.23 \\
62.2135\end{array}$ \\
\hline Health Physicist & & P080REG & 1 & LS & 300 & 300.0 & 78.84 & $23,652.73$ & 0.00 & 0.00 & 0.00 & 23.652 .73 \\
\hline Environmental Engineer & & E050-REG & 1 & LS & 300 & 300.0 & 75.89 & $22,765.63$ & 0.00 & 0.00 & 0.00 & 22.765 .63 \\
\hline Contract Support (300 hrs @\$90/r) & & 21 & $i$ & LS & 0 & 0.0 & 1.00 & 0.00 & 0.00 & 0.00 & $5,000.00$ & $5,000.00$ \\
\hline Title III Engineering Support During Construction & & EO00-REG & 1 & LS & 3600 & 3.600 .0 & 82.62 & 297.422 .29 & 0.00 & 0.00 & 0.00 & 297.422 .29 \\
\hline & al Engineering Support & & & & & $27,600.0$ & & $2,454,913.55$ & & $20,000.00$ & $80,000.00$ & $2,654,913.55$ \\
\hline
\end{tabular}


RPP-RPT-37924 Rev. 0

Cost Estimate

CH2MHILL

Title: IPS 2nd Waste Treatment Project Approach 4b Concentrate in New Evaporator

Est No: 2179-Opt 4b anford Group, Inc.

Date: $\frac{2179-0 p t ~}{5 / 27 / 2008}$

Description

\begin{tabular}{|c|c|c|c|c|}
\hline Sch & & Resource & Quan & Unit \\
\hline ID
\end{tabular}

Labor

Material
Unit Cost

Material

Equip/Sub
Dollars

Total
Dollars

\begin{tabular}{|c|c|c|c|c|c|c|c|c|c|c|c|}
\hline \multicolumn{12}{|l|}{$\begin{array}{l}\text { Procurement } \\
\text { Material \& Equipment }\end{array}$} \\
\hline Instruments and Controls & 10 & 1 & LS & 0 & 0.0 & 1.00 & 0.00 & 40.000 .00 & $40,000.00$ & 0.00 & $40,000.00$ \\
\hline Variable-speed feed pumps & 10 & 2 & LS & 0 & 0.0 & 1.00 & 0.00 & $100,000.00$ & 200.000 .00 & 0.00 & $200,000.00$ \\
\hline Condensate Pumps (40 gpm) & 10 & 2 & LS & 0 & 0.0 & 1.00 & 0.00 & 30.000 .00 & 60.000 .00 & 0.00 & 60.000 .00 \\
\hline Condensate Pumps (50 gpm) & 10 & 2 & LS & 0 & 0.0 & 1.00 & 0.00 & 40.000 .00 & 80.000 .00 & 0.00 & 80.000 .00 \\
\hline Bridge Crane ( 30 ton) & 10 & 1 & LS & 0 & 0.0 & 1.00 & 0.00 & $80,000.00$ & $80,000.00$ & 0.00 & $80,000.00$ \\
\hline HEPA Filters & 10 & 1 & LS & 0 & 0.0 & 1.00 & 0.00 & 280.000 .00 & 280,00000 & 0.00 & $280,000.00$ \\
\hline Exhaust Fans & 10 & 1 & LS & 0 & 0.0 & 1.00 & 0.00 & 60.000 .00 & $60,000.00$ & 0.00 & 60.000 .00 \\
\hline Packaged Boiler & 10 & 1 & LS & 0 & 0.0 & 1.00 & 0.00 & $60,000.00$ & $60,000.00$ & 0.00 & 60.000 .00 \\
\hline Electrical Control Panels, etc. & 10 & 1 & LS & 0 & 0.0 & 1.00 & 0.00 & 100.000 .00 & 100.000 .00 & 0.00 & 100.000 .00 \\
\hline \multicolumn{12}{|l|}{ Fabrication } \\
\hline Evaporator (Separator, Reb oiler, Recirc Pump, Condenser, Loop Piping) & 21 & 1 & EA & 0 & 0.0 & 1.00 & 0.00 & $12,700,000,00$ & $12,700,000.00$ & 0.00 & $12,700,000.00$ \\
\hline Secondary Waste Solutions Receipt Vessels ( 36,600 gal) & 21 & 2 & EA & 0 & 0.0 & 1.00 & 0.00 & $130,000.00$ & $260,000.00$ & 0.00 & $260,000.00$ \\
\hline Concentrate Vessels (750 gal) & 21 & 2 & EA & 0 & 0.0 & 1.00 & 0.00 & 5.000 .00 & $10,000.00$ & 0.00 & 10.000 .00 \\
\hline Evaporator Condensate Vessel ( $10.000 \mathrm{gal}$ ) & 21 & 2 & EA & 0 & 0.0 & 1,00 & 0.00 & 60.000 .00 & $120,000.00$ & 0.00 & $120,000.00$ \\
\hline Clean Condensate Vessels $(2,000$ gal $)$ & 21 & 2 & EA & 0 & 0.0 & 1.00 & 0.00 & $18,000.00$ & $36,000.00$ & 0.00 & $36,000.00$ \\
\hline Piping, fittings, hangers, valves, etc. & 21 & 2 & EA & 0 & 0.0 & 1.00 & 0.00 & $350,000.00$ & $700,000,00$ & 0.00 & $700,000.00$ \\
\hline HVAC ducting, dampers, heating colls, etc. & 10 & 1 & LS & 0 & 0.0 & 1.00 & 0.00 & $500,000.00$ & $500,000,00$ & 0.00 & $500,000.00$ \\
\hline Washington State Sales Tax @ 8.3\% & & & & & & & & & $1,268,738.00$ & & $1,268.738 .00$ \\
\hline Subtotal Procurement & & & & & 0.0 & & 0.00 & & $16,554,738.00$ & 0.00 & $16,654,738.00$ \\
\hline \multicolumn{12}{|l|}{ Procurement Support } \\
\hline Prepare/lissue soW for Fabrication & PO3O-REG & 6 & EA & 120 & 720,0 & 67.72 & $48,756.27$ & 0.00 & 0.00 & 0.00 & 48.756 .27 \\
\hline Revise/ssue SoW for Fabrication & PO3O-REG & 6 & EA & 20 & 120.0 & 67.72 & $8,126.04$ & 0.00 & 0.00 & 0.00 & $8,126.04$ \\
\hline $\begin{array}{l}\text { Award Fabrication Contract } \\
\text { Procurement/Fabrication Work Rele ase }\end{array}$ & PO3O-REG & 6 & EA & 40 & 240.0 & 67.72 & 16.252 .09 & 0.00 & 0.00 & 0.00 & $16,252.09$ \\
\hline $\begin{array}{l}\text { Planner } \\
\text {. }\end{array}$ & P070-REG & 8 & EA & 2 & 16.0 & 76.59 & $1,225.41$ & 0.00 & 0.00 & 0.00 & $1,225.41$ \\
\hline Operations Plant Engineer & E100-REG & 8 & EA & 4 & 320 & 7474 & 2.39176 & 0.00 & 0.00 & 0.00 & 2,39176 \\
\hline System Engineer & E130-REG & 8 & EA & 1 & 8.0 & 95.71 & 765.71 & 0.00 & 0.00 & 0.00 & 765.71 \\
\hline Other Engineer & E130-REG & 8 & EA & 1 & 8.0 & 95.71 & 765.71 & 0.00 & 0.00 & 0.00 & 765.71 \\
\hline \multirow{2}{*}{\multicolumn{12}{|c|}{$\begin{array}{l}\text { Cost Estimator } \\
\text { Prepare Material Requests }\end{array}$}} \\
\hline & & & & & & & & & & & \\
\hline \multicolumn{12}{|l|}{$\begin{array}{l}\text { Material Coordinator } \\
\text { Prepare ECN's to Support Fabrication }\end{array}$} \\
\hline Contract Support (Assume $60 \mathrm{hrs} @ \$ 85 \times 8$ ECN's) & 21 & 8 & LS & 0 & 0.0 & 1.00 & 0.00 & 0.00 & 0.00 & $40,800.00$ & 40.800 .00 \\
\hline Electrical Engineer & E040-REG & 8 & EA & 4 & 32.0 & 80.24 & $2,567.59$ & 0.00 & 0.00 & 0.00 & $2,567.59$ \\
\hline Environmental Engineer & E050-REG & 8 & EA & 1 & 8.0 & 75.89 & 607.08 & 0.00 & 0.00 & 0.00 & 607.08 \\
\hline Quality Assurance Engineer & E110-REG & 8 & EA & 2 & 16.0 & 77.14 & $1.234,30$ & 0.00 & 0.00 & 0.00 & 1.234 .30 \\
\hline Safety Engineer & E120-REG & 8 & EA & 1 & 8.0 & 69.13 & 553.06 & 0.00 & 0.00 & 0.00 & 553.06 \\
\hline System Engineer & E130-REG & 8 & EA & 4 & 32.0 & 9571 & 3.062 .85 & 0.00 & 0.00 & 0.00 & 3.062 .85 \\
\hline Industrial Hygiene & PO90-REG & 8 & EA & 1 & 8.0 & 7493 & 599.45 & 0.00 & 0.00 & 0.00 & 599.45 \\
\hline Radiation Control Supervisor & MO10-REG & 8 & EA & 2 & 16.0 & 73.58 & $1,177.26$ & 0.00 & 0.00 & 0.00 & $1,177.26$ \\
\hline Plant Engineer & E100-REG & 8 & EA & 4 & 32.0 & 74.74 & $2,391.76$ & 0.00 & 0.00 & 0.00 & $2,391.76$ \\
\hline Management & MO30-REG & 8 & EA & 1 & 8.0 & 100.09 & 800.69 & 0,00 & 0.00 & 0.00 & 800.69 \\
\hline Procurement Support - Contracts/Buyer & PO30-REG & 8 & LS & 120 & 960.0 & 67.72 & $65,008,36$ & 0.00 & 0.00 & 0.00 & $65,008.36$ \\
\hline $\begin{array}{l}\text { Material Coordinator } \\
\text { QAIP Support }\end{array}$ & G030-REG & 8 & LS & 24 & 192.0 & 50.26 & 9.649 .58 & 0.00 & 0.00 & 0.00 & 9.649 .58 \\
\hline Quality Control Engineer & E110-REG & 8 & EA & 3 & 24.0 & 77.14 & 1.851 .45 & 0.00 & 0.00 & 0.00 & $1,851.45$ \\
\hline Engineering & E130-REG & 8 & EA & 3 & 24.0 & 95.71 & $2,297.14$ & 0.00 & 0.00 & 0.00 & $2,297.14$ \\
\hline 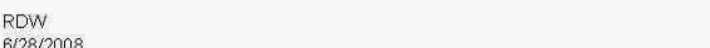 & & & & 3 & & & & & & & \\
\hline
\end{tabular}


RPP-RPT-37924 Rev. 0

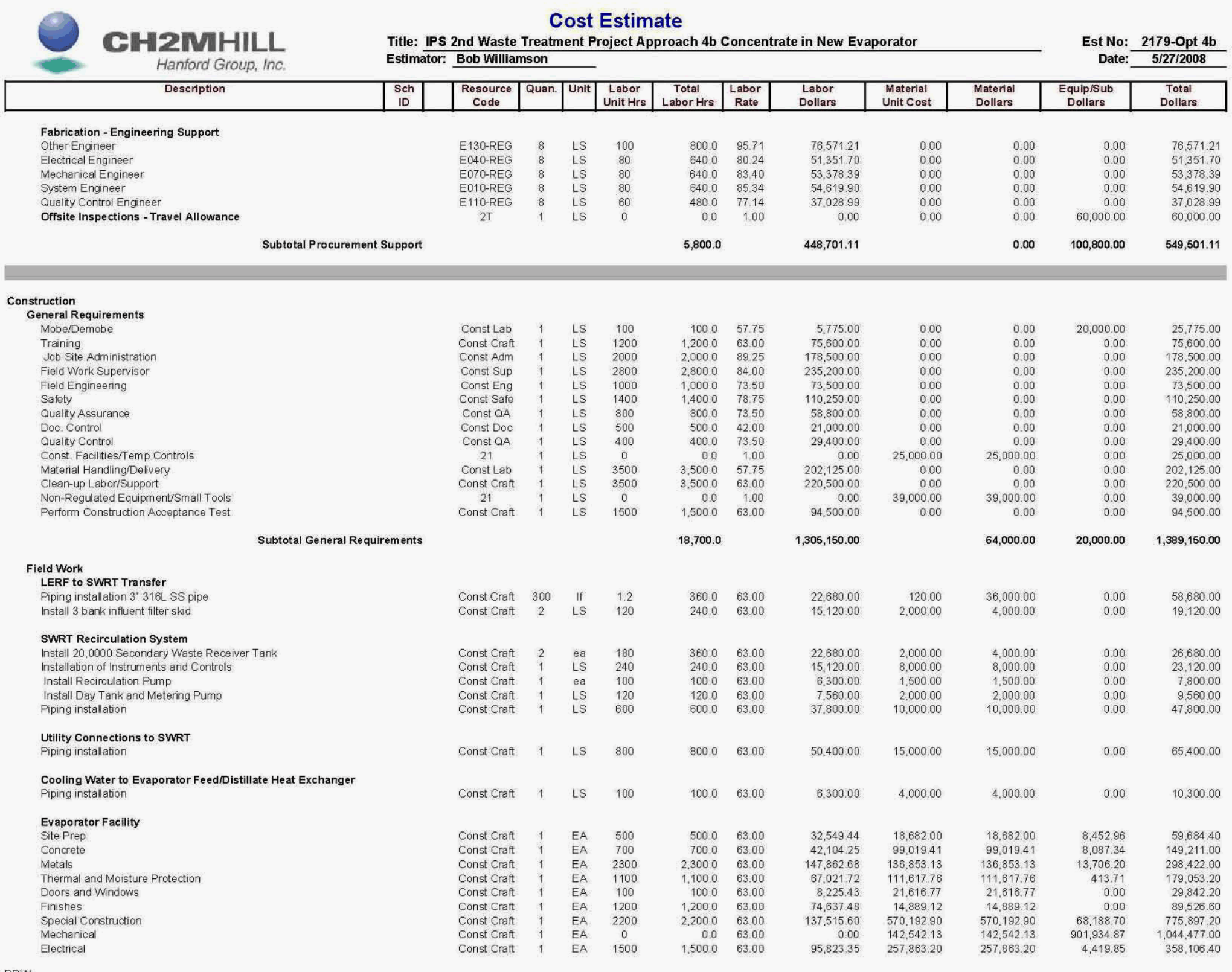


RPP-RPT-37924 Rev. 0

\begin{tabular}{|c|c|c|c|c|c|c|c|c|c|c|c|c|}
\hline \multirow{2}{*}{ 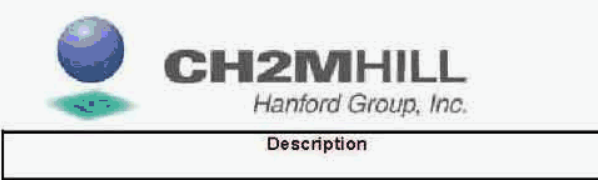 } & \multicolumn{9}{|c|}{ Cost Estimate } & & $\begin{array}{l}\text { Est No: } \\
\text { Date:- }\end{array}$ & $\begin{array}{c}2179-\text { Opt } 4 b \\
5 / 27 / 2008 \\
\end{array}$ \\
\hline & $\begin{array}{l}\text { Sch } \\
\text { ID }\end{array}$ & \begin{tabular}{|c|}
$\begin{array}{c}\text { Resource } \\
\text { Code }\end{array}$ \\
\end{tabular} & Quan. & Unit & \begin{tabular}{|l|} 
Labor \\
Unit Hrs \\
\end{tabular} & \begin{tabular}{c|} 
Total \\
Labor Hrs \\
\end{tabular} & $\begin{array}{c}\text { Labor } \\
\text { Rate }\end{array}$ & $\begin{array}{l}\text { Labor } \\
\text { Dollars } \\
\end{array}$ & $\begin{array}{l}\text { Material } \\
\text { Unit Cost } \\
\end{array}$ & $\begin{array}{l}\text { Material } \\
\text { Dollars }\end{array}$ & $\begin{array}{c}\begin{array}{c}\text { Equip/sub } \\
\text { Dollars }\end{array} \\
\end{array}$ & $\begin{array}{c}\text { Total } \\
\text { Dollars }\end{array}$ \\
\hline \multicolumn{13}{|l|}{ Other Construction } \\
\hline $\begin{array}{l}\text { Evaporator Installation } \\
\text { Evaporator Supply Air and Exhaust System }\end{array}$ & & $\begin{array}{l}\text { Const Craft } \\
\text { Const Craft }\end{array}$ & $\frac{1}{1}$ & $\begin{array}{l}\text { EA } \\
\text { EA }\end{array}$ & $\begin{array}{l}25000 \\
23000\end{array}$ & $\begin{array}{l}25,0000 \\
230000\end{array}$ & $\begin{array}{l}6300 \\
6300\end{array}$ & $\begin{array}{l}1,575,000.00 \\
1449000,00\end{array}$ & $800,000.00$ & $\begin{array}{l}800,000,00 \\
50000000\end{array}$ & 0.00 & $\begin{array}{l}2,375,000,00 \\
1,949,000,00\end{array}$ \\
\hline Feed and Condensate System Installation & & Const Craft & 1 & EA & 12000 & $12,000.0$ & 63.00 & $756,000,00$ & $280,000.00$ & $280,000.00$ & 0.00 & $1,036,000.00$ \\
\hline Electrical and Control System Installation & & Const Craft & 1 & EA & 8000 & 8.000 .0 & 63.00 & $504,000.00$ & 160.000 .00 & $160,000,00$ & 0.00 & 664.000 .00 \\
\hline Condensate Retention Basin & & Const Craft & 1 & EA & 0 & 0.0 & 63.00 & 0.00 & 0.00 & 0.00 & $25,000.00$ & 25.000 .00 \\
\hline Subtotal & Id Work & & & & & $80,520.0$ & & $5,073,699.94$ & & $3,197,776.43$ & $1,030,203.63$ & $9,301,680.00$ \\
\hline \multicolumn{13}{|l|}{ Adders } \\
\hline Productivity Factor - Assume 20\% & & 21 & 1 & LS & & 16.104 .0 & & $1,014.739 .99$ & 0.00 & 0.00 & 0.00 & $1,014,739.99$ \\
\hline Weather Delays - Assume $10 \%$ & & 21 & 1 & LS & & 9.662 .4 & & 608.843 .99 & 0.00 & 0.00 & 0.00 & 608.843 .99 \\
\hline Allowance for Construction Consumables - $3 \%$ of Const Labor & & 21 & 1 & LS & & 0.0 & & 0.00 & 152.211 .00 & $152,211.00$ & 0.00 & $152,211.00$ \\
\hline Material Sales Tax@8.3\% & & 21 & 1 & LS & & 0.0 & & 0.00 & 265.415 .44 & $265,415,44$ & 0.00 & $265,415.44$ \\
\hline Subt & | Adders & & & & & $25,766.4$ & & $1,623,583.98$ & & $417,626.44$ & 0.00 & $2,041,210.42$ \\
\hline \multirow[t]{2}{*}{ Construction Contractor Fee @ 8\% } & & 21 & & & & & & & & & $1,018,563.23$ & $1,018,563.23$ \\
\hline & itruction & & & & & $124,986.4$ & & $8,002,433.92$ & & $3,679,402.87$ & $2,068,766.86$ & $13,750,603.66$ \\
\hline \multicolumn{13}{|l|}{ Construction Management } \\
\hline Management & & M020-REG & 1 & LS & 1800 & 1.800 .0 & 112.40 & $202,314.35$ & 0.00 & 0.00 & 0.00 & $202,314,35$ \\
\hline Construction Manager & & MO30-REG & 1 & LS & 5400 & 5.400 .0 & 100.09 & 540.467 .53 & 0.00 & 0.00 & 0.00 & 540.467 .53 \\
\hline Construction Field Lead & & MO10-REG & 1 & LS & 5400 & 5.400 .0 & 73.58 & $397,324.32$ & 0.00 & 0.00 & 0.00 & 397.324 .32 \\
\hline ClericalDocument Control Support & & G030-REG & 1 & LS & 900 & 900.0 & 50.26 & $45,232,42$ & 0.00 & 0.00 & 0.00 & $45,232.42$ \\
\hline Miscellaneous Office Supplies for CM & & 10 & 1 & LS & 0 & 0.0 & 1.00 & & $50,000.00$ & $50,000.00$ & 0.00 & $50,000.00$ \\
\hline Contract Administration & & P030-REG & 1 & LS & 900 & 900.0 & 67.72 & $60,945,33$ & 0.00 & 0.00 & 0.00 & $60,945.33$ \\
\hline Subtotal Construction N & agement & & & & & $14,400.0$ & & $1,246,283.96$ & & $50,000.00$ & 0.00 & $1,296,283.96$ \\
\hline \multicolumn{13}{|l|}{ Construction Support } \\
\hline Health Physics Technician (HPT) & & T050-REG & 1 & LS & 600 & 600.0 & 58.48 & $35,087,45$ & 0.00 & 0.00 & 0.00 & 35.087 .45 \\
\hline Industrial Health \& Safety & & TO60-REG & 1 & LS & 400 & 400.0 & 57.69 & 23.077 .06 & 0.00 & 0.00 & 0.00 & 23.077 .06 \\
\hline PHMC - Critical Lift Support (Crane \& Rigging Organization) & & $3 P$ & 1 & LS & 0 & 0.0 & 1.00 & 0.00 & 0.00 & 0.00 & $20,000.00$ & $20,000: 00$ \\
\hline $\begin{array}{l}\text { PHMC - Crane Usage Charges } \\
\text { Planning \& Work Package Prep }\end{array}$ & & $3 \mathrm{P}$ & 1 & LS & 0 & 0.0 & 1.00 & 0.00 & 0.00 & 0.00 & $10,000.00$ & $10,000.00$ \\
\hline $\begin{array}{l}\text { Planning \& Work Package Prep } \\
\text { Planner }\end{array}$ & & P070-REG & 10 & EA & 112 & 1.120 .0 & 76.59 & $85,778.55$ & 0.00 & 0.00 & 0.00 & 85.778 .55 \\
\hline System Engineer & & E130-REG & 10 & EA & 20 & 200.0 & 95.71 & $19,142.80$ & 0.00 & 0.00 & 0.00 & 19.142 .80 \\
\hline Radiation Control & & P090-REG & 10 & EA & 20 & 200.0 & 74.93 & $14,986.25$ & 0.00 & 0.00 & 0.00 & $14,986.25$ \\
\hline \multirow{2}{*}{\multicolumn{13}{|c|}{ Enhanced Work Planning }} \\
\hline & & & & & & & & & & & & \\
\hline Planner & & P070-REG & 10 & EA & 3 & 30.0 & 76.59 & $2,297.64$ & 0.00 & 0.00 & 0.00 & $2,297.64$ \\
\hline Carpen & & Co10-REG & 10 & EA & 3 & 30.0 & 55. & 1.67 & 0.00 & 0.00 & 0.00 & $1.675,10$ \\
\hline Electric & & CO20-REG & 10 & EA & 3 & 30.0 & 61. & 1,83 & 0.00 & 0.00 & 0.00 & 1.832 .07 \\
\hline Pipefitter & & CO80-REG & 10 & EA & 3 & 30.0 & 57.11 & 1,7 & 0.00 & 0.00 & 0.00 & 1.713 .16 \\
\hline Miscellaneous Craft & & C120-REG & 10 & EA & 3 & 30.0 & 56.94 & 1,70 & 0.00 & 0.00 & 0.00 & 1.708 .13 \\
\hline Environmental Engineer & & E050-R & 10 & EA & 3 & 30.0 & 75 & 2,27 & 0.00 & 0.00 & 0.00 & 2.276 .56 \\
\hline Quality $\mathrm{C}$ & & E110-REG & 10 & EA & 3 & 30.0 & 77. & 2,31 & 0.00 & 0.00 & 0.00 & $2,314.31$ \\
\hline Safety $E$ & & E120-REG & 10 & EA & 3 & 30.0 & 69 & $2,073.98$ & 0.00 & 0.00 & 0.00 & $2,073.98$ \\
\hline System Engineer & & E130-REG & 10 & EA & 3 & 30.0 & 9571 & 2,87 & 0.00 & 0.00 & 0.00 & 2,87142 \\
\hline Light Vehicle Driver & & L070-REG & 10 & EA & 3 & 30.0 & 47.91 & 1.437 .28 & 0.00 & 0.00 & 0.00 & 1,43728 \\
\hline Field Work Supervisor (FWS) & & M010-REG & 10 & EA & 3 & 30.0 & 73.58 & 2.207 .36 & 0.00 & 0,00 & 0.00 & $2,207.36$ \\
\hline $\begin{array}{l}\text { RDW } \\
\text { K//8//nกก) }\end{array}$ & & & & & 5 & & & & & & & \\
\hline
\end{tabular}


RPP-RPT-37924 Rev. 0

Cost Estimate

Title: IPS 2nd Waste Treatment Project Approach 4b Concentrate in New Evaporator

Est No: $2179-0 p t 4 b$

Estimator: Bob Williamson $\quad$ Date: $\frac{2179-0 p t / 27 / 2008}{5}$

\begin{tabular}{|c|c|c|c|c|c|c|c|c|c|c|c|c|}
\hline Description & $\begin{array}{l}\text { Sch } \\
\text { ID }\end{array}$ & \begin{tabular}{|c|}
$\begin{array}{c}\text { Resource } \\
\text { Code }\end{array}$ \\
\end{tabular} & Quan. & Unit & \begin{tabular}{|l|} 
Labor \\
Unit Hrs \\
\end{tabular} & \begin{tabular}{l|} 
Total \\
Labor Hrs \\
\end{tabular} & \begin{tabular}{|c|} 
Labor \\
Rate \\
\end{tabular} & $\begin{array}{l}\text { Labor } \\
\text { Dollars }\end{array}$ & $\begin{array}{l}\text { Material } \\
\text { Unit Cost }\end{array}$ & $\begin{array}{l}\text { Material } \\
\text { Dollars }\end{array}$ & $\begin{array}{l}\text { Equip/sub } \\
\text { Dollars }\end{array}$ & $\begin{array}{l}\text { Total } \\
\text { Dollars }\end{array}$ \\
\hline Industrial Hygiene: & & PO90-REG & 10 & EA & 3 & 30.0 & 74.93 & $2,247.94$ & 0.00 & 0.00 & 0.00 & $2,247.94$ \\
\hline \multirow{2}{*}{\multicolumn{13}{|c|}{ Review \& Approve Work Packages }} \\
\hline & & & & & & & & & & & & \\
\hline Planner & & P070-REG & 10 & EA & 28 & 280.0 & 76.59 & $21,444,64$ & 0.00 & 0.00 & 0.00 & $21,444.64$ \\
\hline Environmental Engineer & & E050-REG & 10 & EA & 5 & 50.0 & 75.89 & 3.794 .27 & 0.00 & 0.00 & 0.00 & $3,794,27$ \\
\hline Quality Control & & E110-REG & 10 & EA & 5 & 50.0 & 77.14 & 3.857 .19 & 0.00 & 0.00 & 0.00 & 3.857 .19 \\
\hline Safety Engineer & & E120-REG & 10 & EA & 5 & 50.0 & 6913 & $3,456.63$ & 0.00 & 0,00 & 0.00 & 3.456 .63 \\
\hline System Engineer & & E130-REG & 10 & EA & 10 & 100.0 & 9571 & $9,571.40$ & 0.00 & 0.00 & 0.00 & $9,571.40$ \\
\hline Field Work Supervisor (FWS) & & M010-REG & 10 & EA & 5 & 50.0 & 7358 & 3.678 .93 & 0.00 & 0.00 & 0.00 & 3.678 .93 \\
\hline Other Engineer & & E130-REG & 10 & EA & 5 & 50.0 & 95.71 & 4.785 .70 & 0,00 & 0.00 & 0.00 & $4,785.70$ \\
\hline Health Physics Technician (HPT) & & T050-REG & 10 & EA & 5 & 50.0 & 58.48 & $2,923,95$ & 0.00 & 0.00 & 0.00 & 2.923 .95 \\
\hline Industrial Health \& Safety & & TO60-REG & 10 & EA & 5 & 50.0 & 57.69 & 2.884 .63 & 0.00 & 0.00 & 0.00 & 2.884 .63 \\
\hline \multirow{2}{*}{\multicolumn{13}{|c|}{ Closeout Work Packages }} \\
\hline & & & & & & & & & & & & \\
\hline $\begin{array}{l}\text { Planner } \\
\text { Operations Plant Engineer }\end{array}$ & & $\begin{array}{l}\text { P010-REG } \\
\text { E100-REG }\end{array}$ & 10 & $\begin{array}{l}\text { EA } \\
\text { EA }\end{array}$ & $\begin{array}{l}12 \\
4\end{array}$ & $\begin{array}{r}1200 \\
40.0\end{array}$ & 76.74 & $\begin{array}{l}9,190.66 \\
2,989.70\end{array}$ & 0.00 & $\begin{array}{l}0.00 \\
0.00\end{array}$ & $\begin{array}{l}0.00 \\
0.00\end{array}$ & $\begin{array}{l}9,190.56 \\
298970\end{array}$ \\
\hline 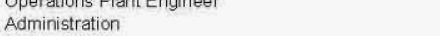 & & GO20-REG & 10 & EA & $\begin{array}{l}4 \\
2\end{array}$ & 20.0 & 33.28 & 665.64 & 0.00 & 0.00 & 0.00 & 665.94 \\
\hline Other Engineer & & E130-REG & 10 & EA & 4 & 40.0 & 95.71 & 3.828 .56 & 0.00 & 0.00 & 0.00 & $3,828.56$ \\
\hline \multirow{2}{*}{\multicolumn{13}{|c|}{$\begin{array}{l}\text { Prepare ECN's } \\
\text { Pols }\end{array}$}} \\
\hline & & & & & & & & & & & & \\
\hline Contract Support (Assume 90 hrs @ $\$ 85 \times 4$ ECN's) & & 21 & 1 & LS & 0 & 0.0 & 1.00 & 0.00 & 0.00 & 0.00 & $30,600.00$ & $30,600.00$ \\
\hline Electrical Engineer & & E040-REG & 10 & EA & 4 & 40.0 & 80.24 & $3,209.48$ & 0.00 & 0.00 & 0.00 & $3,209.48$ \\
\hline Environmental Engineer & & E050-REG & 10 & EA & 1 & 10.0 & 75.89 & 758.85 & 0.00 & 0.00 & 0.00 & 758.85 \\
\hline Quality Assurance Engineer & & E110-REG & 10 & EA & 2 & 20.0 & 77.14 & 1.542 .87 & 0.00 & 0.00 & 0.00 & $1,542.87$ \\
\hline Safety Engineer & & E120-REG & 10 & EA & 1 & 10.0 & 69.13 & 691.33 & 0.00 & 0.00 & 0.00 & 691.33 \\
\hline System Engineer & & E130-REG & 10 & EA & 4 & 40.0 & 95.71 & $3,828.56$ & 0.00 & 0.00 & 0.00 & $3,828.56$ \\
\hline Industrial Hygiene & & PO90-REG & 10 & EA & 1 & 10.0 & 74.93 & 749.31 & 0.00 & 0.00 & 0.00 & 749.31 \\
\hline Radiation Control Supervisor & & M010-REG & 10 & EA & 2 & 20.0 & 73.58 & $1,471.57$ & 0.00 & 0.00 & 0.00 & 1.471 .57 \\
\hline Plant Engineer & & E100-REG & 10 & EA & 4 & 40.0 & 74.74 & $2,989.70$ & 0.00 & 0.00 & 0.00 & $2,989.70$ \\
\hline Management & & MO30-REG & 10 & EA & 1 & 10.0 & 100.09 & $1,000.87$ & 0.00 & 0.00 & 0.00 & $1,000.87$ \\
\hline \multicolumn{13}{|l|}{ Prepare USQ's } \\
\hline Other Engineers & & E130-REG & 4 & EA & 28 & 112.0 & 95.71 & 10.719 .97 & 0.00 & 0.00 & 0.00 & 10.719 .97 \\
\hline Review Engineers & & E130-REG & 4 & EA & 9 & 36.0 & 95.71 & $3,445,70$ & 0.00 & 0.00 & 0.00 & 3.445 .70 \\
\hline \multicolumn{13}{|l|}{ Radiation Work Permit } \\
\hline Planner & & P070-REG & 5 & EA & 14 & 70.0 & 76.59 & $5,361.16$ & 0.00 & 0.00 & 0.00 & $5,361,16$ \\
\hline Electrician & & C020-REG & 5 & EA & 2 & 10.0 & 61.07 & 610.69 & 0.00 & 0.00 & 0.00 & 610.69 \\
\hline Electrical Engineer & & E040-REG & 5 & EA & 2 & 10.0 & 80.24 & 802.37 & 0.00 & 0.00 & 0.00 & 802.37 \\
\hline Environmental Engineer & & E050-REG & 5 & EA & 5 & 25.0 & 75.89 & 1.897 .14 & 0.00 & 0.00 & 0.00 & $1,897.14$ \\
\hline Operations Plant Engineer & & E100-REG & 5 & EA & 2 & 10.0 & 74.74 & 747.42 & 0.00 & 0.00 & 0.00 & 747.42 \\
\hline Safety Engineer & & E120-REG & 5 & EA & 2 & 10.0 & 69.13 & 691.33 & 0.00 & 0.00 & 0.00 & 691.33 \\
\hline System Engineer & & E130-REG & 5 & EA & 5 & 25.0 & 95,71 & $2,392.85$ & 0.00 & 0.00 & 0.00 & $2,392.85$ \\
\hline Field Work Supervisor (FWS) & & E100-REG & 5 & $E A$ & 5 & 25.0 & 74.74 & 1.868 .56 & 0.00 & 0.00 & 0.00 & $1,868.56$ \\
\hline Health Physics Technician (HPT) & & T050-REG & 5 & EA & 5 & 25.0 & 58.48 & $1,461.98$ & 0.00 & 0.00 & 0.00 & 1.461 .98 \\
\hline \multirow{2}{*}{\multicolumn{13}{|c|}{ Material Requests }} \\
\hline & & G030-REG & & & 4 & & & 100516 & & & 000 & 100516 \\
\hline $\begin{array}{l}\text { Material Coordinator } \\
\text { Pre Job Briefings }\end{array}$ & & $\begin{array}{c}\text { G030-REG } \\
-\end{array}$ & 5 & $E A$ & 4 & 20.0 & 50.26 & $1,005.10$ & 0.00 & 0.00 & 0.00 & $1,005.10$ \\
\hline Other Engineers & & E130-REG & 600 & $\mathrm{Hr}$ & 1 & 600.0 & 95.71 & 57.42841 & 0.00 & 0.00 & 0.00 & 57.428 .41 \\
\hline Administration & & G020-REG & 600 & $\mathrm{Hr}$ & 1 & 600.0 & 33.28 & $19,969.08$ & 0.00 & 0.00 & 0.00 & 19.969 .08 \\
\hline \multirow{2}{*}{\multicolumn{13}{|c|}{ Post Job Alara Review }} \\
\hline & & & & & & & & & & & & \\
\hline Planner & & P070-REG & 3 & EA & 2 & 6.0 & 76.59 & 459.53 & 0.00 & 0.00 & 0.00 & 459.53 \\
\hline Electrician & & CO20-REG & 3 & EA & 4 & 120 & 61.07 & 732.83 & 0.00 & 0.00 & 0.00 & 732.83 \\
\hline Electrical Engineer & & E040-REG & 3 & EA & 2 & 6.0 & 80.24 & 481.42 & 0.00 & 0.00 & 0.00 & 48142 \\
\hline Environmental Engineer & & E050-REG & 3 & EA & 1 & 3.0 & 75.89 & 227.66 & 0.00 & 0.00 & 0.00 & 227.66 \\
\hline System Engineer & & E130-REG & 3 & EA & 2 & 6.0 & 9571 & 574.28 & 0.00 & 0.00 & 0.00 & 574.28 \\
\hline Other Engineers & & $\begin{array}{l}\text { E130-REG } \\
\text { S }\end{array}$ & 3 & $\begin{array}{c}E A \\
\text { EA }\end{array}$ & 2 & 6.0 & 9571 & 574.28 & 0.00 & 0.00 & 0.00 & 574.28 \\
\hline $\begin{array}{l}\text { Administration } \\
\text { First Line Supenision }\end{array}$ & & $\begin{array}{l}\text { G020-REG } \\
\text { MO10REG }\end{array}$ & 3 & $\begin{array}{l}\text { EA } \\
\text { EA }\end{array}$ & 2 & $\begin{array}{l}6.0 \\
30\end{array}$ & $\begin{array}{l}33.28 \\
7758\end{array}$ & $\begin{array}{l}199.69 \\
22074\end{array}$ & $\begin{array}{l}0.00 \\
0.00\end{array}$ & $\begin{array}{l}0.00 \\
0.00\end{array}$ & 0.00 & $\begin{array}{l}199.69 \\
22074\end{array}$ \\
\hline First Line Supervision & & MM10-REG & 3 & EA & 1 & 3.0 & 73.58 & 220.74 & 0.00 & 0.00 & 0.00 & 220.74 \\
\hline
\end{tabular}


RPP-RPT-37924 Rev. 0

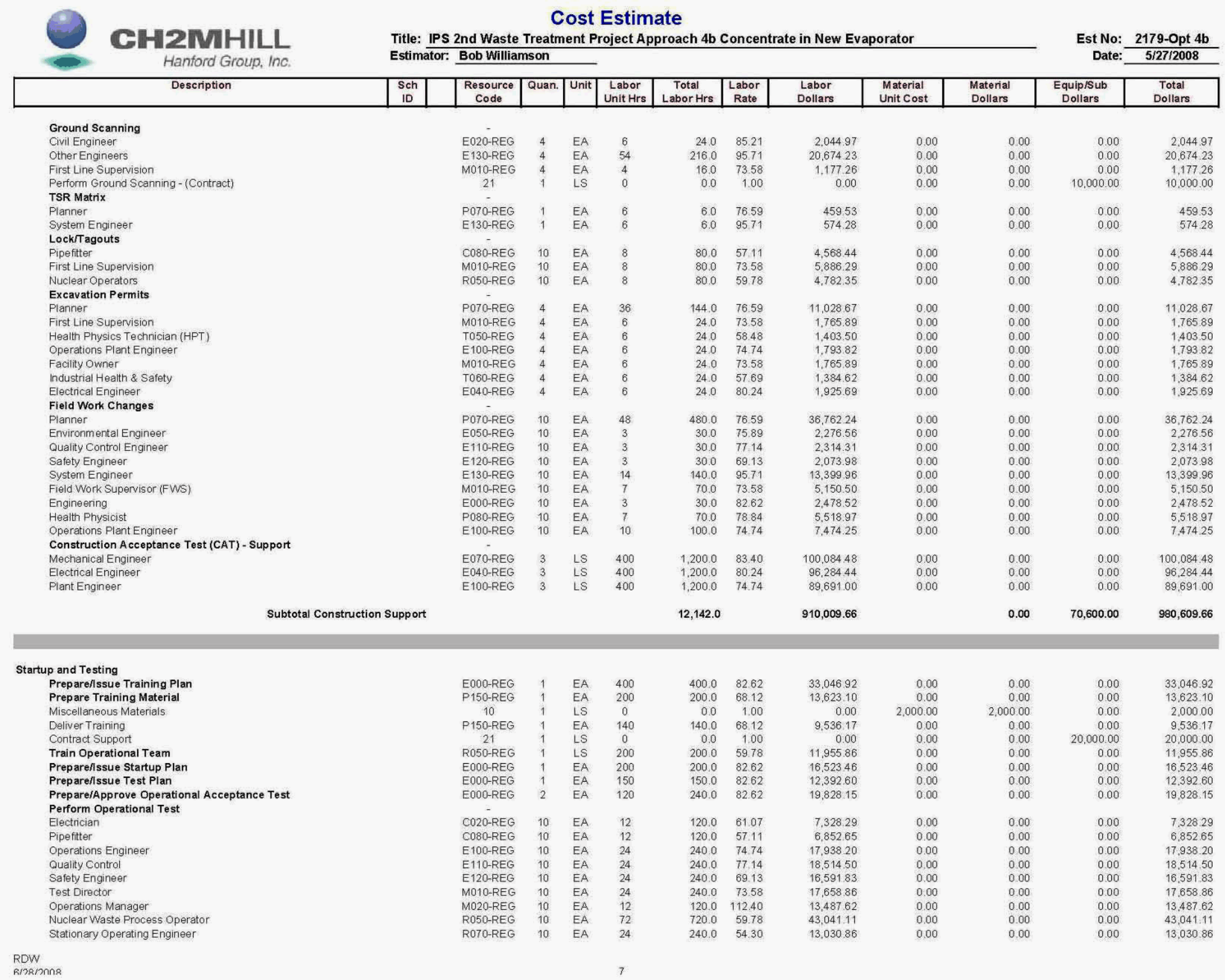


RPP-RPT-37924 Rev. 0

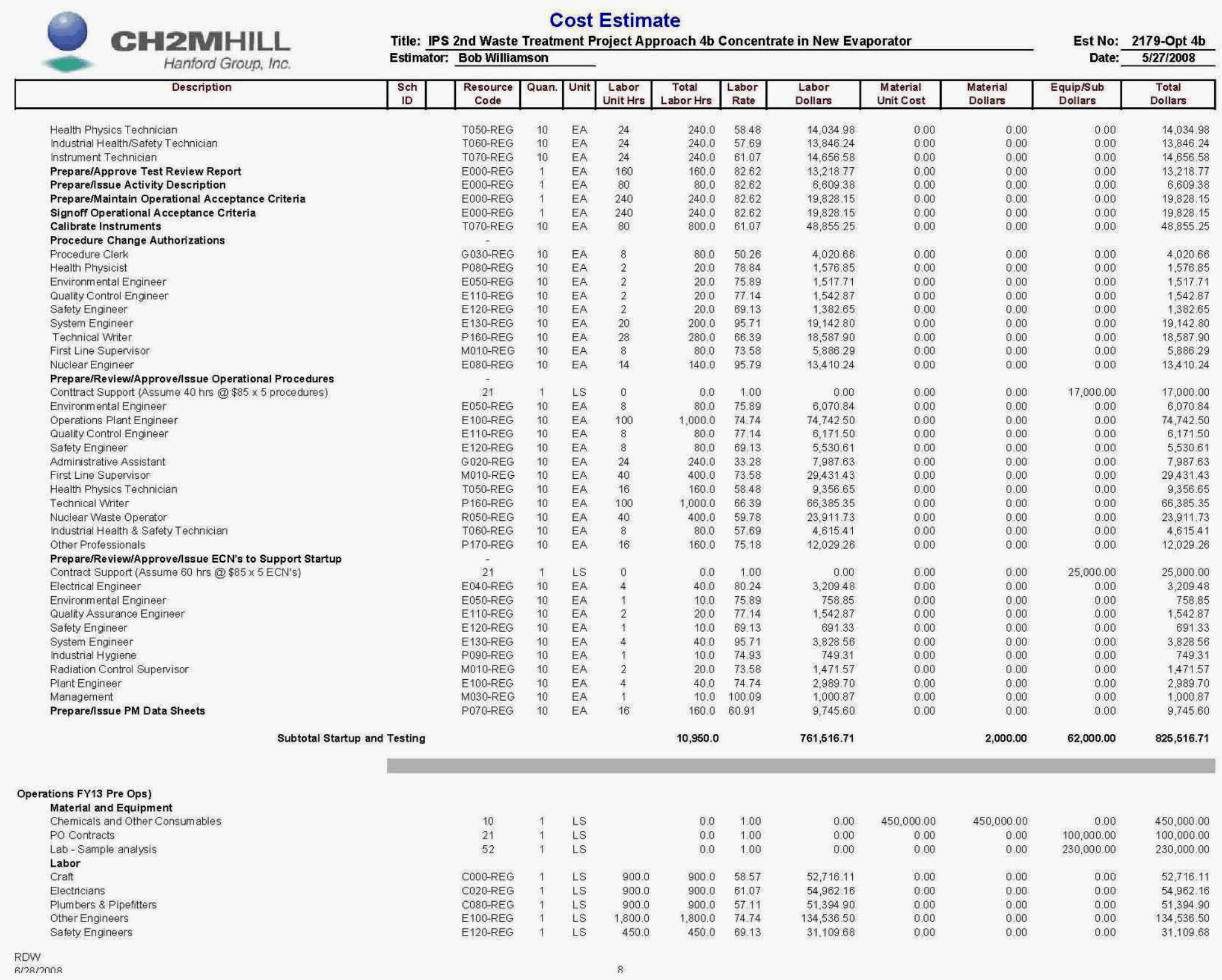


RPP-RPT-37924 Rev. 0

\begin{tabular}{|c|c|c|c|c|c|c|c|c|c|c|c|c|}
\hline \multirow{2}{*}{$\frac{\substack{\text { Hanford Group, inc. } \\
\text { Description }}}{2}$} & \multicolumn{10}{|c|}{$\begin{array}{l}\text { Cost Estimate } \\
\text { Title: IPS 2nd Waste Treatment Project Approach 4b Concentrate in New Evaporator } \\
\text { Estimator: Bob Williamson }\end{array}$} & \multicolumn{2}{|c|}{$\begin{aligned} & \text { Est No: } 2179-\mathrm{Opt} \text { 4b } \\
& \text { Date: } 5 / 2712008 \\
&\end{aligned}$} \\
\hline & \begin{tabular}{|c|} 
Sch \\
ID \\
\end{tabular} & \begin{tabular}{|c|}
$\begin{array}{c}\text { Resource } \\
\text { Code }\end{array}$ \\
\end{tabular} & Quan. & Unit & \begin{tabular}{|l|} 
Labor \\
Unit Hrs \\
\end{tabular} & \begin{tabular}{|l|} 
Total \\
abor Hrs \\
\end{tabular} & \begin{tabular}{|c|} 
Labor \\
Rate \\
\end{tabular} & $\begin{array}{l}\text { Labor } \\
\text { Dollars }\end{array}$ & $\begin{array}{l}\text { Material } \\
\text { Unit cost } \\
\end{array}$ & $\begin{array}{l}\text { Material } \\
\text { Dollars }\end{array}$ & $\begin{array}{l}\text { Equip/sub } \\
\text { Dollars }\end{array}$ & $\begin{array}{c}\text { Total } \\
\text { Dollars }\end{array}$ \\
\hline 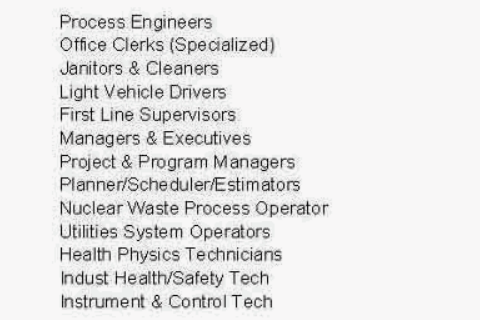 & & $\begin{array}{l}\text { E130-REG } \\
\text { G030-REG } \\
\text { LO30-REG } \\
\text { L L70-REG } \\
\text { M010-REG } \\
\text { M020-REG } \\
\text { M030-REG } \\
\text { P070-REG } \\
\text { R050-REG } \\
\text { R070-REG } \\
\text { T050-REG } \\
\text { To60-REG } \\
\text { TO70-REG }\end{array}$ & $\begin{array}{ll}1 & \\
1 & \\
1 & \\
1 \\
1 \\
1 \\
1 \\
1 \\
1 \\
1 \\
1 \\
1\end{array}$ & $\begin{array}{l}\text { LS } \\
\text { LS } \\
\text { LS } \\
\text { LS } \\
\text { LS } \\
\text { LS } \\
\text { LS } \\
\text { LS } \\
\text { LS } \\
\text { LS } \\
\text { LS } \\
\text { LS }\end{array}$ & $\begin{array}{r}900.0 \\
250.0 \\
0.0 \\
450.0 \\
1,800.0 \\
1,800.0 \\
2500 . \\
1,800.0 \\
10,800.0 \\
1,000.0 \\
2,600.0 \\
900.0 \\
450.0\end{array}$ & $\begin{array}{r}900.0 \\
250.0 \\
0.0 \\
450.0 \\
1,8000.0 \\
1.800 .0 \\
1250.0 \\
10.800 .0 \\
10.800 .0 \\
1.000 .0 \\
2.6000 .0 \\
900.0 \\
450.0\end{array}$ & $\begin{array}{r}95.71 \\
50.26 \\
36.15 \\
47.91 \\
73.58 \\
112.40 \\
100.09 \\
76.59 \\
59.78 \\
54.30 \\
58.48 \\
57.69 \\
61.07\end{array}$ & 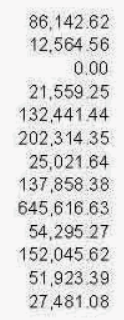 & $\begin{array}{l}0.00 \\
0.00 \\
0.00 \\
0.00 \\
0.00 \\
0.00 \\
0.00 \\
0.00 \\
0.00 \\
0.00 \\
0.00 \\
0.00 \\
0.00\end{array}$ & $\begin{array}{l}0.00 \\
0.00 \\
0.00 \\
0.00 \\
0.00 \\
0.00 \\
0.00 \\
0.00 \\
0.00 \\
0.00 \\
0.00 \\
0.00 \\
0.00\end{array}$ & $\begin{array}{l}0.00 \\
0.00 \\
0.00 \\
0.00 \\
0.00 \\
0.00 \\
0.00 \\
0.00 \\
0.00 \\
0.00 \\
0.00 \\
0.00 \\
0.00\end{array}$ & $\begin{array}{r}86.142 .62 \\
12.564 .56 \\
0.00 \\
21.55 .25 \\
132.441 .44 \\
202.314 .35 \\
25.021 .64 \\
137.258 .38 \\
645.616 .63 \\
54.25 .27 \\
152.045 .62 \\
51.923 .39 \\
27.481 .08\end{array}$ \\
\hline Operations $F$ & & & & & & & & & & & & \\
\hline $\begin{array}{l}\text { Chemicalas and Other Consumabies } \\
\text { PO Contracts } \\
\text { Lab-Sample analysis }\end{array}$ & & $\begin{array}{l}10 \\
21 \\
52\end{array}$ & $\begin{array}{l}1 \\
1 \\
1\end{array}$ & $\begin{array}{l}\text { LS } \\
\text { LS } \\
\text { LS }\end{array}$ & & $\begin{array}{l}0.0 \\
0.0 \\
0.0\end{array}$ & $\begin{array}{l}1.00 \\
1.00 \\
1.00\end{array}$ & $\begin{array}{l}0.00 \\
0.00 \\
0.00\end{array}$ & $\begin{array}{r}450.000 .00 \\
0.00 \\
0.00\end{array}$ & $\begin{array}{r}450,000.00 \\
0.00 \\
0.00\end{array}$ & $\begin{array}{r}0.00 \\
100,000.00 \\
230,000.00\end{array}$ & $\begin{array}{l}450,000.00 \\
100,000.00 \\
230,000.00\end{array}$ \\
\hline 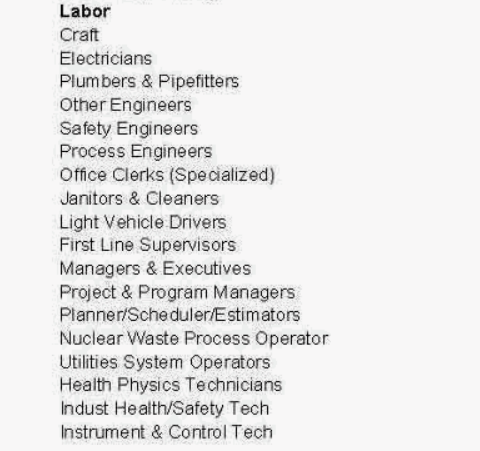 & & $\begin{array}{l}\text { CO00-REG } \\
\text { Co20-REG } \\
\text { Co80-REG } \\
\text { E100-REG } \\
\text { E120-REG } \\
\text { E130-REG } \\
\text { G030-REG } \\
\text { Lo30-REG } \\
\text { Lo70-REG } \\
\text { M010-REG } \\
\text { M020-REG } \\
\text { M030-REG } \\
\text { P070-REG } \\
\text { R050-REG } \\
\text { R070-REG } \\
\text { To50-REG } \\
\text { To60-REG } \\
\text { TO70-REG }\end{array}$ & $\begin{array}{l}1 \\
1 \\
1 \\
1 \\
1 \\
1 \\
1 \\
1 \\
1 \\
1 \\
1 \\
1 \\
1 \\
1\end{array}$ & $\begin{array}{l}\text { LS } \\
\text { LS } \\
\text { LS } \\
\text { LS } \\
\text { LS } \\
\text { LS } \\
\text { LS } \\
\text { LS } \\
\text { LS } \\
\text { LS } \\
\text { LS } \\
\text { LS } \\
\text { LS } \\
\text { LS } \\
\text { LS } \\
\text { LS } \\
\text { LS } \\
\text { LS }\end{array}$ & $\begin{array}{r}900.0 \\
900.0 \\
900.0 \\
1.800 .0 \\
450.0 \\
900.0 \\
250.0 \\
0.0 \\
450.0 \\
1,800.0 \\
1,800.0 \\
250.0 \\
1.800 .0 \\
10,800.0 \\
1,000.0 \\
2.600 .0 \\
900.0 \\
450.0\end{array}$ & 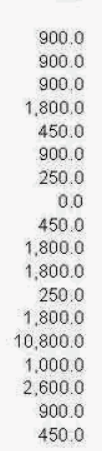 & $\begin{array}{l}58.57 \\
61.07 \\
5711 \\
74.74 \\
69.13 \\
95.71 \\
50.26 \\
36.15 \\
47.91 \\
73.58 \\
11240 \\
100.09 \\
76.59 \\
59.78 \\
54.30 \\
5848 \\
57.69 \\
61.07\end{array}$ & 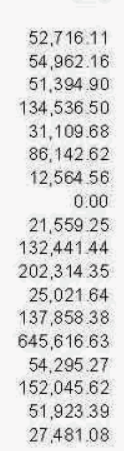 & $\begin{array}{l}0.00 \\
0.00 \\
0.00 \\
0.00 \\
0.00 \\
0.00 \\
0.00 \\
0.00 \\
0.00 \\
0.00 \\
0.00 \\
0.00 \\
0.00 \\
0.00 \\
0.00 \\
0.00 \\
0.00 \\
0.00\end{array}$ & $\begin{array}{l}0.00 \\
0.00 \\
0.00 \\
0.00 \\
0.00 \\
0.00 \\
0.00 \\
0.00 \\
0.00 \\
0.00 \\
0.00 \\
0.00 \\
0.00 \\
0.00 \\
0.00 \\
0.00 \\
0.00 \\
0.00\end{array}$ & $\begin{array}{l}0.00 \\
0.00 \\
0.00 \\
0.00 \\
0.00 \\
0.00 \\
0.00 \\
0.00 \\
0.00 \\
0.00 \\
0.00 \\
0.00 \\
0.00 \\
0.00 \\
0.00 \\
0.00 \\
0.00 \\
0.00\end{array}$ & 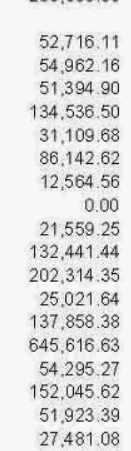 \\
\hline atio & & & & & & & & & & & & \\
\hline $\begin{array}{l}\text { Material and Equipment } \\
\text { Chemincalis and Other Consumables } \\
\text { Po Contracts } \\
\text { Lab - Sammile analysis }\end{array}$ & & $\begin{array}{l}10 \\
21 \\
52\end{array}$ & $\begin{array}{l}1 \\
1 \\
1\end{array}$ & $\begin{array}{l}\text { LS } \\
\text { LS }\end{array}$ & & $\begin{array}{l}0.0 \\
0.0 \\
0.0\end{array}$ & $\begin{array}{l}1.00 \\
1.00 \\
100\end{array}$ & $\begin{array}{l}0.00 \\
0.00 \\
0.00\end{array}$ & $\begin{array}{r}450,000.00 \\
0.00 \\
0.00\end{array}$ & $\begin{array}{r}450,000.00 \\
0.00 \\
0.00\end{array}$ & $\begin{array}{r}0.00 \\
100,000.00 \\
23000000\end{array}$ & $\begin{array}{l}450.000 .00 \\
100,000.00 \\
230.000 .00\end{array}$ \\
\hline $\begin{array}{l}\text { Labo } \\
\text { Carat }\end{array}$ & & COOPREG & 1 & ts & & & & 5271611 & & & & 5271611 \\
\hline $\begin{array}{l}\text { Electricians } \\
\text { Punters }\end{array}$ & & CO20-REG & 1 & LS & 900.0 & 900.0 & 61.07 & $\begin{array}{l}54,962.16 \\
513209\end{array}$ & 0.00 & 0.00 & 0.00 & $\begin{array}{l}54.962 .16 \\
5.9202\end{array}$ \\
\hline Other Engineers & & E100-REG & 1 & LS & $1,800.0$ & $\begin{array}{r}9,800.0 \\
-1,0\end{array}$ & 74.74 & $\begin{array}{r}134,536.50 \\
\end{array}$ & 0 & 0.00 & 0.00 & $\begin{array}{l}5134.534 .90 \\
130.50\end{array}$ \\
\hline $\begin{array}{c}\text { Sa } \\
\text { Proc }\end{array}$ & & $\begin{array}{l}\text { E120-REG } \\
\text { E130-PFG }\end{array}$ & $\frac{1}{1}$ & LS & $\begin{array}{l}450.0 \\
900.0\end{array}$ & 450.0 & $\begin{array}{l}6913 \\
9571\end{array}$ & $\begin{array}{l}31,10968 \\
8614262\end{array}$ & & & 0.00 & $\begin{array}{l}31.109 .68 \\
86.14262\end{array}$ \\
\hline aized). & & $\begin{array}{l}\text { E130-REG } \\
\text { G030REG }\end{array}$ & 1 & LS & 250.0 & 250.0 & 50.26 & $\begin{array}{l}86.14262 .62 \\
12,564.56\end{array}$ & 0.00 & 0.00 & 0.00 & $\begin{array}{l}12,564.56 \\
1806\end{array}$ \\
\hline $\begin{array}{l}\text { Janitors \& Cleaner } \\
\text { Light Venicle Dire }\end{array}$ & & $\begin{array}{l}\text { LO30-REG } \\
\text { Lo70-REG }\end{array}$ & 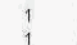 & LS & $\begin{array}{r}0.0 \\
4500\end{array}$ & $\begin{array}{r}0.0 \\
4500\end{array}$ & $\begin{array}{l}36.15 \\
4791\end{array}$ & $\begin{array}{r}0.00 \\
21.55925\end{array}$ & 0 & 0.0 & 00 & $\begin{array}{r}0.00 \\
21559.25\end{array}$ \\
\hline upervis & & $\begin{array}{l}\text { LO70-REG } \\
\text { MO10-REG }\end{array}$ & 1 & LS & $\begin{array}{r}450.0 \\
1.800 .0\end{array}$ & $\begin{array}{r}4.800 .0 \\
1.800 .0\end{array}$ & $\begin{array}{l}47.91 \\
7358\end{array}$ & $\begin{array}{l}21155925 \\
13244144\end{array}$ & & & & $\begin{array}{l}2.1 .1599 .25 \\
32,441.44\end{array}$ \\
\hline ives & & MO20-REG & 1 & LS & 1,8000 & 1.800 .0 & 11240 & 202,31435 & & & 0 & $202,314.35$ \\
\hline Project\& P & & M030-REG & 1 & LS & 250.0 & 250.0 & 100.09 & $\begin{array}{l}25.021 .64 \\
21775832\end{array}$ & & & 0 & $\begin{array}{r}25,021.64 \\
\end{array}$ \\
\hline 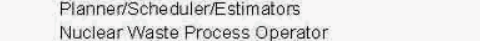 & & 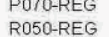 & 1 & LS & $\begin{array}{l}1,00000 \\
10,800.0\end{array}$ & $\begin{array}{l}10.0000 .0 \\
10.000\end{array}$ & 59.78 & $\begin{array}{l}137.855 .88 \\
645.616 .63\end{array}$ & 0.00 & $\begin{array}{l}0.00 \\
0.00\end{array}$ & $\begin{array}{l}0.00 \\
0.00\end{array}$ & $\begin{array}{l}\begin{array}{l}137.855 .38 \\
645.616 .63\end{array} \\
6\end{array}$ \\
\hline
\end{tabular}


RPP-RPT-37924 Rev. 0

Cost Estimate

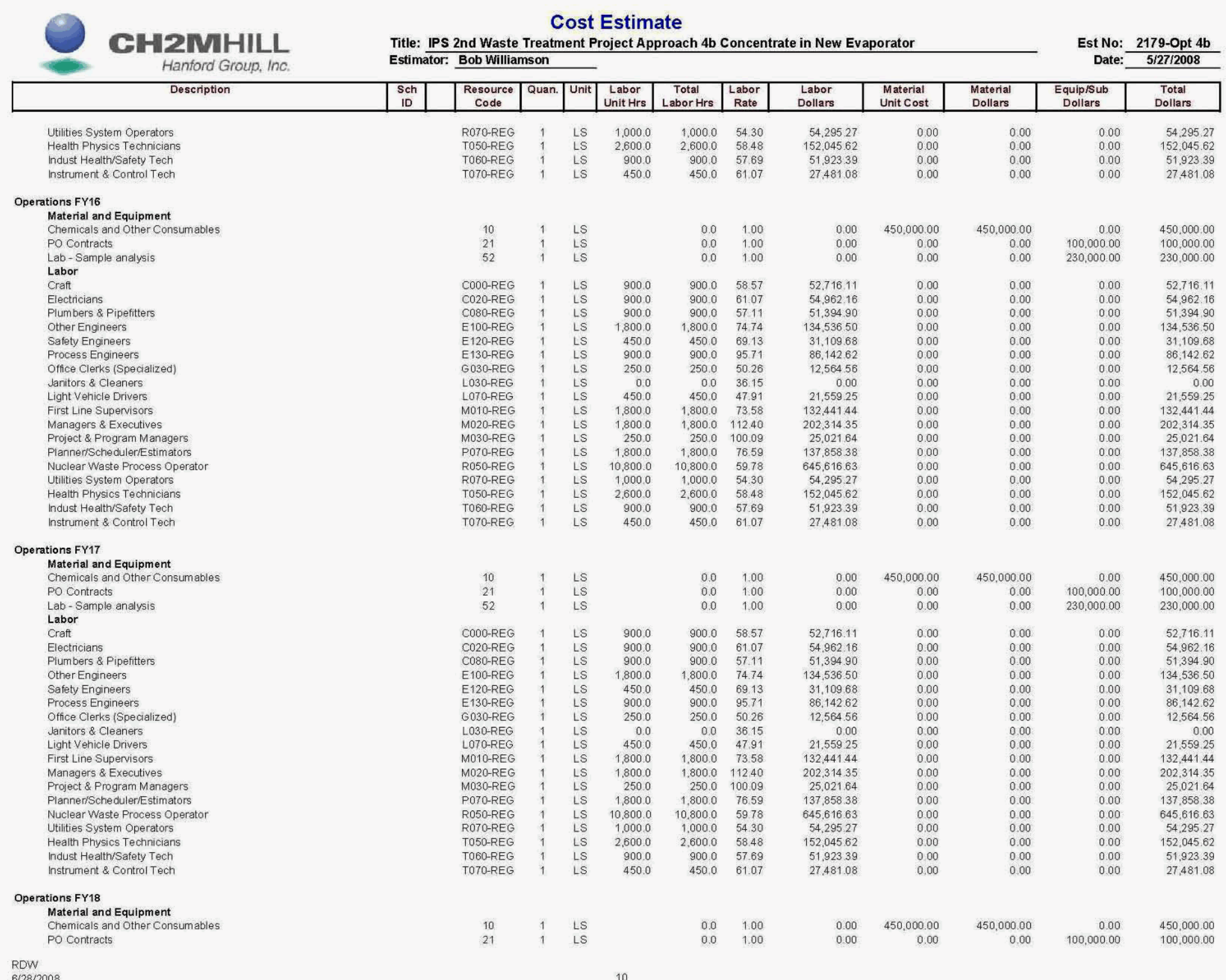


RPP-RPT-37924 Rev. 0

\begin{tabular}{|c|c|c|c|c|c|c|c|c|c|c|c|c|}
\hline CHII 2 Hanford Group, inc. & $\begin{array}{l}\text { Title: } \\
\text { Estima }\end{array}$ & $\begin{array}{l}\text { 2nd Waste } \\
\text { Bob Willial }\end{array}$ & $\begin{array}{l}\text { Treatm } \\
\text { nson }\end{array}$ & $\begin{array}{l}\text { OSt } \\
\text { ient } P\end{array}$ & $\begin{array}{l}\text { Estime } \\
\text { roject App }\end{array}$ & $\begin{array}{l}\text { ate } \\
\text { proach } 4 \mathrm{~b} C\end{array}$ & Concent & te in New Ev & porator & & $\begin{array}{l}\text { Est No: } \\
\text { Date: }\end{array}$ & $\begin{array}{c}2179-0 p t 4 b \\
5 / 27 / 2008 \\
\end{array}$ \\
\hline Description & \begin{tabular}{|c|}
$\begin{array}{c}\text { Sch } \\
\text { ID }\end{array}$ \\
\end{tabular} & \begin{tabular}{|c|}
$\begin{array}{c}\text { Resource } \\
\text { Code }\end{array}$ \\
\end{tabular} & \begin{tabular}{|l|} 
Quan. \\
\end{tabular} & \begin{tabular}{|l|} 
Unit \\
\end{tabular} & \begin{tabular}{l|l} 
Labor \\
Unit Hrs \\
\end{tabular} & \begin{tabular}{c|} 
Total \\
Labor Hrs \\
\end{tabular} & $\begin{array}{c}\text { Labor } \\
\text { Rate } \\
\end{array}$ & $\begin{array}{l}\text { Labor } \\
\text { Dollars }\end{array}$ & $\begin{array}{l}\text { Material } \\
\text { Unit cost } \\
\end{array}$ & $\begin{array}{l}\text { Material } \\
\text { Dollars } \\
\end{array}$ & $\begin{array}{c}\text { Equip/sub } \\
\text { Dollars }\end{array}$ & $\begin{array}{l}\text { Total } \\
\text { Dollars } \\
\end{array}$ \\
\hline $\begin{array}{l}\text { Lab-Sample analysis } \\
\text { Labor }\end{array}$ & & 52 & 1 & LS & & 0.0 & 1.00 & 0.00 & 0.00 & 0.00 & $230,000.00$ & $230,000.00$ \\
\hline Craft & & CO00-REG & 1 & LS & 900.0 & 900.0 & 58.57 & $52,716.11$ & 0.00 & 0.00 & 0.00 & 52.716 .11 \\
\hline Electricians & & CO2O-REG & 1 & LS & 9000 & 900.0 & 61.07 & $54,962.16$ & 0.00 & 0.00 & 0.00 & 54.962 .16 \\
\hline Plumbers \& Pipefitters & & C080-REG & 1 & LS & 900.0 & 900.0 & 57.11 & 51,39490 & 0.00 & 0.00 & 0.00 & $51,394.90$ \\
\hline Other Engineers & & E100-REG & 1 & LS & $1,800.0$ & $1,800.0$ & 74.74 & $134,536,50$ & 0.00 & 0.00 & 0.00 & $134,536,50$ \\
\hline Safety Engineers & & E120-REG & 1 & LS & 450.0 & 450.0 & 6913 & $31,109,68$ & 0.00 & 0,00 & 0.00 & 31.109 .68 \\
\hline Process Engineers & & E130-REG & 1 & LS & 900.0 & 900.0 & 9571 & $86,142.62$ & 0.00 & 0.00 & 0.00 & 86.142 .62 \\
\hline Office Clerks (Specialized) & & G030-REG & 1 & LS & 250.0 & 250.0 & 50.26 & 12,56456 & 0.00 & 0.00 & 0.00 & $12,564.56$ \\
\hline Janitors \& Cleaners & & LO30-REG & 1 & LS & 0.0 & 0.0 & 36.15 & & 0,00 & 0.00 & 0.00 & \\
\hline Light Vehicle Drivers & & L070-REG & 1 & LS & 450.0 & 450.0 & 47.91 & $21,559.25$ & 0.00 & 0.00 & 0.00 & 21.559 .25 \\
\hline First Line Supervisors & & M010-REG & 1 & LS & 1.800 .0 & 1.800 .0 & 73.58 & $132,441,44$ & 0.00 & 0.00 & 0.00 & 132.441 .44 \\
\hline Managers \& Executives & & MO20-REG & 1 & LS & $1,800.0$ & $1,800.0$ & 112.40 & $202,314,35$ & 0.00 & 0.00 & 0.00 & $202,314,35$ \\
\hline Project \& Program Managers & & M030-REG & 1 & LS & 250.0 & 250.0 & 100.09 & 25.021 .64 & 0.00 & & 0.00 & 25.021 .64 \\
\hline Planner/Sche duler/Estimators & & P070-REG & 1 & LS & $1,800.0$ & 1.800 .0 & 76.59 & $137,858.38$ & 0.00 & 0.00 & 0.00 & 137.858 .38 \\
\hline Nuclear Waste Process Operator & & R050-REG & 1 & LS & $10,800.0$ & $10,800.0$ & 59.78 & 645.616 .63 & 0.00 & 0.00 & 0.00 & $645,616.63$ \\
\hline Utilities System Operators & & R070-REG & 1 & LS & 1.000 .0 & 1.000 .0 & 54.30 & 54.295 .27 & 0.00 & 0.00 & 0.00 & 54.295 .27 \\
\hline Health Physics Technicians & & T050-REG & 1 & LS & $2,600.0$ & $2,600.0$ & 58.48 & $152,045,62$ & 0.00 & 0.00 & 0.00 & $152,045,62$ \\
\hline $\begin{array}{l}\text { Indust Health/Safety Tech } \\
\text { Instrument \& Control Tech }\end{array}$ & & $\begin{array}{l}\text { T060-REG } \\
\text { T070-REG }\end{array}$ & ${ }_{1}^{1}$ & $\begin{array}{l}\text { LS } \\
\text { LS }\end{array}$ & $\begin{array}{l}900.0 \\
450.0\end{array}$ & $\begin{array}{l}900.0 \\
450.0\end{array}$ & $\begin{array}{l}57.69 \\
61.07\end{array}$ & $\begin{array}{l}51,923.39 \\
27,481.08\end{array}$ & $\begin{array}{l}0.00 \\
0.00\end{array}$ & $\begin{array}{l}0.00 \\
0.00\end{array}$ & $\begin{array}{l}0.00 \\
0.00\end{array}$ & $\begin{array}{l}51.923 .39 \\
27.481 .08\end{array}$ \\
\hline & erations & & & & & $167,700.0$ & & $11,243,901.42$ & & $2,700,000.00$ & $1,980,000.00$ & $15,923,901.42$ \\
\hline $\begin{array}{l}\text { Other Porject Costs } \\
\text { Other Porject Costs }\end{array}$ & & & & & & & & & & & & \\
\hline Preliminary Design & & & & & & & & & & & & \\
\hline Preliminary Desig & & 21 & 1 & LS & 0 & 0.0 & 1.00 & 0.00 & 0.00 & 0.00 & $250,000.00$ & $250,000.00$ \\
\hline Preliminary Design (Engin & & E130-REG & 1 & LS & 1800 & 1.800 .0 & 95.71 & $172,285.23$ & 0.00 & 0.00 & 0.00 & $172,285.23$ \\
\hline Preliminary Design (Project Management) & & MO30-REG & 1 & LS & 900 & 900.0 & 100.09 & $90,077.92$ & 0.00 & 0.00 & 0.00 & $90,077.92$ \\
\hline Develo & & & & & & & & & & & & \\
\hline ts to Ve & & 21 & 1 & LS & 0 & 0.0 & 1.00 & 0.00 & 0.00 & 0.00 & $300,000.00$ & $300,000.00$ \\
\hline Develop & & E130-REG & 1 & LS & 1800 & 1.800 .0 & 95.71 & $172,285.23$ & 0.00 & 0.00 & 000 & 172.285 .23 \\
\hline Develo & & M030-REG & 1 & LS & 900 & 900.0 & 100.09 & $90,077.92$ & 0 & & 00 & $90,077.92$ \\
\hline Develo & & 21 & 1 & LS & 0 & 0.0 & 1.00 & 0.00 & & 0.00 & 100.000 .00 & $100,000.00$ \\
\hline Laboratory Analysis & & 21 & 1 & LS & 0 & 0.0 & 1.00 & 0.00 & 0.00 & 0.00 & $250,000.00$ & $250,000.00$ \\
\hline Regu & & & & & & & & & & & & \\
\hline Prepar & & 21 & 1 & LS & 0 & 0.0 & 1.00 & 0.00 & 0.00 & 0.00 & $50,000.00$ & $50,000.00$ \\
\hline Prepar & & E050-REG & 1 & LS & 900 & 900.0 & 75.89 & $68,296.90$ & 0. & 0.00 & 0.00 & $68,296.90$ \\
\hline Permi & & 21 & 1 & LS & 0 & 0.0 & 1.00 & 0.00 & 0 & & $200,000,00$ & $200,000.00$ \\
\hline Permitting Preparation/Support (Environmental Engineer) & & E050-REG & 1 & LS & 1800 & $1,800.0$ & 75.89 & $136,593,80$ & $5,000.00$ & 5.000 .00 & 10 & 141.593 .80 \\
\hline Air Permit & & 21 & 1 & LS & 0 & 0.0 & 0.00 & 0.00 & 0.00 & 0.00 & $150,000.00$ & $150,000.00$ \\
\hline Air $\mathrm{Pe}$ & & E130 & 1 & LS & 1808 & 1.808 .0 & 80. & 144.820 .80 & & & & 144. \\
\hline Develop/Review/Approve RCRA Part B Permit & & 21 & 1 & LS & 0 & 0.0 & 0.00 & 0.00 & 0. & 0.00 & $500,000.00$ & $500,000.00$ \\
\hline Develop/Review/Approve RCRA Part B Permit & & E130 & 1 & LS & 3616 & $3,616.0$ & 80.10 & $289,641.60$ & 0.00 & 0.00 & 0.00 & $289,641,60$ \\
\hline Subtotal o & et costs & & & & & $13,524.0$ & & $1,164,079.41$ & & $5,000.00$ & $1,800,000.00$ & $2,969,079.41$ \\
\hline $\begin{array}{l}\text { Chility De } \\
\text { Cha }\end{array}$ & & & & & & & & & & & & \\
\hline Charactenzzation (Subs & & 21 & 1 & LS & 0 & 0.0 & 1.00 & 0.00 & 0.00 & 0.0 & $250,000.00$ & 250,00 \\
\hline Characterization & & E130-REG & 1 & LS & 4000 & 4.000 .0 & 95.71 & $382,856.07$ & 0.00 & 0.00 & 0.00 & 382,85 \\
\hline
\end{tabular}
RDW 
RPP-RPT-37924 Rev. 0

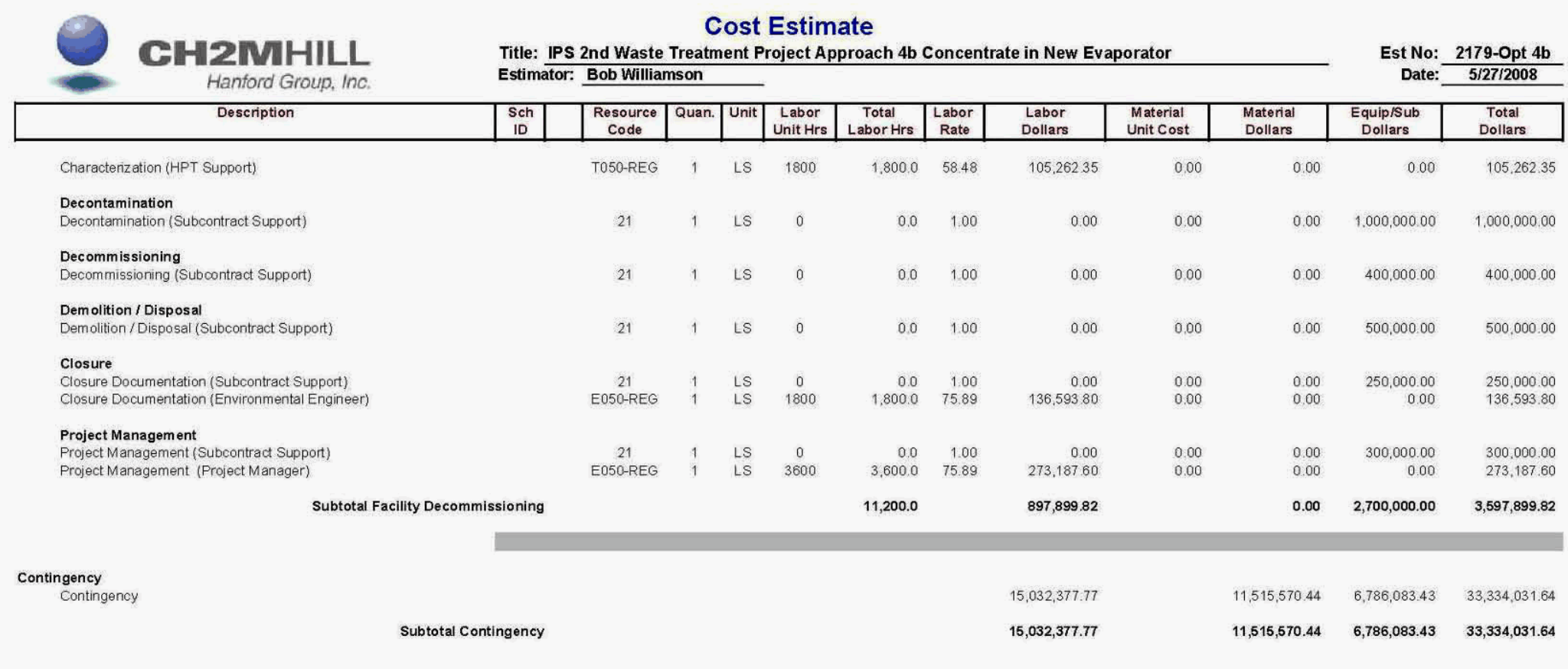


RPP-RPT-37924 Rev. 0

Table G-12. Approach 5a Cost Estimate.

Table begins on next page. 
RPP-RPT-37924 Rev. 0

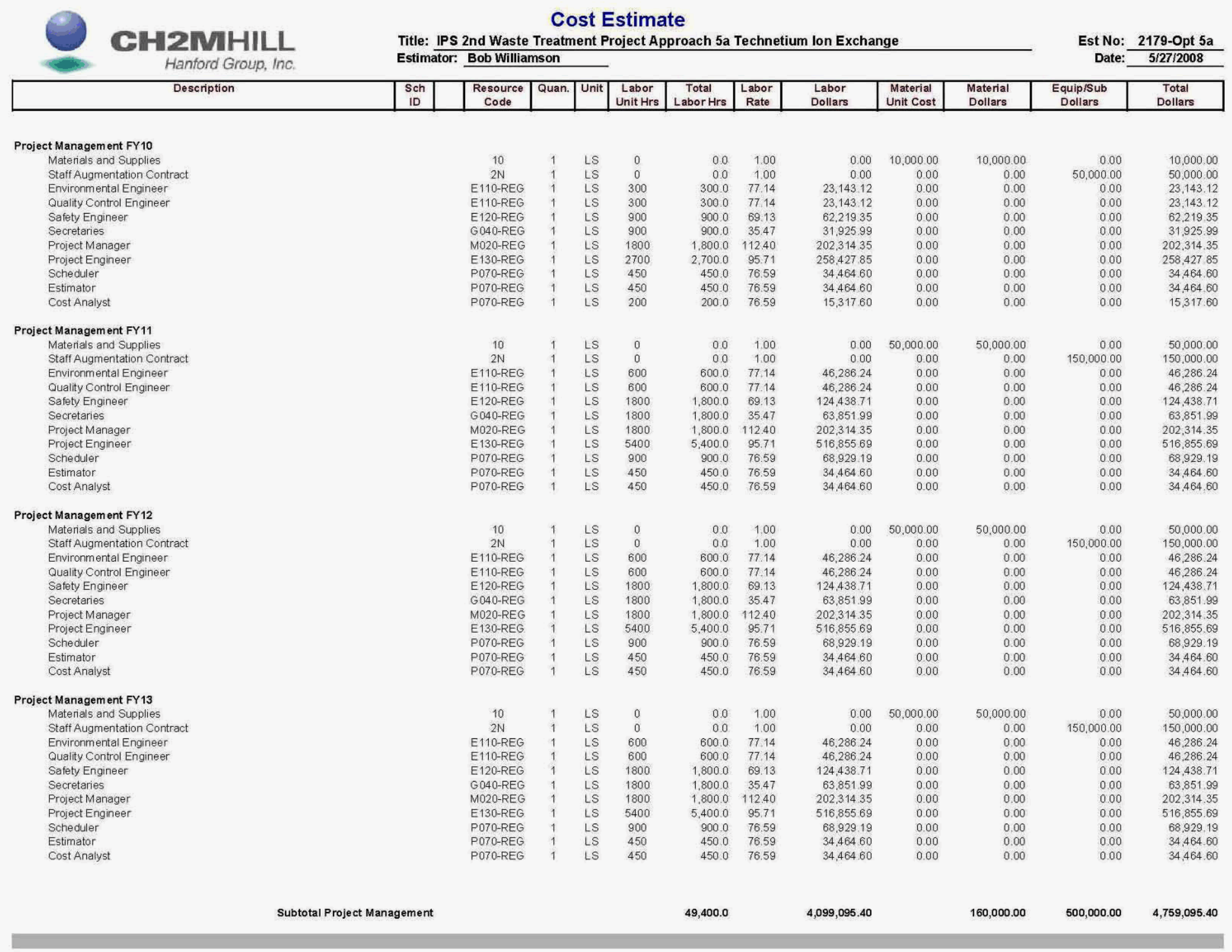


RPP-RPT-37924 Rev. 0

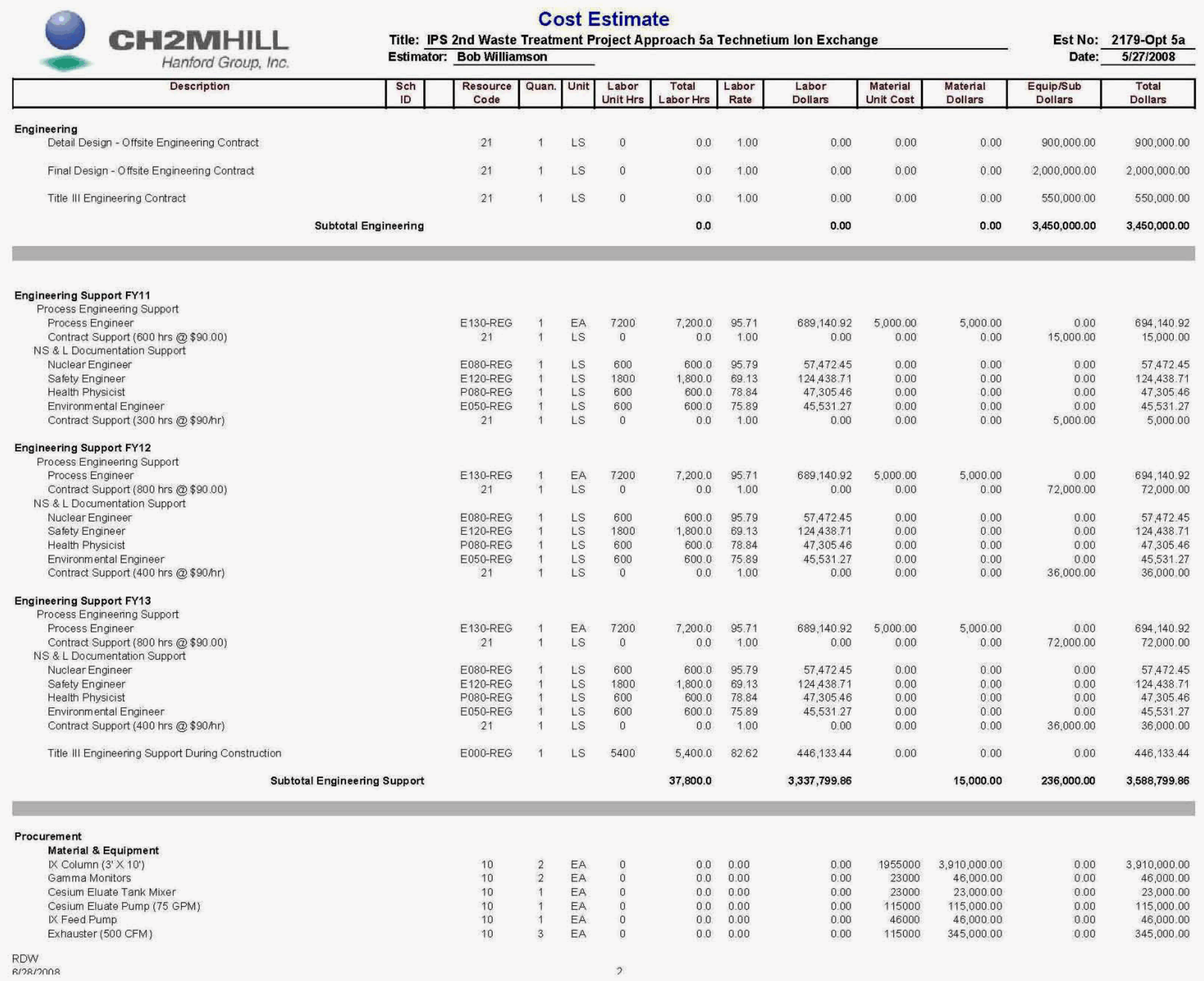


RPP-RPT-37924 Rev. 0

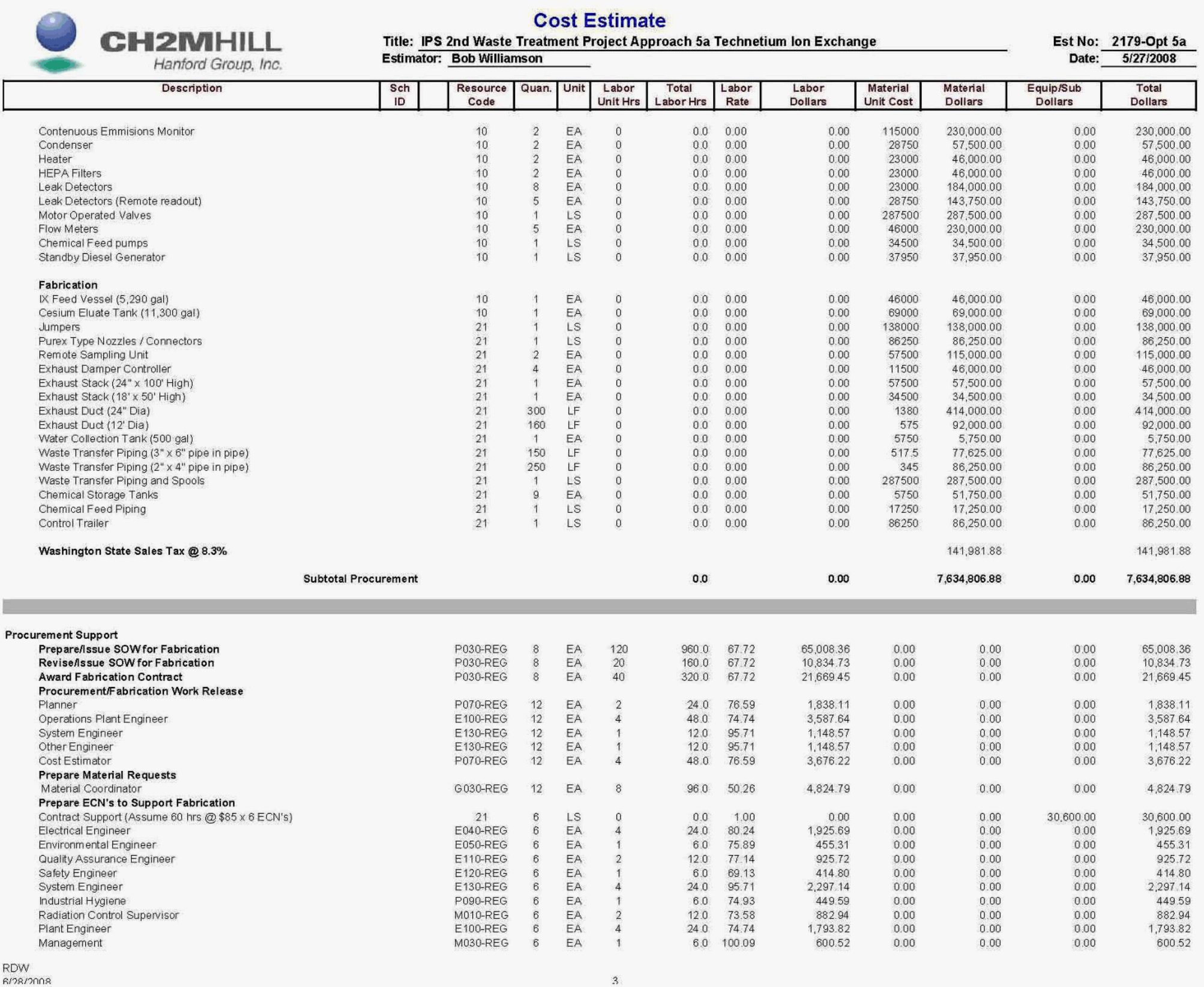


RPP-RPT-37924 Rev. 0

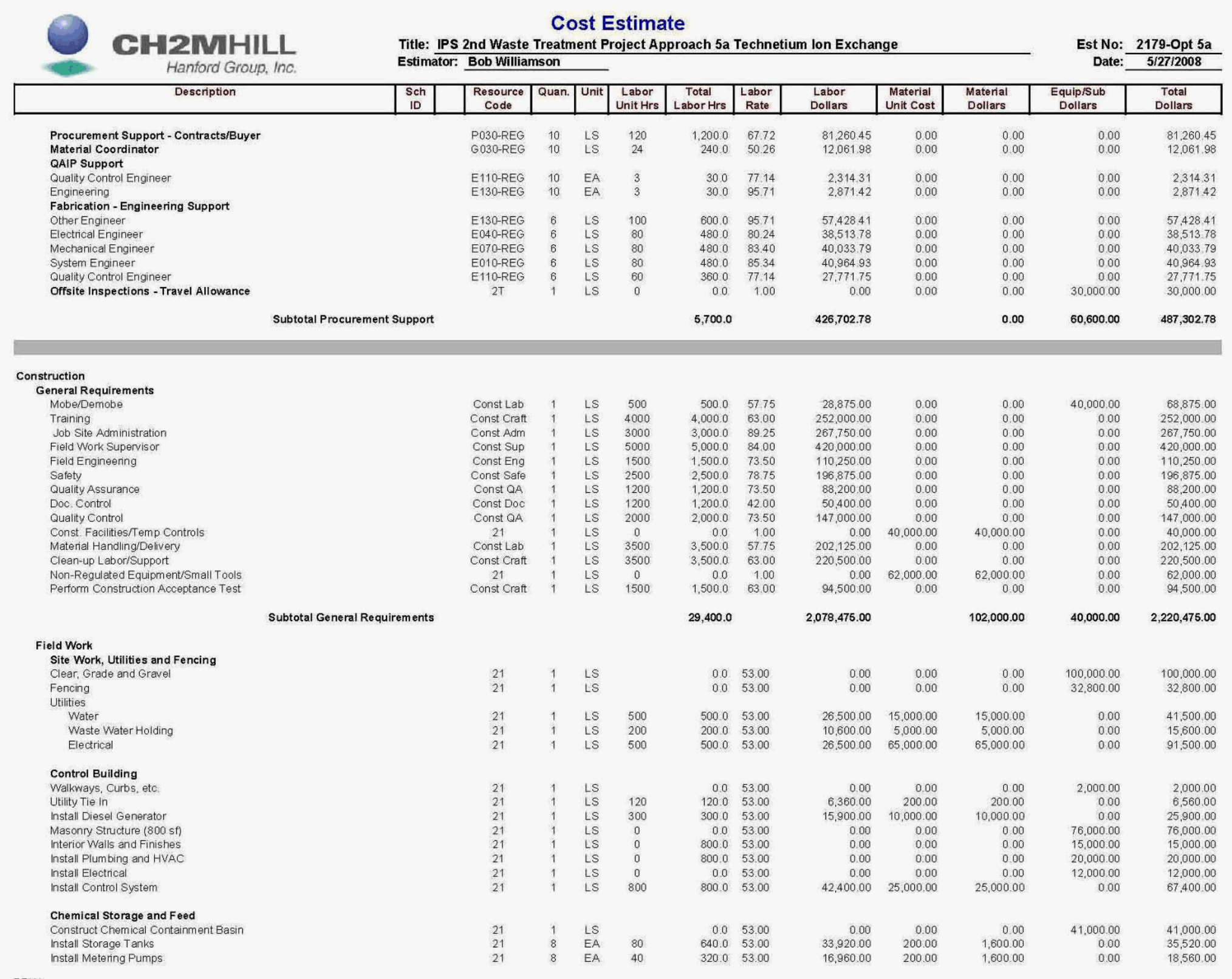


RPP-RPT-37924 Rev. 0

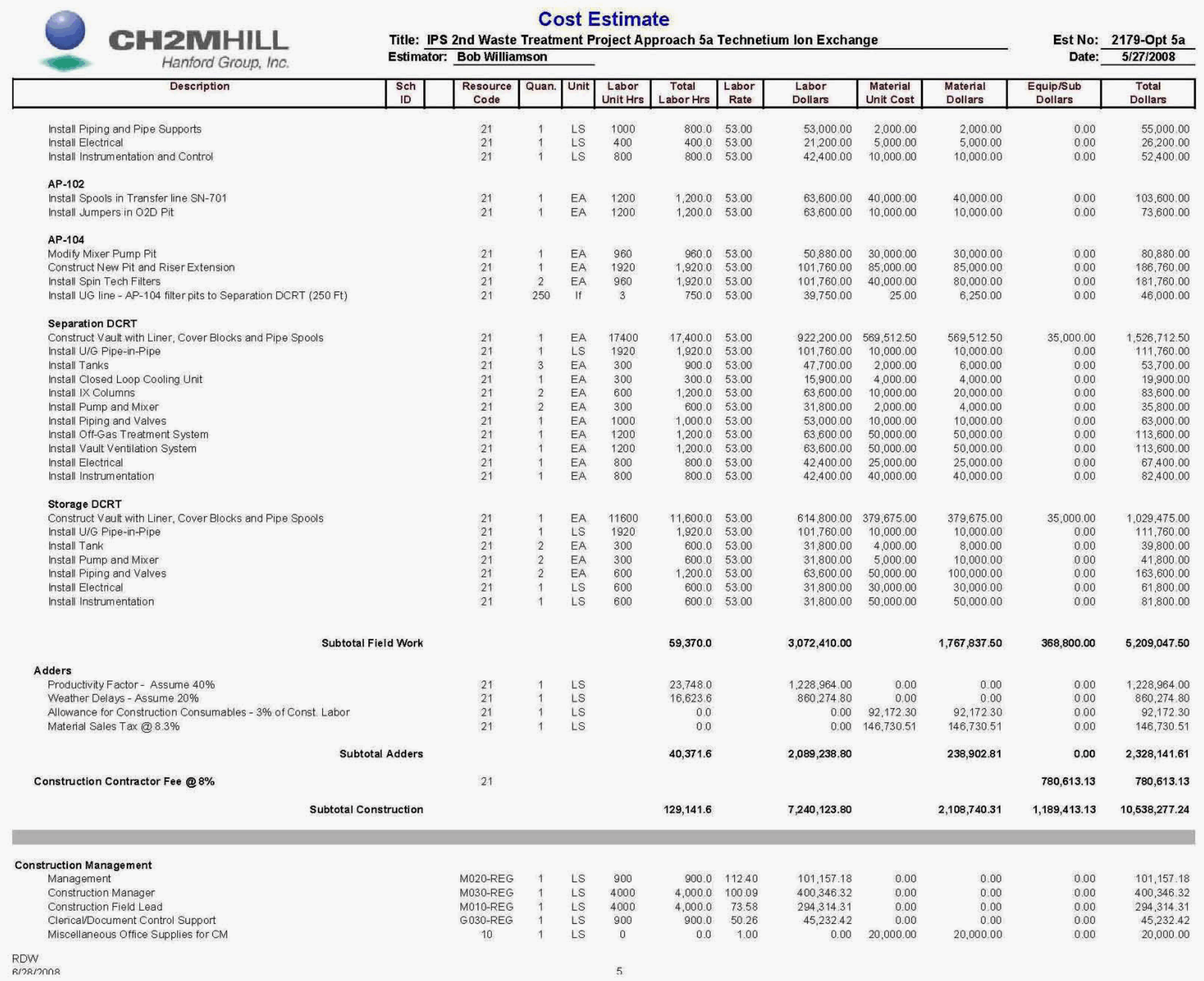


RPP-RPT-37924 Rev. 0

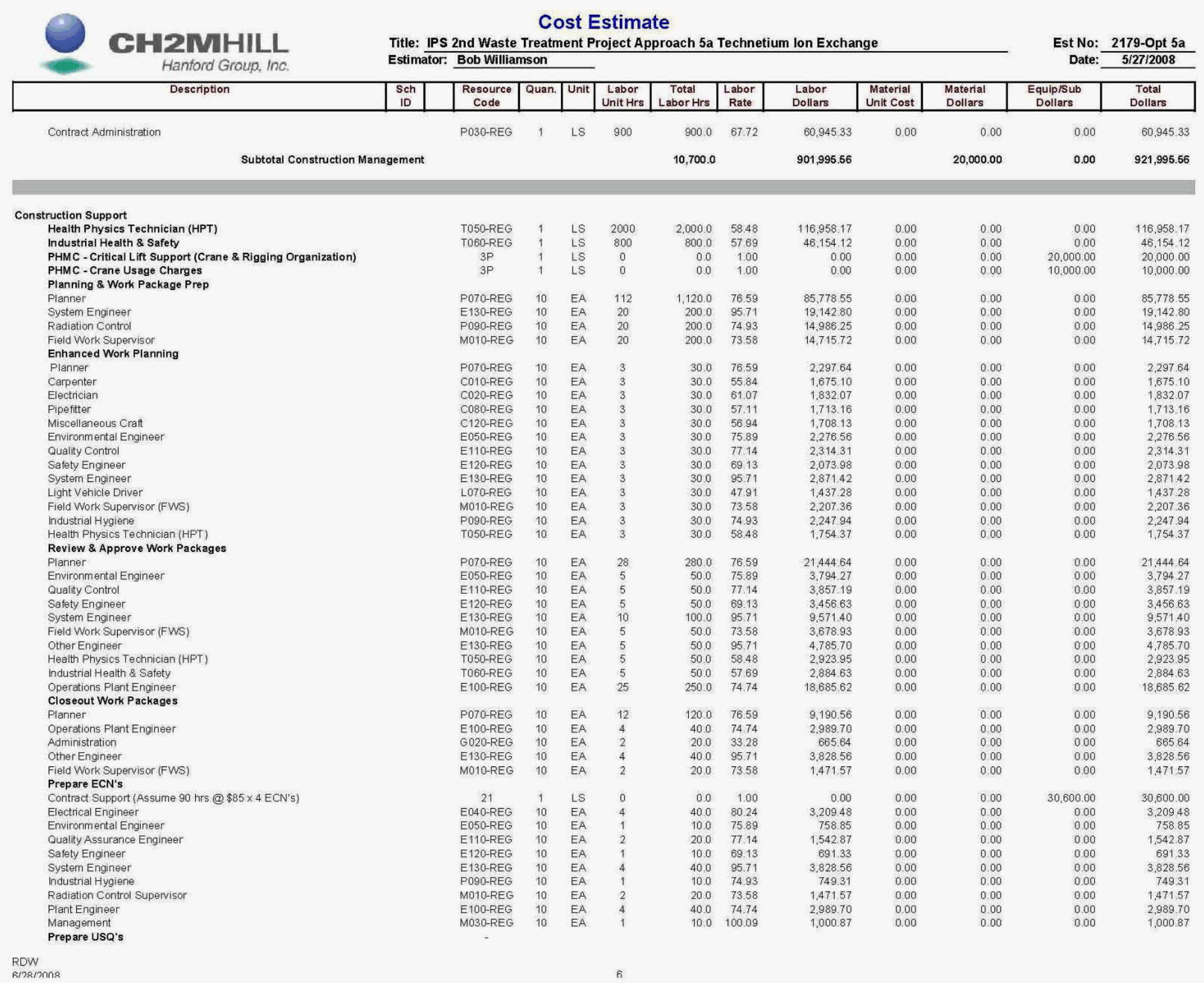


RPP-RPT-37924 Rev. 0

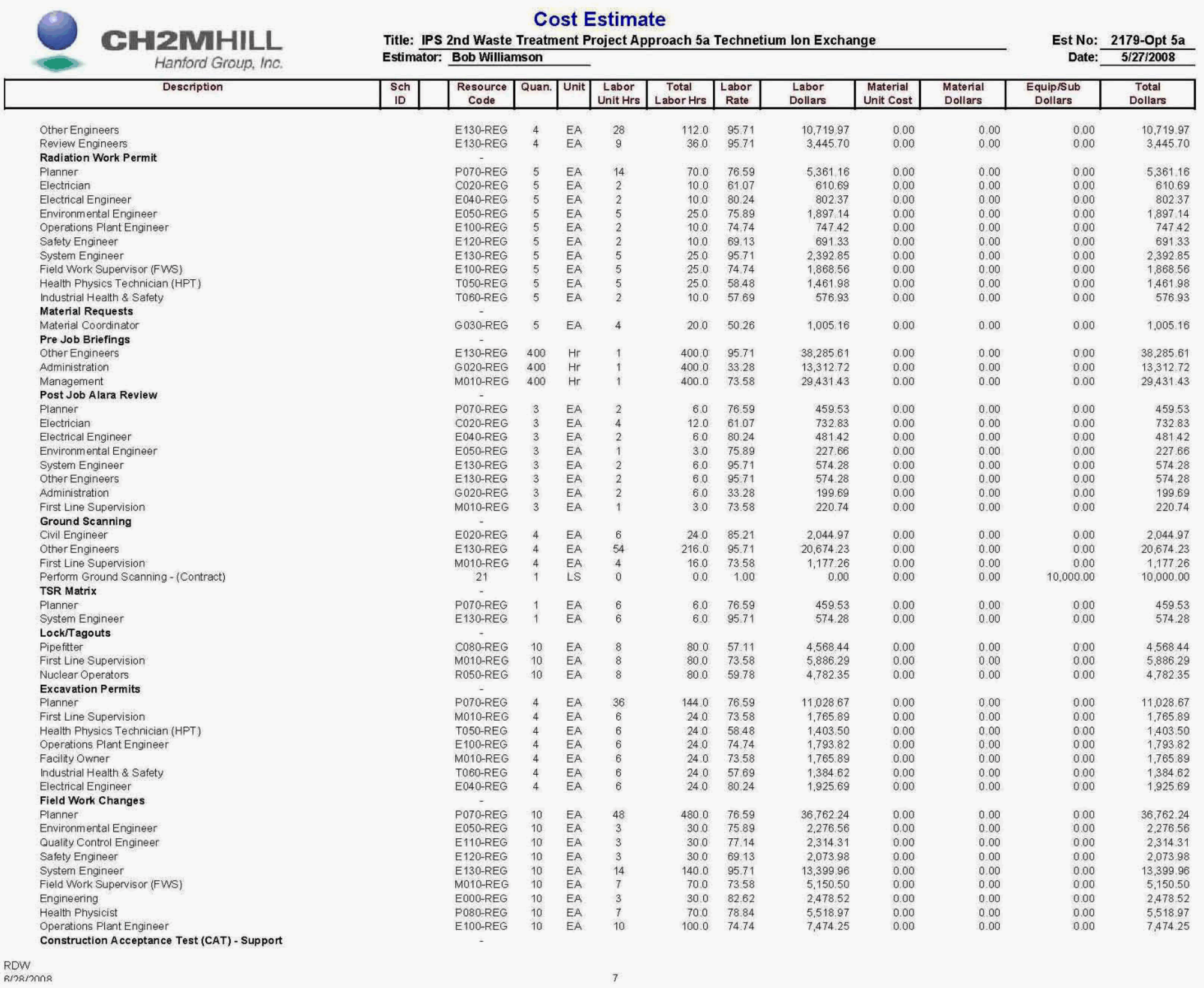


RPP-RPT-37924 Rev. 0

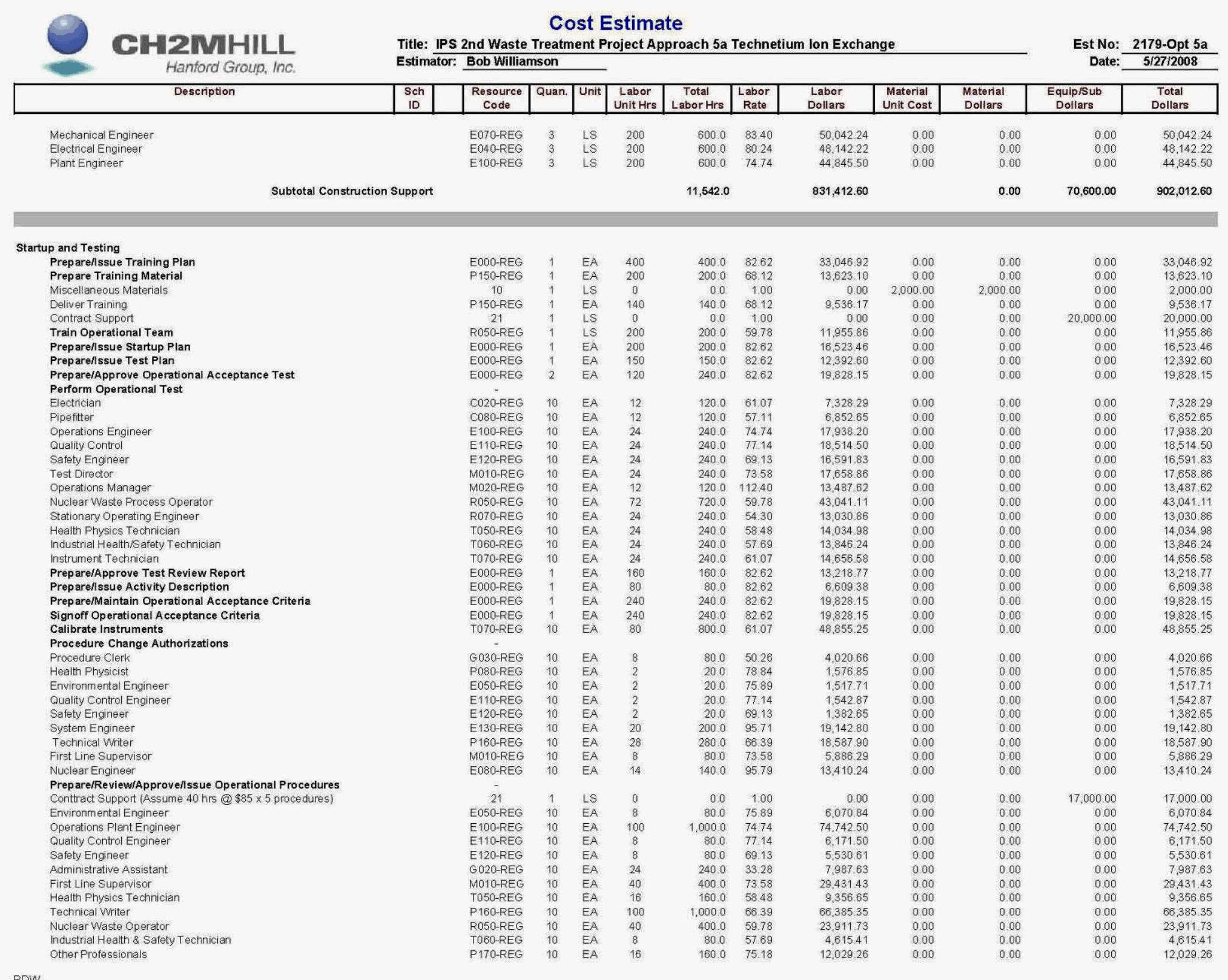


RPP-RPT-37924 Rev. 0

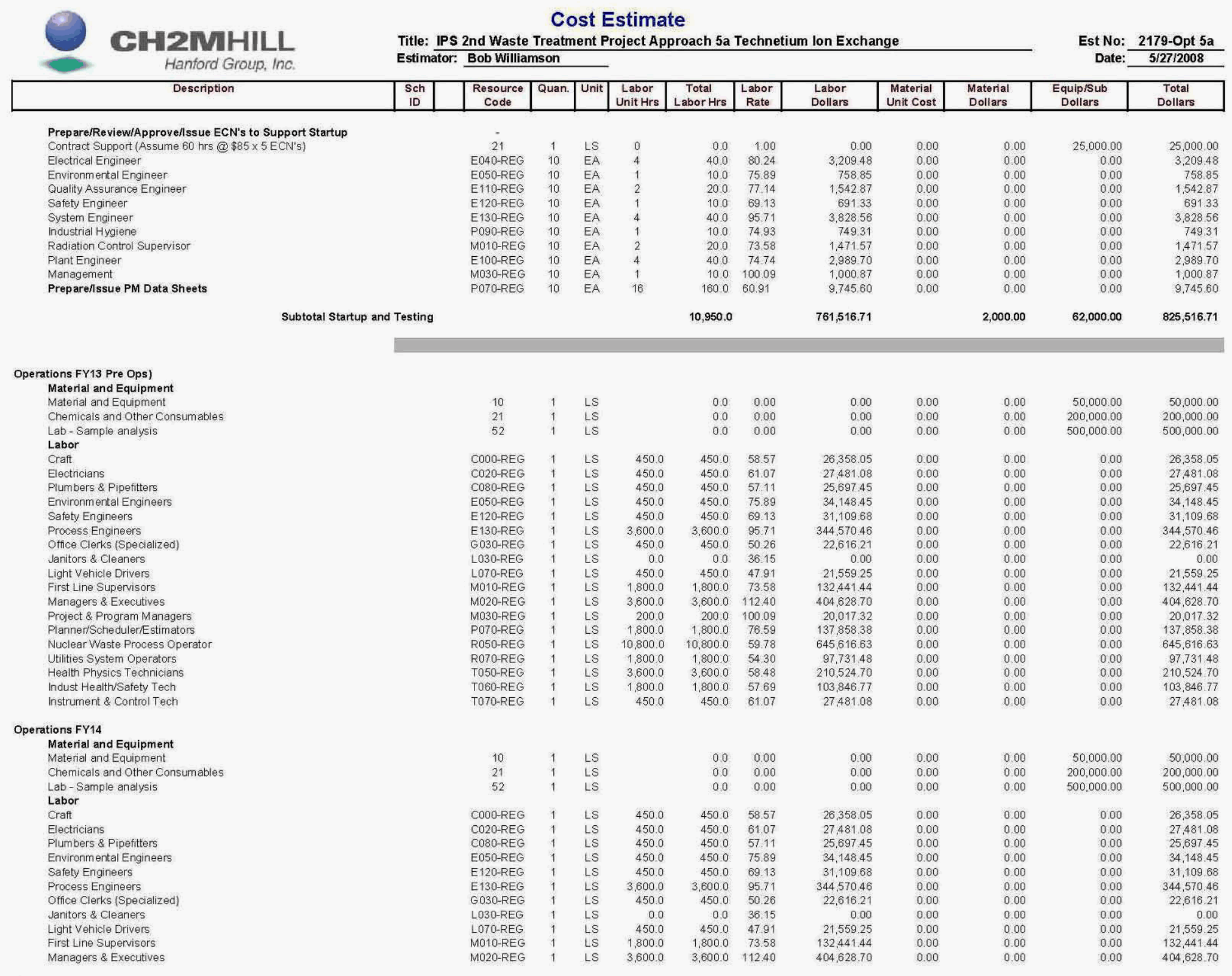


RPP-RPT-37924 Rev. 0

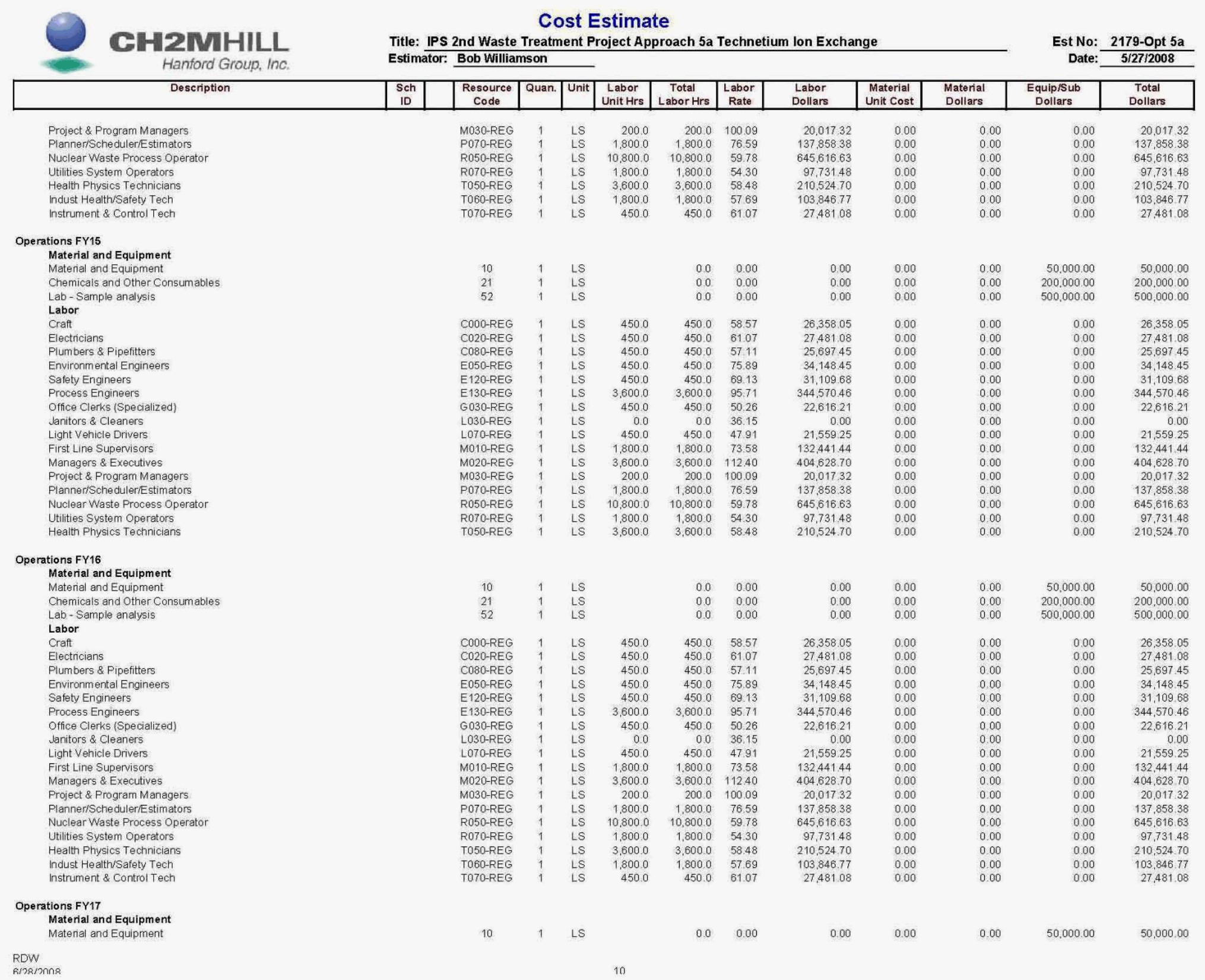


RPP-RPT-37924 Rev. 0

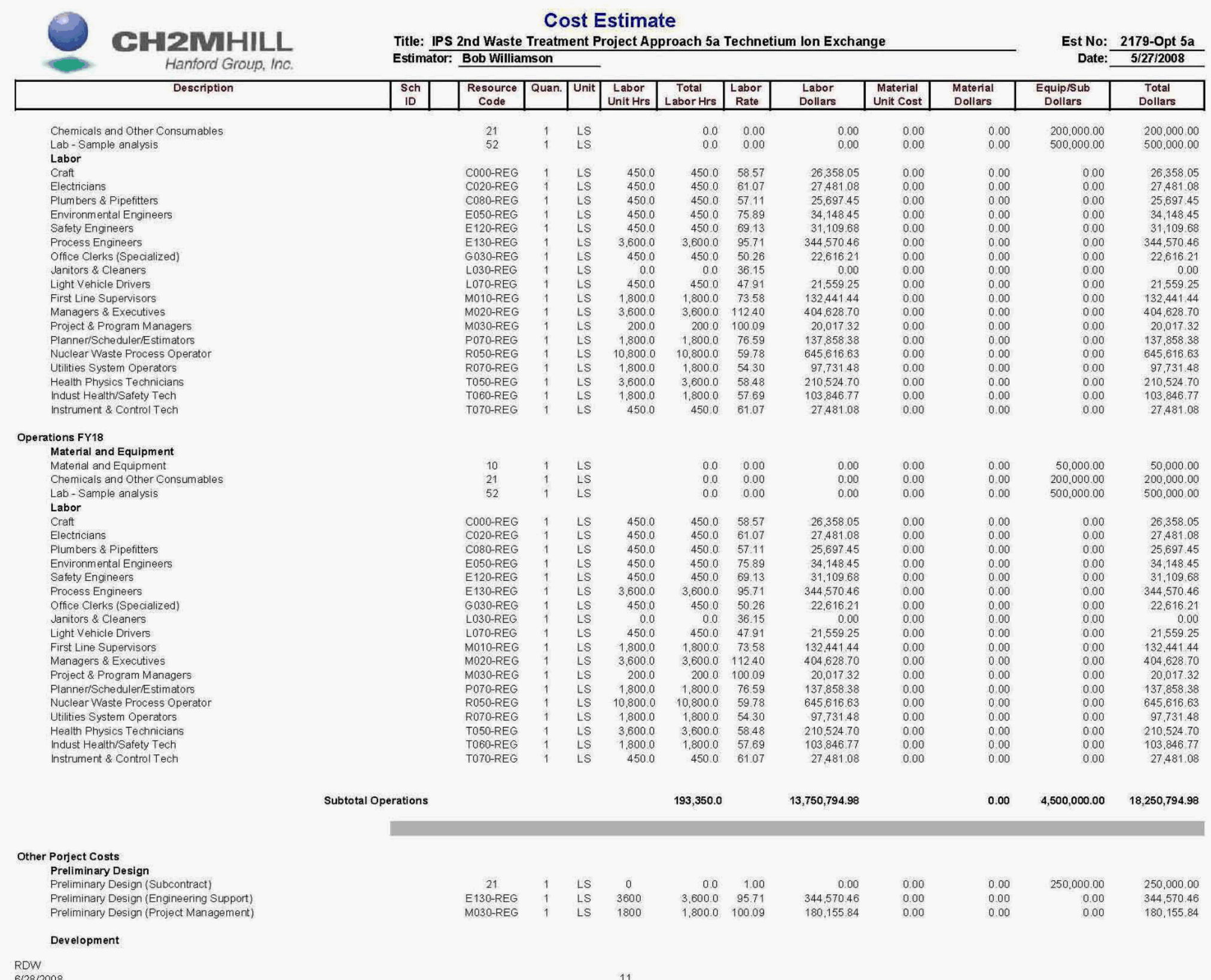


RPP-RPT-37924 Rev. 0

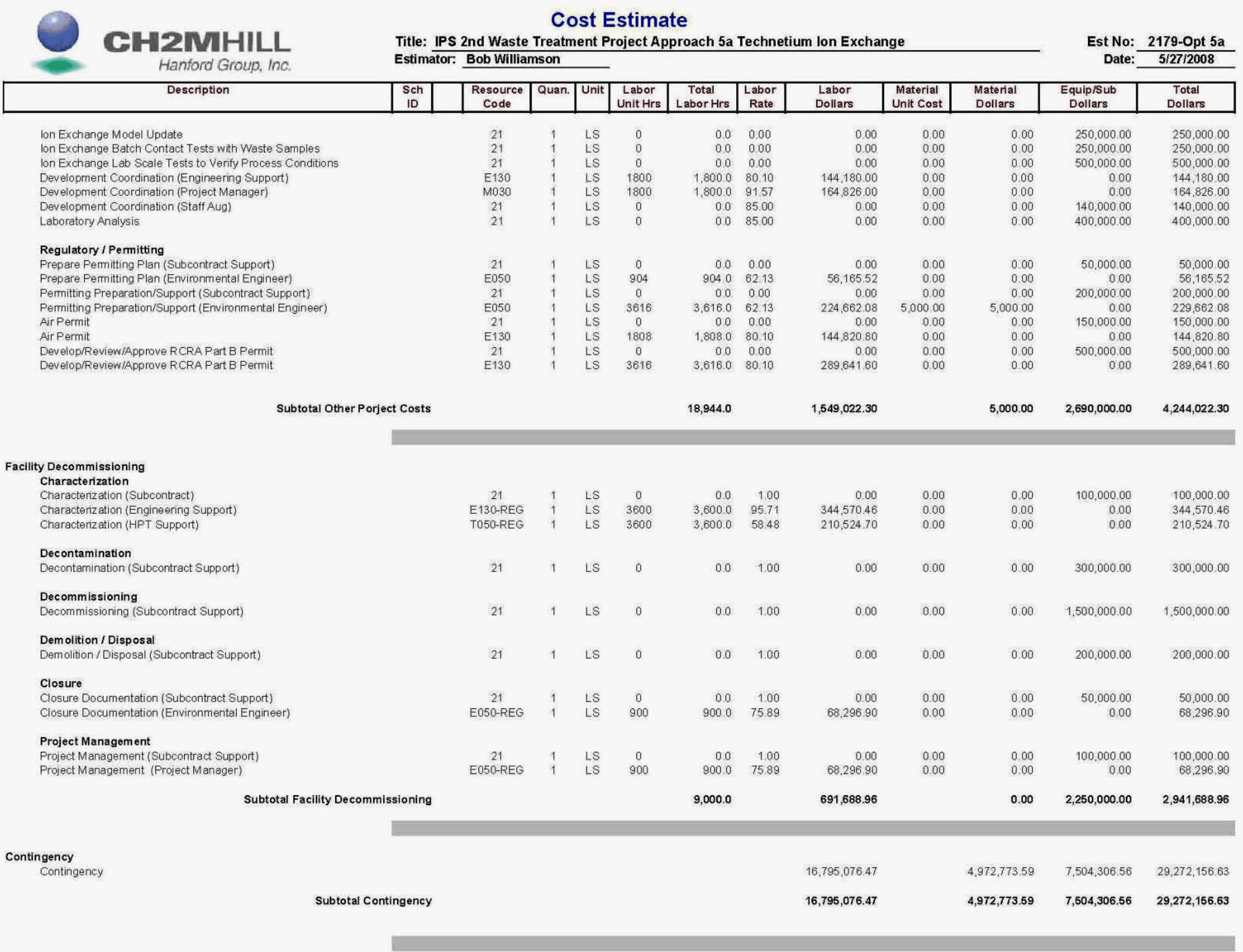


RPP-RPT-37924 Rev. 0

Table G-13. Approach 5b Cost Estimate.

Table begins on next page. 
RPP-RPT-37924 Rev. 0

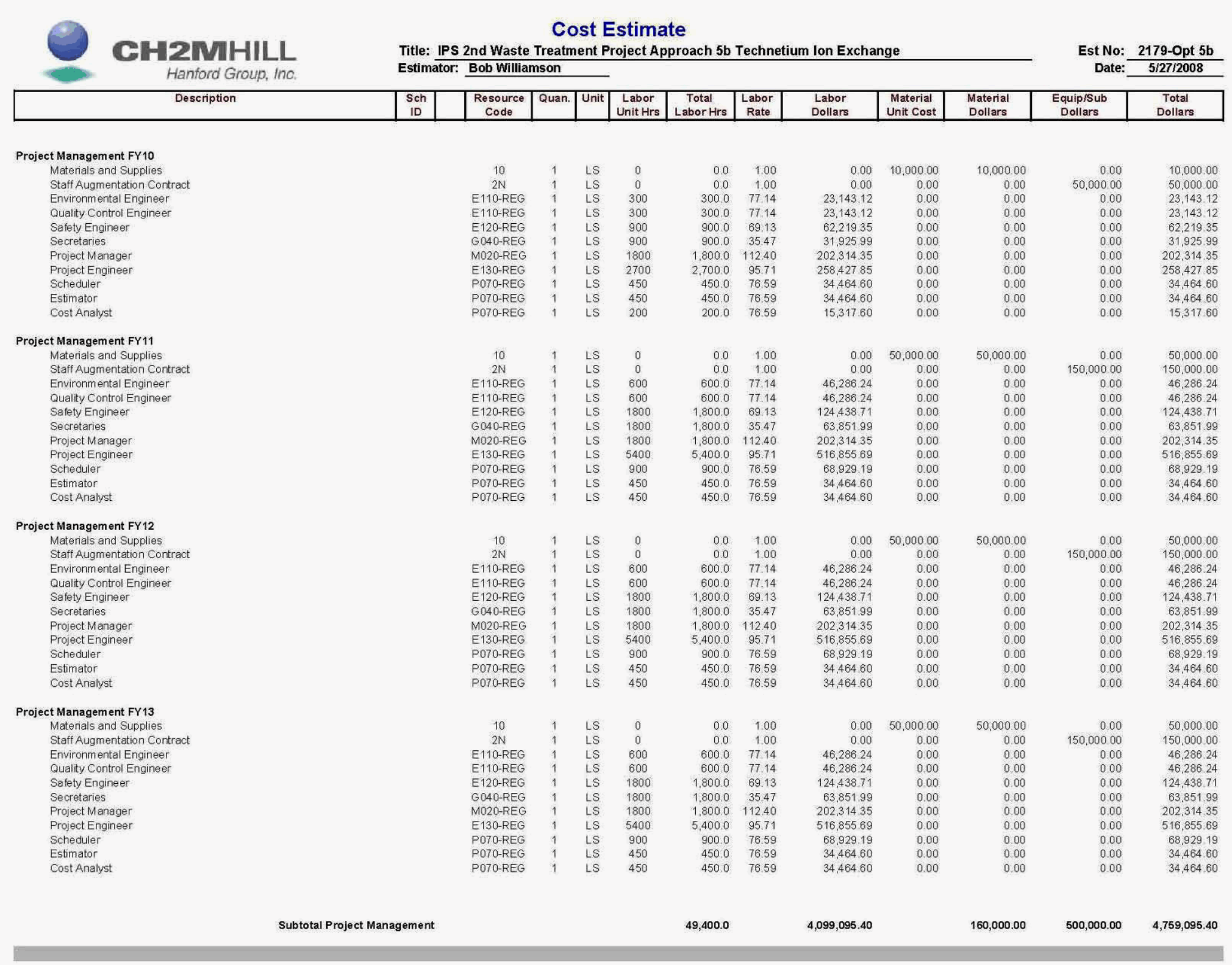


RPP-RPT-37924 Rev. 0

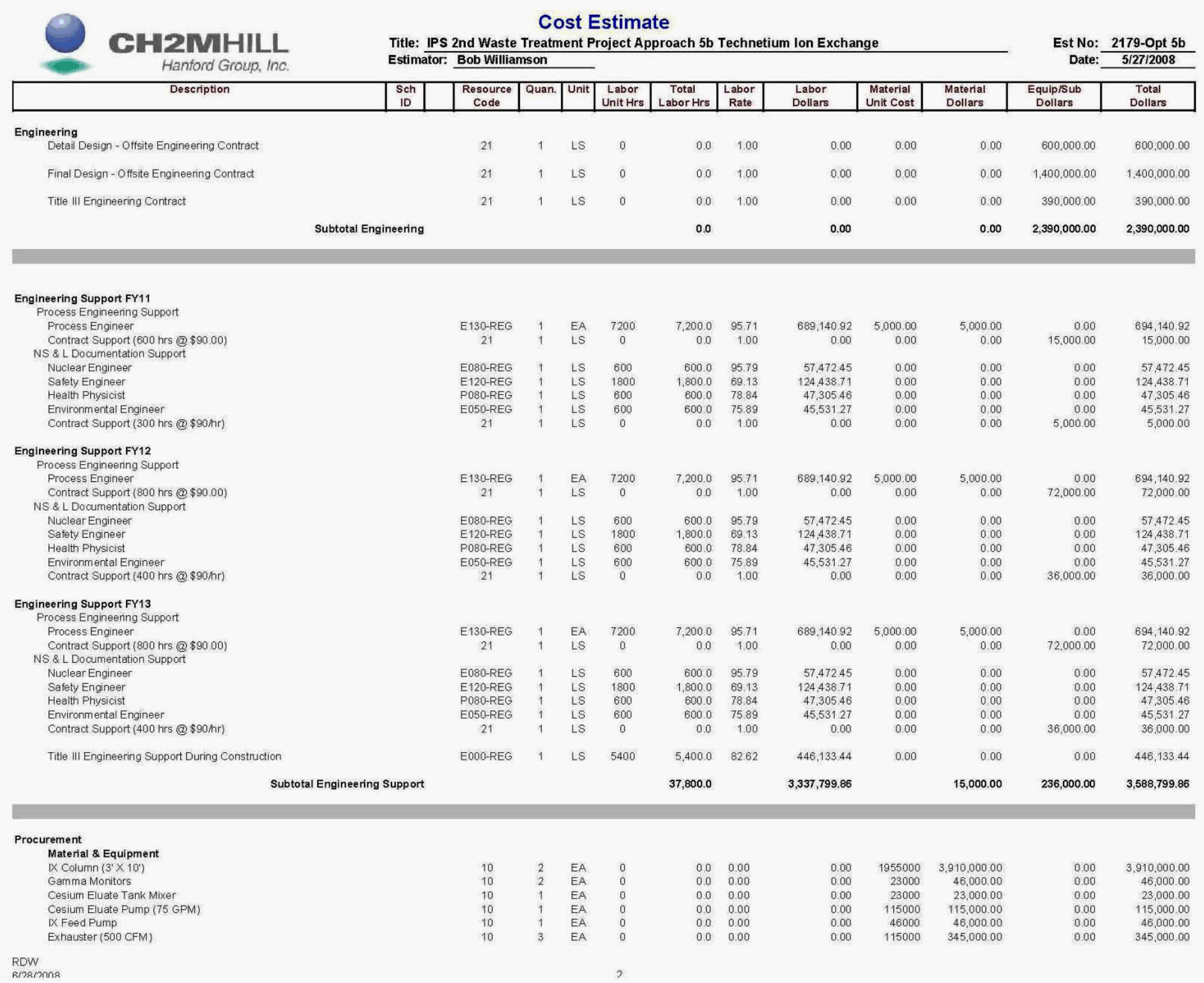


RPP-RPT-37924 Rev. 0

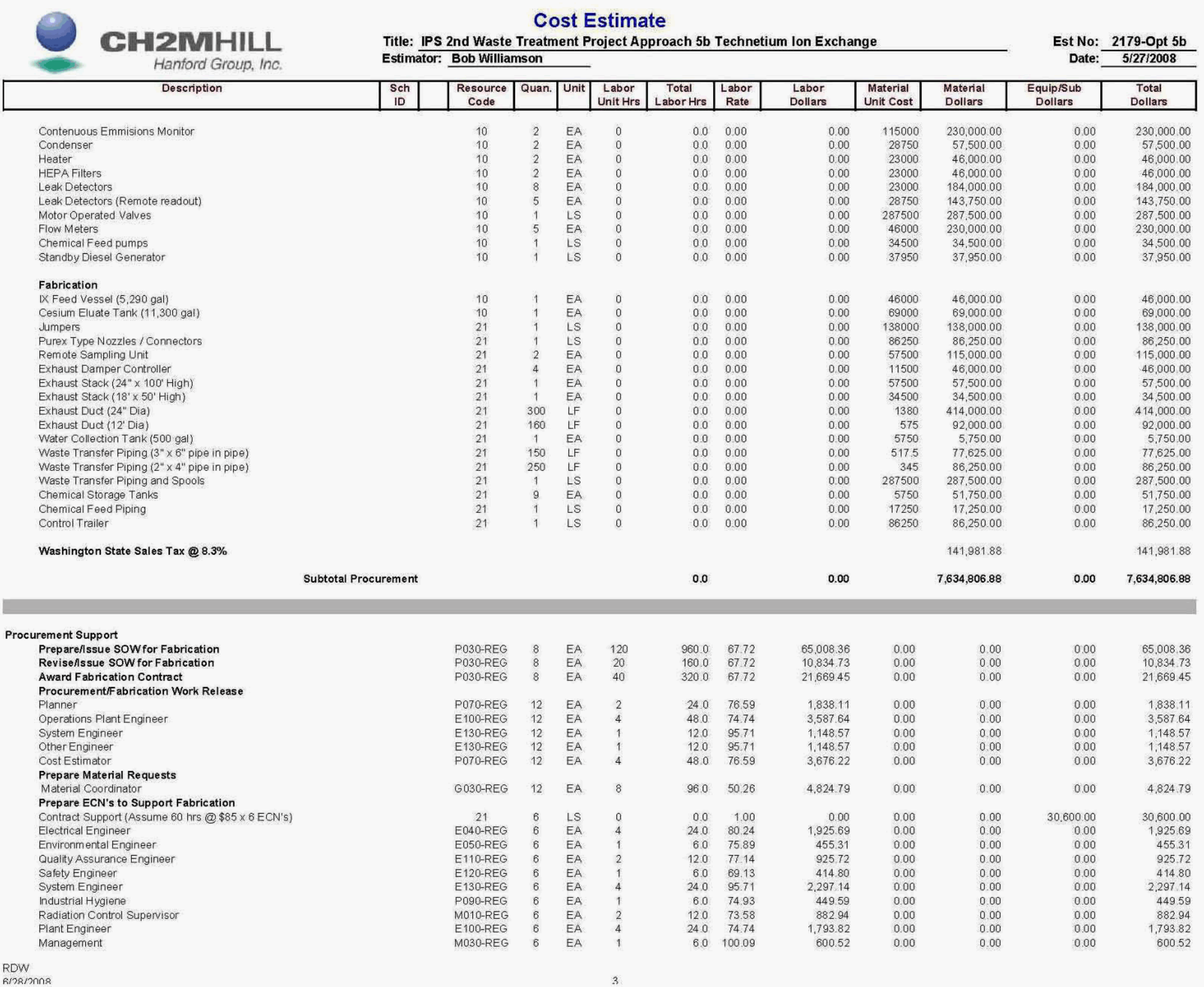


RPP-RPT-37924 Rev. 0

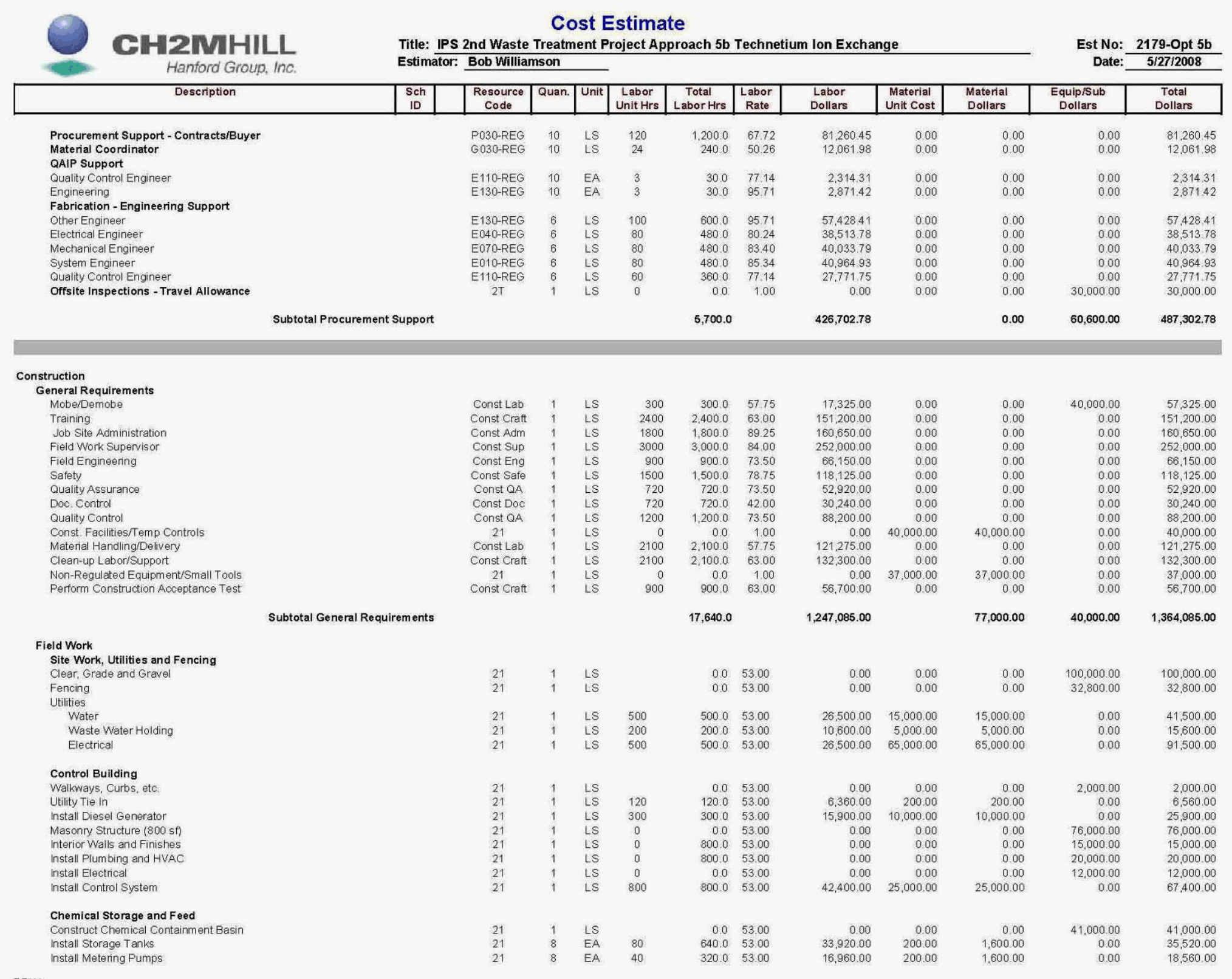


RPP-RPT-37924 Rev. 0

\begin{tabular}{|c|c|c|c|c|c|c|c|c|c|c|c|c|}
\hline CH2MHILL & \multicolumn{10}{|c|}{$\begin{array}{l}\text { Cost Estimate } \\
\text { Title: IPS 2nd Waste Treatment Project Approach 5b Technetium lon Exchange } \\
\text { Estimator: Bob Williamson }\end{array}$} & \multicolumn{2}{|c|}{$\begin{aligned} \text { Est No: } & \text { 2179-Opt 5b } \\
\text { Date: } & \text { 5/27/2008 }\end{aligned}$} \\
\hline Description & \begin{tabular}{|l|l|}
$\begin{array}{l}\text { Sch } \\
\text { ID }\end{array}$ \\
\end{tabular} & \begin{tabular}{|c|}
$\begin{array}{c}\text { Resource } \\
\text { Code }\end{array}$ \\
\end{tabular} & \begin{tabular}{|l|} 
Quan. \\
\end{tabular} & Unit & $\begin{array}{l}\text { Labor } \\
\text { Unit Hrs }\end{array}$ & \begin{tabular}{c|} 
Total \\
Labor Hrs \\
\end{tabular} & \begin{tabular}{|c} 
Labor \\
Rate \\
\end{tabular} & $\begin{array}{l}\text { Labor } \\
\text { Dollars }\end{array}$ & \begin{tabular}{|l|} 
Material \\
Unit Cost \\
\end{tabular} & $\begin{array}{l}\begin{array}{l}\text { Material } \\
\text { Dollars }\end{array} \\
\text { D. }\end{array}$ & $\begin{array}{l}\text { Equip/sub } \\
\text { Doliars }\end{array}$ & $\begin{array}{l}\text { Total } \\
\text { Dollars }\end{array}$ \\
\hline \multicolumn{2}{|l|}{$\begin{array}{l}\text { Install Piping and Pipe Supports } \\
\text { Install Electrical } \\
\text { Install Instrumentation and Control }\end{array}$} & $\begin{array}{l}21 \\
21 \\
21\end{array}$ & $\begin{array}{l}1 \\
1 \\
1\end{array}$ & $\begin{array}{l}\text { LS } \\
\text { LS } \\
\text { LS }\end{array}$ & $\begin{array}{l}1000 \\
400 \\
800\end{array}$ & $\begin{array}{l}800.0 \\
4000 \\
800.0\end{array}$ & $\begin{array}{l}53.00 \\
53.00 \\
53.00\end{array}$ & $\begin{array}{l}53,000.00 \\
21,200.00 \\
42,400.00\end{array}$ & $\begin{array}{r}2.000 .00 \\
5.000 .00 \\
10.000 .00\end{array}$ & $\begin{array}{r}2,000.00 \\
5,0000.00 \\
10,000.00\end{array}$ & $\begin{array}{l}0.00 \\
0.000 \\
0.00\end{array}$ & $\begin{array}{l}55.000 .00 \\
26.200 .00 \\
52.400 .00\end{array}$ \\
\hline \multicolumn{2}{|l|}{$\begin{array}{l}\text { AP-102 } \\
\text { Instal Spools in Transter line SN-701 } \\
\text { Install Jumpers in } 020 \text { Pit }\end{array}$} & $\begin{array}{l}21 \\
21\end{array}$ & $\frac{1}{1}$ & $\begin{array}{l}E A \\
E A\end{array}$ & $\begin{array}{l}1200 \\
1200\end{array}$ & $\begin{array}{l}1,200.0 \\
1,200.0\end{array}$ & $\begin{array}{l}53.00 \\
53.00\end{array}$ & $\begin{array}{l}63.600 .00 \\
63.600 .00\end{array}$ & $\begin{array}{l}40.000 .00 \\
10.000 .00\end{array}$ & $\begin{array}{l}40,000.00 \\
10,000.00\end{array}$ & $\begin{array}{l}0.00 \\
0.00\end{array}$ & $\begin{array}{r}103.600 .00 \\
73.600 .00\end{array}$ \\
\hline \multicolumn{2}{|l|}{$\begin{array}{l}\text { AP-104 } \\
\text { Modify Mixer Pump Pit } \\
\text { Construct Neve Pit and Riser Extension } \\
\text { Inntal Spin Tech Filters } \\
\text { Install UG line - AP-104 fiter pits to Separation DCRT (250 Ft) }\end{array}$} & $\begin{array}{l}21 \\
21 \\
21 \\
21\end{array}$ & $\begin{aligned} 1 \\
1 \\
2 \\
250\end{aligned}$ & $\begin{array}{l}E A \\
\text { EA } \\
\text { EA } \\
\text { If }\end{array}$ & $\begin{array}{c}960 \\
1920 \\
960 \\
3\end{array}$ & $\begin{array}{r}960.0 \\
19200 \\
1.920 .0 \\
750.0\end{array}$ & $\begin{array}{r}53.00 \\
53.00 \\
53.00 \\
53.00\end{array}$ & $\begin{array}{r}50,880.00 \\
101,760000 \\
101,760.00 \\
39,750.00\end{array}$ & $\begin{array}{r}30.000 .00 \\
85.000 .00 \\
40.000 .00 \\
25.00\end{array}$ & $\begin{array}{r}30,000.00 \\
85,000000 \\
80.000 .00 \\
6,250.00\end{array}$ & $\begin{array}{l}0.00 \\
0.00 \\
0.00 \\
0.00\end{array}$ & $\begin{array}{r}80,880.00 \\
186,760.00 \\
181,760.00 \\
46,000.00\end{array}$ \\
\hline \multicolumn{2}{|l|}{ 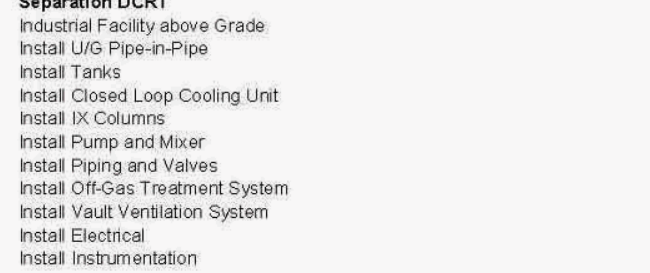 } & $\begin{array}{l}21 \\
21 \\
21 \\
21 \\
21 \\
21 \\
21 \\
21 \\
21 \\
21 \\
21\end{array}$ & $\begin{array}{l}1 \\
1 \\
3 \\
1 \\
1 \\
2 \\
2 \\
1 \\
1 \\
1 \\
1 \\
1\end{array}$ & $\begin{array}{l}E A \\
\text { LS } \\
\text { EA } \\
\text { EA } \\
\text { EA } \\
\text { EA } \\
\text { EA } \\
\text { EA } \\
\text { EA } \\
\text { EA } \\
\text { EA }\end{array}$ & $\begin{array}{l}2000 \\
1920 \\
300 \\
330 \\
600 \\
300 \\
1000 \\
1200 \\
1200 \\
8800 \\
800\end{array}$ & $\begin{array}{r}2,000.0 \\
1,920.0 \\
9000 \\
300.0 \\
1.2000 \\
600.0 \\
1,000.0 \\
1,2000 \\
1,200.0 \\
8000 \\
800.0\end{array}$ & $\begin{array}{l}53.00 \\
53.00 \\
53.00 \\
55.00 \\
53.00 \\
53.00 \\
53.00 \\
53.00 \\
53.00 \\
53.00 \\
53.00\end{array}$ & $\begin{array}{l}106,000.00 \\
101.760 .00 \\
47.700 .00 \\
15,900.00 \\
63,600.00 \\
31,800.00 \\
53,000.00 \\
63,600.00 \\
63,600.00 \\
42,40.00 \\
42,400.00\end{array}$ & $\begin{array}{l}50.000 .00 \\
10.000 .00 \\
2.000 .00 \\
4.000 .00 \\
10.00000 \\
2.000 .00 \\
10.000 .00 \\
50.000 .00 \\
50.000 .00 \\
25.000 .00 \\
40.000 .00\end{array}$ & 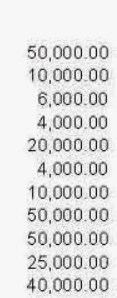 & $\begin{array}{r}200,000.00 \\
0.00 \\
0.00 \\
0.00 \\
0.00 \\
0.00 \\
0.00 \\
0.00 \\
0.00 \\
0.00 \\
0.00\end{array}$ & 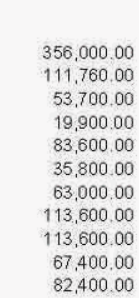 \\
\hline \multicolumn{2}{|c|}{ Subtotal Field Work } & & & & & $26,850.0$ & & $1,348,850.00$ & & $660,650.00$ & $498,800.00$ & $2,508,300.00$ \\
\hline \multicolumn{2}{|l|}{ 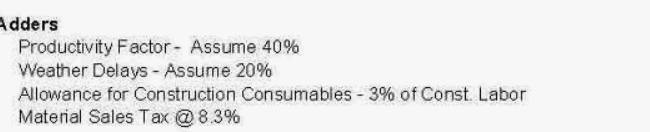 } & $\begin{array}{l}21 \\
21 \\
21 \\
21\end{array}$ & $\begin{array}{l}1 \\
1 \\
1 \\
1\end{array}$ & $\begin{array}{l}\text { LS } \\
\text { LS } \\
\text { LS } \\
\text { LS }\end{array}$ & & $\begin{array}{r}r 0.740 .0 \\
7.518 .0 \\
0.0 \\
0.0\end{array}$ & & $\begin{array}{r}539.540 .00 \\
377.678 .00 \\
0.00 \\
0.00\end{array}$ & $\begin{array}{r}0.00 \\
0.00 \\
40.465 .50 \\
54,83.95\end{array}$ & $\begin{array}{r}0.00 \\
0.00 \\
40.4550 \\
54,833.95\end{array}$ & $\begin{array}{l}0.00 \\
0.00 \\
0.00 \\
0.00\end{array}$ & $\begin{array}{r}539,540.00 \\
377,678.00 \\
40,465.50 \\
54,833.95\end{array}$ \\
\hline \multicolumn{2}{|c|}{ Subtotal Adders } & & & & & $18,258.0$ & & $917,218.00$ & & $95,299.45$ & 0.00 & $1,012,517.45$ \\
\hline \multirow[t]{2}{*}{ Construction Contractor Fee @8\% } & & 21 & & & & & & & & & $390,792.20$ & $390,792.20$ \\
\hline & truction & & & & & $62,748.0$ & & $3,513,153.00$ & & $832,949.45$ & $929,592.20$ & $5,275,694.65$ \\
\hline
\end{tabular}

\begin{tabular}{|c|c|c|c|c|c|c|c|c|c|c|c|c|}
\hline \multicolumn{13}{|l|}{ Construction Management } \\
\hline Management & & MO20-REG & & LS & 900 & 900.0 & 112.40 & $101,157,18$ & 0.00 & 0.00 & 0.00 & $101,157.18$ \\
\hline Construction Manager & & MO3O-REG & 1 & LS & 4000 & 40000 & 10009 & 40034632 & 0.00 & 0.00 & 000 & $400,346,32$ \\
\hline Construction Field Lead & & M010-REG & 1 & LS & 4000 & 40000 & 7358 & 29431431 & 0.00 & 0.00 & 000 & 294.31431 \\
\hline ClericalDocument Control Support & & G030-REG & 1 & LS & 900 & 9000 & 5026 & 45,23242 & 0.00 & 0.00 & 0.00 & 45232412 \\
\hline Miscellaneous office Supplies for CM & & 10 & 1 & LS & 0 & 00 & 100 & $\begin{array}{ll}43,202.42 \\
0.00\end{array}$ & $20,000.00$ & $20,000.00$ & 000 & 200000 \\
\hline Contract Administration & & P030-REG & 1 & LS & 900 & 900.0 & 67.72 & $60,945.33$ & 0.00 & 0.00 & 0.00 & $60,945.33$ \\
\hline & Subtotal Construction Management & & & & & $10,700.0$ & & $901,995.56$ & & $20,000.00$ & 0.00 & $921,995.56$ \\
\hline Construction Si & & & & & & & & & & & & \\
\hline Health Physics Technician (HPT) & & T050-REG & 1 & LS & 2000 & $2,000.0$ & 58.48 & $116,958.17$ & 0.00 & 0.00 & 0.00 & $116,958.17$ \\
\hline RDW & & & & & 5 & & & & & & & \\
\hline
\end{tabular}


RPP-RPT-37924 Rev. 0

\begin{tabular}{|c|c|c|c|c|c|c|c|c|c|c|c|c|}
\hline CHHZ 2 Hanford Group, Inc. & & \multicolumn{7}{|c|}{ 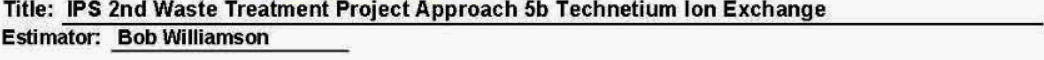 } & & & $\begin{array}{l}\text { Est No: } \\
\text { Date: }\end{array}$ & $\frac{2179-O p t 5 b}{5 / 27 / 2008}$ \\
\hline Description & $\begin{array}{c}\text { Sch } \\
\text { ID }\end{array}$ & \begin{tabular}{|c|}
$\begin{array}{c}\text { Resource } \\
\text { Code }\end{array}$ \\
\end{tabular} & Quan. & Unit & \begin{tabular}{|l|} 
Labor \\
Unit Hrs \\
\end{tabular} & \begin{tabular}{c|c|} 
Total \\
Labor Hrs \\
\end{tabular} & \begin{tabular}{|l|} 
Labor \\
Rate \\
\end{tabular} & $\begin{array}{l}\text { Labor } \\
\text { Dollars }\end{array}$ & \begin{tabular}{|c|} 
Material \\
Unit cost \\
\end{tabular} & $\begin{array}{c}\text { Material } \\
\text { Dollars }\end{array}$ & $\begin{array}{c}\begin{array}{c}\text { Equip/Sub } \\
\text { Dollars }\end{array} \\
\end{array}$ & $\begin{array}{l}\text { Total } \\
\text { Dollars }\end{array}$ \\
\hline \multirow{2}{*}{\multicolumn{2}{|c|}{$\begin{array}{l}\text { Industrial Health \& Safety } \\
\text { PHMC - Critical Lift Support (Crane \& Rigging Organization) }\end{array}$}} & TO60-REG & 1 & LS & 800 & 800.0 & 57.69 & $46,154,12$ & 0.00 & 0.00 & 0.00 & $46,154.12$ \\
\hline & & $3 P$ & 1 & LS & 0 & 0.0 & 1.00 & 0.00 & 0.00 & 0.00 & $20,000.00$ & $20,000.00$ \\
\hline \multirow{2}{*}{\multicolumn{2}{|c|}{$\begin{array}{l}\text { PHMC - Crane Usage Charges } \\
\text { Planning \& Work Package Prep }\end{array}$}} & $3 \mathrm{P}$ & 1 & LS & 0 & 0.0 & 1.00 & 0.00 & 0.00 & 0.00 & 10.000 .00 & $10,000,00$ \\
\hline & $\begin{array}{l}\text { Planning \& work rackage rep } \\
\text { Planner }\end{array}$ & P070-REG & 10 & EA & 112 & 1.120 .0 & 76.59 & 85.778 .55 & 0.00 & 0.00 & 0.00 & $85,778.55$ \\
\hline \multirow{2}{*}{\multicolumn{2}{|c|}{$\begin{array}{l}\text { System Engineer } \\
\text { Radiation Control }\end{array}$}} & E130-REG & 10 & EA & 20 & 200.0 & 95.71 & $19,142.80$ & 0.00 & 0.00 & 0.00 & $19,142.80$ \\
\hline & & P090-REG & 10 & EA & 20 & 200.0 & 74.93 & $14,986,25$ & 0.00 & 0.00 & 0.00 & 14.986 .25 \\
\hline \multirow{2}{*}{\multicolumn{13}{|c|}{$\begin{array}{l}\text { Field Work Supervisor } \\
\text { Enhanced Work Planning }\end{array}$}} \\
\hline & & & & & & & & & & & & \\
\hline \multicolumn{2}{|l|}{$\begin{array}{l}\text { Planner } \\
\text { Plark rianing }\end{array}$} & P070-REG & 10 & EA & 3 & 30.0 & 76.59 & $2,297.64$ & 0.00 & 0.00 & 0.00 & $2,297.64$ \\
\hline \multirow{2}{*}{\multicolumn{2}{|c|}{$\begin{array}{l}\text { Carpenter } \\
\text { Electrician }\end{array}$}} & C010-REG & 10 & EA & 3 & 30.0 & 55.84 & 1.675 .10 & 0.00 & 0.00 & 0.00 & 1.675 .10 \\
\hline & & C020-REG & 10 & EA & 3 & 30.0 & 61.07 & 1.832 .07 & 0.00 & 0.00 & 0.00 & 1.832 .07 \\
\hline \multicolumn{2}{|l|}{$\begin{array}{l}\text { Pipefitter } \\
\text { Ping }\end{array}$} & C080-REG & 10 & EA & 3 & 30.0 & 57.11 & 1.713 .16 & 0.00 & 0.00 & 0.00 & 1.713 .16 \\
\hline \multicolumn{2}{|l|}{ Miscellaneous Craft } & C120-REG & 10 & EA & 3 & 30.0 & 56.94 & 1.708 .13 & 0.00 & 0.00 & 0.00 & 1.708 .13 \\
\hline \multirow{2}{*}{\multicolumn{2}{|c|}{$\begin{array}{l}\text { Environmental Engineer } \\
\text { Quality Control }\end{array}$}} & E050-REG & 10 & EA & 3 & 30.0 & 75.89 & $2,276,56$ & 0.00 & 0.00 & 0.00 & 2,27656 \\
\hline & & E110-REG & 10 & EA & 3 & 30.0 & 77.14 & $2,314.31$ & 0.00 & 0.00 & 0.00 & $2,314,31$ \\
\hline Safety Engineer & & E120-REG & 10 & EA & 3 & 30.0 & 69,13 & $2,073.98$ & 0.00 & 0.00 & 0.00 & 2.073 .98 \\
\hline System Engineer & & E130-REG & 10 & EA & 3 & 30.0 & 95.71 & $2,871.42$ & 0.00 & 0.00 & 0.00 & 2,87142 \\
\hline Light Vehicle Driver & & L070-REG & 10 & EA & 3 & 30.0 & 47.91 & $1,437.28$ & 0.00 & 0.00 & 0.00 & 1.437 .28 \\
\hline Field Work Supervisor (FWS) & & M010-REG & 10 & EA & 3 & 30.0 & 73.58 & $2,207.36$ & 0.00 & 0.00 & 0.00 & $2,207.36$ \\
\hline Industrial Hygiene & & P090-REG & 10 & EA & 3 & 30.0 & 74.93 & $2,247,94$ & 0.00 & 0.00 & 0.00 & $2,247,94$ \\
\hline Health Physics Technician (HPT) & & T050-REG & 10 & EA & 3 & 30.0 & 58.48 & $1,754.37$ & 0.00 & 0.00 & 0.00 & $1,754.37$ \\
\hline $\begin{array}{l}\text { Review \& Approve Work Packages } \\
\text { Planner }\end{array}$ & & POZOPEG & & FA & 28 & 2800 & 7659 & 2144464 & 000 & 000 & & 2144464 \\
\hline $\begin{array}{l}\text { Flanner } \\
\text { Environmental Engineer }\end{array}$ & & E050-REG & 10 & EA & ${ }_{5}^{28}$ & 50.0 & $\begin{array}{l}16.59 \\
7589\end{array}$ & $\begin{array}{r}21.444 .64 \\
3.794 .27\end{array}$ & 0.00 & $\begin{array}{l}0.00 \\
0.00\end{array}$ & $\begin{array}{l}0.00 \\
0.00\end{array}$ & $\begin{array}{r}12,444.64 \\
3.794 .27\end{array}$ \\
\hline Quality Control & & E110-REG & 10 & EA & 5 & 50.0 & 77.14 & $3,857,19$ & 0.00 & 0.00 & 0.00 & $3,857.19$ \\
\hline Safety Engineer & & E120-REG & 10 & EA & 5 & 50.0 & 69.13 & $3,456.63$ & 0.00 & 0.00 & 0.00 & $3,456.63$ \\
\hline System Engineer & & E130-REG & 10 & EA & 10 & 100.0 & 95.71 & $9,571.40$ & 0.00 & 0.00 & 0.00 & $9,571.40$ \\
\hline Field Work Supervisor (FWS) & & M010-REG & 10 & EA & 5 & 50.0 & 73.58 & $3,678.93$ & 0.00 & 0.00 & 0.00 & $3,678.93$ \\
\hline Other Engineer & & E130-REG & 10 & EA & 5 & 50.0 & 95.71 & 4.785 .70 & 0.00 & 0.00 & 0.00 & 4.785 .70 \\
\hline Health Physics Technician (HPT) & & T050-REG & 10 & EA & 5 & 50.0 & 58.48 & $2,923.95$ & 0.00 & 0.00 & 0.00 & $2,923.95$ \\
\hline Industrial Heath \& Safety & & TO60-REG & 10 & EA & 5 & 50.0 & 57.69 & $2,884.63$ & 0.00 & 0.00 & 0.00 & $2,884.63$ \\
\hline Operations Plant Engineer & & E100-REG & 10 & EA & 25 & 250.0 & 74.74 & $18,685.62$ & 0.00 & 0.00 & 0.00 & $18,685.62$ \\
\hline Closeout Work Packages & & & & & & & & & & & & \\
\hline Planner & & P070-REG & 10 & EA & 12 & 120.0 & 76.59 & $9,190.56$ & 0.00 & 0.00 & 0.00 & 9.190 .56 \\
\hline Operations Plant Engineer & & E100-REG & 10 & EA & 4 & 40.0 & 74.74 & $2,989.70$ & 0.00 & 0.00 & 0.00 & $2,989.70$ \\
\hline Administration & & G020-REG & 10 & EA & 2 & 20.0 & 33.28 & 665.64 & 0.00 & 0.00 & 0.00 & 665.64 \\
\hline Other Engineer & & E130-REG & 10 & EA & 4 & 40.0 & 95.71 & 3.828 .56 & 0.00 & 0.00 & 0.00 & 3.828 .56 \\
\hline Field Work Supervisor (FWS) & & M010-REG & 10 & $E A$ & 2 & 20.0 & 73.58 & 1.471 .57 & 0.00 & 0.00 & 0.00 & 1.471 .57 \\
\hline Prepare ECN's & & & & & & & & & & & & \\
\hline Contract Support (Assume90 hrs@ $\$ 85 \times 4$ ECN's) & & 21 & 1 & LS & 0 & 00 & 1.00 & 0.00 & 0.00 & 0.00 & $30,600.00$ & $30,600.00$ \\
\hline Electrical Engineer & & E040-REG & 10 & EA & 4 & 40.0 & 80.24 & $3,209.48$ & 0.00 & 0.00 & 0.00 & $3,209.48$ \\
\hline Environmental Engineer & & E050-REG & 10 & EA & 1 & 10.0 & 75.89 & 758.85 & 0.00 & 0.00 & 0.00 & 758.85 \\
\hline Quality Assurance Engineer & & E110-REG & 10 & EA & 2 & 20.0 & 77.14 & 1.542 .87 & 0.00 & 0.00 & 0.00 & $1,542.87$ \\
\hline Safety Engineer & & E120-REG & 10 & EA & 1 & 10.0 & 69.13 & 691.33 & 0.00 & 0.00 & 0.00 & 691.33 \\
\hline System Engineer & & E130-REG & 10 & EA & 4 & 40.0 & 95.71 & $3,828.56$ & 0.00 & 0.00 & 0.00 & 3.828 .56 \\
\hline Industrial Hygiene & & P090-REG & 10 & EA & 1 & 10.0 & 74.93 & 74931 & 0.00 & 0.00 & 0.00 & 749.31 \\
\hline Radiation Control Supervisor & & M010-REG & 10 & EA & 2 & 20.0 & 73.58 & $1,471.57$ & 0.00 & 0.00 & 0.00 & 1.471 .57 \\
\hline Plant Engineer & & E100-REG & 10 & EA & 4 & 40.0 & 74.74 & $2,989.70$ & 0.00 & 0.00 & 0.00 & 2,98970 \\
\hline Management & & M030-REG & 10 & EA & 1 & 10.0 & 100.09 & 1.000 .87 & 0.00 & 0.00 & 0.00 & 1.000 .87 \\
\hline Prepare USQ's & & E130-REG & 4 & & 28 & 1120 & 9571 & 1071997 & 000 & 000 & 000 & 10719.97 \\
\hline $\begin{array}{l}\text { Other Engineers } \\
\text { Review Engineers }\end{array}$ & & $\begin{array}{l}\text { E130-REG } \\
\text { E130-REG }\end{array}$ & $\begin{array}{l}4 \\
4\end{array}$ & EA & ${ }_{9}^{28}$ & 36.0 & 95.71 & $3,445.70$ & 0.00 & 0.00 & 0.00 & 3.445 .70 \\
\hline $\begin{array}{l}\text { Radiation Work Permit } \\
\text { Planner }\end{array}$ & & P070-REG & 5 & EA & 14 & 70.0 & 76.59 & $5,361.16$ & & 0.00 & 0.00 & $5,361.16$ \\
\hline Electrician & & CO2O-REG & 5 & EA & $\begin{array}{c}14 \\
2\end{array}$ & 10.0 & 61.07 & $\begin{array}{r}5.361 .16 \\
610.69\end{array}$ & 0.00 & 0.00 & 0.00 & $\begin{array}{r}5,361.16 \\
610.69\end{array}$ \\
\hline Electrical Engineer & & E040-REG & 5 & EA & 2 & 10.0 & 80.24 & 802.37 & 0.00 & 0.00 & 0.00 & 802.37 \\
\hline Environmental Engineer & & E050-REG & 5 & EA & 5 & 25.0 & 75.89 & $1,897.14$ & 0.00 & 0.00 & 0.00 & $1,897.14$ \\
\hline Operations Plant Engineer & & E100-REG & 5 & EA & 2 & 10.0 & 74.74 & 74742 & 0.00 & 0.00 & 0.00 & 747.42 \\
\hline & & & & & 6 & & & & & & & \\
\hline
\end{tabular}


RPP-RPT-37924 Rev. 0

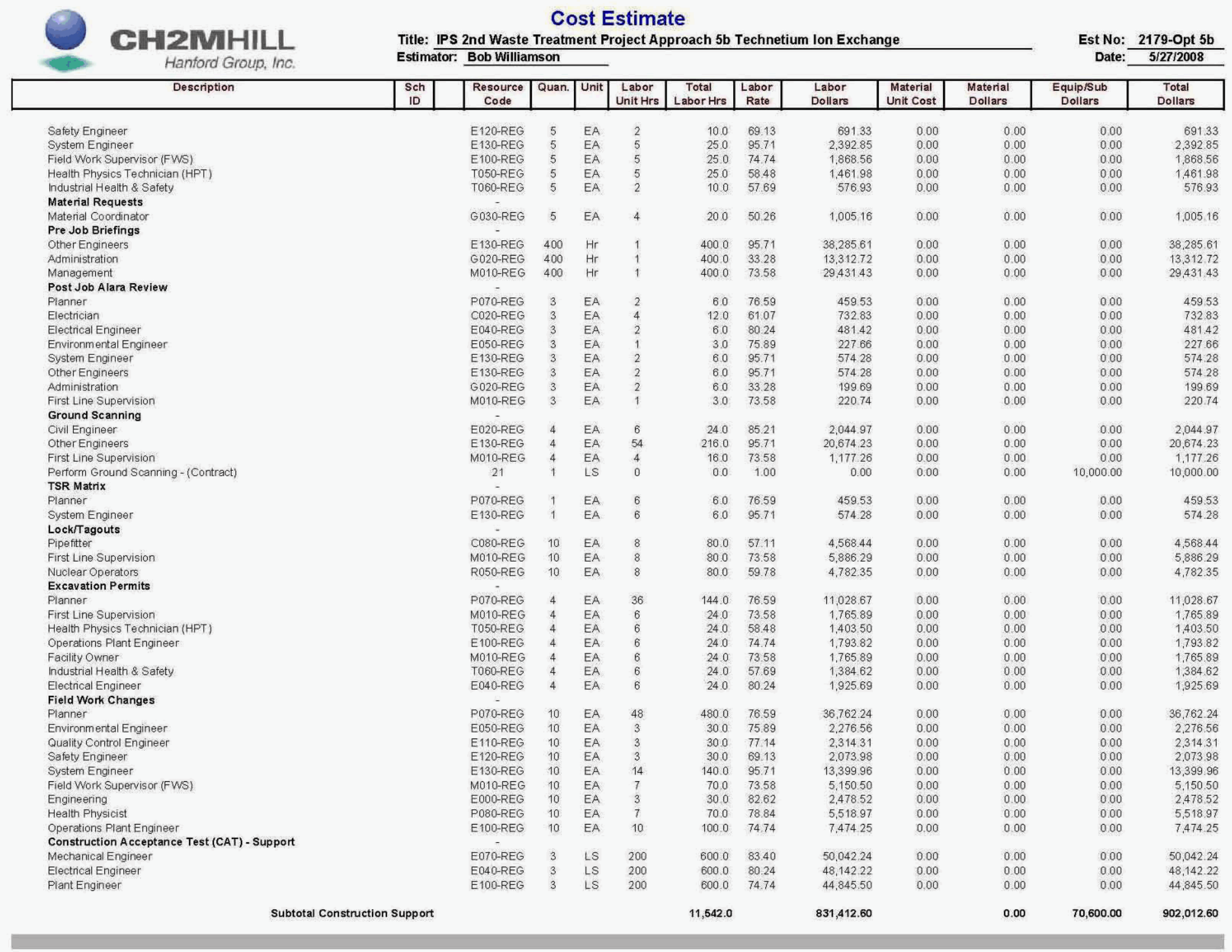


RPP-RPT-37924 Rev. 0

\begin{tabular}{|c|c|c|c|c|c|c|c|c|c|c|c|c|}
\hline \multirow{2}{*}{$\frac{\substack{\text { CHanford Group, Inc. } \\
\text { Description }}}{2}$} & \multicolumn{4}{|c|}{$\begin{array}{l}\text { Cost E } \\
\text { Title: IPS 2nd Waste Treatment Pr } \\
\text { Estimator: Bob Williamson }\end{array}$} & $\begin{array}{l}\text { Estin } \\
\text { roject }\end{array}$ & ach $5 b$ & Techne & Ion Exchan & & & \multicolumn{2}{|c|}{$\begin{aligned} & \text { Est No: } \frac{2179-\text { Opt 5b }}{\text { Date: }} \\
& \text { /2727/2008 }\end{aligned}$} \\
\hline & \begin{tabular}{|l} 
Sch \\
ID
\end{tabular} & \begin{tabular}{|l|}
$\begin{array}{c}\text { Resource } \\
\text { code }\end{array}$ \\
\end{tabular} & & & \begin{tabular}{|l|} 
Labor \\
Unit Hrs \\
\end{tabular} & $\begin{array}{l}\text { Total } \\
\text { LaborHrs } \\
\end{array}$ & $\begin{array}{l}\text { Labor } \\
\text { Rate }\end{array}$ & $\begin{array}{l}\text { Labor } \\
\text { Dollars }\end{array}$ & \begin{tabular}{|l|} 
Material \\
Unit cost \\
\end{tabular} & $\begin{array}{l}\text { Material } \\
\text { Dollars }\end{array}$ & $\begin{array}{l}\text { Equip/Sub } \\
\text { Dollars }\end{array}$ & $\begin{array}{c}\text { Total } \\
\text { Dollars }\end{array}$ \\
\hline 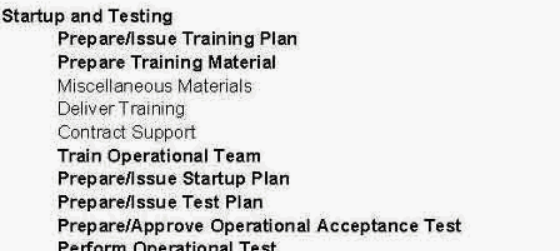 & & $\begin{array}{l}\text { E000-REG } \\
\text { P150-REG } \\
10 \\
\text { P150-REG } \\
21 \\
\text { R050-REG } \\
\text { E000-REG } \\
\text { E000-REG } \\
\text { E000-REG }\end{array}$ & $\begin{array}{l}1 \\
1 \\
1 \\
1 \\
1 \\
1 \\
1 \\
1 \\
1 \\
2\end{array}$ & $\begin{array}{l}\text { EA } \\
E A \\
\text { LS } \\
E A \\
\text { LS } \\
\text { LS } \\
\text { EA } \\
\text { EA } \\
\text { EA }\end{array}$ & $\begin{array}{c}400 \\
200 \\
0 \\
140 \\
0 \\
200 \\
200 \\
150 \\
120\end{array}$ & $\begin{array}{l}400.0 \\
200.0 \\
0.0 \\
140.0 \\
0.0 \\
200.0 \\
200.0 \\
150.0 \\
240.0\end{array}$ & $\begin{array}{l}82.62 \\
68.12 \\
1.00 \\
68.12 \\
1.00 \\
5978 \\
82.62 \\
82.62 \\
82.62\end{array}$ & $\begin{array}{r}33.046 .92 \\
13.623 .10 \\
0.00 \\
9.536 .17 \\
0.00 \\
11,955.86 \\
16.523 .46 \\
12.392 .60 \\
19,828.15\end{array}$ & $\begin{array}{r}0.00 \\
0.00 \\
2.000 .00 \\
0.00 \\
0.00 \\
0.00 \\
0.00 \\
0.00 \\
0.00\end{array}$ & $\begin{array}{r}0.00 \\
0.000 \\
2,000.00 \\
0.00 \\
0.00 \\
0.00 \\
0.00 \\
0.00 \\
0.00\end{array}$ & $\begin{array}{r}0.00 \\
0.00 \\
0.00 \\
0.00 \\
20.000 .00 \\
0.00 \\
0.00 \\
0.00 \\
0.00\end{array}$ & $\begin{array}{r}33,046.92 \\
13,623.10 \\
2,000.00 \\
9,536.17 \\
20,000.00 \\
11,955.86 \\
16.523 .46 \\
12,392.60 \\
19,828.15\end{array}$ \\
\hline 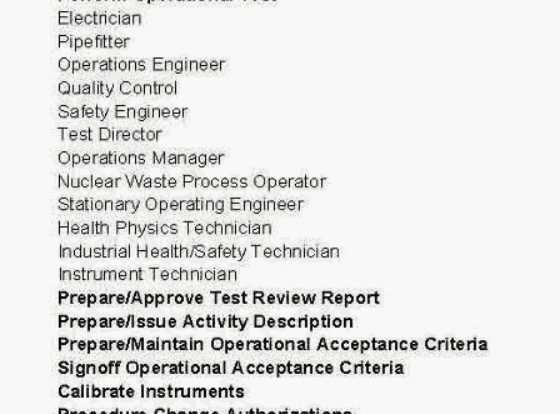 & & 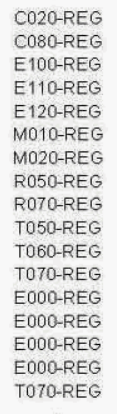 & $\begin{array}{l}10 \\
10 \\
10 \\
10 \\
10 \\
10 \\
10 \\
10 \\
10 \\
10 \\
10 \\
10 \\
1 \\
1 \\
1 \\
1 \\
10\end{array}$ & $\begin{array}{l}\text { EA } \\
\text { EA } \\
\text { EA } \\
\text { EA } \\
\text { EA } \\
\text { EA } \\
\text { EA } \\
\text { EA } \\
\text { EA } \\
\text { EA } \\
\text { EA } \\
\text { EA } \\
\text { EA } \\
\text { EA } \\
\text { EA } \\
\text { EA } \\
\text { EA }\end{array}$ & $\begin{array}{l}12 \\
12 \\
24 \\
24 \\
24 \\
24 \\
12 \\
72 \\
24 \\
24 \\
24 \\
24 \\
24 \\
160 \\
80 \\
240 \\
240 \\
80\end{array}$ & $\begin{array}{l}120.0 \\
120.0 \\
240.0 \\
240.0 \\
240.0 \\
240.0 \\
120.0 \\
720.0 \\
240.0 \\
240.0 \\
240.0 \\
240.0 \\
1600.0 \\
80.0 \\
240.0 \\
240.0 \\
800.0\end{array}$ & $\begin{array}{l}61.07 \\
57.11 \\
7474 \\
7714 \\
69.13 \\
73.58 \\
11240 \\
59.78 \\
54.30 \\
58.48 \\
57.69 \\
61.07 \\
82.62 \\
82.62 \\
82.62 \\
82.62 \\
61.07\end{array}$ & 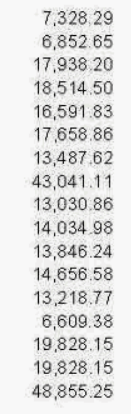 & $\begin{array}{l}0.00 \\
0.00 \\
0.00 \\
0.00 \\
0.00 \\
0.00 \\
0.00 \\
0.00 \\
0.00 \\
0.00 \\
0.00 \\
0.00 \\
0.00 \\
0.00 \\
0.00 \\
0.00 \\
0.00\end{array}$ & $\begin{array}{l}0.00 \\
0.000 \\
0.00 \\
0.00 \\
0.00 \\
0.00 \\
0.00 \\
0.00 \\
0.00 \\
0.00 \\
0.00 \\
0.00 \\
0.00 \\
0.00 \\
0.00 \\
0.00 \\
0.00\end{array}$ & $\begin{array}{l}0.00 \\
0.00 \\
0.00 \\
0.00 \\
0.00 \\
0.00 \\
0.00 \\
0.00 \\
0.00 \\
0.00 \\
0.00 \\
0.00 \\
0.00 \\
0.00 \\
0.00 \\
0.00 \\
0.00\end{array}$ & 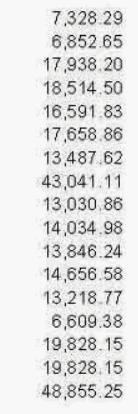 \\
\hline $\begin{array}{l}\text { Procedure cr } \\
\text { Procedure Cle }\end{array}$ & & G030-REG & 10 & EA & 8 & 80.0 & 50.26 & $4,020.66$ & 0.00 & 0.00 & 0.00 & \\
\hline Health Phys & & & & & & 20.0 & 78.84 & $1,576.85$ & & & & 1576.85 \\
\hline $\begin{array}{l}\text { ningeer } \\
\text { nngineer }\end{array}$ & & $\begin{array}{l}\text { E050-REG } \\
\text { E110REG }\end{array}$ & $\begin{array}{l}10 \\
10\end{array}$ & $\begin{array}{l}E A \\
E A \\
E A\end{array}$ & 2 & 20.0 & 75.89 & $\begin{array}{l}1.51771 \\
154287\end{array}$ & 0 & 0 & 5 & $\begin{array}{l}1.51771 \\
15487\end{array}$ \\
\hline nat & & E120-REG & 10 & $E A$ & 2 & 20.0 & 69.13 & $1,382.65$ & & & & $\begin{array}{l}\begin{array}{r}1,542.28 \\
1.382 .65\end{array} \\
\end{array}$ \\
\hline $\begin{array}{c}\text { System E } \\
\text { Technica }\end{array}$ & & $\begin{array}{l}\text { E130-REG } \\
\text { P160-REG }\end{array}$ & $\begin{array}{l}10 \\
10\end{array}$ & $\begin{array}{c}E A \\
E A \\
E A\end{array}$ & ${ }_{28}^{20}$ & $\begin{array}{l}2000 \\
2000 \\
0\end{array}$ & $\begin{array}{l}9571 \\
6639\end{array}$ & $\begin{array}{l}19.142 .80 \\
1158790\end{array}$ & $\begin{array}{l}0.0 \\
0.0\end{array}$ & & $\begin{array}{l}0.1 \\
0.1\end{array}$ & $\begin{array}{l}19.142 .80 \\
1.587790\end{array}$ \\
\hline First Line & & MOTO-REG & 10 & EA & 8 & 80.0 & 10 & $5,886.29$ & & & & $5,886.29$ \\
\hline $\begin{array}{l}\text { NuclearE } \\
\text { Prepare///F }\end{array}$ & & E080-REG & 10 & EA & 14 & 140.0 & 95. & $13,410.24$ & 0.00 & & 0.00 & 13.410 .24 \\
\hline Contract support & & & 1 & LS & 0 & 0.0 & & & & & & \\
\hline $\begin{array}{l}\text { Environm } \\
\text { Operation: }\end{array}$ & & $\begin{array}{l}\text { E050-REG } \\
\text { E100-REG }\end{array}$ & $\begin{array}{l}10 \\
10\end{array}$ & $\begin{array}{l}E A \\
E A\end{array}$ & $\begin{array}{c}8 \\
100\end{array}$ & $\begin{array}{r}80.0 \\
1,000.0\end{array}$ & $\begin{array}{l}75.89 \\
7474\end{array}$ & $\begin{array}{l}6.070 .84 \\
74.74250\end{array}$ & 0.0 & 0.6 & $\begin{array}{l}0.00 \\
0.00\end{array}$ & $\begin{array}{l}6.670 .84 \\
74,74250\end{array}$ \\
\hline ou & & E110-REG & 10 & EA & 8 & 80.0 & 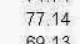 & $\begin{array}{l}6,1 \\
55\end{array}$ & 0.0 & & 0.00 & $6,171.50$ \\
\hline $\begin{array}{l}\text { Safety Ennines } \\
\text { Administrative }\end{array}$ & & $\begin{array}{l}\text { E120-REG } \\
\text { G020REG }\end{array}$ & $\begin{array}{l}10 \\
10\end{array}$ & $\begin{array}{l}E A \\
E A \\
E A\end{array}$ & ${ }_{24}^{8}$ & $\begin{array}{r}80.0 \\
2000\end{array}$ & & & & & a. & $\begin{array}{l}5.530 .061 \\
798763\end{array}$ \\
\hline First Line: & & MO10-REG & 10 & EA & 40 & 400.0 & & 29.431 .43 & & & & $\begin{array}{r}29.431 .43 \\
-133\end{array}$ \\
\hline nicician & & T056 & 10 & $\begin{array}{l}E A \\
\text { EA }\end{array}$ & 16 & 160.0 & & $\begin{array}{l}9.356 .65 \\
60398525\end{array}$ & & & & $\begin{array}{r}9.356 .65 \\
6583555\end{array}$ \\
\hline & & R050- & 10 & EA & 40 & 400.0 & $\begin{array}{l}60 \\
59 \\
59\end{array}-30$ & 23,9 & & & & \\
\hline fety Techniciar & & TO60-REG & 10 & EA & 8 & 80.0 & & 4.615 .41 & & & & $\begin{array}{l}23.91173 / 3 \\
4.61541\end{array}$ \\
\hline $\begin{array}{l}\text { Othe } \\
\text { Prep }\end{array}$ & & P170-REG & 10 & EA & 16 & 160.0 & 75.18 & 12.029.26 & 0. & 0 & 0.00 & 12.029 .26 \\
\hline $\begin{array}{l}\text { contre } \\
\text { Enta }\end{array}$ & & & 1 & LS & 0 & 0.0 & & & & & & $25,000.000$ \\
\hline $\begin{array}{l}\text { Electric } \\
\text { Evyiron }\end{array}$ & & & ${ }_{10}^{10}$ & $\begin{array}{l}\text { EA } \\
\text { EA }\end{array}$ & 4 & 10 & & $\begin{array}{l}3.20948 \\
75885\end{array}$ & & & & $\begin{array}{r}3.20948 \\
7585\end{array}$ \\
\hline $\begin{array}{l}\text { Envror } \\
\text { Quaity }\end{array}$ & & & 10 & $\begin{array}{l}E A \\
E A\end{array}$ & 1 & 200 & & 年 & & & & $\begin{array}{l}1548285 \\
1,247\end{array}$ \\
\hline & & & 10 & EA & & 0 & & 69 & & & & 691.33 \\
\hline & & & 10 & Ef & 4 & 10 & & 3.828 .56 & & & & 3.828 .56 \\
\hline dustrial Hygiene & & PO90-REG & 10 & EA & 1 & 10.0 & 74.93 & 749.31 & 0.00 & 0.00 & 0.00 & 749.31 \\
\hline & & & & & & & & & & & & \\
\hline
\end{tabular}


RPP-RPT-37924 Rev. 0

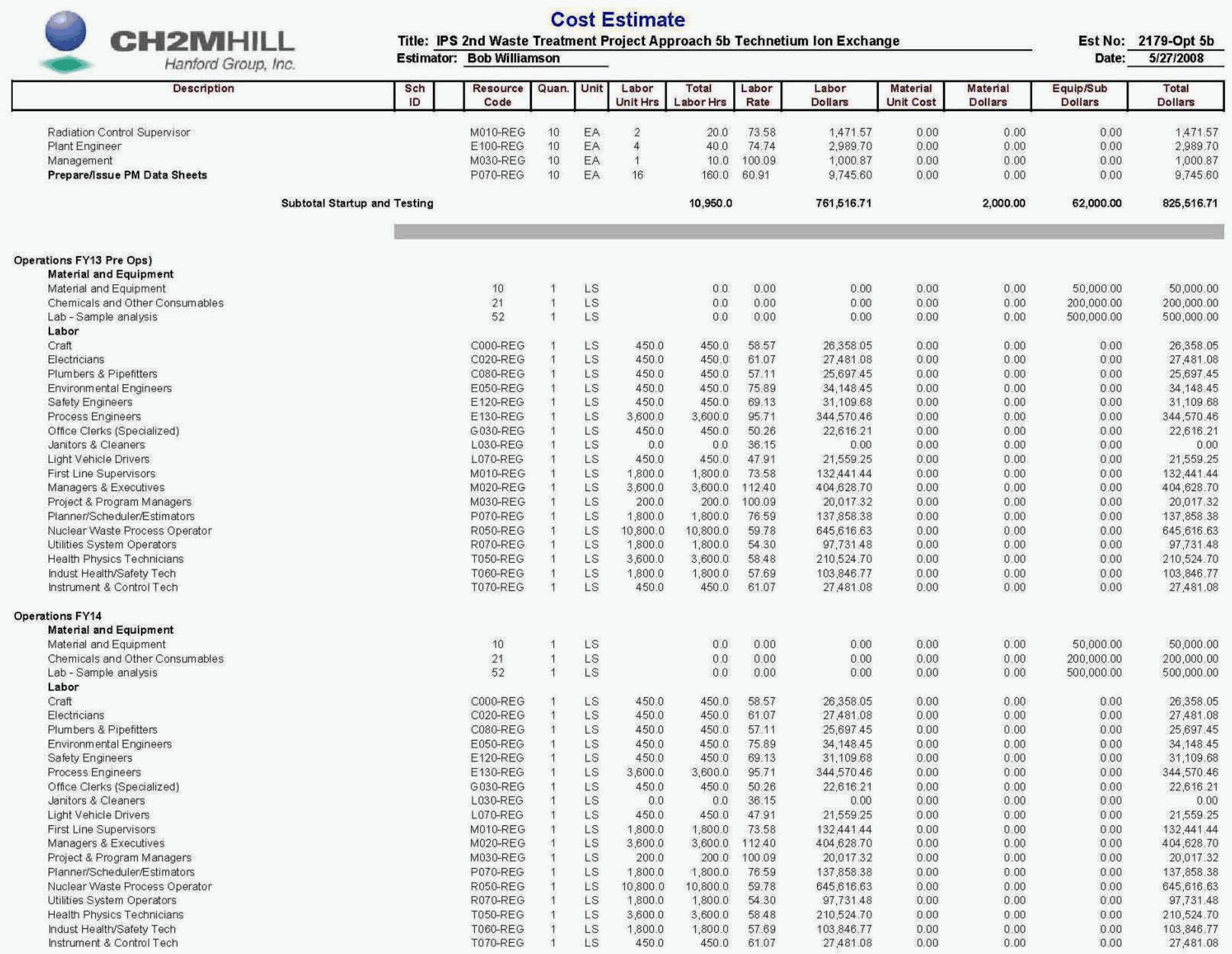


RPP-RPT-37924 Rev. 0

Cost Estimate

CHI2WHILL

Title: IPS 2nd Waste Treatment Project Approach 5b Technetium lon Exchange

Est No: 2179-Opt 5b Hanford Group, In

Date: $5 / 27 / 2008$

Description

\begin{tabular}{|c|c|c|c|}
\hline $\begin{array}{c}\text { Sch } \\
\text { ID }\end{array}$ & & $\begin{array}{c}\text { Resource } \\
\text { code }\end{array}$ & Quan. \\
\hline
\end{tabular}

\begin{tabular}{|c|c|c|}
\hline Labor & Total \\
Unit Hrs & Labor Hrs & Labor \\
Rate
\end{tabular}

Labor
Dollars

Operations FY15

Material and Equipment

Chemicals and Other Consumables

Lab - Sample analysis

Labor

Craft

Electricians

Environmental Engineers

Safety Engineers

Office Clerks (Specialized)

Janitors \& Cleaners

First Line Supervisors

Project \& Program Managers

Planner/Scheduler/Estimators

Utilities System Operators

Health Physics Technicians

Instrument \& Control Tech

Operations FY16

Material and Equipment

Chemicals and Other Consumables

Lab - Sample analysis

Labor
Craft
Electricia

Electricians

Plumbers \& Pipefitters

Safety Engineers

Process Engineers
Office Clerks (Specialized)

Janitors \& Cleaners

Light Vehicle Drivers
irst Line Supenvisors

Managers \& Executives

Project \& Program Managers

Nuclear Waste Process Operator

tilities System Operators

Health Physics Technicians

instrument \& Control Tech

Operations FY17

Material and Equipment

Chemicals and Other Consumables

Lab - Sample analysis

Labor

Craft

Plumbers \& Pipefitters

RDW

\begin{tabular}{|c|c|c|c|c|c|c|}
\hline 10 & 1 & LS & & 0.0 & 0.00 & 0.00 \\
\hline 21 & 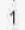 & LS & & 0.0 & 0.00 & 0.00 \\
\hline 52 & 1 & LS & & 0.0 & 0.00 & 0.00 \\
\hline C000-REG & 1 & is & 4500 & 4500 & 5857 & 2635805 \\
\hline CO20-REG & 1 & LS & 450.0 & 4500 & 6107 & 2748108 \\
\hline CO80-REG & 1 & is & 4500 & 4500 & 5711 & 2569745 \\
\hline E050-REG & 1 & is & 4500 & 4500 & 7589 & 34,14845 \\
\hline E120-REG & 1 & IS & 4500 & 4500 & 6913 & 31,10968 \\
\hline E130-REG & 1 & is & 36000 & 3.6000 & 9571 & 344.57046 \\
\hline G030-REG & 1 & is & 4500 & 4500 & 5026 & 2261621 \\
\hline LO30-REG & 1 & LS & 0.0 & 00 & $\begin{array}{l}36.15 \\
36.15\end{array}$ & 0.00 \\
\hline L070-REG & 1 & is & 4500 & 4500 & 47.91 & 2155925 \\
\hline M010-REG & 1 & is & 18000 & 18000 & 7358 & 13244144 \\
\hline MO20-REG & 1 & LS & 36000 & 36000 & 11240 & 40462870 \\
\hline MO30-REG & 1 & is & 2000 & 2000 & 10009 & 2001732 \\
\hline $\begin{array}{l}\text { P070-REG } \\
\end{array}$ & 1 & is & 18000 & 18000 & 7659 & 13785838 \\
\hline R050-REG & 1 & LS & 108000 & 108000 & 5978 & 64561663 \\
\hline R070-REG & 1 & is & 18000 & 1,8000 & 54,30 & 97,73148 \\
\hline TO50-REG & 1 & is & 36000 & 36000 & 5848 & 21052470 \\
\hline TO60-REG & & LS & 18000 & 18000 & 5769 & 10384677 \\
\hline T070-REG & 1 & LS & 4500 & 4500 & 6107 & 2748108 \\
\hline
\end{tabular}

$\begin{array}{ll}0.00 & 0.00 \\ 0.00 & 0.00 \\ 0.00 & 0.00 \\ 0.00 & 0.00 \\ 0.00 & 0.00 \\ 0.00 & 0.00 \\ 0.00 & 0.00 \\ 0.00 & 0.00 \\ 0.00 & 0.0 \\ 0.00 & 0.0 \\ 0.00 & 0.00 \\ 0.00 & 0.0 \\ 0.00 & 0.0 \\ 0.00 & 0.0 \\ 0.00 & 0.0 \\ 0.00 & 0.0 \\ 0.00 & 0.00 \\ 0.00 & 0.0 \\ 0.00 & 0.0 \\ 0.00 & 0.00 \\ 0.00 & 0.0\end{array}$

Equip/Sub
Dollars

Dollar

\begin{tabular}{|c|c|c|c|c|c|c|c|c|c|c|}
\hline 10 & 1 & LS & & 0.0 & 0.00 & 0.00 & 0.00 & 0.00 & $50,000.00$ & $50,000.00$ \\
\hline 21 & 1 & LS & & 0.0 & 0.00 & 0.00 & 0.00 & 0.00 & $200,000.00$ & $200,000.00$ \\
\hline 52 & 1 & LS & & 0.0 & 0.00 & 0.00 & 0.00 & 0.00 & $500,000.00$ & $500,000.00$ \\
\hline COOO-REG & 1 & LS & 450.0 & 450.0 & 58.57 & $26,358,05$ & 0.00 & 0.00 & 0.00 & $26,358.05$ \\
\hline C020-REG & & LS & 450.0 & 450.0 & 61.07 & $27,481.08$ & 0.00 & 0.00 & 0.00 & $27,481.08$ \\
\hline C080-REG & 1 & LS & 450.0 & 450.0 & 57.11 & $25,697.45$ & 0.00 & 0.00 & 0.00 & $25,697.45$ \\
\hline E050-REG & 1 & LS & 450.0 & 450.0 & 75.89 & $34,148,45$ & 0.00 & 0.00 & 0.00 & 34.148 .45 \\
\hline E120-REG & 1 & LS & 450.0 & 450.0 & 69.13 & $31,109.68$ & 0.00 & 0.00 & 0.00 & $31,109.68$ \\
\hline E130-REG & 1 & LS & $3,600.0$ & $3,600.0$ & 95.71 & $344,570.46$ & 0.00 & 0.00 & 0.00 & $344,570.46$ \\
\hline G030-REG & 1 & LS & 450.0 & 450.0 & 50.26 & 22.616 .21 & 0.00 & 0.00 & 0.00 & 22.616 .21 \\
\hline L030-REG & 1 & LS & 0.0 & 0.0 & 36.15 & 0.00 & 0.00 & 0.00 & 0.00 & 0.00 \\
\hline L070-REG & 1 & LS & 450.0 & 450.0 & 47.91 & $21,559.25$ & 0.00 & 0.00 & 0.00 & $21,559.25$ \\
\hline MO10-REG & 1 & LS & $1,800.0$ & 1.800 .0 & 73.58 & $132,441.44$ & 0.00 & 0.00 & 0.00 & $132,441.44$ \\
\hline M020-REG & 1 & LS & $3,600.0$ & $3,600.0$ & 112.40 & 404.628 .70 & 0.00 & 0.00 & 0.00 & $404,628.70$ \\
\hline M030-REG & 1 & LS & 200.0 & 200.0 & 100.09 & $20,017.32$ & 0.00 & 0.00 & 0.00 & $20,017.32$ \\
\hline P070-REG & 1 & LS & 1.800 .0 & $1,800.0$ & 76.59 & $137,858.38$ & 0.00 & 0.00 & 0.00 & $137,858,38$ \\
\hline R050-REG & 1 & LS & 10.800 .0 & $10,800.0$ & 59.78 & 645.616 .63 & 0.00 & 0.00 & 0.00 & $645,616.63$ \\
\hline R070-REG & 1 & LS & $1,800.0$ & $1,800.0$ & 54.30 & $97,731.48$ & 0.00 & 0.00 & 0.00 & $97,731,48$ \\
\hline T050-REG & 1 & LS & $3,600.0$ & 3.600 .0 & 58.48 & $210,524.70$ & 0.00 & 0.00 & 0.00 & $210,524.70$ \\
\hline T060-REG & 1 & LS & 1.800 .0 & 1.800 .0 & 57.69 & $103,846.77$ & 0.00 & 0.00 & 0.00 & $103,846,77$ \\
\hline T070-REG & 1 & LS & 450.0 & 450.0 & 61.07 & $27,481.08$ & 0.00 & 0.00 & 0.00 & $27,481,08$ \\
\hline 10 & 1 & LS & & 0.0 & 0.00 & 0.00 & 0.00 & 0.00 & $50,000.00$ & $50,000.00$ \\
\hline 21 & 1 & LS & & 0.0 & 0.00 & 0.00 & 0.00 & 0.00 & 200.000 .00 & $200,000.00$ \\
\hline 52 & 1 & LS & & 0.0 & 0.00 & 0.00 & 0.00 & 0.00 & $500,000.00$ & $500,000.00$ \\
\hline COOO-REG & 1 & LS & 450.0 & 450.0 & 58.57 & $26,358,05$ & 0.00 & 0.00 & 0.00 & $26,358.05$ \\
\hline C020-REG & 1 & LS & 450.0 & 450.0 & 61.07 & $27,481.08$ & 0.00 & 0.00 & 0.00 & $27,481.08$ \\
\hline C080-REG & 1 & LS & 450.0 & 450.0 & 57.11 & $25,697,45$ & 0.00 & 0.00 & 0.00 & $25,697.45$ \\
\hline
\end{tabular}


RPP-RPT-37924 Rev. 0

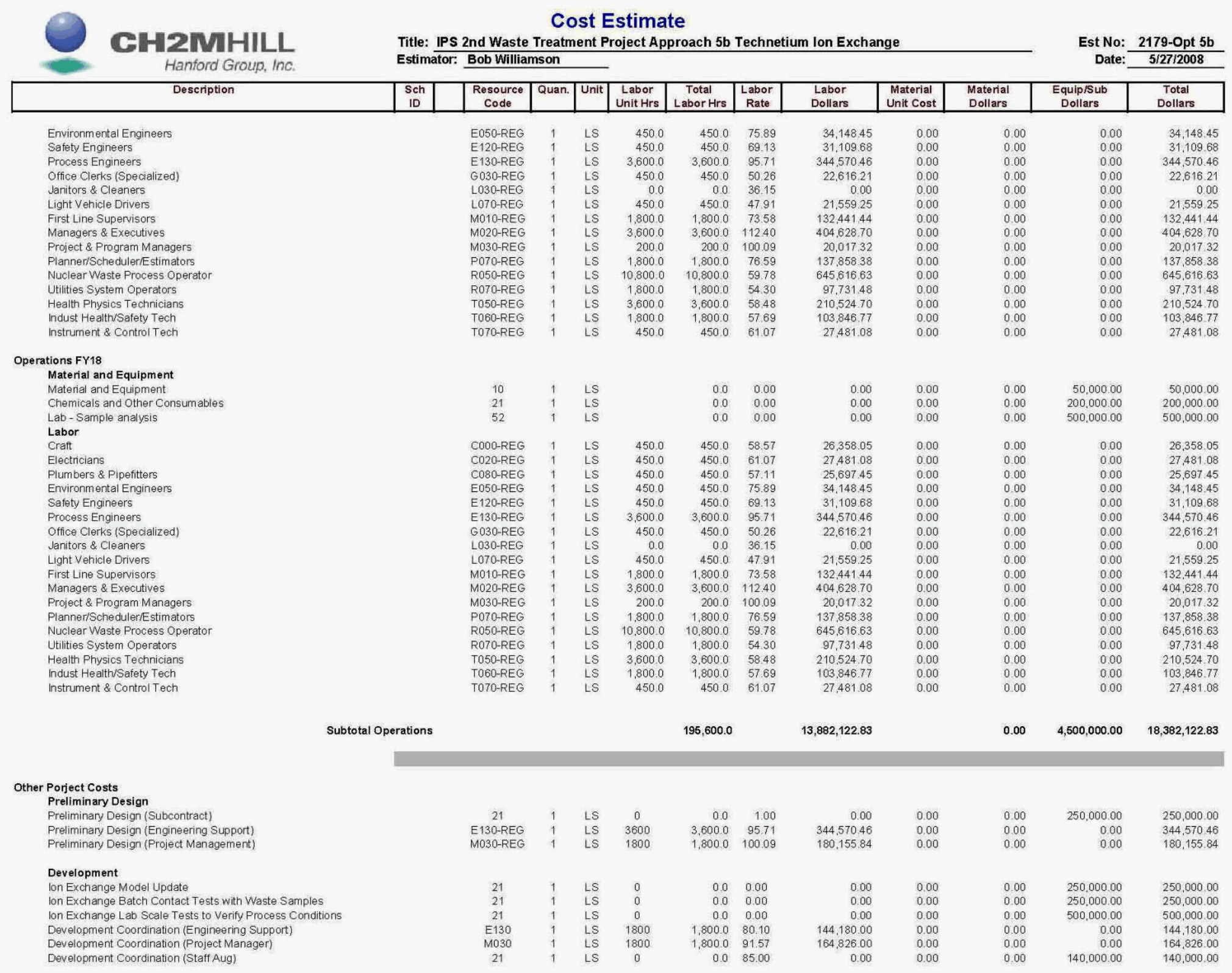


RPP-RPT-37924 Rev. 0

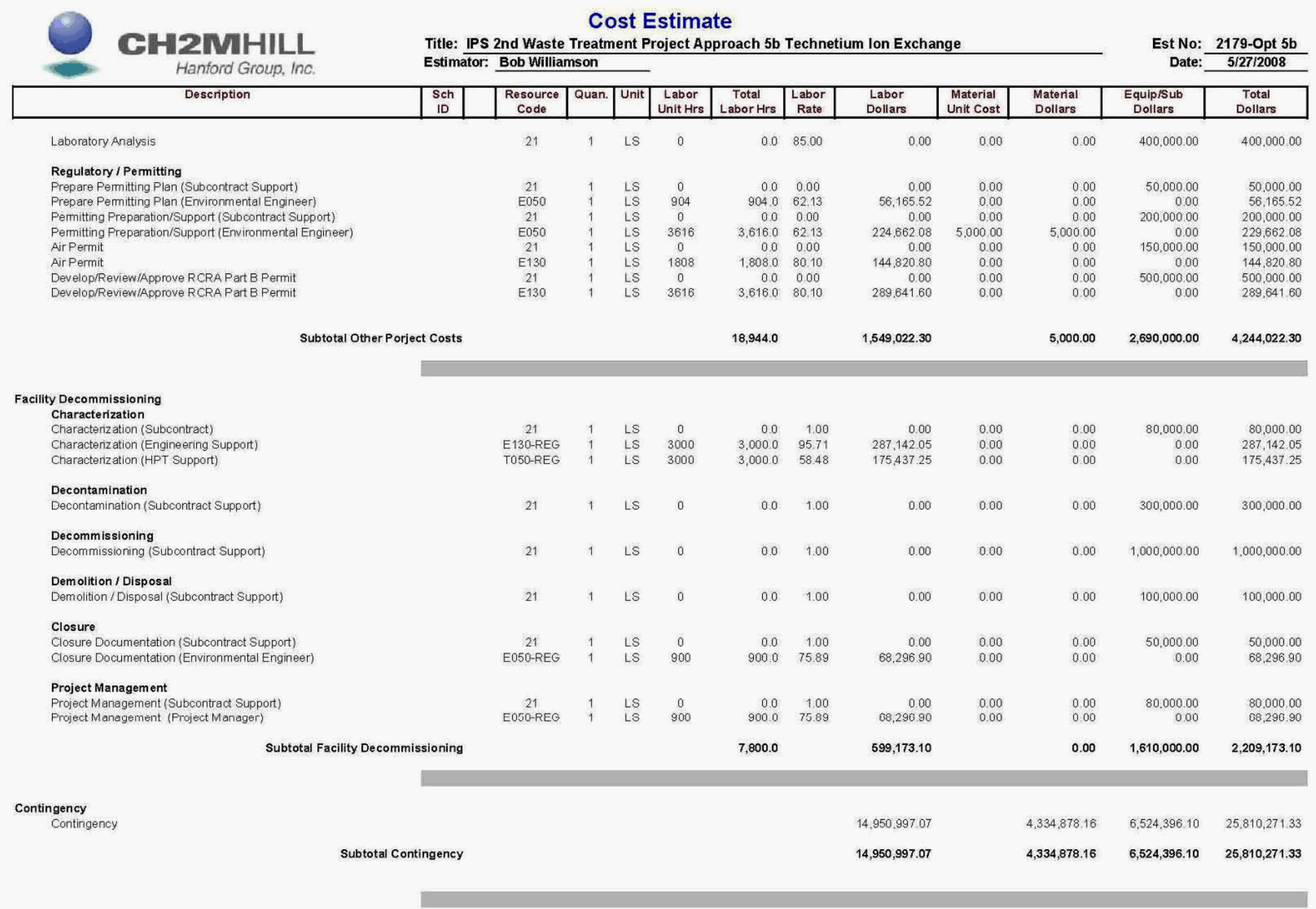




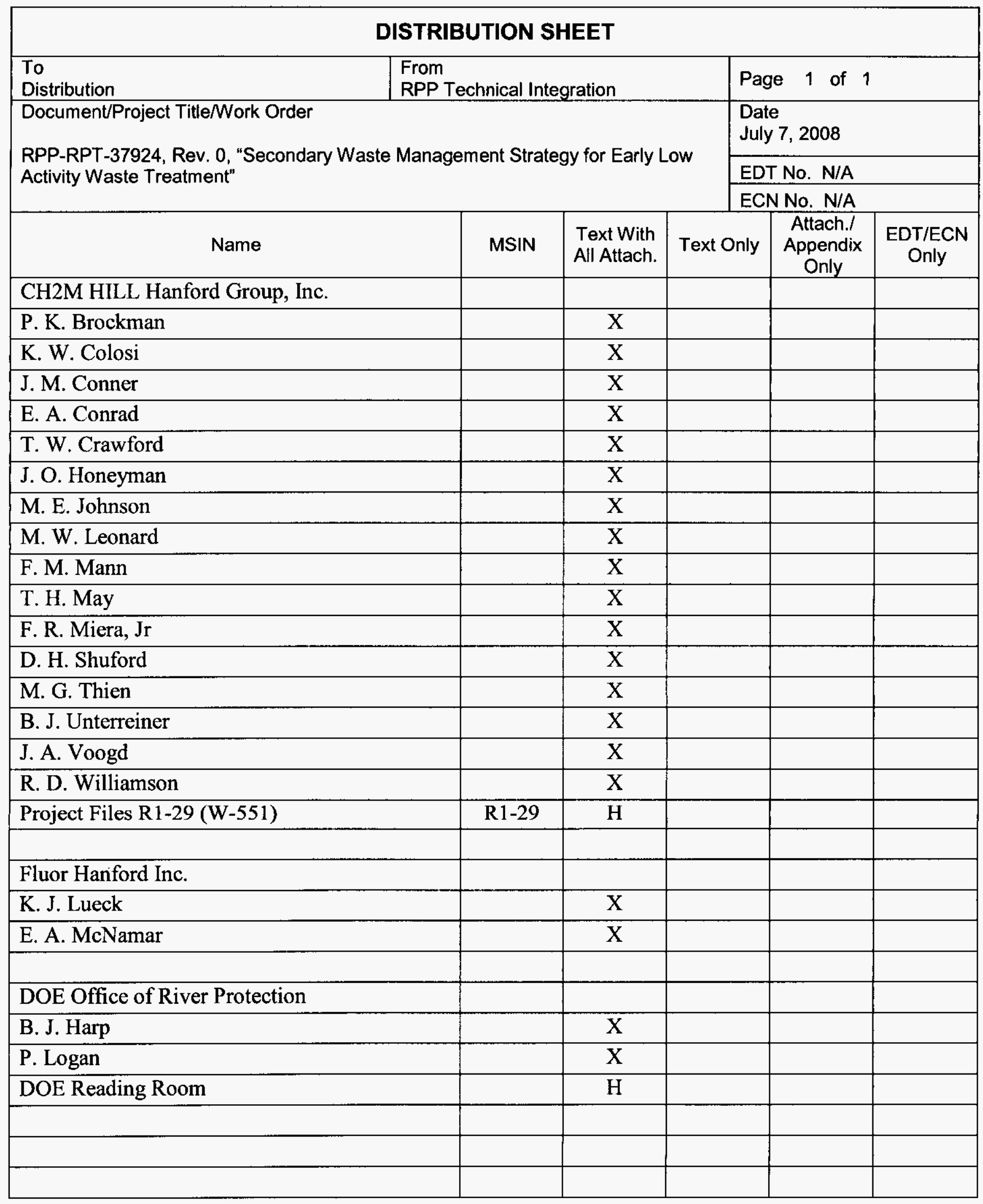

